Natalia Nikolova

\title{
THE CLIENT-CONSULTANT RELATIONSHIP IN PROFESSIONAL SERVICE FIRMS
}

Dissertation Universität zu Köln, 2006 


\section{Foreword}

Professional business service firms are one of the most dynamic and advanced industries in the modern economy. Interestingly, the increasing economic significance of professional business services in all developed economies has been accompanied by increasing client dissatisfaction with those services. As a result, there has been a growing academic interest in the nature of the client-consultant relationship, and it has been recognized that the integration of the client in the consulting process is the most important success factor for professional business service firms. However, existing approaches are contradictory in their theoretical foundations and scientific objectives. Most importantly, they do not address the complexity of the client-consultant relationship offering only restricted view of its nature and success factors.

This thesis concentrates on the relationship between client organizations and professional business service firms. Based on a comprehensive critical discussion of the existing literature on client-consultant relationships, Natalia Nikolova develops an innovative conceptual framework - the "interpretative model" - of the client-consultant interaction. The framework represents an analytical tool that sheds light on two interrelated issues: the cultural relations between clients and professional service providers and their political relations. By showing the connection and the interrelation between the cognitive and political dimension of consulting, the author provides a more nuanced view on the client-consultant relationship and provides new avenues to overcome long existing boundaries between different research streams and perspectives. The result is a multidimensional and multi-disciplinary view of the client-consultant interaction that sheds light on a number of hitherto under-explored issues and makes a significant contribution to the literature on client-consultant relationships. This remarkable thesis deserves high praise in the academic discussion as well as in the business community. The academic advisor and editor of this series as well as Natalia's mentor wish this work a very positive reception. 


\section{Preface}

This book is about professional business service firms in general and consulting companies in particular; about experts and management gurus; about human cognition; about knowledge and knowledge transfer; about power and its influence on knowledge transfer and learning; about management fads and fashions. In short, it is about the nature of client-consultant interactions during consulting projects.

Soon after I started to do research in this area, I realized that I could not write about client-consultant relationships without stressing that such relationships are ultimately relationships between groups of people who bring their different perspectives, views, interests, goals and motivations into their joint work. What fascinated me the most was the opportunity that this topic offered to me to discuss client-consultant relationships from a number of different theoretical perspectives and to connect these different perspectives in order to shed some light on issues that are highly relevant for the outcome of consulting projects but were less explored in the existing research on consulting. This meant that I had to ask questions, such as what is the nature of knowledge in general and of consulting knowledge in particular and what characterizes knowledge transfer and learning within client-consultant teams; what is the nature of power in client-consultant teams and how does power influence consulting projects; and finally, how are both these areas connected to each other, how do they influence each other and what implications does this discussion have for the nature and success of client-consultant relationships? In order to answer those questions, I had to familiarize myself with a number of theoretical areas including philosophy of social sciences, sociology, neurobiology and discourse analysis. This journey was quite demanding but also very enlightening for me as it made me appreciate the complex nature of social interaction as well as the need to include this complexity when studying social issues. I trust that the reader will appreciate the richness of this approach.

A great number of people have supported me in the course of this intellectual journey and I owe them my deepest thanks.

My first thank goes to my mentor, Markus Reihlen, from the University of Cologne, whose advice, suggestions and comments contributed greatly to the outcome of this work. Markus was always very courteous and with his support, I mastered even the most difficult moments of this journey without loosing my confidence that I am on the right track. I would further like to thank my supervisor, Werner Delfmann, for his constructive discussion of this manuscript and his generous advice on substantive matters. Tim Devinney offered not only helpful advice and ideas for my work but he also supported my professional transfer from Germany to Australia and introduced me to the Australian research community. I would also like to thank Stewart Clegg for his helpful comments on parts of this work as well as Anne Ross-Smith for her support during my first year at the University of Technology Sydney when I really needed the time to concentrate on finishing this manuscript. Furthermore, I thank all participants in the Standing Working Group on 'Professional service organizations and professionalization at work' at the 2004 and 2005 EGOS Colloquia for their valuable comments on parts of this work. In 
particular, I would like to thank Timothy Clark, Robin Fincham, Royston Greenwood, Andrew Sturdy and Celeste Wilderom for their helpful advice and critical comments on my work in progress. In addition, my special thanks go to Konstantin Stoyanov who was enthusiastic about this work from the early days on. He read the manuscript several times and his suggestions contributed a great deal to the structure and explanatory power of this work. He never stopped short of encouraging me to go one step further and to reassess my work. I would also like to thank Pauline Olive and Sandra Peter for helping me to finalize the manuscript in its very last and critical details. Finally, great thanks is owed to my family. My husband I thank for his support and patience and for always encouraging me to give my best. My very special thank goes to my parents who have embraced every project that I started and every journey that I undertook. I dedicate this work to my mum whom I owe my confidence, courage and optimism. She is a never-ending inspiration for my life.

Natalia Nikolova 


\section{Contents}

A. INTRODUCTION...............................................................................1 1

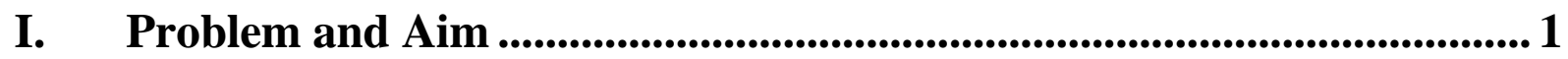

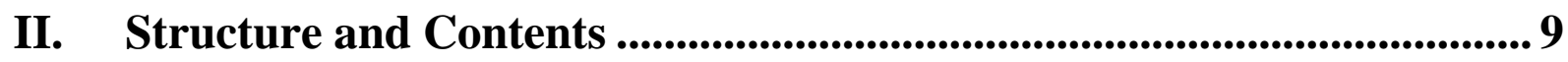

B. CONCEPTUAL FOUNDATIONS.......................................................... 12

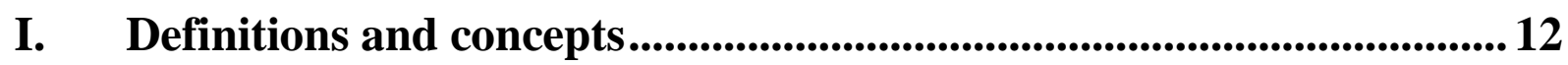

1. Professional business services.................................................................. 12

1.1 Norm-oriented approach .................................................................................. 14

1.2 Structure-oriented approach......................................................................... 15

1.3 Pragmatic approach..................................................................................... 16

1.4 Work - or knowledge-oriented approach ....................................................... 19

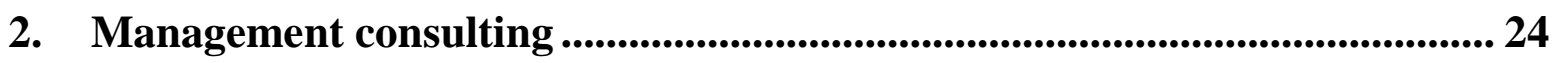

2.1 Management consulting' status as a profession................................................ 25

2.2 Attributes of management consulting services ............................................. 27

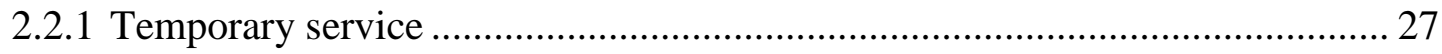

2.2.2 High degree of personal judgment by the service provider.............................. 28

2.2.3 High intensity of interaction ........................................................................ 29

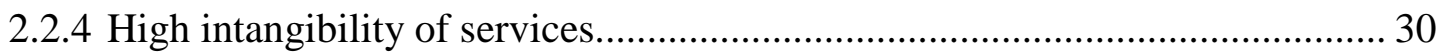

2.2.5 A critical discussion of the attributes of consulting services............................. 31

2.3 Consulting success....................................................................................... 32

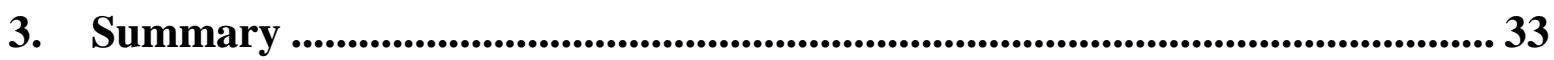

II. A systemic framework for the analysis of client-consultant

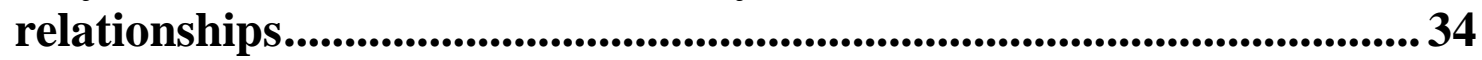

1. A systemic perspective of client-consultant teams.............................................. 35

2. Attributes of clients and consultants................................................................ 39

2.1 Cognitive attributes..................................................................................... 39

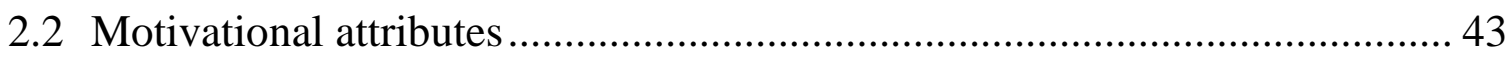

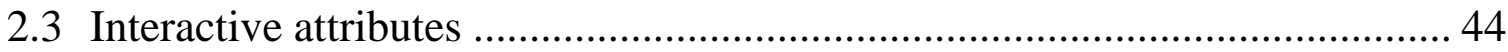

3. (Immediate) environment / Context of project assignments ............................ 46

3.1 A general problem typology ......................................................................... 47 


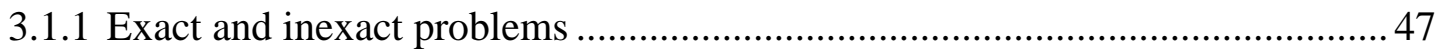

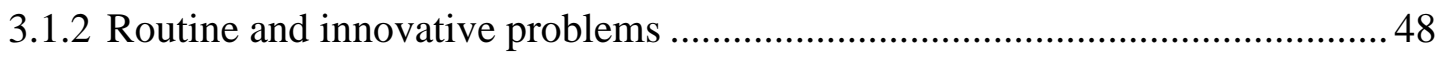

3.2 A problem typology of client-consultant projects.....................................49

3.2.1 Simple routine / low interaction / efficiency problems..................................... 50

3.2.2 Complex routine / moderate-interaction / experience problems........................ 51

3.2.3 Innovative / high-interaction / creativity problems........................................ 53

3.3 Trends within the immediate environment.................................................54

3.4 Organizational field of management knowledge production

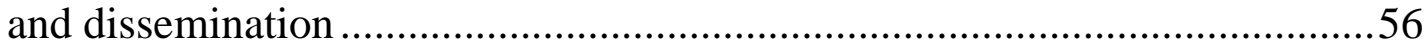

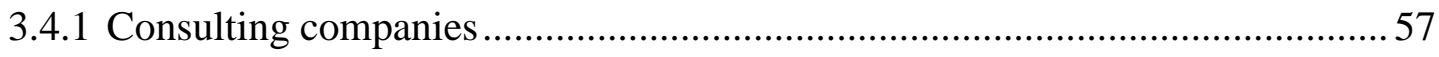

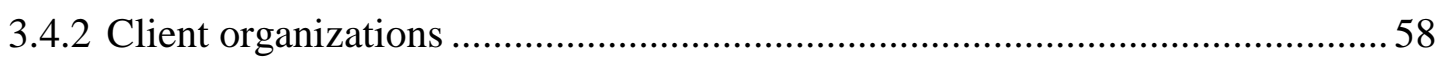

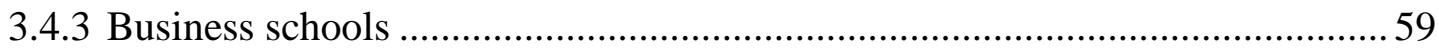

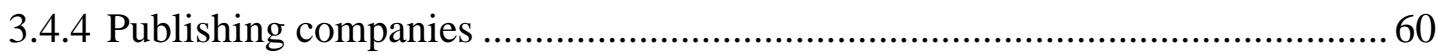

4. Structural relations ......................................................................................662

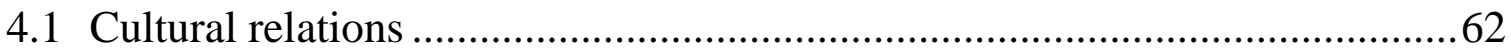

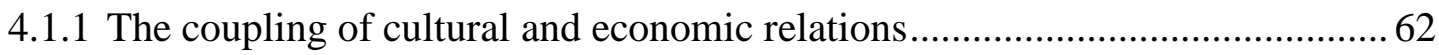

4.1.2 Task-specific and task-related knowledge ...................................................63

4.1.3 Cultural relations: theoretical conceptions of knowledge.................................65

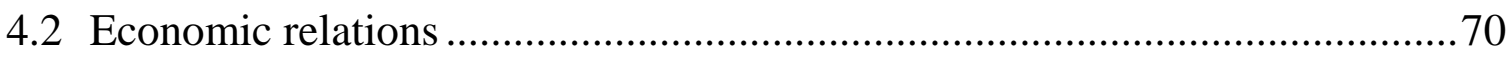

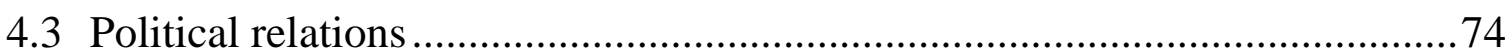

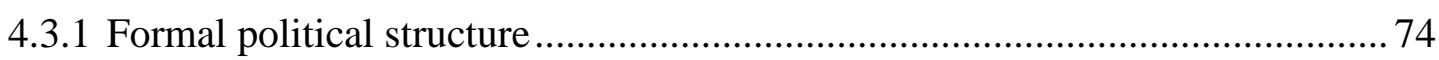

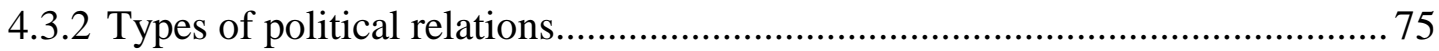

4.3.3 Power relations: theoretical conceptions of power ......................................... 77

4.4 Social mechanisms for integrating and coordinating of cultural production ..................................................................... 86

4.5 Relations with the environment..............................................................92

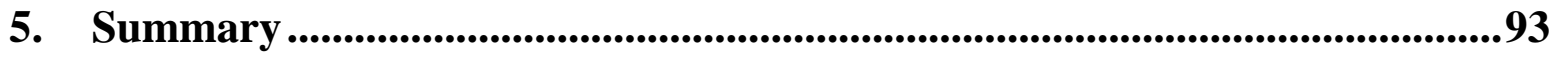

C. ESTABLISHED MODELS OF THE CLIENT-CONSULTANT INTERACTION .........................................................................95

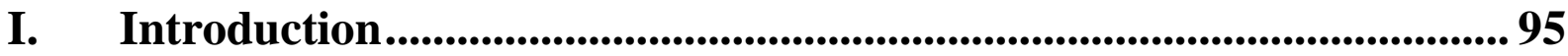

II. The expert model........................................................................ 97

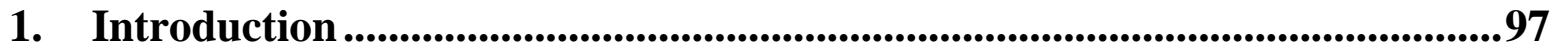

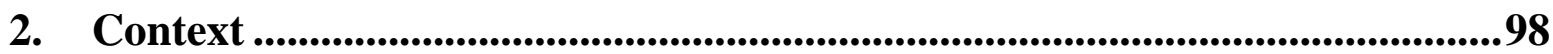

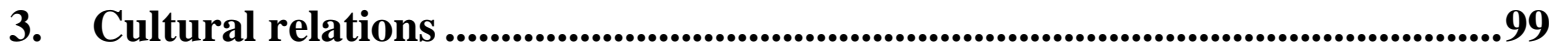




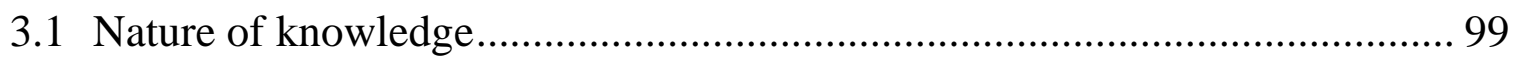

3.2 Knowledge transfer and creation ............................................................. 100

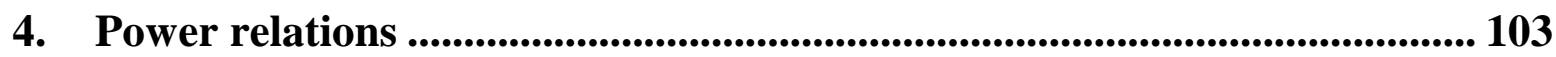

5. Nature of professional business services ............................................................ 103

6. Attributes of clients and consultants.............................................................. 104

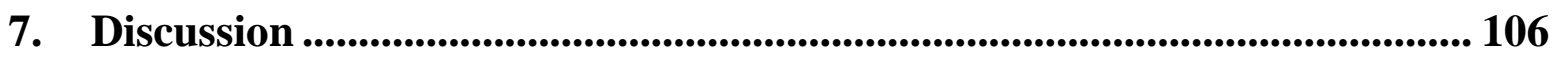

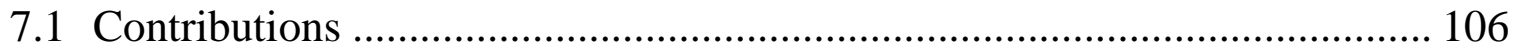

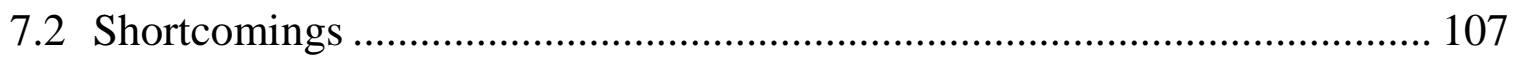

8. Summary …......................................................................................................................... 118

III. The reflective practitioner model ......................................................... 119

1. Introduction ................................................................................................................... 119

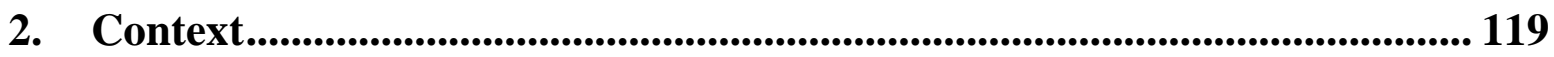

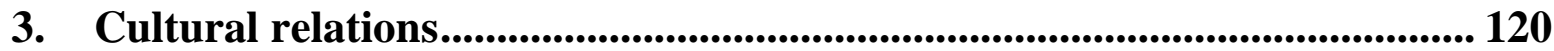

3.1 Nature of knowledge............................................................................ 120

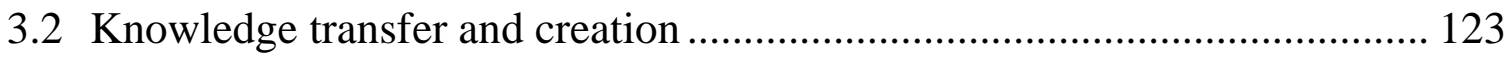

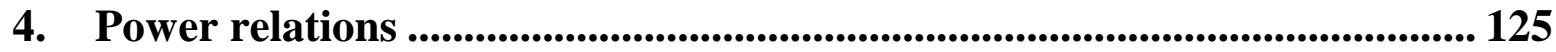

5. Nature of professional business services ............................................................ 126

6. Attributes of clients and consultants........................................................... 127

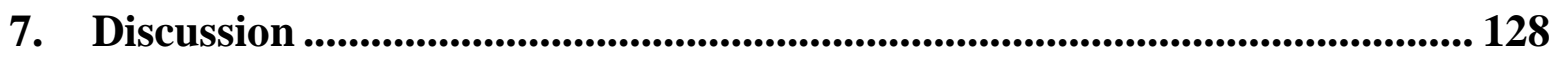

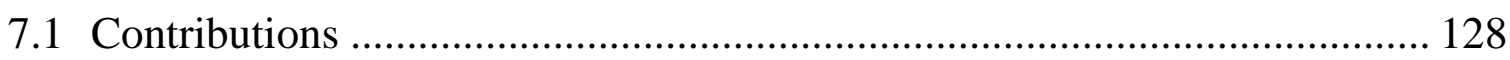

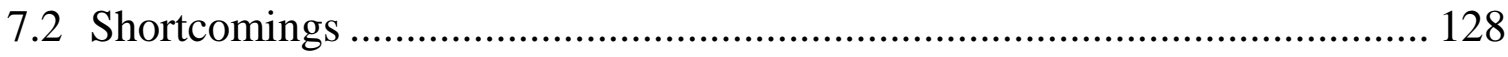

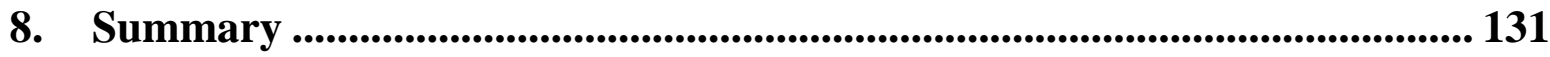

IV. The critical model............................................................................................... 132

1. Introduction ............................................................................................................... 132

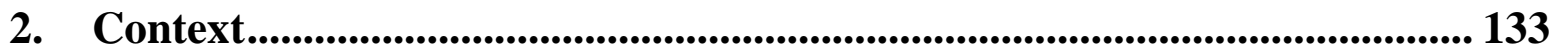

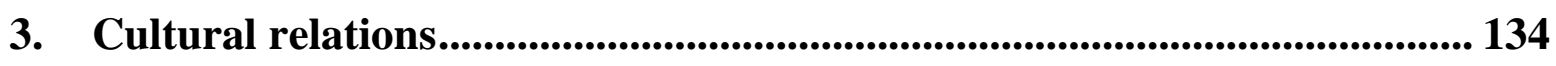

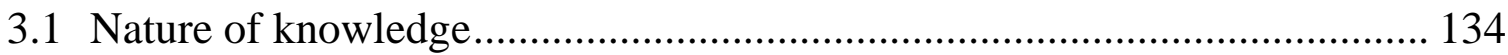

3.2 Knowledge transfer and creation ................................................................. 135

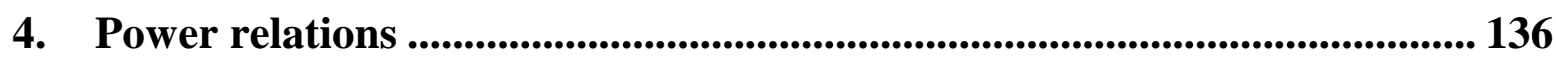

5. Nature of professional business services ........................................................... 139 
6. Attributes of clients and consultants ......................................................139

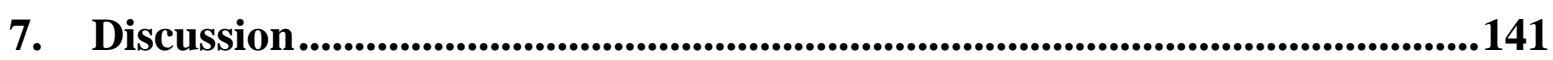

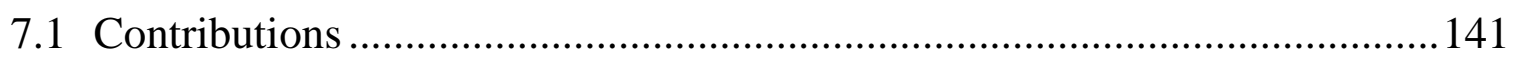

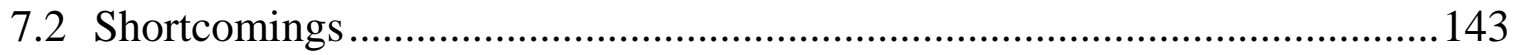

8. Summary .....................................................................................................................148

D. TOWARDS AN INTERPRETIVE MODEL OF THE CLIENTCONSULTANT INTERACTION ............................................. 150

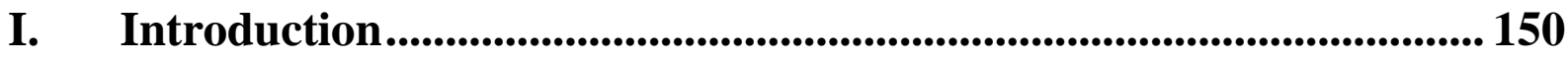

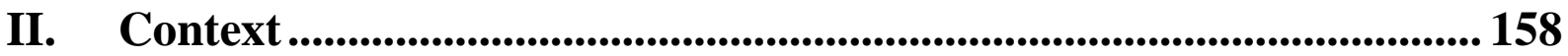

III. Cultural relations .................................................................................... 163

1. Nature of knowledge ............................................................................................163

1.1 Cognition, learning, and knowledge .........................................................163

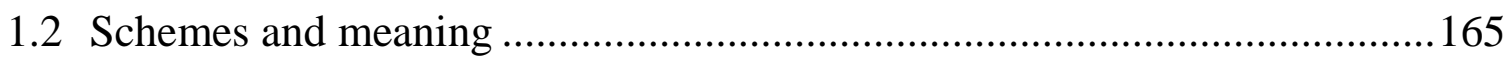

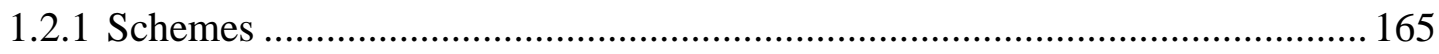

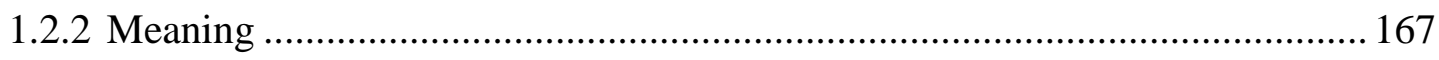

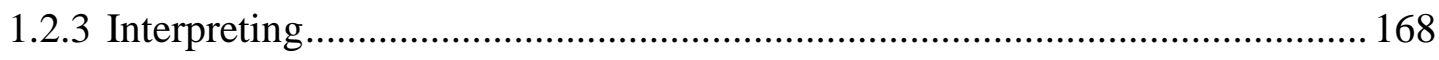

2. Interpretive communities ...............................................................................170

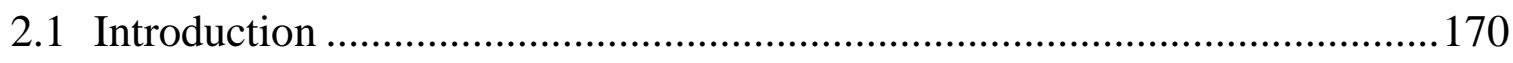

2.2 Origin and nature of interpretive communities ..............................................171

2.3 Relations between interpretive communities .................................................173

2.4 Interpretive communities versus communities of practice or the missing link to cognition and power ......................................................174

2.5 Driving forces of different interpretive communities .....................................177

2.6 Organizations as communities of interpretive communities..........................179

2.7 Management of interpretive communities at McKinsey .................................181

2.8 Interpretive diversity: some implications ......................................................184

3. Knowledge transfer and creation .......................................................................187

3.1 Client-consultant team as a community of interpretive communities............187

3.2 Shared task-specific knowledge ………………............................................189

3.3 Shared task-related knowledge.....................................................................190 
3.4 A model for explaining the role of shared task-related knowledge for team performance

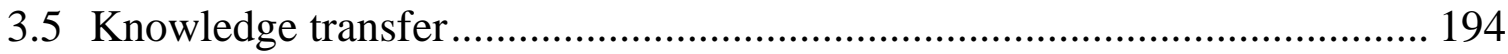

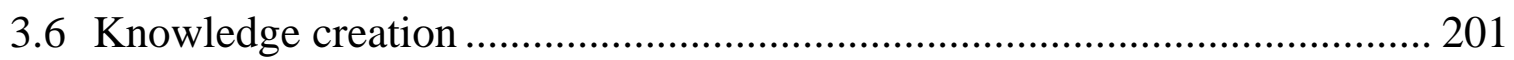

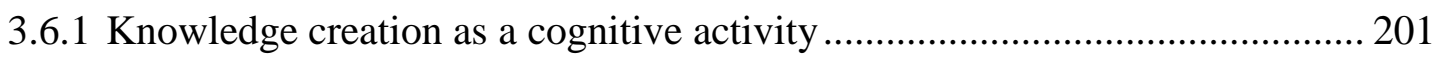

3.6.2 Knowledge creation in client-consultant teams .............................................. 203

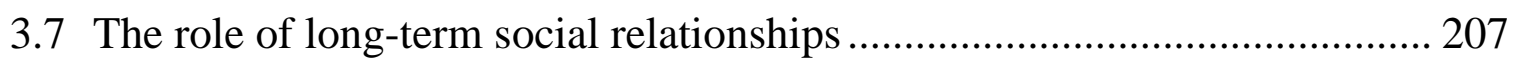

3.8 Mechanisms for knowledge transfer and creation........................................ 208

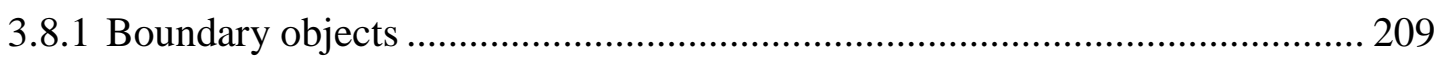

3.8.2 Rational reasoning .................................................................................. 215

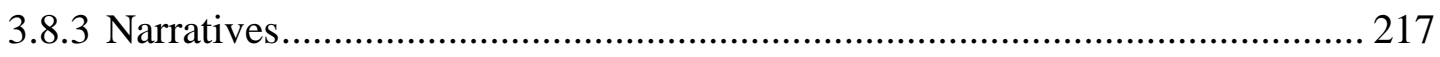

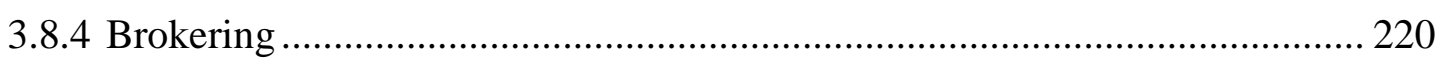

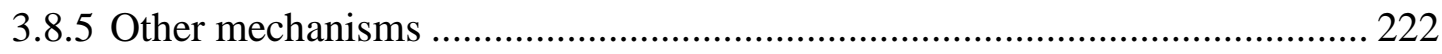

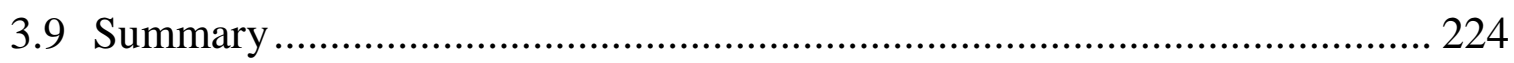

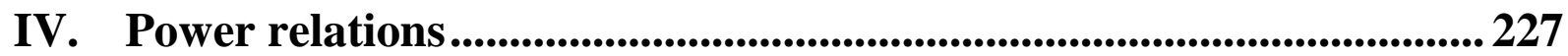

1. Introduction ............................................................................................................ 227

2. Power, rationality and the "ideal speech situation" ......................................... 230

3. Nature of power ............................................................................................................. 233

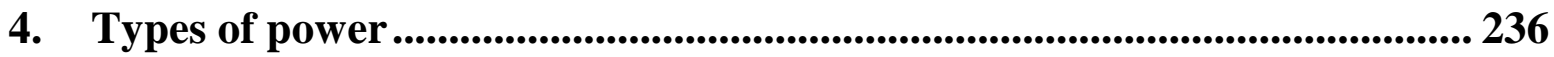

4.1 Positional power ………………………………................................... 236

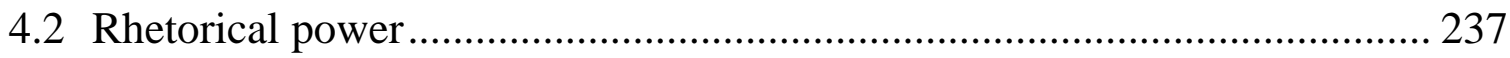

5. Power within the client-consultant team ........................................................... 240

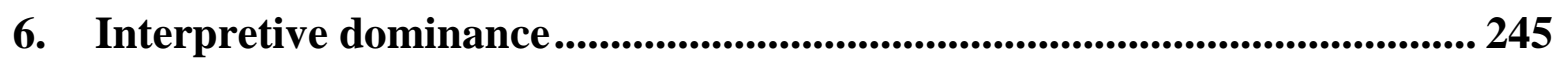

6.1 Callon's four moments of translation .......................................................... 245

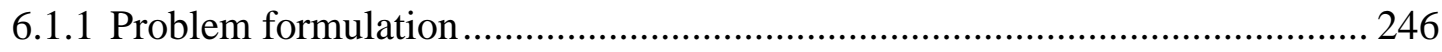

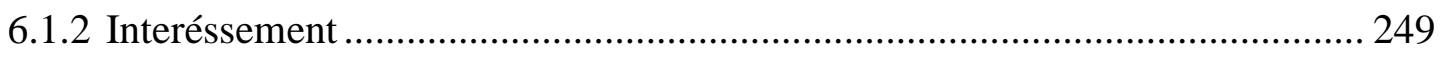

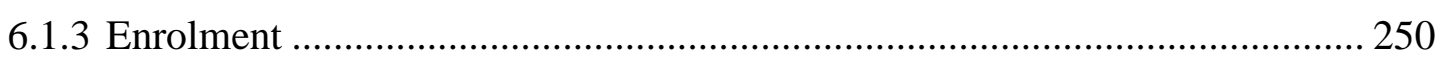

6.1.4 Mobilisation of allies ................................................................................... 250

6.2 The outcomes of interpretive dominance ................................................... 252

6.3 Interpretive dominance as a contested process ................................................. 253

6.4 A socio-cognitive model of the emergence of consulting "fads".................. 254

6.5 Symbolic resources as tools for interpretive dominance ................................ 256

7. Power within one interpretive community ....................................................... 257 
V. Nature of professional business services..................................................... 258

VI. A typology of client-consultant relationships ......................................... 261

1. Expert “consulting” ......................................................................................................263

1.1 Nature of problem-solving process and problem solutions............................264

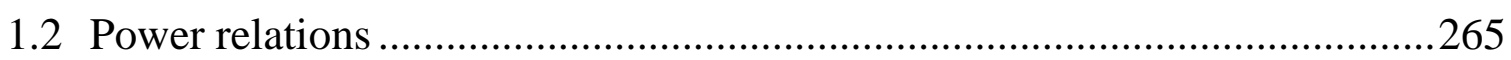

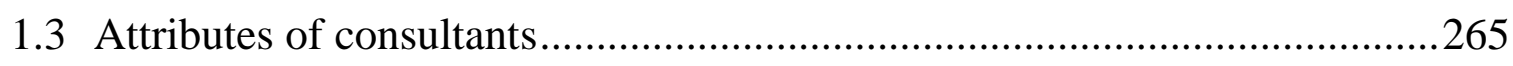

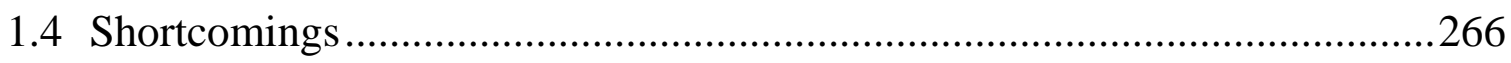

2. Confirmatory consulting ......................................................................................268

2.1 Nature of problem-solving process and problem solutions.............................268

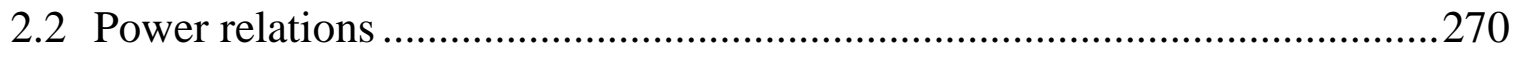

2.3 Attributes of clients and consultants .............................................................271

3. Disturbing consulting............................................................................................2272

3.1 Nature of problem-solving process and problem solutions.............................22

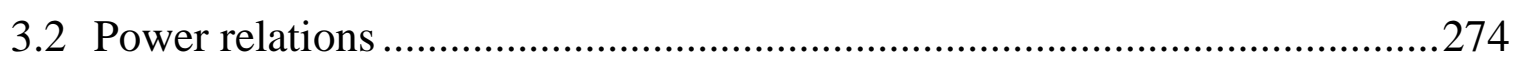

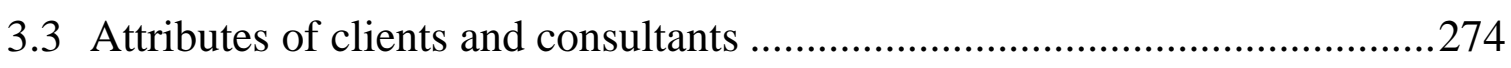

4. Structural relations in client-consultant projects .............................................275

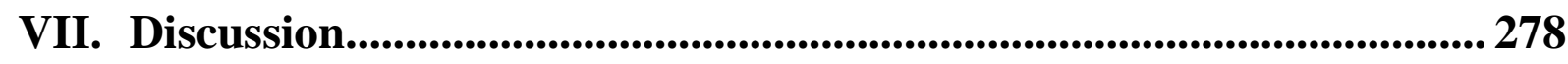

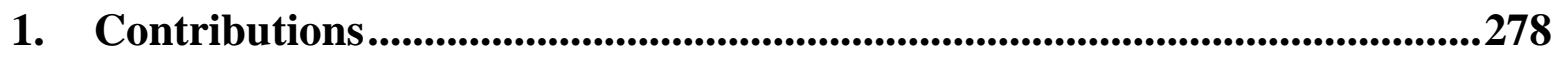

2. Shortcomings ...........................................................................................................280

VIII. Summary ............................................................................................................... 282

E. CONCLUSION ...................................................................................... 285

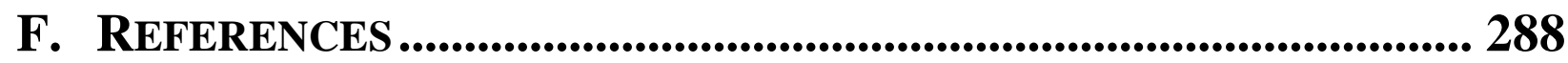




\section{Figures}

Figure 1: Risk and types of consulting tasks................................................................ 32

Figure 2: The main subsystems of any human system................................................... 36

Figure 3: A systemic perspective of client-consultant interaction .................................39

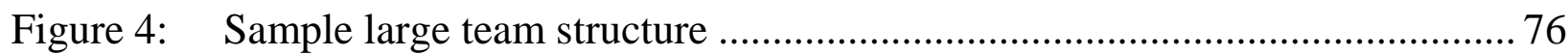

Figure 5: The problem solving process in consulting projects. .................................... 101

Figure 6: Knowledge transfer as a resource transfer.................................................... 110

Figure 7: Power/dependence in client-consulting teams................................................ 112

Figure 8: Knowledge transfer and creation as a reflection ....................................... 125

Figure 9: Knowledge transfer and creation as a symbolic interaction......................... 136

Figure 10: A model for the explanation of the extraordinary growth

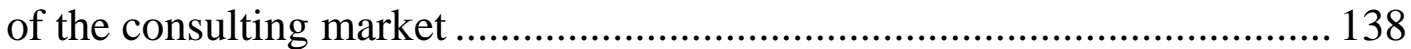

Figure 11: Communities of involvement within McKinsey ........................................ 183

Figure 12: The client-consultant team as a community of interpretive communities... 188

Figure 13: A framework for explaining the role of team mental models in team performance

Figure 14: Development of shared knowledge in the liminal space 201

Figure 15: The role of long-term social relationships on knowledge transfer and creation 208

Figure 16: Knowledge transfer and creation in matching interpretive communities.... 225

Figure 17: Power/dependence in the client-consultant relationship 244

Figure 18: A socio-cognitive model of the emergence of consulting "fads" 254 


\section{Tables}

Table 1: Main approaches to the nature of professional services..................................13

Table 2: Services considered professional—selected studies ........................................18

Table 3: A knowledge-based typology of professional services ...................................20

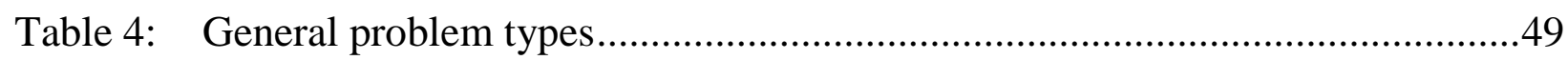

Table 5: Problem types in client-consultant projects and their characteristics ...............55

Table 6: Alternative perspectives on knowledge in organizations ...................................66

Table 7: Alternative perspectives on power in organizations ..........................................79

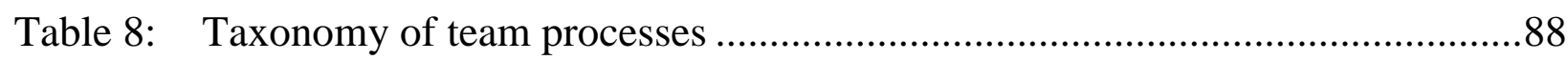

Table 9: Selected consulting concepts .........................................................................102

Table 10: Charisma versus technique ...........................................................................140

Table 11: A summary of models of the client-consulting relationship ............................155

Table 12: Community of practice view vs. Community of interpretation view..............177

Table 13: Sectors and centers as interpretive communities within McKinsey................182

Table 14: Communication mechanisms for knowledge transfer and creation ................224

Table 15: Structural relations in client-consultant projects ..............................................2.27 


\section{A. Introduction}

\section{Problem and Aim}

"The 2002 outlook for professional services is indeed grim []. But the recession is not entirely to blame. Consultants have been the first to preach customer-relationship management [] to their clients-but the last to adopt such practices themselves"1

During the last decade, there has been increasing interest from both practitioners and researchers and, as a result, a growing number of academic studies, in the area of knowledge, knowledge transfer and creation, and knowledge management. ${ }^{2}$ The notion that knowledge is the most significant resource in the modern economy ${ }^{3}$ and that industrial societies are transforming themselves into knowledge societies ${ }^{4}$ has been discussed extensively. It has been argued that knowledge-intensive firms or professional business service firms are at the forefront of these developments. ${ }^{5}$

Due to the dramatic increase in the amount of knowledge available, and necessary, for creating products and services, it has been suggested that companies need to gain access to both their customers' and other organizations' knowledge to ensure their longterm competitiveness. ${ }^{6}$ Furthermore, organizations need to learn how to jointly create knowledge and thus use both their own respective advantages and each other's expertise and experience. For professional business service firms in particular, it has been repeatedly emphasized that the integration of the client in the consulting process is the most important success factor. ${ }^{7}$ However, research rarely states exactly what a close cooperation between clients and consultants implies, and in particular, what it implies for the problem-solving process.

The following work concentrates on the relationship between client organizations and professional business service firms to discuss how companies solve problems during their interaction. Because the problem-solving process involves the exchange and production of knowledge, the following work focuses on questions regarding the nature of knowledge, its transfer, and creation. Professional business service firms are especially suitable for this analysis, as knowledge and experience is what they offer to their clients. ${ }^{8}$ Although there has been increased recognition and research of this topic, it has been

Bonchek (2002), p. 14.

See, e.g., Alvesson/Kärreman (2001); Empson (2001); Tsoukas/Vladimirou (2001); Reihlen/Ringberg (2006); Scarbrough/Swan (2000); Hansen et al. (1999); Sarvary (1999).

See Krogh/Roos (1995), p. 180; Probst et al. (2000), pp. 2-5.

See Bell (1973), p. 212; Drucker (1969), p. 278; Stehr (1994), pp. 5-17.

See, e.g., Alvesson (1995a), pp. 6; Starbuck (1992), p. 715; Sveiby/Lloyd (1987), pp. 10.

See, e.g., Bettencourt et al. (2002), p. 101; von Hippel (1988), Sveiby (1998), p. 41.

See Köppen (1999), p. 84; O’Farrell/Moffat (1991), p. 206; Schön (1983), p. 290; Tordoir (1995), p. 139; Werr/Styhre (2003), p. 43.

See Reihlen (2003a), p. 2. 
argued that much work still needs to be done in order to analyze how knowledge can be exchanged between clients and consultants. ${ }^{9}$

Human interactions, however, are always influenced by power, ${ }^{10}$ and the following work shows how power relations influence knowledge transfer and creation, i.e. how they influence problem-solving within client-consultant teams. ${ }^{11}$ Additionally, by providing insights on the micro processes of power emergence that lead to the development and/or dissemination of management fads or ideas, this work enhances one's understanding of the origin, development, and the factors that influence the success of management practices and their dissemination. This should enable both clients and consultants to gain a better understanding of their role in the production and dissemination of management ideas.

Therefore, this work concentrates on the relationship between clients and professional service providers within the scope of service production. As such, it addresses a gap in the literature by developing a new conceptual model that provides a more differentiated view of the cultural and political relations between clients and consultants during service production. In professional business service firms, cultural relations overlap to some extent with economic relations-the economic process of service production is at the same time a cultural process of knowledge transfer and creation. ${ }^{12}$ This work also sheds some light on the economic aspects of client-consultant interaction. However, other activities that are relevant for the success of client-consultant relationships, such as costing and pricing of assignments; project management; management and integration of professional work and workers within professional service firms; quality management; and the processes of building, maintaining and transferring professional reputation; are not, or only briefly discussed, as they are not at the heart of this work. ${ }^{13}$

Because professional services are created through teamwork, this work focuses on client-consultant teams as the smallest social unit of professional work. ${ }^{14}$ Clearly, these relations are embedded in a broader institutional context, including long-term clientconsultant relationships and alliances between client and consultant companies. ${ }^{15}$ In other

See Czerniawska/May (2004), pp. 20-21. The authors further argue that "it is a process that neither side fully understands at present and to which each side has been only half-heartedly committed in the past”. Ibid, p. 21.

As Townley puts it, "whether explicitly acknowledged, or not, the experience of work is located in, and constituted by, power relations”. Townley (1994), p. 1.

Lawrence et al. point out that because organizations are inherently political, any analysis of organizational learning without an understanding of its political dynamics will always be incomplete. See Lawrence et al. (2005), p. 180. See also Bryson who argues that the client-consultant interaction depends on cultural and power relations. See Bryson (1997), p. 103. Additionally, Brown points out that projects in organizations, including consulting projects, are often vehicles for communicating new sets of power relations, and as such, they legitimate these new power relations. See Brown (1995), p. 962. In contrast, most of the research on consulting assumes that clients and consultants develop trust to each other, which implies that power relations become irrelevant. See, e.g., Köppen (1999), p. 85. See chapter B.II.4.1.1 for an extensive discussion of this issue.

See chapter B.II.4.4 and B.II.4.5. These aspects have to be further developed in consequent research. See also Lowendahl (1997), Kubr (1996), Maister (1982a); Maister (1993), Müller-Stewens et al. (1999) and Sadler (1998) who discuss some of these issues.

See, e.g., O’Farrell/Wood (1999), pp. 134-135. Whereas in the 1960s and 1970s consulting was typically thought of as a single, discrete project where consultants moved after project termination to the next interesting client, today, the general norm in many professional business service firms is to strive for long-term relationships with their clients. Estimates of 
words, client-consultant relationships exist and can be analyzed at different levels. This work concentrates on the micro relations between clients and consultants. ${ }^{16}$ However, some of the insights presented within this work can be appropriated in a subsequent study in order to analyze the long term, project-spanning relationships between clients and professional service providers. ${ }^{17}$ This would imply, in particular, a stronger focus on the so-called mobilizing practices of professional service providers that are oriented towards developing trust and reputation.

Professional business service firms are one of the most dynamic and advanced industries in the modern economy. Throughout the last several decades, most professional business services have gained increased economic significance in all developed economies. For example, the management consulting industry was one of the fastest growing sectors in the last 10 years of the $20^{\text {th }}$ Century. In 1980 , the worldwide industry revenues were around \$3-5 billion; by 2001, this figure had increased to approximately $\$ 62$ billion $^{18}$ and in 2004, it was more than $\$ 123$ billion, ${ }^{19}$ demonstrating that the economic impact of the management consulting industry is undeniable. ${ }^{20}$ With management consultants taking on increasingly active roles within companies, governments, and institutions they serve, ${ }^{21}$ the organizational impact of consulting activities is rising as well. This is true for all professional business service firms. Giddens, for example, points out that experts "provide the systems of technical accomplishment and professional expertise that organize large areas of the material and social environments in which we live today [] and influences many aspects of what we do in a continuous way". ${ }^{22}$ Reed suggests, "the specialized knowledge and skill that experts provide plays a pivotal role in framing decision-making agendas and the substantive outcomes which flow from them." 23 Thus, management consultants have been recognized as important change agents who introduce new perspectives and frames of reference in client organizations. ${ }^{24}$ However, increasing client dissatisfaction, aided by the postdot.com economic slowdown and the wave of corporate scandals (e.g., Enron, WorldCom), has hit management consulting hard. ${ }^{25}$ In 2002, global consulting revenues declined for the first time in more than 30 years, signaling a significant turning point for the prevailing business model of management consulting. More than 24 months later, the industry's long-term growth forecasts of $3 \%$ are a fifth of what they once were, ${ }^{26}$ and still

the consulting industry show that at least 60 percent of current consulting revenues originate from existing of former clients. See Poulfelt et al. (2005), p. 16.

It should be clear that consultants will be successful in establishing long term business relationships with their clients only if they master their relationships within single projects.

Some implications of long-term client-consultant relationships are discussed in D.III.3.7. and D.IV.6.3.

See Fincham/Clark (2002-3), p. 7. Since 1990, the industry has grown at an average rate of 10 percent per year with the top firms growing at rates of 20 to 30 percent. See Fombrun/Nevis (2004), p. 6.

See Byrnes (2004), p. 120.

See also Kipping (2002), pp. 269-270.

See Fombrun/Nevins (2004a), p. vii; Morris (2000), pp. 126-128; Kitay/Wright (2003), p. 21.

Giddens (1991), p. 27.

Reed (1996), p. 574.

See Abrahamson (1996), p. 265; Ginsberg/Abrahamson (1991), pp. 176-177; Suddaby/Greenwood (2001), pp. 938.

See also Armbrüster/Kipping (2002-3), p. 20.

See Byrnes (2004), p. 120. 
there is little evidence of significant change to the prevailing consulting business model. This is accompanied by an increase in the number of potential clients with doubts about the value of consulting services. ${ }^{27}$ As Ashford suggests, "increasingly clients are concerned that consultants are pushing standardized solutions rather than really listening to the issues [of their clients] and being guided accordingly". ${ }^{28}$ Or, even worse, creating solutions for "manufactured problems" associated with the latest "thought leadership" fad. Gable's assessment is even blunter: “...the client and consultant have vested interests in explicitly pursuing diametrically opposed agendas.” ${ }^{29}$ Consultants, on the other hand, regard themselves to be "substantial contributors, in their own right, to the collective store of management knowledge" ${ }^{30}$ and find fault with client demands for quick fixes to deep-seated organizational problems. Some authors predict that due to the gap between actual consulting solutions and increasing and “unserviceable" client's demands for innovative solutions, client's dissatisfaction will continue to rise, ${ }^{31}$ making the client-consultant relationship more difficult to sustain. Thus, this work seeks to narrow this (seemingly widening) gap through addressing alternative views of management consulting, concentrating on the client-consultant interaction, which is centrally important to all professional service firms. ${ }^{32}$ In Mullingan and Barber terms, "the relationship is the major tool and grease of the consultancy function". ${ }^{33}$

In the literature, there are three major models of the client-consultant interaction. ${ }^{34}$ The models have different assumptions regarding the nature of the client-consultant relationship and its success factors. These differences are due to dissimilar understanding of consulting knowledge, and its transfer and creation within the existing models, as well as their dissimilar approach to the nature and role of power in client-consultant projects. As a result, the models represent totally different views of the client-consultant interaction.

The expert model is the oldest and best-established model of client-consultant relationships. ${ }^{35}$ According to this model, what differentiates management consultancies from traditional manufacturing companies is that they create value through their contribution of expertise and experience in solving client problems. ${ }^{36}$ The problemsolving process is characterized by the consultants' independence from clients, which enables the consultants to generate objective information and problem solutions while

See Poulfelt et al. (2005), pp. 3-5.

Ashford (1998), p. xvi.

Gable (1996), p. 1193.

Suddaby/Greenwood (2001), p. 934.

See, e.g., Czerniawska (1999), pp. 18-20.

See Köppen (1999), p. 27; O’Farrell/Moffat (1991), p. 206; Schön (1983), p. 290; Tordoir (1995), p. 139; Werr/Styhre (2003), p. 43.

Mulligan/Barber (1998), p. 67.

Both terms (management) consultant and client are used in this work as generic terms. Consultants are persons who perform all of the typical consulting functions, and consulting is seen as synonymous to a professional advisory service for fee and thus addresses all professional business service firms. The term client applies to any manager, administrator, or organization using advisory services in private businesses, public enterprises, government agencies, or elsewhere. The term professional is discussed more extensively later in this work.

See, e.g., Abbott (1988); Kubr (1996); Schein, (1987, 1988).

See Abbott (1988), pp. 35-58; Lowendahl (1997), p. 12; Müller-Stewens et al. (1999), pp. 20-23. 
remaining separate from internal power struggles and hidden agendas. ${ }^{37}$ Thus, the expert model describes a highly efficient form of client-consultant interaction with no need for an intensive interaction between clients and consultants apart from the transmission of information. The model experiences, however, an increasing criticism due to its positivist assumptions regarding the nature of knowledge and power, which result in an overly simplistic picture of the client-consultant interaction. The practical implication of the model is that the problem-solving process has the characteristics of a buying process where clients buy more or less standardized solutions from consultants rather than to create them jointly with consultants. As already discussed, client's dissatisfaction with consulting services has been rising, putting pressures on consulting companies to rethink their existing business models and change the way in which they work with clients.

A suggestion for a different understanding of the nature of the interaction between clients and professionals was introduced early on by Schön. ${ }^{38} \mathrm{He}$, in particular, recognized that the nature of the consulting expertise has implications for the nature of the client-consultant interaction. ${ }^{39}$ Consequently, he proposed an analytic view of the client-consultant interaction as a "reflective conversation" between clients and consultants. ${ }^{40}$ Although Schön's approach is a first step towards an understanding of the client-consultant relationship as a complex interface, concrete ways for improving knowledge transfer and communication within client-consultant teams remain unexplored, which is one of the major weaknesses of the model. Moreover, Schön's account of the role of power in client-consultant projects is very superficial. In general, Schön's model remains too generic and unspecific in its descriptions of the nature of the client-consultant interaction and in its prescriptions of how to improve it.

The critical $^{41}$ model also emerged as a response to the rising criticism of consulting as described by the expert model ${ }^{42}$ but it differs extensively from Schön's model. This model is grounded in postmodernism, a totally different theoretical tradition from the one behind the expert and Schön's models, which explains its particular view of consulting and the client-consultant relationship. Supporters of this model stress the ambiguity of knowledge in general, and consulting knowledge in particular, and claim that consulting is not an activity involving the transfer of valuable knowledge from consultant to client. Rather, what is at the heart of consulting, they argue, is the creation of images and perceptions that make clients believe in the value of the consulting concepts and models, which are regularly "produced" and introduced to the managers of organizations. Although the critical model provides some important insights toward the nature of clientconsultant relationships, its theoretical assumptions regarding the nature and role of

The name of the model is adopted following Fincham/Clark (2002) who speak about "the critical perspective" on consulting. Fincham/Clark (2002), pp. 6-7. It does not derive from a stream within organization theory called critical management theory. 
knowledge and power in client-consultant interactions as well as some of its practical implications are highly problematic.

Thus, despite their valuable contributions in explaining the client-consultant relationship, the existing models have important shortcomings and do not account for the multifaceted and complex nature of this interaction. One improvement might be to combine these models as a means of compensating for their individual weaknesses. It appears that such a combination would provide the richest view of client-consultant interaction. However, creating such an integrative framework is difficult given the different and perhaps incompatible assumptions of the models about the nature of knowledge, knowledge transfer, and power. Thus, it is suggested here, that in order to account for the complex nature of the client-consultant interaction, a new model is needed; a model that synthesizes the existing models by accounting for their contributions while, at the same time, providing a new theoretical background in order to overcome the incompatibility of the assumptions of the existing models. In other words, such a model should recognize that the existing models provide important insights on the nature and success factors of client-consultant interaction, but that a combination of the existing models is not possible due to the incompatibility of these models. ${ }^{43}$ Moreover, the model should pay attention to important aspects of the client-consultant relationship, which are not recognized by existing research.

This work suggests such a model, called "the interpretive model". The interpretive model emphasizes the need to look at the pluralistic nature of human cognition and understanding and its implication on human interactions. It is grounded in the theoretical tradition of critical realism. It presents a micro view of human interactions starting with a discussion of the nature of human cognition and understanding. It goes further to recognize the social character of human cognition, suggesting that individuals who share some cognitive frames participate in a number of interpretive communities. It deduces from here, that clients and consultants are members of different interpretive communities, which implies that they have important and often different perspectives on the problem at hand. This makes it necessary for them to find ways to share their interpretations if they want to profit from the different knowledge bases present in client-consultant teams. At the same time, the existence of different perspectives increases the probability for creation of novel solutions and new knowledge. In the process of cooperation and transferring of perspectives, however, clients and consultants inevitably also compete with each other about which interpretation should be taken as a basis for the problem solution. The model recognizes, as such, that power is always at work within clientconsultant teams. It looks at the types of power that are characteristic for clientconsultant teams, and shows that whoever develops a dominant interpretation within the client-consultant team will decide upon the problem solution. Such power, it is argued,

43

This mirrors the belief that "all social phenomena may have many potential ways of revealing themselves and that the way they are realized in practice depends on the mode of engagement adopted by the researcher”. Morgan (1983), p. 389. As such, this work, or social research in general, is ultimately a product of the researcher's interaction with a multifaceted phenomenon, and tells much about the researcher and his/her cultural milieu as it does about the phenomenon itself. Such a perspective emphasizes, at the same time, the importance of "the researcher's ability to be consciously self-critical of his/her favored research strategy, recognizing that while it is necessary to adopt a stance that is in some degree affirmational, it is also necessary to see the weaknesses as well”. Morgan (1983), p. 390. 
can have both negative-providing a standardized rather than individualized problem solution-and positive-finding a solution when consensus is not possible-influence on the outcomes of consulting projects.

The aim of the following work is to develop a model of the client-consultant relationship within professional business service firms that is both theoretically well founded, and practically relevant. Building upon a critical discussion of the contributions and shortcoming of existing research the proposed conceptual model provides a critical yet constructive platform for the development of a more differentiated view of professional work. The adopted approach is neither empirical nor normative. Instead, the suggested interpretive model is regarded as an analytical tool that sheds light on two interrelated issues: first, the cultural relations between clients and professional service providers concerned with knowledge transfer and creation; and second, their political relations including the influence of power on knowledge transfer and creation. Both these issues are discussed within the scope of concrete consulting projects. ${ }^{44}$ Additionally, the proposed consulting business model accounts for the existence of different types of client problems and discusses implications for the success of consulting projects. Therefore, a particular emphasis is placed on the different roles, needs, reactions, and behaviors of clients as an under-explored key factor in the success of such collaborations. ${ }^{45}$

For these purposes, this work is based on the management consulting industry as one of the most researched areas and, at the same time, the centre of the most controversial discussions, within the professional business services industry. For management consulting, the last few years have been arguably the most difficult period in the industry's history, ${ }^{46}$ suggesting an end to the dominance of the prevailing business model. The introduced interpretive model offers some suggestions for both clients and consultants as to how to improve their cooperation. It is important to point out that although there is no empirical study providing insights on the extent to which the one or the other model is applied in reality, a look at the consulting and management literature shows that the expert model is still the most commonly used model. This is also reflected in the increasing number of critical works that label consultants as impression managers and their services as "fad surfing” or ineffectual "quick fixes". 47 These results have arisen because the prevalent expert model is unsuccessful in delivering real value to client organizations.

This work builds upon and integrates a number of theoretical areas, such as management and organization studies, economics, sociology, psychology, and political economy. Thus, this work follows Wilson who claims that in order to understand consulting processes one needs to recognize that the "definitions of situations which people develop and the actions which relate to these are informed by real and material

\footnotetext{
44

As already mentioned this means that other important aspects of client-consultant relationships are blinded out. However, such an approach allows for a detailed discussion of the selected areas. in the consulting process and the shaping of the consulting process through the client are recognized, is a multifaceted analysis of the client-consultant relationship possible. See Iding (2000), p. 14.

See Kennedy (2004).

Jackson (2001), p. 13.
} 
differences of interest and experience between groups. These are sociological and economic phenomena as well as psychological ones. The essentially political nature of organizational life has to be recognized [as well]". ${ }^{48}$

Some of the ideas and concepts discussed within the interpretive model are not new. There have been an increasing number of accounts emphasizing that consulting should be seen as a highly interactive and cooperative relationship with the client. ${ }^{49}$ For example, one of the contributors in Block's book, ${ }^{50}$ a consultant himself, argues, "I like to watch a community of meaning emerging, where before it was a community of tasks and efficiency and getting work done. [] It's exciting seeing individuals and teams and whole companies find new mental models, paradigms, and thinking shifts". ${ }^{1}$ Another contributor states, "Consultants can benefit from consciously attending to the symbolic potential of phrases that resonate with the group. Symbols help the group extract meaning from their circumstances and help people find their voice, which is a primary objective of consulting”. "Our wish to give advice betrays our own need to control our clients, to have a stake in a specific process and outcome". ${ }^{52}$ These quotes are similar to some of the ideas that are developed within the proposed interpretive model of consulting. The problem with this and similar books on consulting is, however, that they are practical guides written for managers and consultants to help them enhance their collaboration. They are written in the form of stories that originate in the consulting experience of the contributors, and, as such, they offer only "general prescriptions to guide the practitioner who wishes to develop his relationship-building skills". ${ }^{53} \mathrm{Kubr}$, for example, advises the reader to achieve "joint problem definition" and to "listen, be patient and modest". ${ }^{4}$ McGivern concludes that most of these authors tend to consider the relationship between client and consultant to be almost entirely a matter of "chemistry", emphasizing trust and likeability. ${ }^{55}$ Additionally, such practical concepts and recommendations have no clear theoretical background. In other words, such books and articles do not make clear what are the important variables in the client-consultant relationship, and how are they related to and influence each other. In this sense, they are not scientific research. ${ }^{56}$ They represent only single accounts and do not provide a coherent theoretical view of consulting. The purpose of this work is to undertake, in the most rigorous and deepest way possible, a conceptual study of the nature, characteristics, and success factors of the client-consultant relationship, regarding the transfer and creation of knowledge in the process of problem-solving.

The following quote from Kast and Rosenzweig supports this argument: “Cookbook approaches, while seemingly applicable and easy to grasp, are usually short-sighted, narrow in perspective, and superficial—in short they are unrealistic. Fundamental concepts [] are more difficult to comprehend. However, they do facilitate a more thorough understanding of complex situations and increase the likelihood that appropriate action will be taken.” Kast/Rosenzweig (1973), p. 322.
} 


\section{Structure and Contents}

This work is organized into five main chapters. After this introduction, some general definitions and concepts are presented in section II. In particular, the terms professional business services and management consulting are discussed, and major characteristics of the client-consultant relationship are outlined. First, it is necessary to discuss the existing views of the nature of professional business services, in order to work out the approach that builds the basis for the discussion of management consulting, and the nature of consulting projects within this work. In a second step, the main characteristics of consulting services, as discussed in the literature, are presented, and it is suggested that a high degree of interaction with the clients is regarded as one of the most distinguishable attributes of consulting services. With this, the conceptual foundations of the work are set.

Section B introduces a framework for the analysis of the client-consultant relationship that helps to structure the following discussion and to show the main assumptions of the presented models of the client-consultant interaction. This framework takes a systemic perspective with the consequence that three major elements of clientconsultant relationships have to be analyzed for a complete understanding of this interaction: (1) the attributes of members of the client-consultant team; (2) the environment in which the team operates, that influences and is influenced by the actions of the team, in particular, the (immediate), problem-based environment; and (3) the structure of the client-consultant team, which includes the cultural, political and economic relations between the members of the team.

Three main categories of attributes are suggested and discussed in relation to their relevance for the client-consultant relationship: cognitive, motivational, and interactive. It is suggested that their relevance differs depending on the type of problem clients and consultants face. Next, a consulting-specific problem typology is developed and its implications for the structure and intensity of the client-consultant interaction are discussed. It is concluded that a unifying discussion of consulting services is inappropriate. Some general characteristics of the broader environment of management knowledge creation and dissemination are outlined as well.

When discussing the structural relations between clients and consultants, this work emphasizes that client-consultant teams are cultural systems oriented towards problemsolving. Therefore, the cultural relations among the team members are at the heart of this work. It is argued that both the economic and the political relations within clientconsultant teams are closely interwoven with the cultural relations, and these interrelations are discussed. In particular, it is stressed that power relations have a strong impact on the problem-solving process within client-consultant teams. In the literature on client-consultant relationships, both cultural and political relations are discussed, but within different epistemological traditions. In order to shed some light on the reasons for the existence of these competing views, as well as on their weaknesses, this work provides an overview of the theoretical approaches to the nature of knowledge and power that are reflected in the particular models of the client-consultant relationship. This is 
necessary, as a successful analysis of the interaction between clients and consultants presupposes, first, the clarification of the terms knowledge and knowledge transfer; and second, a discussion of the nature and role of power in human interactions. Additionally, two other types of structural relations are outlined: the first concerning the management and coordination of team members' activities, the second related to the interactions of the team with its broader environment. It is stressed that the development of concrete social mechanisms for the coordination and integration of clients' and consultants' work is an important aspect of successful client-consultant relationships that is mostly ignored in the literature on client-consultant interaction.

Based upon this framework, after a short introduction, the three basic models of client-consultant interaction are presented in section C, chapters C.II, C.III and C.IV. In order to understand these models one needs to explore the nature and consequences of the assumptions that frame these models. Therefore, the models are discussed with emphasis on their assumptions about the nature of knowledge, knowledge transfer and creation, and power structures. Consequently, their main critical points and implications for the interaction process are identified.

On this basis, it is argued that a different model of the client-consultant relationship is required. In chapter $\mathrm{D}$, the new theoretical framework is introduced and its main characteristics and general implications are discussed. It is suggested that client's and consultant's knowledge is embedded in communities of interpretation, and knowledge creation and transfer takes place within such communities. ${ }^{57}$ Because there has been little discussion in the literature about the interaction between separate communities and the difficulties of sharing knowledge across boundaries and reaching synthesis, ${ }^{58}$ as well as on how communities change their perspectives and how they add new perspectives, ${ }^{59}$ the concept of interpretive communities has to be expanded to allow for a better understanding of the interaction process between clients and consultants. By applying the concept of interpretive communities, it is shown that clients and consultants may have problems in understanding each other. ${ }^{60}$ Consequently, within their interaction there is a problem of translation: knowledge transfer and creation will only occur if the individuals involved in the interaction process develop some integration mechanisms in order to coordinate their work, and learn to share their views and interpretations of the problem at hand. Whose perspective will build the basis of the problem solution when there are several legitimate interpretations depends on the power or "interpretive dominance" of each community, which is constructed through discourse. ${ }^{61}$ As the translation of different interpretations is also simultaneously a mechanism of power, ${ }^{62}$ it is necessary to look at the power dynamics and the role of power in the knowledge transfer and creation within client-consultant teams. Additionally, after discussing the cultural and political relations between clients and consultants, as postulated by the new model, in chapter D.VI, the

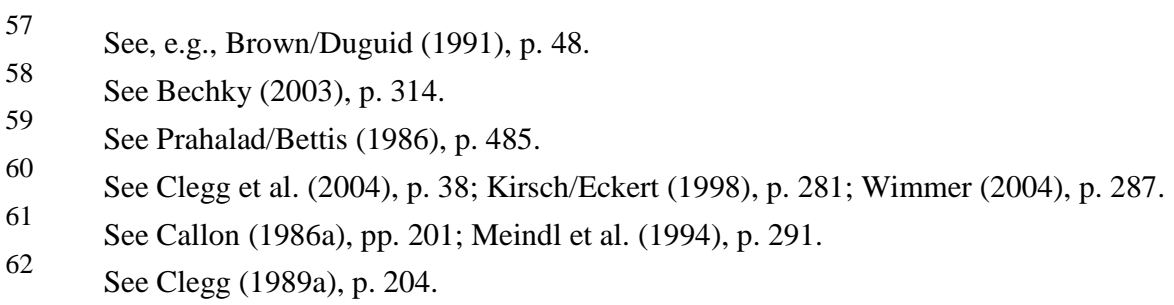


consulting problem typology developed in chapter B.II is enriched with the insights provided by the interpretive model. Some concrete suggestions are then offered as to how the requirements for successful consulting projects differ, depending on the problem at hand or on its interpretation by clients and consultants. Chapter E draws the themes of the work together and restates the main conclusions. 


\section{B. Conceptual foundations}

\section{Definitions and concepts}

\section{Professional business services}

Although professional business services have experienced high interest from researchers for many years, no clear-cut definition or interpretation of their nature and distinctiveness exists: "...there is little agreement on which services are to be considered professional." ${ }^{\prime 3}$ At the same time, there is a growing trend among service companies, such as restaurants, real estate agents, and retailers, to claim the status of professional services ${ }^{64}$ Hence, there is a danger of hollowing out the notion of professional services, which makes it important to determine their real nature. ${ }^{65}$

There have been several attempts in the literature to explain the nature of professional business services. Four major approaches can be outlined. Table 1 summarizes these approaches and outlines their major shortcomings. firms". Peters (1992), p. 11. historical character of the concept and the many perspectives from which it can legitimately be viewed, and from which sense can be made of it, preclude the hope of any widely accepted definition of general analytic value” (Freidson, 1994, p. 27), it is not the aim of this work to provide a definition of professional business services. However, the different perspectives on the term professional services are presented and discussed in order to gain some understanding of the nature of these services. 


\begin{tabular}{|c|c|c|c|c|}
\hline & Norm-oriented approach & Structure-oriented approach & Pragmatic approach & Work-oriented approach \\
\hline Main works & $\begin{array}{l}\text { Haskell (1984); } \\
\text { Merton/Gieryn (1982); } \\
\text { Parsons (1964); } \\
\text { Lowendahl (1997) }\end{array}$ & $\begin{array}{l}\text { Carr-Saunders/ Wilson (1933); } \\
\text { Caplow (1954); Millerson (1964); } \\
\text { Wilensky (1964); Wilson (1972) }\end{array}$ & $\begin{array}{l}\text { Aharoni (1993a, b, c, 1995); } \\
\text { Maister (1982, 1993); } \\
\text { Müller-Stewens et al. (1999); } \\
\text { Nachum (1999); } \\
\text { Noyelle/Dutka (1988); Scott } \\
\text { (1998); Tordoir (1995) }\end{array}$ & $\begin{array}{l}\text { Abbott (1988); Freidson (1970, } \\
\text { 1994); Halliday (1987); Reihlen } \\
\text { (2003a); } \\
\text { Scott (2001); Sibson (1971) }\end{array}$ \\
\hline $\begin{array}{l}\text { Main } \\
\text { assumptions }\end{array}$ & $\begin{array}{l}\text { Professional services are } \\
\text { services delivered according } \\
\text { to special professional norms } \\
\text { or a code of conduct. } \\
\text { Professional norms have } \\
\text { several functions: to ensure } \\
\text { professional's ethical } \\
\text { behavior; to control } \\
\text { professional identity to } \\
\text { enhance communication and } \\
\text { coordination of professionals' } \\
\text { conduct. }\end{array}$ & $\begin{array}{l}\text { The existence of a profession is } \\
\text { what makes professional services } \\
\text { distinctive. Professional } \\
\text { institutions are responsible for } \\
\text { deciding upon and granting } \\
\text { qualifying credentials; } \\
\text { development of professional } \\
\text { standards and formal training } \\
\text { programs; enforcement of peer } \\
\text { sanctions against members not } \\
\text { respecting norms. }\end{array}$ & $\begin{array}{l}\text { Professional services are services } \\
\text { that exhibit the following } \\
\text { characteristics: valuable and } \\
\text { specific knowledge; high } \\
\text { intangibility; high heterogeneity; } \\
\text { high degree of customization; high } \\
\text { degree of interaction with clients; } \\
\text { high credence qualities. }\end{array}$ & $\begin{array}{l}\text { The defining characteristic of } \\
\text { professional services is their abstract, } \\
\text { academic knowledge base, which has } \\
\text { three functions: (1) legitimating of } \\
\text { professional work and creating the } \\
\text { basis for the authority of } \\
\text { professionals; (2) defining the body } \\
\text { of knowledge and skills new students } \\
\text { need to learn in order to become a } \\
\text { competent practitioner as well as } \\
\text { developing of new methods for } \\
\text { solving problems within the } \\
\text { competence area of the profession; } \\
\text { (3) defining the borders of } \\
\text { professional jurisdiction. }\end{array}$ \\
\hline Shortcomings & $\begin{array}{l}\text { The claim of professional } \\
\text { norms serves the political } \\
\text { interests of these occupations; } \\
\text { no empirical evidence that the } \\
\text { behavior of professionals } \\
\text { differs from that of other } \\
\text { occupations; norms do not } \\
\text { explain the historical process } \\
\text { of professionalization. }\end{array}$ & $\begin{array}{l}\text { Explains the institutionalization of } \\
\text { professional knowledge, not the } \\
\text { nature of professional knowledge; } \\
\text { does not explain how } \\
\text { professionals conduct their work; } \\
\text { emphasis on professions serves } \\
\text { the political interests of these } \\
\text { occupations; ignores the fact that } \\
\text { special expertise also develops } \\
\text { outside of professionally } \\
\text { organized occupations. }\end{array}$ & $\begin{array}{l}\text { Provides a description of } \\
\text { professional services, not a basis } \\
\text { for analysis; attributes are not } \\
\text { theoretically related; the } \\
\text { institutionalization of professional } \\
\text { knowledge is not explained. }\end{array}$ & $\begin{array}{l}\text { Emphasizes the formalized, rational, } \\
\text { and objective character of } \\
\text { professional knowledge that is } \\
\text { created in academia or similar } \\
\text { institutions, and underestimates the } \\
\text { role of every day practice for the } \\
\text { creation of professional knowledge; } \\
\text { ignores the importance of } \\
\text { interpreting, narrative practices and } \\
\text { the shaping of meaning in } \\
\text { professional service firms and the } \\
\text { role of professionals in the "social } \\
\text { construction of reality". }\end{array}$ \\
\hline
\end{tabular}

Table 1: Main approaches to the nature of professional services 


\subsection{Norm-oriented approach}

This approach can be traced back to the work of Talcott Parson, who is often regarded as the "father" of studies on professions. ${ }^{66}$ Parson claims that the professional man is the prototype of a rational society, an agent of the following five values: affective neutrality —no emotional engagement with his clients-, universalism - treating all alike-, collectivity_-professionals work for the common goal—, functional specificity to clients-professional focuses on the problem of his expertise ignoring other aspectsand achieved competence-professionals have their position because of demonstrated abilities. ${ }^{67}$ Other supporters of this approach are Merton and Gieryn (1982), ${ }^{68}$ Haskell (1984) ${ }^{69}$ and Lowendahl. ${ }^{70}$ The following citation mirrors the main claim of the normoriented approach:

"The professional man...does not work in order to be paid, he is paid in order that he may work. Every decision he takes in the course of his career is based on his sense of what is right, not on his estimate of what is profitable". ${ }^{71}$

The implication is that professional services are services delivered according to special professional norms or a code of conduct. ${ }^{72}$ Thus, ethical norms that are shared and applied within professional service firms define what a professional behavior is, and a professional behavior is what makes professionals distinctive. Norms make sure, according to this argument, that if there is a conflict of interest between a client and a professional, the professional will decide in the best interest of the client. ${ }^{73}$ In addition, because professional knowledge involves a rather limited sphere of expertise, a professional must recognize that s/he has no expert authority outside the scope of that sphere. ${ }^{74}$ For example, if a client asks for an advice in an area where the professional does not have the necessary expertise, a professional has to decline the client's inquiry. Thus, the client's needs must be seen as more important than profits. ${ }^{75}$ Furthermore, professional norms serve as means for an indirect control over the professionals: by inscribing the logic of professionalism within their employees, companies are able to ensure appropriate work identities and conducts. ${ }^{76}$ Lowendahl states that another function of professional norms is to enhance communication and coordination within professional service firms. It is argued that in companies where the employees belong to the same profession, and thus share similar ethical norms, less time and effort is spent in the

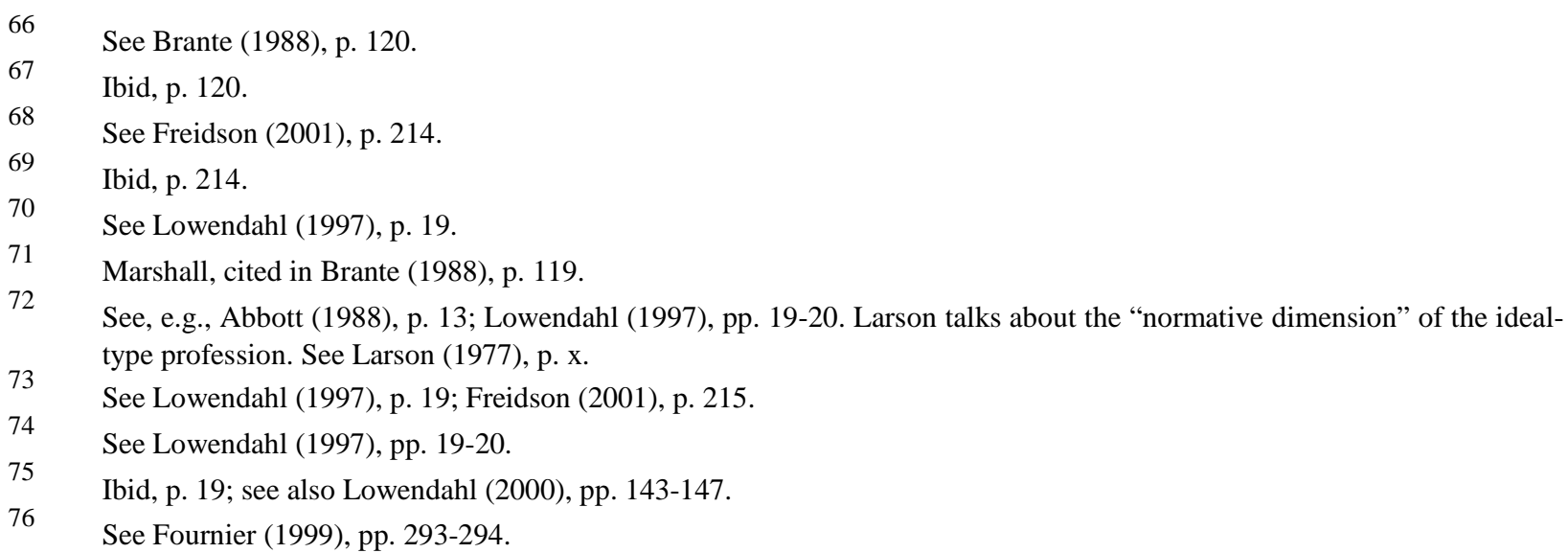


development of shared norms. ${ }^{77}$ This is, for example, the case in law and accounting firms as opposed to management consulting firms, where multiple professions coexist. This explains why consulting companies usually invest more intensively in the development of a company specific culture.

To sum up, this approach emphasizes the importance of professional norms for the work of professionals as a starting point when explaining the nature and existence of professional business services. At the same time, it puts less emphasis on the existence of professions. Professions are important insofar as they define and establish the professional norms of conduct. ${ }^{78}$ Some authors argue, however, that the true function of professional norms and ethical codes is to support the political interests of professions and professional service firms. ${ }^{79}$ They are symbolic vehicles, useful instruments for professions when they claim a special, protected status that gives them the exclusive right to offer certain services. Furthermore, as Larson argues, the implicit assumption that the behavior of professionals is more ethical than that of individuals in lesser occupations has seldom, if ever, been tested for empirical evidence. ${ }^{80}$ She concludes that this view of professions does "not tell us what a profession is, but only what it pretends to be". ${ }^{81}$ Additionally, empirical studies show that the existence of professional norms does not offer a satisfactory explanation of the professionalization of work. ${ }^{82}$ Abbott concludes that ethic codes were not "a culmination of natural growth"; rather, they "served the function of excluding outsiders, a function that became important only after the professional community had been generated and consolidated." 83 Thus, professional norms are a result of the existence of professions, not its cause. Hence, this approach is not sufficient to explain the nature of professions and professional business services.

\subsection{Structure-oriented approach}

The structure-oriented approach stresses that the existence of a profession that regulates the delivery of professional services, the access to the profession, and the education and training of the members of that profession, thus guaranteeing quality of service, is what makes professional services distinctive. ${ }^{84}$ Hence, it concentrates on the constitutive structural attributes of professions when explaining the nature of professional business services. These attributes include the existence of an academic body of knowledge acquired through a system of professional education and training. ${ }^{85}$ It also includes the existence of professional institutions-associations, institutes, chambers etc.- - responsible for granting qualifying credentials necessary to exercise the profession, the development of professional standards and formal training programs that produce the

See Lowendahl (1997), p. 26.

Ibid, pp. 26-27.

See Alvesson (1993) pp. 998-999; Alvesson/Johansson (2002), p. 233.

See Larson (1977), p. xi.

Ibid, p. xii.

See Hall (1969), p. 89.

Abbott (1988), p. 5.

See, e.g., Benveniste (1987), pp. 30-44; Hall (1969), pp. 89-90; Lowendahl (1997), p. 18.

This is the "cognitive dimension” of the ideal-type profession. See Larson (1977), p. x. 
credentials, as well as enforcing peer sanctions against members not respecting norms. ${ }^{86}$ Thus, the institutionalization of professions is the basis for their power and the limitation of client's freedom. It is an attempt of the professions "to solve the problem of persuasion", ${ }^{87}$ To summarize, according to this approach, only services that are delivered by members of a profession are professional. The main supporters of this approach are Carr-Saunders and Wilson, ${ }^{88}$ Caplow, ${ }^{89}$ Millerson, ${ }^{90}$ Wilensky $^{91}$ and Wilson. ${ }^{92}$

Opponents of this approach argue that it emphasizes the institutionalization of professional knowledge, not its nature and fails, hence, to answer what is specific about professional work. ${ }^{93}$ Abbott argues, "professionalization was at best a misleading concept, for it involved more the forms than the contents of professional life. It ignored who was doing what to whom and how, concentrating instead on association, licensure, ethics code." 94 He states further that these contributions fall short in answering the question of how professional teams conduct their work, how do they expand control over a body of knowledge and gain community support for their practices. ${ }^{95}$ Furthermore, the approach ignores the fact that special expertise can develop and exist outside established professions, which is, for example, the case with IT knowledge. ${ }^{96}$ Similar to the critics on the first approach, some authors argue that the emphasis on the existence of professions serves mainly to conserve the exclusive right of professions to deliver certain services, sheltering their position in both external and internal markets. ${ }^{97}$ "Professionalization is thus an attempt to translate one order of scarce resources-special knowledge and skills_-into another-social and economic rewards." 98 Consequently, the approach does not offer sufficient clarity on the nature of professional services.

\subsection{Pragmatic approach}

A third approach includes studies that do not define explicitly professional services. Rather, supporters of this approach study firms that are regarded as professional, e.g., management and engineering consultants, lawyers, accountants, advertising agencies, architects and market research firms, and discuss a list of characteristics of professional business services, which are not theoretically deduced. ${ }^{99}$ For example, Aharoni, one of the major proponents of this approach, argues that professional business service firms offer „...as the name implies, professional services - auditing, consulting, legal advice

86

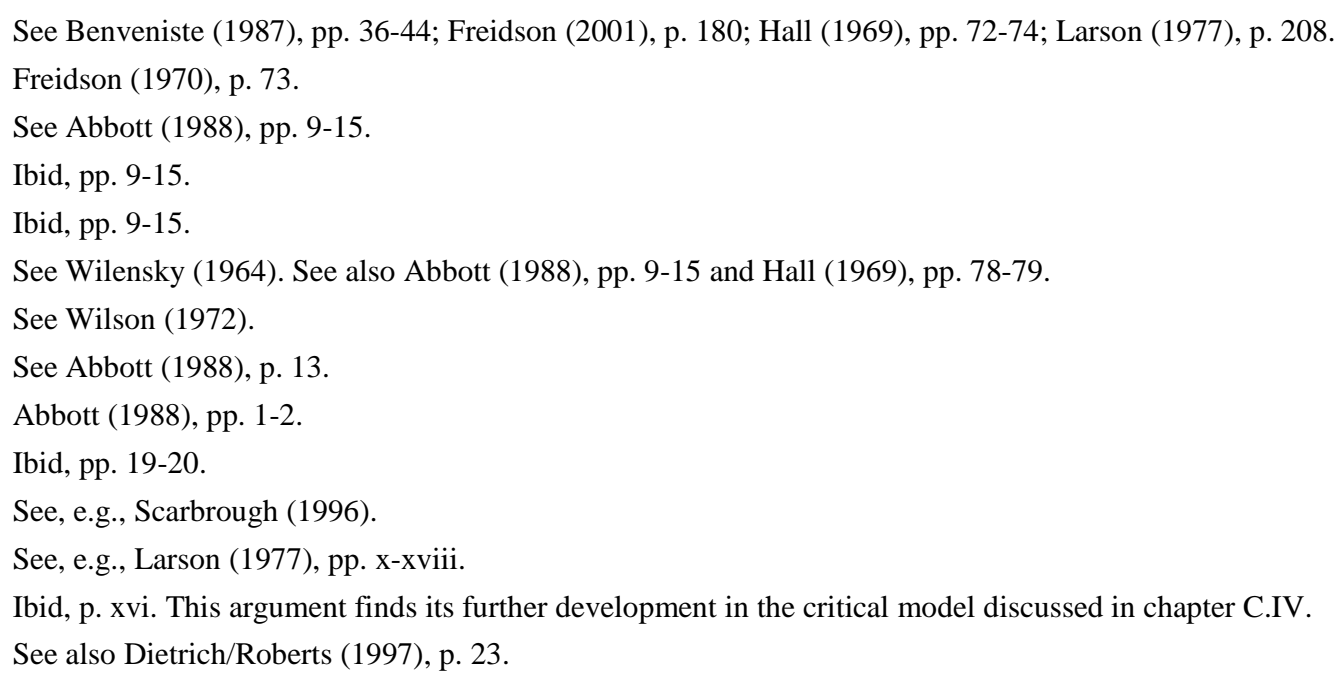


and so on. " ${ }^{100}$ Other supporters of this approach are Maister, ${ }^{101}$ Nachum, ${ }^{102}$ Noyelle and Dutka, ${ }^{103}$ Müller-Stewens et al., ${ }^{104}$ O'Farrell and Moffat, ${ }^{105}$ Scott $^{106}$ and Tordoir. ${ }^{107}$

The pragmatic approach implies that professional business services are a special category of services, which possess unique attributes that distinguishes them from other, non-professional services. ${ }^{108}$ Most of these studies implicitly assume that exceptional knowledge is one of these unique attributes. Professional expertise is valuable for clients lacking these skills, which is what makes professional service firms distinctive. Other main characteristics that these authors regard as constitutive to the nature of professional services are their high intangibility and heterogeneity, their dependence on people and the importance of client relationships. ${ }^{109}$ Such a pragmatic view of professional services is intuitively meaningful to people within professional service industries. ${ }^{110}$

Due to the missing theoretical justification of why particular services are regarded as professional, there is no agreement as to which services should be seen as professional. This is illustrated by table 2, which shows a number of studies within this approach that regard different services as professional.

Other researchers try to establish empirically what services clients perceive as professional. Thakor and Kumar's empirical study of professional services in the US and Canada is an example for this approach. ${ }^{111}$ Their study shows that from the group of professional business services, only legal services are regarded by clients as definitely professional, followed by financial services. However, the study has to be treated with precaution as it includes only legal, tax and finance services in the group of professional business services. ${ }^{112}$

\footnotetext{
100 Aharoni (1995), p. 6. See also Aharoni (1993a, b).

101 See Maister (1982, 1993).

102 See Nachum (1999).

103 See Noyelle/Dutka (1988).

104 See Müller-Stewens et al. (1999).

105 See O’Farrell/Moffat (1991), pp. 206-207.

106 See Scott (1998).

107 See Tordoir (1995).

108 See, e.g., Aharoni (1993a), pp. 7-11; Aharoni (1993b), pp. 129-131; Aharoni (1995), pp. 6-12; Maister (1993), pp. xvxvi; Müller-Stewens et al. (1999), pp. 21-22; Powell et al. (1999), p. 1.

109 See chapter B.I.2.2 for an extensive discussion of these characteristics for the case of management consulting.

110 See Fosstenløkken et al. (2003), p. 862.

111 See Thakor/Kumar (2000).

112 Most of the services that were discussed are professional consumer services, such as medicine and dental services. See Thakor/Kumar (2000).
} 


\begin{tabular}{|c|c|c|}
\hline Study & Service(s) & Comments \\
\hline Boström (1995) & Architectural & $\begin{array}{l}\text { Survey conducted of architectural firms in } \\
\text { Sweden }\end{array}$ \\
\hline $\begin{array}{l}\text { Hooks et al. } \\
(1994)\end{array}$ & Accounting & $\begin{array}{l}\text { Partners of Big } 6 \text { accounting firms surveyed } \\
\text { regarding "practice development” }\end{array}$ \\
\hline Davis (1994) & Advertising & $\begin{array}{l}\text { Advertising executives surveyed in study of } \\
\text { ethical decision making }\end{array}$ \\
\hline File et al. (1994) & $\begin{array}{l}\text { Management consulting, legal, } \\
\text { accounting }\end{array}$ & CEOs of firms buying services surveyed \\
\hline Webster (1993) & $\begin{array}{l}\text { Financial, computer-related and } \\
\text { advertising }\end{array}$ & 129 firms utilizing these services surveyed \\
\hline $\begin{array}{l}\text { Day and } \\
\text { Barksdale } \\
\text { (1992) }\end{array}$ & $\begin{array}{l}\text { Architectural and engineering } \\
\text { (A\&E) }\end{array}$ & Executives and clients of these firms surveyed \\
\hline $\begin{array}{l}\text { Woodside et al. } \\
\text { (1992) }\end{array}$ & Accounting & Surveyed clients of a CPA firm \\
\hline $\begin{array}{l}\text { Milliman et al. } \\
\text { (1991) }\end{array}$ & Legal & Experimental study with consumers as subjects \\
\hline Hite et al. (1990) & Legal and medical & Experimental study with consumers as subjects \\
\hline $\begin{array}{l}\text { Hill and Neeley } \\
\text { (1988) }\end{array}$ & $\begin{array}{l}\text { Medical, dentistry, legal, } \\
\text { psychological counseling, } \\
\text { opthalmological, personal tax } \\
\text { accounting, surgical, architectural }\end{array}$ & Conceptual discussion \\
\hline $\begin{array}{l}\text { Stock and } \\
\text { Zinszer (1987) }\end{array}$ & Logistics consulting & $\begin{array}{l}\text { Survey of logistics executives. Mentions } \\
\text { marketing research, auditing, architectural and } \\
\text { management consulting as professional }\end{array}$ \\
\hline Wheiler (1987) & Accounting, banking, legal & Survey of practitioners of these occupations \\
\hline Bloom (1984) & $\begin{array}{l}\text { Legal, accounting, management } \\
\text { consulting, architectural, } \\
\text { engineering, dentistry, medical, } \\
\text { optometry, editorial consulting }\end{array}$ & Conceptual discussion \\
\hline
\end{tabular}

Table 2: Services considered professional—selected studies

Source: Thakor/Kumar (2000), p. 64. ${ }^{113}$

One of the main criticisms of the pragmatic approach is that it merely provides a description of professional services but does not provide a basis for the analysis of these services. The discussed attributes are not theoretically deduced, and attempts to educe them empirically fail to show a unifying understanding of professional services. Additionally, the pragmatic approach does not pay attention to the institutionalization of professional knowledge. Consequently, although it stresses the importance of professional expertise, it is not able to explain its nature. 


\subsection{Work - or knowledge-oriented approach}

The fourth approach includes works that attempt to explain theoretically why the distinctiveness of professional services is grounded in their professional knowledge base. The main supporters of this approach are Abbott, ${ }^{114}$ Freidson, ${ }^{115}$ Halliday ${ }^{116}$ Reihlen, ${ }^{117}$ Scott ${ }^{118}$ and Sibson. ${ }^{119}$ Regarding the shortcomings of the discussed approaches, Abbott concludes, "the central phenomenon of professional life is [] the link between a profession and its work". ${ }^{120}$ Work, as a productive human activity, is distinguished from the activities of other living creatures by the fact that it is directed by knowledge. ${ }^{121}$ Thus, studying work presupposes the study of knowledge: "The most pressing need confronting the study of professions is for an adequate method of conceptualizing knowledge itself." ${ }^{122}$ Freidson further argues that expertise is not mere knowledge but the practice of knowledge. ${ }^{123}$

For Abbott, the starting point in the analysis of professional services is their abstract knowledge base: "professions do in fact develop abstract, formal knowledge systems from their first origins. We must understand those systems and their effect on professions' jurisdictions." ${ }^{124}$ He further argues that an abstract knowledge base is the source of practical skills, and controlling the abstractions that generate practical techniques is what "best identifies the professions". ${ }^{125}$ Similarly, Freidson argues that the difference between the dominant professions and other occupations is the "existence of a hierarchy of institutionalized expertise". ${ }^{126}$

The abstract knowledge of professions is based on academic knowledge and has three major functions. ${ }^{127}$ First, academic knowledge legitimizes professional work by clarifying its foundations and tracing them back to major cultural values, such as rationality, logic, and science. Demonstrating the scientifically logical character and the rigor of professional work implies its effectiveness and creates the basis for the authority of professionals. ${ }^{128}$ Thus, the true use of academic professional knowledge in this case is less practical than symbolic. ${ }^{129}$ Second, an academic knowledge base defines the body of knowledge and skills new students need to learn in order to become competent

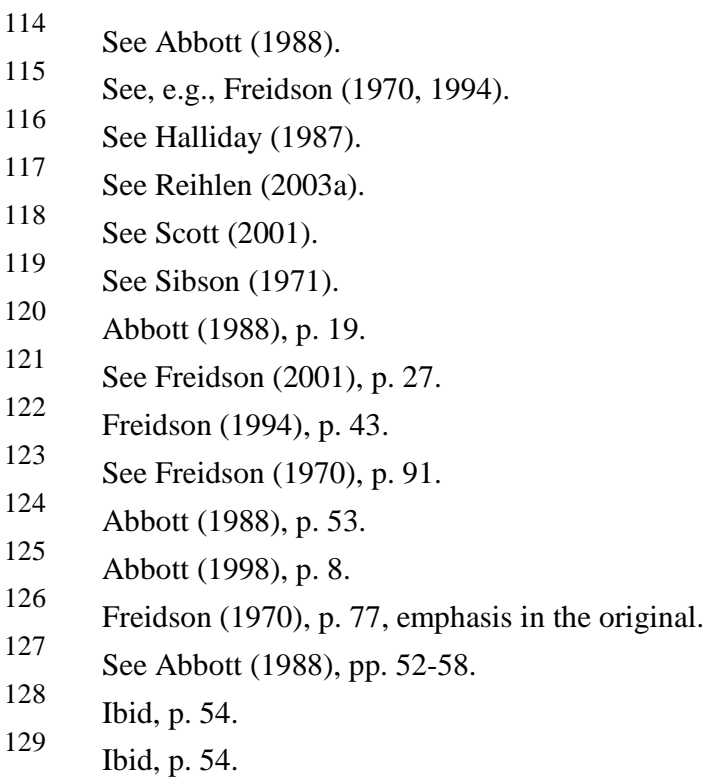


practitioners. ${ }^{130}$ It is also the subject of research activities with the task of creating new methods for solving problems within the competence area of the profession. ${ }^{131}$ Third, it defines the borders of professional jurisdiction; it makes clear what is and what is not part of the professionally claimed universe of tasks. "The academic, abstract knowledge system is thus universally important throughout the professions”, as it shapes the vulnerability of professional jurisdiction to outsiders. ${ }^{132}$ Abbott further argues that, while any occupation can obtain licensure or develop an ethics code, only the existence of an abstract knowledge base that can redefine problems and tasks, defend them from competition, and seize new problems, explains the distinctiveness of professions and enables their survival.

Contrary to the traditional studies that see science as the primary cognitive foundation of professionalism, ${ }^{133}$ Abbott argues that the professional body of knowledge is not always purely scientific. He states that the central value of the musical profession, for example, is not efficacy, but beauty. Other authors suggest that there are different types of professional knowledge. ${ }^{134}$ Halliday argues that two of the three longest standing professions-law and clergy_are not scientific in any narrow sense of the term. ${ }^{135}$ Extending these suggestions, Reihlen proposes a model of four different types of professional services depending on the type of their knowledge base (see Table 3). ${ }^{136}$

\begin{tabular}{lllll}
\hline $\begin{array}{l}\text { Type of } \\
\text { professional } \\
\text { service }\end{array}$ & Scientific services & $\begin{array}{l}\text { Technological } \\
\text { services }\end{array}$ & Normative services & Artistic services \\
\hline Values & Truth & Usefulness & Morality & Beauty \\
\hline $\begin{array}{l}\text { Type of } \\
\text { authority }\end{array}$ & Scientific authority & Technical authority & Moral authority & Esthetic authority \\
\hline $\begin{array}{l}\text { Primary body } \\
\text { of knowledge }\end{array}$ & Science & Technology & Ethics, religion & Arts \\
\hline Examples & University research & $\begin{array}{l}\text { Engineering and } \\
\text { and teaching } \\
\text { accounting, legal } \\
\text { services, management } \\
\text { consultancy, partly } \\
\text { advertising and } \\
\text { architecture }\end{array}$ & $\begin{array}{l}\text { Clerical, ethical } \\
\text { advisory services }\end{array}$ & $\begin{array}{l}\text { Graphical design, } \\
\text { music, and partly } \\
\text { advertising and } \\
\text { architecture }\end{array}$ \\
& & & \\
& & & \\
\hline
\end{tabular}

Table 3: A knowledge-based typology of professional services

Source: Reihlen (2003a), p. 8.

Accordingly, depending on their primary knowledge base, professional services can be categorized as scientific, technological, normative, or artistic in nature. ${ }^{137}$ While some

See Reihlen (2003a), p. 6.

Ibid, p. 6; see also Abbott (1988), p. 55.

Abbott (1988), p. 55.

See, e.g., Larson (1977), p. 32.

See Freidson (2001), pp. 152-176; Halliday (1987), pp. 423-428.

See Halliday (1987), p. 423; also Freidson (2001), pp. 152-159.

See Reihlen (2003a), p. 8.

137 See Reihlen (2003a), pp. 7-8. The difference between science and technology is often misunderstood. Technology is a "branch of knowledge concerned with the design and test of systems or processes with the help of scientific knowledge 
professional services can be clearly assigned to one of these categories because they use primarily one body of professional knowledge, others utilize various stocks of knowledge simultaneously, for example, advertising, and architecture. In other words, these distinctions are not empirically exclusive. ${ }^{138}$

To summarize, the work-oriented approach acknowledges that an abstract, academic knowledge base is the starting point when discussing professional services. It further emphasizes that there are different types of knowledge and consequently different types of professional services and hence, sheds some light on the epistemological foundations of these services. However, the discussed distinction between different types of professional knowledge is "not advanced as an adequate description of practitioner-client exchanges." 139 Halliday further states that in everyday practice all professional work, whether scientific or not, is infused by normative elements, just as normative professional services rely heavily on factual, scientific information. Engineers, for example, are involved in normative issues over nuclear power or pollution; clergy have grounded their theology in historical analysis. ${ }^{140}$

Furthermore, the notion of an academic knowledge base emphasizes the formalized, rational character of professional knowledge that is created in the academia or similar institutions, and underestimates the role of every day practice for the creation of professional knowledge. ${ }^{141}$ Research, and thus knowledge creation, is conducted not only in professional communities and institutions of higher education, but also takes place within the boundaries of firms, in cooperation with clients and other companies, and through informal networking among providers of professional services. ${ }^{142}$ As Reihlen suggests, "professional knowledge-in-use is always blended with pragmatically justified rules of thumb of the experienced practitioner." 143 Freidson also argues, "expertise is not mere knowledge. It is the practice of knowledge”. ${ }^{144}$ Brante points out that the practice of

and with the aim of serving industry or government.” Bunge (1998), p. 240. The main difference between science and technology is that scientific knowledge aims at understanding reality, technological knowledge at supplying tools for altering nature or society. Thus, "technology, rather than science, can help to either solve or originate social problems." Ibid, p. 241. Bunge further emphasizes that technology is different from applied science, craftsmanship or industry, and engineering.

See Freidson (2001), p. 158.

Halliday (1985), p. 425.

Halliday points out that independent of the primary type of authority all professions seek to exercise some moral authority. Moral authority occurs when a profession exceeds narrow scientific, technical, or esthetical activities to intervene in general ethical areas. For example, when lawyers make recommendations about the substance of constitutional revision, engineers advocate certain standards of safety in public housing, or management consultants prescribe the best way to manage people and organizations, they seek to act as a moral authority. See Halliday (1985), pp. 428-431. He further postulates that the "harder" the primary type of authority, the higher the barrier between technical and moral authority. Thus, it is harder for engineers, for example, to engage in broader ethical discussions than for management consultants whose primary type of knowledge is grounded, in fact, in technology, but is based on a weaker technical authority. The distinctiveness of such professional services "lies in their enhanced capacity to smuggle in moral orientations under the cloak of technical complexity." Halliday (1985), p. 430; and "the more a profession can dress its normative contributions in technical clothes, the more legitimacy, and the greater effect it will secure.” Ibid, p. 434. At the same time, this ability of some professional services, such as management consultants, makes the mobilization within such professions more difficult. This is one reason why management consultants are still not organized in the same way as accountants, engineers, or lawyers. See also chapter B.I.2.1.

See Brante (1988), p. 131; Reihlen (2003a), p. 6. See also Yanow (2004), p. S12 for an extensive discussion of the nature of local or practical knowledge.

See Morris/Empson (1998), pp. 613-614; Zelizer (1993), p. 223.

Reihlen (2003a), p. 6.

Freidson (1970), p. 91. 
professionals is context dependent, i.e. solutions to problems are dependent upon general and specific knowledge and the unique circumstances of the client. ${ }^{145}$ He further argues that empirical evidence shows that professionals, when confronted with the same problem, frequently come to diametrically opposed conclusions even though they have access to the same facts. ${ }^{146}$ Hence, the discussion of different types of professional knowledge is not very helpful when it comes to understanding how professionals use their knowledge in practice, how they transfer and acquire knowledge, and how new professional knowledge is created. Freidson concludes, "while the literature does provide some useful distinctions [], modes of analysis are not well developed". ${ }^{147}$

Another major characteristic of the practice of professional business service providers, which is ignored by the formal view of academic knowledge, as well as by the other three approaches to professional services, is the profession's role in the construction of social reality. ${ }^{148}$ The notion of academic knowledge stresses the objectivity and neutrality of professional services, whereas several researchers have suggested that professional business service providers engage in cultural discussion, argumentation, and persuasion across single organizations. Alfieri, for example, shows that lawyers construct their clients' stories and identity, as well as the law that is relevant for a particular case. Lawyers "subordinate[s] clients by erasing their identities, silencing their narratives, and suppressing their histories." ${ }^{149}$ Similarly, Malefyt argues for the case of advertising companies, "the world of advertising, like much of human activity, is socially constructed”. ${ }^{150}$ This is also the case with other professional services, such as architecture $^{151}$ and management consulting. ${ }^{152}$ The recent scandals around accounting practices provide evidence that reality construction also happens in professional services such as accounting, which have traditionally been seen as highly objective. Squires et al. argue, when discussing Andersen's downfall, that the matching of a potential accounting problem with the applicable accounting rule, "can be a lengthy and interpretive process". ${ }^{153}$ Larson supports these examples when claiming that the cognitive foundation of professions is important because it can be used as an argument "in a process that involves both struggle and persuasion”. ${ }^{154}$ In this process, "particular groups of people attempt to negotiate the boundaries of an area in the social division of labor and establish their own control over it”. ${ }^{155}$ Freidson concludes that persuasion is the generic resource

See Zelizer (1993), p. 221; also Hodgson (2002), p. 805. This is not to say that reality in general does not exist but is constructed by actors. Rather, the statement is related to social facts and social reality only. See also chapter D.II for a detailed discussion of this issue.

Alfieri (1994), p. 1759. Thus, law has been defined as "a set of stories and storytelling practices that describe and prescribe social reality and a set of conventions for defining and resolving disputes”. Lopez (1992), p. 43, cited in Alfieri (1994), p. 1760. 
of professionals. ${ }^{156}$ Consequently, the notion of academic knowledge ignores the importance of interpreting, persuading, storytelling, and narrative practices in professional service firms. Moreover, questions such as how professional service providers have ascribed themselves the power of interpretation, how certain favored narratives of events are adopted across organizations, and how narratives have helped professional service providers to neutralize less powerful or coherent narratives of the same event, remain not only unanswered within these approaches but they are assumed as irrelevant. However, studies on professional services show that these questions are quite relevant for a better understanding of a profession's practice. ${ }^{157}$ Therefore, the existing discussions on professional services offer a restrictive way of explaining their practice and community. "The apparent neutrality of expertise obscures its character as power". 158 Consequently, although the work-related approach to professional services rightly puts an emphasis on the work of professionals, it takes a too narrow a view of the nature of professional knowledge and ignores the role of power. Thus, this approach needs to be further developed in order to account for the persuasive and narrative nature of professional knowledge, as well as for the power of professional service providers that originates in their knowledge base. An approach that aims to explain the nature of professional business services needs to discuss how professionals participate in the shaping of meaning, and how they position themselves as "interpretive authorities", ${ }^{159}$ or "symbolic monopolies", ${ }^{160}$ for particular client problems. For this purpose, one needs to recognize that the power of experts or professionals derives not so much from some formal, hierarchical authority, ${ }^{161}$ but mainly from their "interpretive dominance", ${ }^{162}$ based on expertise from their legitimated "authority of competence". ${ }^{163}$ Expert power, as such, extends beyond the formal boundaries of organizations and affects those who work with experts, in particular their clients.

To sum up, the previous discussion shows that studies on professional services need to answer the following two questions: (1) How do professionals produce knowledge? ${ }^{164}$ (2) How is this knowledge institutionalized and legitimated; in other words, what is the

Freidson (2001), p. 105.

See, e.g., Alfieri (1994); Clark/Salaman (1998a); Malefyt (2003).

158 Scott (2001), p. 108. See also Dietrich and Roberts who argue, "power plays a pivotal role in understanding the role and nature of professional activity”. Dietrich/Roberts (1997), p. 25.

Scott (2001), p. 101. A symbolic or discursive monopoly is defined as a "cultural machinery of jurisdiction". Abbott (1988), p. 59; Scott (2001), p. 102. It allows professionals “to assert and legitimate their 'jurisdictional claims' over certain problems and matters that are potential objects of action and further research on them”. Scott (2001), p. 102.

Hierarchical authority is the authority and influence, which is a function of the occupied position within a particular hierarchy. See Scott (2001), p. 102.

162 See Meindl et al. (1994), p. 291 and the discussion in chapter D.IV.

163 Scott (2001), p. 102. Scott further argues that several researchers have criticized Weber's account of administrative power for not distinguishing properly hierarchical authority from expert power. In the first case, administrative rules are established through a process of imposition and lie behind relations of command; subordinates follow these rules due to the authority of principals. In the second case, rules are established through "agreement" among the participants: subordinates are persuaded that expert knowledge is the best way of achieving a particular goal. See Scott (2001), pp. 102-103. Such an "agreement" is the result of deeper levels of power, however. What is stressed is that professional competence might be accepted because it has been institutionalized and is widely seen as helpful in particular situations. This argument is related to the notion of "disciplinary practices", which is discussed in detail in chapter B.II.4.3.3.

See Reihlen (2003a), pp. 5-8.
} 
nature and role of expert power? ${ }^{165}$ The interpretive model that is developed within this work represents an attempt to answer those two questions for the case of consulting services by proposing an interactionist approach to professional services. ${ }^{166}$ This approach is based on the assumptions that knowledge in general, and professional knowledge in particular, cannot be regarded as objective and neutral. Instead, knowledge is regarded as dependent on the interpretive frames of the involved individuals and communities, and is a result of their struggles to establish their knowledge base as the legitimate one for a particular set of problems, at particular times and in particular circumstances. Chapter D.V outlines this view of professional services in detail and presents an attempt for a more differentiated understanding of professional services.

\section{Management consulting}

Management consulting is a very diverse industry, ${ }^{167}$ and estimates of market size or rate of growth vary considerably depend on its definition. Consultancies span a broad range of types, from generalist consultancies to scientific or 'expert' consultancies. ${ }^{168}$ One of the problems in trying to create a clear cut definition of management consulting services, is that they are offered not only by consulting firms, but also by other companies, such as accounting firms, IT firms, and logistics providers, as well as by academics on a parttime basis, and by internal consultants. ${ }^{169}$ Buono concludes, "While the way in which management consulting is defined may shape our perception of its parameters and influence, a brief glimpse at the corporate landscape suggests that consultants are literally everywhere." 170

For these reasons, this work adopts the following very broad definition of management consulting:

Management consulting is a service offered by independent service providers that assist client organizations to develop and implement problem solutions to particular management problems. ${ }^{171}$

Thereby, the notion of a problem refers to both an opportunity and a treat. ${ }^{172}$ It includes not only the solving of management and business problems as a reason for the

165

166

167

See, e.g., Scott (2001), pp. 103-104.

See also Hodgson (2002), p. 805.

At the lower level of the industry, there is a large number of small firms and sole practitioners who supply a range of different services, such as executive research and selection, process consultancy, coaching and training, general management consulting, and highly specialized consulting. On the other hand, there are the large consulting companies that provide a range of technical and specialist services. These firms at the top end of the industry receive a significant part of the spending on consulting, and have a wide, international influence on management practices due to the dissemination of management ideas. See Fincham/Clark (2002-3), p. 4. Furthermore, through the introduction and dissemination of management concepts and models, large management consulting companies also influence the service range of the smaller consulting companies that have to adopt some of these practices due to their broad appeal and recognition. See for a discussion of the recent developments in the management consulting industry Fincham/Clark (2002-3), pp. 3.

See, e.g., Roberson/Swan (1998), p. 835.

See Aharoni (1997), p. 153.

Buono (2001), p. vii.

See Nikolova et al. (2001), pp. 3-4; also Hoffmann (1991), p. 40; Rassan (1998), p.3.

See Reihlen (1997), p. 57. 
engagement of consultants, but also other goals, such as achieving organizational purposes and objectives, identifying and seizing new opportunities, enhancing learning, and implementing changes. ${ }^{173}$

In order to concretize this definition, it is discussed in the following as to what extent management consulting can be regarded as a professional service, and the main attributes of consulting services as indicated in the literature are outlined.

\subsection{Management consulting' status as a profession}

The predominant view of management consulting is as a professional service. "Management consulting has long been recognized as a useful professional service that helps managers to analyze and solve practical problems faced by their organizations, improve organizational performance and learn from the experience of other managers and organizations." ${ }^{174}$ However, both supporters of the norm-oriented and the structureoriented approach regard management consulting as a developing profession. ${ }^{175}$

In relation to the norm-oriented approach, the consulting industry cannot be regarded as a fully established profession because it does not possess widely recognized norms of conduct. For this reason, single consulting organizations establish their own codes of conduct in an attempt to demonstrate professional behavior. One example for such firm specific norms of conduct is McKinsey's “Code of Professional Responsibility”, which includes the following norms: putting client interests first; accepting assignments which "we are fully competent to perform"; serving clients with competence, integrity, and independence; service competitors with care; making fare financial arrangements; and guarding confidences. ${ }^{176}$

In relation to the structure-oriented approach to professional services, management consulting is regarded as a developing profession because it does not possess all of the characteristics of established professions. ${ }^{177}$ In particular, management consultants have sought to establish professional organizations, the responsibilities of which include: defining a common body of knowledge for professional consultants; defining qualification criteria for new consultants; certification of consultants; defining and applying a code of professional conduct and practice for their members; investigation of violations of these norms; organizing trainings for consultants; and in general, representing consultants when dealing with governments and other organizations. ${ }^{178}$ Such consulting associations have been established in many countries. ${ }^{179}$ However, the efforts Unternehmensberater (BDU) in Germany, the Institute of Management Consultants in the UK.
} 
to position and develop them into full professional institutions recognized by government and other institutions have remained unsuccessful. ${ }^{180}$

Other authors, however, have doubts whether management consulting is a professional service at all. ${ }^{181}$ Their argument is that frequently "this occupation and kind of work is characterized by an extreme form of 'non-professionalism'”. ${ }^{182}$ In particular, the claimed expert status and the idea of cognitive rationality are rejected.

Finally, supporters of the work-oriented approach to professional services argue that management consulting is a professional service because it is based on an abstract, technological knowledge. In particular, management consulting can be defined as a "sociotechnology": the branch of knowledge concerned with the design and test of systems or processes with the aim of serving industry. ${ }^{183}$ As such, consulting knowledge is not expected to model reality, which is the case with scientific knowledge; consulting knowledge is rather viewed as a tool for changing reality in an efficient way. ${ }^{184}$

To summarize, according to the more traditional approaches to professions, management consulting is a developing profession. As a result, the consulting industry does not enjoy the protected position of fully established professions, which includes a monopoly over particular types of services, knowledge, and credentialism. ${ }^{185}$ In particular, the delivery of consulting services is not regulated through a government accredited professional association, and no particular credentials are put in place regulating who can offer consulting services. Moreover, there is no generally recognized body of knowledge for the consulting profession. Thus, individuals with different professional or practical backgrounds, such as engineers, IT specialists, physicians etc., offer consulting services as well. ${ }^{186}$ As a result, one of the major problems that consulting companies face, in comparison to professional business service firms that have a stronger professional background, such as law and architecture, is how to demonstrate to client organizations that they possess the necessary expertise to solve management problems, and how to distinguish themselves from non-qualified consulting providers. ${ }^{187}$ The uncertainty regarding the quality of the service provider and the consulting services has a major influence on the client-consultant relationship. ${ }^{188}$ This issue is discussed in more detail in the following chapter.

The main reason for the inability of consulting companies to professionalize the consulting industry is the lack of a strictly specified and definable abstract body of

\footnotetext{
180 See Glückler/Armbrüster (2003), p. 272; Lowendahl (1997), p. 19. In particular, such associations have remained voluntary and their rules are, as such, not enforceable. Many well-established consulting companies have opted, instead, to develop their own standards and reputation. See Kubr (1996), p. 127. 
consulting knowledge. ${ }^{189}$ As within the work-oriented approach to professional services discussed, the primary body of knowledge in management consulting is technology. Bunge states that it is because the management or consulting technology is so young that there are still controversies about questions such as the function of intuition, experience, and mathematical modeling within consulting expertise. ${ }^{190}$ For this reason, the status of the discipline and its relations to other social studies is unclear, as well as the nature of consulting expertise. Accordingly, consulting knowledge

"can be (a) oracular, or following the advice of self-styled experts in how to run other people's businesses, a.k.a. gurus; (b) empirical, or following tradition; or (c) scientific, that is, using experience, analysis, statistics, and occasionally mathematical modeling as well, to craft and discuss policies and plans, as well as to monitor their implementation. Each of these management styles presupposes its own theory of knowledge." 191

This analysis of the nature of consulting expertise has two important implications for this work. First, within this work management consulting is regarded as a special type of profession, one that is concerned with the development of problem solutions with the aim of serving industry, guided by the values of usefulness and efficiency. Second, it is argued that consulting knowledge cannot be regarded as objective and neutral. Furthermore, the above discussion makes it clear that it is necessary to pay attention to the question of how different research streams conceptualize consulting knowledge.

\subsection{Attributes of management consulting services}

\subsubsection{Temporary service}

Consulting is a temporary service, ${ }^{192}$ which has two important implications. First, consultants remain external to the client organization; they have to achieve a valid result in the client organization without being part of its administrative and human system. ${ }^{193}$ As a result, consultants are often rejected by members of the client organization for various reasons, independent of their technical knowledge and quality. This underlines the critical importance of creating and maintaining an effective client-consultant relationship. ${ }^{194}$ Therefore, to achieve success, clients and consultants have to be aware of human, cultural, power and other factors that affect their relationship. This work is an attempt to show the relevance of those factors that are particularly related to knowledge transfer and creation, and to power issues.

Moreover, consulting technology often involves knowledge that is developed within other technologies, such as engineering, information technology, and sociotechnology. As a result, consulting knowledge is fragmented and not easy definable.

192 See Kubr (1996), p. 7. Wohlgemutt speaks in this case about consultants as temporary partners of the client organization. See Wohlgemuth (1995), p. 16, author's translation. 
A second implication of the temporal character of consulting is that consulting projects are characterized by usually tight time restrictions that are determined at the start of the project. This attribute of consulting services has a major influence on the clientconsultant interaction. Due to time restrictions, clients and consultants cannot establish stronger bonds to each other and work on mechanisms to prevent misunderstandings, nor do they have sufficient time to develop efficient instruments and processes in order to direct, align, and monitor their work. Therefore, the temporal character of consulting services has a major impact on the problem-solving process within client-consultant teams. ${ }^{195}$

\subsubsection{High degree of personal judgment by the service provider}

An important attribute of consulting services is what Freidson refers to as "discretionary specialization", which means that management consultants address "tasks in which discretion or fresh judgement must often be exercised if they are to be performed successfully". ${ }^{196}$ In other words, although such services rely to some degree on standardized methods and knowledge they often have to be customized in order to account for the specific circumstances of a particular client organization. Thus, it is argued that consulting services have a high degree of customization ${ }^{197}$ and, as a result, they have the potential for innovation and creativity. ${ }^{198}$

When the service involves a high degree of judgment, it is difficult to evaluate the likely quality of service prior to its delivery. ${ }^{199}$ As a result, consulting companies have to find ways to decrease the uncertainty perceived by their clients regarding the quality of their services. ${ }^{200}$ Client's uncertainty regarding the quality of consulting services is amplified due to the lack of regulations within the consulting industry regarding the quality of the service providers. As in the previous section discussed, there are no established professional institutions within the consulting industry that regulate who can offer consulting services, the necessary training and education of consultants etc. ${ }^{201}$ Thus, consultants have to rely on other mechanisms to signal their quality. The two most important instruments used by consulting companies in this respect are the development of reputation and the use of referral networks. ${ }^{202}$

195 Keegan and Turner, for example, show that time pressures impede members of projects in learning from and through projects. See Keegan/Turner (2001), pp. 83 and the discussion in chapter D.IV where the implications of this attribute are further discussed.

Freidson (2001), p. 23 and p. 111. See also Lowendahl (1997), p. 20 and p. 32; Toirdoir (1995), pp. 4-6.

See Lowendahl (1997), p. 20 and pp. 32-35; Müller-Stewens et al. (1999), p. 22.

See Freidson (2001), pp. 23-24. Additionally, the need of individual judgement when delivering consulting services emphasizes the role of consultants as the main "assets" of consulting companies, which has important implications for the management of consulting companies. See Lowendahl (1997), p. 41; Müller-Stewens et al. (1999), p. 38; Sibson (1973), pp. 13-14. Although important, this issue is not discussed extensively within this work.

See Lowendahl (1997), pp. 35-36; Tordoir (1995), p. 55.

This is also referred to as "transactional uncertainty” of consulting services. See Glückler/Armbrüster (2003), p. 275.

Moreover, the appeal of consulting companies to their own ethical standards and norms of behavior cannot be taken too seriously, which is also confirmed by the recent scandals around Enron and WorldCom. See also Kaas/Schade (1995), pp. 1068-1069.

See, e.g., Lowendahl (1997), p. 37; Müller-Stewens et al. (1999), p. 37. It is beyond the scope of this work to discuss these issues in detail. See Clark (1995), pp. 74-85; Glückler/Armbrüster (2003) and Kaas/Schade (1995) for an extensive discussion of the role of reputation and client networks for the long-term success of consulting companies. 


\subsubsection{High intensity of interaction ${ }^{203}$}

Intensity of interaction refers to the frequency and duration of interaction between clients and service providers. ${ }^{204}$ It has been argued that the intensity of interaction between clients and service providers is higher in management consulting firms and in (professional) service firms in general, in comparison to manufacturing companies. ${ }^{205}$ Although some of these authors recognize that the wide variety of (consulting) services makes it difficult to generalize about their level of interaction with clients, they argue that consulting services in general are characterized by a very high degree of interaction with their clients. ${ }^{206}$ Sharma, for example, points out that professionals and clients jointly create the product that "incorporates values, ethics, and a very specific instrumental, as well as cultural, need. Inevitably, there is a great deal of consultation and interaction between professional and principal." 207 Consequently, clients are seen as indispensable for the production activities of such organizations. ${ }^{208}$ Moreover, clients have been referred to as "partial employees": ${ }^{209}$ in a sense, "the customer is part of the work force of the professional services enterprise”. ${ }^{210}$

As a minimum, the client has to help the consultant in defining the scope of the advice, provide information, and take and implement the advice. ${ }^{211}$ However, increasingly, clients are also involved in the actual problem-solving process, working jointly with the consultants towards a problem solution. Additionally, it has been argued that clients play an important role in the innovation process of consulting services. Innovations in consulting are usually the result of applied research closely linked to the assignments for client firms. ${ }^{212}$ Such innovations more often emerge unplanned and in cooperation with clients during the process of service delivery, instead of being planned and created in R\&D departments. ${ }^{213}$ For example, Kipping and Sauviat found in an empirical study that the management of $R \& D$ in international consulting companies is organized along practice areas and there are usually no permanent R\&D teams. ${ }^{214}$

203

In the literature, different terms are used to express customer involvement in the provision of services, e.g., interaction, interface, coproduction, servuction, and service relationship. See, e.g., Gallouj/Weinstein (1997), p. 541.

204

205

See, e.g., Aharoni (1993a), pp. 3-11; Gallouj/Weinstein (1997), p. 541; Köppen (1999), p. 32; Maister (1982a), p. 15; Maister (1993), p. 71; Mills et al. (1983a), p. 119; Müller-Stewens et al. (1999), pp. 20-23; Lowendahl (1997), pp. 35-40; O’Farrell/Moffat (1991), p. 206; Sharma (1997), pp. 771-772; Sveiby (1992), p. 170; Tordoir, (1995), p. 139.

206

See Lowendahl (1997), p. 16; also Mills/Morris (1986); Ritsema et al. (1992).

Sharma (1997), p. 772; also Mills/Moshavi (1999), pp. 48.

See, e.g., Schneider/Bowen (1995), pp. 2.

See, e.g., Mills et al. (1983b), p. 301; Mills/Morris (1986), p. 726.

Sibson (1971), p. 23.

See Kubr (1996), p. 488.

Gallouj and Weinstein refer to client-consultant interactions as the "laboratory" for innovations. Gallouj/Weinstein (1997), p. 546. See also Davenport/Prusak (2005), p. 309; Fosstenlokken et al. (2003), p. 874 and p. 876; Gadrey/Gallouj (1998), pp. 8-10; Gann/Salter (2000), p. 955; Morris/Empson (1998), p. 614.

Gallouj and Weinstein speak about "ad-hoc” or emergent innovations. See Gallouj/Weinstein (1997), pp. 549-550; also Gadrey/Gallouj (1998), pp. 8-10; Gann/Salter (2000), p. 965.

See Kipping/Sauviat (1996). They found only one consulting company with own R\&D centers-Accenture (previously Andersen Consulting). However, since the mid 1990s, several big professional business service firms have established so-called "centers of excellence" or "knowledge centers" that serve as idea generation sites and which main task is to develop new concepts and methods for use in concrete client's projects. See Davenport/Prusak (2005), p. 311; 
An important implication of the high intensity of interaction between client and consultant is that the quality of the services depends not only on consultant's abilities and knowledge but also on client's abilities and their motivation to cooperate. ${ }^{215}$ This makes consulting services vulnerable to the so-called "double moral hazard problem". ${ }^{216}$ In consulting companies, this problem is usually related to members of the client team holding back relevant information. This might be the case when, for example, consultants are engaged in order to suggest how to increase the efficiency of a particular department. If members of the client organization fear that their jobs might be made redundant because of the consultants' recommendations, they might withhold valuable information or even give false information to the consultants. As a result, the consultants might provide a solution that is seen by the managers, who have commissioned the project, as inappropriate, which could diminish the reputation of the consulting organization not only in the eyes of the particular client but also in regard to other (potential) clients. Kubr concludes, "service quality cannot be measured-and does not even exist-outside of [the client-consultant] relationship, but only as an intrinsic part of it”. ${ }^{217}$

\subsubsection{High intangibility of services}

Another often-proposed characteristic of consulting services is their intangibility: intangible inputs, such as concepts, methods and technical knowledge, are transformed during the problem-solving process into an intangible output, for example a marketing concept, a new strategy or new organizational structure. ${ }^{218}$ The intangibility of services implies not only that the service quality cannot be assessed before the service is delivered, but also that operations management is highly complex, as services cannot be stored. ${ }^{219}$

In addition, the intangibility of consulting services, together with the fact that there is at least some knowledge gap between the client and the service providers, makes it difficult for clients to evaluate the quality of the provided service even ex post. ${ }^{220}$ This characteristic of consulting services puts specific requirements on the management of client-consultant relationships. In particular, consulting organizations need to manage actively the early stages of the consulting project so that consultants know client's expectations. Consulting firms have to ensure that client's expectations are realistic relative to what the consultants are capable of delivering. ${ }^{221}$

Moore/Birkinshaw (1998); Sarvary (1999), p. 103; Sundbo/Gallouj (1999), p. 23. See also Fosstenlokken et al. (2003), p. 874.

Such services are called "contract goods” within the framework of institutional theory. See Kaas/Schade (1995), p. 1071. Clark, on the other hand, speaks about “experience qualities” of consultancy services. See Clark (1995), pp. 61-62.

See Lowendahl (1997), pp. 39-40. Glückler and Armbrüster speak about a mutual transaction uncertainty. See Glückler/Armbrüster (2003), p. 277.

See, e.g., Köppen (1999), p. 31; Kubr (1996), pp. 487-488; Lowendahl (1997), pp. 32-35; Müller-Stewens et al. (1999), p. 21; Ritsema et al. (1992), pp. 25-26. See also Clark (1995), p. 42.

220 See Clark (1995), pp. 57-59; Lowendahl (1997), p. 36; Sibson (1971), pp. 17-19; Tordoir (1995), p. 55.

221 See Lowendahl (1997), p. 33. This is very important because clients evaluate the success of consulting projects in relation to their expectations. See also chapter B.I.2.3. 


\subsubsection{A critical discussion of the attributes of consulting services}

A closer look at the consulting industry shows that there are different types of services with a different degree of intangibility, customization, and interaction with the client. For example, not all consulting services are intangible to the same degree. Rather, tangible outputs, such as reports, databases, CDs etc. have higher importance in some services than in others. ${ }^{222}$

Furthermore, consulting services are sometimes developed in the past and standardized so that they can be applied as ready solutions in various client projects. This is often the case with some standardized models and concepts, such as the BCG matrix, Five Forces Concept, Reengineering, Kaizen, etc. The role of such fully or partially standardized models and procedures has increased over the last 15 years. ${ }^{223}$ Thus, when the degree of customization of a service is low, the service delivery process in consulting companies does not involve high interaction with the client and the perceived uncertainty regarding the quality of the service is lower. ${ }^{224}$ This is also the case when the client has the same educational background and similar practical experience as the consultant. ${ }^{225}$ In such cases, the gap between client's and consultant's knowledge and experience can be quite small, which makes it easier for the client to evaluate the quality of the consulting service.

In some cases, a high degree of customization and interaction with the client is even not efficient. Rather, the reliability of the solution consistent with the knowledge constituting the professional field is what clients value. ${ }^{226}$ This, for example, is the case when a consulting company is engaged by a client to develop a market analysis. In such cases, consultants can follow a predetermined structure when preparing the report and can find most of the relevant information without an intensive interaction with the client. Clients engage consultants with the goal to receive fast and efficient solutions. Thus, some authors conclude, "If every professional problem were in all respects unique, solutions would be at best accidental, and therefore have nothing to do with expert knowledge. What we are suggesting, on the contrary, is that there are sufficient uniformities in problems and in devices for solving them to qualify the solvers as professionals [] professionals apply very general principles, standardized knowledge, to concrete problems []." ${ }^{227}$ The implication of this is that the degree of customization and the intensity of interaction with the client depend upon the problem or task that clients and consultants face. ${ }^{228}$

See Clark (1995), pp. 49-52; Czerniawska (2005), p. 332. It is important to point out that the degree of the perceived uncertainty of the quality of consulting services also varies depending on whether the client has previously worked with the consulting company. See Lowendahl (1997), p. 34. See Kubr (1996), p. 120.

Quinn et al. point out that most of the typical professional's activity is directed at perfection, not creativity. See Quinn et al. (1996), p. 72; also Reihlen (2003a), p. 17. 
Figure 1 gives some examples for types of consulting tasks characterized by different levels of task ambiguity, required interaction with the client and intangibility of outcomes, and different degrees of risk and uncertainty inherent in the consulting task. This issue is discussed further in chapter B.II.3 where a typology of client problems or tasks and its implications for client-consultant interaction are outlined.

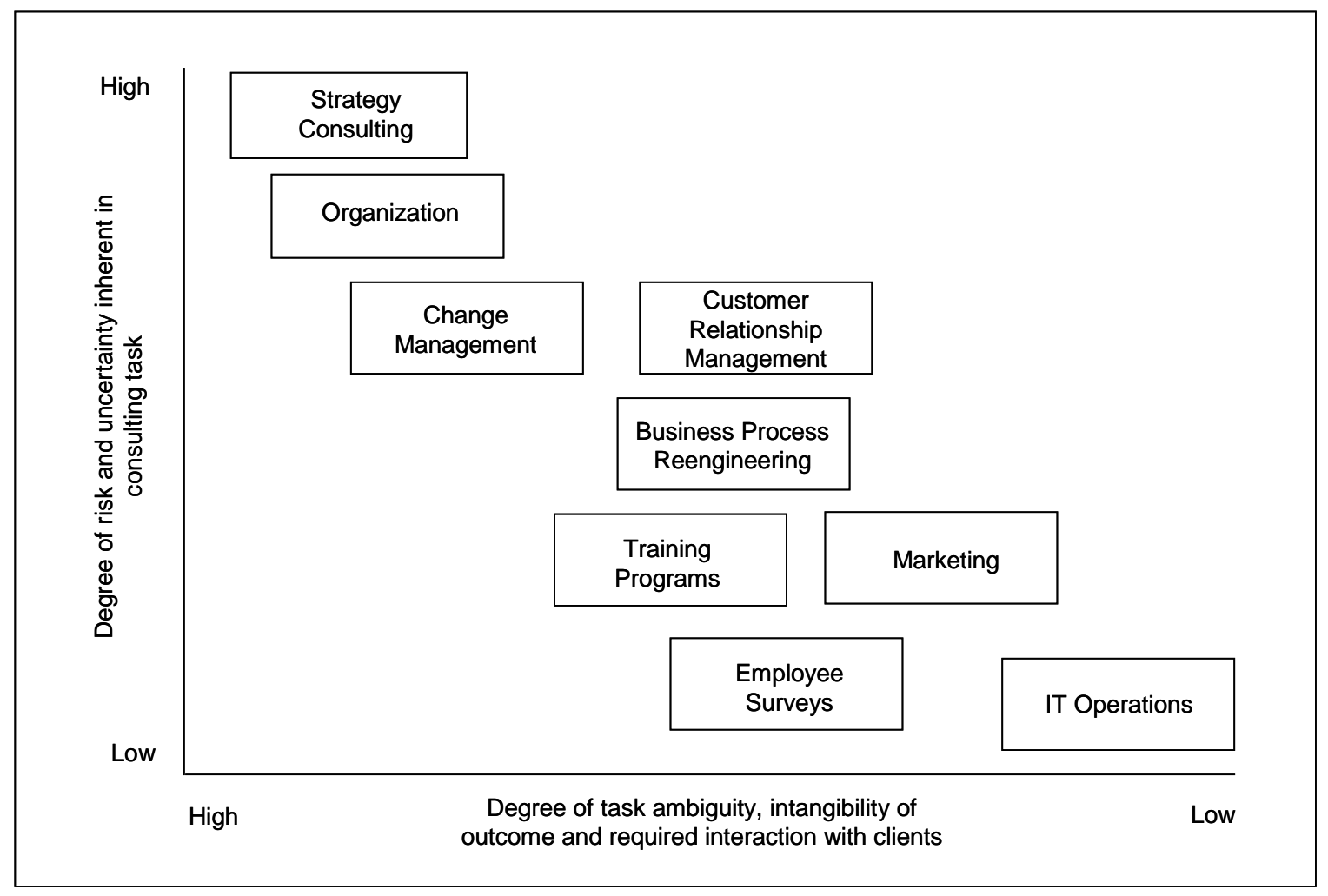

Figure 1: Risk and types of consulting tasks

Source: Adapted from Czerniawska (2005), p. 332.

\section{$2.3 \quad$ Consulting success}

When discussing management consulting and the interaction between clients and consultants as a crucial success factor, it is necessary to shed some light on the issue of consulting success. How is the success of consulting projects defined? The discussion of the characteristics of management consulting implies that the answer to this question is not straightforward.

In most cases, it is not easy to measure the success and value of consulting because the quality of consulting services cannot be assessed prior, and what is even more important, even after the delivery of the service. First, the outcomes of consulting projects usually show results only after long period of time. Additionally, as a number of other factors, such as economic (external) and psychological (internal) factors, also influence client's organizations, it is not possible to establish a causal connection between consultant's services and their value for the client organization. ${ }^{229}$ 
Additionally, it has been suggested that it is important to distinguish between the results of consulting projects on the one hand and the effectiveness of, or client's satisfaction with, the consultant's performance in achieving those results on the other, which is called the consulting process. ${ }^{230}$ Based on previous research, Gabel develops a descriptive measurement model for consulting success that includes three areas of assessment: $^{231}$ (1) consultant's recommendations, (2) client's learning, and (3) consultant's performance or process. As a result, he suggests six dimensions for measuring consulting success: (1) client's acceptance of consultant's recommendations; (2) client's satisfaction with the recommendations; (3) client's understanding of the problem solution (i.e. learning); (4) client's satisfaction with the level of understanding; (5) performance reasonability; and (6) client's satisfaction with the performance. Additionally, Gabel argues that in other scenarios, other dimensions could have a higher relevance, for example, client's education on how to work more effectively with consultants, ${ }^{232}$ or the innovativeness of the problem solution. Without going into further discussion of these issues, it is important to conclude that the success of consulting projects depends to a very high degree on the client's assessment and satisfaction with both the suggested problem solution and the interaction process between clients and consultants. ${ }^{233}$ Therefore, the quality of consulting services and the success of consulting projects have to be assessed relative to clients' expectations. Thus, the success of a project depends "on the clear identification by the client of its requirement as well as a comprehensive understanding by the consultant of the client's needs". ${ }^{234}$ This has important implications for the relationship between clients and consultants as consultants have to monitor continuously clients' satisfaction and understanding. ${ }^{235}$ Additionally, this implies that consultants might be forced to orientate the problem-solving process in a direction expected and required by the client, even if there might be a better problem solution, if this is what will ensure client's satisfaction.

\section{Summary}

This chapter presented some general characteristics of professional business service firms and the client-consultant relationship. It showed that the existence of a professional knowledge base is the main reason why professional service firms in general, and management consulting companies in particular, are regarded to be distinct from other services. However, the possession of specific knowledge and expertise alone cannot explain the existence of professional business services. It was argued that professional business service providers are also extensively engaged in such practices as persuasion,

\footnotetext{
230 See Czarniawska/May (2004), p. 14; Gable (1996), pp. 1176-1177; O’Farrell/Moffat (1991), p. 205; O’Farrell/Wood (1999), p. 133; Stock/Zinszer (1987), p. 4. See Gable (1996), pp. 1176-1177. Ibid, pp. 1176-1177.

In other words, the success of consulting projects can be measured only subjectively. It is important to note that, at the same time, the costs of consulting are a much more objective category. See Köppen (1999), p. 45. idea exactly what is that they want to achieve. See, e.g., Tilles (1961), p. 92. 
meaning manipulation, and ultimately in the construction of social reality. Therefore, the study of professional business services needs to take into account the role of power for the existence of professional services.

Next, the nature of management consulting was discussed. It was argued that management consulting could be regarded as an evolving profession, which has some important implications for consulting companies. Additionally, it was shown that consulting services are regarded as highly customized, intangible, and interactive services. This emphasizes the important role of the client-consultant relationship for the success of consulting projects in particular, and the survival of consulting companies in general, as well as the need to analyze further the nature of their interaction. It is suggested that a systemic perspective offers the possibility for a deep understanding of the components and dynamics of client-consultant relationships. Such a systemic framework for the analysis of client-consultant relationships is developed in the following chapter.

\section{A systemic framework for the analysis of client- consultant relationships}

Although professional business service firms vary in their structure-some operate as professional bureaucracies and others are closer to adhocracies-, they all produce professional services through some kind of teamwork. ${ }^{236}$ Furthermore, as already discussed, this teamwork always includes in some degree an interaction with the client of the service provider. ${ }^{237}$ For example, accountants deliver financial statements in collaboration with their clients; management consultants develop business plans working closely with the client, and an advertising campaign cannot be created without some interaction with the company whose products it presents. Therefore, the analysis of the degree and nature of the interaction with the client is indispensable. ${ }^{238}$ Additionally, the casting of roles and the distribution of powers are very important for the success of the client-consultant team. ${ }^{239}$ Consequently, the professional team consisting of members of the client's and the service provider's company can be regarded as the smallest social unit of professional work. $^{240}$ It is the institutional form of the client-consultant interaction, and "a system whose members are mutually dependent on one another so that individual and collective behaviour and cognition are mutually contingent.”241

Client-consultant teams are not self-organized but formal or artificial social systems that are always “designed, set up, maintained, transformed, or dismantled in accordance

See Reihlen (2003a), p. 11; also Hodgson (2002), pp. 803-804; Maister (1982a), p. 16; Mills et al. (1983b), p. 305; Sommerlatte (2000), p. 32 and pp. 118-124.

See Kubr (1996), p. 54; Larsen (2001), p. 94; Malefyt (2003), p. 139; Reihlen (2003a), p. 11 and the discussion in chapter B.I.2.2.3.

Ibid, p. 8.

See Krohn/Küppers (1989), p. 31; Reihlen (2003a), p. 11.

Reihlen (2003a), p. 12.
} 
with explicit goals, plans, and rules”. ${ }^{242}$ The explicit goal of client-consultant teams is to solve some kind of a management problem, i.e. they are engaged in problem-solving or decision-making. Thus, a study of the client-consultant relationship has to concentrate on the problem-solving process in client-consultant teams. As problem-solving in clientconsultant teams involves at least some learning through exploring, thinking, imitating, questioning and criticizing, client-consultant teams represent social systems called inquiring systems or learning communities. ${ }^{243}$ As such, they can be analyzed from a systemic perspective, which is discussed in what follows.

\section{A systemic perspective of client-consultant teams}

The analysis of the client-consultant relationship and the problem-solving process within this work is undertaken from a systemic perspective: the work does not concentrate merely on individuals and individual behavior within the client-consultant team, nor does it take a holistic view, where only the whole team as an entity is analyzed. Rather, the client-consultant relationship is regarded in a systemic way, where both individual factors and the social context of individual behavior are concerned. ${ }^{244}$ Systemism states that everything is a system or a component of one, and every system can be characterized by its composition, environment, and structure. Thus, client-consultant teams can be regarded as systems and a quintessential study of the client-consultant relationship requires a discussion of: (1) the characteristics of the members of the client-consultant team; (2) the (immediate) environment of the client-consultant team; ${ }^{245}$ and (3) the team's structure, that is, the relations among the members of the client-consultant team (e.g., social relations including communication) plus their relations to the environment, which includes the transformation of that environment through work. ${ }^{246}$

From a systemic perspective, every human social system is composed of four interlinked subsystems-biological, economic, cultural, and political. ${ }^{247}$ Thus, four types of relations link the members of human social systems: (1) biological relations, which include relations of descent, sex, reproduction, or friendship; (2) economic relations, which are characterized by production and exchange; (3) political relations, which are relations of management and control of the social activities of other systems; and (4) cultural relations, which include relations of discovering and inventing, teaching and

Bunge (1996), p. 271; see also Köppen (1999), p. 28.

See Bunge (1983a), p. 108; Reihlen (1997), pp. 76-77. Clients and consultants can be also involved in a number of other learning communities, such as professional organizations, R\&D teams, etc.

See Bunge (1996), pp. 264-281 for an extensive discussion of systemism. See also Bunge (1979), pp. 187-191. Systemism was chosen as the background of the theoretical framework within this work because it helps to identify thoroughly the phenomenon of interest, outlines the key premises of the framework, and describes the relationship among the elements of the framework.

The environment of a system includes all things coupled with components of the system. See Bunge (1979), p. 9. Thus, the total environment, i.e. the set of all things that are not parts of the system, is not relevant for this discussion. Rather, this work discusses only the problem context (the immediate environment) and the organizational field of management knowledge production and dissemination. Iding and Köppen also emphasize the relevance of the environment for the study of client-consultant relationships. See Iding (2000), p. 13; Köppen (1999), p. 28.

See Bunge (1979), pp. 189-190.

Ibid, pp. 189-205; also Bunge (1996), p. 271. 
learning, designing and planning, advising or healing. ${ }^{248}$ In general, mechanisms of the cultural subsystem are those of producing and diffusing cultural products, such as knowledge. Some concrete examples are theorems, chronicles, blueprints, legends, theories, myths, data, computer programs, economic policies, moral maxims, legal precepts, budgets, paintings, and songs. ${ }^{249}$

The four relations enable not only knowledge transfer and creation but also give social systems cohesion and efficiency. ${ }^{250}$ Figure 2 illustrates the systemic view of human societies. $^{251}$

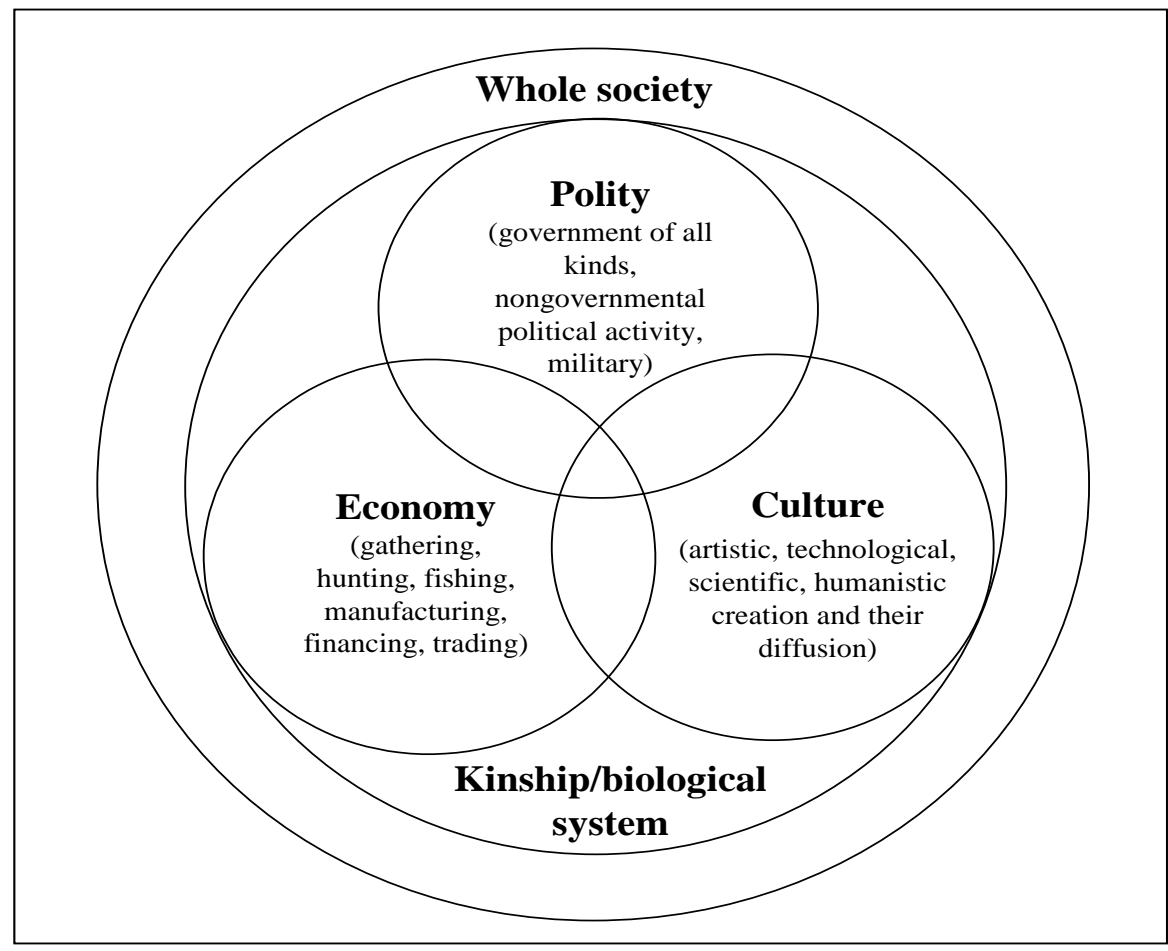

Figure 2: The main subsystems of any human system.

Source: Bunge (1979), p. 203.

The overlaps in the figure emphasize that some individuals participate in two or even three systems. For example, a senior consultant belongs to the cultural system by virtue of his/her consulting work (problem-solving); to the economic system if s/he creates consulting methods and tools; and to the political system if s/he acts as a manager of junior consultants. ${ }^{252}$

Because the main objective of client-consultant teams is problem-solving through the production and/or utilization of knowledge and cultural products, client-consultant teams can be regarded as cultural systems. Therefore, the primary relations between clients and consultants have a cultural character. However, cultural systems are not independent

Bunge states that cultural activities involve “cognitive, technical, artistic, moral, or religious activities”. Bunge (1998), p. 48

Such a systemic perspective implies that social systems and phenomena have to be analyzed in a multidisciplinary manner, a requirement that is followed within this work. See Bunge (1996), pp. 264-273.

The nature of the different subsystems is discussed extensively in what follows. 
from biological, economic, and political relations. It is suggested in what follows, that in the case of client-consultant teams, the cultural, economic, and political relations between their members are closely interlinked. ${ }^{253}$

Following the systemic perspective, this work emphasizes the following important insights. First, it is clear that coping with a problem is determined to a high degree by the characteristics of the problem solver. ${ }^{254}$ The task, therefore, is to identify the fundamental personal attributes of the members of the client-consultant team, which guide their behavior and make an impact upon their problem-solving behavior.

Second, as problem-solving behavior is directed at coping with a specific problem-a problem that is part of the natural or social environment of the client-consultant team-it is necessary to analyze the characteristics of the problem requiring decision. Therefore, when discussing the second systemic element, the environment of the client-consultant team, this work concentrates on the immediate environment, i.e. on the problem context as the "part of the natural or social environment that is the object of contemplation, study or rational action" in client-consultant teams. ${ }^{255}$ This is in accordance with research on problem-solving and decision-making that shows that the general characteristics of a problem determine to a high extent the behavior of problem solvers. ${ }^{256}$ The broader environment of client-consultant teams, including the client organization and the consulting company, as well as other organizations and institutions, such as business schools and publishing companies, which influence the work of client-consultant teams more or less directly, are only briefly discussed. ${ }^{257}$

Both the personal attributes of the members of the client-consultant team and the characteristics of the problem requiring decision influence the relations among the members of the client-consultant team. These relations are orientated toward problemsolving and knowledge creation, including communication, as well as production and utilization of cultural artifacts. ${ }^{258}$ At the same time, a successful cooperation between clients and consultants requires that they establish some social mechanisms in order to coordinate and integrate their activities.

Although this work discusses and shows the relevance of all three aspects of clientconsultant relationships, it puts an emphasis on the study of the third aspect-the structural relations among members of the client-consultant team-stressing the cultural and political relations among members of the client-consultant team. The focus is particularly on the question, what is the influence of cognitive pluralism in client-

See also Bryson who argues that client-consultant interaction depends mainly on cultural and power relations. Bryson (1997), p. 103. The nature of biological relations is not discussed further within this work. It is clear, however, that biological relations influence all other relations within client-consultant teams. Figure 2 illustrates this by showing biological relations as a circle around all other relations.

See Bronner (1993), p. 8. Bunge argues as well that the "workers engaged in direct cultural pursuits" are one of the “pivots” of cultural systems. Bunge (1979), p. 211.

This is in line with the previously stated emphasis on the interaction between clients and consultants during concrete consulting projects within this work. 
consultant teams on these cultural and political relations, and ultimately on the success of client-consultant relationships. There are three main reasons for this focus of the work.

First, the existing models of client-consultant interaction concentrate mainly on the relations among members of the client-consultant team, and do not address extensively the individual characteristics of clients, consultants, or the environment of clientconsultant teams. As this work builds upon a critical discussion of the existing models of client-consultant interaction, it needs to address the same issues that are emphasized within these models. Therefore, the attributes of clients, consultants and the environment of client-consultant teams are discussed to the extent that it is necessary to explain issues related to the main area of interest.

Second, the discussion in chapter I.1 showed that the questions regarding knowledge and power relations are at the heart of the existence of professional services in general and consulting services in particular. This makes it necessary to discuss these issues more extensively in order to shed some light on the client-consultant interaction.

Third, a discussion of some social, integrating mechanisms is necessary insofar as it is important to remember that problem-solving within client-consultant teams is not detached from other social relations. Clients and consultants need to find ways not only to exchange their knowledge but also to integrate their efforts and activities if they are to be successful in their cooperation. Yet, a detailed analysis of integrating mechanisms was not undertaken because it is necessary to focus the analysis on a particular area in order to gain deeper insights into the selected area.

Thus, a detailed discussion of all three components of client-consultant teams and all structural relations within client-consultant teams would not allow for a deep analysis of any of these areas. 
Figure 3 illustrates the systemic perspective of client-consultant relationships that is adopted within this work.

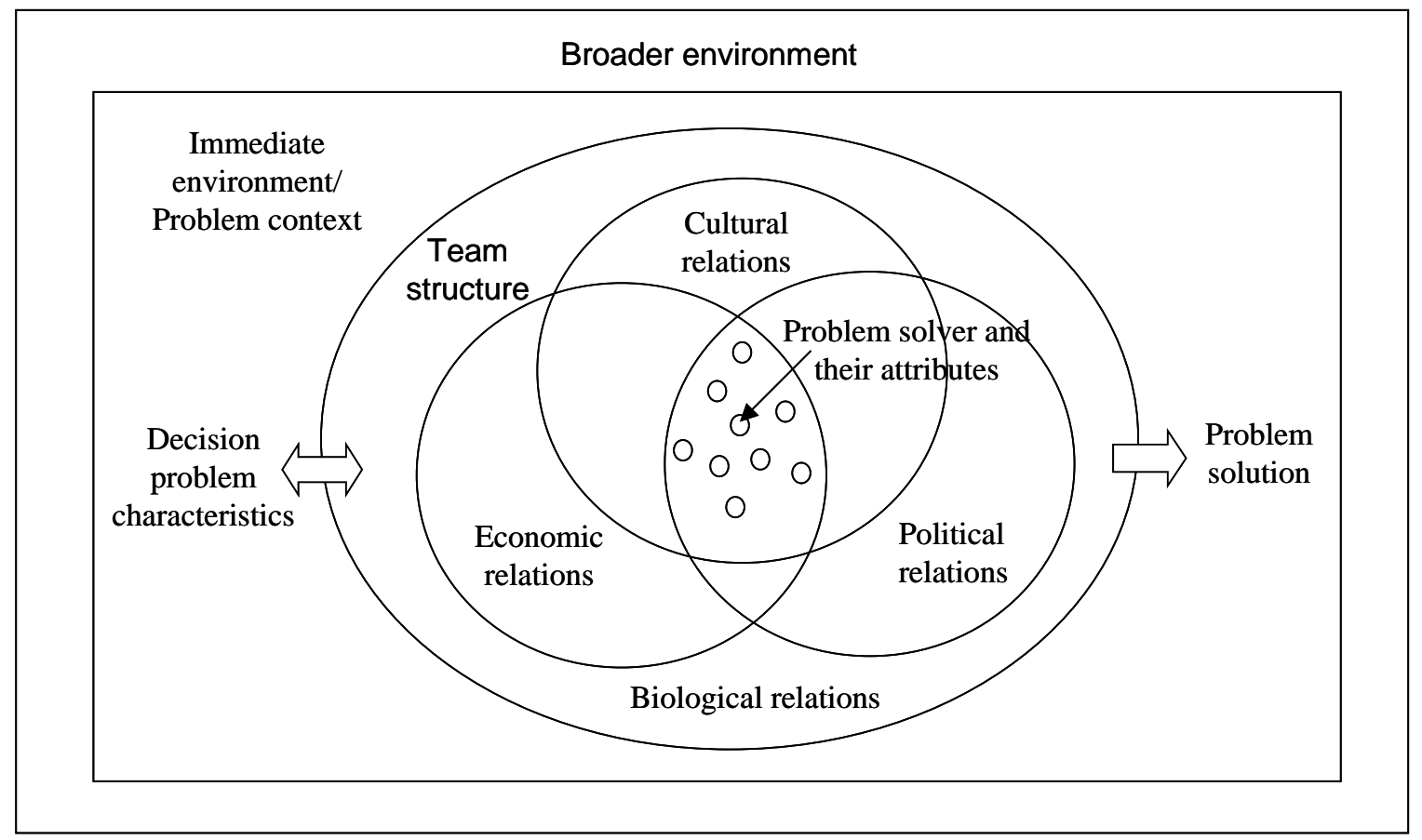

Figure 3: A systemic perspective of client-consultant interaction ${ }^{259}$

In the following, the systemic framework of client-consultant relationships, which is later used as a guideline for the discussion of the models of client-consultant interaction, is developed.

\section{Attributes of clients and consultants}

In general, researchers differentiate between three major types of personal attributes: cognitive, motivational, and interactive. ${ }^{260}$

\subsection{Cognitive attributes}

"When one perceives or conceives an object, investigates it, manipulates it or evaluates it, one engages in a cognitive process". ${ }^{261}$ Therefore, problem-solving processes are cognitive processes, which make it necessary to analyze the cognitive abilities of problem solvers.

\footnotetext{
259 The large overlaps between economic, cultural, and political relations in the figure illustrate the above presented arguments that there is a strong coupling between cultural and economic, and cultural and political relations in clientconsultant teams. Additionally, the figure emphasizes that there is an interrelation between the decision problem and the client-consultant team; in other words, the nature of the problem dependents on the perception of the problem by the problem solver. See Behrens/Delfmann (2002), pp. 14-16; Reihlen (1997), p. 55 and chapter B.II.3.1.1. 


\section{Domain-relevant and creativity-relevant skills}

Cognitive skills can be broadly differentiated into domain-related knowledge and creative thinking abilities. ${ }^{262}$ "Domain-relevant" cognitive skills represent factual knowledge, technical skills, and special talents in the problem area in question. ${ }^{263}$ It includes facts, principles, attitudes toward various issues in the domain, knowledge of paradigms, ${ }^{264}$ techniques, and methods for solving problems in the domain, ${ }^{265}$ and aesthetic criteria. ${ }^{266}$ "This component can be viewed as the set of cognitive pathways for solving a given problem or doing a given task" ${ }^{267}$ Such pathways or algorithms represent set sequences of individual steps for performing tasks or solving problems in a given domain. Therefore, domain-relevant cognitive skills facilitate solving of problems within particular contexts or domains and can facilitate habitual problem-solving even when the problem at hand is novel. ${ }^{268}$ Domain-relevant cognitive skills depend on a number of personal qualities such as innate cognitive, perceptual, and motor abilities as well as the formal and informal education of the individual in a specific domain. ${ }^{269}$

"Creativity-relevant skills include a cognitive style favorable to taking new perspectives on problems, application of heuristics for the exploration of new cognitive pathways, and a working style conducive to the persistent, energetic pursuit of one's work". ${ }^{270}$ In other words, individual creativity is facilitated by the ability of an individual to create unusual interpretations of the issues at hand. ${ }^{271}$ These skills build the "something extra" of creative performance. ${ }^{272}$ Whereas research has traditionally focused on identifying individual differences that distinguish highly creative individuals from their less creative peers, recent research has shown that creativity is a complex phenomenon that depends not only on personal attributes but also on a number of complex social settings. ${ }^{273}$ In the following, some of the major "creativity-relevant skills" are briefly introduced.

Woodman et al. identify fluency of expression, word fluency, figurative fluency, speech fluency, and originality as some of the main cognitive abilities that stimulate individual creativity. ${ }^{274}$ These aspects are essential to divergent thinking and association skills, which are the most frequently studied creative abilities. ${ }^{275}$ Amabile discusses the

262
263
264
265
266
267
268
269
270
271
272
273
274
275

See Amabile (1983, 1988); Ford (1996).

See Amabile (1988), pp. 130-131.

These include anything from formal scientific paradigms to traditional modes of operation in particular areas.

In the case of consulting projects, such skills include knowledge of consulting methods and tools.

Aesthetic criteria may include any standards for artistic merit.

See Amabile (1988), p. 130, emphasis added.

See Ford (1996), p. 1124.

See Amabile (1983), pp. 362-363; Quinn et al. (1996), p. 72.

Amabile (1988), p. 131, emphasis added. See also Amabile (1983), pp. 364-365.

See Ford (1996), p. 1120.

Amabile (1983), p. 364.

See Amabile (1988), Ford (1996).

See Woodman et al. (1993), p. 298.

See Ford (1996), pp. 1124-1125; Guilford (1984), pp. 1-2. Divergent thinking helps an individual to generate many alternative solutions to an open-ended problem; associational abilities help an individual to generate or identify unusual associations or patterns. See Ford (1996), p. 1125. 
following "creativity-relevant skills”: “(a) breaking perceptual set; (b) breaking cognitive set, or exploring new cognitive pathways; (c) keeping response options open as long as possible; (d) suspending judgment; (e) using 'wide' categories in storing information; (f) remembering accurately; and (g) breaking out of performance 'scripts'." 276 Additionally, Woodman et al. propose that individual creativity is influenced by a number of noncognitive factors, such as (1) various antecedent conditions (e.g., biographical variables); (2) relevant knowledge; (3) personality (e.g., self-esteem, locus of control) and motivational factors; and (4) contextual influences (e.g., characteristics of the group task). ${ }^{277}$

Creativity-relevant skills can influence creative behavior in any relevant domain. Creativity within a specific domain is influenced additionally by the individual's familiarity with, and factual knowledge of, the domain in question. ${ }^{278}$ Therefore, "domain-relevant skills" are an important prerequisite of creative behavior. However, creativity implies that an individual breaks out of well used scripts occasionally; or at least proceeds through them critically.

It can be assumed that both clients and consultants need to possess domain-relevant skills in order to contribute to the problem-solving process. However, their domainrelevant skills are usually different. Clients usually possess (factual) knowledge about the concrete problem situation, i.e. their knowledge is more specific to individual contexts. Consultant's skills, in contrast, are certified to deal with particular sets of problems in a variety of situations and contexts, i.e. their knowledge is more general with regard to the particular problem at hand. ${ }^{279}$ Additionally, consultants usually provide knowledge of paradigms and tools for solving of problems.

In contrast, regarding creativity-relevant skills, not all consulting projects require individuals with high creativity. Depending on the problem situation and the objectives of consulting projects, creativity might be more or less important for a successful problem solution. The influence of different problem contexts on the problem-solving process is discussed extensively in next chapter.

\section{Cognitive style}

Additionally to their cognitive skills, research has shown that the cognitive style of problem solvers influences decision-making and decision outcomes. ${ }^{280}$ Cognitive style is "the individual difference in how people perceive, think, solve problems, learn, and relate to each other". ${ }^{281}$ Thus, cognitive style reflects 'how', rather than 'how well' individuals perceive and judge information. ${ }^{282}$ There are two basic types of cognitive styles:

Amabile (1988), p. 131.

See Woodman et al. (1993), p. 297. Amabile states that creativity-relevant skills depend on the following personality characteristics: independence, self-discipline, ability to delay gratification, perseverance in the face of frustration and an absence of conformity in thinking or dependence on social approval. See Amabile (1988), p. 132. Additionally, she argues that training can also improve creativity-related skills.

See Amabile (1983), p. 364; Amabile (1988), pp. 130-131.

See Whitley (1989), pp. 215-216.

See, e.g., Armstrong/Priola (2001), p. 286; Hough/ogilvie (2005); Sadler-Smith (2004).

Hough/ogilvie (2005), p. 421.

See also Armstrong/Priola (2001), p. 287; Sadler-Smith (2004), p. 155; Slocum (1978), p. 142. 
analytical and intuitive. ${ }^{283}$ Analytical problem-solving is characterized by linear and sequential decision-making in an objective, logical, systematic and convergent manner, whereas intuitive problem-solving is relational, holistic, simultaneous, and divergent. ${ }^{284}$ It involves to a high degree judgment processes, which cannot be explicitly articulated. Rather, they are the result of "rules of thumb" or low-effort heuristics, experience, impressions, and feelings. ${ }^{285}$ Research has suggested that analytical problem solvers tend to be more dominant, task oriented, and impersonal, preferring a rather structured and more technique-oriented environment. They tend to concentrate on facts and details during problem-solving. More intuitive problem solvers are, on the other hand, emotionally expressive, submissive, interpersonal, and nurturing. They try to impose less structure and are more accepting of ambiguity in problem situations. ${ }^{286}$ They also tend rely much more on personal relationships and 'hearsay' information during their diagnosis of problems than on facts. ${ }^{287}$

Slocum argues that each of these cognitive styles has its advantages and disadvantages when considering the role of consultants. ${ }^{288}$ Thus, the analytical type can develop a method or procedure that systematically utilizes all knowledge and experience and economizes on effort. At the same time, however, analytical consultants risk failing to interpret and approach the client's problem as a coherent whole. Intuitive consultants, on the other hand, might ignore relevant detail but at the same time, they are better able to approach complex and innovative problems where the volume of information, the criteria for solution, or the nature of the problem itself, "does not allow for a 'scientific' mode of inquiry". ${ }^{289}$ Others have confirmed these arguments by showing that both cognitive styles can be more or less appropriate in different problem situations. For example, there is evidence that individuals do not need to be highly intuitive to be innovative, but being too systematic and rational can inhibit high levels of innovative behavior. $^{290}$ At the same time, individuals with an analytical cognitive style are more effective and efficient in routine situations, which require the analysis of masses of numerical information. ${ }^{291}$ Consequently, some researchers have argued that individuals can and should adjust their cognitive style to fit the problem at hand. ${ }^{292}$ However, there is the counter-argument that cognitive styles are relatively permanent individual characteristics that are likely to remain stable over many years. ${ }^{293}$ Moreover, empirical

See Armstrong/Priola (2001), pp. 287-288; Hough/ogilvie (2005), p. 426. Hough and ogilvie [sic!] also discuss a more detailed differentiation of cognitive styles following Jung's theory of psychological types and the well known and broadly applied in decision-making research and practice Myers-Briggs Type Indicator. Ibid, pp. 421.

See, e.g., Mintzberg (1976), pp. 51; Sadler-Smith (2004), p. 161.

Intuition is, therefore, not some kind of magic or mysticism. Rather, it is a subconscious pattern recognition based on experience. See, e.g., Frantz (2003). See also Bunge (1983a), pp. 248-250. Thus, intuition is one of the major cognitive characteristics that differentiate the performance of experts from that of novices. See Bunge (1983a), p. 274; Rambow/Bromme (1995), pp. 350-353.

See Armstrong/Priola (2001), p. 288; Slocum (1978), p. 142.

Slocum (1978), p. 144.

Ibid, p. 142. His arguments are equally valid for members of the client team. Ibid, p. 142.

Slocum (1978), p. 142.

See Sadler-Smith (2004), p. 162.

See Armstrong/Priola (2001), p. 305; Hough/ogilvie (2005), p. 440; Mintzberg (1976), p. 57.

See Hough/ogilvie (2005), p. 442; Sadler-Smith (2004), p. 157 and p. 176.

See Armstrong/Priola (2001), pp. 288; Slocum (1978), p. 142. 
studies show that attempts to modify individual's preferred cognitive style through training fail. ${ }^{294}$

Thus, it can be concluded that, in the case of routine situations, client-consultant teams should consist mainly of individuals with an analytical cognitive style. In contrast, when clients and consultants face a novel problem that requires creativity, the team will achieve better problem solutions if its members exhibit both intuitive and analytical reasoning. ${ }^{295}$ Such a combination allows clients and consultants, who have to generate a problem solution within the limited timeframe of a project, to use their intuition to rapidly incorporate logical conclusions into decisions within a given timeframe. ${ }^{296}$

\section{$2.2 \quad$ Motivational attributes}

Problem-solving constitutes a considerable mental strain for those involved. ${ }^{297}$ In addition, problem solutions often have consequences for some or all of the involved individuals. Both these factors imply that there is the possibility that the involved individuals would not contribute in accordance with their skills to the problem-solving process. In client-consultant teams, this danger is related mostly to the members of the client team, as they can be influenced negatively by the problem solution. In contrast, because (external) consultants are not part of the organization, they are not influenced by the results of consulting projects. Moreover, consultants are usually motivated to contribute fully to the problem-solving process as their future career within the consulting firm depends on their efforts and their work. Therefore, it is assumed here that the consultant's motivation to contribute to consulting projects is at least to some extent given, and therefore the motivational attributes of clients are particularly critical for the success of consulting projects.

There are two main types of motivation: extrinsic and intrinsic. Extrinsic motivation originates in external rewards, such as financial rewards and promotion. Intrinsic motivation, also called self or task motivation, is described as being self-driven, excited by the work itself, enthusiastic, attracted by the challenge of the problem, having sense of working on something important, and a belief in, or commitment to, the idea. ${ }^{298}$ This type of motivation is regarded as crucial for successful problem-solving, especially when the problem at hand requires creativity, whereas extrinsic motivation is seen as less helpful or even an constraint on individual's creativity. As Amabile puts it, "task motivation makes the difference between what an individual can do and what one will do. The former depends on the level of domain-relevant skills and creativity-relevant skills. But it is task motivation that determines the extent to which domain-relevant skills and creativity-relevant skills will be fully and appropriately engaged in the service of creative performance”. ${ }^{299}$

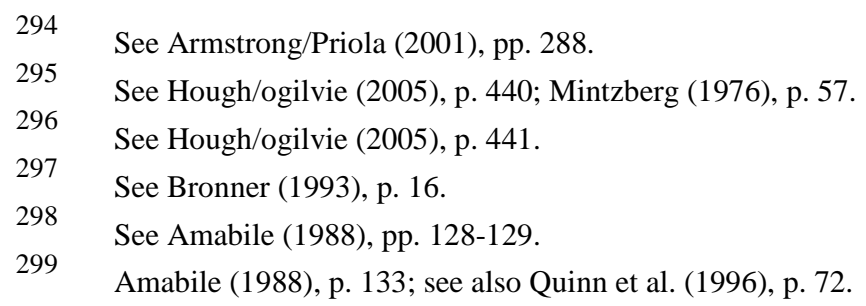


Intrinsic or task motivation includes two elements: individual's thematic interest in the problem, ${ }^{300}$ and the degree to which one's interest or position will be negatively or positively influenced by the project. The individual's thematic interest in the problem is the person's natural inclination toward or away from activites of that sort and towards a particular task or project. ${ }^{301}$ The second aspect, the impact of a particular project on the individual's position, directly influences one's motivation to contribute to a project.

To conclude, whereas motivation in general is very important in order for client team members to be fully commited to consulting projects, the degree of intrinsic versus extrinsic motivation required depends to some extent on the problem at hand. In the case of routine problems, extrinsic motivation is often sufficient for problem-solving. ${ }^{302}$ In such cases, when there are tight deadlines, clear evaluation expectations, surveillance and contracts for reward, extrinsic motivation is both necessary and desirable. Moreover, the technical correctness of work seems not to suffer under extrinsic motivation the way that creativity does. ${ }^{303}$ However, when the problem is rather novel, which clients associate with much higher unsecurity and risk, it is preferable if clients are intrinsically rather than extrinsically motivated to work on the project. This is also true for consultants. Only when consultants are, additionally to their extrinsic motivation, intrinsically motivated to solve a particular problem, they will engage in creative problem-solving. ${ }^{304} \mathrm{~A}$ technological invention, such as a new consulting method and concept, is "a system of ideas-and this only well-trained, curious, imaginative, and strongly motivated individual brains can produce". 305

\subsection{Interactive attributes}

Because problem-solving takes place in the context of a team, decisions are marked by a division of labor, communication, and a need for consensus. ${ }^{306}$ This results in high requirements for an adequate interaction of the involved individuals. Interactive attributes impact upon the problem-solving process in many ways: they direct the exchange of information, control the mutual influence upon the decision makers, and shape the way conflicts are being handled. ${ }^{307}$

Communication skills are regarded often as the most relevant interactive skills. ${ }^{308}$ Communication skills are important both for knowledge transfer and for the development

300

See Amabile (1983), pp. 365-366; Amabile (1988), pp. 132-134; Bronner (1993), p. 16.

See Amabile (1988), p. 133. Amabile stresses that such intrinsic motivation is influenced by a number of extrinsic factors that control or are seen as controlling the individual's performance on the task in a particular instance. For example, having goals set by other in a particular consulting project can decrease the motivation of client's members to contribute to the project.

Ibid, p. 143.

Ibid, p. 145.

See also Amabile (1988), pp. 142-145. In the literature, motivational issues with regard to consultants are generally discussed as a matter of internal management within consulting companies, rather than in relation to client-consultant relationships.

Bunge (1998), p. 251.

See Bronner (1993), pp. 16-17.

Ibid, p. 17. Larsen discusses as well the importance of consultants' interactive skills. See Larsen (2001), pp. 99-100.

See Ford (1996), p. 1124. 
of new knowledge and ideas. Furthermore, they are crucial for gathering support and sponsorship to move a problem solution forward for implementation. ${ }^{309}$ Accordingly, communication skills are emphasized often as crucial consulting skills. ${ }^{310}$

Communication skills include skills such as listening, observing, identifying, and reporting. ${ }^{311}$ One important aspect of active listening, also called empathic communication, is reflecting. ${ }^{312}$ "Reflection is the practice of periodically stepping back to ponder the meaning to self and to others in one's immediate environment about what has recently transpired. It illuminates what has been experienced by both self and others, providing a basis for future action". ${ }^{313}$ Thus, it constitutes the ability to uncover and make explicit to one, as well as to others, what one has planned, observed, or achieved in practice. ${ }^{314}$ Raelin stresses, thereby, that reflection is not merely an introspective or private phenomenon but may be shared in the presence of others. Only an intensive sharing of implicit understandings enables effective communication. "As we develop skill in reflecting on our speech acts, we develop a capacity for dialogue that is generative, that is, which can generate new ways of thinking and imagining". 315 Schön was among the first to emphasize the crucial importance of reflective skills for the success of consulting projects. ${ }^{316}$ He points out that both clients and consultants need to possess such skills in order to be able to work effectively together.

Rhetoric is another important communication skill, "which is focused on how to use ideas and language in order to be able to produce eloquent discourse in any given situation". ${ }^{317}$ In its narrow sense, rhetoric is regarded as a persuasive discourse. ${ }^{318}$ Therefore, communication skills also involve persuasive skills. ${ }^{319}$ Consequently, all communication inevitably involves some form of influence. ${ }^{320}$ Hargie and Tourish support this when they argue, "all interactions between people consist of some attempt at reciprocal influence []. In this sense, influence can be defined as attempts to affect the behavior, emotions, and cognitions of others in a direction favored by the person attempting to exercise change". ${ }^{321}$ Often people are not even aware that they try to persuade others. As such, the use of persuasion skills is present in most social encounters

Ibid, p. 1124.

See, e.g., Gallessich (1982), p. 385; Lippitt/Lippitt (1978), p. 96; Wootton (1996), pp. 104-106. Interestingly, few consultants report that they have been trained in such human interactive skills during their business education. The entire education usually evolves around logic, rationality, and intellect. In contrast, several consulting companies argue that they invest heavily in trainings of interpersonal skills. See Maister (2005), pp. 25-28. See also Ashford who argues that clients themselves focus too much on technical skills when selecting their consultants and do not pay enough attention to their interactive skills. See Ashford (1998), p. xvii.

See, e.g., Lippitt/Lippitt (1978), p. 96.

See Hargie/Tourish (1994), p. 1384.

Raelin (2001), p. 11.

Ibid, p. 11.

Raelin (2001), p. 16.

See Schön (1983).

Skerlep (2001), p. 180.

This narrow understanding of rhetoric was most famously expressed by Aristotle. See Skerlep (2001), p. 180.

See, e.g., Lippitt/Lippitt (1978), p. 96.

See Hargie/Tourish (1994), p. 1383.

Ibid, p. 1382. 
and can be both positive and negative. Persuasion skills may have a negative effect when they are used to manipulate people. ${ }^{322}$ However, effective persuasion can be also positive; it can be an important part of the negotiating and learning process through which a persuader leads others to a problem's shared solution. ${ }^{323}$ Good persuasion skills imply active listening to others and the incorporation of other's perspectives into one's viewpoint. Additionally, persuasion skills imply the use of stories, examples, metaphors, and analogies in order to increase the quality of persuader's point of view. ${ }^{324}$ Whereas a number of researchers as well as practitioners have emphasized the importance of consultant's persuasion skills, ${ }^{325}$ no such references have been made concerning clients.

To sum up, the above discussion of personal attributes shows that clients and consultants need to possess a number of different skills in order to work effectively together as well as to solve problems successfully. However, it is emphasized that not all skills are important in all problem contexts. This makes it necessary to discuss different problem contexts and to analyze their implication for the client-consultant relationship and the required personal attributes of the members of client-consultant teams.

\section{3. (Immediate) environment / Context of project assignments}

As already stated, the main goal of client-consultant teams is to solve some kind of a management problem. Problem-solving can be characterized, thereby, by four elements: a body of background knowledge, a problem, a set of aims or goals, and a set of methods. ${ }^{326}$ Thus, if client-consultants teams are to be successful, it is necessary to ensure not only that their members possess certain individual characteristics, but also that they adjust their work to the type of problem they face. It is argued that both the required intensity of interaction between clients and consultants, and the required degree of customization of the consulting service, vary depending on the problem type. As discussed, the problem to be addressed also influences what attributes clients and consultants need to possess in order to create a better problem solution. In the following, first, a general problem typology is introduced that outlines major problem categories as proposed in the literature. Based on this discussion, a consulting specific problem typology is presented and its implications for the client-consultant relationship are outlined.

\footnotetext{
322 See Hargie/Tourish (1994), pp. 1382-1383.

323 See Conger (1998), p. 84.

324 Ibid, p. 84.

325 See, e.g., Alvesson (1993, 2001); Bloomfield/Danieli (1992), pp. 23; Clark (1995), p. 60 and pp. 90-94; Kaye (1996), pp. 17-21; Lippitt/Lippitt (1978), pp. 96-97. 


\subsection{A general problem typology}

\subsubsection{Exact and inexact problems}

Every problem is posed against a certain background of antecedent knowledge. ${ }^{327}$ In other words, problems can only be identified in relation to some background knowledge. This background contains the context or setting of the problem. Furthermore, every problem can be approached in more than one manner, i.e. it has more than one setting or context. Therefore, problems should not be seen as objective facts that are simply discovered by problem solvers. ${ }^{328}$ Rather, problems are conceptual objects constructed and shaped by individuals, and as such, they are bound to the individuals' background knowledge, experience, and beliefs. ${ }^{329}$ This has two important implications: First, different people will interpret a particular problem situation in a different way. Second, problem solvers have to account for such different interpretations in order to ensure the best possible and comprehensive problem formulation. ${ }^{330}$

Not all problems are characterized by the same degree of ambiguity and plurality of possible perspectives, however. Reihlen suggests that problems can be regarded as either exact or inexact depending on the degree of ambiguity of their interpretation, the quality of their representation and the existence of a problem solution. ${ }^{331}$ Inexact problems are, by definition, complex problems. ${ }^{332}$

The main methodological implication of this differentiation for the work of clients and consultants is as follows:

(1) Exact problems are relatively unambiguous and there is no need for clients and consultants to invest extensive time and effort in defining the problem that they face.

(2) Exact problems can be solved in a rational and formalized process using logical deductions, and as such, the problem-solving process does not require highly intensive interaction between clients and consultants.

(3) Inexact problems require high creativity and intensive interaction of both clients and consultants during both problem formulation and problem-solving. It is necessary for clients and consultants to present and discuss different perspectives of the problem and problem solution. ${ }^{333}$

See Bunge (1983a), p. 271.

See Behrens/Delfmann (2002), p. 16; Reihlen (1997), p. 55.

In other words, problems are never context free. See Behrens/Delfmann (2002), p. 16; Reihlen (1997), p. 55. See also Bloomfield and Danieli who argue, "a recognition of the difficulties inherent in the status of organizational problems is all but absent from the literature on management consultants". As a result, they point out, there has been no serious discussion of the role of consultants in defining and constructing client’s problems. Bloomfield/Danieli (1995), p. 32.

See Reihlen (1997), p. 55.

A problem's interpretation is unambiguous when the assumptions about the problem are consistent with the background knowledge of the interpreting individual; a problem is well represented when all variables, parameters, and relations are familiar to the interpreting individual. See Reihlen (1997), pp. 55-57 for an extensive discussion of these characteristics. See also Bronner (1993), p. 13.

See Behrens/Delfmann (2002), pp. 15-21 and Reihlen (1997), pp. 54-64 for an extensive discussion of exact and inexact problems and their implications regarding the appropriateness of different problem-solving techniques. 


\subsubsection{Routine and innovative problems}

In the context of consulting projects, it is also necessary to differentiate between routine and innovative problems, depending on whether the consultants engaged to solve the problem have some previous experience with similar problems or not.

\section{Routine problems}

Problems that consultants are familiar with from previous projects are called routine problems. In this case, consultants have background knowledge for solving similar problems, which helps them to transform the information about the problem situation into problem relevant knowledge. ${ }^{334}$ Bunge summarizes the main characteristics of such problems as follows: "a routine problem is well posed, its approach is well defined, and its solution can be foreseen, at least in outline, for it requires only existing knowledge and more or less hard work. Schematically, a routine problem solving process is the sequence formulation-analysis—search-solution—checking of solution." 335

There are two types of routine knowledge. Individual routine knowledge is based on individual capabilities to solve problems, for example, when a consultant needs to prepare an analysis of a particular market. Organizational routines are based on organizational rules and procedures for accomplishing tasks. ${ }^{336}$ In consulting companies, the second type of routine knowledge takes the form of consulting concepts, methods, and models. 337

\section{Innovative problems}

If the problem is new, and the consultants do not have any experience and background knowledge in solving similar problems before, they have to deal with an innovative problem. One result of the perceived novelty of the problem is its higher complexity. ${ }^{338}$ A major difficulty an innovative problem raises is to formulate it correctly. Furthermore, its solution cannot be foreseen even in an outline, as it requires the creation of new knowledge. ${ }^{339}$ To solve such problems, consultants have to initiate learning processes and to create new knowledge, ${ }^{340}$ which results, at the same time, in altering the existing expertise.

There are two basic forms of innovations. Incremental innovations involve only small changes and improvements in the existing routine knowledge. This is why Tushman and Anderson call them "competence-enhancing" innovations. ${ }^{341}$ An example for an incremental innovation in the area of consulting services is the development of the McKinsey portfolio matrix after the Boston Consulting Group portfolio analysis/matrix 
was introduced. Radical innovations, on the other hand, lead to fundamental changes and to the emergence of totally new products and services. Tushman and Anderson refer to such innovations as "competence-destroying". ${ }^{342}$ Active intelligence, value chain integration, and virtual shared services are recent examples of radical innovations within the area of consulting services. ${ }^{343}$

\subsection{A problem typology of client-consultant projects}

Table 4 shows that when the two problem classifications (degree of exactness of the problem; degree of innovativeness of the problem) are integrated, three general problem types can be defined. ${ }^{344}$

\begin{tabular}{|c|c|c|}
\cline { 2 - 3 } \multicolumn{1}{c|}{} & Exact problems & Inexact problems \\
\hline Routine problems & Simple routine problems & Complex routine problems \\
\hline Innovative problems & & Innovative problems \\
\hline
\end{tabular}

Table 4: General problem types

Source: Reihlen (1997), p. 64.

This definition of three general types of problems is compatible, on the one hand, with a consulting project typology developed by David Maister, which is well recognized in the consulting literature. ${ }^{345}$ On the other hand, it can be enriched with insights of a recently developed problem typology by Nickerson and Zenger. These authors suggest that depending on the problem context, different levels of interaction between individual knowledge sets relevant to the problem are necessary, and accordingly, different degrees of interaction are necessary between the involved individuals. ${ }^{346}$ In the following discussion, the insights of these two problem typologies are integrated into a consulting specific problem typology.

342

343

Ibid, p. 442.

See Laud (2004), p. 52. Some authors suggest a more differentiated view of innovations for the service sector introducing additional innovation types such as improvement innovations, ad hoc innovations, architectural innovations, and formalization innovations. See Gallouj/Weinstein (1997), pp. 548. However, these innovation types cannot be clearly distinguished from each other. Moreover, whereas some types differ in the degree of their innovativeness, others differ in the way they are created (e.g., they are planned or unplanned). Thus, the criteria used to conceptualize these innovation types differ themselves. For the purpose of this work, it is sufficient to adopt the traditional differentiation between radical and incremental innovations.

The existence of an exact innovative problem would be inconsistent with the presented arguments. Only routine problems can have a guaranteed problem solution. Because innovative problems are unfamiliar, it is not possible to validate a potential solution of such problems in advance. See Reihlen (1997), p. 64.

See Maister (1982a), pp. 24-25. Maister's problem or project typology has been adopted by a number of other researchers. See, e.g., Müller-Stewens et al. (1999), pp. 40-41. Maister also discusses implications for the management of these different types of problems. See Maister (1982a), pp. 24-25 and Maister (2004), pp. 21-23.

See Nickerson/Zenger (2004), pp. 618-621. They argue that depending on the type of problem, the "solution landscape” is either "ragged, with many high-value solutions scattered across the terrain"-in the case of problems characterized by the need of highly interdependent knowledge sets for their solution-, or "smooth, with a single, high-value solution or with high-value solutions concentrated in a particular region of the landscape-in the case of problems that do not require highly interdependent knowledge sets in order to be solved. Consequently, problems differ in the optimal form of solution search. For some, "directional search or search based on trial and error leads efficiently to a high-value solution []. For others, search guided by a cognitively developed heuristic of the landscape's topography is preferred”. Nickerson/Zenger (2004), p. 618. 


\subsubsection{Simple routine / low interaction / efficiency problems}

In the consulting literature, exact or simple routine problems have been referred to as efficiency problems and projects that deal with such problems have been called "procedure" projects. ${ }^{347}$ Simple routine problems are decomposable problems and as such, the problem solution depends very little on the interactions among different knowledge sets. With such problems, groups of individuals possessing rather distinct knowledge sets can independently apply their knowledge to solve sub problems "with a reasonable expectation that the aggregation of their independent efforts, along with the independent efforts of other with distinctly different knowledge sets, will uncover valuable problem solutions”. ${ }^{348}$ Furthermore, because efficiency problems are familiar and well recognized, the knowledge that individuals have accumulated by solving similar problems in the past is often sufficient for the formulation and the solving of the problem. ${ }^{349}$ Consequently, such problems can be solved by directional or local search"search guided solely by feedback or experience from prior trials []. The key feature of this form of search is that independent actors, either individuals or groups, independently pursue trials and independently observe performance." ${ }^{350}$ Rescher speaks in this case about "distributive cooperation": "different investigators take on different constituent sub-problems of the whole, like subcontractors contributing their separate operations to an overall effort”. ${ }^{351}$

It follows that, in consulting projects characterized by simple routine problems, there is no need for an extensive knowledge transfer between clients and consultants as it can be reasonably expected that the simple aggregation of clients' and consultants' independent efforts will uncover valuable problem solutions. Moreover, consultants themselves can independently accomplish different tasks and simply integrate their solutions towards the final outcome. The service delivery process is standardized and formalized following a rational, logical procedure: "while some customization [of the problem solution] is still required, the steps necessary to accomplish this are somewhat programmatic." ${ }^{352}$ In such cases, consultants are selling their routine knowledge, efficiency, and availability. ${ }^{353}$ Creativity skills as well as a more intuitive cognitive approach are not required and can be even counterproductive. Thus, no innovations take place within the "procedure" project type; the service output is highly predictable. For this reason, Tordoir calls such consulting projects "sales relations". ${ }^{354}$ Preparing a market research study is, for example, a low-interaction problem. ${ }^{355}$

$\begin{array}{ll}347 & \text { See Maister (1982a), pp. } 24 . \\ 348 & \text { Nickerson/Zenger (2004), p. } 619 . \\ 349 & \text { See Reihlen (1997), p. 62. } \\ 350 & \text { See Nickerson/Zenger (2004), p. } 620 . \\ 351 & \text { Rescher (2005a), pp. 33-34. } \\ 352 & \text { Maister (1982a), p. 24. } \\ 353 & \text { Ibid, p. 24. } \\ 354 & \text { See Tordoir (1995), p. 141. } \\ 355 & \text { See also Wohlgemuth (1989), p. } 214 .\end{array}$


It is important to emphasize that, whereas simple routine problems are always familiar to the consultants, ${ }^{356}$ they may be familiar or unfamiliar for the clients. In other words, clients are not a homogenous group; some are knowledgeable and therefore active, whereas others are less knowledgeable. ${ }^{357}$ In the first case, clients may be able to solve such problems themselves, but engage a consulting firm because it can perform the service more efficiently, or because the client's staff may be employed better elsewhere. Maister compares such consulting services to a "pharmacist practice". ${ }^{358}$ In such cases, the client simply wants the service to be performed to strict technical standards at a minimum cost. This type of work is common in systems installation and other IT consultancies, but it can be found in high-end strategy firms, in which a number of studies, such as component analysis of cost structures, market shares, and competitive positioning, have been highly proceduralized and can be conducted in a routine manner, even by junior staff. ${ }^{359}$ The most relevant personal attributes in such projects are the domain-related skills of the consultants.

There are cases, however, when a problem that is a simple routine problem for consultants might not be familiar for the client, and when the client wishes to be engaged more intensively in the problem-solving process in order to learn about the problem. In Maister's terms, “the client wants to be nurtured and nursed". ${ }^{360}$ Maister calls such projects "nursing practices" and argues that they are characterized by consultants spending a much longer time in contact with the client in comparison to the "pharmacist practice" projects. Consultants still follow a standardized procedure and rely on their existing knowledge. The only difference is that in this case, they explain and help the client's organization to arrive at its own decision and conclusions, rather than solving the problem independently of the client. ${ }^{361}$ In such projects, the consultants' analytical skills as well as well developed communication skills are highly relevant.

\subsubsection{Complex routine / moderate-interaction / experience problems}

Complex routine problems represent complex systems in which recombinations of existing knowledge represent solutions. ${ }^{362}$ Such problems are nearly decomposable in the sense that sub problems associated with distinctive knowledge sets can be defined, but the solution of these sub problems is not fully independent of the solutions of other sub problems. Still, the interactions among knowledge sets within a particular sub problem are greater than among sub problems. ${ }^{363}$ The implication is that although clients and consultants have background knowledge regarding the sub problems of a particular complex routine problem, due to its nature there is always some scope of discretion in

See Nickerson/Zenger (2004), p. 619. A complex system is "made up of a large number of parts that interact in a nonsimple way”. Simon (1962), p. 486 cited in Nickerson/Zenger (2004), p. 619. See Behrens/Delfmann (2002), pp. 3840 for a detailed discussion of Simon's view of complex systems. 
both problem's definition and solution path. ${ }^{364}$ Thus, there are different perspectives about the interactions of the relevant knowledge sets and, accordingly, about how to solve the problem. Consequently, complex routine problems require an intermediate level of interaction between clients and consultants during problem formulation and problemsolving. An intermediate degree of interaction implies that on the one hand, sub problems can be defined and solved in a standardized and formalized manner, and without high interaction between the individuals responsible for their solution. ${ }^{365}$ In other words, a directional search is effective in finding solutions to sub problems. On the other hand, however, the interaction between the different knowledge sets is not trivial as there is some degree of interdependence between these knowledge sets, which makes a more intensive interaction necessary. Nicherson and Zenger speak in this case about heuristic search, which is a form of search in which an actor or a group of actors cognitively evaluate the probable consequences of solutions rather than to solely rely on feedback after solutions have been implemented. In other words, heuristics are used to trial particular problem solutions and to select those trials that maximize the probability of quickly discovering a high-value solution. ${ }^{366}$ Because different individuals have different knowledge they will often concentrate on different sub problems, and on a diverse set of interactions between these sub problems, and as a result, they will often recommend different trials and different orders of trials. For these reasons, Nickerson and Zenger emphasize that the successful solving of complex routine problems requires some sharing of the knowledge between the involved individuals. ${ }^{367}$ "Only by developing heuristics that encompass the knowledge of all actors can the probability of discovering highly valued solutions be enhanced". ${ }^{368}$ Rescher speaks in this case about cooperative problemsolving with different investigators fusing their efforts in conjoint interaction. ${ }^{369}$

It follows that the clients' knowledge and their involvement in the problem-solving process can help to solve the problem. Thus, clients and consultants can still work in a distributive cooperative way when solving sub problems, but the integration of the sub solutions towards a final solution cannot be achieved by simply combining the results of the separate work of different individuals. Therefore, both clients' and consultants' domain-related knowledge is crucial for successful problem-solving. Furthermore, because they need to share their knowledge sets and to interact more intensively when developing heuristics, their interactive skills are important. However, what matters most in solving such problems successfully is the experience and judgment ability of the consultants. ${ }^{370}$ For this reason, Maister calls projects that face complex routine problems "grey hair" or experience projects. ${ }^{371}$ Thus, it can be assumed that in the context of

See Maister (1982a), p. 24; Reihlen (1997), pp. 62-63.

See Nickerson/Zenger (2004), p. 621.

See Nickerson/Zenger (2004), p. 621. Heuristics speed problem-solving by enabling problem solvers to evaluate information before making a decision upon the problem solution. See Behrens/Delfmann (2002), pp. 118 for a detailed discussion of heuristics.

See Nickerson/Zenger (2004), p. 621.

Ibid, p. 621.

See Rescher (2005a), p. 34.

See Maister (1982a), p. 24.

See Maister (1982a), p. 24. 
complex routine problems, not only individuals with an analytical cognitive style, but also those with an intuitive cognitive style, i.e. highly experienced individuals, should be selected as members of the client-consultant team.

To sum up, "grey hair" projects require customized solutions, but they usually involve incremental rather than radical innovations, the main task of which is to adjust previous solutions to a concrete client's situation. The service output of such projects is only to some degree predictable.

\subsubsection{Innovative / high-interaction / creativity problems}

Innovative problems require, in contrast to the previous two types of problems, the creation of new knowledge ${ }^{372}$ and cannot be factored into sub problems. Furthermore, a successful solution cannot be created on the basis of a single knowledge set but requires the involvement and interaction of a number of different knowledge sets. ${ }^{373}$ Additionally, the interactions and interdependencies between individual knowledge sets are so extensive that it is not possible to decompose the problem into simple routine problems and aggregate, afterwards, the sub solutions towards an integrated problem solution. ${ }^{374}$ Such, in Maister's terms, "brains" type of projects require the "creativity, innovation and the pioneering of new approaches, concepts, or techniques." 375 However, whereas consultants' creative thinking is a necessary condition for successful problem-solving, it is not a sufficient condition. With such problems, consultants cannot generate a valuable problem solution independent of the client. ${ }^{376}$ Rather, the intensive involvement of the client and the sharing of relevant knowledge sets, together with creativity, are required for the successful solution of innovative problems. ${ }^{377}$ An intuitive cognitive style, as well as interactive skills, including reflective and persuasion skills, are also crucial for a successful solving of innovative problems. This is why Tordoir speaks in such cases about "sparring relations", ${ }^{378}$ and Rescher about "collective cooperation in knowledge development", which requires interactive teamwork. ${ }^{379}$ Directional search is not appropriate in such contexts; only heuristic search can lead to successful problemsolving. ${ }^{380}$ The development of new strategy, or the reorganization of a company, are a few examples for innovative problems.

372

See Reihlen (1997), pp. 63-64. McGivern and Fineman talk about not clearly defined problems, when the problem is complex and novel. See McGivern/Fineman (1983), p. 436.

See Nickerson/Zenger (2004), p. 620.

Ibid, p. 620.

Maister (1982a), p. 24.

This is in contrast to Maister's suggestion that there are the what he calls "brain surgeon" practices, which are characterized by high innovation of the problem-solving but low interaction with the client. See Maister (2004), p. 21. If consultants face an innovative client problem, they cannot solve it successfully without an intensive interaction with the client. This follows from the characteristics of innovative problems as inexact problems. Maister might be rather referring to problem solutions that are developed internally in consulting companies independent of any particular client problem. In such cases, however, the implementation of these problem solutions in a particular client organization will require again an intensive interaction with the client.

See Nickerson/Zenger (2004), p. 621.

See Tordoir (1995), p. 140.

See Rescher (2005a), pp. 34-35, emphasis added.

See Nickerson/Zenger (2004), p. 621. 
To sum up, in the case of "brains" projects, consulting firms sell their services on the basis of the creativity of their staff. Furthermore, intensive interactions between the involved individuals are required in order to ensure successful problem-solving. Thus, both clients' and consultants' domain-related and creativity-related skills are important, as are their interactive skills. Furthermore, a high degree of intrinsic motivation is required in order to solve such problems successfully. Solutions are highly customized and not predictable at the start of the project. Such projects can involve both incremental and radical innovations. Table 5 summarizes the characteristics of the three problem types.

It is important to note that some consulting firms work on all three types of projects, ${ }^{381}$ whereas other concentrate mainly on one type. However, even in full-service consultancies, individual consultants need to specialize in one type of project because it is highly unlikely that any one will excel simultaneously in all three project types, due to the different requirements that these problem contexts put on individual skills, knowledge and problem-solving abilities. ${ }^{382}$

\subsection{Trends within the immediate environment}

There are few important and to some extent, contradictory trends in the consulting market that influence where the bulk of the market lies. ${ }^{383}$ First, the increased complexity and pace of change in the business environment implies that companies face more and more complex problems. In other words, each management problem is to some degree different, such that a problem solution generated for a particular problem in a particular context is most probably not the best possible solution for a similar problem of another company or in another context. Second, clients increasingly want to be involved in the consulting process and want to understand "what is going on and why". ${ }^{384}$ Third, when engaging consultants clients look more and more for a successful implementation of innovative ideas. ${ }^{385}$

These three trends suggest that the importance of simple routine problems for consulting companies decreases and that complex routine and innovative problems are becoming more common in the professional context. At the same time, clients frequently want to tap into a firm's accumulated experience and methodologies. ${ }^{386}$ Accordingly, they engage consultants more often to solve complex routine problems rather than innovative problems. Therefore, it can be hypothesized that the bulk of the consulting demand is concentrated on projects that deal with complex routine problems. "While critical, the role of [innovative projects] is not a high-volume area”. ${ }^{387}$ Additionally,

In this sense, they are full-service providers. See Maister (2004), p. 23.

See also Maister (2004), p. 23.

These trends have been suggested in the literature and are of rather hypothetical nature. However, some of the cited authors base their assumptions in knowledge of the empirical field of consulting services. See, e.g., Maister (2004); Lead (2004).

Maister (2004), p. 24; Poulfelt et al. (2005), p. 19.

See Laud (2004), p. 43.

See Maister (2004), p. 24.

Ibid, p. 24. 
Maister argues that client organizations still engage consultants in the case of simple routine problems, ${ }^{388}$ even though more and more client organizations possess relevant management knowledge and skills to solve such problems themselves. ${ }^{389}$ In such cases, projects that involve the client to a higher degree, i.e. what was referred to as "nursing practices”, have higher economical relevance than the so-called "pharmacist practices", which are characterized by a very low client-consultant interaction. ${ }^{390}$

\begin{tabular}{|c|c|c|c|}
\hline $\begin{array}{l}\text { Complexity/ } \\
\text { innovativeness } \\
\text { of problem }\end{array}$ & $\begin{array}{l}\text { Simple routine/familiar } \\
\text { problems }\end{array}$ & $\begin{array}{l}\text { Complex routine } \\
\text { problems }\end{array}$ & $\begin{array}{l}\text { Innovative/novel } \\
\text { problems }\end{array}$ \\
\hline \multirow[t]{9}{*}{ Characteristics } & $\begin{array}{l}\text { Low customization of } \\
\text { problem solution. }\end{array}$ & $\begin{array}{l}\text { Some customization of } \\
\text { problem solution. }\end{array}$ & $\begin{array}{l}\text { High customization of } \\
\text { problem solution. }\end{array}$ \\
\hline & $\begin{array}{l}\text { No innovation, no new } \\
\text { knowledge. }\end{array}$ & $\begin{array}{l}\text { Some (incremental) } \\
\text { innovation. }\end{array}$ & $\begin{array}{l}\text { Incremental and radical } \\
\text { innovation. }\end{array}$ \\
\hline & $\begin{array}{l}\text { Low interaction with the } \\
\text { client in the case of }\end{array}$ & $\begin{array}{l}\text { Medium intensity of } \\
\text { interaction. }\end{array}$ & High intensity of interaction. \\
\hline & $\begin{array}{l}\text { “pharmacist” projects” and } \\
\text { higher in "nursing” projects. }\end{array}$ & $\begin{array}{l}\text { Standardized/formalized } \\
\text { problem-solving only of sub }\end{array}$ & $\begin{array}{l}\text { problem-solving possible. Use } \\
\text { of heuristic search only. }\end{array}$ \\
\hline & $\begin{array}{l}\text { Standardized/formalized } \\
\text { problem-solving (directional }\end{array}$ & $\begin{array}{l}\text { problems (directional search); } \\
\text { use of heuristic search to }\end{array}$ & $\begin{array}{l}\text { Consultants are selling their } \\
\text { creativity. }\end{array}$ \\
\hline & $\begin{array}{l}\text { Consultants are selling their } \\
\text { routine knowledge, }\end{array}$ & $\begin{array}{l}\text { search and to trial possible } \\
\text { problem solutions. }\end{array}$ & $\begin{array}{l}\text { Both consultants and clients } \\
\text { need domain-related }\end{array}$ \\
\hline & efficiency, and availability. & Consultants are selling their & well-developed interactive \\
\hline & $\begin{array}{l}\text { Consultants need domain- } \\
\text { related knowledge, and in }\end{array}$ & $\begin{array}{l}\text { experience and judgment } \\
\text { ability. }\end{array}$ & $\begin{array}{l}\text { skills as well as a degree of } \\
\text { intrinsic motivation. Emphasis }\end{array}$ \\
\hline & $\begin{array}{l}\text { the case of "nursing } \\
\text { projects" some interactive } \\
\text { skills. Emphasis on } \\
\text { analytical cognitive style. }\end{array}$ & $\begin{array}{l}\text { Both consultants and clients } \\
\text { need domain-related } \\
\text { knowledge and interactive } \\
\text { skills. Both analytical and } \\
\text { intuitive cognitive styles are } \\
\text { emphasized. }\end{array}$ & on intuitive cognitive style. \\
\hline
\end{tabular}

\section{Table 5: Problem types in client-consultant projects and their characteristics}

Thus, it can be concluded that independent of the concrete problem type that clients and consultants face, a factor that is more and more important for the success of clientconsultant projects is the client-consultant interaction. Therefore, it is important to discuss the nature of the client-consultant interaction and to outline what factors influence its success. This work shows how this question has been analyzed in the existing literature on client-consultant relationships and proposes ways to improve the understanding and the management of client-consultant interactions.

Before discussing the third element of the systemic view of client-consultant relationships, the structural relations between the members of the team, it is necessary to shed some light on the broader environment, in which client-consultant teams are

388

389

See Maister (2004), p. 24.

It can be hypothesized that such outsourcing of management problems takes place in the wave of generally increasing importance of outsourcing. See also Poulfelt et al. (2005), p. 19. Poulfelt et al. further argue that outsourcing should not be regarded as consulting. Consulting does not involve the taking over of the managerial function, which is exactly what happens when companies outsource services. See Poulefelt et al. (2005), p. 20.

See Maister (2004), p. 24. 
embedded. $^{391}$ This is also referred to as the organizational field of management knowledge production and dissemination. ${ }^{392}$

\subsection{Organizational field of management knowledge production and dissemination}

The organizational field of management knowledge production is comprised of all organizations engaged in the process of developing and filtering new managerial practices and management fashions, as well as the subsystems of application, consumption, and dissemination of those practices. ${ }^{393}$ Consulting companies and their clients are regarded as two of the major players in the production and dissemination of management practices. ${ }^{394}$ Concrete consulting projects provide the setting where the main part of the production and dissemination of management concepts and practices takes place. Thus, the cooperation between clients and consultants within the scope of concrete consulting projects both influences and is influenced by management fashions. Additionally, other actors, such as business schools and publishing companies, also take part in the production and dissemination of management fashions, and as such, influence problem-solving within the scope of specific consulting projects. Therefore, when discussing problem-solving in specific client-consultant relationships, one needs to analyze the interrelation between client-consultant teams and management fashions. ${ }^{395}$

On the one hand, when client-consultant teams create innovative problem solutions, and when these solutions are further disseminated and adopted in other consulting projects, clients and consultants can be regarded as creators of new management fads. ${ }^{396}$ On the other hand, however, specific client-consultant projects are affected by existing management fads and fashions. That is, existing management practices influence the work of clients and consultants by offering ideas for creative problem-solving or proven paths and standardized templates for problem-solving. Management fashions are presented by a variety of fashion setters as "good" and "rational" management practices, ${ }^{397}$ and for this reasons clients and consultants often adopt them for the problemsolving process during specific consulting projects. Therefore, existing management practices influence the direction of problem-solving and the degree of innovativeness and efficiency of the problem-solving process within the scope of specific consulting projects.

391

Only these aspects of the broader environment are discussed that have a more direct influence on client-consultant interactions within the scope of single consulting projects. See Hoffmann (1991), pp. 30-34 for a broader discussion of the consulting environment. See also Kirsch and Eckert who develop a systemic model of the broader environment of consulting projects. See Kirsch/Eckert (1998), pp. 286-292. Their concept is quite similar to the systemic perspective suggested within this work. However, they concentrate on the macro level relations between consultants, clients, and other actors. As such, their work will not be discussed in detail. Some of their arguments will be utilized later on when discussing the interpretive model of the client-consultant relationship.

The term organizational field is broader and more interactive than traditional notions of industry or market sector. See Suddaby/Greenwood (2001), p. 934.

See Suddaby/Greenwood (2001), p. 934.

See, e.g., Abrahamson (1996), p. 265; Kieser (2002a), pp. 168-170; Suddaby/Greenwood (2001), pp. 938.

This is discussed in detail in chapter D.IV.

See, e.g., Morris (2000), p. 132.

See Abrahamson (1996), pp. 261-263. 
The processes of knowledge production and dissemination within client-consultant teams, also called micro processes of knowledge production and dissemination, are discussed intensively in chapter D.III.3 and D.IV of this work. However, it is also necessary to shed some light on the actors that are involved in the production and dissemination of management fads and fashions on a macro level, and to show how these actors and their actions influence the micro processes of knowledge production and dissemination that take place between clients and consultants within the scope of single consulting projects. In the following, the main organizations involved in the production and dissemination of management practices, and their impact on client-consultant interaction, are briefly introduced.

\subsubsection{Consulting companies ${ }^{398}$}

Consulting companies are the major actor in commodifying and storing management practices. ${ }^{399}$ They influence client-consultant projects directly by enabling consultants to tap into the knowledge, concepts, and methods created and used in previous consulting projects. ${ }^{400}$ As a result, consultants can access and use previously produced knowledge in future projects. Reihlen and Ringberg differentiate two types of codified and stored knowledge artifacts that consultants usually have access to: cases and methods. ${ }^{401}$ Cases include project documentation such as proposals, offerings, reports, presentations, data, and references to applied tools. ${ }^{402}$ Methods represent general "rules of thumb" practices generated and preserved from previous projects. Both types of artifacts can be used (1) as a source of inspiration for the development of creative solution paths for particular clients; (2) as a resource to control and validate consultants' ideas for problem-solving; or (3) as standardized templates for problem-solving. ${ }^{403}$ Additionally, and in order to enhance the use of cases and methods, consulting companies also enable consultants to contact directly other, more experienced consultants or consultants who possess very

Only those members of the consulting company are regarded here who are not directly involved in a particular consulting project. Similarly, the term client organization, which is used in the next section, includes only members of the client organization who do not participate in a particular consulting project.

See Kieser (2002a), p. 168; Morris (2000), p. 132. Suddaby and Greenwood argue that consulting companies convert local knowledge generated in single consulting projects into codified and abstracted knowledge, which is reusable in other projects and saleable to other clients, through three processes: codification, abstraction, and translation. See Suddaby/Greenwood (2001), pp. 938-939 for a detailed discussion of these processes. Of course, consulting companies can also influence consulting projects by investing into research with the aim of developing new ideas and new services for potential clients. See Davenport/Prusak (2005), p. 309. However, the results of such research cannot be sold in a standardized way to clients but need to be modified, further developed, and implemented in specific consulting projects. These processes of problem-solving are analyzed extensively when discussing the cultural relations between clients and consultants. Additionally, consulting companies also influence consulting projects by providing them with other resources for their work, for example with contacts to experienced consultants, materials resources, etc. This aspect is not further discussed within this work. See, e.g., Davenport/Prusak (2005), pp. 305; Reihlen/Ringberg (2006), pp. 327-329; Sarvary (1999), pp. 99.

See Reihlen/Ringberg (2006), p. 327. Additionally, consulting companies also store specific calculation tools developed for specific client problems, which cannot be used offhand in other projects. As such, they are not commonly shared within consulting companies. Such previously created but specific tools do not influence future consulting projects to the same extent, as do cases and methods. Ibid, p. 329. consulting companies invest heavily in developing their knowledge management systems, the knowledge stored into cases and methods is not easily accessible by other consultants. Ibid, pp. 330-336 and the discussion in chapter D.III.3.8. 
specific and valuable knowledge. Such personal contacts are a very rich source of existing knowledge and artifacts. ${ }^{404}$

Thus, it can be concluded that consulting companies influence particular consulting projects through enabling consultants to tap into existing, more or less standardized knowledge. This can lead to better problem solutions and/or increasing efficiently of the problem-solving process. ${ }^{405}$ At the same time, however, for efficiency reasons, consultants might be forced to use existing concepts and methods even when they do not fit the concrete client problem. This would be the case if, for example, they do not have the time to develop customized services. Moreover, even if they have the time and opportunity to develop innovative concepts and methods, the availability of previously developed knowledge can prevent them from developing alternative solution paths and novel management practices. It has been argued that existing categories attached to certain events influence negatively the knowledge creation process: “once a phenomenon is categorized, a confirmatory bias reinforces the original labeling and categorizing of the phenomenon. This bias affects processing of new information and recall of old information". ${ }^{406}$ Previously generated knowledge and artifacts may have a standardizing effect on consultant's interpretations "by dictating the range and interpretation of experiences made". ${ }^{407}$ Therefore, consulting companies that expect consultants to work extensively with established knowledge and artifacts might not be able to generate innovative solutions. ${ }^{408}$ Rather, they reinforce and disseminate established knowledge and as such, play an important role in the dissemination of management fads and fashions.

Additionally, consulting companies influence indirectly concrete client-consultant projects by disseminating consulting methods and practices developed by other consulting companies. For example, small consulting organizations in particular are often forced to adopt the consulting methods of larger competitors due to their broad appeal and recognition within the organizational field of management knowledge. ${ }^{409}$ However, even larger consultancies have often to conform to widely legitimized and "sought after" practices and offer them to their clients.

\subsubsection{Client organizations}

Members of client organizations can influence the work of concrete client-consultant teams indirectly by creating new management fashions. This is the case when

In fact, Reihlen and Ringberg found that personal contacts are a much more advantageous form of knowledge sharing and transfer between consultants than computer-mediated transfer of cases and methods. See Reihlen/Ringberg (2006), pp. 336-337; see also Davenport/Prusak (2005), p. 318.

Converting managerial knowledge into products allows consulting companies to "leverage” their knowledge product, i.e. to hire a large number of junior consultants at a lower cost than the revenue they generate. See Suddaby/Greenwood (2001), p. 942. Other advantages of commodifying management practices involve facilitating of internationalization due to "portability" of this knowledge and decreased dependency of consulting companies on individual consultants and their knowledge. Additionally, standardized knowledge practices increase the predictability of consulting services and provide a degree of "branding" for the firm. Ibid, pp. 942-943.

Dutton/Jackson (1987), p. 81.

Werr/Stjernberg (2003), p. 900.

See Semadeni (2001), pp.47-48 and p. 52.

See, e.g., Fincham/Clark (2002-3), pp. 3. 
management fashions originate in ideas of top managers like Jack Welch or Percy Barnevik, which are disseminated through published materials and are later adopted by consultants when working on client projects. ${ }^{410}$ However, in most cases, management concepts and methods are created or advanced during the interaction between clients and consultants within the scope of consulting projects. ${ }^{411}$ Thus, client organizations usually play an important role in the dissemination of management fads. For example, if members of the client organization, who are not involved in a particular client-consultant project, express support for the implementation of established management practices and problem solutions, they affect the work of client-consultant teams directly by influencing the direction of problem-solving. ${ }^{412}$ Several authors point out that there is an increasing demand amongst clients for management knowledge products, ${ }^{413}$ and there are different suggestions why clients favor and continuously purchase commodified consulting services. $^{414}$ Independent of the exact reasons why client organizations increasingly "consume" established management practices, it is clear that in doing this, they can influence the problem-solving process within the scope of specific consulting projects. ${ }^{415}$

\subsubsection{Business schools}

Business schools can be sources of new management fashions when academics develop new or "reinvent" existing management concepts and transfer them into the management field through their work as consultants. Well-known examples of academics transferring ideas originating in their business schools are Michael Porter, Gary Hamel, and Kaplan and Norton. Additionally, such guru-like academics often appropriate and legitimate management practices used in client organizations and disseminate them through the popular business press, for example through publications in practitioner journals such as Harvard Business Review, as well as through academic publications. ${ }^{416}$

410

See Kieser (1997), p. 53; also Abrahamson (1996), p. 266.

See Davenport/Prusak (2005), p. 309; Gadrey/Gallouj (1998), p. 8; Gallouj/Weinstein (1997), pp. 546; Morris (2000), p. 131 and the discussion in chapter B.I.2.2.3.

See Suddaby/Greenwood (2001), p. 940. Client organizations influence client-consultant relations also by providing resources for concrete projects, including human resources-e.g., project manager and members of the client organization who work with the consultants on problem-solving-and financial resources.

See, e.g., Abrahamson (1996), pp. 270-275; Kieser (2002a), pp. 173; Suddaby/Greenwood (2001), pp. 939-940.

Some suggest that clients prefer "package solutions" because they create the impression that the methods of the respective management concept have been tested in many companies, which guarantees their "quality". See Kieser (2002a), p. 168. Another explanation involves a view of consultants as impression managers who make clients dependent on management fashions in order to sale their services. See Kieser (2002a), pp. 173-176 and the discussion in chapter C.IV.4. Others stress that organizations have to adopt practices that have become institutionalized in society in order to appear rational and to acquire and retain legitimacy and support by stakeholders. See, e.g., Abrahamson (1996), pp. 261263.

By following particular management fashions, client organizations also guide the demand for related fashions. See Abrahamson (1996), p. 267. For example, he argues, the quality circle fashion can be seen as a precursor of a number of related management fashions belonging to the total quality fashion trend. Ibid, p. 267.

See Abrahamson (1996), p. 266; Morris (2000), pp. 131-132; Saint-Martin (2000), p. 48; Suddaby/Greenwood (2001), p. 938 and pp. 941-942. There are different arguments as to whether academics shape management and consulting practice, or vice versa. See Abrahamson (1996), p. 269 and Suddaby/Greenwood (2001), pp. 941-943. Suddaby and Greenwood propose that new managerial knowledge occurs first among practitioners, it is appropriated consequently by consultants, and, over time, moves into business schools. Ibid, pp. 942-943. In contrast, Morris suggests that academics often create fashionable management practices by observing the work of practitioners. See Morris (2000), p. 131. 
On the other side, business schools often provide a forum for evaluation and refinement of consulting knowledge and concepts that were developed during consulting projects, and then disseminated outside of the involved client and consulting organizations. ${ }^{417}$ Business schools also develop suggestions for improvement of these practices, contributing to the further dissemination and institutionalization of management practices. ${ }^{418}$ In addition, by educating management students, they provide future managers (i.e. clients) and future consultants with shared knowledge, a common language and unified values and assumptions. With this, business schools "provide the cognitive foundation for the legitimacy of extant management knowledge". 419

\subsubsection{Publishing companies}

Publishing companies play an important role in the dissemination of management fads. "To turn into a management fashion a management concept must become an object of public discourse". ${ }^{420}$ Thus, in contrast to the other three groups of actors, publishing companies are not directly involved in the production of new management practices. ${ }^{421}$

A public discourse is usually initiated by the publishing companies when they publish an article, a presentation, a management book, or a combination of such events. The discourse then gains momentum when widely read management magazines pick up the management concept. ${ }^{422}$ Additionally, publishing companies also organize or coorganize management seminars and congresses through which they further promote the circulation of their publications. Because such publications reach broad audiences, they have the potential to draw widespread attention to particular management fashions. ${ }^{423}$

However, it is necessary to acknowledge that not only publishing companies, but also other actors within the organizational field of management knowledge production and dissemination, can contribute to the dissemination of management fashions by developing their own publications. For example, McKinsey, a consulting company, publishes McKenzie Quarterly; academics publish the Academy of Management Executive (now Academy of Management Perspectives); and Business Week is an example of a journalists' publication. Additionally, there is the book-publishing industry, and the textbook industry. ${ }^{424}$ Thus, it is clear that some actors, e.g., consulting companies and academics, can play different roles in the production and dissemination of management fashions.

See Abrahamson (1996), p. 269. Saint-Martin argues that for large consultancies such as McKinsey, Booz Allen and Hamilton, and Gemini, the publication of books and artickles is one of the key instruments for disseminating ideas. The most famous book produced by consultants is In Search of Excellence by Peters and Waterman (1982). See Saint-Martin (2000), p. 47; see also Jackson (2001), p. 176.
} 
Next, the third component of the systemic view of client-consultant relationshipsthe team's structure-is discussed. 


\section{Structural relations}

\subsection{Cultural relations}

When considering the cultural relations within client-consultant teams, two main questions need to be clarified. First, what are the characteristics of problem-solving activities in client-consultant teams? The answer to this question is not straightforward due to the interrelation between cultural and economic activities during problem-solving. The second question that needs an examination is related to the results of cultural production. These two issues are clarified in the following discussion.

\subsubsection{The coupling of cultural and economic relations}

Problem-solving, also called inquiry, ${ }^{425}$ involves work and communicative interaction. ${ }^{426}$ Work includes the "transformation of matter and/or symbols for human purposes". ${ }^{427}$ Communication is the process of sharing cognitive attitudes and findings with others, and the influence of others' cognitive processes. ${ }^{428}$ Communicative interaction refers to the sharing of meaning in a community of inquirers. It involves the learning of a particular "language" and "a set of procedures for thinking and arguing about the object of study". ${ }^{429}$

To the extent that clients and consultants are engaged in communication and knowledge transfer, which result in changes in their perspectives and thinking, they are engaged in cultural production. In other words, all activities of clients and consultants oriented towards evoking feelings or thoughts and developing ideas through processes, such as forming concepts, transforming, and interrelating them to construct propositions, as well as through communicative interactions, represent cultural relations within clientconsultant teams. At the same time, these cultural activities almost always involve the transformation of some thing or other ${ }^{430}$ through conducting experiments, surveys and fieldwork, as well as through design of methods, concepts and other cultural artifacts, such as reports, presentations, software, etc. ${ }^{431}$ For example, when working on ideas for problem-solving, clients and consultants communicate by writing down their arguments, drawing figures, using computers to prepare presentations, etc. Such activities orientated

See Tsoukas/Knudsen (2003), pp. 7-8. Bunge argues that both are highly interconnected: "all social relations among humans are accompanied by communication of some sort or other”. Bunge (1983a), p. 124.

See Bunge (1979), pp. 196-203; Tsoukas/Knudsen (2003), pp. 7-8. to the growth or the decline of knowledge. Ibid, p. 97. including anything made or done with the help of learned knowledge and utilizable by others. Bunge (1985), p. 222-230. There has been a controversy regarding the nature of cultural artifacts. In this work, the view is supported that knowledge in the form of artifacts cannot exist independently of an inquiring subject, i.e. from a living brain. See Bunge (1985), p. 227 and chapter D.III.1 for an extensive discussion of this issue.
} 
towards the production and employment of cultural artifacts constitute the economic relations within client-consultant teams. ${ }^{432}$

It is clear that because consulting means that clients and consultants are engaged in problem-solving processes in which they communicate, transfer, and transform ideas, perspectives and thoughts, with the help of cultural artifacts, the cultural and economic relations of client-consultant teams are closely interwoven. ${ }^{433}$ In other words, the economic relations between clients and consultants have an inherently cultural, i.e. economicocultural, character. ${ }^{434}$ For this reason, this work concentrates on the study of the cultural relations within client-consultant teams as well as their interconnectedness with economic relations. It discusses how clients and consultants transfer and share meanings and ideas and how artifacts are used and created during consulting projects, as well as their role for knowledge transfer and creation. ${ }^{435}$ In other words, it is shown that economic activities towards production and exchange of artifacts are based on communication and interpretation processes, and at the same time, existing work practices and consulting artifacts enable effective communication. ${ }^{436}$ The focus on the cultural relations within client-consultant teams is also in line with the earlier presented conclusion that every study on professional business services needs to discuss the process of knowledge production in professional business service firms. ${ }^{437}$

This is not to say, however, that economic considerations are not relevant when discussing the nature of client-consultant relations. Rather, economic factors greatly influence cultural activities and need to be taken into account when analyzing the interaction between clients and consultants. ${ }^{438}$ Therefore, it is necessary to shed some light on the impact of economic relations on problem-solving. Chapter 4.b offers some insights on this topic.

\subsubsection{Task-specific and task-related knowledge}

The second question that was identified as relevant for the discussion of the nature of cultural relations within client-consultant teams is related to the results of cultural production. The previous discussion made it clear that there are two major outcomes of cultural production: ${ }^{439}$ first, encultured people, i.e. the knowledge that is held in the

432

433

434

See Bunge (1979), p. 209. The production and employment of any kind of artifacts—cultural (e.g., books, records) or economic (e.g., paper, computers)—is part of the economic subsystem of social systems. See Bunge (1979), p. 206.

It is often hard to differentiate between these relations in practice. See Tsoukas/Knudsen (2003), p. 8.

See Bunge (1979), pp. 211-215. Clearly, the knowledge generated as a result of consulting projects is a cultural input to primary production, and thus to the economic system (of the client organization). Ibid, p. 208. However, as clients and consultants are not involved in primary production during consulting projects, their relations during problem-solving are orientated towards cultural production.

Because there is an extensive consulting literature about the "work" and concrete consulting methods and techniques used in consulting projects, this work does not discuss these issues in detail. See Fombrun (2004), pp. 78-97; Fombrun/Nevins (2004b), pp. 98-111; Hussey (1998), pp. 310-326; Nichols (2004), pp. 153-175; Obolensky (1998), pp. 281-309; Tetenbaum/Carucci (2004), pp. 179-203 for a detailed discussion of different consulting methods and techniques.

See chapter D.III.3.8. Consulting methods are a form of "boundary objects”, which are critically important for successful knowledge transfer. Artifacts also enable knowledge creation and stimulate innovation.

See chapter B.I.1.4.

However, as stated in the introduction to this work, economic relations are not at the heart of this work.

Bunge states that waste products are a third outcome of cultural production. See Bunge (1979), p. 212. 
brains of the involved individuals, and second, the knowledge that is encoded and externalized in the form of cultural artifacts. ${ }^{440}$ Both types of knowledge involve, on the one hand, task-specific knowledge that is required for problem-solving, and on the other hand, task-related knowledge, which includes shared beliefs, attitudes and intentions, as well as concrete practices and procedures within the client-consultant team that shape the specific working or thinking "style" of the team and enable its cooperation. ${ }^{441}$ Shared understanding about roles and responsibilities, interaction patterns, communication channels and role interdependencies are few examples of task-related knowledge. ${ }^{442}$ Thus, task-specific knowledge represents the shared understanding between the members of the client-consultant team of some external phenomenon-i.e. the problem issue at hand - including theories, hypothesis and data, as well as methods, designs and plans how to solve problems. ${ }^{443}$ In contrast, task-related knowledge includes individual's understanding of the components of teamwork and their interrelation that are critical for effective team performance. ${ }^{444}$ The production and application of task-related knowledge fosters cohesion, motivation, and consensus within client-consultant teams ${ }^{445}$ and provides, therefore, the conditions for successful communication and knowledge transfer. ${ }^{446}$ In other words, the development of task-related knowledge within clientconsultant teams is a prerequisite for the successful development and utilization of taskspecific knowledge during problem-solving. As such, task-related knowledge is an output that is fed back into the client-consultant system. The creation of task-related knowledge is an expression of the self-management of client-consultant teams ${ }^{447}$ and is influenced by a number of social mechanisms that serve the management and coordination of the team's activities. ${ }^{448}$

Both task-specific and task-related knowledge can be regarded epistemologically in a number of different ways: knowledge in general can be seen as a resource that can be managed and organized, or as a social construct that is more or less shared between individuals. In other words, in the literature, there is no consensus on the nature of knowledge and cultural relations in general and of consulting knowledge in particular. Rather, there are different epistemological perspectives on knowledge and cultural artifacts that are also reflected in the existing models of client-consultant interaction. Therefore, a discussion of the epistemological approaches to knowledge that underlie these models is necessary in order to analyze the nature of cultural relations in client-

See Bunge (1979), p. 212. Because cultural artifacts represent encoded and externalized knowledge that could be transferred to other individuals, they greatly facilitate knowledge sharing and storing. This was made possible with the invention of drawing, writing, etc. See Bunge (1983a), p. 65.

See Cannon-Bowers/Salas (2001), p. 197; Krohn/Küppers (1989), pp. 36-42; Marks et al. (2001); Reihlen (2003a), pp. 12-13.

See Mathieu et al. (2000), pp. 274-275.

See Bunge (1985), p. 232; Klimocki/Mohammed (1994), p. 412. Because this knowledge is so specific to the particular task, it can be generalized only to other projects with similar tasks. See Cannon-Bowers/Salas (2001), p. 197.

See Krohn/Küppers (1989), pp. 34-42; Reihlen (2003a), p. 4 and pp. 11-13. See also the discussion in chapter D.III.3 on the importance of shared cognition.

See Krohn/Küppers (1989), p. 36.

This issue is extensively discussed in chapter B.II.4.4. 
consultant teams as proposed in the consulting literature. Such an analysis will clarify the main propositions and shortcomings of the different models of the client-consultant relationship. In this way, the foundation for the development of a new model of clientconsultant interaction will be provided.

\subsubsection{Cultural relations: theoretical conceptions of knowledge}

When looking at cultural relations within client-consultant teams, one is concerned with such questions as how do clients and consultants exchange knowledge, how do they create solutions for the problems they face, what are the factors that inhibit or enhance communication, etc. It is clear that the answer to these questions depends on the underlying understanding of the nature of knowledge.

The concept of knowledge, while being one of the most "fashionable" terms for both researchers and practitioners in the last decade, is in no case clearly defined. Several authors who are engaged actively in research in the area of knowledge conclude that it is still not clear what knowledge is. ${ }^{449}$ In line with this, Bunge argues, "What is traditionally called the 'problem of knowledge' is actually an entire system of problems, including the following: What is knowledge? What can know: minds, brains, computers, or social groups? [] How does one get to know: from experience, reason, action, a combination of two or all three, or none of them?" ${ }^{450}$ Consequently, all related terms, such as knowledgeintensive firms, knowledge work, and consulting knowledge, are unclear terms, explained in different ways depending on the author's underlying understanding of knowledge.

There have been several attempts to systematize different epistemological approaches to knowledge in the literature. The following discussion attempts to provide a very broad structure to the debate on knowledge and knowledge transfer and creation, without claiming to be exhaustive of all perspectives and approaches. ${ }^{451}$ The discussion is based on Empson's suggestion to differentiate between the two broad alternative perspectives on the nature of knowledge: (1) the "knowledge as an asset view", which is embedded in a positivist tradition, and as such was prevalent among management researchers and practitioners for the most of the last century; and (2) the "knowing as a process" perspective that originates in sociology and was accepted in management writings only in the last two decades. This view emphasizes the interpretive and socially constructed character of knowledge. ${ }^{452}$

It is important to note that the chosen distinction is incomplete, as it assumes that there is a unifying view of knowledge within the interpretivist school. This is, however, not the case. The interpretivist school includes several different critical streams, such as critical theory, postmodernism, social constructivism, and poststructuralism. ${ }^{453}$ Whereas

As Empson argues, "any attempt to impose a structure on this debate, or to develop a typology for classifying this research, represents [a] kind of reductivist thinking”. Empson (2001), p. 812.

452 See Empson (2001), pp. 813-814. See Putnam (1983), pp. 34 for a similar distinction.

453 See Hatch/Yanow (2003), p. 65. See Bunge (1996), pp. 343-346 and Schwandt (2000), pp. 189 for a critical discussion of interpretivism (and its related disciplines) as philosophy of social sciences.
} 
all interpretive approaches are characterized by the view of meaning as central to social action, they "differ in their definitions and treatments of meaning, in their concern with social activities, and in their examination of language and action". ${ }^{454}$ The result is that different schools of thought within the interpretive approach make different assumptions about the nature of knowledge, knowledge transfer and creation, and ultimately about the nature of social reality. ${ }^{455}$ However, due to the lack of a general scheme for classifying diverse theories and schools within this approach, a broad view of interpretivism as opposed to positivism is the less problematic way to go. ${ }^{456}$ In the following, the two main existing epistemological approaches to knowledge are introduced (see table 6).

\begin{tabular}{|c|c|c|}
\hline & $\begin{array}{l}\text { Resource (positivist) school } \\
\text { Knowledge as an asset }\end{array}$ & $\begin{array}{l}\text { Interpretivist School } \\
\text { Knowing as a process }\end{array}$ \\
\hline Main works & $\begin{array}{l}\text { Barney (1991); Casson (1999); Kogut and } \\
\text { Zander (1992, 1996); Grant (1996); Hansen et } \\
\text { al. (1999); Scott (1998). }\end{array}$ & $\begin{array}{l}\text { Berger and Luckman (1967); Blackler (1995); } \\
\text { Boland/Tenkasi (1995); Hassard (1999); Parker } \\
\text { (1992); Tsoukas (1996). }\end{array}$ \\
\hline \multirow{2}{*}{$\begin{array}{l}\text { Purpose of } \\
\text { research }\end{array}$} & Normative. & Descriptive. \\
\hline & $\begin{array}{l}\text { To identify valuable knowledge and to } \\
\text { develop effective mechanisms for managing } \\
\text { that knowledge within organizations. }\end{array}$ & $\begin{array}{l}\text { To understand how knowledge is created, } \\
\text { articulated, disseminated, and legitimated within } \\
\text { organizations. }\end{array}$ \\
\hline $\begin{array}{l}\text { Disciplinary } \\
\text { foundations }\end{array}$ & $\begin{array}{l}\text { Economics, knowledge-based and resource- } \\
\text { based view of the firm. }\end{array}$ & Sociology, cultural anthropology. \\
\hline $\begin{array}{l}\text { Underlying } \\
\text { paradigm }\end{array}$ & Positivist, functionalist. & Interpretive. \\
\hline $\begin{array}{l}\text { Epistemolo- } \\
\text { gical } \\
\text { assumptions }\end{array}$ & $\begin{array}{l}\text { Knowledge as an objectively definable } \\
\text { commodity; individuals as carriers of } \\
\text { knowledge. }\end{array}$ & Knowledge as a social construct. \\
\hline $\begin{array}{l}\text { Models of } \\
\text { knowledge } \\
\text { transmission }\end{array}$ & $\begin{array}{l}\text { Exchanges of knowledge among individuals } \\
\text { are governed by an implicit internal market } \\
\text { within organizations. }\end{array}$ & $\begin{array}{l}\text { Knowledge is disseminated and legitimated } \\
\text { within organizations through an ongoing } \\
\text { process of interaction among individuals. }\end{array}$ \\
\hline $\begin{array}{l}\text { Main levels } \\
\text { of analysis }\end{array}$ & Organization and its knowledge base. & Individual in a social context. \\
\hline
\end{tabular}

Table 6: Alternative perspectives on knowledge in organizations ${ }^{457}$

\section{The resource (positivist) school}

The resource school to knowledge originates in the economic theory of the firm, in particular in works from information economics, ${ }^{458}$ the knowledge-based view of the firm, ${ }^{459}$ the resource-based view of the firm ${ }^{460}$ and the information-processing approach

Putnam (1983), p. 32.

Different assumptions regarding the nature of social reality (ontological assumptions) result in different perspectives regarding the nature of knowledge, and knowledge transfer and creation (epistemological assumptions). "Ontology is the enquiry into the nature of being, of existence. [] Epistemology [] is an enquiry into our knowledge of being". Acroyd/Fleetwood (2000), p. 6. See also Bunge (1996), p. 2. For an extensive discussion of these perspectives and their critic, see Bunge (1996), pp. 241.

"The interpretive approach, when pitted against the functionalist [positivist] view of reality, projects a sense of unity". Putnam (1983), p. 33. Some of the streams within interpretivism, which are relevant for the discussion of the concrete models of client-consultant interaction, are outlined when analyzing these models.

The table summarizes the main propositions of the two approaches on knowledge. It is based on Empson (2001), pp. 812814 and Reihlen/Ringberg (2004), pp. 4. 
to human cognition. ${ }^{461}$ As such, the resource school is grounded in a positivist philosophy of social sciences. Positivism seeks to transfer methods and views of the natural sciences to the study of society. This implies in particular that the orientation of the study of societies and their members is objective, "in that they are observed from without by detached observers" with the goal to create general, law-like theories about organizations and their members. ${ }^{462}$

When applied in the context of knowledge and learning, the main proposition of the resource school is that knowledge-often used synonymously with informationrepresents an asset or a resource, the meaning of which is pre-existent and universal, independent of its carriers. ${ }^{463}$ Knowledge is regarded as a collection of abstract symbols that are stored in the mind. They arrive in the mind via transducers that transform external stimuli into internal representations. Knowledge is treated, consequently, "as if it [was a] tangible good that is transported in containers called messages". ${ }^{464}$ Supporters of this view implicitly assume that individuals "know how to use the information that they merely need to obtain 'the facts' in order to take action”. ${ }^{465}$ In other words, it is assumed that knowledge contains the necessary codes for its successful decoding. ${ }^{466}$ Consequently, the resource school ignores the influence of social and contextual factors on individuals and human cognition. It "portrays knowledge as independent of its carriers and their interpretive world" ${ }^{467}$ and perceptions, and equals human cognition with the information processing ability of computers.

The implication of this view of knowledge for knowledge transfer is that it is seen as a simple transfer of data and information. Accordingly, learning is the result of data acquisition $^{468}$ and problem-solving is a search process designed to find a match between external stimuli and the existing collection of stored representations. ${ }^{469}$ Communication is regarded as a language-based process that is used instrumentally by social actors to achieve their ends-e.g., actors use communicative actions for the facilitation of managerially relevant processes and outcomes-rather than as a process for sharing

See, e.g., Wernerfelt (1984); Barney (1991). See Reihlen/Ringberg (2004), pp. 4-8 for an extensive discussion of these approaches regarding the nature of knowledge. See also Empson (2001), pp. 812-813.

See Lorenz (2001), pp. 309-314. See for an extended discussion of this paradigm Newell/Simon (1976) and Simon (1979). See also Neisser (1976), pp. 15-18.

Donaldson (2003), p. 40. Positivism emerged by the early 1800s as social positivism, and was reformulated into a range of different streams. See Hatch/Yanow (2003). Donaldson stresses that modern positivism should not be confused with logical positivism, which argues that science can only study observables, and behaviorism, which explains behavior as being shaped by the reinforcement through the environment only. Modern positivism sees unobservable processes and concepts, such as thinking, feeling and abstract concepts, as legitimate but postulates that they have to be studied in an objective way. See Donaldson (2003), pp. 50-51. United with functionalism, which holds that the social structure is shaped by the imperative to adapt in a way as to provide fundamental societal needs, positivism implies that the explanation of human behavior lies in situational causation, not in the consciousness of actors (that is individual and subjective), which is, accordingly, made superfluous. Ibid, pp. 51-51. Some of the main proponents of positivism and functionalism in sociology and organizational science are Parsons, Blau, Lawrence and Lorsch, Child, Hannan and Freeman, Donaldson. Ibid, pp. 39-62.

Daft/Huber (1987), p. 8.

See Reihlen/Ringberg (2004), p. 7.

Daft/Huber (1987), p. 8; see also Spender (1998), p. 234.

See Daft/Huber (1987), pp. 5-6.

See Lorenz (2001), p. 311. 
knowledge. ${ }^{470}$ Thus, the focus of the resource school is on the storage, retrieval, transmittal channels, and absorption of knowledge. ${ }^{471}$ Content and meaning of messages play a secondary role. ${ }^{472}$ Moreover, meaning is simply defined as "message fidelity". 473 For example, Gubta and Govindarajan argue that knowledge flows are dependent on the value of the transferred knowledge assets, the motivational disposition of the involved units, the characteristics of the transmittal channels-e.g., informality, openness, and density of communications-, and the absorptive capacity of the target unit. ${ }^{474}$

Empirical research shows, however, that the assumptions of the resource school are too restricted and do not account for the "divergence in the meaning of words, concepts, and codified knowledge". ${ }^{475}$ Consequently, this approach ignores difficulties in knowledge transfer and creation stemming from the existence of distinct individual cognitive frameworks. Its explanation value is reduced, as it can only explain how individuals understand and exchange simple, and very general, concepts and statements. Moreover, due its economic foundations, this view generally abstracts from the role of single individuals for knowledge transfer and learning and adopts the firm as a unit of analysis. $^{476}$

\section{The interpretivist school}

Interpretivism ${ }^{477}$ developed out of the critic on positivism. ${ }^{478}$ It can be traced back to a set of philosophical arguments that developed largely in the first part of the $20^{\text {th }}$ century in Europe. ${ }^{479}$ Droysen, Richert, Windelband, Simmel, Husserl and Schutz are some early interpretive thinkers. Later, interpretivist ideas were addressed by Weber, Barnard, Selznik, Silverman, Turner, Weick, Van Maanen. These researchers introduced and further developed the interpretive perspective into organizational studies. ${ }^{480}$ Some of the more recent supporters of the school are Berger and Luckman, ${ }^{481}$ Blackler, ${ }^{482}$ Boland and Tenkasi, ${ }^{483}$ Tsoukas, ${ }^{484}$ Parker, ${ }^{485}$ Hassard. ${ }^{486}$ Interpretivism is based on the assumption positivism"- also known as the 'Vienna Circle'. See Hatch/Yanow (2003), p. 65; also Putnam (1983), pp. 34-35. Logical positivism is a stream within positivism, which has been criticized even by modern positivists because it argues that science can only deal with observables. See Donaldson (2003), pp. 50-52 for both a discussion and critic of logical positivism. 
that the social world cannot be understood in the same ways as the natural world. "Unlike rocks and atoms, humans make meaning, and so a human (or social) science needs to be able to address what is meaningful to people in the social situation under study. This requires understanding how groups, and individuals within them, develop, express, and communicate meaning, something that objective, unmediated observation (if that were even possible) cannot yield". ${ }^{487}$

The main argument is that because people have some prior knowledge that shapes or filters what they apprehend, the knowledge process cannot be regarded as objective, as positivists argue. ${ }^{488}$ Therefore, "what we claim as knowledge in this social world comes from interpreting our sense perceptions, not from an uninterpreted grasping of them". ${ }^{489}$ Because knowledge depends on the individual's interpretations, it is never unconditionally true as regarded in the resource school, but always fallible; it does not reside in messages but evolves from interaction processes and is contextualized by "history and surrounding elements". ${ }^{490}$ Moreover, there is no external authority that can verify certain interpretations or knowledge. ${ }^{491}$ As a result, universal, objective laws are not possible; rather, the social reality may be seen differently by different people. "The social world we inhabit and experience is potentially a world of multiple realities, multiple interpretations". ${ }^{492}$ Thus, in contrast to positivist and functionalist approaches, interpretivists usually adopt a pluralistic perspective by treating organizations as "array[s] of fractionalized groups with diverse purposes and goals. Organizations are not monolithic entities; rather they are coalitions of participants with different priorities" ${ }^{493}$ The primary units of analysis for interpretative researchers are, therefore, the individual's values, goals, and interactions that create and sustain meaning. Furthermore, because "meanings are embedded in (or projected onto) artifacts by their creators", the access or study of meanings requires the study of artifacts. ${ }^{494}$

In organization theory, Polanyi was one of the first to emphasize that knowledge is not always explicit, i.e. it cannot always be perceived or accessed directly. Rather, there is the realm of tacit knowledge, knowledge that cannot be articulated easily. ${ }^{495}$ Extending Polanyi's argument, interpretivism argues that intersubjective understanding requires the sharing of meaning. This process of creating of intersubjective understandings results, at the same time, in the creation of a community of interpreters who, within a particular context, share a view of how to approach and interpret situations. This shows that knowing has a communal character: "modes of interpreting (or 'making') meaning are developed among a group of people-a community of interpreters, a circle-acting and

See Hassard (1999).

Hatch/Yanow (2003), p. 66; also Burrell/Morgan (1979), p. 253.

See, e.g., Empson (2001), p. 813.

Hatch/Yanow (2003), p. 67, emphasis in the original. Central to interpretivism is the notion of "verstehen", which was introduced by Weber. See, e.g., Heracleous (2004), p. 175.

Hatch/Yanow (2003), p. 67; Putnam (1983), pp. 39-40.

See Hatch/Yanow (2003), p. 69.

Ibid, p. 67.

Putnam (1983), p. 37.

See Tsoukas/Knudsen (2003), p. 17; also Hatch/Yanow (2003), p. 67.

Hatch/Yanow (2003), p. 69; also Polanyi (1966), pp. 3-25.
} 
interacting together in that process, thereby coming to share an approach to understanding a problem". ${ }^{496}$ Acting together, those actors construct social realities. In this sense, knowing and understanding are subjective processes; knowledge is "a social construct, developed, transmitted and maintained in social situations". ${ }^{497}$

The appreciation for the plurality of possible meanings and the importance of interpretation leads to an increased attention to the persuasive elements of language and artifacts, such as stories, myths, rituals and metaphors, ${ }^{498}$ which brings in considerations of power and power relations. ${ }^{499}$

After this brief introduction into the different perspectives on cultural relations, next, the economic relations within client-consultant teams are outlined, with an emphasis on the interrelation between economic and cultural relations.

\subsection{Economic relations}

Economic relations, in general, are characterized by production and exchange. ${ }^{500}$ As already discussed, in the consulting process cultural relations overlap to some extent with economic relations. In other words, the economic process of service production within consulting projects, which involves the use and modification of existing or newly created cultural artifacts, such as reports, presentations, consulting methods, concepts and models, computer programs and benchmarking data, ${ }^{501}$ is at the same time a cultural process of knowledge transfer and creation. Consequently, economic considerations about the production and reuse of cultural artifacts directly influence the problem-solving process within client-consultant teams.

In consulting projects, cultural artifacts have two main functions. First, the use of artifacts can facilitate communication between clients and consultants and foster knowledge transfer and learning. ${ }^{502}$ Thus, cultural artifacts have the "ability to provide a common framework and terminology for the consultant's work process”503 and facilitate the development of shared understanding within client-consultant teams. Second, they act as repositories of accumulated experience, ${ }^{504}$ and as such are used both as a source of

496

497

498

499

Hatch/Yanow (2003), pp. 68-69.

Empson (2001), p. 813.

See Heracleous/Barrett (2001), p. 757.

See Hatch/Yanow (2003), p. 70. However, those questions are not discussed extensively within all interpretive approaches. See Tsoukas/Knudsen (2003), p. 18. The major perspectives on power are discussed extensively in chapter B.II.4.3.3.

See Bunge (1979), pp. 189-205; Bunge (1996), p. 271.

Client-consultant teams also use economic artifacts such as paper, computers, tables, projectors, etc., but they do not produce them. Cultural artifacts are usually created during particular consulting projects as a result of work and communication processes. As in chapter B.I.2.2.3 discussed, there are usually no permanent R\&D teams in consulting companies. Only recently have some of the big consulting companies tried to create internal research centers, the main task of which is to develop new concepts and methods for use in concrete client projects. This is, however, not primarily a consulting but a research activity.

See Lane (1994), p. 110.

Werr/Stjernberg (2003), p. 896.

See Brown/Duguid (1991), pp. 45-46; Werr/Stjernberg (2003), p. 897. 
templates for the solving of routine problems and as an inspiration for the development of a new understanding of clients' problems. ${ }^{505}$

Cultural artifacts that serve the development of knowledge for problem-solving can be either generic or (client) specific. Most consultants draw on a common repertoire of generic cultural artifacts in the form of models, frameworks, and concepts for solving of management problems when they work with clients. ${ }^{506}$ "These core generic models constitute a frame of reference that consultants use to diagnose client problems and which they often customize to the circumstances at hand". ${ }^{507}$ Examples for such frameworks are the 5-Forces model, the Value Chain model, the Marketing Mix model and the Life Cycle model. The main functions of such methods are to guide the structuring of the client problem and to provide suggestions or ideas for its resolution. ${ }^{508}$ These models are often widely known and are used with more or less modifications by consultants in a number of different contexts and client situations. ${ }^{509}$

Additionally, consultants use specific tools that represent rather "local knowledge", as they are "cultivated at the interplay between specific client needs and the existing methodological background of consultants". ${ }^{510}$ Contrary to the generic methods, such tools require in-depth and detailed background knowledge both of the model's formal structure and the particular client cases where they are applied. Such tools often originate in specific knowledge fields, e.g., engineering, physic, mathematics, etc. and are quite complex. Mastering them requires "intensive and personal interaction, practical training, and application before consultants could use the tools properly for problem-solving”. 511 Whereas the generic consulting models and frameworks represent standardized knowledge, such specific tools are consulting artifacts that cannot be standardized.

The availability and cost of production of more or less standardized artifacts have important implications for the cultural relations between clients and consultants and influence the nature of client-consultant relationships. Rescher argues that the costs and benefits of any cultural artifact shape and condition cognitive processes and as such, they need explicit attention. "Only by heeding the concrete processes that engender our knowledge in a way that takes account of their economic dimension can we adequately explain the nature of its operations and properly understand the character of its products". ${ }^{512}$ This issue is discussed briefly in what follows.

The development and use of standardized cultural artifacts is the result of economic pressure on cost effectiveness in the management of cultural production. The production

See Reihlen/Ringberg (2006), pp. 327-329. See also Pringle who argues that consulting artifacts offer the following major advantages: cost saving, for example by saving data gathering and researach time; througness as such models can show just what information is necessary to reach solid conclusions; efficiency by avoiding unproductive areas of analysis; use of specialized expertise; and peer review and staff development. See Pringle (1998), p. 5. 
of knowledge involves the expenditure of limited resources, such as manpower, artifacts, energy, and time. ${ }^{513}$ In other words, it engenders cost. This implies that knowledge production in general, and in client-consultant teams in particular, has to take into account economic considerations of efficiency and effectiveness. ${ }^{514}$ In particular, it implies that consultants will repeatedly use the same consulting methods and concepts across a number of clients in order to decrease the cost associated with the delivery of these services. ${ }^{515}$ Thus, the standardization of consulting methods and concepts is a favorable option for consulting companies. ${ }^{516}$ Furthermore, clients and consultants will engage in the creation of new knowledge only when the benefits of it outweighs the cost. In other words, the problem at hand has to be important enough to justify the cost of knowledge production. ${ }^{517}$ Thus, when discussing different problem types in the context of consulting projects, both cultural and economic aspects influence the nature of clientconsultant interactions.

As discussed in chapter 3.2.1, in the case of simple routine problems the knowledge that consultants have accumulated by solving similar problems in the past is often sufficient for problem formulation and solving. ${ }^{518}$ The existence of generic consulting artifacts and practices means that consultants will not engage in an extensive knowledge transfer with the clients and will not develop highly customized solutions. ${ }^{519}$ In most cases, this is also in the interest of the clients who, due to the nature of simple routine problems, will not wish to pay a higher price for a new solution if there is an existing solution that works quite well. The outcomes of such client-consultant relationships are modified artifacts and more or less encultured people, depending on whether the client had previous experience with such problems or not. No new knowledge is created.

In contrast, complex client problems require customized solutions. ${ }^{520}$ The reason is that such problems are so complex that existing practices and solutions do not account for the problem specifics. In such cases, consultants can still rely on the use of generic cultural artifacts but at the same time, they need to develop a deeper knowledge of the particular client problem. Thus, they need to develop and use, in addition, some specific consulting tools, which requires the modification of existing knowledge, and possibly the creation of new knowledge. However, in doing this, clients and consultants will try to find a balance between the cost of the development of such specific knowledge and artifacts, and their benefits. This is all the more the case when clients and consultants face innovative problems. In such cases, existing artifacts are used mainly to support the communication and problem-solving process but cannot be used as a template for problem-solving. Rather, new knowledge and artifacts need to be created. Again, the

This implies that the work can be done with a minimum of high-priced senior consultants and with an extensive use of low-cost junior consultants. Therefore, simple routine projects are characterized by low fees and high leverage. See Maister (2004), p, 21.

See the discussion in B.II.3.2.2. 
production of new knowledge and artifacts needs to be motivated by some benefits. When consultants develop new consulting artifacts based on new ideas, the services lack efficiency and experienced consultants, thus increasing cost and risk for the consulting company. ${ }^{521}$ This implies that if the client's problem is innovative, but the client organization is not prepared to engage in long-term and resource-intensive collaboration with the consultants, nor to pay a higher price for the service, it may receive a problem solution that does not account for the specifics of its problem. Additionally, if the consulting services are so client specialized or proprietary that the consulting company cannot reuse the created knowledge and artifacts in subsequent projects, consulting companies will only engage in the creation of such services if the client is willing to pay a premium price for such a highly customized consulting service. ${ }^{522}$

To sum up, cultural artifacts are important as facilitators and mediators of cultural relations between clients and consultants but they also carry economic considerations. It is important to recognize that the nature of client-consultant interaction and the degree of customization of problem solutions depends not only on the knowledge of the involved individuals and their abilities to work effectively together, but is also influenced by economic considerations.

In addition, it is necessary to emphasize that economic considerations can influence the problem-solving process within client-consultant teams directly, i.e. without considering cultural artifacts. For example, it has been argued that consultants often try to broaden the scope of their work with a particular client by suggesting problem solutions, which point toward new problems and open for them new opportunities to work with this client. ${ }^{523}$ In such cases, the economic interests of consultants might prevail with the result that they do not suggest the best possible solution but the one that opens more possibilities for the company to work with the client. ${ }^{524}$ Although such economic considerations cannot and should not be ignored when discussing problem-solving in client-consultant relations, it should also be clear that consultants still need to present satisfactory problem solutions to their clients in order to survive. In other words, they have to pursue their economic interests in a way that does not cost them their reputation in an industry in which reputation is one of the most important company resources. ${ }^{525}$ In this regard, it is necessary to consider the role of power in client-consultant teams. Such power is a mechanism that, inter alia, can enable consultants to persuade clients to accept particular problem solutions that are also favorable for the consultants without risking client's dissatisfaction with the proposed solution. ${ }^{526}$

However, if consultants manage to develop a "blockbuster" idea or concept, they can receive returns that exceed grossly their competition. See Scott (1998), pp. 28-29.

See Pringle (1998), p. 6; Scott (2004), pp. 133-134. An example for a highly client-specific consulting service is the consulting work done for Goddard Space Center in Alabama. See Scott (2004), p. 133-134. When consulting projects are highly innovative and risky, such as, for example, when a radically new product or service is developed, the establishment and joint ownership of a new enterprise is an option that can make joint work on such highly innovative problems possible. See Hart et al. (2004), pp. 317-325 who discuss one such project. See, e.g., Ashford (1998), p. 31.

This argument has been developed further within the critical literature on consulting. See chapter C.IV for a detailed discussion. 
Because of this interconnection between cultural, economic, and power relations within client-consultant teams, next it is necessary to shed some light on the political relations, which are characterized by relations of power. The emphasis within this work is on the interrelation between cultural and political relations. It has been argued that the formation and accumulation of knowledge is a simultaneous mechanism of power"power makes knowledge as knowledge makes power". ${ }^{527}$ Additionally, a particular view of knowledge implies a particular approach to power. The following chapter offers some general insights on the nature of power. Later, this topic is discussed more extensively within the distinct models of the client-consultant relationship.

\subsection{Political relations}

\subsubsection{Formal political structure}

Political relations within client-consultant teams are relations of control of the cultural production within client-consultant teams. ${ }^{528}$ When addressing the political relations within client-consultant teams one needs to be aware that various categories of clients and consultants with varying motivations, roles, and responsibilities are involved in consulting projects. As a result, different actors exercise different levels of control over the cultural production in client-consultant teams, which makes the client-consultant interaction to a highly complex and insecure process. ${ }^{529}$ It means, in particular, that consultants can encounter different perspectives, interests, or agendas during the consulting project, as well as different views on what exactly is the problem that they need to address. ${ }^{530}$

On any consulting project, there are three broad roles required for accomplishing the work. ${ }^{531}$ First, every project involves a partner of the consulting company who bears the final responsibility for client service. Usually this partner maintains an ongoing client relationship and regular communications with the client in order to understand and address client satisfaction. ${ }^{532}$ The partner is usually in a close contact with the "buyer" or the sponsor of the project who has initiated it from the client organization. Sponsors play a key role in the consultants' selection, negotiation of the consulting contract and the provision of guidance concerning the main project objectives. They often provide the financial resources for the consulting project, or organize these resources to be provided.

Clegg/Palmer (1996), p. 5; see also Foucault (1980), p. 133.

See Bunge (1979), p. 201 and p. 215.

See Kirsch/Eckert (1998), pp. 278-279.

This issue is discussed in detalail in section 0 .

531 See Hoffmann (1991), pp. 28-30; Nichols (2004), pp. 164-167; Maister (1982a), pp. 16-17; Maister (2004), p. 17. This political structure is associated with different skills, knowledge, and experience of the individuals involved on each of the three levels. The individuals in the highest hierarchical level are usually the most senior, experienced, and knowledgeable, whereas individuals at the lower level are usually more junior, inexperienced, and/or less knowledgeable. Additionally, it should be pointed out that this view of the political structure of client-consutlant teams obviously disregards cases when the consultant is a sole practitioner. As such, this work follows Wimmer who argues that management problems are usually so complex that it is rarely possible for a single consultant to respond adequately to this complexity and to steer successfully the problem-solving process in client organizations. See Wimmer (2004), p. 289. 
The sponsor can be also involved in reviewing the project progress and his/her support is crucial for the adoption of the project's recommendations. ${ }^{533}$

Second, there are project managers from both the consulting and the client side. ${ }^{534}$ In some cases, the consulting project manager is responsible for the planning of the work and the management of the team: s/he supervises quality of work, directs and schedules team activities, identifies resources and resolves issues, whereas the client project manager has a rather supportive role. However, there are also cases when both client and consultant project manager work hand-in-hand. ${ }^{535}$

Third, there are team members from both client and consultant organization who perform the work, i.e. who are engaged in the problems solving process. ${ }^{536}$ On large engagements, some of these roles can be shared between several people. ${ }^{537}$ It is important to note that this group involves the main or primary clients - the clients who "own" the problem for which the consultants are brought in. They are the consultants' principal collaborators and are usually affected by the assignment (although there might be also other affected members of the client organization who may not be directly involved in the consulting project). ${ }^{538}$

Figure 4 illustrates the typical formal political structure of a large client-consultant team. To sum up, both the consulting partner and the sponsor are not involved in the dayto-day work of the consulting team. The project managers on both sides are, in contrast, more actively involved. However, their main responsibility is the management and coordination of the team, not problem-solving. The consulting and client team members, who can come from different levels of their organizations, are the actors that are intensively involved in the problem-solving process. ${ }^{539}$

\subsubsection{Types of political relations}

Political relations influence the work of client-consultant teams in two different ways. First, control includes activities orientated toward organizing and managing the cultural production to achieve collective goals. ${ }^{540}$ Such activities are used to "direct, align and monitor" cultural work and facilitate the development of task-related knowledge. ${ }^{541}$ In client-consultant teams, such organizing and coordinating activities are also called

\footnotetext{
533 See Hoffmann (1991), p. 29; Nichols (2004), pp. 166-167; Kubr (1996), p. 57; Mulligan/Barber (1998), pp. 70-71; Sommerlatte (2000), p. 134.

534 See Hoffmann (1991), p. 29; Nichols (2004), pp. 166-167.

535 See Durrant/Baxley (2004), p. 310.

536 See Hoffmann (1991), p. 29.

537 See Durrant/Baxley (2004), p. 310.

538 See Kubr (1996), p. 57; Mulligan/Barber (1998), pp. 70-71.

539 See, e.g., Nichols (2004), p. 169.

540 See Bunge (1979), pp. 201-203.

541 See Marks et al. (2001), p. 357.
} 
integrating practices ${ }^{542}$ and are usually developed and implemented under the guidance of the project manager(s). ${ }^{543}$

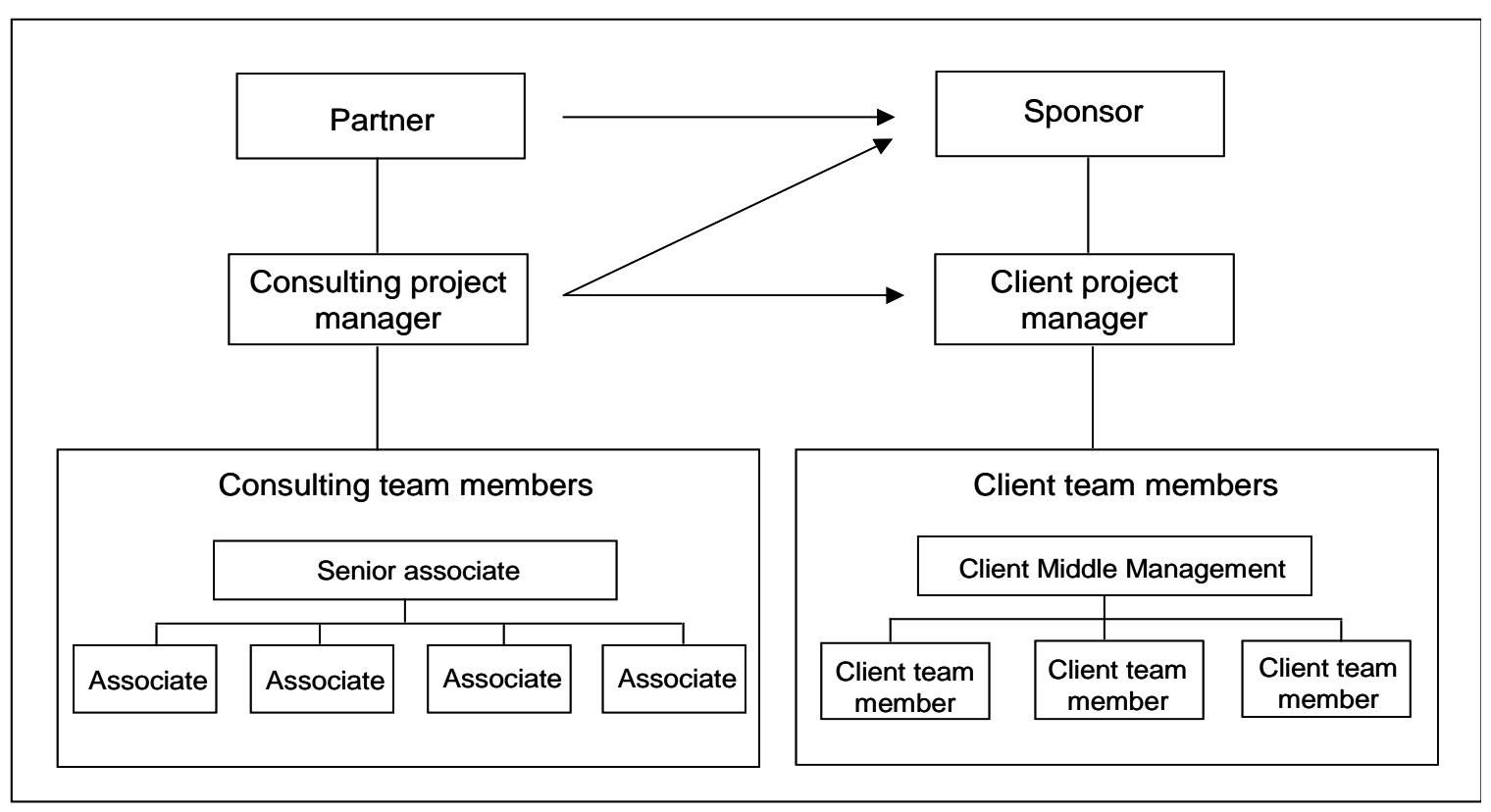

Figure 4: Sample large team structure

Source: Adapted from Nichols (2004), p. 168.

An emphasis of integrating practices is necessary because client-consultant teams as learning communities are at the same time social communities, whose members' efforts need to be integrated and coordinated. In other words, team success is not only a function of team members' talents, shared problem relevant understanding and their ability to transfer and create knowledge, but also of the processes that team members use to manage and coordinate their interactions in order to accomplish their task. ${ }^{544}$ These social mechanisms are discussed extensively in the next section of this chapter.

Control within client-consultant teams is, however, often not restricted to planning and implementing of integrating practices. Rather, political activities are much more diffused, and influence, in addition, the problem-solving process and the development of task-specific knowledge. Thus, the project managers and the individuals with the highest position within the formal hierarchy of the client and consultant organizations are not the only actors who engage in political activity or control economic and cultural work. Rather, within this work it is argued that, in client-consultant relationships, all involved individuals can influence problem-solving if they establish interpretive dominance. ${ }^{545}$

542

543

See Reihlen (2003a), pp. 12-13. Marks et al. speak in this case about teamwork. See Marks et al. (2001), pp. 357.

Marks et al. and Reihlen argue that in practice, the distinction between practices directed towards the integration of individuals' activities and practices oriented towards problem-solving or cultural work may become blurry. See Marks et al. (2001), p. 357; Reihlen (2003a), p. 13. For the purpose of this work, all practices that involve the creation of knowledge are regarded as cultural work, and all practices that involve the development and application of particular coordination and management mechanisms are seen as integrating practices. See Marks et al. (2001), pp. 357-358 who take a similar stand and explain the reasons for this differentiation. See Reihlen (2003a), pp. 12-14 for a somewhat different view.

See Marks et al. (2001), p. 358. Additionally, as in chapter B.I.2.3 discussed, the success of consulting projects depends on both clients' assessment of the suggested problem solution and of the interaction process with the consultants.

See chapter D.IV for an extensive discussion of this issue. 
Yet, much of the existing research on knowledge transfer and learning has tended to neglect or simplify such issues of power and political activity. ${ }^{546}$ This is also true for the consulting literature. Although it has been recognized that consulting processes are inherently political, ${ }^{547}$ and that the development and application of expertise involves power relations, not only with other professions but also with clients, ${ }^{548}$ the nature of power in client-consultant teams, the process of power emergence, and the specific role of power for successful problem-solving, is still poorly understood. Therefore, this work pays special attention to these political relations within client-consultant teams that directly influence problem-solving. In this work, these relations are referred to as power relations. It is discussed, which actors influence the problem-solving process in the client-consultant team and the origins of their power. As such, the work focuses on the second requirement identified in chapter I.1.4: in order to study professional business services one needs to look at the nature and role of expert power. For the case of clientconsultant interaction, what is of most interest is the power relation with clients.

Similar to the notion of knowledge, the term power is discussed differently within different theoretical traditions, which is also mirrored in the research on client-consultant interaction. Therefore, in order to analyze the models of the client-consultant relationship, and their position on the nature and role of power in consulting projects, one first needs to discuss the underlying theoretical assumptions behind different views of power and power relations.

\subsubsection{Power relations: theoretical conceptions of power}

Typically, power has been seen, following Weber and Dahl, as the ability to get others to do what one wants them to, even against their will. ${ }^{549}$ This definition has been, however, "challenged, emended, critiqued, extended and rebuffed over the years" and "remains the starting point for a remarkably diverse body of literature". ${ }^{550}$ Bunge points out that power has been seldom correctly analyzed. ${ }^{551}$ Moreover, it has been discussed often in relation to terms such as control, dominance, authority, legitimacy, resistance, and emancipation without a clear definition of the relationships between these terms.

See Armbrüster/Kieser (2001), p. 693; Blackler (2000b), p. 833; Coopey/Burgoyne (2000), p. 869; Easterby-Smith et al. (1998), p. 261; Ferdinand (2004), p. 435; Iding (2000), p. 7 and p. 21; Marshall/Rollinson (2004), p. S72. Walsh and Fahey as well as Iding are amongst the few researchers who discuss the connection between power and cognitive schemes in teams and how both influence decision-making processes. See Walsh/Fahey (1988); Iding (2000). Iding, for examples, points out that the issue of power has been a "terra incognita" in the consulting research (p. 83) and that it needs to be put in the centre of an analysis of the consulting process. See Iding (2000), p. 10.

See, e.g., Ginsberg/Abrahamson (1991), p. 179.

See Scott (2001), p.101.

See Hardy/Clegg (1996), p. 623.

Ibid, p. 623. In particular, other researchers on power argue that power can be manifested also in "ensuring that things do not get done” ("second face of power"). See Clegg (1989a), p. 11; Luke (1974), pp. 16-20. Luke (1974) adds a third dimension of power by arguing that power is exercised also "when A affects B in a manner contrary to B's interests". Luke (1974), p. 34. Poststructuralists and followers of Foucault argue, in turn, that power is ubiquitous and represented in a number of techniques and disciplines institutionalized in modern societies. This is discussed in what follows.

See also Law who claims "power is surely one of the most contentious and slippery concepts in sociology". Law (1991), p. 165. 
Reed concludes that power is probably the "most overused and least understood concept in organization analysis". 552

The existing misunderstandings and variety of views on power can be traced back to two central traditions: (1) to treat power as an object for ownership and to concentrate on the relation of power to structure; or (2) to discuss power as a process or strategy. The first perspective goes back to the work of Hobbes, whereas the second was developed originally in the writings of Machiavelli. ${ }^{553}$ Works that build upon and extend Hobbes' view of power conceive power in positivist terms as something directly observable and measurable, and as something held by people, rather than organizations. ${ }^{554}$ In contrast, works that are based in Machiavelli's tradition regard power as imprecise, contingent, strategic, and organizational, embedded in many diverse forms of practice. Such works provide a quite distinctive interpretation of power. ${ }^{555}$

In order to enhance the understanding of power aspects characterizing clientconsultant relationships and consulting projects, the following discussion attempts to summarize the diverse research on power that can be ascribed into these two main perspectives. ${ }^{556}$ Table 7 introduces the two schools of power. ${ }^{557}$

\section{The resource (positivist) school}

The understanding of power within this school originates in the Hobbesian view of the "sovereign power", the power of an established authority over a set of actors: 'Hobbes' representations have left their mark on modern theory in their insistence on the casual, atomistic and mechanistic nature of the relations of power, as well as the implicit concern with the essential centre of power". 558 This "modernist" view of power has been the dominant representation of the concept of power ${ }^{559}$ and has influenced a large number of researchers, including Locke, Hume and later Lasswell and Kaplan, Simon, Dahl, and Bachrach and Baratz. ${ }^{560}$ There are two main sub-perspectives within the positivist school of power, which are presented briefly, in what follows.

552

Reed (1999), p. 34. Clegg argues as well that power is the “most 'contested' of concepts”. Clegg (1989a), p. xv; see also Hardy (1985), pp. 384-385.

See, e.g., Clegg (1989a), pp. 5-7, Fincham (1992), pp. 741-742. See also Scott who talks about a "mainstream and second stream" of power research. Scott (2001), pp. 6-12.

See Clegg (1989a), pp. 3-9.

See Clegg (1989a), pp. 3-9. This work cannot discuss extensively both views and how they are related to later research on power. Clegg's work offers an extensive discussion of these issues. See Clegg (1989a), pp. 21-38.

This work does not claim to be exhaustive of all research done on power. In particular, not all works on power can be subsumed clearly under these two schools. Luke's three dimensions on power, for example, cannot be subsumed within a single epistemology of power. See Clegg (1989a), p. 127. Additionally, as others have noted earlier, power is a term that cannot be precisely defined, nor can the research on power be precisely systemized. See Hardy (1985), p. 385. Therefore, the goal of this work is to present a systematization that can help to analyze merely the differences in the views of power as presented in the models of client-consultant interaction, not to propose a universal systematization. For an extensive discussion of power, see, e.g., Clegg (1989a, b); Fincham (1992); Hardy/Clegg (1996).

Although theories of knowledge and learning are related closely to theories of power, it is an open question if and to what extent do these theories share the same epistemological and ontological assumptions and, consequently, to what extent categories developed in the one or another type of theories are compatible. See also Contu/Willmott (2003), pp. 170-171. It is beyond the scope of this work to discuss this question.

Clegg (2001), p. 130; see also Clegg (1989a), p. 4 and Fincham (1992), p. 742.

See Clegg (1989a), p. 34.

Ibid, pp. 39-65 and Scott (2001), pp. 6-8. 
The rationalist perspective focuses on the existence of conflicting interests and examines power as domination. It emphasizes legitimate power, equating power with the structures by which certain interests are dominated. ${ }^{561}$ Two main sources of power are stressed: the ownership of the means of production and the organizational structures and rule systems. ${ }^{562}$ The main difference between power originating in the control of the means of production and power originating in organizational structures is that the former implies that agents, i.e. individuals, have little room for discretion, whereas the latter recognizes that agents have "some control over their disposition to exercise power, both to challenge and to reproduce the formal organization structure in which differential powers are vested, legitimated and reproduced". ${ }^{563}$ In other words, the former sees power as determined by social structure, the latter shows that organizational structures of dominancy do not depend on economic power only, but also on the "labour power" of workers who have options and possibilities to challenge the power that controls them. ${ }^{564}$

\begin{tabular}{lll}
\hline & \multicolumn{1}{c}{ Resource (positivist) school } & \multicolumn{1}{c}{ Interpretivist school $^{\text {565 }}$} \\
\hline $\begin{array}{l}\text { Main } \\
\text { supporters }\end{array}$ & $\begin{array}{l}\text { Hume (1902); Lasswell/Kaplan } \\
\text { (1950); Simon (1953); Thompson } \\
\text { (1956); Dubin (1957); Locke (1959); } \\
\text { Dahl (1961); Bachrach/Baratz (1962); } \\
\text { Crozier (1964); Pettigrew (1973); } \\
\text { Pffeffer/Salancik (1974). }\end{array}$ & $\begin{array}{l}\text { Gramsci (1926); Arendt (1959); Foucault } \\
\text { (e.g.,1977, 1980); Habermas (1981); }\end{array}$ \\
$\begin{array}{lll}\text { Barnes (1988); Alvesson/Willmott (1992); } \\
\text { Gergen (1992); Knights/Vurdubakis (1994). }\end{array}$ \\
\hline $\begin{array}{l}\text { Disciplinary } \\
\text { foundations }\end{array}$ & Sociology, management theory. & Sociology, cultural anthropology. \\
\hline $\begin{array}{l}\text { Underlying } \\
\text { paradigm }\end{array}$ & Positivist, functionalist. & Interpretive. \\
\hline $\begin{array}{l}\text { Theoretical } \\
\text { assumptions }\end{array}$ & $\begin{array}{l}\text { Power as a given resource/capacity to } \\
\text { secure outcomes; deployed by agents } \\
\text { in pursuits of their interests; negative. }\end{array}$ & $\begin{array}{l}\text { Power as a social construct. Negative and/or } \\
\text { positive. }\end{array}$ \\
\hline $\begin{array}{l}\text { Main levels } \\
\text { of analysis }\end{array}$ & $\begin{array}{l}\text { The power of class, groups and } \\
\text { individuals. }\end{array}$ & $\begin{array}{l}\text { Individuals and the power of social structures } \\
\text { and practices. }\end{array}$ \\
\hline
\end{tabular}

\section{Table 7: Alternative perspectives on power in organizations ${ }^{566}$}

In summary, from this perspective, power is legitimated in the form of organization structures that reinforce the power by owning and controlling the means of production,

561

562

See Hardy/Clegg (1996), p 626.

The former argument can be traced back to the work of Marx and related authors, whereas the latter originates in the work of Weber. See Hardy/Clegg (1996), pp. 623-624. It is important to stress that this argument does not imply that Marx and Weber should be seen as positivists. Weber, for example, is one of the founders of the interpretive sociology, and some of his ideas can be seen as the origin of the interpretive school of power. See Clegg et al. (2006), pp. 4-3-4-6. However, as Clegg et al. (2006) stress, the original translation of Weber's work through Parsons and Henderson appears as compatible to some extent with a functionalist and positivist perspective of power. See Clegg et al. (2006), pp. 4-3-46; also Scott (2001), p. 6-12. Similarly, Marx is not a positivist but some of his arguments on power can be traced back to the Hobbesean understanding of power. See Clegg (1989a), pp. 22 for an extensive discussion of this issue.

Hardy/Clegg (1996), p. 624.

Ibid, p. 624. See also Bradshaw-Camball and Murray who call the former the "radical perspective on power". BradshawCamball/Murray (1991), pp. 382-384.

Similar to the interpretivist approach to knowledge, the interpretivist school of power does not represent a unifying view of power. Rather, there are several streams that emphasize different aspects of power and power relations. Later on, when discussing the concrete models of client-consultant interaction, some additional differences in the conception of power as proposed in these models are outlined, which originate in the different theoretical understanding of power.

This table is loosely based on Hardy/Clegg (1996); Clegg (1989a), pp. 21 and Scott (2001), pp. 6-30. 
and represents domination. One important implication is that the study of power must concern the hierarchical structure of organizations. ${ }^{567}$ Additionally, it is suggested that actions taken to challenge this legitimated power constitute resistance. "There is a given distribution of power within any society, and some agents have more of this power than others. Struggles over the distribution of power will always involve both winners and losers." 568 Thus, this perspective concentrates, in addition, on the possibilities for resistance present to subordinate groups. ${ }^{569}$ As such, it views power relations as asymmetrical, hierarchical and as "zero sum" in which one agent can gain only at the expense of another. ${ }^{570}$

The second, contrasting perspective within the resource school, developed out of the management field. Important proponents of this perspective are Thompson, Dubin, Crozier, Pfeffer and Salancik, and Pettigrew. ${ }^{571}$ These researchers regard the existing organization structures not as "structures of domination but of formal, legitimate, functional authority". ${ }^{572}$ They concentrate on the question of how groups acquire and use power not granted to them under official arrangements. As such, this view emphasizes power as illegitimate and dysfunctional, as those actions that fall outside the legitimated structures. ${ }^{573}$ Thus, power is a perturbation from and within the formal, legitimated authority structure of hierarchical power, and originates in the illegitimate or informal use of resource control in organizations. ${ }^{574}$ Such power appears outside of rationality; it is the result of uncertainty and self-interested behavior. The contestation of existing, legitimate management structures is considered to be organizational politics. It is regarded as a disruptive and negative activity, as the unsanctioned (illegitimate) use of power to achieve unsanctioned (illegitimate) ends. ${ }^{575}$

This view takes the power vested in authority, structure, ideology, culture, and expertise for granted and as natural, and its existence as such is seen as analytically nonproblematic. Critics of this view argue that as a consequence, the approach denies that the structure and hierarchy of organizations have been formed to create and protect certain interests while denying or illegitimating others. In other words, the problem with this approach is that within it, legitimate structures are not seen as related to power: "It attributes too much power to subordinate groups who are chastised for using it; while the hidden ways in which senior managers use power behind the scenes to further their position by shaping legitimacy, values, technology and information are, conveniently based on resource dependency. For an extended discussion of the resource dependency theory, see Pfeffer (1992); Pfeffer/Salancick (1974); Salancick/Pfeffer (1974). See also Hickson et al. (1971), Mintzberg (1984); Thompson (1956). Bradshaw-Campball and Murray speak in this context about the pluralist perspective of power and politics. BradshawCampball and Murray (1991), pp. 381-383. 
excluded from analysis." ${ }^{576}$ Furthermore, this perspective leaves unanswered questions about the sources of power and the dynamics and outcomes of the political process. ${ }^{577}$

To sum up, whereas the rationalist perspective equates power with the structures by which certain interests and people are dominated, management theorists see power as those actions that fall outside the legitimated structures. ${ }^{578}$ However, both legitimate and illegitimate perspectives on power share a common characteristic by implying that power is a thing vested in a specific person or agency, ${ }^{579}$ a resource that can be used to achieve specific goals. ${ }^{580}$ It is a purely individualistic view of power stressing the autonomy and rationality of agents as they choose from among alternative courses of action. ${ }^{581}$ Consequently, it studies "the most obvious and overt processes of formal decision making”. 582

This perspective on power is highly problematic. $^{583}$ In particular, it does not recognize the role of enduring structured constraints when discussing power. ${ }^{584}$ It ignores that "power is practiced before it is possessed and it is this that gives rise to the roundaboutness of power". ${ }^{585}$ Moreover, it has been argued that power cannot be located within predetermined structures and resources but is rather a more dynamic concept and phenomenon. In order to understand power, one needs to look at the process of power emergence and at its contested and unstable nature. ${ }^{586}$ This is the starting point for the interpretivist school of power.

\section{The interpretivist school}

The origin of this perspective is to be found in Machiaveli's work, which focuses on power as a strategy that is unstable, imprecise, contingent, and not centralized. ${ }^{587}$ It regards power as diffused throughout society, rather than as confined to a sovereign of some kind. ${ }^{588}$ "It is exercized rather than held, a property of relations, manifest through practices". ${ }^{589}$ Some of the key contributors in the development of this approach are Gramsci, Arendth, Habermas, Barnes, and Foucault. ${ }^{590}$

This is in line with the positivist view of knowledge, which assumes that knowledge is power, i.e. having or possessing knowledge gives its holder choices and influence. See Alvesson/Deetz (2000), p. 46.

See Scott (2001), p. 7.

Ibid, p. 8.

See Allen (2003), p. 9; Hardy/Clegg (1996), p. 632-637.

See Scott (2001), p. 9.

Allen (2003), p. 9.

See, e.g., Clegg (1989a), pp. 6-7 and pp. 154-155.

See, e.g., Clegg (1989a), pp. 29-34; Scott (2001), p. 9.

See Scott (2001), p. 9; Townley (1994), p. 8.

Townley (1994), p. 8.

See Scott (2001), pp. 9-11.
} 
The interpretivist school on power views individuals as "signifiers of meaning". 591 Because individuals' interpretations differ, when they construct meanings they rely on different rules and perspectives. ${ }^{592}$ As a result, the construction of meaning is a contested activity where there is always some discretion and the possibility of resistance through individuals, who do not share the same interpretations of the issue at hand. Thus, actors can exercise influence by constructing the meaning of what others experience: "power increases to the extent that the powerless, implicitly or explicitly, surrender to the powerful the ability to define the nature of their experience." ${ }^{593}$ In this, actors seek to build alliances with other actors in order to institutionalize meanings in structures and practices. As such, power is "the collective property of whole systems of cooperating actors, of the fields of social relations within which particular actors are located". 594 Therefore, this school sees power as distributed throughout society and contested. It stresses that power can have negative as well as facilitative or productive aspects in the form of collective empowerment. Because it is believed that everybody can gain from the use of power, power is regarded as a 'variable sum'; “it is positive and creative, not just negative or repressive". ${ }^{595}$ Additionally, this view emphasizes the role of language, metaphors, symbols, myths, and rhetoric in power relations. ${ }^{596}$ In the following, Foucault's view of power is summarized, as it is one of the most influential works within this approach. ${ }^{597}$

Foucault concentrates not on power as a manipulable and deterministic resource and a right, which a class or any other social agency can possess, transfer, and alienate, but on the historical process of power emergence and its pluralistic and dispersed nature. ${ }^{598}$ In a nutshell, Foucault's main argument is that the existing structures, resources and knowledge that some view as sources for (legitimate) power of actors are, in fact, the result of prevailing discourses about what is true, right and "normal”. Discourses are, thereby, "bodies of knowledge that 'systematically form the object of which they speak", ${ }^{599}$ Power is represented in the struggles between such discourses; it is a strategy to achieve dominance over other discourses and it is visible only in its effects. ${ }^{600}$ As such, power is always at work. Because it is the medium and the result of such discourses, ${ }^{601}$ it is embedded in everyday life. ${ }^{602}$ It is both inescapable and something active, something

\footnotetext{
$591 \quad$ Hardy/Clegg (1996), p. 633.

592 Ibid, pp. 633-634; see also Townley (1994), pp. 2.

593 Bradshaw-Camball/Murray (1991), p. 382.

594 Scott (2001), p. 9.

595 Scott (2001), p. 9; see also Foucault (1977), p. 194; Townley (1994), p. 8.

596 See Scott (2001), p. 10.

597 Ibid, p. 11. Foucault's work is regarded as a representation of the poststructuralist perspective on power, which is one of the undercurrents of interpretivism. See, e.g., Clegg (1989a), pp. 149.

See, e.g., Foucault (1980), p. 98; also Hardy/Leiba-O’Sulllivan (1998), pp. 458-459; Scott (2001), p. 12. Foucault‘s work builds implicitly upon Weber's ideas on bureaucracy and legitimate power but reinterprets and advances them. See Clegg (1989a), p. 175; Clegg (1989b), p. 100; Hardy/Clegg (1996), p. 631. His work also acknowledges the charismatic type of power as discussed by Weber. 
done, something exercised, but not something that is possessed. ${ }^{603}$ This power emanates from organized systems of practice and discourse rather than from the discrete actions of interested individuals and groups. ${ }^{604}$ It can advantage particular groups without those groups being connected clearly to the establishment or to the maintenance of these practices. ${ }^{605}$ Historically, it is "the apparent order of taken for granted categories of existence fixed and represented in myriad discursive forms and practices". ${ }^{606}$

A starting point of Foucault's argument is the understanding of “modern” practices such as routinization, formalization, mechanization, legislation, design, and expertise as surveillance or disciplinary practices. ${ }^{607}$ Through such practices, individuals and groups seek to inscribe and normalize not only other individuals but also collective bodies (i.e. organizations). ${ }^{608}$ These disciplinary practices are not simply about direct control but encompass cultural control such as moral endorsement, enablement and suasion, and more formalized technical knowledge. ${ }^{609}$ Because they are related to knowledge bases and include discourses, they are also called "discursive practices". That is, practices that reproduce knowledge as a result of discourses, which, at the same time, were made possible by the framing assumptions of that knowledge. ${ }^{610}$ Moreover, these practices differ in their specificity of time, place, aims, and objectives, and they influence each other. ${ }^{611}$ Power is then "expressed in and through disciplinary practices and in and through struggles against or in resistance to such practices". ${ }^{612}$ "What is struggled against is a particular legitimated interpretation of rules as a given, specific regime of

603

604

605

606

See Clegg et al. (2006), p. 8-11; also Covaleski et al. (1998), pp. 298-230.

See, e.g., Lawrence et al. (2001), p. 629.

Ibid, p. 629.

Clegg (2001), p. 138; see also Contu/Willmott (2003b), p. 180.

See Foucault (1977), pp. 135. The importance of disciplinary practices was recognized early on by Marx, Durkheim, and Weber. See Lawrence et al. (2001), p. 636.

See Clegg (1989a), p. 191; Clegg (1989b), p. 100; Hardy/Clegg (1996), p. 631.

See Clegg (1989a), p. 191; Clegg (1989b), p. 100. This view of power is related closely to institutional theory. Institutional theory is an approach that has been developed in organization studies. Institutional theorists discuss why, for instance, almost all public sector organizations in the Western World apply similar business models. The theory argues that organizations tend to adopt the same strategies, structures, and practices because of their fashionability. It suggests that practices, such as Business Process reengineering, Total Quality Management, etc., have become conventional-that business and other organizations find it normal to mimic these practices because they have become so widely institutionalized. The reasons for their institutionalization - that these practices were associated with actions, such as cost reductions, improved quality, etc. - - have faded with time, such that it now seems natural, normal, and necessary to adopt them. Thus, institutional theorists argue that modern societies consist of many institutionalized rules providing a framework for the creation and elaboration of formal organizations. Many of these rules are rationalized myths that are widely believed but rarely if ever tested. They originate and are sustained through public opinion, the educational system, laws, or other institutional forms, e.g., consulting, which are the same disciplinary practices that Foucault regards. See Meyer/Rowan (1977), pp. 340. Thus, many of the factors shaping management and organization are not based on efficiency or effectiveness but on social and cultural pressures to conform to already legitimate practices. For instance, there is a lot of pressure on organizations to adapt to new tools invented by fashionable management consultants. Management fads, such as Total Quality Management, Business Process reengineering etc, are by no means proven to lead to success but are concepts that challenge organizations since, if they do not apply them, they are seen as inert and reactive. Consultants exert, therefore, normalizing pressures on organizations. See also the discussion in chapter D.V. Institutional theory analyses the impact of this pressure on organizations and management decisions. Much modern institutional theory is developed from Berger and Luckman's 'social constructionist' perspective. See Berger/Luckman (1967). A leading example of the institutional focus is the work of DiMaggio and Powell. See DiMaggio/Powell (1983), pp. 149.

See Clegg (2001), p. 134; Fairclough (2005), p. 925; Foucault (1972), pp. 46-49; Townley (1994), pp. 5-7.

See Clegg (1989b), p. 101.

Ibid, p. 109. 
disciplinary practices.” ${ }^{613}$ Moreover, because of these struggles, meanings and knowledge are always unstable and relational; there can be only partial fixation of meanings. Power is expressed exactly in such partial fixity of meanings, practices and, accordingly, agents and relations. ${ }^{614}$ In this, the relation between the positivists' and interpretivists' power concepts becomes apparent: ${ }^{615}$ Power can be "possessed" only to the extent that the relational conditions that constitute power are reproduced through making a particular actor's role the central point of power-also called an "obligatory passage point"-in particular practices. ${ }^{616}$

Because "power is implicated in authority and constituted by rules [by previous discourses]; the interpretation of rules must be disciplined, must be regulated, if new powers are not to be produced and existing powers transformed. In fact, given the inherent indexicality of rule use, things will never be wholly stable". ${ }^{617}$ Thus, due to this instability of rules and meanings, resistance to practices and rules is irremediable. ${ }^{618}$ As a result, power and control result not only in a restriction of others' actions but are also a potential source of emancipation and resistance for the suppressed others. ${ }^{619}$ However, in Foucault's view, the "prospects of escape" from the prevailing web of power relations as represented in the existing structures of dominancy, are "limited for dominant and subordinate groups alike”. ${ }^{620}$ Prevailing discourses are experienced as fact by agents, which reduce resistance. When resistance develops, it only reinforces the existing systems of power. Additionally, actors advanced by the existing power relations are usually in the best position to develop strategies, such as managing and manipulating meaning, that protect their positions and the established rules and structures. ${ }^{621}$

To sum up, power within the interpretivist school is seen as complex, changing and ubiquitous. It is a strategy for creating and legitimizing knowledge domains and practices in order to control individuals' actions. Practices and discourses are techniques of power as far as they induce in others appropriate forms of conduct. Hence, power is only visible in its effects, ${ }^{622}$ which is the reason why power is often associated with the ownership of a resource or authority. Foucault's work aims to dissolve this view of privileged and transcendent positions of power. Such positions, he argues, can only ever be constituted within specific discursive practices. Therefore, “a Foucauldian analysis involves tracing

614 Ibid, p. 109.

614 See Clegg (1989a), pp. 182-184.

615 Whereas it is important to keep in mind that the interpretivist school is based on a different theoretical background, i.e. it does not adopt the epistemological assumptions of the positivist school.

See Alvesson Willmott who speak about “microemansipation”. Alvesson/Willmott (1992), pp. 446-447. See also Gergen (1995), pp. 41-44. Emancipation, in general, "describes the process through which individuals and groups become freed from repressive social and ideological conditions, in particular those that place socially unnecessary restrictions upon the development and articualation of human consciousness”. Alvesson/Willmott (1992), p. 432.

Hardy/Clegg (1996), p. 632.

621 Ibid, p. 634.

622 See Clegg et al. (2006), p. 8-5.
} 
knowledge production and its power effects, an analysis of webs of power rather than classes or groups". ${ }^{623}$

The previous discussion makes it clear that the positivist school of power ignores the dynamic and contested nature of power by regarding power as a thing or a resource, which individuals possess or do not possess. Furthermore, it does not explain the emergence of power, e.g., why are certain positions within the organizational hierarchy associated with more power than others. In contrast, the interpretivist school explains both existing power structures and the micro processes through which these structures are rendered powerful, but it bears some critical points as well. ${ }^{624}$ One important critical point of the interpretivist school of power is its failure to recognize that power/knowledge discourses can be an expression of strategies of identifiable actors within a wider historical and institutional context. ${ }^{625}$ In other words, this view makes it difficult to investigate the role of dominant groups in influencing discourses and producing systems of advantage and disadvantage in society. ${ }^{626}$ It concentrates on the process character of power and excludes from the analysis, at the same time, enduring structures of material, social and political power. ${ }^{627}$ According to Reed, Foucault's writings in particular "have been largely exploited and appropriated to legitimize repeated deconstruction of the concept of organization into a miniaturised, decentralized, and localised discursive or representational practice". ${ }^{628}$ As a result, "Foucault inspired analysis rests on a view of the social world as consisting only in and through an endless, and ultimately meaningless, series of power games bereft of any enduring institutional rationale or structural embodiment”. 629

The discussion of the conceptual and theoretical foundations to the nature of power relations in client-consultant teams provides the background for the analysis of power as presented within the existing models of client-consultant interaction. Next, it is necessary to shed some light on the social relations that serve the integration and management of client-consultant interaction, relations that influence problem-solving only indirectly by improving the conditions for successful cooperation between clients and consultants.

629 Mouzelis (1995), pp. 43-45, cited in Reed (2000b), p. 51. These critical points are recognized within the interpretive model proposed in this work, which suggests a different view of power and power relations. See the discussion in chapter D.IV.
} 


\subsection{Social mechanisms for integrating and coordinating of cultural production}

As previously argued, in order to work effectively together, clients and consultants need to develop some shared understandings about roles and responsibilities, interaction patterns, communication channels, and role interdependencies. ${ }^{630}$ A number of social mechanisms, which are usually initiated and organized by the project manager(s), facilitate the development of task-related knowledge within client-consultant teams. The following chapter briefly introduces the most important social mechanisms that serve the integration and coordination of cultural work within client-consultant teams. ${ }^{631}$

Marks et al. argue that different integrating processes and activities are crucial at different phases of task execution during teamwork. ${ }^{632}$ At the same time, (consulting) teams are typically engaged in the pursuit of multiple goals simultaneously, implying that several tasks are often being juggled at any one time. ${ }^{633}$ Thus, teams use different processes simultaneously in order to multitask effectively. Marks et al. identify three main process phases, each of which is characterized by a number of sub processes.

Transition phases are periods of time when client-consultant teams focus primarily on evaluation and/or planning activities to guide their taskwork, i.e. to guide the problemsolving process. ${ }^{634}$ Action phases, in contrast, are times when clients and consultants are actively engaged in defining the problem situation and creating paths for its solution. In addition, a number of processes occur during both phases. They are called interpersonal processes as their focus is on the interpersonal relations between members of the clientconsultant team during both transition and action phases. Table 8 summarizes the main process phases and provides (generic) examples for each of the sub processes.

It is beyond the scope of this work to discuss the nature and characteristics of all sub processes in detail. ${ }^{635}$ In the following, only a brief description of these processes is provided and their relevance for client-consultant teams is outlined.

\section{Mission analysis and goal specification}

Within client-consultant teams, the phases of mission analysis and goal specification are very similar and include stating the objective of a particular assignment. ${ }^{636}$ In consulting projects, the goal specification takes place in the engagement letter prepared

See Fritz/Effenberger (1998), p. 117; Mathieu et al. (2000), pp. 274-275; Sommerlatte (2000), pp. 140-141; Wimmer (2004), p. 277. Ashford argues that clients in particular often fail to give this element the attention it deserves. See Ashford (1998), p. 40.

631

These activities and mechanisms are discussed rarely within the models of client-consultant interaction. It is emphasized in this work that a consideration of these issues is necessary because the success of client-consultant projects, like all types of projects, depends not only on communication and problem-solving but also on practices and activities oriented towards management and coordination of the individual efforts and activities. Thereby, these activities are not limited to the initial phases of consulting projects but take place throughout the cooperation between clients and consultants. See also Sommerlatte (2000), pp. 150-151. for the case of client-consultant teams.

Ibid, p. 359.

Ibid, p. 362. 
by both the leader of the consulting team and the sponsor of the consulting project from the client organization. ${ }^{637}$ It has been stressed that the definition of the objectives of consulting projects has to be as clear and specific as possible in order to avoid later misunderstanding and conflicts. It is necessary to define each deliverable in terms of how it will satisfy the clients' requirements. ${ }^{638}$ However, goal clarity is not always possible in consulting projects, as there are often cases when the problem is not clear at the start and part of the responsibility of the team is to find out exactly what the problem is. ${ }^{639}$ Thus, consulting projects are usually characterized by rather generic objectives. This leaves wide scope for discretion when it comes to evaluation of results. ${ }^{640}$

Defining the objective of a project also involves stating its scope as well as the identification of any assumptions and constraints around the work. ${ }^{641}$ The scope tells what aspects of the problem are included in the project, and what aspects are excluded. A clearly stated scope prevents the need of doing additional work that was originally not planned. Assumptions and constraints further confine the scope of the project. ${ }^{642}$

\footnotetext{
637 See Nichols (2004), pp. 153-154.

638 See Scott (2004), p. 136; Wimmer (2004), pp. 278-279. See also Mills et al. who argue that "goal clarity" is very important for the service delivery process. Mills et al. (1986), p. 306-307.

639 See, e.g., Schein (1999), p. 5.

640 Bettenhausen and Murnighan support this when they argue, "ad hoc [] special work teams force people who have no history of prior interaction to work on often poorly defined tasks”. Bettenhausen/Murnighan (1985), p. 369.

642 See Nichols (2004), p. 154. See also Scott (2004), p. 136
} 


\begin{tabular}{|c|c|}
\hline Process dimensions & Definition \\
\hline \multicolumn{2}{|l|}{ Transition processes } \\
\hline $\begin{array}{l}\text { Mission analysis, formulation } \\
\text { and implementation }\end{array}$ & $\begin{array}{l}\text { Interpretation and evaluation of the team's mission, including } \\
\text { identification of its main tasks as well as the operative } \\
\text { environmental conditions and team resources available for mission } \\
\text { execution. }\end{array}$ \\
\hline Goal specification & $\begin{array}{l}\text { Identification and prioritization of goals and subgoals for mission } \\
\text { accomplishment. }\end{array}$ \\
\hline Strategy formulation & $\begin{array}{l}\text { Development of alternative courses of action for mission } \\
\text { accomplishment. }\end{array}$ \\
\hline \multicolumn{2}{|l|}{ Action processes } \\
\hline $\begin{array}{l}\text { Monitoring progress toward } \\
\text { goals }\end{array}$ & $\begin{array}{l}\text { Tracking task and progress toward mission accomplishment, } \\
\text { interpreting system information in terms of what needs to be } \\
\text { accomplished for goal attainment, and transmitting progress to team } \\
\text { members. }\end{array}$ \\
\hline Systems monitoring & $\begin{array}{l}\text { Tracking team resources and environmental conditions as they relate } \\
\text { to mission accomplishment, which involves (1) internal systems } \\
\text { monitoring (tracking team resources such as personnel, equipment, } \\
\text { and other information that is generated or contained within the } \\
\text { team), and (2) environmental monitoring (tracking the } \\
\text { environmental conditions relevant to the team). }\end{array}$ \\
\hline $\begin{array}{l}\text { Team monitoring and backup } \\
\text { behavior }\end{array}$ & $\begin{array}{l}\text { Assisting team members to perform their tasks. Assistance may } \\
\text { occur by (1) providing a teammate verbal feedback or coaching, (2) } \\
\text { helping a teammate behaviorally in carrying out actions, and (3) } \\
\text { assuming and completing a task for a teammate. }\end{array}$ \\
\hline Coordination & Orchestrating the sequence and timing of interdependent actions. \\
\hline \multicolumn{2}{|l|}{ Interpersonal processes } \\
\hline Conflict management & $\begin{array}{l}\text { Preemptive conflict management involves establishing conditions to } \\
\text { prevent, control, or guide team conflict before it occurs. Reactive } \\
\text { conflict management involves working through task and } \\
\text { interpersonal disagreements among team members. }\end{array}$ \\
\hline $\begin{array}{l}\text { Motivation and confidence } \\
\text { building }\end{array}$ & $\begin{array}{l}\text { Generating and preserving a sense of collective confidence, } \\
\text { motivation, and task-based cohesion with regard to mission } \\
\text { accomplishment. }\end{array}$ \\
\hline Affect management & $\begin{array}{l}\text { Regulating member emotions during mission accomplishment, } \\
\text { including (but not limited to) social cohesion, frustration, and } \\
\text { excitement. }\end{array}$ \\
\hline
\end{tabular}

Table 8: Taxonomy of team processes

Source: Adapted from Marks et al. (2001), p. 363.

\section{Strategy formulation and planning}

Strategy formulation and planning involves decision-making about how consultants are going to approach the problem or task at hand, discussion of client's and consultant's expectations, agreement upon the degree and form of client's involvement, stipulation of the involved consultants as well as role assignment and the communication of plans to all 
team members. ${ }^{643}$ Checking the team members' competences, the situation and time restrictions, and the team resources, is an important precondition of effective project management. The resulting strategies provide information about members' roles and responsibilities, the order and timing of actions, and how task-related activities should be executed. ${ }^{644}$ Several different project management tools are used in consulting projects for planning of task-related activities.

The starting point for planning is the issue diagram that provides a connection between the high-level project objectives as stated in the engagement letter and the specific tasks that the project manager must direct. ${ }^{645}$ The issue diagram is a graphical tool built in a hierarchical way, which provides the problem statement, the issue questions, the hypotheses that are potential answers to the issues, and the data and analysis necessary to test the hypotheses. ${ }^{646}$ Next, the Project Work Plan (PWP) is created, which summarizes the tasks and activities to be accomplished, the time frame in which they must be completed, and the assignment of responsibility for them to members of the team. ${ }^{647}$ One of the most often used tools in this relation is the Gantt chart. ${ }^{648}$ The Gantt chart is very effective for the management of short and simple project stages. However, more complex project stages with multiple and interconnected streams of work dependencies require a planning tool that accounts for this complexity. ${ }^{649}$ Such a tool that is often used in consulting projects is the Program Evaluation and Review Technique (PERT), which involves flowcharting all the project activities and connecting together all those activities and tasks that are dependent on others. ${ }^{650}$ PERT not only helps with planning of the work to be done but also serves as a coordination mechanism for activities that take place simultaneously. As such, PERT also serves the coordination processes within client-consultant teams.

The length of projects affects planning. Shorter projects must be planned in detail in order to complete them on time. Longer plans require thorough monitoring, as there is the danger of neglecting planning since there is no immediate pressure. ${ }^{651}$ Monitoring processes are discussed next.

\section{Monitoring processes ${ }^{652}$}

Monitoring processes involve the tracking of the progress toward goals, monitoring of internal resources, monitoring of external conditions and changes, and monitoring of individuals' behavior. ${ }^{653}$ Typically, consulting projects have both a client and a

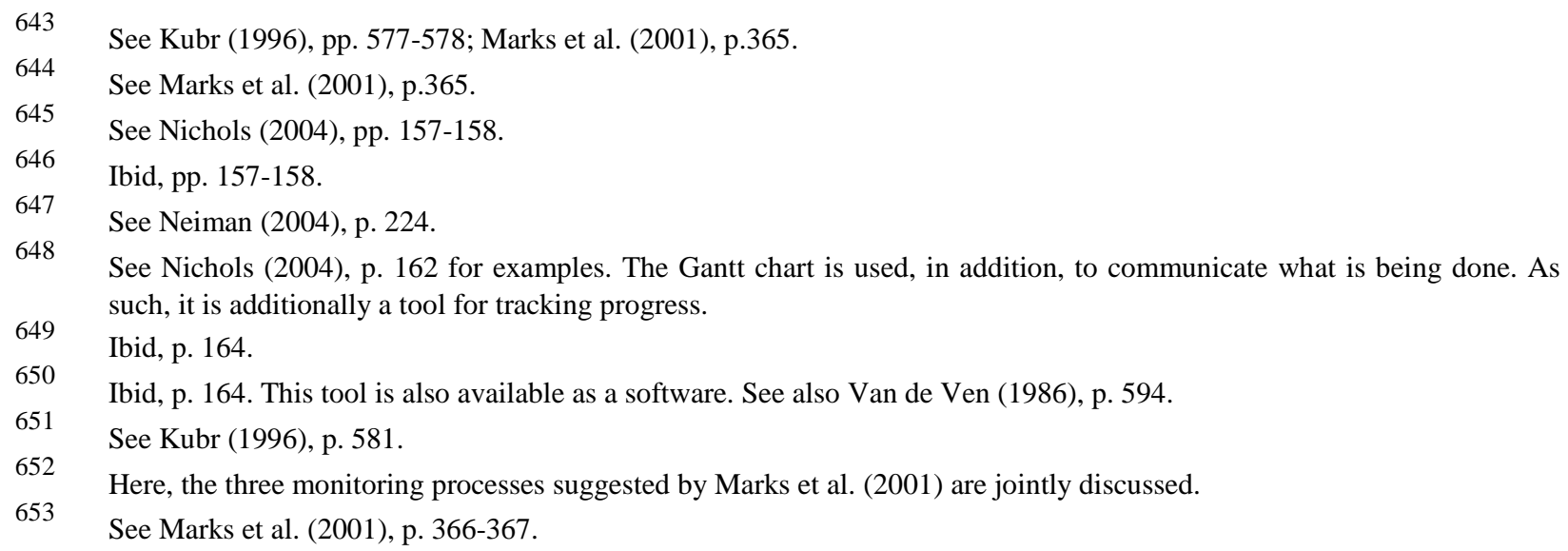


consultant project manager, who must report the project progress to the upper management of each of the organizations. ${ }^{654}$ Examples for instruments that accomplish the monitoring of the project progress are the status reports and reviews. The status report is prepared by the consultant project manager and includes updates about intermediate deliverable milestones. ${ }^{655}$ Reviews of the project work are usually signed off by the initiator or sponsor of the consulting project within the client organization who is not directly involved in the work of the client-consultant team. ${ }^{656}$

Additionally, the consultant project manager periodically visits the operating consultants on the client project, assists them with technical guidance and support, and works closely with the client project manager in order to be aware of changes in the client organization that could be relevant for the project. ${ }^{657}$ The consultant project manager is also responsible for discussing with the client project manager the support provided by the client team members and can request, when necessary, the involvement of additional members of the client organization.

\section{Coordination}

Coordination refers to the management of synchronous and/or simultaneous activities and involves information exchange and mutual adjustment of team members' actions. ${ }^{658}$ In general, coordination activities and tools involve the "process of orchestrating the sequence and timing of interdependent actions". ${ }^{659}$ Coordination is crucial for the timely conclusion and the success of consulting projects. With the increasing size of projects, the need for coordination increases as well. The Gantt chart and PERT, which were previously discussed, are two examples for coordination tools within client-consultant teams.

\section{Conflict management}

Conflicts can arise when members of the client-consultant team have different opinions, values, and beliefs regarding a particular issue. ${ }^{660}$ Conflicts are not always negative. Some degree of differences between the members of the team can stimulate the development of different ideas and approaches, and thus, facilitate innovative problemsolving. ${ }^{661}$ However, there is the danger that a conflict can distort communication and result in the inability of the team to make a decision. ${ }^{662}$ Therefore, it is important that the client-consultant team agrees upon and adopts conflict management mechanisms. Conflict management involves, in general, “establishing conditions to prevent, control, or

662 See, e.g., Reihlen (1997), pp. 278-279. See also Kubr who lists a number of reasons for the emergence of conflicts. Kubr (1996), pp. 88-89.
} 
guide team conflict before it occurs", and "working through task, process, and interpersonal disagreements among team members". ${ }^{663}$ Thus, an important aspect of conflict management is that participants communicate in a collaborative manner with the "explicit desire to find mutually beneficial solutions to whatever problems are being discussed, or negotiated”. 664

There are few principal methods for resolving of interpersonal conflicts. Withdrawal as an option means a retreat from the conflict situation. ${ }^{665}$ Smoothing involves a strategy of emphasizing areas of agreement and deemphasizing areas of difference. Compromising is the search for solutions that bring some degree of satisfaction to all conflicting parties. Forcing takes place when actors force their viewpoint at the expense of others. Confrontation involves addressing a disagreement directly in order for the affected parties to work through their disagreement. Each of these strategies has its advantages and disadvantages. Withdrawal, for example, provides only a provisional solution and can be used to buy time and allow the parties to rethink their positions. Forcing uses authority and power and can cause resentment but may be necessary in extreme cases where agreement cannot be reached, or when there is no time for extensive discussions. ${ }^{666}$ Compromising helps to avoid conflicts but it is not always achievable or can take very long time. In addition, it does not always yield optimum results because all involved parties have to offer some concessions. ${ }^{667}$ Confrontation is regarded generally as the most effective option because it is based on problem-solving processes and the active search for possible alternative solutions of the conflict. ${ }^{668}$ The involved parties try to justify their conflicting views through providing the best available arguments for their positions. The goal is to persuade the other party that one's own view is the right one regarding the particular issue or situation. ${ }^{669} \mathrm{~A}$ consensus is achieved if all parties develop, as a result of an argumentative dialog, a common understanding of the issue at hand. However, such a consensus is often not possible in the real world. ${ }^{670}$ Moreover, team members often use power in order to influence the direction of consensus. ${ }^{671}$ It has been argued that in order to resolve conflicts without resorting to the use of power, while ensuring that all individuals agree upon the suggested problem solution, team members have two other conflict solving options: (1) the democratic ballot following the majority principle, and (2) the independent expert decision. ${ }^{672}$ However, these conflict-solving practices do not always work in the case of client-consultant teams. ${ }^{673}$ (1988), p. 86

Marks et al. (2001), p. 364-369.

Lovelace et al. (2001), p. 781.

See Lippitt (1982), cited in Kubr (1996), p. 89.

See Kubr (1996), p. 89.

See Reihlen (1997), p. 281. For this reason, compromise is referred to as a “distributive agreement”. See Thompson et al.

See Lippitt (1982), cited in Kubr (1996), p. 89. As such, it aims at maximizing the joint outcome of the negotiating actors. For this reason, it is called "integrative agreement". See Thompson et al. (1988), p. 86. 


\section{Motivating/ confidence building/ affect management}

It was emphasized previously that motivation is one of the most important attributes that clients and consultants need to possess in order to work successfully together. Motivating team members is important as it encourages team members to perform better or to maintain high levels of performance. ${ }^{674}$ Whereas the level of intrinsic motivation cannot be influenced directly from the outside, the degree of extrinsic motivation can be easily managed, for example through offering bonuses or promotions in the case of success. Nevertheless, a number of tools and techniques can be used to influence the level of intrinsic motivation.

Motivation in client-consultant teams is of a particular importance due to the nature of consulting projects. Consultants are often regarded with suspicion by the "problemowners" and other members of the client organization, because consulting projects usually involve insecurity about what is going to happen with their positions and responsibilities. Thus, client team members may withhold important information and not provide the necessary support to consultants. This can cause frustrations and anger on the side of the consultants and can decrease their motivation to perform. ${ }^{675}$ Therefore, both the client and consultant project manager have to communicate openly with the members of the team and have to overcome any closures and negative feelings. In particular, it is a major responsibility of the client project manager to choose which individuals from the client organization will participate in the project, depending on both their relevant knowledge and expertise and their motivation to participate. At the same time, the consultant project manager has to take into account the expertise and interests of the consultants when assigning members to a particular project. Finally, as Kubr argues, it is helpful to try to match the clients' and consultants' personalities in order to ensure better performance on both sides. ${ }^{676} \mathrm{~A}$ good match between the members of the team has a positive influence on their emotions and social cohesion. Marks et al discuss, in this regard, several different techniques that can be used in relation to affect management. ${ }^{677}$

\subsection{Relations with the environment}

The discussion of the structural relations within client-consultant teams also requires a discussion of the relations of the team with its environment. These relations are called mobilizing practices and are briefly discussed in what follows. ${ }^{678}$

In the case of client-consultant teams, which exist only temporarily until a problem solution is generated (and sometimes implemented), mobilizing practices are performed by members of the team with the purpose of creating favorable conditions for the team's work. Such mobilizing activities are oriented towards marketing the task and the progress

\footnotetext{
674 See Marks et al. (2001), p. 368.

675 See, e.g., Kubr (1996), p. 586.

676 Ibid, pp. 579-580.

677 See Marks et al. (2001), p. 369. they are not central for this work. Some aspects of mobilizing practices are discussed further in chapter D.VI.4. For a detailed discussion, see, e.g., Reihlen (2003a), pp. 14. 
of the project. At the end of the project, mobilizing practices are used to promote the generated problem solution, i.e. the task-specific knowledge, within both the client and consultant organizations, for example, through writing reports, speaking at meetings, and engaging in workshops with members of both companies who have not been involved in the consulting project. Through such activities team members can secure additional resources for their work. For example, the results of a particular consulting project are reported to the consulting company, where it can build the basis for the evaluation of the consultants' performance and can be a source of new knowledge, which is further distributed within the consulting company. Communicated in the client organization, these results are used to gain support for the implementation of the suggested solution, or, for example, for the initiation of other (consulting) projects.

Additionally, mobilizing practices are directed towards the broader environment of client-consultant teams, including business schools, business media, competitors, professional organizations, etc., with the aim of communicating and legitimizing the created problem solutions. The role of mobilizing practices in this case is to show that the team's work has been successful. This type of mobilizing practice is called informing. Additionally, when results generated in client-consultant teams are communicated to the outside environment they also serve the task of reputation and image creation. ${ }^{679}$ Consultants in particular engage in such reputation creation activities, also called impressing, as reputation is one of the major factors that clients take into account when selecting consulting companies. ${ }^{680}$ Impressing involves, for example, publishing knowledge generated in consulting projects in prestigious management journals and books. The intention is to win new clients. ${ }^{681}$

\section{Summary}

This chapter presented a systemic framework for the analysis of the client-consultant relationship that offers important insights on the nature of this relationship and provides the basis for the discussion of the models of client-consultant interaction. It was argued that from a systemic perspective, the client-consultant relationship is characterized by three major aspects: (1) the characteristics of the individuals involved in consulting projects, (2) the (project) characteristics that build the immediate environment of clientconsultant teams, and (3) the structural relations among the members of client-consultant teams.

Three major categories of personal attributes of clients and consultants were introduced, and it was argued that they are more or less important depending on the problem context that clients and consultants encounter during their joint work. Additionally, the discussion of different problem and project types showed that a unifying view of client-consulting interactions, as suggested in the literature and outlined

679

680

681

See Davenport/Prusak (2005), p. 308; Reihlen (2003a), pp. 19-24.

See, e.g., Lowendahl who argues that reputation is one of the most important strategic resources of professional business service firms. Lowendahl (1997), p. 88. See also Glückler/Armbrüster (2003) who offer an extensive discussion of the role of reputation in management consulting.

See Davenport/Prusak (2005), p. 308. Maister speaks in this case about “broadcasting”. Maister (1993), pp. 53-57. 
in chapter I.2, is not appropriate. Rather, it was shown that clients and consultants develop different relationships depending on the nature of the problem that they have to solve. In addition, the nature of the organizational field of management knowledge production and dissemination was discussed, emphasizing the interdependency between the actors within this field and their influence on concrete client-consultant projects.

Next, it was argued that client-consultant relationships involve different types of structural relations, including (1) cultural relations oriented towards problem-solving and knowledge production; (2) economic relations including the production and utilization of cultural artifacts, which are closely interlinked with cultural relations; (3) political relations and their influence on problem-solving processes; (4) social practices and mechanisms that are used in order to manage and integrate the activities of the team members and ensure successful cooperation; and (5) structural relations of clients and consultants with their environment in the form of mobilizing practices. Whereas the last two types of structural relations have been neglected within the existing models of the client-consultant relationship, cultural and political relations within client-consultant teams in particular have been put in the centre of a controversy originating from different and contrasting epistemological traditions regarding the nature of knowledge and power. Therefore, a unifying discussion of the nature of cultural and political relations in clientconsultant teams is not possible as evidenced by the different models of the clientconsultant relationship. The next three chapters of this work are dedicated to an analysis of these models. 


\section{Established models of the client-consultant interaction}

\section{Introduction}

Three basic models dominate the existing literature on client-consultant interaction. Prior research has focused on the client-consultant relationship as a client-expert interaction ${ }^{682}$ and as a symbolic interaction. ${ }^{683}$ Both views stress, however, single features of the clientconsultant interaction without recognizing its multidimensional and complex character. Reviewing contemporary research on consultancy projects, Engwall and Kipping conclude that the interaction process between consultants and their clients is still poorly understood, ${ }^{684}$ perhaps because, as Hislop claims, "the nature of the client-consultant relationship and the role of the client firm shaping this relationship has tended to remain neglected and unexplored." ${ }^{685}$ Fullerton and West supports this when arguing that the role of the client in the success of the relationship has been underemphasized. ${ }^{686}$ Fosstenlokken et al. conclude that the client interaction still lacks understanding and call for further investigation into the nature of client relationships, as well as into the role clients play in the knowledge creation process in professional service firms. This suggestion is all the more relevant given that learning through project work is increasingly being considered as "the most important source of knowledge development" in consulting firms. ${ }^{687}$

Recently, researchers have directed their attention to the interpretive and multilayered character of consulting work. Fincham and Clark argue that interpretationabout whether knowledge is needed (whether the client has a problem), what kind of problem the client has, how to apply and create knowledge with this particular client, and how to make sure that change occurred-is the basis of consulting expertise. ${ }^{688}$ Kipping and Armbrüster stress that the "otherness" of consultants-the fact that consultants are outsiders to the client organization and therefore their knowledge, their work methods, and language differs from the client's — can be a considerable burden for a successful interaction with the client, and may prevent consultants from being involved more intimately in the client's business. ${ }^{689}$ At the same time, the consultants' independent, outsider view is considered as one of the main strengths. ${ }^{690}$ Therefore, a critical issue for 
client-consultant teams is how to overcome the differences between clients and consultants in order to improve their communication and cooperation, without losing the "otherness" of the external advisors and, consequently, their ability to foster change in practices, processes, and organizations.

Early on Schön recognized that the "otherness" of professionals and the nature of their expertise has implications for the nature of the client-consultant interaction. ${ }^{691}$ Their "otherness", he argues, is due to the fact that clients and consultants belong to different practice communities and hence have different perspectives on problems and problem solutions. Consequently, he proposes an analytic view of the client-consultant interaction as a "reflective conversation" between clients and consultants. However, although Schön provides some new insights into the nature of the client-consultant relationship, his model does not cover entirely all-important aspects of the client-consultant interaction. It is too general and unspecific, as concrete ways for improving knowledge transfer and communication within client-consultant teams remain unexplored.

Building upon the contributions and shortcomings of the existing research on the client-consultant relationship, this work proposes the need for a new model, called "the interpretive model”, of the client-consultant interaction. This model would advance the existing research on the one hand and put it into a new theoretical background on the other. In this manner, it would solve the existing models' problem of incompatibility. The new model is based on the assumption that organizations can be seen as a community of different interpretive communities. ${ }^{692}$ By applying the concept of interpretive communities, it is shown that clients and consultants may have problems in understanding each other's language. ${ }^{693}$ Consequently, within their interaction there is a problem of translation: knowledge transfer and creation will only occur if the individuals involved in the interaction process learn to share their understandings and to develop new meanings to familiar topics. ${ }^{694}$ Whose perspective will build the basis of the problem solution when there are several possible and legitimate interpretations is often dependent on the power or "interpretive dominance" of each community, which is constructed through discourse. ${ }^{695}$ Thus, it is argued that the translation of different interpretations is simultaneously always also a mechanism of power. ${ }^{696}$ This view of the client-consultant interaction has some important theoretical consequences for the discussion of the nature of professional service firms, as well as practical implications regarding the management of consulting projects.

In the following chapters, the existing models of the client-consultant interaction are discussed extensively before the new model is presented. 


\section{The expert model}

\section{Introduction}

The expert model dates back to the start of academic interest in the area of consultancy work and was pre-eminent in the consulting literature from the late 1950s until the mid1980 s. $^{697}$ It has several different streams; most notable are works concentrating on the nature and management of professional business services in general ${ }^{698}$ and on management consultancies in particular. ${ }^{699} \mathrm{~A}$ big part of this literature has a prescriptive character.

The following definition illustrates the view on consulting as proposed within the expert model:

"Management consulting is an advisory service contracted for and provided to organizations by specially trained and qualified persons who assist, in an objective and independent manner, the client organization to identify management problems, analyse such problems, recommend solutions to these problems, and help, when requested, in the implementation of solutions". ${ }^{700}$

According to this model what differentiates management consultancies and all professional business services in general, from traditional manufacturing companies, is that they create value through their contribution of expertise and experience in solving client problems. ${ }^{701}$ Hence, an important characteristic of the client-consultant relationship is the unidirectional knowledge asymmetry between consultants and clients. The reason for the existence of such unidirectional knowledge asymmetry is the belief that "certain work is so specialized as to be inaccessible to those lacking the required training and experience." ${ }^{702}$ Another important characteristic of the relationship is the consultants' independence from clients, which enables consultants to generate objective information and problem solutions and remain separate from internal power struggles and hidden agendas. ${ }^{703}$ Additionally, it is assumed that the content, duration and terms of the relationship are clearly defined, which implies that clients are rational buyers who are aware of what results they can expect. ${ }^{704}$

A look at the consulting industry shows that this model is regarded as broadly applicable, from situations involving complex, highly uncertain, and innovative

See Fincham/Clark (2002), pp. 4-6.

See, e.g., Abbott (1988); Hall (1969); Sibson, (1971).

See, e.g., Gallessich (1982); Kubr (1996); Lipitt/Lipitt (1978); Sadler (1998); Schein (1987, 1988).

Greiner/Metzger (1983), cited in Kubr (1996), p. 3, emphasis added. See also Czerniawska (1999), p. 8 for a very similar definition.

See Abbott (1988), pp. 35-58; Lowendahl (1997), p. 12; Müller-Stewens et al. (1999), pp. 20-23; Schrädler (1995), pp. 20-24.

Freidson (2001), p. 17.

See Werr/Styhre (2003), p. 47. See also Fritz and Effenberger who argue that empirical studies of consulting clients confirm that clients often engage consultants because they believe that consultants will provide them with an objective picture regarding the issue at hand. Fritz/Effenberger (1998), p. 107.

See Kubr (1996), p. 7; Werr/Styhre (2003), pp. 46-48. 
problems, as is the case in strategy consulting, to more familiar and routine outsourcing tasks, which is the case in contractor style consulting. ${ }^{705}$

\section{Context}

The expert model is the oldest model of client-consultant interaction. It is anchored in traditional management theory, ${ }^{706}$ or what Schön calls the "Technical Rationality". 707 Schön traces the origins of Technical Rationality back to the time of Reformation in the Western world, the time of the industrial movement and the rise of science and technology, a time period that is also called “modernism”. Modernism was at its height in the nineteenth century and is associated with positivism, empiricism, and science, which all share "a faith in the power of the mind to understand nature". ${ }^{708}$ In this time, professions were seen as vehicles for the application of new sciences to the achievement of human progress.

At its emergence, the main assumption of the expert model is that "professional activity consists in instrumental problem-solving made rigorous by the application of scientific theory and technique." ${ }^{709}$ Additionally, professional knowledge is regarded as objective, impersonal and standardized, claims that are typical for modern societies: "professionals apply very general principles, standardized knowledge, to concrete problems." ${ }^{\prime 10}$ Problem solutions are seen as the result of the expert's problem-solving abilities. Therefore, the nature of expertise and consulting in this model reflects "the particular socio-technical conditions and organizational configurations that define 'late modernity",. ${ }^{711}$ Schön concludes, "Technical Rationality is the Positivist epistemology of practice". ${ }^{712}$

That management consulting is embedded in the tradition of modernism is obvious, as some of the first management approaches were linked to the emergence of scientific management in the United States at the start of the $20^{\text {th }}$ century. ${ }^{713}$ Taylor's scientific management, publicized in 1911, became the first widely known consulting method. It conceived management as a form of human engineering based on a science of work. ${ }^{714}$ Taylor saw the manager as well as the management consultant as a "scientist in action, whose practice would consist in the trial and measurement of designs and methods aimed

See Czerniawska (1999), p. 111; Kitay/Wright (2003), p. 29 and p. 32; Lane (1994), p. 88.

See, e.g., Fincham (1999), p. 337.

See Schön (1983), pp. 21-49; also Fombrun/Nevis (2006), p. 9. In this context, authors also talk about the information processing paradigm. See Alvesson/Deetz (2000), pp. 31-33; Carlile (2002), pp. 443-444 and Nonaka (1994), pp. 15-16 for a general discussion of this paradigm.

Parker (1992), p. 3. "In the organizational context, we use the term 'modernist' to draw attention to the instrumentalization of people and nature through the use of scientific-technical knowledge (modelled after positivism and other 'rational' ways of developing safe, robust knowledge) to accomplish predictable results, measured by productivity, and technical problem-solving leading to the 'good' economic and social life, primarily defined by accumulation of wealth by production investors and consumption by consumers”. Alvesson/Deetz (2000), p. 13.

Schön (1983), p. 21.

Moore (1970), p. 56.

Reed (1996), p. 576.

Schön (1983), p. 31.

See Armbrüster/Kipping (2002-3), pp. 21-22; Kipping (1999), pp. 3-6; also Czerniawska (1999), p. 111.

See Schön (1983), pp. 237-238; also Saint-Martin (2000), pp. 41-44.
} 
at the discovery and implementation of the one best way."715 In 1930, another consulting method stemming from this tradition, Bedaux' System of work measurement, became the most widely used method of payment-by-results in the United States.

After World War II, this "scientific" view of management was transferred to other management areas, such as sales, personnel selection and training, budgeting, and financial control, marketing, strategic planning, and information technology. ${ }^{716}$ Some examples for management and consulting techniques in this tradition are value analysis, management by objectives, planning programming and budgeting, and zero-based budgeting. Furthermore, many of today's most successful consulting companies were built on the principle that rigorous analysis of problems using 'objective data' and general principles of decision-making could be applied to organizations regardless of sector or origins. ${ }^{717}$ Thus, "the strong analytical approach to managing the organization is reflected in their rationalistic 'methodologies"”. 718

\section{Cultural relations}

\subsection{Nature of knowledge}

The nature of consulting expertise is mostly, though not explicitly, addressed by the supporters of this view. They merely state that it is partly based on a universal, abstract body of knowledge, which is normally maintained through professionals or professional associations, ${ }^{719}$ and partly on methods and concepts developed during the consulting practice. ${ }^{720}$ The former is also called esoteric knowledge, ${ }^{721}$ the latter technical knowledge. ${ }^{722}$

There is, as already argued, an implicit agreement about the existence of unidirectional knowledge asymmetry between consultants and clients based on the belief that "certain work is so specialized as to be inaccessible to those lacking the required problems because of this training and additional practical experience. See Bromme et al. (2001), p. 317; also Morris/Empson (1998), p. 613.

721 See Starbuck (1992), p. 716; Blackler (1995), p. 1028.

722 See Kitay/Wright (2003), p. 23. It is necessary to clarify that whereas some authors argue that technical methods and concepts are based entirely on scientific research or theory (see, e.g., Abbott, 1988, pp. 52-54), others see their origin in experience. The philosophical stream that underlies the former view is positivism, which implies, in this context, a radical rationalist approach to the study of reality, and the one behind the latter view is pragmatism. Consultant's aim is, in the second case, to use whatever technique or knowledge s/he believes may be useful in improving particular situations. See McGivern/Fineman (1983), pp. 426. Because positivism and pragmatism are distinct approaches in regard to the question how professional knowledge is gained (see, e.g., Bunge, 1996, pp. 305), it seems contradictory to combine these two approaches in one model. However, what is emphasized in the following is that whether knowledge is gained through a strict scientific process or through practice experience, in both cases knowledge is regarded within this model as objective and easily transferable. Thus, both views conceptualize the problem-solving process within client-consultant teams in a similar way.
} 
training and experience”. ${ }^{723}$ This (professional) specialization into distinct areas of expertise or knowledge is portrayed as the inevitable product of the division of labor, as well as the outcome of a process of rationalization that is the most efficient way of organizing and applying an increasingly complex knowledge base. ${ }^{724}$ Furthermore, within this model consulting expertise is seen as the simple reflection and organization of truth, rationality, and wisdom, ${ }^{725}$ and/or as the result of long experience, ${ }^{726}$ which legitimizes the powerful and protected position of consultants. It is believed that consultants even know better than their clients what services their clients really need. ${ }^{727}$ Thus, consultant's knowledge is seen as being "superior" to the knowledge of the clients. ${ }^{728}$

\subsection{Knowledge transfer and creation}

When they discuss knowledge transfer between clients and consultants most of the proponents of the expert model concentrate on the different stages of the problem-solving process. For example, Abbott suggests that knowledge transfer takes place in two phases: ${ }^{729}$ (1) "diagnosis" that "takes information into the professional knowledge system” and (2) "treatment”, which "brings instructions back out from it”. In the case of familiar problems, the diagnosis of a problem implies its treatment, or solution. For example, if the "diagnosis" of the client situation indicates high costs related to processes within the client organization, such as order fulfillment, consultants suggest "treatment" through the implementation of Business Process Reengineering, which is meanwhile the "standard" concept for optimizing processes in organizations. When, however, the connection between diagnosis and treatment is obscure, as in the case of unfamiliar problems, consultants engage in "inference", which "is a purely professional act [that] takes the information of diagnosis and indicates a range of treatments with their predicted outcomes." 730 This is the phase when existing knowledge is adjusted to the concrete client situation or new knowledge is created. Through these activities, consultants “construct tasks into known 'professional problems", ${ }^{731}$ The degree to which inference predominates, rather than the routine connection of diagnosis and treatment, determines the degree of customization of the service and depends on the type of client problem.

Gadrey and Gallouj suggest a similar model that involves four stages: identification of the problem, study, or diagnosis of the problem, advice, or generation of recommendations, and implementation of the problem solution. ${ }^{732}$ They argue that there is a high-level interaction between clients and consultants during the first phase of the

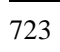

724

725

726

Freidson (2001), p. 17.

See Fournier (1999), p. 303.

Ibid, p. 303.

See McGivern/Fineman (1983), pp. 426.

See Walsh (2001), pp. 34-37.

See O’Farrell/Moffat (1991), p. 210, emphasis added.

Abbott (1988), pp. 40.

Ibid, p. 40.

Ibid, p. 59. See also Kieser who argues that in this process, consultants break complex unstructured problems down into a sequence of well-structured problems. Kieser (2002b), p. 212.

See Gadrey/Gallouj (1998), pp. 2-4; see Lippitt/Lippitt (1978), pp. 8-26 for another differentiation. 
process. However, during the diagnosis and the advice generation there is only a low to moderate level of interaction. In the fourth phase, there is either high or low level of interaction depending on the project.

This view of the problem-solving process is in line with the assumed unidirectional knowledge asymmetry between clients und consultants. The consultant's role is to generate the "right" problem solution with the client's role is limited to the delivery of information and the implementation of the proposed solution. ${ }^{733}$ "Once the information is obtained from the client/customer, the employee [consultant] can proceed directly to employ the discretion and knowledge inherent in the task."734 Therefore, a successful knowledge transfer and creation is mostly dependent on consultants' problem-solving abilities and their judgment ability, and to a lesser degree on the client's motivation to cooperate with the consultants, ${ }^{735}$ the client's possession of related knowledge-that will increase the probability of successful implementation of the problem solution ${ }^{736}$ - and the client's ability to absorb knowledge. ${ }^{737}$ Figure 5 illustrates the problem solution process in consulting projects as viewed within the expert model.

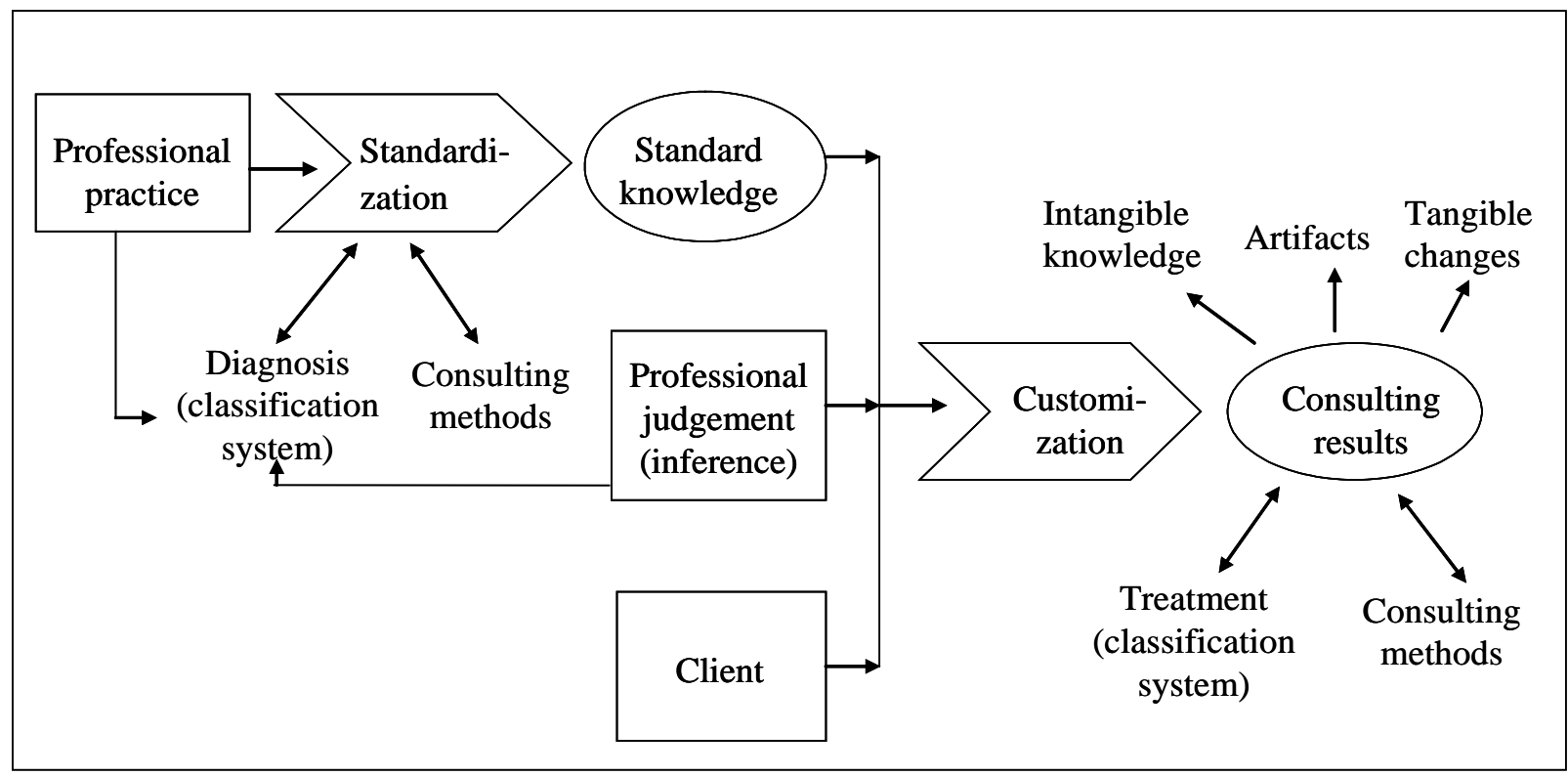

Figure 5: The problem solving process in consulting projects.

Source: Adapted from Nikolova et al. (2001), p. 12.

Accordingly, clients are involved in the problem-solving process insofar as they provide the necessary information about the problem, for example, in the form of organizational data, policy manuals, and organizational charts to the consultants. ${ }^{738}$ The consultants provide standardized methodologies and the experience from previous projects, which enhances the process of professional judgment. The interaction process is 
described as follows: during the consulting project, "explicit knowledge is catalogued along with tacit knowledge that is generally extracted or harvested by consultants as part of the consulting engagement. [] As objective outsiders, management consultants work to capture this tacit knowledge through interviews, observation, or other forms of collection." ${ }^{739}$ The results of the project include: first, the intangible knowledge that the involved individuals gain; second, knowledge that has been made explicit during the project and turned into "deliverables", for example in the form of reports, summaries of findings, concepts; and third, tangible changes in the organization, such as, for example, a reorganization of the production process. Additionally, consulting companies retain the created artifacts into databases or in the form of changed consulting methods. ${ }^{740}$

Table 9 shows some of the standardized consulting concepts and techniques developed since the 1970s.

\begin{tabular}{llll}
\hline Concept & Year & Consultant & Organization \\
\hline Portfolio Analysis & 1976 & Henderson & The Boston Consulting Group \\
\hline Five Forces & 1980 & Porter & Monitor Company \\
\hline Value Chain Analysis & 1985 & Porter & Monitor Company \\
\hline Core Competencies & 1990 & Hamel and Prahalad & Harvard/Michigan/Strategos \\
\hline Customer Retention & 1990 & Reichheld & Bain \& Company \\
\hline Cycle Time Reduction & 1990 & Stalk & The Boston Consulting Group \\
\hline Mass Customization & 1992 & Pine & $\begin{array}{l}\text { Strategic Horizons/Diamond } \\
\text { Technology Partners }\end{array}$ \\
\hline Reengineering & 1993 & Hammer and Champy & CSC \\
\hline $\begin{array}{l}\text { Shareholder Value } \\
\text { Analysis/ }\end{array}$ & 1993 & Stewart & Stern Stewart \\
Economic Value Added & & & \\
\hline Value Migration & 1996 & Slywotsky & Corporate Decisions, Inc. \\
\hline Value Net & 1996 & Brandenburger and & Harvard and Yale \\
\hline
\end{tabular}

Table 9: Selected consulting concepts

Source: Biswas/Twitchell (1999), p. 10. services and service providers. Jacobs and Heracleous, for example, argue for the case of controlling science "real-world problems are decontextualized, aggregated, and 'translated' into generalizable, abstract problems to which the scholar finds adequate, abstract solutions. [] These prescribed solutions are then to be applied by the Controlling practitioner with a real-world problem. [] The organization is reduced to a tool of plan fulfillment, and its members are seen as resources to be efficiently allocated in the planning process. [Thus], controlling science is [] positivist, nomothetic, and abstract, firmly rooted in the functionalist paradigm”. Jacobs/Heracleous (2001), p. 121. 


\section{Power relations}

A main assumption of the expert model is the consultant's autonomy and power ${ }^{741}$ resulting from the assumed knowledge asymmetry. Supporters of the model recognize that clients provide valuable information that consultants need in order to solve client problems, and which can be seen as a source of external dependence for consulting companies. ${ }^{742}$ However, the argument is that clients deliver just the raw information, whereas only the consultants are believed to possess the necessary expertise to solve the problem. "Consultants, like other specialists, occupy positions of relative power, as they are often the sole authorities on certain technical problems and their implications." "743 Hanlon supports this when arguing that the traditional view of professional service provision is one in which the professional controls the interaction: s/he "translates client's desires into a professional meta-language and explains to clients what is possible in their situation" ${ }^{744}$ In other words, the experts understand the problem and know how to solve it. They diagnose and prescribe solutions unilaterally whereas the "client is left unaware of what has been going on and is, thus, in a weak position when it comes to having an influence on the outcome". ${ }^{745}$ Consequently, consultants see clients as dependent on them for the credibility their expertise. ${ }^{746}$ Moreover, some authors argue that an equal relationship between clients and consultants is counterproductive due to "reduction of rationality in the decision-making process". ${ }^{747}$ They conclude that such a relationship will alter the fundamental nature of client-consultant interactions from a superior-subordinate alliance to peer interaction.

At the same time, however, supporters of this model emphasize client's contractual power. For example, they emphasize consultants' dependency on the client for receiving future projects. ${ }^{748}$ Thus, clients are seen as being in control as they have the ability to hire and fire consultants. ${ }^{749}$ Consequently, this approach is characterized by some ambivalence regarding the power distribution within the client-consultant relationship.

\section{Nature of professional business services}

Within this model, professional groups are presumed to act rationally, deploying trained and specialized expertise and competence. ${ }^{750}$ Thus, the special relation between clients and professionals grounded in the knowledge asymmetry between them is seen as the

\footnotetext{
741

See Hall (1969), p. 131; Haug/Sussman (1969), p. 154; Kubr (1996), pp. 6-7; Mills/Moshavi (1999), pp. 54-55; Mills et al. (1983a), p. 119; Quinn et al. (1996), p. 75; Sharma (1997), p. 764 and pp. 768-770. See also Alfieri (1994) for the case of lawyers.

See, e.g., Mills et al. (1983a), pp. 120-121.

Gallessich (1982), p. 381.

Hanlon (1997), p. 124.

McGivern/Fineman (1983), p. 435.

See Walsh (2001), pp. 34-37

Mills/Moshavi (1999), p. 53.

See Werr/Styhre (2003), p. 47 and pp. 57-58.

See Maister (1993), pp. 111-120; Werr/Styhre (2003), p. 47.

See Fores et al. (1991), p. 97.
} 
core of the phenomenon of a profession. ${ }^{751}$ Professions are regarded as a means to control the asymmetric expert-client relationship: "Professionalization was simply the evolution of structural guarantees for that control." ${ }^{\text {"72 }}$ Hence, this model explains the existence of professions and, respectively, the nature of professional services, on the basis of an economic rationale: because professional knowledge is only transferable with significant costs, e.g., educating the client in law or accounting. Accordingly, a guarantee is necessary that non-knowledgeable clients (or principles) can trust the professionals (or agents) to behave in appropriate ways. ${ }^{753}$ Thus, professionalism is seen as a means for this guarantee.

It is important to note that the knowledge asymmetry in the case of professional services is different from the knowledge asymmetry discussed in the Principal-AgentTheory. The Principal-Agent-Theory regards knowledge asymmetry as an information asymmetry and postulates that a principal is able to reduce this asymmetry through investments in monitoring or additional information search. ${ }^{754}$ In contrast, the knowledge asymmetry in the case of professional services is caused by specialization - the client is not able to reduce this asymmetry because the knowledge of the expert is built through long lasting academic education and experience in the profession. Thus, the client cannot reduce the knowledge asymmetry without becoming him/herself a professional. ${ }^{755}$ Consequently, within the expert model, consultants are seen as the powerful actors, whereas the principal-agent theory regards the principal, i.e. the client, as the actor in control. ${ }^{756}$ Thus, knowledge asymmetry implies non-contestable activities with the corresponding monopoly power on the side of the professionals. ${ }^{757}$

\section{Attributes of clients and consultants}

Supporters of the expert model do not address the issue of client's cognitive skills in detail. Only few studies point out that clients need to possess domain-related knowledge that is to some degree similar to the consultant's domain-related knowledge, ${ }^{758}$ which increases the probability of successful implementation of the problem solution. In other words, clients need to possess absorptive capacity $^{759}$ in order to implement consultants' solutions successfully. Absorptive capacity is, thereby, the individual's ability to recognize the value of new information, assimilate it, and apply it. ${ }^{760}$ Additionally,

See Sharma (1997), p. 767-768. He further argues that because of the high interaction intensity between clients and consultants during service delivery, issues such as social influence, interpersonal attraction, and trust become vital in examining client-professional exchanges, whereas they are totally neglected in the traditional principal agent-theory. He concludes that knowledge asymmetry in client-professional relationships can be effectively reduced via supervision by professional peers and via profession-wide standards rather than via direct control of professionals by lay principals. See Dietrich/Roberts (1997), pp. 24. 
client's motivation to cooperate with the consultants is emphasized ${ }^{761}$ but there is no detailed discussion of this issue. Communication skills are only implicitly assumed to be important, as it is assumed that the main role of client-consultant interaction is the exchange of objective information.

In regard to consultant's attributes, works within the expert model emphasize the consultant's competence to analyze, solve and possibly implement client's problems. Two main types of consultants can be differentiated with an emphasis on different cognitive abilities. ${ }^{762}$ In the following, the main characteristics of these sub forms are briefly introduced.

\section{Expert consultant}

The "expert consultant" applies predetermined solutions to problems, almost irrespective of the contexts in which s/he finds them. ${ }^{763}$ The knowledge of the expert consultant originates almost entirely in experience; in other words, the nature of consulting experience is in this case empirical or practical. Practical knowledge is "largely free of formal concepts and theories, learned by experience, and instrumental for performing concrete tasks in concrete settings". ${ }^{764}$ Thus, expert consultants are trained mainly on the job. ${ }^{765}$

The main task of consulting according to this sub type is the solution of practical problems and its value lies in its functionality and usefulness. Thus, creativity is not a very important attribute for the expert consultants. As Freidson argues, innovation does exist but is at best part-time and is seldom pursued systematically. ${ }^{766}$ What is rather emphasized is the experts' ability to connect their existing knowledge to a number of different contexts and problem situations. The practical domain-related knowledge of consultants is more important than their abstract theoretical knowledge. Thus, an intuitive cognitive style based on consultant's experience rather than an analytical cognitive style is emphasized.

\section{Pure researcher}

At the other end of the spectrum is the consultant who studies social issues and problems independent of a particular problem and client. McGivern and Fineman talk in this case about "pure researchers". ${ }^{767}$ They use their scientific expertise and accumulated experience to develop theoretical knowledge and address abstract, logically derived problems independent of concrete client problems. ${ }^{768}$ Thus, pure researchers rely mainly on formal, abstract, scientific knowledge. Although some of this formal knowledge rests on taken-for-granted assumptions stemming from both everyday and practical 
knowledge, and some of it even becomes part of practical knowledge, most of it is "divided among specialized disciplines practiced by different groups of specialized workers". ${ }^{769}$ Such formal knowledge is acquired within universities or institutes with university status. ${ }^{770}$

This is a research-oriented approach to consulting and is the case when, for example, university professors work as consultants. Examples for this type of consultant are Henri Fayoul, Frederick Taylor, Michael Hammer and James Champy, and Michael Porter. Abstract, logical, rather than practical domain-related knowledge is emphasized in the case of the pure researcher. In other words, logical and abstract thinking is more important than the experience of such consultants. Consequently, an analytical cognitive style is regarded as important; the intuitive cognitive style is ignored or even disapproved of, as it is seen as being non-scientific. Thus, the goal of the researcher-consultant is to bring scientific expertise into the client organizations. From a historical point of view this type of consulting was more important in the early years of consulting, when managers did not have enough scientific knowledge, e.g., before so many people went to universities.

In an empirical study, McGivern and Fineman found that both sub forms of consulting share similar features. Emphasis is put on (1) a normative way of workingthe methods employed are independent of the particular situation and standardized; in other words, in both cases it is assumed that consulting knowledge is generally valid-; (2) strict roles for the consultant or researcher and the client so that the need for trust is eliminated; and (3) the cognitive skills, in particular technical and analytical skills, of the consultants or researchers rather than their interactive skills. ${ }^{771}$ When interactive skills are discussed, supporters of the model emphasize consultants' professional attitude and behavior. ${ }^{772}$ Communication skills are important to the extent that consultants "must be able to communicate and deal with people in an atmosphere of tact, trust, politeness, friendlessness, and stability". ${ }^{773}$ The ability to negotiate and persuade clients, i.e. consultant's persuasion skills, is not discussed in relation to both expert consultant and pure researcher. Communication is seen as a matter of transfer of objective knowledge so persuasion and negotiation skills are not seen to be important within the expert model.

\section{Discussion}

\subsection{Contributions}

The relationship between clients and consultants, as presented in the expert model, is highly efficient because it does not require clients and consultants to engage in an intensive and time consuming interaction. The model builds upon the assumption that relevant knowledge can be standardized and applied to a number of clients requiring

\footnotetext{
769 Freidson (2001), p. 33.

$770 \quad$ Freidson (2001), p. 97.

771 McGivern/Fineman (1983), pp. 433-436.

772 See, e.g., Lippitt/Lippitt (1978), p. 101.

773 Lippitt/Lippitt (1978), p. 104.
} 
small adjustments only. Accordingly, clients can rely on consultants' expertise in solving management problems and only have to provide the necessary input (information) to the consultants without the need to participate in the actual problem-solving process extensively.

A look at the consulting industry shows that there are such cases when clients do not wish to participate actively and learn during consulting projects but rather prefer "experts" to do the work. For example, organizations sometimes outsource tasks to external consultants when they do not have the resources to do the work, or they desire a proven and fast solution to their problem. In other words, they engage consultants when they face simple routine problems and expect them to do the work as efficiently as possible. ${ }^{774}$ Thus, in terms of the model's assumptions regarding the problem-solving process in professional service firms, the client is in the position to do the diagnosis and select the proper treatment but prefers to "buy the treatment procedure from the market of standardized professional services”. ${ }^{775}$ Examples for such consulting services include areas such as recruitment, remuneration, training, process mapping, and outplacement, where the consultant's role is to provide a flexible source of external labor with the required knowledge. ${ }^{776}$ Additionally, large-scale problems or issues where extensive quantitative data on large populations is required also bear the same characteristics. ${ }^{777}$ Thus, it can be assumed that in the case of such routine problems this type of consulting is more appropriate and practical. ${ }^{778}$

However, a number of problems arise when this model is applied in cases when the issue at hand is rather complex or innovative. Thus, it is necessary to point out all the shortcomings of the expert model, which explain its failure to deliver appropriate results when applied in such problem contexts. This practical critic builds upon a theoretical critic regarding the main assumptions of the model and is presented in the following chapter.

\subsection{Shortcomings}

\section{Theoretical shortcomings}

\section{Nature of knowledge and knowledge transfer and creation}

The implicit assumption behind the expert model is that professionals' expertise in their field alone makes them successful or unsuccessful service providers. ${ }^{779}$ In the expert model, knowledge is assumed to be a decontextualized asset or resource, an "objectively definable commodity", ${ }^{780}$ the meaning of which is pre-existent and universal. Thus, the model's assumptions regarding the nature of knowledge are consistent with the positivist

See also the discussion in chapter B.II.3.2.1.

Lilja/Poulfelt (2001), p. 8.

See Kitay/Wright (2003), pp. 32-33. Gadrey and Gallouj speak about a “jobbing” type of interaction. See Gadrey/Gallouj (1998), p. 6-7. 
approach to knowledge, which was outlined in chapter B.II.4.1.3 of this work. ${ }^{781}$ Consultants are seen as experts who give "the right advice, [] in the right way, to the right person and at the right time. They are said to be in a position to make an unbiased assessment of any situation, tell the truth and recommend frankly and objectively what the client organization needs to do without having any second thoughts on how this might affect his or her interests." ${ }^{782}$ As Fox points out, the consulting process is presented as "ultimately impersonal, detached, asocial, ahistorical, and apolitical". ${ }^{783}$ Such a view requires consultants to achieve an external "God's-eye view of the world" "784 based on being panoptical hunters, gatherers and processors of information. ${ }^{785}$

Furthermore, in line with the positivist school of thought, the expert model postulates that consulting knowledge is independent of its carriers and retains its meaning while being transferred across individuals and organizations. ${ }^{786}$ This is the reason why the client-consultant communication is seen as an error-free process of message sending and message receiving through obvious and clear transmission channels. ${ }^{787}$ It is assumed implicitly that both client and consultant understand the exchanged information in the same way and know how to use it. ${ }^{788}$ In other words, it is assumed that knowledge contains the necessary codes for its successful decoding. ${ }^{789}$ Accordingly, learning is viewed as an exchange of information, and as such, it is a consequence of the number, direction, and the physical characteristics of messages. ${ }^{790}$ It becomes a process of implementing procedures for encoding and decoding messages. ${ }^{791}$ Communication problems are attributed to an insufficient motivation and absorptive capacity, i.e., to the intelligence of the client $^{792}$ or to inadequate transmission channels rather than to the existence of cognitive differences and contrasting interpretations of clients and consultants. Content and meaning of messages play a secondary role. ${ }^{793}$ Furthermore, due to the assumed knowledge asymmetry, learning is seen as a unidirectional process: the implicit tone is that "as experts, consultants should not look at their clients as potential teachers". ${ }^{794}$ When consultants learn something, it is regarded as the result of their individual abilities. Consequently, the client-consultant interaction is regarded as a “conventional purchase-sale transaction". ${ }^{795}$

See also McGivern/Fineman (1983), p. 436; Schipper (1999), p. 480; Schön (1983), pp. 21-37.

Alvesson/Johansson (2002), p. 230, emphasis added.

Fox (1991), p. 735.

Boland et al. (2001), p. 396.

See Daft/Huber (1987), pp. 5-9; also McGivern/Fineman (1983), p. 435.

See Alvesson/Kärreman (2001), pp. 99-998; Bechky (2003), p. 313; Werr/Stjernberg (2003), pp. 883-884.

See Daft/Huber (1987), pp. 6-8; Boland/Tenkasi (1995), p. 352.

See, e.g., Daft/Huber (1987), p. 9; Lindlof (1988), p. 84; Scott (1994), p. 476; Tilles (1961), p. 89.

See Reihlen/Ringberg (2004), p. 7.

See Daft/Huber (1987), pp. 6-8.

See Boland/Tenkasi (1995), p. 352.

See also Brown/Duguid (2001), p. 201.

See Putnam (1983), p. 39.

Walsh (2001), p. 35.

Tilles (1961), p. 88.
} 
As argued in chapter B.II.4.1.3, a view of knowledge and learning based in the tradition of the positivist school is problematic. First, as Winter notes, "it is decidedly problematic whether realities denoted by such terms as knowledge, competence, skills, know-how, or capability are the sorts of things that can be adequately discussed as items or property". ${ }^{796}$ Although knowledge can be analyzed and understood as an objective reality, in order to understand the process of knowledge creation and transfer one needs to study knowledge in the context within which it is created and applied. Researchers speak, in this connection, about knowledge as "situational, cultural and contextual”, as argued by the interpretivists approach to knowledge. ${ }^{797}$ Bromme and Tillema conclude, "current expert research [] often overlooks the fact that expert activity is mostly professional activity, and that the information processed in its course belongs mainly to the culture of the respective profession”. ${ }^{798}$

Several authors, who study knowledge transfer between individuals with different personal and cultural backgrounds empirically, suggest that the view of knowledge as being independent from the particular context and situation in which it is produced and used, is highly limited and problematic, and prevents clients and consultants from working effectively together. ${ }^{799}$ Empirical research shows that little learning between clients and consultants takes place within expert forms of consulting, ${ }^{800}$ mainly because of the absence of understanding and reflection between the individuals involved. ${ }^{801}$ That a limited interaction between clients and consultants is seen as appropriate is exactly the result of the consulting-centric view of the relationship. "The scoping of the assignment, the planning and conduct of the intervention, and the achievement of the required outcomes are [] largely divorced from the consultant-client relationship."802 Consequently, the expert model ignores the influence of social and contextual factors on individuals and individual cognition. ${ }^{803}$ 
Figure 6 summarizes the assumptions of the expert model regarding the nature of knowledge transfer during consulting projects.

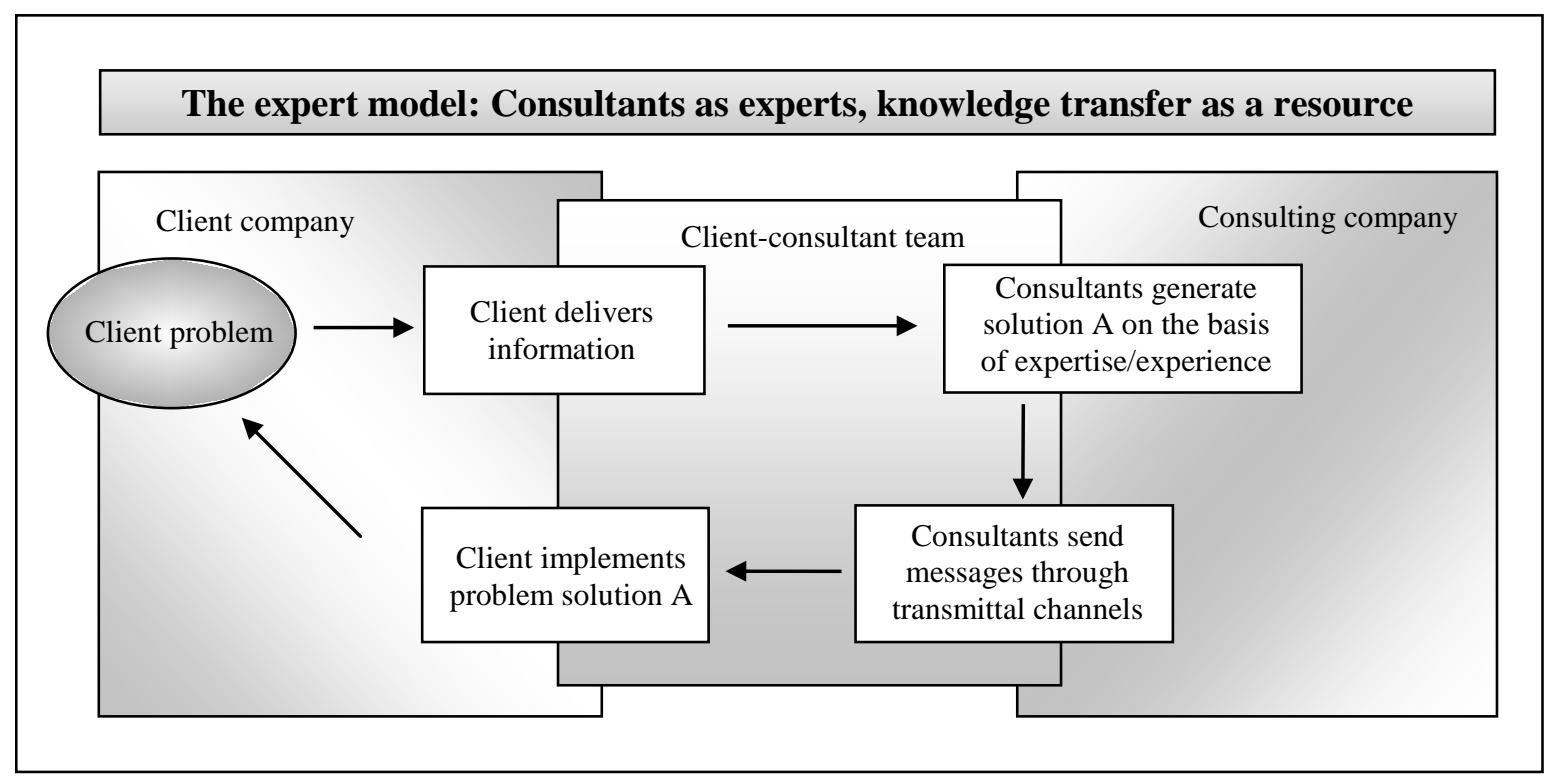

Figure 6: Knowledge transfer as a resource transfer

\section{Nature of power and dependency}

As already argued, supporters of the expert model regard consultants as the powerful actor within the client-consultant relationship, ${ }^{804}$ whereas their power originates in their expertise. ${ }^{805}$ Consultants are seen as the professional experts that can solve clients' problems; they possess the necessary knowledge and experience to deal with management problems. Therefore, they are the dominant actor in the client-consultant relationship.

What is assumed implicitly is that consultants are the legitimated providers of management expertise. Although supporters of the expert model do not explicitly discuss this issue, it is clear that their arguments are grounded in the view of consultants as professionals whose jurisdiction covers the area of management problems. It follows that consultants have power by virtue of their occupational position within the division of labor; their power originates in the structures of expertise, by which the interests of client organizations are dominated.

However, supporters of the model also recognize that clients have some contractual power, power that originates in the economic relation between clients and consultants. ${ }^{806}$ Clients are in control as they have the ability to hire and fire consultants. ${ }^{807}$ Consultants' dependency on clients increases with increasing economic power of clients. Thus, large Sharma (1997), p. 764 and pp. 768-770. See also Alfieri (1994) for the case of lawyers. 
commercial organizations and governments are able to restrict the power of consultants significantly. ${ }^{808}$

This discussion shows that according to the expert model, both consultant's and client's power is based upon the ownership of some kind of a resource: expertise in the case of consultants, financial resources in the form of future projects in the case of the clients. As such, this view of power represents the resource approach to power, which equates power with the possession of certain resources, by virtue of which certain interests and people are dominated. ${ }^{809}$ It represents power as asymmetrical and as a 'zero sum' where consultants gain power at the expense of clients and vice versa. It is a purely individualistic view of power stressing the autonomy of clients and consultants as they choose from among alternative courses of action ${ }^{810}$ without recognizing that these actors are embedded in wider social structures that influence their power relations as well. ${ }^{811}$ For example, it is not recognized that clients often engage consultants or adopt a particular consulting concept in order to gain legitimacy within the broader management environment, where this particular concept might have been institutionalized as a necessary practice to increase the profitability or competitiveness of organizations. ${ }^{812}$ At the same time, consulting companies are also forced to adapt and offer particular consulting services that are seen as "right”, “efficient”, and "rational” by the management environment. Thus, a particular client-consultant relationship is not only the result of the concrete actions of clients and consultants but is also influenced by a number of outside forces.

Additionally, supporters of the expert model do not recognize that a number of different actors are involved in consulting projects. ${ }^{813}$ In particular, the model does not differentiate between the members of the client organization who commission the project, i.e. the client's (top) managers, and the organizational members who are directly involved into the project, i.e. the "problem owners". Garratt points out, however, that this differentiation has a major influence on the understanding of power within clientconsultant teams. ${ }^{814} \mathrm{He}$ describes the situation as follows: "The Client [manager] typically plays a dominating role in the whole project. He brings in the Consultant and briefs him about 'the problem'. The Consultant is then sent to sort it out, often without the Problem-Owners having to say in the formulation of the problem statement". ${ }^{815}$ Figure 7 exemplifies this situation. exclusive right to use or evaluate certain bodies of knowledge and skill. See Freidson (1994), p. 68 and Freidson (2001), p. 128. This view clearly mirrors the sovereign understanding of power. 


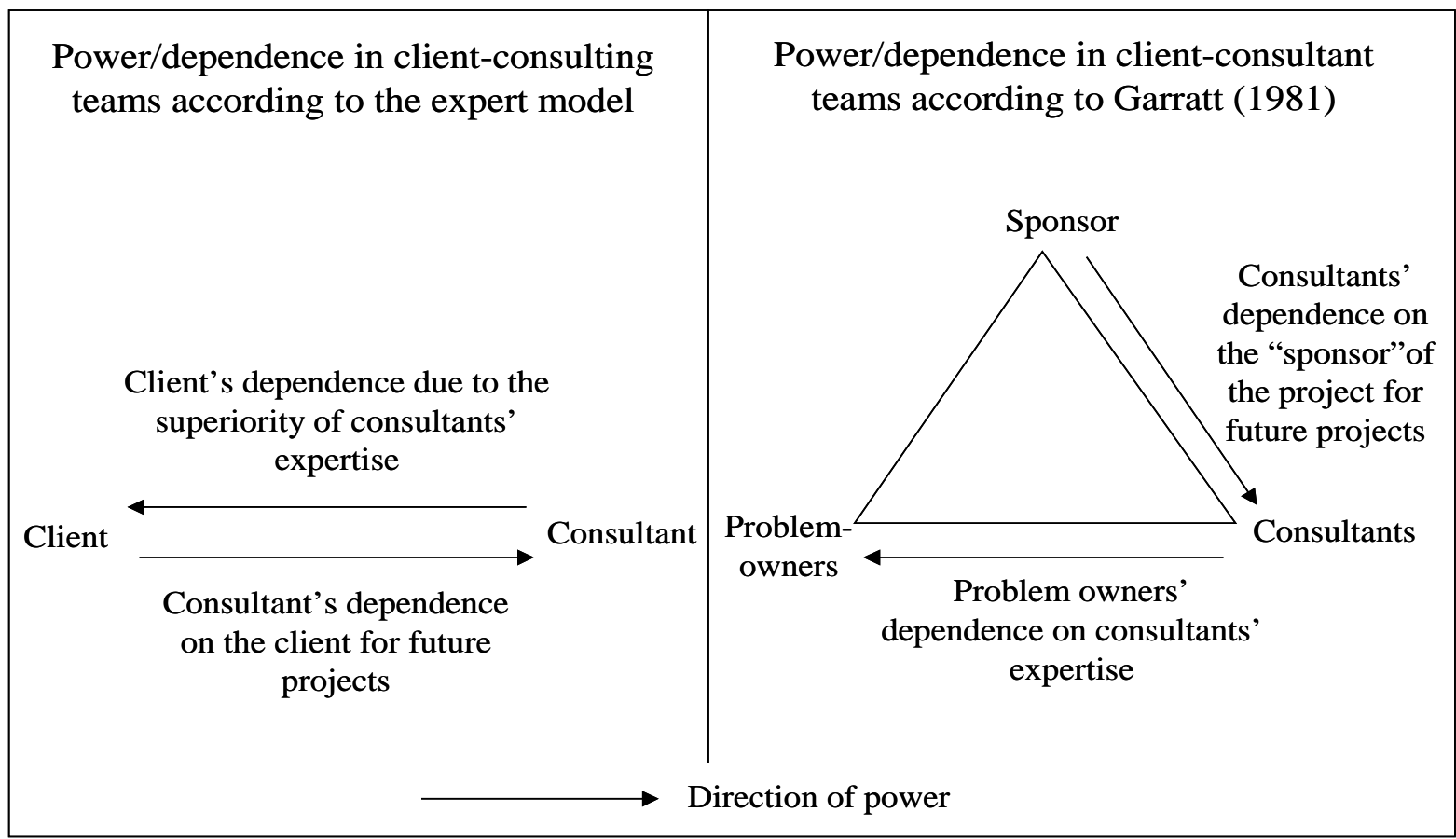

Figure 7: Power/dependence in client-consulting teams

Source: Adapted from Garratt (1981), p. 98.

From this figure, it is clear why the supporters of the expert model offer an ambiguous account of the nature and direction of power within client-consultant teams. Garratt's model shows that the sponsor of the consulting project has an influence over the consultants because s/he decides to employ them or not. According to the expert model, this dependency originates in existing, predetermined market relations and structures between client organizations and consulting companies. Therefore, the possibility that the sponsor might be influenced by wider social structures that "force" him/her to adopt particular consulting methods is not acknowledged. In particular, it is not recognized that consultants in cooperation with other actors in the organizational field of management knowledge "produce" consulting knowledge and "stimulate" and "feed" consumer demand. ${ }^{816}$ The result is the emergence of new management discourses that influence clients and their demand for consultants. ${ }^{817}$

Garratt's model further explains why supporters of the expert model at the same time regard consultants as the dominant actor within client-consultant relationships. The model implies that consultants develop dominance in their relation with the problem owners. This power originates, according to the expert model, in consultants' claim to possess the necessary expertise for solving client's problem. Thus, the model ignores the fact that the problem owners often possess valuable knowledge, which could equalize their relationship with the consultants. The reason why the supporters of the expert model regard the relation between the problem owners and the consultants as dominated by consultants can be traced back to their understanding of the problem-solving process within client-consultant teams. Schön provides a good analysis of this issue. He argues that due to the restricted interaction between clients and consultants during the problem- 
solving process, there is a lack of understanding as to what exactly is the problem and what the client expects from the consultant, which results in increased uncertainty on both sides. $^{818}$ As a consequence, the consultant may "use vagueness in a strategy of mystery and mastery by which he seeks to control his client, and the client can respond in kind with a passive, apparently compliant version of the same strategy". ${ }^{819}$ It has been argued that clients' motivation to cooperate with consultants is especially low when they feel overstrained because they do not know and understand consultant's techniques or tools. ${ }^{820}$ Thus, a lack of understanding leads to a unidirectional dependency on the part of the client. ${ }^{821}$ Because of the absence of real interaction and knowledge transfer, the clientconsultant relationship is not effective and it often ends with frustration on both sides. Moreover, clients feeling marginalized by the dominant behavior of the consultants might try to exert some degree of control by retaining relevant knowledge. ${ }^{822}$ Therefore, in order to regain some power, the problem owners might hold back on transferring important information. Hislop found that the higher the level of the consultant's power and autonomy in the process of problem-solving, the lower would be the scale of customization of the solution. ${ }^{823}$ Thus, clients get less innovative and individualized problem solutions, solutions that tend to formulated and formalized nothingness rather than the specific situational and locally orientated "somethingness" that clients find value in. ${ }^{824}$ McGivern and Fineman conclude that a successful consulting relationship is characterized by a mutual and balanced interdependency between consultant and client rather than a client's dependency. ${ }^{825}$

To summarize, the concept of power as presented within the expert model is unclear and incomplete. By treating power as a resource, which is possessed by one or another party, the model follows the resource view of power. As such, it does not explain the origins of this power, as well the influence of wider social structures on the power relations within client-consultant teams. Furthermore, the model does not recognize that the problem owners possess important knowledge that can be a source of power as well. As such, supporters of the expert model do not acknowledge that power within clientconsultant teams can be contested, unstable, and shifting.

\section{Nature of professional services}

Additionally, the expert model does not explain the nature of professional services in a satisfactory way. It is incomplete, as it says nothing about possible institutionalization processes that are necessary for professions to emerge. ${ }^{826}$ "By linking the development and function of the professions to 'objective' notions of truth, knowledge, and

See Schön (1983), p. 305; also Argyris/Schön (1996), p. 35.

Schön (1983), p. 305.

See Lachman (2000), pp. 619-620.

Similarly, Alfieri argues that the pre-understanding of dependency on the site of law clients "operates to marginalize, subordinate, and discipline” them. See Alfieri (1994), p. 1758.

See Coopey/Burgoyne (2000), p. 877; also Lane (1994), p. 89.

See Hislop (2002), p. 667.

See Ritzer (2004), pp. 1-10.

See McGivern/Fineman (1983), pp. 435-436.

See Dietrich/Roberts (1997), p. 22. 
rationalisation, functionalist analysis presents a universalist and a historical account of the professions". ${ }^{827}$ The notion of consulting knowledge as objective and true should be seen rather as an attempt to connect it to modernist values of rationality ${ }^{828}$ and to legitimize it, as such, in the eyes of clients and the wider society. Some authors even argue that the claim that consultants as professionals apply rational, scientific knowledge and act rationally, only serve the mystification of their expertise: "close association with knowledge/science does not make human actors themselves scientific or rational: the focus on knowledge-rationality-predictability of outcome distracts from the more important qualities of skill, creativity, judgement, and savoir faire, and the constructive response to the uncertain and unprogrammable". ${ }^{829}$ These authors emphasize that skills such as listening, bargaining, presenting, persuading, and innovating are at the heart of consulting as a profession. Additionally, the expert view of professional knowledge ignores the connection between professions and power. ${ }^{830}$

\section{Practical relevance}

As already discussed, when applied in practice, such views of knowledge prevent clients and consultants from working intensively together. As a result, consultants tend to over-generalize their methods and solutions, and to ignore context-specific variables, which means that clients get solutions that have worked elsewhere but are unlikely to provide unique advantages. At worst, consulting interventions of such type can undermine any inherent competitive advantage that a client organization may have developed. ${ }^{831}$

As previously argued, the problem-solving process, as proposed in the expert model, can be seen as appropriate only in the case of simple routine problems, which are previously known to the problem solvers and are well defined. "It depends on agreement about ends. When ends are fixed and clear, then the decision to act can present itself as an instrumental problem. But when ends are confused and conflicting, there is as yet no 'problem' to solve". ${ }^{832}$ Schön points out that the main characteristic of new and complex problems is the uncertainty about the nature of the problem. Such "puzzling, troubling, and uncertain" situations often fall outside categories of existing knowledge or existing systems of diagnosis, treatment, and prognosis so that problem solvers need first to find out and define the problem they have to deal with. ${ }^{833}$ Thus, it is highly problematic to apply the expert model of consulting in other types of problem contexts. 
Another major problem of the expert model, which is connected to the previous point, is that the model assumes that problems are an objective reality, which is observed and understood in the same way by all who are involved in a problem-solving process. ${ }^{834}$ Thus, while consultants can interpret a particular client problem as a routine one, it is possible that there are characteristics of the problem that consultants do not see or are not able to see without engaging in an intensive interaction with the client. In this case, the client-consultant interaction is not an error-free process of information exchange but rather a "reflexive", "non-technical" process of problem naming and framing. ${ }^{835}$ As a result, several divergent, legitimate perspectives on the problem situation and solution will emerge. This is stressed by Schön who argues that there are "conflicting paradigms of professional practice", a "contention over multiple ways of framing the practice role, each of which entrains a distinctive approach to problem setting and solving" ${ }^{836}$ rather than a one-best way of solving problems. The expert model downplays, however, this relative pluralism of knowledge and, in particular, the importance, and legitimacy of client's knowledge. Therefore, the expert model concentrates exclusively on problemsolving without giving recognition to the importance of problem setting. ${ }^{837}$ Its assumption about the existence of problem solutions, which are always true and as such, more or less standardized, is highly problematic. This is in line with the Fincham and Roslender's findings, which argues that some popular management concepts and models "may have become conventional, relatively commodified methods and adoption is pretty much a 'take it or leave it' choice; others are more diffuse and require interpretation and customizing by mediating and user agents". ${ }^{838}$

Furthermore, even in cases of simple routine problems, the expert model does not sufficiently explain the following questions: Given the rather intangible character of consulting services, ${ }^{839}$ how do consultants persuade clients that they are the experts for particular types of problems? How do they enforce and legitimize their problem solutions and expertise implying that they as experts know the best solution so that clients can trust them to solve the problem almost independently? It has been shown that reputation is a major mechanism for creating such trust. ${ }^{840}$ However, it is still unclear how is this reputation built. These questions are related to the micro processes of knowledge creation, production and dissemination and require considerations of power. Whereas these processes have been discussed on a macro level, ${ }^{841}$ they are still poorly understood on a micro level, especially when involving clients. ${ }^{842}$ As it will be shown, the 'interpretive' model of the client-consultant interaction concentrates on the micro

834

835

836

837

838

This was already discussed in chapter B.II.3.1.1.

See Schön (1983), p. 42.

Ibid, p. 41.

See also Nonaka (1994), pp. 15-16.

Fincham/Roslender (2004), p. 323.

See e.g., Kubr (1996), pp. 487-488; Lowendahl (1997), pp. 32-35; Müller-Stewens et al. (1999), p. 21; Ritsema et al. (1992), pp. 25-26.

See, e.g., Glückler/Armbrüster (2003).

See, e.g., Suddaby/Greenwood (2001).

Ibid, pp. 939-940. 
processes of knowledge creation, production, and dissemination that take place within client-consultant teams and advances, as such, the expert model.

\section{Modifications of the model}

Some of the supporters of the expert model recognize, in line with the critics on professionalism, that the traditional model on consulting has shortcomings and suggest a more interaction intensive consulting model where the problem-solving process is presented as a joint diagnosis ${ }^{843}$ or a learning process. ${ }^{844}$ Schein, for example, realizes that clients should have a more active role in the client-consultant relationship because only they have access to "hidden cultural, political, and personal factors", which are important for the problem-solving process. ${ }^{845}$ Similarly, Schaffer suggests the concept of the "high impact consulting", main idea of which is that consultants need to assist their clients more effectively during the implementation phase of consulting projects ${ }^{846}$ Moreover, "one of the easiest shifts a conventional consulting firm can make toward high-impact consulting is to face up to the need to learn about each client organization, to learn from each group of clients, and to value relationships with the clients' people". ${ }^{847}$

A major idea of this so-called process-consulting is that the consultants' main role is to teach their clients to release their human potential and as such, the potential to solve organizational problems themselves through self-discovery, self-actualization and selfenrichment. ${ }^{848}$ In other words, the consultant does not transfer any specific expertise to the client's organization but only helps clients to realize their own potential to solve problems. ${ }^{849}$ Thus, whereas the "expert consultant" suggests to the client what to change, the "process consultant" suggests mainly how to change, and "helps the client to go through the change process and deal with human problems as they arise" ${ }^{850}$ This view obviously puts an emphasis on the relationship between the problem-owners and the consultants. Implicit in this model is the assumption that clients and consultants share the responsibility for the insights obtained and actions planned; that they both remain in power. $^{851}$

Although these contributions recognize that it is important for clients and consultants to work intensively together and to maintain a balanced relationship, they still regard consultants as the experts and the supreme actors who are there to transfer their diagnostic and intervention skills to clients (but not any technical expertise), ${ }^{852}$ and help

Kubr (1996), p. 58. This separation between expert consulting, which main function is to transfer some specific knowledge into the client system with the task of problem-solving, and process consulting, which concentrates on training clients to solve their problems themselves, is still very popular in the consulting literature. See, e.g., Wimmer (2004), p. 254. 
them "by forcing” or "benignly manipulating” them into starting to work on their own problem. ${ }^{853}$ Schaffer, for example, argues, "the more consultants learn about how their relationship with the client is developing and how the client really operates, the more powerful their contributions will be." ${ }^{854}$ Lippitt and Lippitt define the consultant as an "objective reflector/observer" even when they argue that one of the roles of the consultant is to stimulate the client toward some insight in a nondirective way. ${ }^{855}$ All these suggestions are, in the tradition of the expert model, prescriptive in nature, focusing on how to improve consultants' efforts. ${ }^{856}$ Even more recent and advanced texts on consulting, such as Fombrun and Nevins' compilation, remain by the view of clients as an audience that is separated from the consultants. For example, according to Nevins, consultants are responsible to "build a bridge" between their knowledge and that of the client. ${ }^{857}$ The client's role is represented as one of a passive listener. Consultants are the active actors that teach clients how to solve their problems.

Others criticize this view of consulting because it ignores that consultants can offer to their clients valuable specialized knowledge that clients do not possess. In other words, the process-consulting model implies that clients and consultants do not differ regarding their technical knowledge; by emphasizing consultant's process skills it implies that clients and consultants share the same understanding and knowledge and that there is no value in any transfer of technical, specialized knowledge during consulting projects. ${ }^{858}$ Consequently, consultants are seen as trainers, and lose their particular identity as a different group of professionals. ${ }^{859}$ In contrast, as argued later, clients and consultants have more often than not different perspectives and knowledge regarding the same topic so that they can greatly profit from sharing these interpretations with each other. ${ }^{860}$ Thus, as Wimmer states, neither consultants with specialized knowledge who lack process skills, nor process consultants without any specialized knowledge, can survive in the current competitive consulting market. ${ }^{861}$ In other words, a separation between "mere" expert consulting and process consulting is no longer viable in the practice of consulting.

There are, additionally, three other critical aspects of the modified view of consulting. First, it is grounded in the assumption of political harmony, in the belief that neutral consultants facilitate shared understanding and commitments without recognizing that consulting as a communicative activity does not simply represent a particular issue, but more or less influences and constructs it. ${ }^{862}$ Thus, power and politics tend to be downplayed by these authors. Second, their suggestions are, as Garratt points out, not

Schein (1987), p. 83.

Schaffer (2002), p. 137.

Lippitt/Lippitt (1978), p. 40, emphasis added.

See Buono (2001), p. viii.

See Nevins (2004), pp. 114-116. Nevins argues, for example, “your audience is primarily concerned with the story you are telling - they are curious to know where you are taking them and how they will get there”. Nevins (2004), p. 116.

See Iding (2000), pp. 181-183.

Ibid, p. 182 and p. 188.

See the discussion in chapter D.III.3. See also Iding (2000), p. 183.

See Wimmer (2004), p. 254.

See Alvesson/Johansson (2002), p. 237; Marshak et al. (2000), pp. 246-247. See also Idling who argues that only because consultants are external to the client organization does not mean that they are neutral. Idling (2000), p. 80. 
sensitive towards other cultural environments, especially in the case of countries where the notion of self is much less important. ${ }^{863}$ Third, although supporters of this view often have a psychological background, they do not discuss sufficiently the theoretical background of their suggestions. Thus, these writings stay vague and too unspecific in their recommendations, and deliver, consequently, only a slightly different view of the client-consultant interaction. Schön concludes referring to Schein, one of the first authors to put this different emphasis on consulting, stating that his writings preserve the traditional consulting model. ${ }^{864}$

\section{Summary}

The expert model seems to provide a consulting business model that fits well the case of simple routine problems when the efficiency of the problem-solving process is regarded as the main success factor rather than its innovativeness. ${ }^{865}$ It implies that clients can rely, under circumstances, on consultants' reputation for being experts in solving particular problems and thus do not need to engage in time, effort, and resources-intensive discussions with the consultants. In such cases, the problem-solving process has the characteristics of a buying process: clients buy more or less standardized solutions from consultants rather than to jointly create them with the consultants. Consultants possess the authority and power to decide upon problem solutions. Even in cases where the sponsors of the project describe exactly what results they expect, and in doing so they limit consultant's power, consultants still have total autonomy and a free hand during the problem-solving process. Apart from such routine situations, the prescriptions of the expert model of consulting are highly problematic for several reasons, as discussed above. As chapter B.II.3.3 outlined, most of the problems that consultants are engaged to deal with are either complex routine problems or innovative problems. The use of the expert model of consulting in such cases does not lead to successful results and is one possible explanation for the growing dissatisfaction of clients with consulting services. ${ }^{866}$

However, it is important to note that although the expert model shows some limited applicability and relevance for the practice of consulting, its theoretical assumptions are highly problematic. Thus, it is wrong to conclude that the model has some, although limited, explanatory power of real-life client-consultant interactions. Rather, as within the later proposed interpretive model, some of the insights of the expert model are legitimate when considering the consulting practice but they can be developed from a different theoretical background. This argument is developed further in chapter D.VI.

863 See Garratt (1981), p. 99. For example, in countries with rather collectivist type of culture, if using Hofstede’s model, the notion of processes such as self-actualisation and self-discovery will be regarded rather suspiciously. See, e.g., Hofstede (1983).

864 See Schön (1983), pp. 47-48. Interestingly, in a newer version of his work on process consultation, Schein argues that double-loop learning is the theoretical background of the process consultation model. See Schein (1999), p. 19. The notion of double loop learning was introduced by Schön and Argyris and represents the basis for Schön's suggestion for professionals to adopt a different consulting model, called the reflective practitioner model. See chapter C.III for an extensive discussion of this model. Thus, it can be speculated that in his later work, Schein acknowledges some of the critical points raised against his work. Therefore, Schein's latest work on process consultation cannot be clearly subsumed under the expert model. 
In the following, a different model of consulting as proposed by Donald Schön is presented, which was developed because of the rising dissatisfaction of clients with the prevalent (expert) model of consulting.

\section{The reflective practitioner model}

\section{Introduction}

Schön developed the reflective practitioner model of consulting as a response to the growing criticism of the expert model. ${ }^{867}$ His concern was primarily with the question: how should clients and consultants interact in the case of novel and complex problems, that are the most typical type of professional problems, in order to generate the best possible problem solutions? Schön suggests viewing the client-consultant interaction as a reflective conversation between the involved individuals. He argues that consultants are engaged in a process of reflection on their knowledge during problem-solving in order to account for the context dependency of their knowledge, to explore their assumptions and interpretations, and to share them with the client. These actions are at the heart of his view of consulting. However, Schön emphasizes that consultants seldom reflect on the process of reflection. In other words, consultants do not discuss the contextual nature of their knowledge. They rather articulate it to others as an "intuitive thinking”. As a result, the nature of their expertise often remains private and inaccessible to others. Schön proposes that such a mysteriousness of the art of consulting has several harmful consequences, ${ }^{868}$ one of which is the growing criticism of consulting and consulting "expertise" as being unclear, ambiguous and of no real value for clients. ${ }^{869}$ Therefore, one of Schön's goals is to contribute towards the demystification of consultant's expertise.

\section{Context}

Schön developed his model as a result of the loss of confidence regarding both the ability of professionals to contribute to problem-solving and the superiority of their knowledge. This crisis of confidence in professions was the result of a number of scandals-when highly esteemed professionals misused their autonomy for private gain-and failures of professional action-when professionally designed solutions to public problems had unanticipated negative consequences. ${ }^{870}$ Schön further states, that additionally, there has been a deeper questioning of the professional's claim to extraordinary knowledge.

867

See Schön $(1983,1987)$. He is not the only one who recognized the shortcomings of the expert model on consulting and suggested a different model. Other authors developed similar concepts. See, e.g., Argyris (1970); McGivern (1983); as well as Lilja/Poulefelt (2001); Schein (1999), Walsh (2001) for more recent examples. Argyris and Schön worked together on a new approach called action research, so that Schön's reflective practitioner model (1983, 1987) has its origin in action research. Because Schön's approach is the most comprehensive of all, and the one that introduces a clearly distinctive type of consulting, his work is chosen as basis for the presentation of a second type of consulting. A summary of the main assumptions of similar approaches can be found in McGivern and Fineman who, however, do not discuss the topic extensively. See McGivern/Fineman (1983).

See the discussion within the critical model on consulting in chapter C.IV. 
Consequently, "in the period between 1963 and 1981, the expression of lagging understandings, unsuitable remedies, and professional dilemmas has become the norm". ${ }^{871}$ The main reason for the critic of professional knowledge is seen in its mismatch "to the changing character of the situations of practice-the complexity, uncertainty, instability, uniqueness, and value conflicts which are increasingly perceived as central to the world of professional practice". ${ }^{872}$ Thus, " the situations of practice are not problems to be solved [as seen in the expert model] but problematic situations characterized by uncertainty, disorder, and indeterminacy”. ${ }^{873}$

Introducing a different concept of what professionals do and the nature of their expertise, Schön suggests a way to overcome this crisis, and thus a new view of professionalism and professional services. He argues that complexity, instability, and uncertainty are not removed or resolved by applying specialized knowledge to welldefined tasks, as suggested in the expert model. ${ }^{874}$ Rather, professionals work in a different way by reflecting in action.

Schön does not explicitly discuss the theoretical background behind his understanding of the nature of reflection-in-action. Rather, he argues that his model is the result of a close examination of what some practitioners, such as consultants, actually do. ${ }^{875}$ Thereby, he uses empirical examples of the interaction between senior and junior practitioners. On this basis, Schön develops implications for the relationship between practitioners and their clients. A close look at his main ideas, such as reflection-in-action and meaning construction, and at the research he builds upon, implies, however, that his work can be related to an approach called action science, also associated with Chris Argyris. ${ }^{876}$ Action science itself shows some similarities to interpretivism in its emphasis on questioning taken-for-granted assumptions. ${ }^{877}$

\section{Cultural relations}

\subsection{Nature of knowledge}

Schön's conception of professionals and professional services is based on the assumption that the nature of their work is what differentiates them from other occupations and services. As a result, his understanding of consulting and the client-consultant relationship is centered on the question regarding the nature of consulting knowledge with emphasis on two types of consulting expertise-knowing-in-action and reflectionin-action.

873 Ibid, p. 15-16. Schön argues that exactly the awareness of uncertainty, complexity, instability, uniqueness, and value conflict led to the emergence of professional pluralism, i.e. to the awareness of the existence of different views between different communities within the professions and the fostering of these differences. See Schön (1983), p. 19.

Ibid, p. viii.

876 See, e.g., Argyris/Schön (1996).

877 In fact, some of the works that Schön uses when developing his ideas are seen by others as interpretivist (e.g., Chomsky, and Kuhn).
} 
The starting point of Schön's arguments regarding the nature of knowledge is the realization that knowing is "in our action" 878 and that skillful action often reveals, "a knowing more than we can say" ${ }^{879}$ Accordingly, the main characteristics of such tacit knowledge include the spontaneous application of tacit knowledge without having to think about it, the unawareness of having learned to do things, and the inability to describe this type of knowledge. ${ }^{880}$ Thus, knowing-in-action is knowledge that is based on tacit rules and procedures. It is routinely applicable when solving familiar problems.

When individuals start thinking not only about their action but also about the underlying knowledge of these actions, they engage in a reflective activity. Raelin defines reflection as the ability to uncover and make explicit to oneself what has been planned, observed, or achieved, "hence it is concerned with the reconstruction of meaning" ${ }^{881}$ Through reflection, people can make clear and criticize previous understandings and can make new sense of situations of uncertainty or uniqueness. ${ }^{882}$ Thereby, reflection usually focuses on three levels: ${ }^{883}$ (1) the outcomes of action, also referred to as "content reflection", which entails a review of the way one has consciously applied ideas in strategizing and implementing each phase of solving a problem; (2) the action itself or "process reflecting" - the examination of how one goes about problem-solving including the procedures and assumptions in use; and (3) the intuitive knowing implicit in the action, also called "premise reflection", which is the questioning of the very presuppositions attending to the problem.

Schön's main argument is that consultants, like other professionals in general, do reflect on their knowing-in-action, also called "knowing-in-practice": "sometimes [] they think back on a project they have undertaken, a situation they have lived through, and they explore the understandings they have brought to their handling of the case. They may do this in a mood of idle speculation, or in a deliberate effort to prepare themselves for future cases". ${ }^{884}$ However, they also reflect on their practice and actions while they are in the midst of it, engaging in reflection-in-action. Reflection-in-action is central to the "art" through which consultants cope with unfamiliar situations where there is no obvious fit between the characteristics of the situation and the available body of theories and techniques. In such situations, consultants may surface and criticize their initial understanding of the issue at hand, construct a new description of it, and test the new description by an on-the-spot experiment, which Schön calls a "frame experiment". ${ }^{885}$ In this way, new rules and new knowledge are created through reflection-in-action. ${ }^{886}$ Schön summarizes the process of reflecting in action as follows:

878

879

880

881

882

Schön (1983), p. 49, emphasis in the original.

Schön (1983), p. 51.

Ibid, p. 54.

Raelin (1997), p. 567.

See Schön (1983), pp. 55-69. Reflection is concerned with double-loop and triple-loop forms of learning. See Argyris/Schön (1996), pp. 1-46; also Raelin (2001), p. 12.

See Schön (1983), p. 56 and Raelin (2001), p. 12.

See Schön (1983), p. 61.

Schön (1983), p. 63.

Ibid, pp. 62-69; also Schön (1987). 
"When someone reflects-in-action, he becomes a researcher in the practice context. He is not dependent on the categories of established theory and technique, but constructs a new theory of the unique case. His inquiry is not limited to a deliberation about means which depends on a prior agreement about ends. He does not keep means and ends separate, but defines them interactively as he frames a problematic situation. He does not separate thinking from doing, ratiocinating his way to a decision which he must later convert to action. Because his experimenting is a kind of action, implementation is built into his inquiry. Thus reflection-in-action can proceed, even in situations of uncertainty and uniqueness, because it is not bound by the dichotomies of Technical Rationality". ${ }^{887}$

Schön points out that the ability of consultants to reflect in action is not generally accepted by supporters of the prevalent expert model, and as a result, even practitioners do not see it as a legitimate form of professional thinking. Nevertheless, he states that for some professionals, it is the core of their practice. ${ }^{888}$

Schön emphasizes that both knowing-in-action and reflection-in-action are "embedded in the socially and institutionally structured context shared by a community of practitioners", 889 whereas under context he understands the body of professional knowledge and the appreciative system and frames of a particular community of practice. ${ }^{890}$ Furthermore, he emphasizes that consulting knowledge is "constructed" as a result of individual actions embedded in this context: through "countless acts of attention and inattention, naming, sense making, boundary setting, and control” community members make and maintain the world matched to their professional knowledge, appreciative systems and role frames. They have, in short, a particular, professional way of seeing their world and a way of constructing and maintaining the world as they see it”. ${ }^{891}$ It follows, that consulting in particular, and professional knowledge in general, represents just one way of looking at topics, one possible interpretation of problems. "Each view of professional practice represents a way of functioning in situations of indeterminacy and value conflict, but the multiplicity of conflicting views poses a predicament for the practitioner who must choose among multiple approaches to practice or devise his own way of combining them.” ${ }^{892}$ Thus, Schön recognizes that consultants as reflective practitioners should be aware that their expertise is a way of looking at topics that can be reconstructed during their interactions with the client. He argues, "depending on our disciplinary backgrounds, organizational roles, past histories, interests, and political/economic perspectives, we frame problematic situations in different ways". 893 He does not consider problems as "given" as in the case of the expert model, but rather

\footnotetext{
887 Schön (1983), pp. 68-69.

888 Ibid, p. 69.

889 Schön (1987), p. 33.

890 He does not discuss, however, the exact nature of the appreciative system and frames, as well as the processes through which such frames can be transferred. See for a detailed discussion of these topics chapter D.III.1.2. 
has a constructionist view of reality and stresses that problems need to be set and formulated jointly by client and consultant. Consultants have to make sure that their interpretation is accessible to the client and they understand the client as well. It follows from this that individuals from different communities interpret situations in different ways. Consequently, clients and consultants will usually have different perspectives on problems and problem solutions and successful problem-solving requires both their knowledge.

\subsection{Knowledge transfer and creation}

\section{Knowledge transfer}

Because "both client and professional bring to their encounter a body of understandings which they can only very partially communicate to one another and much of which they cannot describe to themselves", ${ }^{894}$ the communication between members of the client-consultant team is very difficult and requires intensive interaction. Schön sees the solution as an open and minimally defensive interaction, as a reflective conversation where both client and consultant commit to have their positions and interpretations confronted and tested and both are open to the reciprocal exploration of risky ideas. Consultants have to make their understandings accessible to the client; in other words, they have to be ready and competent to explore their perspectives in the experience of the client and to reflect anew on what they know. ${ }^{895}$ It is a process of reflection on the own reflection-in-action, which is necessary to make sure that communication and knowledge transfer will occur.

Schön points out that clients in particular have to be involved to a much higher degree in the problem-solving process; in essence, they have to function as reflective practitioners as well. Without the exchange of perspectives, consultant's expertise will remain a black box for the client. Therefore, clients must be willing to engage in communication processes and the exchange of meanings: they should "develop a new kind of skill in asking questions" 896 and "cultivate competence in reflective conversation with the professional". ${ }^{897}$ Thus, "the behavioral world is an artifact which professional and client jointly create". 898

\section{Knowledge creation}

When discussing knowledge creation, Schön points out that the clients role is to make their understanding of the situation accessible to the consultants. However, in his view, clients are not directly involved in knowledge creation. ${ }^{899}$ Thus, the consultants role is to reflect upon their interpretation of the problem in front of the clients and to "help the client understand the meaning of the professional's advice and the rationale for his

\begin{tabular}{ll}
\hline 894 & Schön (1983), p. 296. \\
895 & Ibid, p. 296. \\
896 & Ibid, p. 301. \\
897 & Ibid, p. 302. \\
898 & Ibid, p. 303. \\
899 & Ibid, pp. 295-297
\end{tabular}


actions" ${ }^{900}$ without involving the clients in a creative team performance. Furthermore, because Schön regards knowledge creation as an art and an action that even consultants do not often reflect upon, his description of the process remains quite unspecific. He acknowledges that when consultants have to deal with a new and unfamiliar situation, they do not try to apply a standardized solution but seek to discover the particular features of the problem. In his words, knowledge creation is the "reflective conversation [of a practitioner] with a unique and uncertain situation", ${ }^{901}$ a process which he describes as follows.

Based on a "repertoire of story types, interpretive explanations, examples, images and actions", consultants focus on certain details while leaving others in the background, thus framing the problem in a particular way. ${ }^{902}$ It is to "see the unfamiliar, unique situation as both similar to and different from the familiar one, without at first being able to say similar or different with respect to what. [] The familiar situation functions as a precedent, or a metaphor, an exemplar for the unfamiliar one." 903 This enables consultants to bring their experience to bear on the unique case through conducting an experiment to discover what consequences and implications follow from the situation their knowledge frames. Through a "web of moves, discovered consequences, implications, appreciations, and further moves" consultants try to adapt the situation to their frame. ${ }^{904}$ Most likely, these moves will also produce unintended changes into the situation, introducing new meanings. "The situation talks back, the practitioners listens, and as he appreciates what he hears, he reframes the situation once again." ${ }^{005}$ Thus, the "phenomena that he seeks to understand are partly of his own making; he is in the situation that he seeks to understand." ${ }^{906}$ In this way, consultants yield new discoveries, which require new reflection-in-action. "The process spirals through stages of appreciation, action, and reappreciation." ${ }^{907}$ As a result, consultants build gradually from their perception of the client's problem towards an interpretive synthesis congruent with their fundamental values and theories.

In this process, consultants are guided by four criteria: "whether they can solve the problem they have set; whether they value what they get when they solve it; whether they achieve in the situation a coherence of artifact and idea, a congruence with their fundamental theories and values; whether they can keep inquiry moving." ${ }^{908}$ In other words, there is not an anything-goes-logic behind this process; rather, affirmation is the logic that sets the boundaries of "experimental rigor". The inquirer as the interpreter of the problem has to take responsibility for the order s/he imposes. "Hence, he must adopt a kind of double vision. He must act in accordance with the view he has adopted, but he

\begin{tabular}{ll}
\hline 900 & Ibid, p. 297. \\
901 & Schön (1983), p. 130. \\
902 & Ibid, p. 125. \\
903 & Ibid, p. 138. \\
904 & Ibid, p. 131. \\
905 & Schön (1983), p. 131-132. \\
906 & Ibid, p. 151, emphasis in the original. \\
907 & Ibid, p. 132. \\
908 & Ibid, p. 141.
\end{tabular}


must recognize that he can always break it open later, indeed, must break it open later in order to make new sense of his transaction with the situation." 909

Schön makes it clear that this process of inquiry or knowledge creation is radically different from the one in the expert model. The reflective practitioner constructs the problematic situation, and identifies both the ends to be sought and the means to be employed. Therefore, "problem solving is a part of the larger experiment in problem setting". ${ }^{910}$ It is an "artistic performance". ${ }^{911}$ Furthermore, the knowledge that consultants produce is objective, in the sense that they can disconfirm it, but it is also personal, bounded by their commitment to the context of the decision. "It is compelling only to members of a community of inquiry who share these commitments." 912

Figure 8 summarizes Schön's view of knowledge transfer and creation in consulting projects.

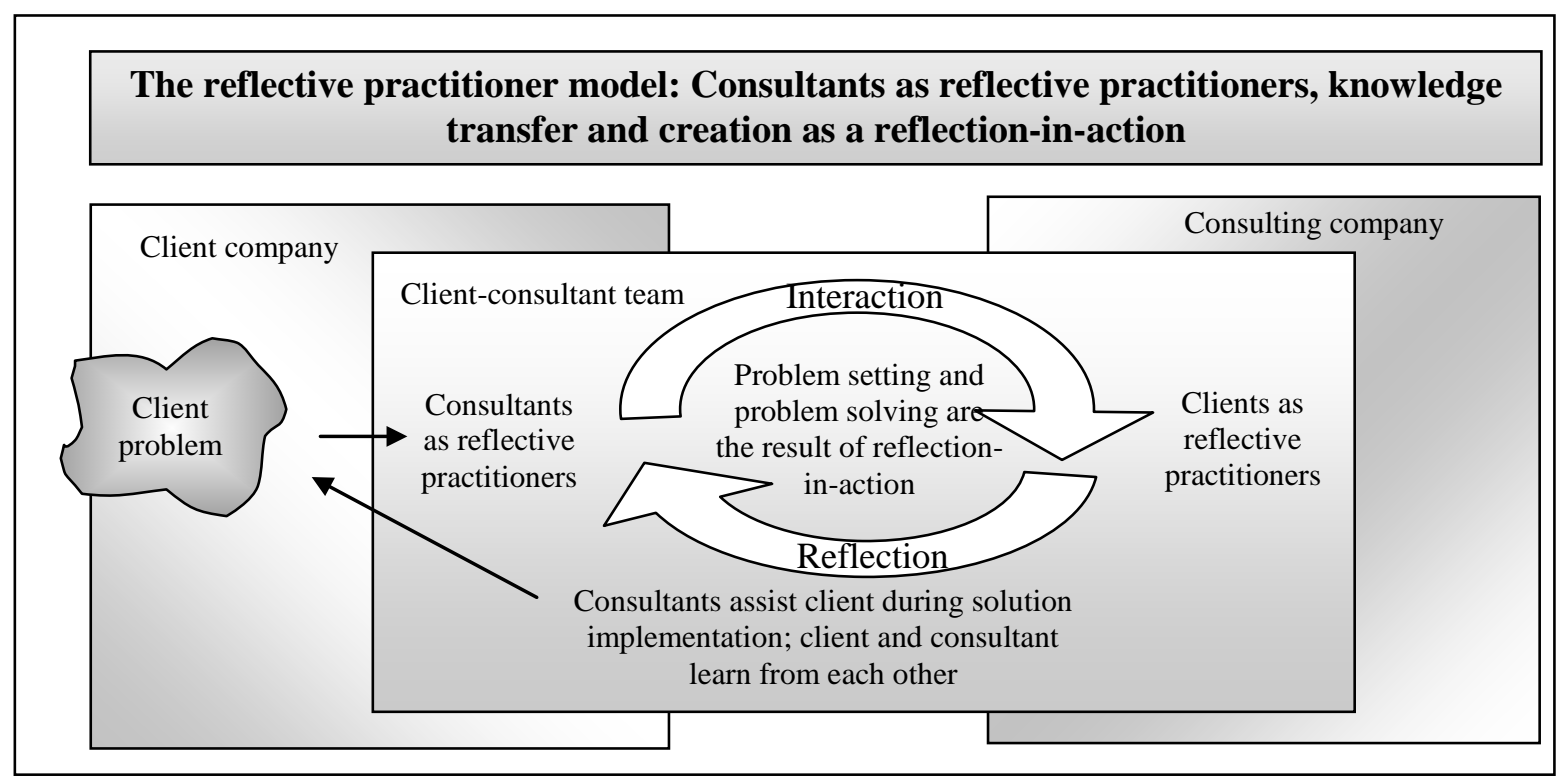

Figure 8: Knowledge transfer and creation as a reflection

\section{Power relations}

In this model, the relationship between client and consultant is more balanced and is based on the demystification of expertise and on mutual exploration. Schön views both consultants and clients as powerful and interdependent. ${ }^{913}$ Their power arises from the fact that both parties make valuable contributions to the problem-solving process. Consultants need client's cooperation for defining the nature of the problem, and for studying and resolving associated problems. Thus, they accept that the client knows most about the problem, so that an outsider, i.e. a consultant, cannot control or direct so much: “...the choices are not imposed upon the client but [] arise out of the stages through 
which the (joint) experience evolves; and the next stages are contingent upon both parties agreeing on the following objectives." ${ }^{914}$ Consultants are now expected to reflect on their expertise, in the presence of clients, thus making themselves confrontable by their clients, rather than keeping their expertise private and mysterious, which is the case in the expert model. ${ }^{915}$ By abdicating their unquestioned authority and the comfort of relative invulnerability, they gain access to a new type of interaction, one of discovery and selfreflection. On the other side of the relationship, clients agree to join the consultant in the problem-solving process and to work to make their knowledge and experience clear to themselves and to the consultants. Furthermore, they agree to confront the consultant when they do not understand or agree, and to make public their questions over what should be counted as effectiveness. The relationship becomes equilibrated as both parties give and receive help. It is clear that both client and consultant are responsible for reshaping the norms and expectations that the other party brings to the relationship. ${ }^{916}$

\section{Nature of professional business services}

In putting consulting practice and knowledge in the centre of his arguments, Schön implicitly follows the work-related approach to professionalism. ${ }^{917}$ He regards the ability of professionals to reflect on their knowledge and reflect in the midst of practice as their major characteristics. When consultants encounter certain types of problems repeatedly, their work becomes increasingly tacit, spontaneous, and automatic. When, however, they have to deal with divergent situations of practice, reflection-in-action is central to the "art" through which practitioners solve such problems. Therefore, Schön develops an epistemology of practice, which places "technical problem-solving within a broader context of reflective inquiry, shows how reflection-in-action may be rigorous in its own right, and links the art of practice in uncertainty and uniqueness to the scientist's art of research."918

The reflective practitioner model emphasizes, furthermore, that professional knowledge is embedded in "evaluative frames" and is limited by "situations of uncertainty, instability, uniqueness and conflict". ${ }^{919}$ Schön concludes that there is a need for some social constraints on professional freedom; and that "the idea of reflective practice leads to a vision of professionals as agents of society's reflective conversation with its situation, agents who engage in cooperative inquiry within a framework of institutionalized contention”. ${ }^{920}$

\footnotetext{
914 McGivern (1983), p. 435.

915 See Schön (1983), pp. 296-297.

916 Ibid, p. 303.

917 See chapter B.I.1.4.

918 Schön (1983), p. 69, emphasis added.

919 Ibid, p. 345.

$920 \quad$ Ibid, p. 353.
} 


\section{Attributes of clients and consultants}

Schön recognizes that both clients and consultants have to function as reflective practitioners. This implies, on the one hand, that clients should "develop a new kind of skill in asking questions" and "cultivate competence in reflective conversation with the professional", ${ }^{221}$ and, on the other hand, that consultants have to be ready and competent to explore their perspectives in the experience of the client and to reflect anew on what they know. ${ }^{922}$ Additionally, both of them must be willing to engage in intensive communication processes and the exchange of meanings. ${ }^{923}$

Accordingly, reflection-in-action is the major attribute that clients and consultants need to develop in order to work effectively together. As already discussed, reflection in or on action involves the questioning of old beliefs and assumptions, the ability to have an open and vivid conversation with others, the development of awareness of how one's own actions create the systemic structures that produce one's problems, to unlearn old ways of doing things, and to let go of old habits. ${ }^{924}$ Additionally, clients and consultants must have the ability to undertake an open inquiry where individuals openly share their views and develop knowledge about each other's assumptions. This ability presupposes an inquisitive, nonjudgmental attitude towards others' viewpoints as well as towards group phenomena; it requires activities such as "inviting questions and comments, considering one's own positions as hypotheses to be tested, acknowledging expressions of vulnerability by others". ${ }^{925}$ As such, Schön implicitly stresses the role of creativity as well as an intuitive cognitive style for both clients and consultants. However, his notion of professionals following strict rules and procedures when creating new knowledge ${ }^{926}$ also implies that he regards logical and formal problem-solving abilities as important consulting skills.

To question one's own often deeply embraced assumptions and habits and to engage in an open interaction takes time and practice and can be extremely challenging. Thus, Schön argues, motivation to engage in such activities is crucial for the type of clientconsultant relationships he proposes. ${ }^{927}$ Additionally, he recognizes that interactive skills are also necessary for the development of the ability to reflect-in-action: "skills in the manipulation of media, languages, and repertoires are essential to a practitioner's reflective conversation with his situation". 928

\footnotetext{
921 Ibid, p. 301.

922 See Schön (1983), pp. 296-297.

923 Ibid, p. 302. 


\section{Discussion}

\subsection{Contributions}

The reflective practitioner model is a first attempt to account for the complexity of the consulting and professional practice. Compared to the expert model it provides a more comprehensive view of the knowledge creation process in client-consultant teams. Schön emphasizes that different individuals "frame problematic situations in different ways", 929 which acknowledges the context dependency of knowledge and rejects the objectivity of knowledge as proposed by the expert model. Furthermore, he emphasizes that individuals who participate in the same community do not have troubles understanding each other and transferring knowledge. This is, however, not the case when the individuals participate in different communities. What is at the heart of the communication problems between clients and consultants is, therefore, the existence of "multiple ways of framing the practice role, each of which entrains a distinctive approach to problem setting and solving". ${ }^{930}$

This insight has several implications for the reflective concept of a professional practice. First, problems are not "given" as in the case of the expert model but rather constructed in a process of reflection-in-action. Second, consulting knowledge represents one particular way of looking and interpreting topics, which was once constructed and can be reconstructed. Third, because clients and consultants belong to different communities, they will have a different view of the problem setting and solution than consultants. Hence, knowledge pluralism is typical for the client-consultant team, requiring both clients and consultants to reflect on their interpretations and frames and share them with each other if there are to work effectively together. Furthermore, only through reflection-in-action can clients and consultants handle unfamiliar situations and create new knowledge.

This discussion reveals that the reflective practitioner model proposes a number of aspects to improve client-consultant interactions in the case of innovative problems and overcomes, therefore, some of the shortcomings of the expert model. However, it has itself several limitations.

\subsection{Shortcomings}

\section{Theoretical shortcomings}

Schön's model has some important theoretical shortcomings. For example, Schön's emphasis on reflection and the need for practitioners to reflect critically upon their knowledge is in line with the interpretivist approach to knowledge, which also emphasizes one's ability to be critical or suspicious of one's own intellectual 
assumptions. $^{931}$ Interpretivists argue that meaning is contextualized by prior knowledge and by "history and surrounding elements". ${ }^{932}$ As a result, knowledge is regarded as dependent on the individual's interpretations; it is never unconditionally true but always fallible. Schön, however, does not explicitly state the theoretical background of his model. His account of reflection is based on the assumption about "autonomous, selfdirecting individuals and authentic selves", in the understanding that individuals “critically reflect on their 'own' experiences of work in order to understand the influences that have shaped that experience". ${ }^{933}$ Therefore, some authors argue that his view of reflection implies that practitioners actively define their own experiences by attaching meanings to events; that they are able to objectively reflect upon their subjective understandings. As such, this view is criticized as still being grounded in positivism because it does not recognize that individuals and their self-understanding are shaped by a number of “technical, political, structural, cultural and 'dramaturgical' perspectives". ${ }^{934}$ In other words, one's understanding of oneself is not autonomous and independent of the context, in which one is embedded; rather, it is influenced by disciplines and discourses, as suggested by Foucault and other interpretivists. ${ }^{935}$ It follows that objective reflection is never possible; one is never able to recognize all discourses and power relations that influence one's thinking. Consequently, the knowledge that is created as a result of reflection “is never as clear cut (or beneficial)” as discussed by Schön. ${ }^{936}$

Similarly, Schön mentions the existence of different communities of practitioners but does not discuss their nature and the process of their emergence; they are assumed, rather simply, to just exist. Additionally, the reflective practitioner model recognizes that because clients and consultants participate in such communities their interpretations vary, which "may not be objectively resolvable" due to the legitimacy of their perspectives. Yet it does not offer a solution for how these differences can be overcome. Schön, himself, is aware that his suggestion for an open and intensive communication between clients and consultants is not specific enough to enhance the cooperation within clientconsultant teams: the "resolution of such differences depends on the little-understood ability of inquirers to enter into one another's appreciative systems and to make reciprocal translations from one to the other". ${ }^{937}$ Thus, the model fails to explain the process of translation and does not show exactly how the communication between client and consultant can be improved.

Furthermore, although Schön provides a very promising view of knowledge transfer and creation, he considers knowledge creation to be executed entirely by the professional without including clients in this process. Schön recognizes, indeed, that clients should participate actively at the start of the problem-solving process through sharing their understanding of the problem with the consultants. Similarly, consultants have to give 
clients an access to their understanding of the problem and to the rationale of their advice. Thus, consultant's advice is seen as a result of a construction process and as such, as an advice that needs to be reflected upon and explained to the clients until they understand the underlying assumptions. However, the actual process of the creation of this advice is still seen, similarly to the expert model, as a consulting centric process where clients play no role. It is merely the professional's "conversation with a unique and uncertain situation", ${ }^{938}$ where the client does not have a place.

Some additional critical points are related to Schön's understanding of the nature of power within client-consultant teams. Thus, Schön's account does not answer the following important questions, which have indeed high practical relevance: Whose perspective will build the basis for the problem solution in situations when clients and consultants have different and legitimate perspectives on the problem? Who leads the problem-solving process in such cases? Is it necessary in such cases that one of the parties takes over the power to decide upon the problem solution and how does this process look like? Instead, Schön proposes that there are no real power issues in clientconsultant teams when they function as reflective practitioners. ${ }^{939}$

Finally, although Schön understands that "skills in the manipulation of media, languages, and repertoires are essential to a practitioner's reflective conversation” when they solve problems, ${ }^{940}$ he does not discuss the implication of this insight for the nature of consulting knowledge and the interaction process between clients and consultants, something that the proponents of the critical model pay special attention to.

\section{Practical relevance}

Schön recognizes that the reflective practitioner type of consulting is difficult and time consuming to implement, so that it is worth applying only when a particular problem is of sufficient importance. The difficulty results from the "different demands on competence, and the different sources of satisfaction that are presented both to the professional and to the client". ${ }^{941}$ Therefore, any client or consultant who wishes to move from the expert to the reflective type of consulting needs first to reshape the norms and expectations, which the other party brings to the interaction. Schön concludes that in situations that are routine or emergencies, such that a fast solution is necessary, a more restricted interaction as proposed in the expert model would be more appropriate and efficient. Thus, Schön suggests two types of consulting, which he regards as appropriate under different sets of conditions: the expert consulting should be applied in the case of simple routine problems, whereas the reflective consulting is more appropriate in the case of innovative problems. In other words, only when the client's problem is of sufficient

938

939

Ibid, p. 130.

Schön points out, indeed, that professionals are often agents of power. For example, he states "views of reality are both cognitive constructs, which make the situation understandable in a certain way, and instruments of political power". Schön (1983), p. 348. The result is that professional's descriptions of social reality are always embedded in a process of political contention. However, his statement is related to a macro perspective on the power of professionals. In other words, he discusses professional's role and power in the macro-political process, at the society level. The micro view of the nature of power relations within client-consultant teams, i.e. the political subsystem of the client-consultant team, is not investigated.

Ibid, p. 271.

Schön (1983), p. 298. 
importance should the reflective practitioner type of interaction be adopted. ${ }^{942}$ Consequently, Schön leaves a large grey area of problems unexamined: the complex routine problems. As outlined in chapter B.II.3.2.2, these problems are more complex than simple routine problems and need a more intensive type of interaction between clients and consultants than simple routine problems. At the same time, they are not innovative problems, so it is inefficient for clients and consultants to create a totally new solution given that there is valuable existing knowledge about such problems. From Schön's account, it is not clear what type of interaction he regards as appropriate in such cases, although it can be speculated that they should fall in the realm of the reflective consulting. In this case, however, it is unclear if he sees any difference between consulting in the case of complex problems and in the case of innovative problems.

With his suggestion that the expert and the reflective practitioner consulting models are appropriate in different problem contexts, Schön takes a contingency approach, which leads to the idea that there is no one best set of assumptions to study a particular phenomenon, and that it is appropriate to vary assumptions from one situation to another according to the problem being solved. ${ }^{943}$ Such a contingency approach does not overcome, however, the differences in the fundamental assumptions between both models. While such an approach is a legitimate way to combine perspectives, it is argued here that it is not appropriate for the purposes of this work. Instead of simply combining existing perspectives, this work has the more ambitious aim of developing a new integrated model of the client-consultant relationship. It is believed that this approach would offer a more sophisticated approach to account for differences between contexts and consulting relationships. ${ }^{944}$

\section{Summary}

Schön's model attempts to account for both routine and novel problem situations. Whereas he agrees that the expert model is most practical in the case of routine problems, he suggests a different view of the client-consultant interaction when the problem situation is novel and complex. In such cases, the problem-solving process looks like a reflective conversation between clients and consultants, he argues, during which both sides share their perspectives in order to find a solution cooperatively. The relationship is equilibrated as both clients and consultants possess relevant knowledge.

In retrospection, being less one-dimensional than the expert model, the reflective practitioner model provides a promising starting point for a more sophisticated understanding of client-consultant cooperation. However, by trying to be conceptually broad, this model ends up lacking specificity. It offers only limited concrete suggestions as to how to improve the cooperation between clients and consultants and it pays insufficient attention to the multifaceted character of the interaction between clients and consultants, and the pluralist and political nature of consulting knowledge. Thus, it is 
suggested that a new model of the client-consultant interaction is needed that sheds some light on these important questions.

A look at the more recent research on consulting suggests that the situation in the consulting industry has not changed radically since the development of Schön's model with clients continuing to express dissatisfaction with consulting services. In this critical environment, a different stream of research developed, aiming to explain the nature of consulting in general, and the reasons for client's dissatisfaction with consulting services in particular. In the following, a model that brings together several of these critical works on consulting is presented and critically discussed.

\section{The critical model}

\section{Introduction}

The critical approach to consultancy work emerged during the 1980s. It focuses on consultants as impression managers and regards knowledge transfer as a symbolic interaction between clients and consultants. ${ }^{945}$ Important proponents of this model are Alvesson, ${ }^{946}$ Clark, ${ }^{947}$ Clark and Salaman, ${ }^{948}$ Kieser, ${ }^{949}$ and Jackson. ${ }^{950}$

In line with these rather academic works, a very critical view of consulting was also promoted by a number of management journalists ${ }^{951}$ as well as by some former consultants. ${ }^{952}$ The following citations reflect the underlying tone of these works:

"In Jackall's (1988) seminal study of corporate power and politics, consultants are heavily implicated in the Byzantine and Machiavellian world of U.S. corporate life. He saw them as a kind of benign parasite, living off the power process that wholly defines interaction at these levels of management. In this sense, consultants seem to 'crop up everywhere', and seem to be key actors of bit players in many current management dramas being played out in the world's media"; 953

and

"We used to call this 'selling by creating client dependency' because the more worried the client got...the more they would switch their loyalties 
away from their own staff and start to bond with you. [] If you can create client dependency, it's unlikely they'll ever ask you to leave."954

The following discussion concentrates on the academic part of the critical view of consulting.

\section{Context}

Despite Schön's suggestion on how to improve the client-consultant interaction in order to achieve better outcomes from consulting projects, during the 1980s a growing number of researchers engaged in the study of client-consultant interactions developed an extreme scepticism about the value of consulting knowledge. ${ }^{955}$ Similar to Schön, supporters of the critical model argue that pro-consultancy texts are preoccupied with badly substantiated claims of professionalism of the management consulting industry, which caused critical texts to deal with causes of extreme non-professionalism. ${ }^{956}$ However, these authors go in their criticism one step further than Schön. They argue that positivism, which is the theoretical foundation of the expert model, is "a form of intellectual imperialism that ignores the fundamental uncontrollability of meaning". 957 Instead, reality should be seen as constructed by individuals' discursive conceptions of it. Therefore, language has an important role in constructing 'reality'. ${ }^{958}$ These arguments are based on a completely different philosophical approach than modernism, in particular on a stream of research called the "linguistic turn". ${ }^{959}$ The linguistic turn is one of the most contemporary trends within the social sciences and is expressed in an increased interest in and focus on language. ${ }^{960}$

The main argument within this approach is that language does not represent reality, because language is “context dependent, metaphorical, active, built upon repressed

\footnotetext{
954 Craig (2005), cited in Skapinker (2005), p. 13

See, e.g., Alvesson (1993, 1995, 2000); Ashford (1998), p. sv; Clark (1995), pp. 60-63 and pp. 90-94; Clark/Salaman (1996a, b); Jackson (2001), pp. 13-22; Kieser (1997, 2002a, b).

See Parker (1992), p. 3. The argument is that "it is the structured nature of language that creates the impression that reality itself is stable, pre-organized, law-like in character. [] without the social acts of differentiating, identifying, naming, classifying, and the creation of a subject-predicated structure through language, lived reality is but a 'shapeless and indistinct mass'. Saussure (1966), p. 111, cited in Chia (2003), p. 127. In consequence, "individual elements [of phenomena] have no real existence apart from the process of which they are but particular points of emergence". Chia (2003), p. 133.

This stream is an interpretivism spin off and is influenced by literary approaches and the postmodern approach to knowledge. The postmodern school to knowledge is not a fully developed approach within the knowledge management field. It is based in postmodern epistemology as proposed within the works of Derrida and Lyotard. See Reihlen/Ringberg (2004), p. 14. It is in opposition to the modernist, positivist epistemology: "Critical questioning, and often outright rejection, of the ethnocentric rationalism championed by modernism”, characterizes it. See Cooper/Burrell (1988), p. 92. For a discussion of the emergence of postmodernism, see Chia (2003), pp. 124-126. The postmodern approach to knowledge should not be confused with postmodernism as a period, which is characterized by a rapid and a large scale social change, and represents a break up with modernity. See Alvesson (1995b), pp. 1052-1062; Hassard (1999), pp. 175176; Parker (1992), p. 8; Reihlen/Ringberg (2004), pp. 14-15.

See Alvesson/Kärreman (2000), pp. 136-137. See also Rorty (1992) for a detailed discussion of the Linguistic turn in philosophy. 
meanings, and capable of constituting 'other' phenomena”. ${ }^{961}$ In other words, language is a technology of organization that helps individuals to fix, locate, and represent different aspects of their experiences. ${ }^{962}$ Therefore, individuals in general, and clients and consultants in particular are not "abstract, disengaged tellers of truths" or "romantic revealers of genuine experience". ${ }^{963}$ The implication is that a different view of the clientconsulting interaction is required. Thus, the critical approach to consultancy work regards consultants as impression managers and knowledge transfer as a form of symbolic interaction between client and consultant. ${ }^{964}$ It treats the professional's claim to extraordinary knowledge as mystique, whereas this mystique is seen as an instrument to control laypersons. ${ }^{965}$

\section{Cultural relations}

\subsection{Nature of knowledge}

Supporters of this model do not regard the objectivistic and reified view of knowledge represented in the expert model as realistic. Rather, consulting knowledge is seen, similarly to Schön, as constructed during client-consultant interaction. For example, Alvesson claims that knowledge is a socially constructed phenomenon dependent on social recognition. ${ }^{966}$ In contrast to Schön, however, the proponents of the critical model regard consulting knowledge as a social product that does not exist prior to the clientconsultant interaction. Rather, they see it as developed in interaction with the clients through translation, where translation is defined as the process of actors convincing other actors that their interests coincide. Thus, consultants “do not possess and cannot deploy a body of formal, authoritative theoretical professional knowledge to underpin their work, because there is no such knowledge". ${ }^{967}$ Their knowledge is not "a set of expert solutions" as pictured in the expert model but "a language for representing mutually acceptable ways of knowing and defining and talking about management, managers and organizations". ${ }^{968}$ What differentiates management consultancies, and all knowledgeintensive firms, from other kinds of companies is not the possession of superior knowledge, but the "degree of elaboration of the language through which one describes oneself and one's organization, regulates client orientations and engages in identity work". ${ }^{969}$ As already mentioned, this view of knowledge as language has its origins in the

\footnotetext{
961

Alvesson/Kärreman (2000), p. 154. One implication of this claim is that supporters of the approach concentrate on studying discursively produced outcomes, such as texts and conversations when investigating organizational reality. See Alvesson/Kärreman (2000), pp. 137; Hatch/Yanow (2003), pp. 76-79.

See Chia (2003), pp. 128-129.

Alvesson/Kärreman (2000), p. 154.

See Fincham/Clark (2002), pp. 8-9.

See also Schön (1983), pp. 288-289. He points out that a demystification of professional knowledge may consist in treating professional knowledge as the emperor's new clothes; or it may mean that professionals know in fact something valuable, but that it is not as complex and specific as professionals present it. The works discussed in the following swing sometimes between both views but the second view is the prevalent one.

See Alvesson (2001), p. 872. With this, he takes a constructivist position regarding the nature of knowledge.

Clark/Salaman (1998a), p. 147, emphasis in the original.

Ibid, p. 147, emphasis added.

Alvesson (2001), p. 871, emphasis added.
} 
“linguistic turn”, emphasizing knowledge’s ambiguous, metaphorical, and contextdependent nature. ${ }^{970}$ In other words, according to this model, the real nature of consulting expertise is oracular. ${ }^{971}$ Supporters of the critical model conclude that as a result, consulting knowledge is to a large degree a matter of beliefs, impression management, and negotiation of meaning. ${ }^{972}$

\section{Knowledge transfer and creation}

Because consulting knowledge is regarded as ambiguous and idiosyncratic, what consultants create and deliver are images, impressions, and rhetorical acts that become a substitute for the ambiguities of the consultant's knowledge. ${ }^{973}$ Proponents of this viewpoint argue that consultants communicate to clients mainly through a series of narratives that define problems and problem solutions in the form of organizational myths. ${ }^{974}$ When consultants tell success stories, for example, about the realization of cost reductions and quality improvements through some management concept or model, e.g., Total Quality Management, Business Process Reengineering, Balance Scorecard, etc., they make organizational realities, such as structures, strategies, competences, etc., accessible to management action and understanding. Rhetoric, images, metaphors, and humor are, thereby, important mechanisms for impressing clients. ${ }^{975}$ The variety and diversity of consulting stories acting in the form of models and frameworks, and the lack of a demarked body of knowledge, are the reasons why some authors talk about the "fashion-led, faddish and ephemeral" character of the consulting industry. ${ }^{976}$

Because rhetoric and linguistic strategies appear too insufficient to account for the increasing influence of management ideas and consulting companies on organizations, some writers claim that consultants' stories reflect the innate need of managers for "dramatic" impulses. "A need to dramatize events in order to ascribe meaning and sift out the significant from the mundane". ${ }^{977}$ In other words, "consultants seek to create and sustain reality that persuades clients of their value in the same way that actors seek to create a theatrical reality". ${ }^{978}$ In this, consultants involve clients as actors who contribute actively to the performance: "The audience is the performance, or at least the means of the performance, its accomplice and its measurement." ${ }^{979}$ Consequently, impression management is regarded as crucial for the success of the client-consultant cooperation

970

971

Ibid, p. 870; see also Alvesson/Käreman (2000), p. 141; Clark (1995), p. 60 and p. 91.

The proponents of this model do not discuss whether theory or experience is the basis of consulting knowledge because they deny the existence of any shared, non-ambiguous knowledge. For example, Alvesson and Kärreman argue, "In pragmatic contexts, such as the composition and use of train timetables and the counting of people, the view of [knowledge] as a mirror of reality has practical advantages and functions. In social sciences [and social practice], studying complex phenomena constituted within a specific vocabulary, this is frequently not the case." Alvesson/Käreman (2000), p. 140.

See, e.g., Alvesson (1993), pp. 1006-1007; Alvesson (2001), p. 870.

See, e.g., Alvesson (1993), pp. 1006-1007; Alvesson (2001), p. 870.

See Clark/Salaman (1998a), pp. 148-155.

See Clark/Salaman (1998a, b); Greatbach/Clark (2003).

See Clark (1995), p. 90; Clark/Salaman (1996b), p. 165; Jackson (2001), pp. 8-22; Kieser (1997).

Fincham/Clark (2002), p. 9.

Clark/Salaman (1998b), p. 25.

Clark/Salaman (1996b), p. 170. 
and for the survival of consulting companies in general. ${ }^{980}$ Accordingly, Alvesson calls this "systems of persuasion". ${ }^{981}$ To complete this picture, Micklethwait and Wooldridge, as representatives of the journalist strand of this model, conclude that consultants are little more than “con artists, the witch doctors of our age, playing on business people's anxieties in order to sell snake oil”. ${ }^{982}$

Figure 9 provides a schematic of the critical model's main arguments. The proponents of this approach are disapproving of the expert model for overemphasizing both the rational quality of consulting expertise and the professional elements of the consultancy activity, and for underestimating the role of the client-consultant interaction. ${ }^{983}$ The interaction aspects emphasized by the critical model go beyond the prescriptive recommendations of the expert model and include: (1) keeping the client happy, (2) preserving the image of the consulting expertise, and (3) securing a personal relationship with the client. ${ }^{984}$

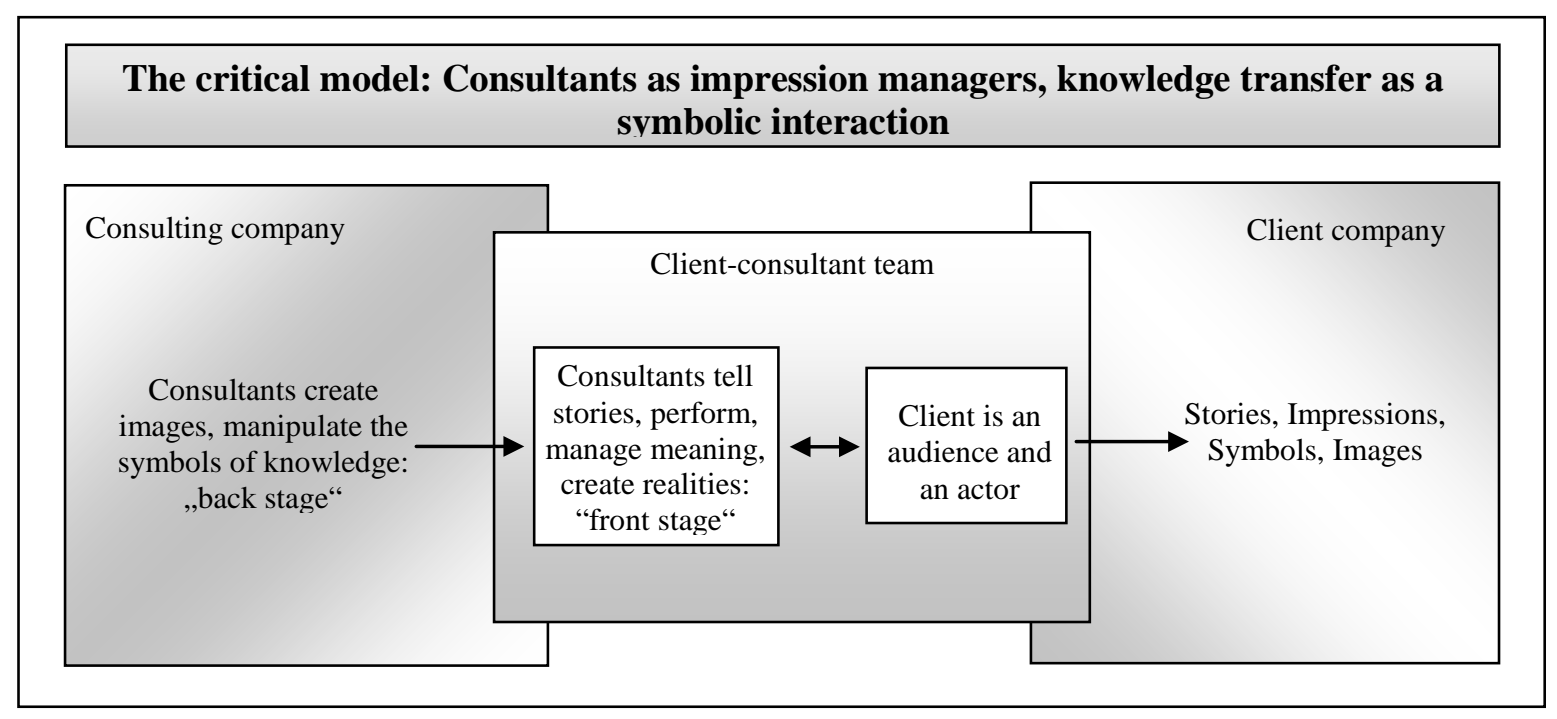

Figure 9: Knowledge transfer and creation as a symbolic interaction

\section{Power relations}

Supporters of this model emphasize that clients are involved to a much higher extent in the client-consultant interaction than suggested by the expert model. Clark and Salaman, for example, argue that the consultant's use of stories constitutes an open and interactive relation with the client. ${ }^{985}$ Consultants do not just impose meanings on clients, they do not "autocratically and manipulatingly produce", and clients do not "docilely consume". ${ }^{986}$ This situation is rather characterized by negotiations where consultants reflect and modify client's meanings together with the client. Consequently, this view of

Clark/Salaman (1998), p. 152.
} 
managers as co-producers of consulting services implies that the success of consultants in selling their service, and accordingly, consultants' success in establishing dominance in the client-consultant relationship, is dependent on the managers' reactions towards consultants' actions. In other words, consultant's dominance is not absolute but depends on clients reactions. Consultants are empowered only when managers accept their dominance.

However, supporters of the model argue that in reality, clients do not resist consultants' dominance. Rather, they emphasize the influence and power of consultants: due to the ambiguity of consulting knowledge, only with the help of power can consultants persuade clients in the "value" of their services. For example, Clark and Salaman argue that consultants act in an authoritative and persuasive way in order to impress and convince their clients of the value of the consulting services. Consultants "define the managerial role" and "must seem to be authoritative, must behave confidently, must be in command" if they are to impress the client and be successful. ${ }^{987}$ Consultant's work is described as producing a "series of narratives which constitute, make up" clients' reality. Thus, "their seemingly knowledgeable descriptions of organizational structures, processes and purposes become authoritative exercises of power". ${ }^{988}$ Thus, consulting stories, symbols, and metaphors act as power instruments: consultants use them to exercise control over the problem-solving process and the generated solutions. They are "means of creating legitimacy [] with regard to [consulting] actions and outcomes." ${ }^{989}$ In other words, in this model, power is seen as a strategy: consultant's power does not originate in their expertise, as no such expertise exists, but is the result of consultant's persuasions and manipulations of meaning. ${ }^{990}$ Thus, this model takes an interpretivist view to the nature of power within client-consultant teams.

Supporters of the critical model further argue that client's dependency on consultants can be attributed to the emergence and nature of consulting fads and fashions. Kieser, for example, argues that consultancies boost the sales of their services predominantly by promising clients that they will transfer knowledge to them, which will help increase the performance of their company. ${ }^{991}$ At one and the same time, however, consultants contribute to the client's perception of rising complexity and uncertainty by continuously "producing" and introducing new concepts, management fashions, and future trends. Managers' insecurity increases also because competitors usually implement the current fashion as well, which leads to higher competition. Thus, the receptivity towards new management fashions increases again. The result is an environment in which clients experience an increasing fear of loss of control and become dependent on consultants who promise to help them regain that control. In this way, consultancies have made clients "marionettes on the strings of their fashions". ${ }^{992}$ Figure 10 illustrates this argument. 
Abrahamson, who provides an in-depth description of the process through which consultants launch management fashions, confirms this view. ${ }^{993}$ He differentiates four phases of the process. During the creation phase, consultants create new management techniques, or what is more often the case, they rediscover, or reinvent management techniques they attempt to launch into fashion. Such management techniques are created either to fit some incipient client demand for new fashions or to fit the type of management technique the client prefers. In the selection phase, consultants select those techniques they believe will satiate client's demand. In the processing phase, consultants need to elaborate a rhetoric that can convince clients that the chosen management technique is both rational and at the forefront of management progress. This rhetoric "must create the belief that the technique allows managers to pursue an important managerial goal in the most efficient fashion". 994 In the dissemination phase fashion setters disseminate their rhetoric directly, for example through publications they control, or indirectly, with the help of other institutions, for example business schools. Thus, it is clear from this argument that consultants possess the power to create management fashions and to make clients dependent on them.

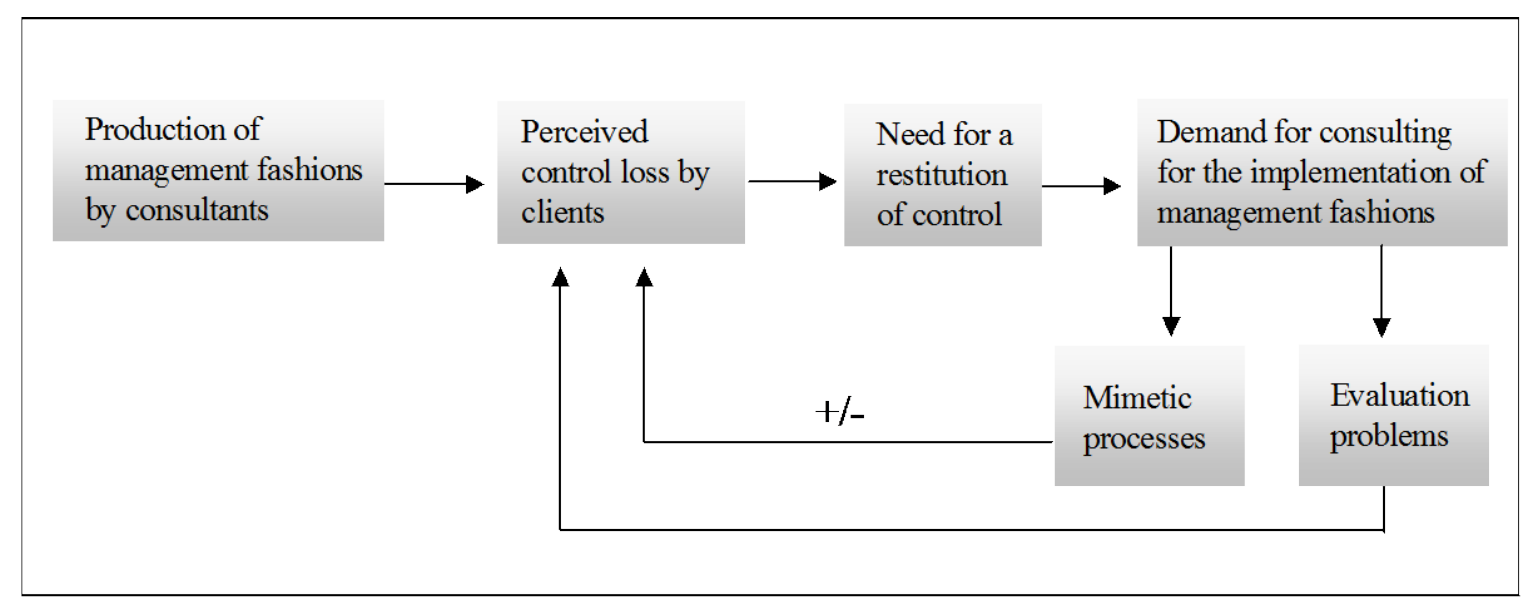

Figure 10: A model for the explanation of the extraordinary growth of the consulting market

\section{Source: Kieser (2002), p. 173.}

Some authors acknowledge, however, that there are situations when clients use management consultants to propose unpopular solutions in the client's organization, such as, for example, workforce reductions. ${ }^{995}$ In such cases, the client, usually the sponsor of the consulting project, defines the problem, and rules and directs the consultants towards the expected results. ${ }^{996}$ Thus, it can be speculated that in such cases, consultant's image and rhetoric are used to serve top management's political interests. Consultants are powerful instruments in the hands of top managers who wish to undertake unpopular actions without putting their own reputation at risk. In other words, consultants are the 
dependent actor, who follows the guidelines of top management hoping for future projects.

\section{Nature of professional business services}

Supporters of the critical model argue, when discussing the notion of professionalism, that it "cannot be equated solely with rationality, moral or cognitive superiority or problem solving abilities", 997 as suggested within the expert model. They further state that factors usually associated with professionalism, such as the central role of science and knowledge, the autonomy of the professionals, the solving of problems vital to society, and the affective neutrality and altruistic service to clients, are often emphasized in order to produce an image of being rational and altruistic rather than being real characteristics of professionalism. In claiming this, the critical perspectivists relate themselves to the so-called power approach to professionalism ${ }^{998}$ that emerged from symbolic interactionism. ${ }^{999}$ The approach claims that professions are essentially the same as other occupations, and that the distinguishing feature of professionalism is purely the ability of professions to gain societal recognition as professions. Hence, "there is no unique definition of professions; it is merely a title claimed by certain occupations at certain points in time". ${ }^{1000}$ The relevant question is, consequently, not what a profession is in the absolute sense, but rather how society determines who and what is professional. ${ }^{1001}$ Here, the link between the critical model's view of professionalism and the nature of professional knowledge becomes clear: professional service firms possess high legitimacy in the modern society because they are regarded as providers of institutionalized myths, which other organizations seek to act in accordance with if they want to conform to the institutionalized expectations of their environments. ${ }^{1002}$ Thus, professional business services become “vital symbols for client organizations' elaboration of rules and requirements for rationality". ${ }^{1003}$ In other words, the real distinctiveness of professionals lies in their ability to act in an 'expert-like' way and to institutionalize management myths.

\section{Attributes of clients and consultants}

Within the critical model, managers are seen as irrational actors that follow every new management fashion suggested by consultants. The reason for this is argued to be (1) their "unconscious anxieties" and insecurity about their job tasks, personal career, functional, or departmental power and "even the status/legitimacy of the managerial 'profession'”, 1004; and (2) their wish to be up-to-date with new developments in the field

Alvesson/Johansson (2002), p. 232-233.

See, e.g., Abbott (1988), p. 15; Dietrich/Roberts (1997), p. 25.

See Dietrich/Roberts (1997), p. 23.

Ibid, p. 23.

See Macdonald/Ritzer (1988), pp. 268-269.

See, e.g., Alvesson (1993), pp. 1003-1004. The nature of such institutionalized techniques and practices was discussed within the interpretivist school of power in chapter B.II.4.3.3.

Ibid, p. 1004.

Sturdy (1997b), p. 514.
} 
of management. ${ }^{1005}$ As a result, there is less emphasis on the skills and attributes of clients within this model. They are regarded as passive actors concentrated on managing their own insecurities and fears. Instead, the emphasis is on the consultants who are seen as the active actor in client-consultant relationships.

With regard to consultants, the supporters of this model emphasize the importance of their persuasion and rhetorical skills. ${ }^{1006}$ Because the work of consultants involves impression management and persuasion of clients, cognitive skills, i.e. domain-relevant knowledge, are presented as less crucial for the success of consultants than their persuasion skills. However, the exact nature of consultant's persuasion skills differs. Depending on whether consultant's persuasion skills originate in their charisma, which is "personalized and reliant on heroic or even mystical powers", or are reliant upon consultant's appeal of systematic knowledge and technical legitimacy, Fincham differentiates between management gurus and "ordinary" management consultants. ${ }^{1007}$ Accordingly, he proposes that one of the crucial distinctions between guru and consultant lies in the different kinds of legitimacy they draw on: charisma versus rational or technical authority. Based on this argument Fincham proposes the following table that summarizes the main distinctions between management gurus and consultants. These differences are briefly explained in the following section. ${ }^{1008}$

\begin{tabular}{lll}
\hline & $\begin{array}{l}\text { Management Gurus } \\
\text { Persuasion as charisma }\end{array}$ & $\begin{array}{l}\text { Management Consultants } \\
\text { Persuasion as technique }\end{array}$ \\
\hline Structure & Managerial audiences & Corporate clientele \\
\hline Legitimacy & Dramatic intensity & Procedural models \\
\hline Expertise & Creating universal appeal & Matching client needs \\
\hline
\end{tabular}

Table 10: Charisma versus technique

Source: Fincham (2002), p. 194.

\section{Management gurus}

Gurus operate on the public stage, for example in mass seminars, or through media, such as books, where no real personal contact is possible. Consequently, they can develop only loose relationships to their audiences, without having any stable relationships to particular clients. Therefore, gurus are seen in much higher degree as "performers", using actively the sense of drama and ritual. ${ }^{1009}$ Hence, gurus are primarily orators employing public media, and their rhetoric tends to be based on simple story lines and the appeal of the "fundamental application" of their knowledge. The following quote illustrates what supporters of the critical model see as the main skill of gurus: 
"The management guru works through a 'performance of a definite metaphorical type' creating a sense of display capable of transporting the audience into the realm of business success. The guru's ability to use the intensity of performance to change (if only temporarily) the audience's consciousness is what sets them apart”. ${ }^{1010}$

\section{Management consultants}

Consultants work with individual clients in a more private arena, and the projects are usually kept confidential. Thus, whereas gurus have more loose relationships with their audiences, consultants try to develop long-term relationships with their clients. Furthermore, consultants, like gurus, have a repertoire of performances, but in contrast to gurus, consultants put more emphasis on the "rational" character of their knowledge. Like gurus, consultants rely on rhetoric as well, but their rhetoric tends to be built around particular clients and situations, as well as upon the use of objective, rational techniques for solving management problems. Such "techniques have a ritualistic appearance, like incantations designed to convince the client (and perhaps the consultant too) that complex changes can be wrought in a series of discrete moves". ${ }^{1011}$

The above presentation of the two sub forms of consulting makes it clear that the differences between management gurus and management consultants are only "a matter of emphasis rather than category distinctions". ${ }^{1012}$ In both cases, persuasion and rhetorical skills are seen as crucial for the success of consultants. Fincham admits that consultancy can be highly theatrical as well, ${ }^{1013}$ and the "different kinds of performance are thus not exclusive to one group or another". ${ }^{1014}$ Thus, "the emotional, moral, and symbolic aspects of organizations" remain essential to both roles. ${ }^{1015}$ Furthermore, because some management gurus start up their own consultancies, there is "an important area of overlap in the activities of gurus and consultants". ${ }^{1016}$ It can be concluded that there is no qualitative difference in the nature of both sub forms of consulting, so that the presented arguments are valid for both management gurus and management consultants. "In both cases the legitimacy of the expert's advice is maintained by the persuasiveness of live performance". 1017

\section{Discussion}

\subsection{Contributions}

An important contribution of the critical model is its elaboration of the view of knowledge as a socially constructed phenomenon, rather than as an objectively definable

\footnotetext{
1010 Fincham (2002), p. 198. See also Clark/Salaman (1996a, b, c).

1011 Fincham (2002), pp. 198-199, emphasis added.

1012 Ibid, p. 200.

1013 See also Bloomfield/Vurdubakis (2002).

1014 Fincham (2002), p. 200.

Ibid, p. 200; see also Clark/Salaman (1996c), p. 104.

Fincham (2002), p. 196.

Fincham (2002), p. 203, emphasis added.
} 
commodity as held in the expert model. Against the conventional view of knowledge as a transparent medium for the transport of meaning, this model emphasizes its ambiguous, metaphorical, context-dependent, and active nature, ${ }^{1018}$ something that has not been recognized by the expert model and what Schön referred to as the "mysterious artistry" of professional practice. ${ }^{1019}$ This view implies that consultants do not possess any objective, testable knowledge. Rather, meanings are subjectively constructed. As such, the critical model is based in the tradition of the interpretivist approach to knowledge emphasizing the importance of interpretation and construction of meaning when studying clientconsultant interactions. ${ }^{1020}$ This appreciation for the importance of interpretation leads to an increased attention to the persuasive elements of language. Because of this characteristic of consulting services, supporters of the critical model argue that it is crucially important for consulting companies to find ways to persuade clients of the value of their services. This is achieved with the help of symbolic mechanisms such as consulting stories, metaphors, rhetoric, and images. ${ }^{1021}$ Thus, the model emphasizes the role of narratives and performance in consulting projects rather than of analytical rationality and argument. ${ }^{1022}$ Additionally, stories and images are regarded as powerful persuasion instruments that consultants use in order to impress clients and to sell new management concepts and models. Therefore, impression management is crucial for the success of consulting projects. In this way, the model stresses that consultant's dominance does not originate in their expertise as held by the expert model but develops during the client-consultant interaction as a result of consultants' rhetorical and impression skills. This brings in considerations of power and power relations. According to the critical model, consultants exercise influence over clients by constructing the meaning of what they experience and by producing and disseminating new management fashions. In this, clients pay a role as well, as consultants need to build alliances with them in order to institutionalize new consulting practices. Therefore, this school adopts an interpretivists view of power. ${ }^{1023}$ Thus, by acknowledging the evolving and strategic character of power, the model provides a more sophisticated understanding of the power processes within client-consultant teams.

Therefore, the critical model offers important insights into the nature of the clientconsultant relationship, insights that are ignored within the expert and the reflective practitioner models. At the same time, the critical approach to consulting has several important weaknesses.

\footnotetext{
1018 See Alvesson/Kärreman (2000), p. 141. 


\subsection{Shortcomings}

\section{Nature of knowledge and knowledge transfer and creation}

Firstly, supporters of the critical model argue that meaning is produced individually in accordance with each individual's unique set of cultural codes, which structure the individual's understanding and interpretations. ${ }^{1024}$ Thus, alternative interpretations are always possible and any interpretation is necessarily a subjective one. ${ }^{1025}$ As a result, knowledge is seen as highly idiosyncratic and subjective and for this reason, supporters of the critical model question the value of consulting knowledge for clients in general. Their arguments imply that is not possible to know whether clients and consultants fully understand each other when interacting. ${ }^{1026}$ Rather, it is assumed that even when clients and consultants share the same social context, when interpreting topics they produce equivocal knowledge. Consequently, client-consultant interactions are seen as a series of idiosyncratic discourses rather than as a source for the development of some shared understanding $^{1027}$ that offers a basis for communication. However, such a view overemphasizes the ambiguous and linguistic character of consulting knowledge. It also ignores the fact that clients and consultants can develop some shared knowledge in the process of their interaction, which would enable knowledge transfer. It can be argued that members of the client team who have a management education or were consultants themselves, which is often the case, share consulting specific meanings and interpretations schemes to some degree. ${ }^{1028}$ Because they have some knowledge about consulting concepts and models, and speak the "consulting language", they have fewer difficulties in evaluating consulting expertise and suggested problem solutions. Therefore, consulting expertise is not highly ambiguous and idiosyncratic when clients and consultants possess some shared frameworks, and knowledge transfer is possible, at least to some degree.

To sum up, the problem with this perspective on knowledge is that it ignores the ability of individuals to develop shared meanings, at least to some extent, when they are are embedded in a similar social context. Hence, it cannot explain knowledge formations within and across groups and organizations in general ${ }^{1029}$ or the nature of the clientconsultant interaction in particular. In other words, this school overemphasizes the nonobjective, contested nature of knowledge to the extent that it ignores the existence of even locally shared knowledge, knowledge that is shared in particular social groups. ${ }^{1030}$

See Reihlen/Ringberg (2004), p. 14; Lindlof (1988), p. 86.

See Weiss (2000), p. 717. This view is characteristic for the postmodern approach to knowledge.

See Reihlen/Ringberg (2004), p. 15; also Rescher (2005b), pp. 14-28.

See Hassard (1999), pp. 183-187.

Poulfelt et al. argue that "management knowledge and techniques are widely disseminated and available, especially analytical concepts, techniques, and best practices”. Poulfelt et al. (2005), p. 19.

See Loasby (2000), pp. 22-24; Lindlof (1988), p. 87; Reihlen/Ringberg (2004), pp. 17-18.

This view of knowledge is based on the problematic assumption that the social world is merely socially constructed or is determined by the concepts individuals hold about it: "subjects' social reality is constructed through language as a symbolic medium”. Heracleous/Barrett (2001), p. 756. Clark, for example, argues that the specific characteristics of consulting services permit consultants "to create and construct reality". Clark (1995), p. 133. In other words, social reality is seen as an effect of language. See Reed (2004), p. 413. As such, "non-discursive [i.e. non linguistic] practices
} 


\section{The role of stories and rhetoric}

The above argument points out a further weakness. Although proponents of this model see the importance of stories and rhetoric during the client-consultant interaction, they concentrate on their symbolic character rather than on their role for knowledge transfer and creation within client-consultant teams. In other words, because they deny the possibility of any transfer of knowledge between clients and consultants, stories and rhetoric are seen merely as impression and persuasion instruments, not as mechanisms for knowledge transfer and creation. However, as Huczynski points out, consultants have to use stories and rhetoric in order to enhance their communication with managers: "They [managers] have difficulty understanding excessively technical language; have a short span of attention; a limited span of memory and judgement; and tend to be more convinced by certain modes of communication than others. Popular management ideas take these limitations into account". ${ }^{1031}$ Furthermore, others have stressed the importance of symbolic and dramatic elements for knowledge creation during problem-solving processes. Kanter, for example, argues that a symbolic form of knowledge production is necessary in order to enhance the creativity of the involved individuals, to give free flow to imagination and as a result, to enable innovation. ${ }^{1032}$ Similarly, Clark and Mangham propose that the use of drama and performance can stimulate the creation of new insights out of the participants' contributions. ${ }^{1033}$

Furthermore, the critical model ignores the potential and importance of analytical approaches in consulting projects in favor of performance and stories. ${ }^{1034}$ Therefore, unlike the expert and the reflective practitioner models, the critical model pays attention to image creation and positive client expectations, which are important aspects of successful consulting. However, it ignores the fact that consultants do provide some valuable, specific knowledge to their clients and that cooperation of both parties generates tangible and valuable outputs rather than only symbolic and emotional results. It does not take much effort to ask the question of how managers can justify the huge sums investing in contracting consultants if there are no direct benefits for companies and management from engaging consultants other than mere rhetoric and drama? Similarly, how is the long lasting and large growth in consulting companies to be explained in a world with both strong governance and demands for cost control? Thus, claims have been made that there are some long-term positive financial market effects of hiring management consultants, ${ }^{1035}$ a fact inconsistent with the critical model. Additionally, McKenna suggests that the exponential growth of consulting services can be explained if considering consulting services as an additional insurance for corporate directors. In other words, by using consultants, managers transfer part of their liability towards

cannot be investigated or elaborated because they have been ruled out of contention”. See Ackroyd/Fleetwood (2000), p. 10. This is a position of ontological constructivism. See Bunge (1996), p. 295-297.

Huczynski (1993), p. 60. That stories and images have an important role for the transfer and creation of knowledge is discussed in detail in chapter D.III.3.8.

See Clark/Mangham (2004a), p. 54; Clark/Mangham (2004b), p. 847; also Sturdy et al. (2004), p. 338. The authors speak about forum theatre, which is a specific form of an organizational theatre.

See Schipper (1999), pp. 473-474. 
shareholders to consulting companies. ${ }^{1036}$ Finally, as Wright and Kitay stress, consultants may use stories, rhetoric, and images to impress clients and sell their services, but this does not equate with the mere selling of drama and rhetoric. They argue that very often consultants believe not only "that their proposals will be good for [the client's] business, but also are inherently worthwhile in terms of social values". ${ }^{1037}$

\section{Nature of power}

Supporters of the critical model view consultants as the powerful actor in clientconsultant relationships and ignore the possibility of clients resisting this power. On the one hand, because it is assumed that consultant's knowledge is ambiguous and inherently fluid, it is implied that consultants' "rational" sayings are of indeterminate meaning, i.e. they can mean almost anything to clients. ${ }^{1038}$ Consequently, the value of consulting knowledge is seen as highly contested and the "rationality" of consulting statements as dependent on the audience's reactions. In other words, clients are co-producers of the interpretations of consultant's statements. ${ }^{1039}$ This implies that there is the possibility that consultants' “expertise" may be devaluated or considered irrelevant within clients' local understanding. ${ }^{1040}$ Thus, whether consultants are the dominant actor in a particular clientconsultant project depends upon the actions of the clients. If the clients do not contest consultants' expertise, and do not refuse to coordinate their actions around the consultant's models and solutions, they will "empower" the consultants. ${ }^{1041}$ In the opposite case, resistance to this power is exercised when the "suppressed" clients refuse to coordinate their actions around the specified definitions and choose a different action. ${ }^{1042}$ Consultant's power is, therefore, the result of its acceptance through others, in this case through the managers who need the "dramatic experience" of consulting projects. ${ }^{1043}$ At the same time, however, supporters of the model deny the potential of clients to resist consultant's power by pointing out that clients are highly dependant and "addicted" to "management fads" created by consultants. ${ }^{1044}$ In other words, consulting fashions are seen as strategies for exercising control over managers, ${ }^{1045}$ and consultant's

1036

1037

1038

1039

1040

1041
See McKenna (2006), ch. 9.

Wright/Kitay (2004), p. 283.

See Hassard (1999), p. 191.

See e.g. Clark/Salaman (1998), pp. 151-152.

Gergen (1995), p. 42. The starting point of this argument is the view that the construction of meaning is a contested activity, which is not unified or guided by any integral and inclusive set of rules and interpretations. Gergen speaks about the "fragmented character of cultural languages". Gergen (1995), p. 36. Therefore, the valued meanings of any given group of individuals may be devaluated or considered irrelevant within the local understanding of other groups: "in generating agreeable assertions concerning what is the case [] the soil is also prepared for the growth of an oppositional discourse”. See Gergen (1995), p. 42. This threat of opposition leads to a further strengthening of the original assertions. As a result, the search for power of the own position feeds upon its own doubts.

See Hassard (1999), p. 192.

Ibid, p. 192.

This concept of a contested and undetermined nature of power is characteristic to a stream of research within the interpretivist school of power called the postmodern approach to power. Postmodern views of power are represented in some of the works of Gergen, Alvesson and Willmott, and Knights and Vurdubakis but these works do not represent a fully developed perspective on power. See Hardy/Clegg (1996), p. 636. These authors are mainly concerned with resistance to legitimate power within and across organizations. As such, they build upon Weber's work on dominancy and resistance but put it into a different theoretical context as they incorporate postmodernist ideas into Weber's tradition. See Hardy/Clegg (1996), p. 631.

See, e.g., Kieser (2002a), pp. 173-176.

Ibid, p. 182. 
power is both the result and the medium of such institutionalized organizational practices. ${ }^{1046}$ Consequently, consultants are regarded as the powerful actor within clientconsultant teams, and the nature of power as a strategy is emphasized.

However, this view of the power relation between clients and consultants does not explain consulting projects in which managers prescribe what solution should be proposed, with consultants' role restricted to introducing the preferred solution into the client organization. In other words, the view of consultants as the powerful actor contradicts research that argues that in some cases managers are the dominant actors. ${ }^{1047}$ As Sturdy argues, managers challenge consultants' sense of control, and play an increasingly active role in the relationship. ${ }^{1048}$ In other words, managers often choose whether to follow particular management fashions or not. ${ }^{1049}$ Consequently, consultants are not immune from the insecurities of modern life or those peculiar to their job. This means that the client-consultant relationship has a rather interactive, dialectic character and is one of mutual dependence. ${ }^{1050}$ Consultants are not always powerful and clients not always powerless and dependent. ${ }^{1051}$ Some authors suggest that client's ability to resist consultant's persuasive power is based in consultant's dependence on clients for future projects. ${ }^{1052}$ However, this type of dependency cannot be explained within this model because power is seen as a strategy. In other words, the relation between power and existing economic structures, in which client-consultant relationships are embedded, is ignored. Furthermore, it has been argued that client's ability to resist consultant's dominance is also based in client's knowledge. Thus, "the reputational and proprietary knowledge of the consultant versus the organizational and operational knowledge of managers defines the limits of the political process". ${ }^{1053}$ However, the relevance of client's knowledge is ignored within the critical model because the model is based on the assumption that knowledge is ambiguous, and that knowledge transfer is not about knowledge sharing but about persuading others in the value of one's knowledge.

To summarize, although some supporters of this model recognize that clients have the potential to resist consultant's dominance, they do not discuss this issue further, neither do they state the sources of this resistance. Rather, the view that clients are highly "addicted" to consulting fashions prevails. As a result, consultants are confirmed as the dominant actor within client-consultant teams. Furthermore, the emphasis on the relationship between clients and managers within this model reveals another critical point of the model. Similarly to the expert approach, it does not differentiate between the three groups of actors that are involved in consulting projects: client's managers who commission the project: i.e. the project sponsors; client's employees who participate in

This argument has its origins in the work of Foucault. See the discussion in chapter B.II.4.3.3.

See Alvesson/Johansson (2002), p. 237; Jackall (1988), p. 140.

See Sturdy (1997a, b).

Reasons why managers choose to adopt particular consulting fads are discussed in the next chapter.

See Sturdy (1997a), pp. 390; Sturdy (1997b), pp. 512; also Poulfelt et al. (2005), p. 19.

See Carter et al. (2004), pp. 27-28.

See, e.g., Alvesson/Johansson (2002), p. 237.

Fincham (1999), p. 350.
} 
the particular project: i.e. the problem owners; and the consultants. ${ }^{1054}$ Supporters of the critical model concentrate, in particular, on the role of the managers as the initiators of consulting projects, and ignore the role of the problem owners, which biases their analysis of the client-consultant relationship.

\section{Role of management fashions}

Furthermore, the critical model is based on the implicit assumption that management fashions created and disseminated through consulting fulfill, in the best-case only, symbolic functions such as signaling innovativeness. It is implicitly assumed that this does little to improve organizations' performances and in fact, in the worst-case, will even harm organizations by either facilitating the adoption of technically inefficient administrative technologies or processes, or rejecting efficient ones. ${ }^{1055}$ In general, consulting practices are seen as power mechanism that serve to control managers and make them dependent on consultant's services. It is implicated that such consulting fashions are adopted not because it is proven that they enhance organizations' performance, but because organizations seek to imitate other organizations that have the reputation to be at the forefront of management developments, e.g., competitors, suppliers, consulting companies, etc.-in order to gain legitimacy and signal innovativeness. ${ }^{1056}$ In contrast, Abrahamson argues that management fashions may play vital functions in drawing attention to problems and solutions that have long remained overlooked. ${ }^{1057}$ Furthermore, organizations that appear innovative or ethical because of the adoption of some fashion may gain some economic benefits, such as an easier access to capital or higher attraction to customers. Therefore, management fashions may have some positive effects on organizations ${ }^{1058}$ and consultants might be able to contribute to a better performance of the client's organizations.

\section{Nature of professional services}

Additionally, the critical model does not offer a complete picture of the nature of professional services. It recognizes the central role of impressing and the struggle of professions and professional service firms to gain legitimacy and power in the eyes of their clients. However, it fails to establish a rationale for the emergence of professional organizations. ${ }^{1059}$ If professions existed with the mere task to monopolize an area of service production and to prevent others from offering the same services, governments would have taken actions to prevent such monopolies, as it has been the case in other industries. In practice, however, the opposite is true: governments enable and encourage the existence of professional organizations. The reason for this is, ultimately, to be found in the nature of professional expertise, something that the critical model cannot explain.

\section{Practical relevance}

Because of its restricted assumptions regarding the nature of knowledge, the model does not explain those types of consulting that are characterized by the transfer of 
specific, technical knowledge from consultants to clients. An example for this type of consulting would be the case when consultants are engaged to develop a new production layout for a factory where technical considerations play the critical role for successful problem-solving. Thus, it can be argued that rhetoric and symbols are not equally important for all kinds of consulting projects. In general, when the client's problem is relatively familiar, it is easier for clients to define the service they require and to evaluate the presented solution. Ambiguity is high only in situations when clients have to deal with innovative, complex problems. ${ }^{1060}$ Thus, it can be proposed that problems associated with the idiosyncratic character of consulting expertise, which result in difficulties transferring knowledge to clients or evaluating its quality, as discussed in the critical model, are more relevant when "it is not clear what expectations one ought to have, and therefore it is not clear what would constitute an outcome mismatched to expectation. When one's system of understanding is internally inconsistent, the very same outcome may seem an error and not an error.” ${ }^{1061}$ Ambiguity and quality uncertainty are, therefore, less relevant in the case of simple routine problems. The critical model ignores the existence of different types of client problems and, as such, does not account for the complex nature of the client-consultant relationship. It emphasizes one type of consulting projects-i.e. those concerning complex and innovative problems-ignoring the reality that there are different motives for why clients engage consultants, for example, when clients want a fast and efficient solution for a familiar problem.

\section{Summary}

It can be speculated that the critical model, in contrast to the expert model, and similar to Schön's model, concentrates on problem situations that are ambiguous and uncertain, in which knowledge transfer between clients and consultants is complicated. The supporters of the model argue, as did Schön as well, that the ambiguous and context dependent character of consulting knowledge requires clients and consultants to engage in an intensive interaction. However, the critical model describes the client-consultant interaction in a different way and reaches to completely different conclusions than Schön. It argues that due to the idiosyncratic nature of consulting knowledge, consultants use stories and rhetoric in order to impress the clients and persuade them to buy their services. Thus, the emphasis on the ambiguous character of consulting expertise, pointing to the importance of meaning construction and persuasion during client-consultant interactions, and stressing the difficulties regarding knowledge transfer between clients and consultants, provides ultimately a more advanced understanding of the clientconsultant relationship than provided by the previous two models. Consequently, the problem-solving process is compared to a theatrical performance where consultants involve clients as actors and an audience. During this performance, both clients and consultants are engaged, to some degree, in a process of legitimization of existing consulting models and concepts or act as co-producers of new consulting concepts and fads. One important implication of the model is, therefore, that uncertain, novel problem situations are a prolific basis for the development of consulting fads and fashions.

However, to assume that consulting knowledge is highly symbolic with often no real value for clients, and moreover, that clients are "addicted" to consulting stories and 
concepts for whatever reason, is a highly unrealistic view of the consulting industry and its services. The critical model offers, as such, a very pessimistic perspective on consulting and the ability of consulting companies to provide anything of value to their clients. It also provides a pessimistic view of the consultants' clients, describing them as dependent on fashions and fads created by consultants. In particular, supporters of this view do not provide any solutions how to solve this problem of uncertainty, because they, in their extreme interpretations, deny the existence of shared, specific knowledge. Therefore, any activity that is based on the transfer of such knowledge is, ultimately, a mere selling of stories and myths. This focus on the tools and techniques used by consultants to impress the client is due to the oversimplification of the process of social construction during the client-consultant interaction that is present in the critical model. ${ }^{1062}$ Additionally, the model offers a too limited view of the meaning and sense of stories and rhetoric. Consequently, the model underplays the input of clients. As in the case of the expert model, the critical approach suggests a rather consulting-centric view of the client-consultant relationship, which is dominated effectively by the consultants. As such, the model fails to provide a complete picture of the client-consultant interaction. In particular, the model's explanations appear misleading in cases when the client's problem is familiar and when the clients possess themselves consulting knowledge. Thus, Fincham and Clark conclude that a more interactive approach to the client-consultant relationship is needed, one which sees the dissemination of ideas as a joint product. ${ }^{1063}$

To conclude, the rise of critical works on consulting can be seen as one sign for the growing dissatisfaction of clients with the existing business model of consulting. It can be speculated that whatever (prescriptive) models are used in the practice, they must be ignoring important characteristics of the client-consultant relationship and do not represent a business model that can ensure the long-term success of consulting companies. Although the critical model offers a view of consulting that seems to explain clients' dissatisfaction with consulting services, its assumptions are highly problematic and do not account for the multifaceted nature of consulting. For example, if the critical model was right about the nature of consulting and consulting expertise, it would imply that the future of this industry is not very bright. The relevant question is, then, how long can an industry that is built on rhetoric, symbols, dependence, and fear of loss of control survive?

This work attempts to provide a new business model for consulting, one that builds upon the contributions of the existing models and accounts for the multifaceted nature of the client-consultant interaction. As such, the model could contribute to a more complete understanding of the nature of the client-consultant relationship and its success factors. This model is presented in the following chapters. 


\section{Towards an interpretive model of the client- consultant interaction}

\section{Introduction}

The previous discussion showed that the three existing models of the client-consultant relationship provide some valuable contributions in explaining the interaction between clients and consultants. It was suggested that these contributions could be very helpful for a better understanding of this relationship when the different assumptions regarding the characteristics of the client-consultant relationship, as well as the different forms of interaction that the single models emphasize, are related to different types of client problems. ${ }^{1064}$ At the same time, it was argued that all of these models have important shortcomings and do not account for the multifaceted and complex nature of the clientconsultant interaction. One improvement might be to combine these models as a means of compensating for their individual weaknesses. It appears that such a combination would provide the richest view of client-consultant interaction. It is also apparent that, at this stage in the development of the theory about client-consultant interaction, some form of integration among the different perspectives remains underdeveloped. However, creating such an integrative framework is difficult given the different, and perhaps incompatible, assumptions of the models regarding the nature of knowledge and knowledge transfer and creation. Whereas the expert model is based on a positivist epistemology, the critical model builds upon an interpretivist epistemology. Schön's model represents a mixture of a positivist and an interpretivist view of knowledge without discussing any implications from the combination of these two perspectives. Additionally, the models have conflicting assumptions regarding the nature of power: the expert model assumes power relations as given and independent of the concrete clientconsultant relationship; Schön argues that power is balanced, and as a result, irrelevant for the outcome of consulting projects; and the critical model regards power as a strategy, the result and medium of institutionalized organizational practices. Consequently, the three models present a limited view of the nature of power and do not discuss, or not in a detail, how power emerges and is executed. Another problem with these models is that, when discussing the client-consultant relationship, they do not clearly differentiate between the working relationship within the client-consultant team, e.g., between the "problem owners" and the consultants, and the relationship between the sponsors of the consulting project, who hire and assess the quality of the consultants' work, and the consultants. This missing differentiation is the major reason for the existing ambivalence within both the expert and the critical model when discussing power relations in the client-consultant relationship. It is clear that client managers who hire and evaluate

1064 It is important to note that neither the expert model nor the critical model are seen in this way by their supporters. Rather, they are proposed as valid for all types of consulting projects. Only Schön's model argues that depending on the client problem either the traditional expert model or the reflective practitioner model provides a better basis for a successful client-consultant interaction. 
consultants and the members of the client organization, who participate in the daily work of the client-consultant team, have different positions, roles, and influence within the client organization, which influences their relationships with consultants. Consequently, the nature of power relations varies according to the level of analysis of the clientconsultant relationship. This important aspect needs further attention.

Morgan suggests four possible approaches to integrate apparently irreconcilable differences between divergent perspectives. ${ }^{1065}$ These are briefly explored in terms of their potential for the development of an integrated model of client-consultant interaction. The four approaches are supremacy, anything goes, contingency, and dialectic/synthesis.

\section{Supremacy}

This approach implies that one of the presented models can be seen as supreme according to some pre-stated criteria. The previous discussion of the existing models shows that none of the three approaches can be regarded to be the best. They all make important contributions for a better understanding of the nature of client-consultant interaction but have, at the same time, some important shortcomings. ${ }^{1066}$

\section{Anything goes}

This approach for dealing with the nature and claims of competing assumptions adopts a complete relativism. It suggests that every perspective may have something to offer and whether or not one attempts to synthesize different insights is of little real concern. ${ }^{1067}$ Although this approach is the less ambitious from all four approaches, it has some important shortcomings, the main of which is that it is unscientific. ${ }^{1068}$ Moreover, the critical discussion of the existing models as presented in the previous chapters implies that such an "anything goes" approach is not enough and not appropriate for the study of the phenomenon at hand. There is value in the development of an integrated model of the client-consultant interaction.

\section{Contingency}

This approach appeals to a pragmatist criterion that suggests that different perspectives should be judged according to their usefulness. In other words, they should be used as tools in a very practical manner. This view is based on the insight that there is no one best set of assumptions to study a particular phenomenon, and that it is appropriate to vary assumptions from one situation to another according to the issues being studied or the problem being solved. ${ }^{1069}$

See Morgan (1983), pp. 377; also Churchman (1971), pp. 190-205.

There are some flaws in the search for a supreme model or theory in general, such as that different grounds can be used for the evaluation of the models, which leads to the problem of relativism. See Morgan (1983), p. 378.

This approach was first suggested by Feyerabend (1975) who advocates “theoretical and methodological anarchism”. See Morgan (1983), p. 380. Feyerabend recognized the potential contradiction between creativity and method and rejected the idea that one form of knowledge can be determined as superior to another. Only the individual is in position to choose what kind of knowledge should guide his/her behavior. 
The contingency approach, although less ambitious than the dialectic approach adopted in this work, is not appropriate for the purposes of this work for the following reasons. The expert and the critical models have been proposed as general models accounting for all problem types that clients and consultants face. It is not in accordance to their fundamental assumptions to reduce their explanatory power to particular situations or problem types. Schön's model, on the other hand, follows the contingency approach, and some of the problems associated with such an approach were presented in chapter C.III.7.

This work attempts to expand on Schön's suggestions by following, as argued below, the more ambitious dialectic approach. It is believed that in this way, a more complete understanding of client-consultant interaction will be offered. At the same time, the new model recognizes that, depending on the problem being solved, the nature of the clientconsultant interaction would differ. As such, it introduces a contingency perspective on a lower level of the analysis by suggesting that there are different types of client-consultant interaction depending on the problem type.

\section{Dialectic/synthesis}

This approach accepts the diversity of assumptions as an inevitable feature of theory and research and attempts to use the differences among competing perspectives as a means to learn more about the phenomenon being studied. "The dialectic approach deliberately counterposes the insights of different perspectives in the hope that $a$ completely new mode of understanding will emerge from the debate generated by this opposition". ${ }^{1070}$ The purpose of this approach would be to show why each model views the client-consultant relationship as it does, and what the assumptions underlying these viewpoints are; to show that what one model regards as a set of natural assumptions, the other regards as a set of unwarranted assumptions. The essence of the dialectic approach lies in the idea that all models have something to offer and their competing insights have to be used within the context of a single analysis. ${ }^{1071}$ This would require the emergence of an "ultratheory", which would resolve the apparent paradoxes between the different perspectives. ${ }^{1072}$ In other words, as a result of the dialectic and conflict between the existing perspectives, it is hoped that a new, synthesized model will emerge. That is, the dialectic approach is a pre-stage for synthesis.

However, dialectic does not always lead to synthesis. In such cases, Morgan argues that synthesis is still possible through the development of an all-embracing paradigm and the translation of different views into a common language. In other words, whereas a dialectic approach requires the use of differences and tensions between competing perspectives to produce new understandings, a synthesis approach involves the search for common ground that combines strengths and minimizes weaknesses. ${ }^{1073}$ The search is for 
a common ground that can be recognized by everyone as the superior or most reasonable way to study the particular phenomenon. ${ }^{1074}$

It is suggested here that the existing models of client-consultant interaction do not have a common ground due to their incompatible assumptions regarding the nature of knowledge and power. Therefore, a dialectic approach is adopted: having counterposed the existing models and outlined their differences, next, a new model of the clientconsultant interaction can be proposed, a model that takes into account the insights of the existing models, but is based upon a completely different theoretical background. The proposed model is not, however, a mere synthesis of the existing models, as each of them ignores important aspects of the client-consultant relationship, such as the existence of cognitive pluralism within client-consultant teams ${ }^{1075}$ as well as how power emerges and influences client-consultant interactions. ${ }^{1076}$ Rather, the proposed model offers a number of "new" insights on the nature of the client-consultant interaction. Thus, it is claimed that the suggested model offers a multifaceted description of the nature of their relationship and develops, at the same time, a number of suggestions for both clients and consultants as to how to improve their cooperation. As already discussed, although there is no empirical study providing insights about the extent to which the one or the other model is applied in reality, a look at the consulting and management literature shows that the majority of consulting projects exhibit characteristics of the expert model. At the same time, the critical model does not propose any avenues for improving the cooperation between clients and consultants due to its critical and pessimistic view of consulting services. Finally, it can be only speculated if and to what extent Schön's suggestions have been adopted in practice. However, the growing evidence of clients' dissatisfaction with consulting services is a sign that whatever model clients and consultants have been following, there must be some disfunctionalities in their relationship that have been preventing them from realizing the real potential of their collaboration. It is hoped that the interpretive model will shed some light on some of these disfunctionalities and will help clients and consultants to develop a better understanding of their interaction.

In the following, the underlying theoretical assumptions of the new model, called the interpretive model, are briefly drawn together. Table 11 summarizes the main differences of this new model in comparison to the existing models.

The interpretive model draws on Schön's ideas about the existence of different practice communities and advances it taking into consideration Fish's ${ }^{1077}$ and Loasby's ${ }^{1078}$ concept of interpretive communities. The model argues that the origin of the different understandings of clients and consultants, and the difficulties with knowledge

1074

1075

1076
Ibid, p. 378.

Robertson and Swan point out that the study of different cultural perspectives has been largely overlooked when studying knowledge-intensive firms such as management consultancies. See Robertson/Swan (2003), pp. 838-839.

A topic that is widely ignored not only when studying professional service firms but also within the literature on knowledge transfer and learning. See Armbrüster/Kieser (2001), p. 693; Blackler (2000b), p. 833; Coopey/Burgoyne (2000), p. 869; Easterby-Smith et al. (1998), p. 261; Ferdinand (2004), p. 435; Iding (2000), p. 7 and p. 21; Lawrence et al. (2005), p. 180; Marshall/Rollinson (2004), p. S71.

See Fish (1980).

See Loasby (1983, 2000, 2001a, b, 2002). 
transfer, can be found in the existence of different interpretive communities. Knowledge is created and transferred within such socio-culturally constituted interpretive communities or discursive practices and is the result of an ongoing process of interaction between individuals. ${ }^{1079}$ The concept of interpretive communities makes it clear that because people participate in multiple interpretive communities they will often develop different and legitimate perspectives about the best way to solve a problem and will have difficulties in understanding one another fully. For example, when looking at the same phenomenon members of different communities will not only see different solutions to the same problem but may see quite different problems from what appear to be similar conditions. Thus, communities may have problems in understanding each other's language, much of which "might be perceived as pure noise". ${ }^{1080}$ Management consulting differs from other types of professional services exactly because clients are not always laypersons without any relevant knowledge for the problem-solving. In other words, the knowledge gap between clients and consultants is not as big as the knowledge gap between, for example, a doctor and a patient. Rather, consulting clients often possess valuable knowledge and expertise themselves that needs to be combined with the knowledge of the consultants in order for them not only to create a better picture of the problem but also to generate a better solution. Additionally, team members might have different perspectives on teamwork and might disagree on their roles and responsibilities in the problem-solving process, the interaction patterns within the team and/or the communication channels to be used. As a result, client-consultant teams are often characterized by pluralist situations. ${ }^{1081}$ It follows that the development of shared understanding with respect to both task-specific and task-related knowledge, is the foundation for a successful communication and problem-solving between clients and consultants. $^{1082}$ On the one hand, clients and consultants need to develop a shared understanding and knowledge of the problem at hand, as well as its possible solution paths in order to solve the problem successfully; on the other, they need to develop a shared understanding about how they are going to coordinate and integrate their activities. ${ }^{1083}$ Such shared interpretations and knowledge are not seen as given and universal, as in the expert model, but as dependent on and the result of intensive interactions and translations within the client-consultant team. Translation is, thereby, not the same thing as transfer. “'Transfer' suggests an objectification or commodification of knowledge, extrapolated from its context, with the translator serving as a mere conduit or

\footnotetext{
1079

1080

1081

See Bechky (2003), pp. 313-314; Empson (2001), p. 813; Reihlen (2003b), pp. 576-577.

Clegg et al. (2004), p. 38; also Kirsch/Eckert (1998), p. 281; Wimmer (2004), p. 287.
}

This insight also builds the basis for Wimmer's theory of organizational consulting. See Wimmer (2004); also Iding (2000), pp. 55-80. However, Wimmer proposes a view of organizations as systems of communications. See Iding (2000), p. 183. Such a view ignores that organizations are material systems made of people. Consequently, Wimmer's theory cannot explain any issues that are related to their members, in particular, power relations. See Iding (2000), pp. 183-188 for a critical discussion of Wimmer's theory.

See the discussion in chapter B.II.4.1.2.

Similarly, Sommerlatte suggests that the analysis of the consulting process requires an emphasis on project and communication structures within client-consultant teams. See Sommerlatte (2000), p. 42. In general, Sommerlatte's model of learning-oriented consulting shows some similarities to the interpretive model proposed within this work. However, his model remains too unspecific in its analysis and consequences for client-consultant interaction. In particular, Sommerlatte does not explicitly discuss his assumptions about the nature of knowledge and as a result, his suggestions how clients and consultants transfer and create knowledge leave many open questions. Additionally, he does not discuss in detail the important issue of power. 
channel through whom the meaning simply passes”. ${ }^{1084}$ In contrast, translation involves not only linguistic dimensions, but also psychological and cultural. It is always affected and shaped by the translator. ${ }^{1085}$

The interpretive model therefore concentrates on the influence of divergent perspectives on knowledge transfer and creation in client-consultant teams, and on the question of how clients and consultants develop a shared understanding and achieve coordinated action. However, it does not suggest that the development of shared cognition is a sufficient condition for successful client-consultant interaction. Rather, there are additional necessary conditions for successful problem-solving including shared aims or goals that direct the problem-solving process, as well as an agreement on the set of methods to be used. ${ }^{1086}$ Moreover, trying to develop a shared understanding does not only include communication. It also includes the possibility of verifying it in an objective manner ${ }^{1087}$ with the help of appropriate and utilizable general and specific problemsolving methods, techniques, and social practices, both existing and new. ${ }^{1088}$ However, the nature and characteristics of such methods and practices, as well as the nature of rational problem-solving processes that take place in client-consultant teams, ${ }^{1089}$ are not at the heart of this model for two reasons:

(1) Problem-solving issues as discussed in the literature on decision-making and planning focus on the dynamics of individual problem-solving. Whereas individual knowledge and beliefs (concerning means and ends) are certainly the fundamental elements of any team cognitive and belief structure, to assume that some configuration of individual knowledge and beliefs underscores problem-solving belies the complexity of the political processes that produce such a configuration. ${ }^{1090}$ As to be shown, individuals have different interpretive frames and are members of different interpretive communities, so that every problem-solving group is not only cognitively heterogeneous, but is possibly ripe for conflict over the negotiation of the members' fundamental interpretations and beliefs. ${ }^{1091}$ In other words, individuals' cognitive differences imply that they will not only diagnose problems differently, but will, as a result, suggest different problem solutions that might be more or less functional depending on the set of conditions and the goals of

Yanow (2004), p. S15. This understanding of knowledge transfer is typical for the expert model. See chapter C.II. See Yanow (2004), p. S15. In the following, the notion of knowledge transfer is used with the understanding that it implies also translation, not a simple transfer of meaning. See also Kirsch/Eckert (1998), p. 296.

See Bunge (1996), p. 79. Thus, problem-solving requires some aim or goal, either practical or cognitive, and the aim determines the method of handling the problem.

See Bunge (1998), p. 18. This includes also causal (and probalistic) explanations of individuals' knowledge and perspectives.

These methods and practices are one of the elements that characterize learning communities. See Bunge (1983a), pp. 90.

Rational problem-solving processes include in general five phases: problem formulation, design of a model that represents the problem, design of a plan for problem-solving, testing of the model and implementation of the design. See Bunge (1985), pp. 225; Reihlen (1997), pp. 187. See also Hoffmann (1991), pp. 58-59 for a consulting specific desription of this procedure.

See Walsh/Fahey (1986), p. 327.

It has been suggested that even efficiency, as a criterion for decision-making, is context dependent and can be evaluated differently by different groups of people. See, e.g., Hoffmann (1991), pp. 150-151. 
the involved individuals. ${ }^{1092}$ Thus, the functionality of a particular solution in a particular context can be evaluated only after the solution is put to test in a particular context. ${ }^{1093}$ Such an evaluation is, however, time consuming, and in the case of social problems, never complete. ${ }^{1094}$ Thus, there are situations in which rational problem-solving cannot guarantee an agreement on the problem solution to be pursued. Therefore, the study of processes that lead to the development of shared knowledge and beliefs including political disputes and power relations, not their elimination, is necessary in order to understand what influences the success of client-consultant interaction. ${ }^{1095}$

(2) Problem-solving processes based on the assumption that rational decision-making takes place-i.e. that shared cognition is given or possible as a result of rational social practices-have been extensively discussed elsewhere so that a detailed discussion within this work will not provide any further insights into the topic. ${ }^{1096}$

Consequently, the interpretive model suggests that shared cognition might not always be achievable and that the application of rational problem-solving methods might not always lead to consensus between the involved individuals on how to approach a particular problem. ${ }^{1097}$ Thus, it is suggested that pluralist situations, which are typical for client-consultant teams, often can be resolved only with the help of power. This power is, however, not necessarily associated with a particular position or resource, but is the result of translations and discourses during the client-consultant interaction. ${ }^{1098}$ It is power associated with interpretive dominance, which implies that any competing interpretations are prevented from further development. Thus, it is suggested that power is to be found not only in the hierarchical positions of individuals but more so in the discourse between different interpretive communities, "in the way in which the available categories for talk in particular contexts [are] lodged within the mode of rationality". ${ }^{1099}$ It follows that the power of a particular interpretive community is dependent on the relevance and

1092 See Tichy (1975), pp. 793-798. Tsoukas and Hatch argue as well that goals, or motives, are interpretations and as such, they differ between members of different interpretive communities. See Tsoukas/Hatch (2001), p. 1003. This argument contradicts views of consulting, which postulate that interpretation differences exist only in problem situations characterized by lack of information and knowledge. Such views assume that with the increasing amount of knowledge the political character of decision-making loses ground. See, e.g., Kirsch/Eckert (1998), pp. 266-306; also Schräder (1995), pp. 40-41. In contrast, within this work, knowledge is regarded as related to power. See the discussion in chapter D.IV.

When different legitimate perspectives exist, they are regarded as hypothetical and need to be evaluated and assessed by the members of the team. See also Schräder (1995), p. 42.

Tests cannot prove the functionality of a problem solution exactly as a number of other factors also influence social contexts, such as economic (external) and psychological (internal) factors. In addition, some problem solutions can be evaluated only after longer periods of time. See also Fritz/Effenberger (1998), p. 111; Sommerlatte (2000), p. 154.

See also Schräder (1995), pp. 41-42; Walsh/Fahey (1986), p. 327

See Behrens/Delfmann (2002) for a detailed discussion of quantitative methods and procedures for problem-solving. See Reihlen (1997), pp. 187 who suggests a framework for the analysis and design of rational innovative problem-solving. Dialectical inquiry plays a main role in this framework. Schweiger et al. discuss as well the nature of dialectical inquiry. They also provide a good overview of existing research in the area. See Schweiger et al. (1989), pp. 747 and the discussion in chapter D.IV.2. 
importance of its knowledge and on the ability of the community to enforce its perspective and persuade members of other interpretive communities in the superiority of its knowledge. ${ }^{1100}$ Such a multidimensional view of power can help members of interpretive communities to develop a broader array of mechanisms to ensure joint action. Moreover, it can help to prevent conflict over divergent interpretations from emerging. ${ }^{1101}$ This view of power implies, furthermore, a different understanding of the nature and role of professional business services in modern societies. 



\begin{tabular}{|c|c|c|c|c|}
\hline & The Expert Model & The Reflective Practitioner Model & The Critical Model & The Interpretive Model \\
\hline ڤ્仓 & $\begin{array}{l}\text { Aharoni (1993a,b; 1997), Gallessich (1982), Hall } \\
\text { (1969), Kubr (1996), Lowendahl (1997), Sadler (1998), } \\
\text { Schein (1988), Sibson (1973). }\end{array}$ & Schön $(1983,1987)$ & $\begin{array}{l}\text { Alvesson (1993, 1995, 2001), Clark (1995), Clark } \\
\text { and Salaman (1996a,b, 1998a, b), Kieser (1997), } \\
\text { Jackson (2002) }\end{array}$ & $\begin{array}{l}\text { Boland/Tenkasi (1995), Bronw/Duguid (1991), Fish } \\
\text { (1980), Fox (2000), Loasby (1983, 2000, 2001a,b, } \\
\text { 2002), Reihlen (2003), Tsoukas/Vladimirou (2003) }\end{array}$ \\
\hline 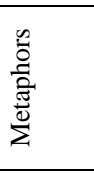 & $\begin{array}{l}\text { The consultant as: "helper” (Schein, 1987, 2002;); } \\
\text { "seller of expertise” (Aharoni 1997); “doctor” } \\
\text { (Gallessich, 1982; Rassam, 1998; Schein, 1988). }\end{array}$ & $\begin{array}{l}\text { The consultant as: "reflective practitioner" } \\
\text { (Schön, 1983). }\end{array}$ & $\begin{array}{l}\text { The consultant as: provider of institutionalised myths } \\
\text { and rhetorician (Alvesson, 1993, 1995); “impression } \\
\text { manager” / "storyteller” (Clark, 1995; Clark/Salaman, } \\
\text { 1996b); creator of management fads (Jackson, 2002; } \\
\text { Kieser, 1997, 2002). }\end{array}$ & $\begin{array}{l}\text { The consultant as: "obligatory passage point", } \\
\text { reflective practitioner, interpreter, translator, and } \\
\text { storyteller. }\end{array}$ \\
\hline 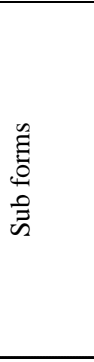 & $\begin{array}{l}\text { The "expert consultant" applies predetermined } \\
\text { solutions to problems, almost irrespective of the contexts } \\
\text { in which s/he finds them. The main task of this kind of } \\
\text { consulting is the solution of practical problems and its } \\
\text { value lies in its functionality and usefulness. The "pure } \\
\text { researcher" studies social issues and problems, } \\
\text { independent of a particular problem and client. This is } \\
\text { the case when, for example, university professors work } \\
\text { as consultants. The goal of the researcher-consultant is to } \\
\text { bring scientific expertise into the companies. Examples } \\
\text { are Fayoul, Taylor, Hammer and Champy, Porter. }\end{array}$ & $\begin{array}{l}\text { The "reflective practitioner" solves only } \\
\text { s cases when the client's problem is of } \\
\text { sufficient importance because the } \\
\text { establishment of this relationship is difficult } \\
\text { and time consuming. In emergent or routine } \\
\text { situations when clients usually want a fast and } \\
\text { efficient solution, rather than a long and risky } \\
\text { conversation process, the expert type of } \\
\text { o consultant is more appropriate. }\end{array}$ & $\begin{array}{l}\text { There are two sub forms: management gurus and } \\
\text { management consultants. Management consultants } \\
\text { rely less on charisma than management gurus. While } \\
\text { management gurus create a universal appeal, } \\
\text { consultants address individual client's needs. These } \\
\text { ddifferences are, however, a "matter of emphasis rather } \\
\text { than category distinctions" (Fincham, 2002). Also, } \\
\text { some management gurus establish their own } \\
\text { consultancies so that guru and consulting activities } \\
\text { overlap. }\end{array}$ & $\begin{array}{l}\text { Consultants, who offer legitimized, fixed through } \\
\text { previous discourses problem solutions, act as experts or } \\
\text { "obligatory passage points" for such problems. On the } \\
\text { other hand, there are consultants who engage in } \\
\text { disturbing and bringing "noise" in fixed interpretations } \\
\text { and, as such, act more as reflective practitioners. }\end{array}$ \\
\hline 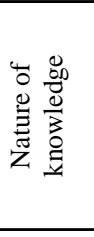 & $\begin{array}{l}\text { Knowledge is a decontextualized, objectively definable } \\
\text { asset or a resource; it is independent of its carriers and } \\
\text { their interpretations. Consulting knowledge is based } \\
\text { partly on an abstract body of knowledge and partly on } \\
\text { consulting methods. }\end{array}$ & $\begin{array}{l}\text { Consulting expertise is embedded in the } \\
\text { professional body of knowledge. It is only } \\
\text { partly based on technical expertise (abstract } \\
\text { body of knowledge). An important part of it is } \\
\text { embedded in a skilful practice and is } \\
\text { constructed in a process of "reflection-in- } \\
\text { action". }\end{array}$ & $\begin{array}{l}\text { Knowledge is a social product. Consulting } \\
\text { knowledge is developed in interaction with the client } \\
\text { and is ambiguous and idiosyncratic. Images, stories } \\
\text { sand symbols serve as "rationality-surrogates" and } \\
\text { constitute consultant’s real expertise. }\end{array}$ & $\begin{array}{l}\text { Knowledge is created and shared within socio- } \\
\text { culturally constituted discursive practices. Consulting } \\
\text { knowledge is based on abstract concepts and experience } \\
\text { developed, transmitted, and maintained in shared } \\
\text { interpretive communities. }\end{array}$ \\
\hline 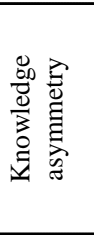 & $\begin{array}{l}\text { Consultants as experts have the capacity to solve } \\
\text { clients' problems; the client is a lay person and is more } \\
\text { or less excluded from the problem-solving process. } \\
\text { There is a unidirectional knowledge asymmetry. }\end{array}$ & $\begin{array}{l}\text { Client and consultant both possess } \\
\text { knowledge important for the problem } \\
\text { solution; there is a mutual knowledge } \\
\text { asymmetry. }\end{array}$ & $\begin{array}{l}\text { Because of the intangible and interactive character of } \\
\text { the consulting service, clients have difficulties in } \\
\text { evaluating the consultant's knowledge and the } \\
\text { provided service before and after it has been delivered. } \\
\text { There is a unidirectional "knowledge" asymmetry. }\end{array}$ & $\begin{array}{l}\text { Knowledge necessary to solve routine problems is } \\
\text { more common and shared across different interpretive } \\
\text { communities. There is no substantial knowledge } \\
\text { asymmetry. When clients and consultants face a novel } \\
\text { and complex problem, they will have different } \\
\text { perspectives on the problem and the right solution. } \\
\text { There is a mutual knowledge asymmetry. }\end{array}$ \\
\hline 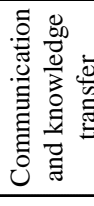 & $\begin{array}{l}\text { Communication is a process of information transfer } \\
\text { between client and consultant. Important aspects of the } \\
\text { communication process are the communications } \\
\text { channels, the characteristics of messages and the } \\
\text { motivation and absorptive capacity of the involved } \\
\text { individuals. }\end{array}$ & $\begin{array}{l}\text { Communication is a process of reflecting on } \\
\text { one's own understanding and sharing it with } \\
\text { others. This requires intensive interaction } \\
\text { between the involved individuals. }\end{array}$ & $\begin{array}{l}\text { Communication is a process of creating impressions, } \\
\text { images, and stories. In this way, consultants try to } \\
\text { impress the clients and convince them that they have } \\
\text { something valuable to offer. Rhetorical skills and acts } \\
\text { are important aspects of the communication process. }\end{array}$ & $\begin{array}{l}\text { Communication is a process of translation and of } \\
\text { creating alignment between interpretive communities. } \\
\text { Only when some conceptual frameworks are shared is } \\
\text { knowledge transfer possible. Through the process of } \\
\text { translation, new meanings emerge and new knowledge } \\
\text { is created. }\end{array}$ \\
\hline 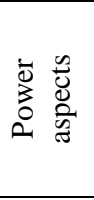 & $\begin{array}{l}\text { Because consultants possess a unique scientific body of } \\
\text { knowledge, it is the right of the consultant to determine } \\
\text { the problem solution on the basis of professional } \\
\text { judgment. The client does not participate in the problem- } \\
\text { solving process and is dependent on the knowledge of } \\
\text { the expert (consulting-centric view). }\end{array}$ & $\begin{array}{l}\text { f Both consultant and client are powerful and } \\
\text { interdependent because both parties possess } \\
\text { relevant knowledge and make important } \\
\text { - contributions to the problem-solving process. } \\
\text { Because power is balanced, it does not } \\
\text { influence the knowledge transfer process. } \\
\end{array}$ & $\begin{array}{l}\text { Consultants are powerful and persuasive figures; they } \\
\text { use rhetoric, stories, and symbols to impress clients } \\
\text { and sell management fads. The client is passive and } \\
\text { dependent on consultants and the management fads } \\
\text { they create (consulting-centric view). }\end{array}$ & $\begin{array}{l}\text { Client and consultant are mutually dependent. Power } \\
\text { is constructed through discourse; it is dependent on } \\
\text { knowledge and vice versa. Power is the "interpretive } \\
\text { dominance" over other interpretive communities. }\end{array}$ \\
\hline
\end{tabular}

Table 11: A summary of models of the client-consulting relationship 


\section{Context}

The perspective that builds the foundations of the interpretive model, and includes some of the insights of interpretivism, is critical realism. In order to understand better the theoretical background of the interpretive model, ${ }^{1102}$ as well as its difference from the existing models, the main assumptions of critical realism that build the basis of the interpretive model are outlined in the following.

Critical realism is one of the streams that developed out of the criticism on positivism. Although it has a much longer tradition, it has been formally applied to the social sciences since the 1970 s. ${ }^{1103}$ Some of the main proponents of critical realism in the social sciences are Harré, Bhaskar, Archer, Lawson and Sayer. ${ }^{1104}$ Additionally, many other researchers have implicitly drawn upon realist ontology-an ontology that is both non-positivist and non-postmodernist. ${ }^{1105}$ Because critical realist philosophers assume that the natural and the social world does not consist of discrete atomistic events but of complex structures, they strive to show how things are connected, how the particular is connected with the general. ${ }^{1106}$ As such, critical realism follows the tradition of systemism, ${ }^{1107}$ which is adopted within this work for the discussion of the clientconsultant relationship.

Critical realism challenges positivism arguing that it merely searches for "correlations and laws without any real insight or explanation as to why these events occur". ${ }^{1108}$ Similarly, critical realists criticize interpretivists on the grounds that in their focus on the social construction of reality they often confine attention to superficial and abstract study of the surface of reality. ${ }^{1109}$ Thus, "both approaches are viewed as seriously lacking in that they fail to explain reality as the manifestations of a complex, deep structure of relations". ${ }^{1110}$ From a critical realist perspective, social phenomena, such as client-consultant relationships, are determined by their internal and external relations; they are an "outcome of interacting tendencies". ${ }^{1111}$ Thus, critical realists concentrate on the study of social structures, powers, and relations that govern perceptions, actions, and

The name of the model embraces understanding (Verstehen) as "the name of a complex process by which all of us in our everyday life interpret the meaning of our own actions and those of others with whom we interact". Bernstein (1976), p. 139, cited in Schwandt 2000. See also Bunge (1996), pp. 150-154 on the meaning of "meaning” and section D.III.1.2.2 of this chapter. The name should not imply, however, that the model embraces a postmodern and a relativist understanding of reality. See the following discussion.

See Ackroyd/Fleetwood (2000), p. 5.

Ibid, p. 5.

See Ackroyd and Fleetwood who stress that the explicit adoption of critical realism in the field of management and organization studies has been relatively rare. Interestingly, many social researchers assume that critical realism is similar to positivism and regard postmodernism as the only alternative to study the social world. Ackroyd and Fleetwood emphasize that critical realism is rather compatible with some of the assumptions of interpretivists but follows clearly the realist ontology. See Ackroyd/Fleetwood (2000), pp. 8; also Tsoukas (2000), pp. 531-532.

See Reed (2000b), p. 54.

Morgan (1983), p. 38.

See Morgan (1983), p. 38.

Ibid, p. 38.

Ibid, p. 38.
} 
events. ${ }^{1112}$ These structures, powers, and relations are, on the one hand, an ever-present condition for human action. On the other hand, they are a continuously reproduced and/or transformed outcome of human action. ${ }^{1113}$ As such, critical realists examine the interface of concrete material reality and social construction of reality, and particularly the effects of power and domination on the mediation of socially created and reified structures. ${ }^{1114}$

Of a particular relevance in this work are the realists' assumptions regarding the nature of knowledge and power. Critical realism, similarly to the interpretivist school of thought, accepts the importance of meanings and interpretation when studying the nature of knowledge. "The meanings attributed to situations by people are [] central to the realist project”. ${ }^{1115}$ Furthermore, critical realists accept that there are multiple perspectives or competing claims about the nature of the social world and about any social issue. Meanings are not independent of history and "exist as multiple and overlapping resources from which social actors select, combine, and juxtapose". ${ }^{1116}$ It follows that people differ in their interpretations of the same events and issues and only those with a common background and experience develop some shared understanding. Therefore, knowledge transfer is possible within socio-culturally constituted communities where individuals share conceptual frames and meanings as well as concrete social practices. Thus, communication is embedded in social practices and is a matter of gaining mutual understanding. ${ }^{1117}$ Learning is the result of a joint discussion and interpretation of events, and of gradual changes in assumptions and perspectives of the involved individuals. ${ }^{118}$ These are central arguments within the interpretive model of client-consultant interaction.

Furthermore, critical realists, similar to interpretivists, argue that cognitive functions like meaning, intending, purposing, and valuing are bound to experience and can be comprehended only from within, through performing them, "through one's own firsthand experience”. ${ }^{1119}$ As such, knowledge has an ideational character. At the same time, realists acknowledge the biological and physical characteristics of the human mind and

See Ackroyd/Fleetwood (2000), p. 13. Interpretivists concentrate, in contrast, on the study of perceptions and actions only.

Ibid, pp. 12-13.

See Deetz/Kersten (1983), p. 156; Putnam (1983), p. 36. Thus, critical realism acknowledges that social reality is constructed through the actions of actors but refuses to conclude that the social world is completely socially constructed or determined by individuals' concepts of it as done by postmodernists. Rather, critical realists view social phenomena as concept dependent or socially constructed but stress that "underlying the concept dependent nature of social reality is an irreducible material substrate”. Ackroyd/Fleetwood (2000), p. 12, emphasis added. As such, critical realism is committed to materialism. Ibid, p. 12; see also Bunge (1996), pp. 353-358. In other words, critical realists state that social reality has a degree of objectivity in the sense that it can be reproduced by human interactions independently of its identification by the individuals who constitute it. Therefore, social relations are "reproduced, in part, via discourse, but are irreducible to, or are not, only discourse". Ackroyd/Fleetwood (2000), p. 12, emphasis in the original. Discourse, in this sense, is similar to the notion of language and is constructed through language.

Ackroyd/Fleetwood (2000), p. 19.

Holt (1997), p. 328. This statement is in contrast to the view of structuralists that "culture [is] a closed, idealist, and often universal system of meaning”. Holt (1997), p. 328.

See Holt (1997), p. 328; also Heracleous/Barrett (2001), pp. 757-758. Thus, critical realism differs from postmodernism and the linguistic turn as it argues that individuals interpret knowledge according to distinct socio-culturally constituted and shared conceptual frameworks, which enables the development of shared, non ambiguous knowledge. 
knowledge. ${ }^{1120}$ Therefore, the interpretive model acknowledges both the importance of meaning and interpretations, i.e. the ideational character of knowledge, as well as its biological, material nature. Rescher's perspective on the nature of knowledge offers a useful summary of this approach showing that there is no reason to assume that these two arguments are incommensurable. ${ }^{1121}$

Rescher suggests that whereas brain processes can be fully explained by an external observer, the ideational aspect of thinking can be only apprehended through one's own first hand experience. ${ }^{1122}$ "[A] scientific, evolutionary, neurophysiological account of thought processes does nothing to eliminate or diminish the contentual aspect of meaning and purpose, which can be appreciated only from the 'internal' performer's standpoint". ${ }^{1123}$ In other words, "how minds arise and come to acquire their talents and capacities is one thing, what they do with them is another". ${ }^{1124}$ Biological, in particular neurobiological insights, have to do with the first; cultural studies based on hermeneutical idealism, i.e. interpretivism, with the second. "There is - and can be-no incompatibility between them, seeing that different issues are involved”. ${ }^{1125}$ Rescher concludes,

"[] an evolutionary account of mind is predicated on a position that is 'materialistic' in viewing the mind as having a crucial basis for its operations in the processes of the body (and the brain in particular). But this sort of causal-origin materialism is nowise at odds with a hermeneutical idealism that maintains that we understand various of the world's processes in terms of concepts and categories drawn from the 'inner' experience of the mind's self-observation. [] The former issue belongs to the domain of the causal explanation of experiencing as events in the physical world, the latter to the phenomenology of our experiences as phenomena in the world of thought". ${ }^{1126}$

These insights build the foundation of the view of knowledge and learning within the interpretive model. The model takes a neurobiological perspective on the human mind and knowledge but acknowledges, at the same time, that because of the plurality of

In other words, critical realists are committed to materialism when studying human cognition and knowledge. See Ackroyd/Fleetwood (2000), p. 12. See Bunge (1996), pp. 298-304 for an extensive discussion of materialism.

See Rescher (1990), pp. 119-127. See Scherer/Steinmann (1999) who discuss the problem of incommensurability in organization studies. Incommensurability means that there is a radical difference between systems of orientation and, at the same time, a relationship of conflict of competition between those systems of orientation. Finally, the thesis of incommensurability states that there are no objective standards of comparison with which the conflict between the systems of orientation can be resolved. See Scherer/Steinmann (1999), pp. 521-523. For the specific case discussed here, it could be argued that an ideational understanding of knowledge is not compatible with a materialist understanding of the nature of human mind and cognition. However, Rescher's realist perspective on knowledge shows that there is no reason to assume that such a realistic view of knowledge is not theoretically sound. See also Tsoukas (2000), pp. 531 for a similar argument.

See Rescher (1990), pp. 119-127.

Rescher (1990), p. 124.

Rescher (1990), p. 124.

Ibid, p. 124.

Ibid, p. 125, emphasis in the original. Thus, taking Rescher's perspective, this work also agrees with Bunge that "Verstehen” or interpreting of others' perspectives is not an alternative to causal (and probalistic) explanation but rather its complement. See Bunge (1998), p. 18. In other words, trying to understand somebody's perspective does not exclude the possibility to check it in some more or less objective manner. 
meanings and understandings, knowledge transfer and learning are only successful when individuals learn to share their interpretations and access each other's viewpoints. Additionally, this view acknowledges that one's interpretations of the actions or perspectives of others are not the only determinant of one's own actions. Individuals are also motivated or inhibited by a number of material, natural and social, constraints. ${ }^{1127}$

Critical realism also builds the foundation of the view of power as developed within the interpretive model. It connects debates about power, emanating from interpretivism, to traditional views of power; it is an approach that creatively uses the resources that Foucault provides ${ }^{1128}$ but introduces some important insights that differ from those of interpretivists. It views organizations as networks of social practices, which include "an 'order of discourse', a relatively stabilized and durable configuration of discourses". 1129 Thus, the here proposed view of power also integrates ideas from critical discourse analysis, which concentrates on the study of interrelated discourses and their role in constituting and sustaining power relations. ${ }^{1130}$

First, it is argued that power should not be seen as ubiquitous as suggested by the interpretivists. Rather, it can be regarded as flowing "through different circuits of social relations, with different effects". ${ }^{1131}$ On the one hand, there is the episodic, agency concept of power that emphasizes notions of causality. In this view, power is seen "as a locus of will, as a supreme agency to which other will would bend, as prohibitory; the classic conception of power as zero-sum; in short, power as negation of the power of others". ${ }^{1132}$ On the other hand, the interpretive model acknowledges the dispositional and facilitative nature of power. Power is seen as a strategy and is "equalized" with "practice” and “discipline”. 1133

See Bunge (1996), p. 289.

See Clegg et al. (2006), p. 8-25; also Clegg (1989a), pp. 187-240 and Scott (2001), pp. 13.

Fairclough (2005), p. 918.

See Phillips (2003), p. 224. Discourse analysis draws upon the work of Foucault (and other poststructuralists) and utilizes, at the same time, methods and ideas originating in conversational analysis, studies of institutional dialogue, and pragmatics. See Grant et al. (2004), pp. 11-12. Discourse analysis is regarded as a powerful qualitative method that can be used to study empirically interpretive communities and their discourses as well as the emergence and role of power. From particular interest for the discussion in this work is a form of discourse analysis called critical discourse analysis (CDA), which concentrates on the study of interrelated discourses and their role in constituting and sustaining power relations. See Phillips (2003), pp. 224. In this work, the realist version of CDA as suggested by Fairclough (2005) and Reed (2000) is followed. See also Heracleous who speaks about an "interpretive discourse analysis". Heracleous (2004), pp. 186-187. CDA looks at the relationships between relative stabilized discourses as an element of "relatively durable social practices" and organizational texts created by other social actors or within other discourses. Fairclough (2005), p. 924. The objective of CDA is not the analysis of discourse per se, but to analyze the relations between discourse and nondiscoursal elements of the social world. However, CDA shows one important shortcoming. Although it emphasizes the role of non-discursive elements for the creation and dissemination of discourses, and thus power, it does not refer to the cognitive element of discourses. Texts are in the centre of the analysis, not the brains that produce these texts. In a recent handbook on organizational discourse, there was no single chapter solely devoted to this issue, as the editors of the handbook recognize themselves. See Grant et al. (2004), p. 22. Thus, an important question to ask is "where do the discourses, narratives, texts and words that are analyzed in organizational discourse come from?” Marshak et al. (2000), p. 250. It is suggested that the concept of interpretive communities is the missing concept within CDA. In this, this work follows van Dijk's proposition that cognition is the "missing link" between discourse and action. Van Dijk (1993), p. 251. Additionally, CDA does not discuss the concrete steps through which a particular discourse develops into a dominant discourse. The following work makes some suggestions how to combine CDA with a realist conception of knowledge and knowledge transfer. It also proposes how discourses develop into dominant positions.

Clegg et al. (2006), p. 8-25.

Clegg (1989a), p. 4.

See Clegg (1989a), pp. 1-5 and the discussion in chapter B.II.4.3.3. 
Second, this work assumes that agency and structure are in a reciprocal relationship. In other words, there are recurring social structures in which social interaction is embedded and at the same time, forms of social action influence such structures. ${ }^{1134}$ "Social structures necessarily pre-date the social actions which reproduce and transform them []. Social actors draw on the unequally distributed assets that such pre-existing structures make available as a basis for their engagement in forms of social activity which will reproduce and transform the institutionalised positions-practices in which they are located.” 1135 At the same time, actors do have a choice: structural constraints are operating only through the intentional motives and actions of agents, and are inherently tied to their capacity to act and "make a difference". ${ }^{1136}$ Therefore, "it is neither the intentions of subjects, as they are usually understood, nor the determination of structures which explains power. Instead, power is best approached through a view of more or less complex organized agents engaged in more or less complex organized games”. ${ }^{1137}$

In acknowledging the reciprocal relationship between agency and structure, this work takes, third, a materialist view of power. In other words, power is seen not as a result of immaterial discursive practices, but as a result of practices that are made up of participating individuals.

The trigger for the development of the here suggested interpretive model can be found, on the one hand, in the recent critical developments in the consulting industry as described at the start of this work. More and more clients express dissatisfaction with consulting services, which implies that there are weaknesses in the existing business models of consulting. Additionally, due to changes in the broader business environment such as increased globalization, the steady and fast emergency of new technologies, the growth of competition etc., management problems, such as those addressed by consultants, have become more and more complex. The implication of these developments is that clients and consultants need to consider a different consulting business model, a model that increases the chances for both actors to realize successful outcomes from consulting projects. On the other hand, the development of the interpretive model is motivated by the lack of research that combines insights from different and relevant research disciplines within the social sciences. This motivation arises out of the systemic perspective adopted for the analysis within this work, and is also a result of the growing number of voices indicating the need of multidisciplinary research in the social sciences. In the following chapters, the model's assumptions regarding the nature and characteristics of cultural and power relations in general and in client-consultant teams in particular are outlined. 


\section{Cultural relations}

\section{Nature of knowledge}

In this work, knowledge is viewed as an end product of human cognition. ${ }^{1138}$ Therefore, a discussion of the nature of knowledge has, ultimately, to include a discussion of cognition and the nature of cognitive processes.

\subsection{Cognition, learning, and knowledge}

According to Bunge, "when one perceives or conceives an object, investigates it, manipulates it or evaluates it, one engages in a cognitive process”. ${ }^{1139}$ He further argues that all cognitive processes are brain processes; they are a function of the nervous system. Therefore, there are "no any ideas in themselves but, instead, ideating brains". ${ }^{1140}$ At the same time, cognitive processes are in an intensive interaction with individuals' natural and social environment. Concepts and symbols, which are the basis of thinking, are expressed in words that derive their meaning from the way they are used in specific "language games", which are located in distinct social settings. ${ }^{1141}$ Therefore, cognition and discourse are mutually constituted in a process of continuous interaction. ${ }^{1142}$ It follows that context, of which existing discourses are part, influences cognition significantly. Or in other words, cognition is a situated process. Moreover, knowledge transfer and creation occur through people interacting in multiple contexts. ${ }^{1143}$ Thus, there is no cognition in a social vacuum but cognition is a brain process, not a social one. ${ }^{1144}$ As Lakomski states, cognition is both embodied, because people's physical composition determines their thinking, and embedded, because the specific context and situations people find themselves in determine cognition. ${ }^{1145}$

This view reveals the following important assumptions of the interpretive model on the nature of knowledge: First, the interpretive model is based on the assumption that knowledge resides in people's minds and is an individual ability. ${ }^{1146}$ Second, similarly to Schön's notion that "a professional knowing-in-action is embedded in the socially and institutionally structured context shared by a community of practitioners", ${ }^{114}$ it is See Bunge (1996), p. 105; Maturana (1980), pp. 29-30; Neisser (1976), p. 1. Reihlen et al. call this view "emergent materialism”. Reihlen et al. (2005), pp. 4.

See Tsoukas (2005), p. 98.

See Heracleous (2004), p. 179.

See Tyre/von Hippel (1997), p. 71.

See Bunge (1983a), p. 67; also Sommerlatte (2000), pp. 28-29.

See Lakomski (2004), p. S93.

See also Reihlen (2003b), p. 576.

Schön (1987), p. 33.
} 
emphasized that the individual's cognitive processes are embedded in a social context. ${ }^{1148}$ Tsoukas and Vladimirou argue that this context can be interpreted as "a collectively generated and sustained domain of action" or "a language-mediated domain of sustained interactions", and "to engage in collective work is to engage in a discursive practice". ${ }^{1149}$ It follows that knowledge is created and transferred within socio-culturally constituted interpretive communities or discursive practices through an ongoing process of interaction between individuals. ${ }^{1150}$ However, it is neither aggregated from individual cognitive processes nor does it originate entirely within social processes. ${ }^{1151}$ Third, knowledge is the result of perception, conception, and action, and as such, "knowledge has no ultimate epistemic foundation, either rational or empirical. It has only an ultimate factual or material foundation: namely, the real world." ${ }^{1152}$ Therefore, the capacity of individuals to make judgments, i.e. to create knowledge, can be based on action, experience, and theory, whereas the notion of theory is rather broad including any framework or abstract instructions. ${ }^{1153}$ It follows that from a cognitive point of view, consulting knowledge is developed as a product of professional action, and is established through work and interaction with other professionals and with clients, not merely through accumulation of theoretical knowledge. ${ }^{1154}$ Consequently, within this model it is assumed that consultant's body of knowledge is a synthesis of abstract concepts and theories, a technological body of knowledge, and of practical experiences. It involves the "integration, tuning and restructuring of theoretical knowledge to the demands of practical situations and constraints". ${ }^{1155}$

To summarize, the interpretive model is a representation of the critical realist approach to knowledge. It differs from the expert model by treating professional knowledge as situational, cultural, and contextual, rather than as given and universal. At the same time, knowledge is not seen as idiosyncratic and symbolic as argued in the critical model. Although the interpretive model states that different interpretations of topics are possible and common, it postulates that a particular meaning is accessible to individuals who share some conceptual frameworks and meanings, or in other words, to individuals who are members of the same interpretive community. The interpretive model advances, additionally, Schön's understanding of professional knowledge by explicitly revealing the theoretical and epistemological foundations of this knowledge.

\footnotetext{
1148 Bunge summarizes aptly these arguments by stating, "without some common knowledge we could not communicate with one another; without some idiosyncratic knowledge there would be no point in communicating”. Bunge (1983a), p. 68.

See Tsoukas/Vladimirou (2003), p. 976. They further state, "Whatever abstract principle enables an individual to generalize across contexts counts as theory and forms an additional basis for exercising judgement.” Ibid, p. 979. Therefore, theory in Tsoukas and Vladimiorou's terms involves both abstract principles stemming from rational analysis, and from experience. 


\subsection{Schemes and meaning}

There are two major cognitive processes: perceiving and thinking: "We get to know ideas by thinking of them, and concrete things by perceiving, conceiving, or manipulating them." 1156 Therefore, perception and conception, together with action, are the sources of knowledge. When perceiving something, people construct a perception of it with sensations, memories, and expectations. They look for similarities and differences, or for patterns. This process involves the mapping of the event into events of one's perceptual system. ${ }^{1157}$ Such maps are also called schemes. Perceptions themselves do not have a meaning. They can guide the actions of the individual, but they are difficult to share with others because they are non-verbal and subconscious. ${ }^{1158}$ Only through a process of interpreting do individuals assign a meaning to a registered particular stimuli. ${ }^{1159}$ Thus, meanings are a result of thinking processes. ${ }^{1160}$ Thinking may also occur in the absence of external stimulation and involves the "forming of concepts, transforming and interrelating them to construct prepositions, questions and directions" ${ }^{1161}$ This process, which is also referred to as sensemaking, ${ }^{1162}$ or signification, ${ }^{1163}$ results in the development of conceptual maps. ${ }^{1164}$ "Once a conceptual map has been drawn, written down or taped, it becomes cultural artifact, i.e. one that can be examined, modified or used by others." 1165 In the following, the concept of schemes and meanings is briefly introduced. ${ }^{1166}$

\subsubsection{Schemes}

Schemes refer to the cognitive structures used by individuals to encode and represent incoming messages efficiently. ${ }^{1167}$ They represent organized knowledge about a given

Bunge (1996), p. 76.

See Bunge (1983a), pp. 146-150.

See Crossan et al. (1999), p. 526

See Neisser (1976), pp. 70.

Language plays a critical role in the development of meaning "since it enables individuals to name and begin to explain what were once simply feelings, hunches, or sensations”. Crossan et al. (1999), p. 528.

Bunge (1983a), p. 39 and pp.159-174.

See, e.g., Sackman (1992), p. 141; Weick (1995), pp. 1-16.

See, e.g., Bloor/Dawson (1994), p. 278.

See Bunge (1983a), 191-194. Bunge states, "all animals endowed with a central nervous system form perceptual maps, but only the higher vertebrates seem capable of forming conceptual maps, i.e. representations that overreach perception. Ibid, p. 191. When a conceptual map is externalized, it becomes perceptible to other subjects. Examples are diagrams, geographical maps and systems of sentences or utterances.

Ibid, p. 194.

There is a fast growing literature on the nature and role of meaning and schemes for studying individuals and groups. An important question within this research is how to measure schemes and shared conceptual maps. Verbal protocol analysis, analytical modeling, and experimental methods are some of the more common techniques. See Klimoski/Mohammed (1994), p. 405. For an overview discussion of different methods, see Mohammed/Dumville (2001). For a more detailed presentation of different methods see, e.g., Barley et al. (1988); Carley (1997); Goodman (1952); Hill/Carley (1999); Laukkanen (1994); Smith-Jentsch et al. (2001).

See DiMaggio (1997), p. 269; Harris (1989), p. 178; Harris (1994), p. 310; Neisser (1976), pp. 51. Others speak about categories and belief structures. See Klimoski/Mohammed (1994), p. 405. The schema construct found its way into modern psychology, and from there into organization theory, from clinical neurology. See Walsh (1995), p. 281.
} 
stimulus, as well as rules that direct cognitive processes. ${ }^{1168}$ Schemes permit individuals "to categorize an event, assess its consequences, and consider appropriate actions (including doing nothing), and to do so rapidly and often efficiently”. ${ }^{1169}$ As such, schemes are central to the process of perception ${ }^{1170}$ and serve as a guide for interpretations. ${ }^{1171}$ Without schemes, individuals would become paralyzed by the need to analyze an enormous number of ambiguous and uncertain situations. On the negative side, they may cause individuals to ignore discrepant information and may inhibit creative problem-solving. ${ }^{1172}$

Schemes direct individual behavior during the exploration of the environment, and influence which information is picked and how is this information processed. However, the exact nature of this exploration is determined by the interaction with the environment, not by the schema itself. ${ }^{1173}$ As a result, schemes are either confirmed, if the perceived information is compatible with the existing schemes, or adjusted as a result of dissimilar information. ${ }^{1174}$ The modified schemes, in turn, direct a somewhat different exploration. Thus, schemes are learned and direct future learning. ${ }^{1175}$ Individuals have many cognitive schemes, utilize different schemes at different times, and adapt or alter them over time. $^{1176}$

The notion of cognitive schemes is often discussed in relation to the terms "cognitive maps", 1177 “cognitive scripts”, 1178 "mental models", ${ }^{1179}$ and "cognitive frames"1180. Mathieu et al. propose that cognitive maps or mental models serve three crucial purposes: they help people to describe, explain, and predict events in their environment, ${ }^{1181}$ and Giola and Poole suggest that they enable the understanding of situations and provide a guide to appropriate behavior to those situations. ${ }^{1182}$ Thus, the difference between schemes and cognitive maps, scripts or mental models lies in their level of representation: schemes about certain events are embedded into broader cognitive maps or mental

\footnotetext{
1168 See Bunge (1983a), pp. 37-39; Walsh (1995), p. 282. Therefore, Neisser argues that schemes are "the pattern of action as well as a pattern for action”. Neisser (1976), p. 56, emphasis in the original.

Prahalad/Bettis (1986), p. 489; also Klimoski/Mohammed (1994), p. 405.

See Bunge (1983a), pp. 37-38; Harris (1989), p. 178; Neisser (1976), pp. 20-27.

See Giola/Poole (1984), p. 450.

See Dutton/Jackson (1987), pp. 81-82; Klimoski/Mohammed (1994), p. 405.

See Neisser (1976), p. 56. This has been recently confirmed also for the natural sciences. In quantum theory, the discovery that Bohr called " quantum wholeness" shows that light can behave like a particle or a wave depending on how one sets up the experiment. What one perceives, in other words, is not determined by independent external properties of "parts of reality", but is a function of the ways in which one tries to perceive that reality. See Isaacs (1993), pp. 30-31; Morgan (1983), pp. 386-387.

See Dutton/Jackson (1987), pp. 81-82.

See Harris (1989), p. 178.

See Carley (1997), p. 535.

See Neisser (1976), pp. 110. See Schwenk (1988) for a summary of the early research on cognitive maps.

See Giola/Poole (1984); Louis (1980), pp. 239.

See Mathieu et al. (2000).

See, e.g., Benford/Snow (2000); Spybey (1989). Some authors argue that frames are different from schemes because they represent the outcome of negotiated shared meaning. See Benford/Snow (2000), p. 614.

See Mathieu et al. (2000), p. 274. 
models of the world and its possibilities. ${ }^{1183}$ Furthermore, cognitive maps or scripts are only appropriate for particular contexts, for example for conversations with the boss, attending meetings, participating in decision-making processes, etc. ${ }^{1184}$ In other words, they are more specific than cognitive schemes.

\subsubsection{Meaning}

Meaning is a cognitive phenomenon, i.e. it is the result of brain processes. ${ }^{1185}$ Bunge defines meaning as "sense (connotation) together with reference (denotation), or as what is being said about what”. ${ }^{1186}$ Once meaning is assigned to an experience or an event, it becomes encoded in memory and becomes a referent for future interpretations (or assignments of meaning). ${ }^{1187}$

Individuals construct meanings out of a range of aspects like ambient social and physical circumstances, as well as histories and social relations with other people, and beliefs, theories, and propositions that have developed over time based on the individual's experiences. ${ }^{1188}$ As people are embedded in a specific social context at any point of time, and this social context can change quickly, "there is never a moment when one believes nothing, when consciousness is innocent of any and all categories of thought”. 1189

Gray et al. state that at the most basic level meaning is encoded in the form of concepts. ${ }^{1190}$ "Through communication, concepts come to embody similar meanings for two or more individuals, that is, they become coincident”. ${ }^{1191}$ Meaning is also acquired by training through which individuals acquire meanings associated with specific rolerelated behavior. ${ }^{1192}$ Once established, meanings are sustained through sharing between different individuals, i.e. between members of different interpretive communities as discussed below.

Some concepts can have, however, different senses and consequently different meanings in different contexts. ${ }^{1193}$ Such concepts can be only understood in relation to other concepts referred to in the same context. Therefore, "interpretation inherently depends on the relationships among the concepts. [] Hence, the content of a concept

1183

1184

1185

1186

1187

1188

1189

1190

1191

See Neisser (1976), pp. 112-113.

See Giola/Poole (1984), p. 450; Poole et al. (1990), p. 213.

See Gray et al. (1985), p. 84.

Bunge (1996), p. 55.

See Bloor/Dawson (1994), pp. 277-278; Gray et al. (1985), p. 85.

See Brown/Duguid (1991), p. 47; also Axelrod (1997), p. 205; Bloor/Dawson (1994), p. 277; Prahald/Bettis (1986), p. 489; Schön (1983), pp. 49-69.

Fish (1980), pp. 319-320.

According to Bunge, concepts are "the units of meaning and hence the building blocks of rational discourse". Bunge (1996), p. 49. He further states that concepts are neither true nor false because they neither assert nor deny anything. Concepts can only be exact or fuzzy, applicable or inapplicable, fruitful or barren.

Gray et al. (1985), p. 85. Communication is a social process and in contrast to learning, which is direct or personal way for acquiring of meanings, it represents an indirect way for acquiring knowledge, i.e. through the interaction with others. See Bunge (1983a), p. 97. Giola and Poole argue as well that indirect acquisition occurs by means of communication or media. See Giola/Poole (1984), p. 451; also Poole et al. (1990), pp. 214-215.

See Bunge (1983a), pp. 53.

See Bunge (1996), p. 57; Harris (1984), p. 179. 
resides in its pattern of relations with other concepts present in a particular context”. 1194 Gray et al. conclude that the sharing of meaning among several individuals may be inherently problematic, since it implies that they hold in memory the same concepts and the same pattern of relationships among the concepts. Additionally, researchers have argued that meaning construction depends upon the subjective interests of the meaninggiving individual so that for meaning to be fully coincident across several individuals, they must hold similar views about how their interpretations affect their personal interests. ${ }^{1195}$ Therefore, when value interpretations differ, there is potential for conflict and misunderstanding between the involved individuals.

\subsubsection{Interpreting}

As already discussed, interpreting is a cognitive process through which individuals assign meanings to registered stimuli. ${ }^{1196}$ In other words, individuals do not "acquire" meanings and schemes but rather interpret them according to their existing meanings and schemes. As such, individual's interpreting is often an unconscious, automatic process rather than conscious processing where some reflection and reconciliation is required. ${ }^{1197}$ Moreover, more experience with the particular domain is likely to facilitate unconscious, tacit processing of meanings and interpretations. In contrast, reflective processing is rather typical for inexperienced members of the community. ${ }^{1198}$ In general, reflective and conscious choice of interpretations is likely to occur in the case of novel or unexpected social stimuli, i.e. problems or events, ${ }^{1199}$ or when interacting with individuals with different interpretive schemes. ${ }^{1200}$

Schemes and meaning are the cognitive structures in which an individual's knowledge is retained and organized. They serve as knowledge repositories. ${ }^{1201}$ At the same time, they direct information acquisition and processing and as such, they also influence the creation of new knowledge. It becomes clear that individuals need to learn how to share meanings and schemes in order to be able to understand and work with each other.

Because schemes and their meanings are developed by individual experience, individuals will assign different meanings to the same stimulus: "the same stimulus can

1194

1195

1196

1197

1198

1199

1200

1201

Gray et al. (1985), p. 86.

See Gray et al. (1985), pp. 87-88 for an extensive discussion of this argument.

See Neisser (1976), pp. 70-75

See Giola/Poole (1984), pp. 453-455; Harris (1994), p. 315. Crossan et al. call such subconscious processes of interpreting “intuiting”. Crossan et al. (1999), pp. 526-527.

See Crossan et al. (1999), pp. 526-527.

See Giola/Poole (1984), p. 453; Harris (1994), p. 315; Louis (1980), p. 239. See also Crossan et al. who differentiate between expert and entrepreneurial "intuiting". "Whereas expert intuition may be past pattern oriented, entrepreneurial intuition is future possibility oriented”. Crossan et al. (1999), p. 526. Experts in a particular area have highly sophisticated and complex maps that enable them to perceive patterns that novices cannot. See, e.g., Neisser (1976), p. 180. Additionallly, entrepreneurial intuition is characterized mostly by the ability to make novel connections. See Crossan et al. (1999), pp. 526.

See Bloor/Dawson (1994), pp. 281.

They "serve as individual's repository for organizational culture knowledge including the values and beliefs attributed to various individuals and collectivities, appropriate behaviors for various situations, traditional ways of doing things, reinforcement contingencies, peer and normative pressured, role knowledge, the meaning ascribed to verbal, physical, and behavioral artifacts, and the defining characteristics of the organization and its subgroups”. See Harris (1994), p. 313. 
evoke different or equivocal meaning for different people”. ${ }^{1202}$ However, individuals confronted with similar or the same physical and cultural environment can develop similar schemes and meanings: ${ }^{1203}$ individual's interpretations become similar as a result of “shared experience and shared exposure to social cues regarding others' constructions of reality”. ${ }^{1204}$ Furthermore, the process of consciously manipulating existing schemes or interpretive frameworks to make sense of organizational experiences requires individuals to take the perspective of others. ${ }^{1205}$ In this way, individuals engage in "conversations between self and others", or in so-called "mental debates". ${ }^{1206}$ As a result of such "mental debates", individuals identify how the normative pressures arising from the behaviors of others can influence their interpreting. Through the course of regular social interaction, individuals begin to favor one interpretation over others and their exchange of experiences leads to the emergence of shared schemes and meaning. ${ }^{1207}$ When individuals gain more experience and conduct a number of mental debates, interpreting when facing similar problems or events, or when repeatedly interacting with the same individuals, requires less conscious effort. In other words, with repeated experience and interactions, the results of previous interactions and mental dialogues are incorporated into the individual's schemes, and sensemaking becomes increasingly unconscious and tacit. ${ }^{1208}$ "Individuals gradually shift from relatively improvised behavior in novel situations to relatively structured behavior guided by clear expectations of events”. ${ }^{1209}$ Thus, social interactions and communication in particular are the primarily vehicles by which coincident interpretations of events and issues are created, transmitted, and sustained across individuals. ${ }^{1210}$ Thus, language is pivotal in the process of developing of a sense of shared understanding. ${ }^{1211}$ Gray et al. describe this process as follows:

"Initially these coincident symbols or concepts arise through reference or denotation: that is, the direct assignment of an object or event to a category through use of the category's label. Repeated use of the concept label among members of a speech [i.e. interpretive] community confirms the coincident denotative value and establishes the basis for communication

1202

Crossan et al (1999), p. 528.

See Neisser (1976), pp. 187-188.

Harris (1994), p. 313. This argument emphasizes that the development of a so-called "collective identity" of individuals is not the result of convergent linguistic practices per se, as argued by some supporters of discourse analysis who reject the cognitive background of linguistic practices. See, e.g. Hardy et al. (2005), p. 62. This is a version of social constructivism. See Fairclough (2005) and Reed (2000) who support a rather realist version of discourse analysis. In this work, the view of Fairclough is followed and it is emphasized that convergent linguistic practices exist only when there are some shared cognitive frames and understandings between the involved individuals that generate such shared linguistic practices and enable effective conversations.

In the following, the terms "perspective”, “meaning”, and “understanding” are used interchangeably.

Harris (1994), p. 315.

This is the social component of interpreting.

See Harris (1994), p. 315.

Poole et al. (1990), p. 215.

See Gray et al. (1985), p. 85.

See, e.g., Crossan et al. (1999), p. 528. 
and regularity in our relations, because the meaning of these concepts is assumed to remain constant over time”. ${ }^{1212}$

Similarly, Hakkio and Laaksonen argue, " the more you communicate with someone, the more probable it is that you will begin to understand and even adopt her or his messages and the meanings in them, even if this other person is not similar to you". ${ }^{1213}$ Heracleous and Barrett speak about "dialogic" communication. ${ }^{1214}$ It is a form of communication, which acknowledges that "meaning is always incomplete and partial, and the reason I talk with others is to better understand what I and they mean, hoping to find new and more satisfying ways of being together". ${ }^{1215}$ The ultimate goal of communication and dialogue is the integrating of the individual perspectives, which would allow for a coherent, collective action across a number of individuals. ${ }^{1216}$

The integration of individual perspectives on a larger scale results in the emergence of different interpretive communities each of which is characterized by shared cognitive schemes and discourses. ${ }^{1217}$ The nature and role of interpretive communities are extensively discussed in the following chapter.

\section{Interpretive communities}

\section{$2.1 \quad$ Introduction}

The concept of interpretive communities implies that human groups and collectives must be understood as communities of individuals who differ in their "language games”"1218 and their shared interpretive schemes, i.e. in the way they interpret and compartmentalize reality and events (as discussed above), and ultimately utilize and create knowledge. This view of individual cognition and communication is grounded in the tradition of systemism ${ }^{1219}$ emphasizing the multiple social embeddedness of

1212 Gray et al. (1985), p. 85. See also Barley who argues that interpretive consistency across individuals (or coherence of their perspectives) exists when meanings of constructs are coherent and consistent across diverse activities, events, and objects so that these meanings take on a thematic quality. See Barley (1983), p. 409.

Hakkio/Laaksonen (1998), p. 218. Both shared schemes and meanings can be transferred into structural elements such as rules, regulations, norms, and rituals. See Gray et al. (1985), p. 89. The authors further state that this is an inherently political process, something that is discussed extensively in chapter D.IV of this work. See also Dutton/Jackson (1987) who develop a model about how the meanings attached to strategic issues by decision makers are translated into organizational responses.

See Heracleous/Barrett (2001), p. 756; also Isaacs (1993), pp. 25.

Deetz (1995), pp. 97-98. Several researchers have recognized that metaphors, in particular, are a critical link in the evolution from individual intuiting to the development of shared interpretations. Individuals use metaphors to help explain their intuition to themselves and share it other others See, e.g. Crossan et al (1999), pp. 527-528 and the discussion under D.III.3.8.5.

See Crossan et al (1999), pp. 528-529.

See Fish (1980), pp. 14-17; Hymes (1980), p. 27; Zelizer (1993), p. 226. Zelizer in particular stresses that it is wrong to speak of a unitary interpretive community; rather, there are a number of different interpretive communities or subcultures. Zelizer (1993), p. 226. Crossan et al discuss directly the next level of analysis—organizations, arguing that through a process of institutionalization organizations capture the patterns of interaction between individuals and groups and formalize them through the development of structures, systems, and procedures. See Crossan et al (1999), pp. 529-530. This work argues, however, that one needs to study first the intermediate level, the level of interpretive communities, before one discusses organizations. See the following chapter for more detail.

See Koppl/Langlois (2001), pp. 288-291. 
individuals ${ }^{1220}$ and how this affects what they know, how they learn what they know, and what they may do with that knowledge. Ultimately, it is proposed that human groups, firms, and client-consultant teams, accordingly, are complex aggregations of interpretive communities. This is also supported by research on culture. Riley, for example, found in an empirical study of organizational culture that there is no "a" culture but rather a number of subcultures within the studied organizations. ${ }^{1221}$ Blau concludes that groups and organizations have unclear boundaries, lack spatial fixity, and should be rather seen as "loosely constituted overlapping circles of partialled participation." 1222

\subsection{Origin and nature of interpretive communities}

Through the process of interaction in the form of communication, participation, and problem-solving, including channels such as informal talks and meetings, individuals with similar interpretive positions regarding particular issues build specific worldviews or perspectives and create a community, or a dominant logic in Prahalad and Bettis' terms. ${ }^{1223}$ This learning process through which conceptual frameworks are aligned and shared meaning and understanding is formed is a spontaneous process emerging from the usually informal networking between individuals. ${ }^{1224}$ As individuals become aware of how their thoughts are guided by such frameworks, they can start to choose between them when circumstances demand. ${ }^{1225}$ In this way, different interpretive communities evolve, made up of those who share interpretive frames ${ }^{1226}$ but who are themselves potentially members of many evolving communities. ${ }^{1227}$ Therefore, interpretive communities are not universal or natural but learned. ${ }^{1228}$

Shared interpretations include not only a body of shared background knowledge but also an accepted thought style including certain methods for handling problems of a given type. ${ }^{1229}$ Thus, shared perspectives can be expressed as a problem-solving behavior. ${ }^{1230}$ Additionally, interpretive communities establish "conventions" as to how community members can recognize, create, experience, and talk about social events and act as "communities of memory". ${ }^{1231}$ Members of an interpretive community create "stories that contain certain constructions of reality, certain kinds of narratives, and

1220

Kates talks about "structured polysemy”. Kates (2002), p. 5.

See Riley (1983), p. 436. See also Bloor/Dawson (1994), pp. 280; Martin/Siehl (1983), pp. 53; Rose (1988), pp. 142-144; Sackmann (1992). Sackman suggests that shared cognitive schemes or maps include four types of knowledge: dictionary knowledge, directory knowledge, recipe knowledge and axiomatic knowledge, and that individuals from different communities might share some of these knowledge categories but differ in others, which explains the existence of different subcultures within organizations. See Sackman (1992), pp. 141-143.

Blau (1996), p. 174.

See Prahalad/Bettis (1986), pp. 490-494; also Harris (1994), pp. 313-314.

See Swan et al. (2002), p. 478; Zelizer (1993), p. 221.

See Reihlen/Ringberg (2004), p. 22.

See Fish (1980), p. 14; Hymes (1980), p. 27.

Lindlof argues that the most common case of multiple interpretive community overlays is represented in the family. See Lindlof (1988), p. 93.

See Fish (1976), p. 484.

Bunge speaks about “conceptual frameworks”. See Bunge (1983b), p. 175.

See Prahalad/Bettis (1986), p. 491.

Zelizer (1993), p. 223. 
certain definitions of appropriate practice". ${ }^{1232}$ As such, interpretive communities "have no existence other than their instantiation in action and memory traces (or interpretive schemes) orienting agents' conduct”. ${ }^{1233}$

The concept of interpretive communities explains two important issues: the relative stability of interpretation among different individuals, due to the fact that they belong to the same community, and the regularity with which a single individual will employ different interpretive strategies because s/he belongs to different communities. ${ }^{1234}$ It also explains that disagreements between individuals from different interpretive communities exist because of the relative stability in the makeup of interpretive communities and therefore the opposing positions they make possible.

Fish stresses that this stability is always temporary. An interpretive community builds and expands itself through the shaping of individuals. "Since the thoughts an individual can think and the mental operations he can perform have their source in some or other interpretive community, he is as much a product of that community (acting as an extension of it) as the meanings it enables him to produce". ${ }^{1235}$ Unfortunately, schemes are not infallible guides to individuals. Some of them can be, rather, relatively inaccurate representations of the world, particularly as conditions change. In such situations, solutions based on experience or solutions by analogy may be inappropriate. ${ }^{1236}$ Therefore, it is important that individuals learn to revise their perspectives. This process is facilitated when newcomers access the community or the environment conditions within which it is embedded change. As a result of such events, individual's perspectives, preferences, and dispositions will change, ${ }^{1237}$ and the shared meanings of the community can, and generally will, be transformed. ${ }^{1238}$ It follows that large-scale, more-or-less simultaneous frame switches by many independent actors may cause large-scale changes in interpretive communities and whole organizations. ${ }^{1239}$ "Interpretive communities grow larger and decline, and individuals move from one to another”. ${ }^{1240}$

Therefore, the evolution of interpretative communities is not one sided as individuals transform the community as well. Interpretive communities are influenced by existing interpretations and discourses, some of them fixed in rules and procedures and, and at the same time, actors participating in this communities influence these structures through their ongoing interpretations and actions. As Hardy and Phillips put it, "discourses are never completely cohesive and devoid of internal tensions, and are therefore never able totally to determine social reality. They are always partial, often cross-cut by inconsistencies and contradiction, and almost always contested to some degree". ${ }^{1241}$ The

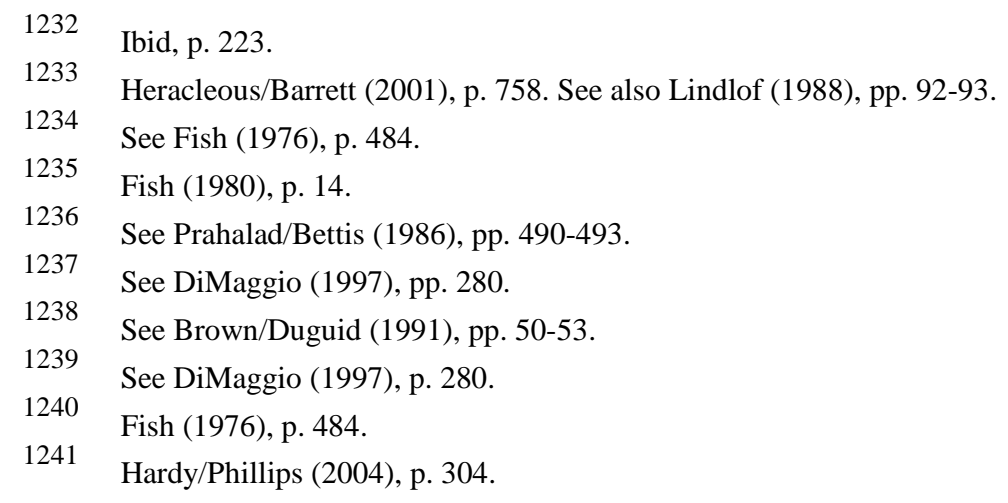


point of this discussion is to recognize how, at any point in time, individuals are embedded within any number of different interpretive communities through which they make sense of an incidence or topic ${ }^{1242}$ and how this influences their actions, thinking, and speech. ${ }^{1243}$ Through their involvement in multiple communities and discourses individuals can, as Hardy and Phillips argue, "produce a discursive space in which [they] can play one discourse against the other, draw on multiple discourses to create new forms of interdiscursivity, and otherwise move between and across multiple discourses". ${ }^{1244}$ Accordingly, interpretive communities are not stable and do not represent unalterable "fixed systems of positions". ${ }^{1245}$ They are, rather, fluid and evolving. Some interpretive communities can be quite durable and broad whereas others are only short-lived and involve a restricted number of members.

\subsection{Relations between interpretive communities}

Bloor and Dawson suggest that there are four types of relations between a particular interpretive community and other interpretive communities. The type of relation depends on the similarity in the interpretations of the members of each of the regarded communities regarding a particular issue. Bloor and Dawson point out that changes in existing interpretive schemes of a particular community are more probable when this interpretive community interacts with members of so-called "dissenting" and “orthogonal” interpretive communities. ${ }^{1246}$ Dissenting interpretive communities advocate "alternative methods and work practices" due to alternative interpretive schemes with regard to the issue at hand and as such, offer the possibility for innovation and change in the interpretations of the interpretive community in question. Orthogonal interpretive communities contain some unique beliefs and interpretive schemes but also share some of the frameworks of the regarded community. Interactions with members of orthogonal communities offer, therefore, the potential for redefining shared interpretations through incremental adjustment. Additionally, Bloor and Dawson differentiate two other types of interpretive communities: enhancing interpretive communities, which support the interpretations of a given community, and deferential interpretive communities that defer to and yet are remote from the interpretive community in question. ${ }^{1247}$ Interactions with members from enhancing and deferential interpretive communities do not lead to substantial changes in the interpretive schemes of the regarded community.

It can be concluded that while the alignments between interpretive communities are not permanent, "they are always there, providing just enough stability for the interpretive battles to go on, and just enough shift and slippage to assure that they will never be

See Kates (2002), pp. 3; Reihlen/Ringberg (2004), p. 22; Watson (1982), p. 265.

See Koppl/Langlois (2001), pp. 290-291.

Hardy/Phillips (2004), p. 304.

Clegg (2001), p. 135. Carley argues as well that groups and communities are in flux because members are continually acquiring new information and communicating it to each other. She further states, "a group is perfectly stable only when no new information enters the group and everyone in the group knows everything that anyone else in the group knows". Carley (1991), p. 332.

See Bloor/Dawson (1994), pp. 283-292; also Martin/Siehl (1983), pp. 52; Rose (1988), pp. 161-166.

See Bloor/Dawson (1994), pp. 283-292.
} 
settled." 1248 Therefore, both perfect agreement and interpretive anarchy are impossible situations. "It is the fragile but real consolidation of interpretive communities that allows us to talk to one another, but with no hope or fear of ever being able to stop”. ${ }^{1249}$

\subsection{Interpretive communities versus communities of practice or the missing link to cognition and power}

The idea of interpretive communities is related to the concepts of Communities of Practice (CoP), ${ }^{1250}$ discursive communities, ${ }^{1251}$ and communities of knowing. ${ }^{1252}$ The CoP approach grew out of work on the situated nature of learning. ${ }^{1253}$ It emphasizes that knowledge and problem-solving abilities are situated in a local context that includes individuals' interactions with one another and with social artifacts. Supporters of this view provide empirical evidence that cognitive processes depend on a subject's interaction with the external environment. They conclude that knowledge emerges out of individuals’ actual practice and remains both highly contextualized and tacit, which is in a strong opposition to mainstream cognitive science. ${ }^{1254}$ People who participate in a shared practice, called "community of practice”, socially construct a common language or a text during their joint activities. The practice is regarded as the carrier of knowledge. Consequently, it is assumed that knowledge has a univocal meaning for all members of a particular CoP. In other words, individuals within the same practice transmit and receive information non-problematically.

A major contribution of the CoP view is its emphasis of the situated nature of knowledge and the existence of multiple practices within organizations. However, the approach has a number of important shortcomings that are presented in what follows. First, the supporters of the CoP approach view the engagement within the same practice as a single explanatory factor for the emergence of different communities and different knowledge bases. However, practice is one among other factors, such as educational background, social histories and site-specific or local knowledge, that influence individuals' cognition. ${ }^{1255}$ It is one among other factors that lead to the development of different interpretive positions, with the consequence that even individuals who

See Boland/Tenkasi (1995), pp. 351-352. The concept of interpretive communities is also related to the more established concept of culture, as both terms are based on the discussion about meanings, shared interpretive schemes, interpretation, etc. The main difference is that researchers who study culture assume that organizations are characterized mainly by coincident meanings, i.e. one type of culture, whereas the notion of interpretive communities emphasizes the existence of multiple meanings in organizations, and as a result, regards organizations as communities of different subcultures, some of which have contradictionary interpretive schemes. See also Zelizer (1993), pp. 223-225. Harris suggests that schemes that emerge in such communities or subcultures tend to be more specific, better defined, and more generally shared that those emerging across an organization's entire membership. See Harris (1984), p. 313. As such, the interpretive model is a response to voices that emphasize the need to focus "on uncovering the multiplicity of meanings present at any time". Gray et al. (1985), p. 94. These authors further state that "further articulation and demonstration of how powerful members construct meaning for others is needed", a topic that is discussed in chapter D.IV of this work.

See Brown/Duguid (1991), p. 48; Brown/Duguid (2001), pp. 202; Gherardi (2001); Lave/Wenger (2002), pp. 34; Wenger (1998), pp. 11-15. 
participate in the same practice still may interpret topics differently. ${ }^{1256}$ Reihlen and Ringberg support this argument. In an empirical study, they found that consultants had difficulties in understanding knowledge artifacts, such as documents and tools, created through other consultants in previous projects, or misinterpreted them. ${ }^{1257}$ "Even with a high degree of sharedness (practice, background, training), the consultants [] had persistent difficulties in making sense of one another's computer-mediated artifacts, leading to either miscommunication or a creative but unrelated usage of the information". ${ }^{1258}$ Their findings show that some consulting tools could be only understood by a small group of consultants. It can be concluded that members of the same CoP are not always able to understand each other. The reason is that the notion of CoP is too narrow to account for all cognitive differences that exist between people. In the case of Reihlen and Ringberg's study, it can be argued the consultants who are engaged in a particular consulting project develop site-specific knowledge and as such, temporarily join a different interpretive community.

Second, the CoP approach is based on the assumption that CoP evolve as knowledge repositories and knowledge carriers and exist, as such, independent of their current members. The problem with the idea of CoP is the underlying idealistic assumption that ideas or knowledge exist independent of individuals, in this case in the form of practice. However, it is individuals' cognitive maps that give meaning to practice, not vice versa. ${ }^{1259}$ It is not the engagement in similar activities but the univocal understanding of these activities that is important in order to make sure that knowledge transfer happens as intended. Similarly, Lakomski points out, "the patterns of relating and the cognitive activities encapsulated by the concept 'community of practice' are possible in the first place because of the pattern recognition and completion ability of real brains". ${ }^{1260}$ Therefore, knowledge and cognition are always related to individuals and individual actions, although neither exists in a social vacuum, and social context undoubtedly influences individual cognitive processes. ${ }^{1261}$ Thus, the notion of interpretive communities puts an emphasis on the material character of such social systems. Interpretive communities consist of interacting individuals rather than disembodied practices. Individuals, as members of interpretive communities, access and interpret topics according to the shared conceptual frameworks of these communities. As such, the communities of interpretation view reflects the critical realist approach to knowledge.

Third, because the CoP approach emphasizes the local contextualization of knowledge, it ignores the importance of generally held rules and knowledge. In other words, it rejects the existence of generalized knowledge, as knowledge makes sense only in relation to peoples' local contextualized experience. ${ }^{1262}$ Consequently, the CoP approach discourages serious inquiry into the "mechanisms that might serve to transmit

See Lorenz (2002), pp. 317-318.
} 
and diffuse knowledge beyond the confines of particular places and times". ${ }^{1263}$ Therefore, questions regarding the forces of influence behind the transfer of knowledge outside particular $\mathrm{CoP}$, and outside consulting methods and concepts, remain not only unexplored but they are also implicitly represented as irrelevant.

Forth, the CoP view discusses only learning from action, i.e. action based knowledge. It considers knowledge to be "essentially pragmatic, partial, tentative and always open to revision”. ${ }^{1264}$ Similarly, Brown et al. argue, “a theory of situated cognition suggests that activity and perception are importantly and epistemologically prior - at a nonconceptual level - to conceptualization”. ${ }^{265}$ In other words, the CoP approach overemphasizes the importance of procedural and pragmatic knowledge and of learning as a process of participating and being able to perform the practice. It ignores the importance of conceptual knowledge and the possibility to learn through labeling, describing, analyzing, and justifying, i.e. independently of participating in a particular practice. ${ }^{1266}$ However, cognition and action cannot be divorced from each other. ${ }^{1267}$ "People learn by being told as well as by 'participant observation' and by doing”. 1268 Therefore, verbal instruction or written text is as important as organizational practice. In this regard, Lakomski stresses, "narratives are second-order linguistic representations and reconstructions of experience gone by". ${ }^{1269}$ They reflect organizational events from someone's point of view and people's point of view may differ to a very large degree regarding the same event. Therefore, the collection of workplace narratives is not a sufficient mechanism to provide evidence that CoP are successful in delivering value.

Fifth, although the proponents of the CoP approach acknowledge that knowledge and learning are influenced by power relations, they do not further discuss the issue of power. ${ }^{1270}$ They acknowledge, that CoP are characterized by asymmetrical power relations. In other words, the position of individuals within these social relations influences their opportunities to participate in the knowledge transfer and creation process of a certain CoP, and therefore their power. Thus, the concept of power is closely related to the major concept of "legitimate peripheral participation", which makes clear that power relations can enable or inhibit access to the learning practices of a particular CoP. ${ }^{1271}$ Thus, legitimate peripherality "can be a source of power or powerlessness, in affording or preventing articulation and interchange among communities of practice”. ${ }^{1272}$ These arguments imply, as such, that power is regarded as something that the different states that power is exercised by dominant groups who manipulate other people's preferences, perceptions and cognitions. The result is that the manipulated do not know their "true" interests and accept dominant values and practices without to feel resentment. This is a supreme form of power. See Contu/Willmott (2003b), pp. 188.
} 
actors in a CoP possess or do not possess depending on their position within the CoP. ${ }^{1273}$ This is, however, as Contu und Willmott argue, problematic. To view power as something that can be possessed means that power is attributed to individuals and groups rather than to the practices, which creates conditions that make individuals and groups powerful. ${ }^{1274}$ They further stress that power is rather relational: it produces the relations and identities of groups and individuals, the practices that make certain individuals more powerful than others. As such, power cannot be owned. ${ }^{1275}$ In general, the discussion of power within this approach is too fragmented and insufficient to contribute to a better understanding of power and its role in human interactions.

The main differences between the CoP and the community of interpretation view are summarized in table $12 .^{1276}$

\begin{tabular}{lll}
\hline & Community of practice view & Community of interpretation view \\
\hline $\begin{array}{l}\text { Explanatory factor } \\
\text { for the emergence } \\
\text { of different } \\
\text { communities }\end{array}$ & $\begin{array}{l}\text { Single factor: engagement within } \\
\text { same practice }\end{array}$ & $\begin{array}{l}\text { Multiple factors: engagement within } \\
\text { same practice, educational } \\
\text { background, social histories, site- } \\
\text { specific or local knowledge }\end{array}$ \\
\hline $\begin{array}{l}\text { Epistemological } \\
\text { tradition }\end{array}$ & $\begin{array}{l}\text { Structuralism, social } \\
\text { constructivism }\end{array}$ & $\begin{array}{l}\text { Critical realism, cognitive } \\
\text { constructivism }\end{array}$ \\
\hline $\begin{array}{l}\text { Nature of } \\
\text { knowledge }\end{array}$ & $\begin{array}{l}\text { Knowledge exists independent of } \\
\text { individuals; practices/objects as } \\
\text { carriers of knowledge }\end{array}$ & $\begin{array}{l}\text { Only individuals can be carriers of } \\
\text { knowledge }\end{array}$ \\
\hline Knowledge transfer & $\begin{array}{l}\text { Engagement in similar activities } \\
\text { (practices) enables knowledge } \\
\text { transfer; knowledge transfer outside } \\
\text { of CoP not explained; irrelevant }\end{array}$ & $\begin{array}{l}\text { Univocally interpretation of activities } \\
\text { enables knowledge transfer; knowledge } \\
\text { transfer outside interpretive } \\
\text { communities as a result of the } \\
\text { interaction between communities; } \\
\text { investigates the forces behind it }\end{array}$ \\
& $\begin{array}{l}\text { Power depends on one's position in } \\
\text { the CoP; however, power issue is not } \\
\text { explicitly addressed }\end{array}$ & $\begin{array}{l}\text { Power is located not only in the } \\
\text { position of individuals but in social } \\
\text { relations; it is relational and diffused } \\
\text { throughout society }\end{array}$ \\
\hline
\end{tabular}

\section{Table 12: Community of practice view vs. Community of interpretation view}

\subsection{Driving forces of different interpretive communities}

The aim of the following discussion is to discuss briefly important factors, which can lead to different interpretations of similar experiences and topics. Such factors can represent both cross-sectional attributes-such as gender, social background of the individual, industry or functional divisions operating in the firm-as well as longitudinal and path dependent characteristics that place a specific firm or individual into a specific set of circumstances-e.g., current interests and priorities, built up infrastructure, prior 
understandings, etc. ${ }^{1277}$ Although a list of that kind is undoubtedly only a subsection of all aspects that have the potential to be important, the significance of combining these factors for the client-consultant relationship is highlighted in the brief discussion that follows.

\section{Learning by doing}

Learning-by-doing is an important way in which people acquire knowledge and skills. What one learns and what capabilities one develops depends on what one does, which is a result of the division of labor, specialization, and job requirements. ${ }^{1278}$ Thus, different specialization affects people's interpretations. Because management consultants and clients are usually engaged in very different activities, clients' members and consultants often differ in their specialization, and therefore in the way they interpret and frame problems and problem solutions.

\section{Site-specific (situated) knowledge}

Even when client and consultant are engaged in similar activities-e.g., as might be expected between the corporate strategy or strategic planning group of a company and a management consultancy specialized in strategy consulting-they still may develop dissimilar understandings due to the different ways in which things are done and problems solved. For example, external consultants will have a very different view of a specific problem compared to internal consultants if they are trained in using different methods for solving problems. Consequently, due to different resources and ways of accomplishing tasks, knowledge is grounded in site-specific work and practices. Individuals will have difficulties in recognizing and applying such situated knowledge, unless they have direct, local experience of the knowledge. ${ }^{1279}$

Such site-specific knowledge is generated also within consulting companies, when consultants work on client projects. For example, Reihlen and Ringberg found that project teams often develop their own tools for solving client problems, so that several different tools for similar problems coexist within the same consulting company, which differ in relation to the particular client context for which they were created. ${ }^{1280}$

See also Alfieri who argues "differences in knowledge and education, cognition and interpretation, language and symbol all erect boundaries”. Alfieri (1994), p. 1749. It is important to note that different interpretive communities evolve in different contexts. In other words, if one discusses the context of consumption, one could differentiate between, for example, gay men, Christian fundamentalists, Star Trek enthusiasts, devoted Apple users, etc. See Kates (2002), pp. 8-10. Lindlof looks at interpretive communities in the context of communication media. See Lindlof (1988). Moreover, Kates argues that within these communities there might be differences depending on the respective physical location and social positioning of the individuals so that there might be different interpretive communities of Apple enthusiasts or Star Trek enthusiasts, for example. It follows that in depth studies of interpretive communities might reveal "subtle (and perhaps dramatic) shades of meaning” within what people see as a single community”. Kates (2002), p. 21. Thus, because this is a conceptual work, it cannot offer any insights into the different layers of meanings within client-consultant teams. Rather, only some general suggestions for different interpretive communities within such teams are provided.

See Becker (1991), p. 1039; also Lave/Wenger (2002), pp. 31; Schein (1996), pp. 12.

See Sole/Edmondson (2002), p. S31. The difference between Sole and Edmondson's argument and the previous one is that the latter examines role-based communities of interpretation while the former identifies the co-location as a source of common interpretations and perspectives. 


\section{Educational background}

Several authors have discussed learning and communication problems between people with different educational backgrounds. ${ }^{1281}$ Dougherty found when examining successful product innovations that departments are in fact like different "thought worlds". ${ }^{1282}$ Investigating four departments-technical, field, manufacturing and planning - she shows that each department has its individual view and interpretation, emphasizing alternative aspects of the same developments and conceiving situations in diverse ways. Furthermore, the inward focus of the departments limits the possibility of comprehensive understanding and learning. This implies that in order to enable effective collaboration, it is important to overcome the barriers created as a result of different interpretive schemes.

\subsection{Organizations as communities of interpretive communities}

The starting point for the concept of organizations as communities of interpretive communities is the argument that, for many purposes, the dispersed knowledge of different interpretive communities must be reassembled, "not only in the form of artifacts but also in the form of organised knowledge communities". ${ }^{1283}$ Others have suggested that organizations are dispersed or distributed knowledge systems: a firm's knowledge is distributed between different individuals; no single mind owns the totality of relevant knowledge. ${ }^{1284}$ Thus, as Loasby notes, “a firm is composed of a group of people who all, in varying ways and to varying extents, interpret what they observe and take decisions according to their interpretation." 1285 One consequence of the distributed cognition in organizations is that the main goal of managers becomes the coordination of the divergent interpretations among employees. ${ }^{1286}$ Therefore, firms can be regarded as organized pluralities of intersecting and competing interpretive communities or "system[s] of interpretative systems". ${ }^{1287}$ Heracleous and Barrett support this argument when they emphasize that organizations are "constituted of fragmented, competing, and, less often, complementary discourses [i.e., interpretive communities]”. ${ }^{1288}$ Robertson and

See, e.g., Bechky (2003), pp. 313-314; Dougherty (1992), pp. 186; Schein (1996), p. 12. See also Hakkio/Laaksonen (1998) who provide a very interesting study of differences in the cognitive structures of manufactures, designers and retailers.

Dougherty (1992), p. 179.

Loasby (2000), p. 25, emphasis added.

See Boland/Tenkasi (1995), p. 351; Tsoukas (1996), p. 22. Tsoukas argues that knowledge is not only dispersed but also indeterminate: "nobody knows in advance what knowledge is or need to be.” Tsoukas (1996), p. 22. There is no knowledge out there that just needs to be collected and assembled in a database. See also Becker (2001), pp. 1038.

Loasby (1983), p. 357. See also the discussion in D.III.1.2.

See Boland et al. (1994), p. 457. Similarly, Loasby argues that "a firm is a response to human cognitive limitations”. Loasby (2000), p. 25.

Ibid, p. 26. Similar terms are “communities-of-communities”. See, e.g., Brown/Duguid 1991, p. 53; Fox 2000; see also Acroyd (2000), p. 101. This argument builds upon the tradition of scholars who have emphasized that firms facilitate the use and transfer of valuable but tacit knowledge. See, e.g., Conner/Prahalad (1996); Grant (1996); Kogut/Zander (1992, 1996); Madhok (1996); Nickerson/Zenger (2004). However, these authors, as most of the work on the nature and boundaries of the firm, concentrate on the characteristics and the role of individuals and individual cognition (unrelated to social aspects) for the existence of firms. In contrast, it is emphasized here that individuals, e.g., clients and consultants, are not free agents but members of communities.

Heracleous/Barrett (2001), p. 774. 
Swan point out that cultural ambiguity is not uncommon for organizations. ${ }^{1289}$ Therefore, it is argued that a firm represents a particular combination of interpretive communities and that "individuals will find themselves as members of several communities [] operating within a firm and its environment”. 1290

However, as firms require solidity, they must decide which interpretive communities will be included within the organizational hierarchy, which will dominate, which need to be alternated, and which will remain part of a larger network but ultimately remain outside the structured hierarchy. As such, a firm structures and economizes on connections between interpretive communities. ${ }^{1291}$ Furthermore, it provides mechanisms that decrease communication and coordination costs between members of different interpretive communities. ${ }^{1292}$ The development of such mechanisms often involves the investment of significant fixed costs, implying long-term involvement and interaction amongst members of different interpretive communities. Organizations provide such a long-term and relative stable combination of interpretive frameworks, compared to the fluid nature of interpretive communities. Thus, organizations make very real trade-offs that solidify certain communities and relationships between communities but also isolate them from other interpretive frameworks, some of which might be theoretically and practically valuable. Furthermore, each firm favors a particular network of connections between interpretive communities, the result of which is that different firms produce differentiated responses to identical events even in the case where their resources are fundamentally similar. ${ }^{1293}$ Consequently, organizations should be seen "in terms of the infinite play of differences that discourse constitutes”1294 and as a community of communities where meanings are continually created and destroyed. ${ }^{1295}$ The previously mentioned study by Reihlen and Ringberg on the success of computer-mediated knowledge transfers in a consulting company confirms this view. ${ }^{1296}$ The authors found that consultants had difficulties in understanding knowledge artifacts, such as documents and tools, created through other consultants in previous projects, or misinterpreted them. Their findings show that some tools and methods are understood only by a small group of consultants, and that a number of different tools exist even for the same type of client problems. It can be concluded that members of the same organization are not always able to understand each other due to their participation in different interpretive communities. ${ }^{1297}$ Moreover, the transfer of local knowledge between different interpretive

See Robertson/Swan (2003), pp. 838-839.

Boland/Tenkasi (1995), p. 352. As such, this argument partly confirms Gray’s et al. understanding of organizations as "dynamic, conscious, and subconscious processes through which meanings are constructed and deconstructed". Gray et al. (1985), p. 83. However, Gray et al. argue that meanings shared by the organizational members can be ordered along a continuum whereas this work states that they are grouped in different and partly intersecting interpretive communities.

See also Loasby (2000), p. 25.

See, e.g., Kogut/Zander (1996), pp. 503; also Nickerson/Zenger (2004), pp. 626-627. Some of the mechanisms for coordinating and integrating of team members' activities, which are discussed in chapter B.II.4.4, are also examples for coordinating practices that can be used organization-wide.

See Loasby (2002), p. 1234.

Clegg (2001), p. 135.

See Gray et al. (1985).

See Reihlen/Ringberg (2006), pp. 330-336.

See Reihlen/Ringberg (2006), p. 338. 
communities is only possible if, (1), clients and consultants learn to reflect on their own interpretations $^{1298}$ and are successful in the development of shared understanding; or (2) a dominant interpretive community institutionalizes a dominant interpretation, together with rules and procedures that allow for an implicit aligning of communities' interpretive schemes. ${ }^{1299}$ Which of both mechanisms is used in order to enhance the cooperation between interpretive communities depends on the nature of the problem or issue that these communities need to jointly address. ${ }^{1300}$

Next, the view of organizations as communities of interpretive communities is illustrated with the example of McKinsey, a large international strategy consulting company. The chapter provides an example how this particular company tries to manage the interpretive diversity of its consultants, i.e. how it coordinates and utilizes differences in the interpretive frames of its consultants.

\subsection{Management of interpretive communities at McKinsey}

It has been argued that McKinsey is a professional business service firm with a very strong firm culture based on firm wide coordination of decision-making, group identity, and high conformity. ${ }^{1301}$ Maister refers to organizations with similarly strong cultures as "one-firm firms" and emphasizes that their strong social integration is achieved with the help of a number of mechanisms, such as specific entrance requirements, intensive and continuous job-related training, and constant testing of individual consultants to ensure conformity. As a result, strong integration and extensive consultations are typical for such organizations. ${ }^{1302}$ For example, McKinsey has developed a code of conduct, which each new consultant needs to learn in order to ensure that all McKinsey consultants develop shared understanding of their work principles and norms. This could lead to the conclusion that in McKinsey, as in other "one firm-firms", different interpretive frameworks do not exist; their development is inhibited because members of such organizations are forced to develop early on a shared understanding and a very strong social cohesiveness in order to create a highly integrated interpretive community. However, research indicates that this might not be the case. A look at the organization structure of McKinsey, to take the same example, shows that the company recognizes the existence of different interpretive communities within its borders and has made efforts to facilitate and manage their existence while at the same time closely monitoring the reinforcement of their integration. ${ }^{1303}$

In McKinsey it has been recognized at an early stage that there are diverse interpretive communities within the company cutting across the different geographic offices, which are the primary organizational entities in consulting companies. The company tried to nourish such interpretive communities early on by changing its 
organizational structure. In the late 70's the company created industry-based sectors in consumer products, banking, industrial goods, insurance, and so on. Additionally, 15 Centers of Competence were built around existing areas of management expertise like strategy, organization, marketing, change management, and systems. These centers were virtual, rather than geographically located, and their main task was to enhance communication and sharing of interpretations and perspectives between consultants with similar specialization and expertise. Later, additional formal mechanisms for the sharing of knowledge were introduced within these virtual structures, in the form of, for example, regular meetings and seminars, practice knowledge base, conference proceedings, knowledge documents etc.

In the early 90s, these groups were integrated into seven sectors and seven functional capability groups, as table 13 shows.

\begin{tabular}{ll}
\hline \multicolumn{1}{c}{ Functional Capability Groups } & \multicolumn{1}{c}{ Clientele Industry Sectors } \\
\hline Corporate Governance and Leadership & Financial Institutions \\
\hline Organization & Consumer \\
\hline Information Technology/Systems & Energy \\
\hline Marketing & Basis Materials \\
\hline Operations Effectiveness & Aerospace, Electronics, and Telecom \\
\hline Strategy & Transportation \\
\hline Cross Functional Management & Automotive, Assembly, and \\
& Machinery \\
\hline
\end{tabular}

Table 13: Sectors and centers as interpretive communities within McKinsey

Source: Bartlett (2000), p. 17.

McKinsey was hoping that these organizational arrangements would provide for enhanced communication and sharing of knowledge within interpretive communities. Interpretive communities evolve, however, as discussed in the previous section, also when consultants work on the same site, i.e. with the same client. To enhance the communication within such communities, McKinsey introduced additionally the concept of the client service team (CST). The idea is that individuals that work with a particular client over an extended period of time develop client-specific expertise, and that the facilitation of the cooperation between the involved consultants can improve the interaction with this client. Therefore, consultants were motivated to link across geographical borders and sector specializations to share interpretations and perspectives gained while working on projects with single clients.

As a result, McKinsey consultants belong to several different sectors and groups at the same time. Through this arrangement, which requires consultants to engage in activities within each of the groups and sectors they belong to, McKinsey is hoping to enhance the sharing of perspectives and interpretations not only between members of one interpretive community, but also between different interpretive communities. For 
example, frequent meetings between industry groups and client service teams are encouraged. Furthermore, the company stimulates consultants to connect to external partners from bank associations, research and academic institutions, which represent diverse interpretive communities.

Figure 11 illustrates the involvement of a single consultant into a number of different groups and clusters within McKinsey.

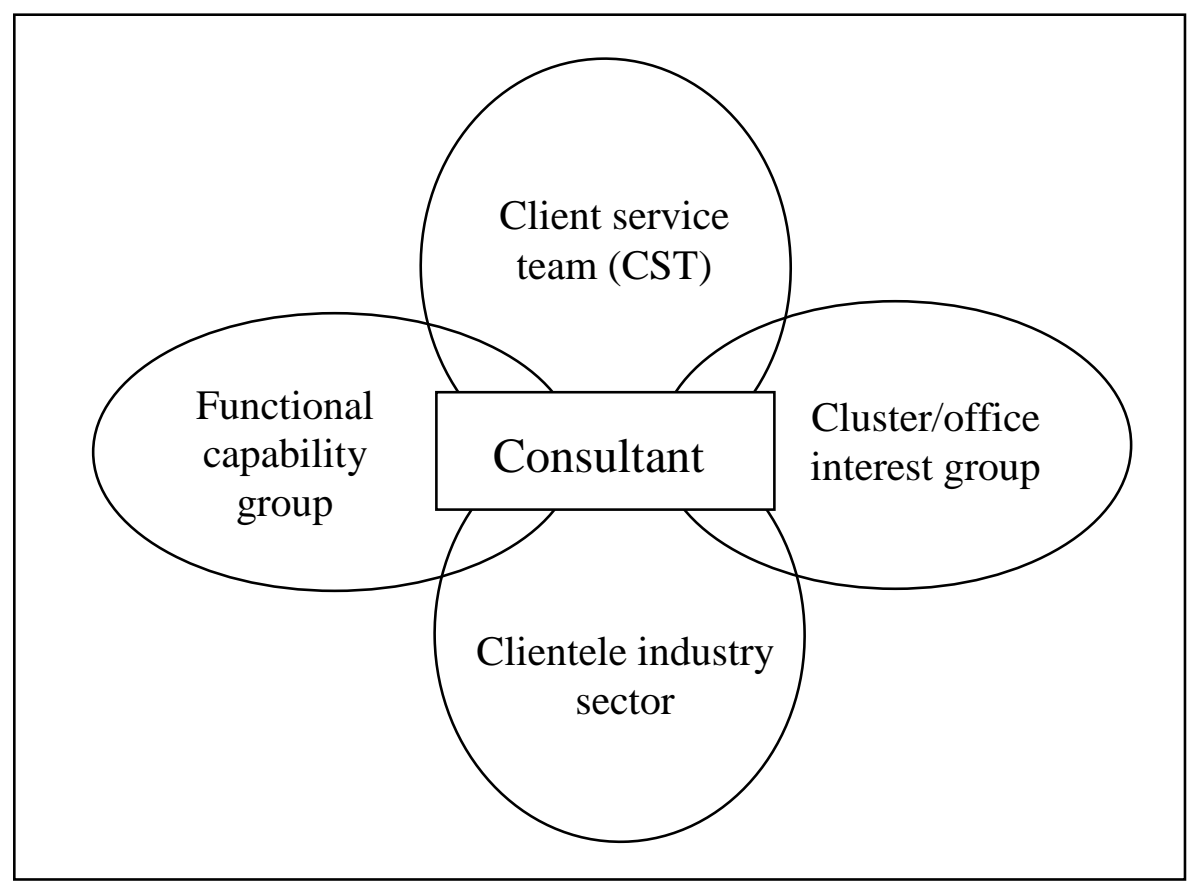

Figure 11: Communities of involvement within McKinsey

Source: Adapted from Bartlett (2000), p. 18.

A major problem of the approach of companies trying to nourish and manage interpretive communities by establishing organizational structures and clusters around these communities is, however, that interpretive communities evolve and change continuously as their members continuously interact with different people. They leave and join different interpretive communities, a process they often are not even aware of. Organizational structures are, in contrast, much more rigid structures and cannot be changed all the time. Therefore, efforts to manage interpretive communities can have only limited success. What is much more important for organizations that wish to facilitate the interaction between members of different interpretive communities within their borders is to enable individuals from different departments, clusters, geographical areas, and levels of the organization to freely communicate and interact with each other. In this way, members of an organization can exchange their perspectives and develop shared knowledge regarding particular issues at particular times and in particular contexts. Moreover, organizations need to pay special attention to less dominant, 
marginalized interpretive communities if they wish to tap into different knowledge and perspectives available within and across their boundaries. ${ }^{1304}$

\section{$2.8 \quad$ Interpretive diversity: some implications}

Interpretive communities are maintained at the group level but operate and are manifested through individuals' interpretive schemes and shared cognitive maps. ${ }^{1305}$ Thus, the selection of environmental elements to be analyzed is likely to be affected by the shared schemes of an interpretive community, and different schemes can lead to dramatically different analysis of the same event or topic. ${ }^{1306}$ Therefore, one can argue persuasively that the norms and rules associated with the interpretation of any topic are embedded in the practices and assumptions of interpretive communities. "A specific interpretation of a topic is not constrained by the topic itself, nor does it originate from a general true way of looking at this topic; rather, it proceeds from a collective decision as to how to interpret the topic, a decision that will be in force only as long as the interpretive community continues to abide by it". ${ }^{1307}$ Accordingly, interpretive communities differ in their knowledge base not only at a certain point of time but permanently, as they interpret even the same events in a different way. This implies that individuals who participate in different interpretive communities may have problems in understanding one another fully: "if knowledge leaks in the direction of shared [meaning], it sticks where [meaning] is not shared”. ${ }^{1308}$

These points are well recognized by others. Schön argues that members of different communities develop a "feel for the media and languages of their practices", which is why they "cannot convey the art of [their] practice to a novice merely by describing [] or even demonstrating [their] ways of thinking”. ${ }^{1309}$ Similarly, Tushman points out, the "inherent conceptual and linguistic differences [between specialized communities] act as communication impedance or as a communication boundary hindering the free flow of information". ${ }^{1310}$ Clegg et al. speak about problems in understanding each other's "language", 1311 much of which "might be perceived as pure noise", 1312 a situation that appears also when the involved individuals have similar goals, for example, finding the best problem solution. ${ }^{1313}$ Lopez argues for the case of lawyer-client interactions "the multiplicity of client voice, narrative, and story demands the practice of 'bicultural and

\footnotetext{
1304 See Yanow (2004) who pays special attention to this issue. The notion of dominant interpretive communities is discussed in chapter D.IV. consultant relationship, clients and consultants need to use the same language. Fullerton/West (1996), p. 45.

The term language is used here broadly, meaning not only different national languages but also language that differs between individuals with different age, sex, social background, professional background, etc. 
bilingual' translation”. ${ }^{1314}$ Gherardi and Nicolini point out that when different communities are involved in a joint work they are more often characterized by distinct perspectives than by mutual understanding. ${ }^{1315}$ As Fish suggests, "members of different communities will disagree because from each of their respective positions the other 'simply' cannot see what is obviously and inescapably there". ${ }^{1316}$ Gherardi and Nicolini conclude that when different interpretive communities work together they form a discursive community, "where each community maintains its own voice while listening to the voice of the Other, [sic!] and where communication is both negotiated order and disorder." 1317

Because the background knowledge of members of different interpretive communities differs, the theories, hypothesis and data, as well as the methods, designs and plans compatible with their specific background knowledge will differ as well. ${ }^{1318}$ As a result, members of different interpretive communities not only diagnose and analyze problem situations differently, ${ }^{1319}$ but also approach problems differently, apply different theories and methods and ultimately, suggest different problem solutions. ${ }^{1320}$ Arguments that persuade their own community convincingly may have little or no weight in other communities. ${ }^{1321}$ Carroll's empirical findings support this by showing that different interpretive communities are characterized by different problem-solving and that they use different objects as a primarily communication mechanism. ${ }^{1322}$ Design engineers, for example, concentrate on anticipating problems and use primarily visual objects, such as schematics, drawings, flowcharts, and pictures. Managers are similarly focused on anticipation, except they are dealing with financial issues that are more abstract, longer term and primarily numerical rather than visual. Operators and craftspeople, in contrast, develop a variety of local adaptations in order to enact their assignments. They are mostly concerned with the concrete equipment; their world is manual and tactile. Finally, management consultants concentrate on "the verbal world of ideas, written publications and persuasive conversations". ${ }^{1323}$ Carroll concludes that these distinctive "logics" are a main reason for conflicts and communication problems in organizations. ${ }^{1324}$ Moreover, these distinctive logics are the reason why members of different interpretive communities disagree on how to evaluate the potential of different solution paths. While they all are

Fish (1980), p. 15.

Gherardi/Nicolini (2002), p. 421.

See Bunge (1985), p. 234.

In this sense, problems do not have an objective existence; rather, they are defined and constructed in the interaction process. See Behrens/Delfmann (2002), pp. 15-16; McGivern/Fineman (1983), pp. 435-436. See also the discussion in chapter B.II.3.1.1.

See Tichy (1975), pp. 793-798. As Prahalad and Bettis put it, shared perspectives can be expressed as a problem-solving behavior. See Prahalad/Bettis (1986), p. 491.

See Boland/Tenkasi (1995), pp. 351-352.

See Carroll (1998), pp. 710-714.

Ibid, p. 711.

Ibid, p. 711, see also Reihlen/Ringberg (2006), pp. 330-336.
} 
guided by the same aim, i.e. the creation of functional solutions, ${ }^{1325}$ members of different interpretive communities might have, at the same time, different agendas, as well as beliefs regarding the value of different problem solutions. ${ }^{1326}$ Moreover, the value of particular problem solution depends on the particular situation and context, and a final decision is only possible after putting the different solution paths and problem solutions to test. ${ }^{1327}$ However, in the case of social and socio-technical problems, such as those typical in consulting projects, tests require long time to show results. In addition, their results are never ultimate, as a number of other factors also influence these problem situations. For this reason, problem-solving in the context of social problems requires not only the sharing of interpretations regarding the problem at hand but also an agreement between the involved individuals regarding their values and beliefs, as well as regarding evaluation methods and practices. Therefore, it can be concluded that teams and organizations will not learn effectively until they "recognize and confront the implications” of the existence of different interpretive communities. ${ }^{1328}$

Thus, to prevent misunderstanding between members of different interpretive communities, it is not sufficient to enable an open and minimally defensive interaction between them, as Schön suggests. ${ }^{1329}$ Rather, it is necessary to span the boundary between interpretive communities and to establish and sustain cognitive and social connections amongst these communities. ${ }^{1330}$ Without alignment of their perspectives, i.e. their task-specific knowledge including their understanding of what makes one or the other perspective more appropriate, ${ }^{1331}$ members from different interpretive communities will not be able to transfer valuable knowledge and will disagree about the problem and the way to solve it, which will result in longer lasting problem-solving processes and in lower creativity. ${ }^{1332}$ Without alignment of their social activities and their task-related knowledge, individuals will not work effectively together. ${ }^{133}$ Both require an intensive interaction between members of different communities.

\footnotetext{
1325 Functionality, or usefulness, was indicated as the main value orientation for services such as consulting. See chapter B.I.1.4.

Thus, it is important to note that the involved individuals might pursue also other goals. In addition, in pursuing these goals, individuals might contribute to the achievement of other goals without being aware of it. These issues are further discussed in chapter D.IV where the hidden ways of influence of discourses and problem-solving practices are analyzed. See Tichy (1975), p. 797. Because of the context dependency of management problems, previously generated evidence about the functionality of particular solutions can be used by members of interpretive communities to come to a joint conclusion only in situations that are quite similar to the circumstances in which the solution was evaluated. In other words, previous evidence can be only used in routine problem situations.

Schein (1996), p. 18.

See Cannon-Bowers/Salas (2001), pp. 196-198; Lindlof (1988), pp. 90-92; Schein (1993), p. 41; Wenger (1998), pp. 315. 


\section{Knowledge transfer and creation ${ }^{1334}$}

\subsection{Client-consultant team as a community of interpretive communities}

As argued in chapter B.II, client-consultant teams are specific learning communities or inquiring systems, which are designed, set up, maintained, transformed, or dismantled with the explicit goal to solve some kind of a management problem. The ultimate aim of client-consultant interaction is to generate a functional problem solution for the problem at hand, i.e. to provide an effective and efficient problem solution that is useful in the given context. ${ }^{1335}$ However, management problems vary in their nature and are related to different bodies of knowledge. Therefore, there is no unified method for solving such problems, as different bodies of knowledge imply different methods and procedures for problem-solving ${ }^{1336}$ and even different evaluation criteria. ${ }^{1337}$ This implies that there will be different solutions to one and the same problem. ${ }^{1338}$ Because client-consultant teams represent collaborations between two organizations, they can be regarded as specific combinations of interpretive communities, as communities of interpretive communities. Consequently, members of client-consultant teams will have different perspectives, frames, and knowledge. As a result, they will more often than not disagree about the nature of the problem at hand, as well as about the appropriate way to solve it. ${ }^{1339}$ Figure 12 illustrates the client-consultant team as a community of interpretive communities.

The figure emphasizes the following important characteristics of client-consultant teams as communities of interpretive communities: (1) interpretive communities exist beyond the boundaries of single organizations, e.g., the client and consultant company; ${ }^{1340}$ (2) members of interpretive communities who participate in consulting companies are all characterized by the development of some specialized body of formal knowledge and skill. They learn and practice this knowledge, identify with it to some extent, distinguish it from other disciplines, and recognize each other as colleagues by virtue of their common training and experience with some common set of tasks, techniques, concepts, and working problems; ${ }^{1341}$ (3) at the same time, however, members of different interpretive communities within a particular consulting company develop some firm-specific knowledge and firm-specific methods and concepts. Moreover, they also develop some specific client- or industry-based expertise and practices. Therefore, a

As in chapter D.I discussed, knowledge transfer implies the stability and objectivity of meaning whereas the interpretive model regards meaning as context dependent and contested. For this reason, it is more appropriate to use the term knowledge translation when discussing the sharing of interpretations and knowledge between members of interpretive communities. However, the term knowledge transfer is further used within this model but it is regarded as a process that involves translation, not the simple exchange of knowledge. See Kirsch/Eckert (1998), p. 296 for a similar argument.

See Bunge (1985), p. 226. As such, consulting is seen as a technological service. This was suggested within the workoriented approach to professional services in chapter B.I.1.4.

See Bunge (1985), p. 227-228.

See also Tsoukas/Hatch (2001), p. 1003.

See Bunge (1996), p. 80.

See also Kirsch/Eckert (1998), pp. 266-306 who develop a similar argument about the nature of client-conslutant teams.

It is important to imagine the figure in a 3-D format as different interpretive communities intersect with different organizations.

This argument is related to the view of consulting as a specific occupation. See Freidson (2001), p. 202. 
particular consultant shares some interpretive frames with consultants from other organizations, some frames with his/her colleagues within his/her consulting company, and at the same time, s/he develops some shared understanding with a particular group of consultants only and with members of client organizations; ${ }^{1342}$ (4) as a result of (3), a consultant within a particular consulting company does not have all of his/her cognitive frames shared with all other consultants but only with a limited number of consultants, which implies that communication problems and disagreements regarding appropriate solutions paths will exist even in the same consulting company. ${ }^{1343}$ This is also true for members of the client organization. To illustrate this, in the figure, only some of the interpretive communities have intersections; (5) not all interpretive communities represented in these companies are involved in a particular client-consultant team. For example, in this figure, the internal consultants of the client organization do not participate in the client-consultant team; (6) some of the interpretive communities are involved in a particular client-consultant team to a higher degree than others.

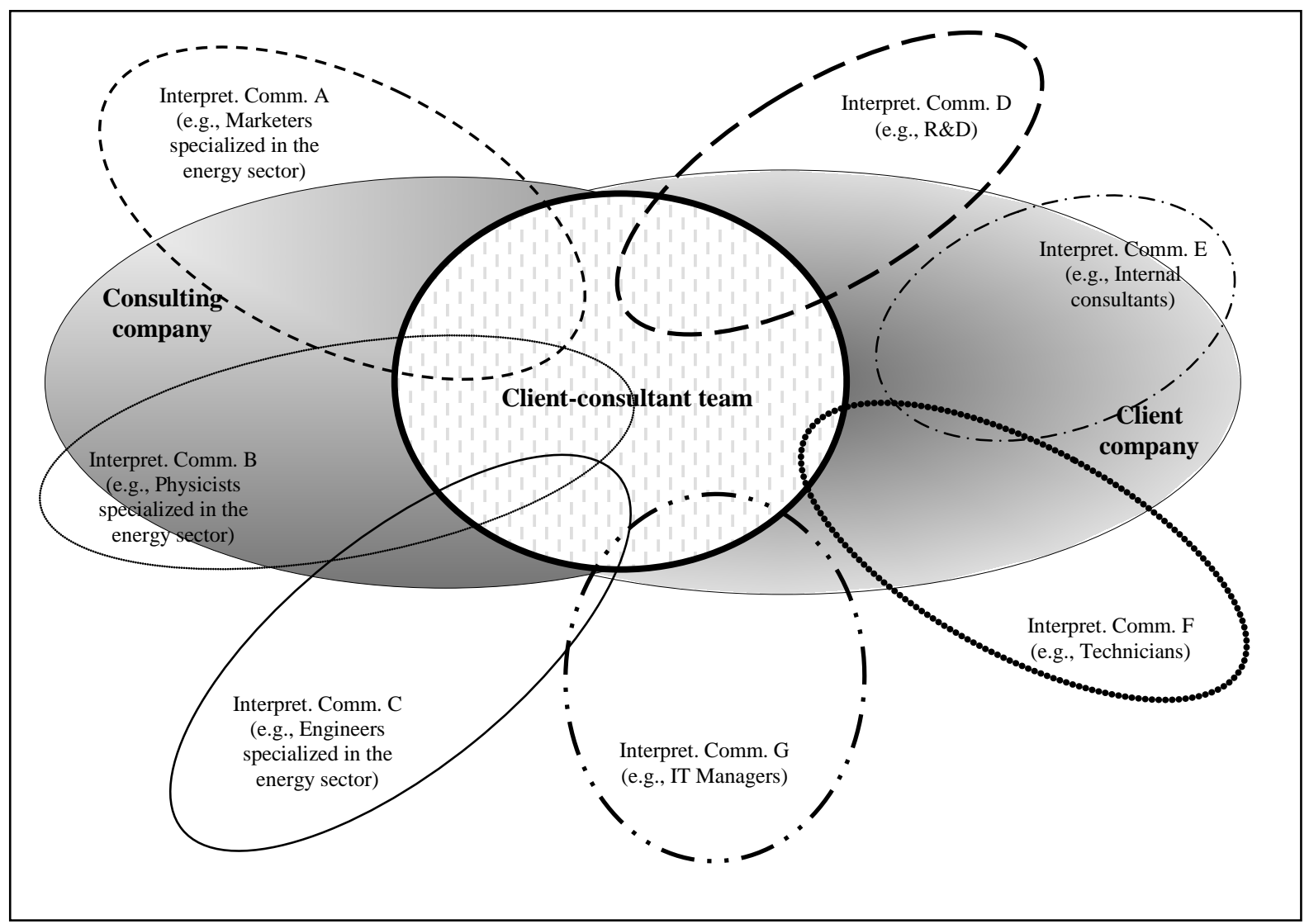

Figure 12: The client-consultant team as a community of interpretive communities

The view of client-consultant teams as communities of interpretive communities has important implications for one's understanding of the interaction process in clientconsultant teams. As the discussion in the previous chapter shows, this view of clientconsultant teams implies that clients and consultants differ in their interpretations

The discussion of the organizational structure of McKinsey illustrates this aspect to some degree. 
regarding both the problem at hand and the possible solution paths, as well as regarding the way the team should work together and perform its tasks. In other words, clients and consultants encounter some differences regarding their task-specific knowledge on the one hand, and their task-related knowledge, on the other hand. In the following, the relevance of both task-specific and task-related knowledge is discussed.

\section{Shared task-specific knowledge}

Research on expert-layperson communication confirms that consultant's task-specific knowledge that is developed as a result of learning and training in a particular field, and through additional practical experience, and which is distinct from everyday knowledge, differs at least to some extent from client's task-specific knowledge. ${ }^{1344}$ It has been further shown that in such situations, consultants' estimations of what clients know are often biased in the direction of consultants' own knowledge. ${ }^{1345}$ As a result, clients and consultants often ignore the need for an intensive transfer and sharing of their taskspecific knowledge in order to develop shared interpretation of the issue at hand. It is obvious that in the absence of shared knowledge regarding the problem, clients and consultants will not only have trouble communicating effectively but will also suggest different methods and procedures for solving the problem. This leads to disagreement about which solution path is the most appropriate in the given situation.

Whereas decisions can be made and problems can be solved even in the absence of shared task-specific knowledge and despite differences of interpretation among team members regarding the issue at hand, ${ }^{1346}$ the development of shared interpretation of the problem and the suggested solution has a major influence on the implementation of the problem solution. ${ }^{1347}$ Teams with shared task-specific knowledge are likely to implement problem solutions and decisions more quickly and with fewer problems than teams that do not develop shared understanding. ${ }^{1348}$ What this work stresses, however, is that the development of some shared task-specific knowledge between clients and consultants is important not only for the successful implementation of problem solutions but is also necessary for cooperative and creative problem-solving. In other words, this work stresses the need of cooperative problem-solving rather than problem-solving directed by an expert. Cooperative problem-solving takes into consideration the perspectives and knowledge of all individuals and promises higher effectiveness and creativity. ${ }^{1349}$

See, e.g., Bromme et al. (2001), pp. 317-318.

This systemic bias in knowledge estimation is characteristic for a number of “expert groups”, i.e. not only for consultants. Ibid, pp. 317.

This is basically what the proponents of the expert model assume. Because consultants are regarded and accepted as experts, there is no need for them to interact intensively with the client in order to develop shared understanding of the issue at hand. Rather, the solution is created by the consultants and later suggested to the clients for implementation. See Klimoski/Mohammed (1994), p. 428. 


\subsection{Shared task-related knowledge}

The need of shared task-related knowledge emphasizes the fact that client-consultant teams are social communities. As such, their members are engaged in social interactions during their joint work that need to be coordinated and integrated. Thus, shared taskrelated knowledge, which includes shared understanding of the components of teamwork, the roles and responsibilities of team's members, interaction patterns, communication channels, and role interdependencies, is crucial for effective team performance ${ }^{1350}$ and facilitates the problem-solving process. Shared attitudes and beliefs about the teamwork have the important function of guiding, coordinating, and integrating team members' activities and efforts towards the project objectives. Another important role of shared task-related knowledge is to create emotional connections with the client. For example, advertising agencies "draw the client deeper into long-term relations of affinity" "by presenting proprietary models that engage social interaction and by expressing ideas in a language that evokes shared emotion". ${ }^{1351}$ Therefore, in Hardy et al. terms, "cooperative talk" ${ }^{\prime 352}$ is important not only for effective team performance, but is also the precondition for the creation of long-term relationships with the client.

The development of shared task-related knowledge is thereby closely related to the use of concrete social mechanisms for the management of team processes, some of which were introduced in chapter B.II.4.4. Next, in order to illustrate the potential of how shared task-related knowledge between clients and consultants can improve their social interaction and ultimately their team performance, a model of the factors that influence team performance as proposed by Klimoski and Mohammed is outlined and applied to the case of client-consultant teams. ${ }^{1353}$

\subsection{A model for explaining the role of shared task-related knowledge for team performance}

The model explicitly discusses the role of shared task-related knowledge in team performance and outlines, additionally, what other factors influence team performance and their interrelations with shared task-related knowledge. Figure 13 illustrates the proposed model.

According to the model, team performance depends on the quality of a number of team processes. Team processes are social mechanisms that are used to coordinate and integrate the activities of the team members towards the joint objective. Examples for such team processes were discussed in chapter B.II.4.4 of this work. Klimoski and Mohammed argue that although all team processes have an impact on team performance,

See also Klimoski/Mohammed (1994), p. 428.

Malefyt (2003), p. 144.

Hardy et al. (2005), p. 69.
}

See Klimocki/Mohammed (1994). The authors use the notion of team mental models instead of shared task-related knowledge but explicitly state that they mean shared knowledge regarding team processes. See Klimoski/Mohammed (1994), p. 428. In this work, the term task-related knowledge is preferred because it helps to clearly differentiate between shared understanding regarding the problem at hand, i.e. task-specific knowledge, and shared understanding regarding teamwork. 
those that are particularly important include strategy formulation and planning, as well as all processes that improve the quality of interpersonal relations, such as, conflict solving processes and affect management. ${ }^{1354}$

The model emphasizes, further, that there are a number of antecedents of effective team processes, and the figure highlights the proposed functional relationships between antecedents and group processes. First, the members of the team need to possess some potential for effective performance. ${ }^{1355}$ This factor considers the personal attributes of individuals. As discussed in chapter B.II.2, important personal attributes in this context are the cognitive skills of clients and consultants, their motivation, and their interpersonal skills, in particular communication and persuasion skills. In the above framework, the individual's potential for performance interacts with two team level parameters: (1) the composition-i.e. gender, age, experience of team members-as well as the size of the team-number of individuals involved-and (2), the resources available to the team, such as, operating budget, equipment, amount and kind of information, time for completion of project, etc. Taken together, these factors create the team capacity, which represents the latent potential of the team to work effectively together.

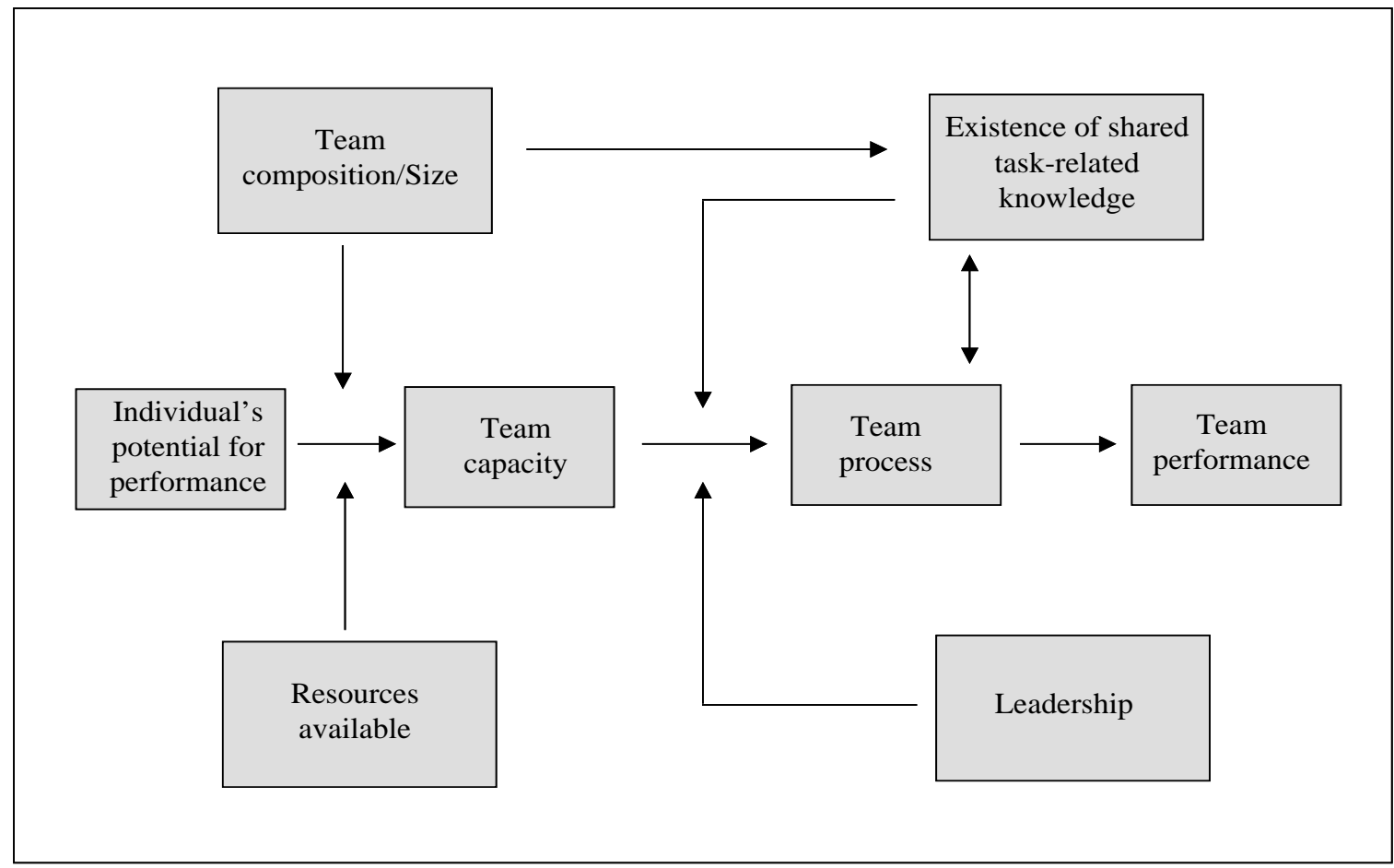

Figure 13: A framework for explaining the role of team mental models in team performance

Source: Klimoski/Mohammed (1994), p. 429.

Klimoski and Mohammed argue that team's capacity is transformed into effective team processes with the help of two "orientating, guiding or harnessing” factors. ${ }^{1356}$ The 
first of these factors is the existence of shared task-related knowledge. ${ }^{1357}$ The main role of this type of shared cognitive frames is the enhancement of harmonious social interaction of clients and consultants, especially under conditions of stress or pressure. ${ }^{1358}$ The existence of shared task-related knowledge can evoke positive feelings between the involved individuals and facilitate social integration, which can result in higher effort, coordinated actions, assertiveness, etc., all factors that determine team effectiveness. ${ }^{1359}$ Moreover, if some shared task-related knowledge exists at the start of consulting projects, less communication and negotiations need to take place, and there is a lower potential for conflict between the involved individuals. As such, shared task-related knowledge has also a direct impact on team processes. ${ }^{1360}$ At the same time, effective team processes, if they are adopted early on, influence the further development of shared understanding. Thus, there is a reciprocal relationship between shared task-related knowledge and team processes.

The existence of shared task-related knowledge is particularly important for clientconsultant teams because they operate with very restricted time frames and do not have much time to adjust divergent perceptions and preferences regarding their teamwork. Without any shared understanding regarding their work, clients and consultants will have to spend valuable time bringing to the "surface their mutual perceptions, assumptions, options, and preferences". ${ }^{1361}$ Sharing some task-related knowledge also implies that even when clients and consultants have different perspectives regarding the problem and its possible solution, they can more easily find ways to integrate their interpretations and create shared task-specific knowledge. Donnellon et al. support this when they argue that cognitive consensus requires some minimal degree of shared understanding among different communities about the nature of the relationship and the rules governing it. ${ }^{1362}$ They further suggest that members of different communities will take organized action despite holding different interpretations of common experience if they share "a repertoire of behavioural options that members of a given society recognize, respond to, and use to interact with one other". ${ }^{1363}$ Such shared repertoire of communication behaviors leads to the development of so-called "equifinal" meanings-dissimilar interpretations with similar behavioral implications. Thus, to create alignment amongst different communities is not "a case of deciding which one has the right viewpoint, but of creating enough mutual understanding among them to evolve solutions that will be understood and implemented". ${ }^{1364}$

It is assumed, for now, that such shared knowledge is already achieved. The processes that lead to the development of shared understanding are discussed extensively in chapter D.III.3.5.

Ibid, p. 430. See also Walsh et al. (1988) who support empirically the view that increased sharing of task-related knowledge increases group performance. 
Thus, it can be concluded that if there is no shared task-related knowledge within client-consultant teams, "collective effort would be lower and interpersonal relationships might be damaged". ${ }^{1365}$ In other words, the management of cognitive pluralism is the key to more efficient cooperation in diverse teams. ${ }^{1366}$ This makes it clear that clients and consultants have to carefully choose the members of their team in order to ensure the existence of at least some minimal shared task-related knowledge. In particular, it is helpful if at least some of the members of the client-consultant team have experience in working in diverse teams. ${ }^{1367}$ In addition, some preliminary training in such teamwork of junior consultants and inexperienced members of the client team can decrease the time required for the development of shared task-related knowledge. It is clear that the members of the client-consultant team need to learn to share their perspectives as quickly as possible in order to prevent the emergence of negative feelings and misunderstandings.

As discussed in chapter B.II.4.4, the initiation and management of team processes is the responsibility of the project manager(s). Thus, project managers have a direct influence over group processes. In this regard, Klimoski and Mohammed propose that an effective leadership can serve a similar function as shared task-related knowledge in enhancing team processes. The project manager can guide and manage the team through activities such as assigning tasks to team members, integrating information and interpretations, adjudicating disagreements, and directing team members into action. ${ }^{1368}$ However, although effective leadership might be important, it cannot substitute for the development of some shared attitudes and beliefs among team members. ${ }^{1369}$ Thus, the development of shared task-related knowledge amongst the involved individuals is regarded as the main factor that influences the quality of group processes and ultimately team performance. When team members share understanding about their work it is more probable that they will also develop some shared task-specific knowledge. At the minimum, shared task-related knowledge increases the cohesiveness and motivation of the team and results in integrated social interactions.

These issues related to the social interaction between clients and consultants are neglected within the existing models of the client-consultant relationship. In contrast, although the interpretive model concentrates on the discussion of the interaction between clients and consultants that is explicitly oriented towards decision-making and problemsolving, it also acknowledges the importance of the development of shared task-related knowledge within the team. This is in line with the critical realist approach. In other words, this work emphasizes that client-consultant teams are not combinations of disembodied interpretations and knowledge but consist of real people with beliefs, emotions, interests, hidden agendas, etc., which implies that not only their interpretations

Klimocki/Mohammed (1994), p. 430.

See, e.g., Cannon-Bowers/Salas (2001), p. 200; Klimocki/Mohammed (1994), p. 412. Empirical studies further support this argument. See, e.g., Lovelace et al. (2001), p. 790.

This is one of the main characteristics of project managers within client-consultant teams. Their main role is exactly to facilitate the development of shared task-related knowledge. See the discussion in chapter B.II.4.3.1 and the following point.

Klimocki/Mohammed (1994), p. 431. Lovelace et al. also discuss the role of effective leadership for the success of diverse teams. See Lovelace et al (2001), p. 782 and pp. 790-791.

Klimocki/Mohammed (1994), p. 431. 
of the issue at hand need to be integrated but also their understanding regarding their work, roles, and responsibilities.

In practice, however, it is difficult to differentiate between both types of shared knowledge and activities. Moreover, the above presented model postulates that there is a direct relation between shared task-specific knowledge and shared task-related knowledge. The construct that connects both terms is the team diversity, i.e. team composition. As already discussed, factors, such as shared educational background, shared situated knowledge, and similar experiences decrease differences between individuals' interpretations. Thus, team members who share a number of cognitive frameworks, i.e. who share task-specific knowledge, will develop shared task-related knowledge faster and more easily: "the likelihood that a given cultural feature will spread from one individual (or group) to another depends on how many other features they may already have in common". ${ }^{1370}$ Increasing sharing of task-related knowledge facilitates, at the same time, a further sharing of task-specific knowledge.

In the following, some concrete mechanisms and steps are discussed that can lead to the development of shared understanding within client-consultant teams.

\subsection{Knowledge transfer}

The previous discussion on the nature of knowledge and interpretive communities makes it clear that from the perspective taken within the interpretive model a successful knowledge transfer between members of different interpretive communities requires the development of some shared cognitive frames. In the literature, there have been few suggestions as to how to develop shared understanding or how to achieve cognitive consensus. ${ }^{1371}$ Sociologists, for example, suggest that individuals have to engage in socalled "aligning actions", which are forms of conduct, mainly verbal, in which individuals bring individual acts in line with one another and the shared understanding of other interpretive communities. ${ }^{1372}$ Such aligning actions often involve an interaction that goes beyond the particular issue or problem that the involved individuals have to deal with. In other words, the establishment of some shared cognitive frames that might be relevant for the particular issue at stake requires the sharing of broader frames. For example, when members of interpretive communities substantially differ in their interpretations of a particular issue (within a particular context) they can still develop shared understanding on the basis of being members of the same or similar interpretive communities in a different context. For example, if a client and consultant have quite different understandings about the particular issue they have to deal with, they might be both, at the same time, members of another community. Starting with a discussion in the context of this community, they can gradually bridge over to the particular problem at hand and establish some shared understanding. Hardy et al. refer to this type of conversation as to "private constructions". "In our daily interactions, we continuously

See Stokes/Hewitt (1976), p. 844. They speak about culture and not interpretive communities or subcultures but their argument can be transferred for the case of subcultures.
} 
switch between different contexts" and, accordingly, different interpretive communities. ${ }^{1373}$ Often, through such private construction it is possible for members of different interpretive communities to develop a feel for others' perspectives and "language". It has been argued, for example, that getting a "feel" for the client's situation - what a client "thinks, feels, needs, and desires"-is pivotal for the success of lawyers. ${ }^{1374}$ "By getting the feel of a 'client's social (not just legal) situation' [], lawyers may be able to acquire fluency in discourses of difference and to construct client identity in terms of problem-solving and managerial competence". ${ }^{1375}$

In the following, a process model that illustrates how clients and consultants transfer knowledge and develop shared cognition is proposed. Thereby, this process of transferring understanding, and establishing shared meanings, involves both task-related and task-specific knowledge. ${ }^{1376}$ This model is based on Czarniawska and Mazza's view of consulting as a liminal space. ${ }^{1377}$

The notion of liminal space was first introduced in anthropology and was later adopted in organization studies. It broadly means "a condition where the usual practice and order are suspended and replaced by new rites and rituals". ${ }^{1378}$ It is, therefore, a condition of transition, “otherness”, and uncertainty. Czarniawska and Mazza argue that consultants in particular face such conditions of transition and otherness when they work on client projects. ${ }^{1379}$ This is also true for clients, who work on a particular consulting project, although to a lesser degree, as clients usually do not leave their organization, so that they are not confronted with a totally different environment. Thus, it is suggested that consulting projects represent liminal spaces, where consultants and clients face different understanding, rules, beliefs, and practices. Members of such liminal spaces have to be very flexible and pliable in order to understand the perspectives of the other actors.

Czarniawska and Mazza propose that three major process phases characterize interactions within the liminal space: forming, transition/transformation, and separation. ${ }^{1380}$

\section{Forming}

The first phase begins with the start-up meeting, which is characterized by consultants "investiture" into the clients organization. At the same time, the involved members of the client team undergo a separation or "divestiture" from their organization, in other words, they become separated from their original communities. This phase is very rich on symbolic and narrative resources, as both sides need to learn about the

Hardy et al. (2005), p. 67.

See Lopez (1992), p. 61 cited in Alfieri (1994), p. 1759.

Ibid, p. 1759.

As it was argued, it is not easy to differentiate between both types of knowledge in practice, as they are usually interwoven and strongly influence each other.

See for the following discussion Czarniawska/Mazza (2003).

Ibid, p. 267.

See also Kipping/Armbrüster (2002), pp. 203-204.

See Czarniawska/Mazza (2003), pp. 279-283.
} 
others and the liminal space they will be engaged in. Being made a member of the team and being given some understanding of why the team has come about is the start of the communication process. ${ }^{1381}$ The main discussion points at this stage are, first, the perceptions of the team members of the task to be performed, and second, the possible problems to be encountered by the team. ${ }^{1382}$ Thus, these first steps are usually concentrated on the agreement upon, and establishment of, some social integration mechanisms that will guide and coordinate individual activities. In other words, these first steps concentrate mainly on the development of some shared task-related knowledge. Through the sharing of artifacts and communication, team members usually reach some minimum understanding of the nature of the team, its tasks, and the rules that will govern team behavior. ${ }^{1383}$

At the same time, the uncertainty over appropriate interpretations of the problem situation leads group members to anchor the current problem situation to what they perceive are similar, previously experienced problems. ${ }^{1384}$ Thus, one way to start with the problem-solving process is to initiate a discussion of the problem in a way that is familiar for the other involved interpretive communities, in order to show them the legitimacy of their own perspective. This would involve the description of the problem in some general and simple terms so that no misunderstanding takes place. This results, usually, in a very simple picture of the problem. Thus, in the next step, the goal is for each interpretive community to outline their view of the major aspects of the problem. If all members use similar cognitive schemes and define the problem in the same way, interaction is easy. ${ }^{1385}$ However, this is a highly hypothetical situation, even if team member recruitment and selection increases the probability for some initially shared task-specific knowledge.

\section{Transition/transformation}

Because client-consultant teams are composed of individuals from different organizations and interpretive communities with different knowledge and experience, they will, more often than not, have different perspectives on the problem. Thus, the transition phase starts with misunderstandings, suspicion, and anxiety of disclosure and can only be successfully completed if all involved actors reach "a similar status resulting from the shared condition of liminality". ${ }^{1386}$ In other words, that the success of this phase, and the development of shared task-specific knowledge, depends on the achievement of some shared task-related knowledge, the stripping away of differences in rank and status, and the development of a sense of "togetherness among liminals". ${ }^{1387}$

A first step in this phase is the simple recognition that interpretive differences exist between the members of the team. ${ }^{1388}$ An important next step is the inquiry into the

\footnotetext{
1381 See Klimoski/Mohammed (1994), p. 423; Wimmer (2004), p. 276. 
reasons underlying the diversity of perspectives. Through listening to other members clarifying their interpretations, actors may proceed from being aware that there are differences to accepting the legitimacy of alternative points of view. ${ }^{1389}$ The integration between the perspectives of the involved interpretive communities is, however, a major challenge because different perspectives are usually based on different models and concepts, or in general, upon a diverse set of theories. Therefore, bridges between the different points have to be built that would enhance one's understanding of the major points in one's own "language" and "thought world". Such bridges need to be created jointly in order for them to have a double meaning. In practice, different cultural artifacts, also called boundary objects, are often used to point out different aspects/decompositions of the problem. ${ }^{1390}$ They are the supporting mechanisms used when individuals bring forward their arguments for a particular interpretation of the problem. In a consequent step, the involved interpretive communities are asked to generate their own solution paths. This makes them conscious, creative members of the problem-solving process and offers more interpretations to the client-consultant team. Through this activity, members of different interpretive communities start to share meanings, reflect upon, evaluate, and validate community procedures in a collaborative process. ${ }^{1391}$ In this regard, Kirsch argues that strong and persuasive arguments exhibit the so-called "progression logic": they are based on logical interrelations between existing knowledge, gaps in this knowledge and new knowledge that can be used to fill these gaps. ${ }^{1392}$ In other words, a strong argument in a particular context is, (1) based to some degree on existing knowledge, and (2) suggests ideas and ways of how to solve a particular problem that cannot be accounted for on the basis of this existing knowledge. Given the plurality of interpretations and knowledge bases that are present in clientconsultant teams, it is clear, however, that members of different interpretive communities will suggest different arguments and that many of them can be seen as strong arguments. ${ }^{1393}$ Thus, the evaluation of alternative arguments is a major issue. The aim of functionality can enable a preliminary validation of arguments and solution paths by putting additional constraints on suggested solutions, including: evidence for feasibility, effectiveness, and reliability; that the cost of the solution do not exceed certain figures; and the benefits that can be expected outweigh its predictably undesirable side effects. ${ }^{1394}$ A substantial validation requires the generation of evidence on the basis of existing data,

Ibid, p. 316. The authors further state that techniques such as Social Judgment Analysis, which promotes the free exploration and examination of individual differences in cognition, have been shown to be helpful for the development of group consensus. The main characteristic of this approach is that groups, the members of which differ in their interpretations of the task at hand, are provided with cognitive feedback on their individual interpretations. See, e.g., Harmon/Rohrbaugh (1990) for an extensive discussion of the approach. See also the discussion in chapter D.III.3.8.

Sommerlatte speaks about a reflective learning process that allows the involved individuals to reassess critically their perspectives. See Sommerlatte (2000), p. 143.

See Kirsch (1997), pp. 354-357; translation through the author. The logic that is followed in this procedure is called argumentative logic and is further discussed in chapter D.III.3.8.2.

As previously stated, different interpretations imply differences in individuals' interests and values. Consequently, the development of shared understanding involves the development of joint valuing. See Gray et al. (1985), p. 87.

See Bunge (1985), p. 226. These conditions are scientific, technical, and social and are often mutually related. Ibid, p. 227. 
previous experiences and, where possible, tests. ${ }^{1395}$ Thus, given the restrictions of tests, often the experience of the involved individuals is the crucial factor that influences the choice of the solution path to be followed. ${ }^{1396}$ However, experience is not always a helpful basis for evaluation, particularly in the case of complex and innovative problems. ${ }^{1397}$ In other words, team members might need to engage in innovative problem generation and solving processes, including practices such as dialectic reasoning. ${ }^{1398}$ If the involved individuals are successful in developing some shared task-specific knowledge, the distance between divergent perspectives decreases, and a better understanding is developed to deal with the counterparts. ${ }^{1399}$ As a result, the liminal space is transformed into a more 'comfortable' space. The whole process is successful when members of the client-consultant team begin to act and interpret using the meanings that have developed within the team rather than their original interpretations. ${ }^{1400}$ This is considered the most crucial stage in the decision-making processes ${ }^{1401}$ because how an issue or event is jointly interpreted by the team members shapes the rest of the problemsolving process.

Bettenhausen and Murnighan point out that when group members proceed deliberately in testing the appropriateness of their interpretations, and in establishing shared understanding of the group aim and the actions that are appropriate for its performance, the probability for successful problem-solving increases. If, however, team members assume that everyone has similar views, they will proceed in "pluralistic ignorance until someone questions the appropriateness of the group's actions". ${ }^{1402}$ Consequently, team members will become aware of the discrepancies in their interpretations of the situation but they will not necessarily find ways to resolve their differences. Furthermore, resolution at this stage is often more difficult because team members may find it difficult to abandon the perspectives that have guided their behavior since the group's initial interactions. "The likelihood of a threat or challenge, then, leads to an expectation of relatively poor performance by groups who do not discuss the basis for their interaction but simply begin working”. ${ }^{1403}$

1395 See Sommerlatte (2000), p. 146. See for a detailed discussion of data and its sources Bunge (1996), pp. 84-87; also Rescher (2005b), pp. 33-37 and pp. 68-80. Raelin also stresses that conceptualization, i.e. the development of interpretations and concepts, needs to be complemented by experimentation and experience. See Raelin (1997), pp. 565566.

See Bronner (1993), p. 17; Raelin (1997), p. 566-567; Rambow/Bromme (1995), pp. 351-353; Rescher (2005a), p. 32. Rambow and Bromme argue that more experienced problem solvers possess "economically well-selected criteria for assessment”, which help them to evaluate alternative problem solutions. They further suggest that what makes one problem solution better than others depends sometimes to a high degree on personal assumptions and convictions. See Rambow/Bromme (1995), p. 351. Bronner supports this when he points out that evaluation of decisions is considerably shaped by preferences that are closely linked to individual’s personality. See Bronner (1993), p. 17.

Therefore, it can be conlcluded that in such cases, decisions based on the functionality of problem solutions and on the experience of certain team members might not involve the agreement of all team members. See also Bunge (1985), p. 227. This issue is further discussed in chapter D.IV.

This is a type of argumentative reasoning, which is further discussed in chapter D.III.3.8.2. See also Reihlen (1997), pp. 232-243 for a detailed discussion of this procedure. The process of knowledge creation is further discussed in the next chapter of this work.

See Sharma (1994), p. 27.

See Bettenhausen/Murnighan (1985), p. 357.

See Mohammed/Ringseis (2001), p. 312.

See Bettenhausen/Murnighan (1985), p. 369.

Ibid, p. 369. 
The development of shared understanding implies that some of the team members change their initial perspectives during their interaction within the liminal space. ${ }^{1404}$ As above suggested, this process often involves attempts by some actors to persuade others to accept their own interpretation by emphasizing their experience with similar problems. ${ }^{1405}$ In many cases, however, it is not clear whose and what experience is crucial for problem-solving. In the case of innovative problems, in particular, no participant in the problem-solving process can claim to possess experience in how to solve such a problem. In this cases, a decision about the appropriateness of one's experience and about what knowledge is more or less important is often the result of negotiations and persuasion and is influenced by existing practices, discourses and power relations, an issue that is discussed extensively in chapter IV. ${ }^{1406}$ However, the process of developing shared knowledge, as described by Czarniawska and Mazza, is characterized by cooperation, and the willingness and the ability of the involved actors to overcome differences in their interpretations to achieve a synthesis or compromise on the problem solution. As such, this view ignores the role of power in human interactions.

If the process of developing some shared meaning is successful, the client-consultant team transforms into a new interpretive community or inquiring system. It will have its own communication style and shared understanding of the problem and solution path, and can develop valuable site-specific knowledge and artifacts. ${ }^{1407}$ The previously cited study on computer-mediated knowledge transfer in consulting companies confirms this argument. ${ }^{1408}$ It shows that clients and consultants often develop specific knowledge artifacts, such as specific consultant tools and methods, which cannot be understood by consultants who did not participate in the project in which they were developed. In other words, those who were not part of the interpretive community that emerged do not understand it. Thus, client-consultant teams as emerging interpretive communities have the potential to grow into sources for the generation of new perspectives that can feed back into the central organizational domains and arenas, supplying them with new aspirations and interpretations. ${ }^{1409}$ Figure 14 summarizes the major steps of the discussed process.

It is clear that the whole process may go through several phases of reflection, sharing of perspectives, reframing of one's own interpretations of the problem and problem solution, and reflection on the reframed understanding. As with every other creative and highly interactive process, these steps are not clearly separable in practice but overlap

1404

See Tindale et al. (1993), p. 470; also Bettenhausen/Murgnighan (1985), p. 365.

See Bettenhausen/Murnighan (1985), p. 356; also Kirsch (1997), pp. 351-358. Kirsch speaks in this case about persuasion based on the "primary knowledge" of the decision-makers. Translation through the author.

The exact steps that individuals follow to persuade others that they are the experts in solving a particular problem are discussed in chapter D.IV.6. See also Kirsch (1997), pp. 358-362. He refers in this case to the "secondary knowledge" of decision makers. Translation through the author.

Czarniawska and Mazza argue that participants in such emerging interpretive communities prefer not to discuss details of the process through which sharing of perspectives and the creation of new representations take place. "A successful consultant helps to replace one type of representation with another in a magical way, without revealing the details of the process itself”. Czarniawska/Mazza (2003), p. 284. This inability or unwillingness of consultants to describe the process of knowledge sharing is one possible explanation why supporters of the critical model describe consultants as "witch doctors".

See Reihlen/Ringberg (2006), pp. 330-336.

See Garsten (1999), p. 615. 
each other. Malefyt confirms this in a study, which investigates the service delivery process in advertising agencies. ${ }^{1410}$ He reveals that the sequence of the interaction process is anything but smooth and continuous. The process is more one that progresses in jumps and starts, from inspirational meetings to setbacks. "Brilliant strategies are created, only to be altered later to accommodate the wishes of contentious clients, rushed deadlines or legal restrictions.” 1411 Not infrequently, strategies are dropped altogether in mid development and new ones taken up.

\section{Separation}

The last phase of the interaction process in the liminal space is the separation of the consultants, which is marked by the presentation of a final report. It is usually followed by the, at least, part liquidation of the liminal space for some of the client employees. ${ }^{1412}$ With this, the developed shared perspectives within the client-consultant teams are open to new influences and perspectives. In consulting projects in which consultants are also involved in the implementation of the suggested problem solution, the liminal space continues to exist until the involved clients and consultants work jointly on the implementation process. In such cases, the involved individuals might have to extend the liminal space by involving other members of the client organization in order to gain support and to successfully implement the problem solution.

To sum up, the previous discussion showed that the development and/or existence of shared meanings and schemes is positively associated with the transfer of both taskrelated knowledge and task-specific knowledge within client-consultant teams. It is clear that if there is a large variety of perspectives in the client-consultant team, team members have to be able and willing to find ways to share and make clear to each other their understandings in order to enhance knowledge transfer within the team.

Most of this discussion emphasizes the importance of communication, reflection and the use and transformation of artifacts and reasoning for achieving some mutual understanding across members of different interpretive communities. It is clear that the process of developing shared cognition within client-consultant teams also introduces new ideas and fosters change. It can bring into existence new understandings and perspectives. In other words, it can produce intentional change, although on a miniature scale $^{1413}$ and foster knowledge creation. ${ }^{1414}$ This issue is the topic of the following chapter.

\footnotetext{
1410 See Malefyt (2003), pp. 139.

Ibid, p. 139.

See Czarniawska/Mazza (2003), p. 283.

See Ford/Ford (1995), p. 544.

See Harris (1994), pp. 310.
} 


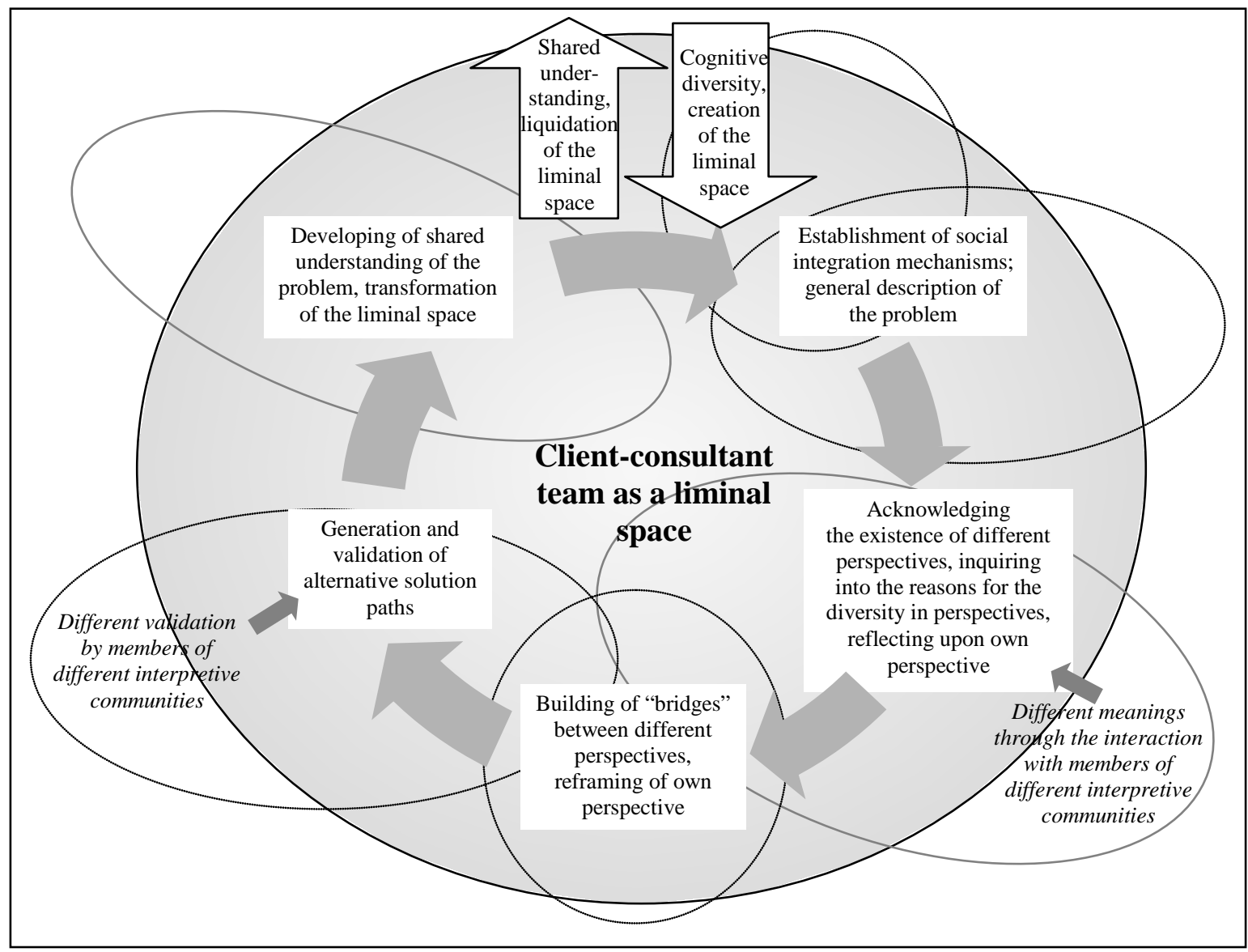

Figure 14: Development of shared knowledge in the liminal space

\subsubsection{Knowledge creation as a cognitive activity}

Acquiring knowledge (learning) is a cognitive activity and consists in a change in the connectivity of neuronal systems. ${ }^{1415}$ It involves certain brain processes and as such, it is completely different from acquiring some commodity. Similarly, exchanging information involves the interacting with another individual in such way that each party elicits certain learning processes in the other's brain. ${ }^{1416}$ Knowledge creation is, therefore, a process consisting of cognitive operations, and can involve social interaction. It results in changes in individual's plastic neural super-system. ${ }^{1417}$ Thus, knowledge creation is a complex process that includes thinking, experimenting, exploring, imitating, questioning, and criticizing including the use, transformation, and creation of some artifacts. Psychologists note that such critical and reflexive thinking, also called deliberative cognition, which alters existing cognitive schemes and has the potential to create new ones, takes place when: (1) people face a problem; (2) they are motivated to search for new solutions psychons. See also Maturana (1980), pp. 13-30. 
because they are dissatisfied with the status quo; and (3) the existing schemes or knowledge fail to account adequately for the new problem. ${ }^{1418}$

It has been argued that individuals develop new knowledge by conjecturing: on the basis of their knowledge and empirical data individuals formulate some preliminary preconceptions of the issue at hand. Next, they formulate hypothesis, which, consequently, are tested against individuals' background knowledge as well as empirically. ${ }^{1419}$ This process results in the creation of new knowledge about the particular issue. Because existing knowledge, i.e. cognitive schemes, structures the way people search for and use information, ${ }^{1420}$ different individuals will usually create different hypothesis and knowledge. This poses the question of how are different perspectives in a team consisting of a number of individuals from different interpretive communities can be aligned in order to ensure coordinated action and problem-solving, an issue that was extensively discussed in the previous chapter.

It is clear that the creation of new knowledge is not an easy process as it presupposes that individuals alter some existing cognitive schemes and develop new ones. ${ }^{1421}$ In other words, an unlearning of some established perspectives is often necessary. ${ }^{1422}$ As Schön emphasized, this is only possible when individuals learn to reflect critically on their knowledge and to reframe it. ${ }^{1423}$ Tsoukas and Vladimirou support this argument when claiming that knowledge is created through stimulating the capability of individuals to draw new distinctions and to develop new meanings to familiar topics. ${ }^{1424}$ In Lane's words, "learning is either the addition of information to a participant's mental model, or an increase in the coherence of such a model." ${ }^{1425}$ Furthermore, "the individual will rearrange his/her knowledge while being located somewhere-certain standpoint or tradition. Accordingly, the capacity to exercise judgment involves two aspects: The ability of an individual to draw distinctions and, the location of an individual within a collectively generated and sustained domain of action". ${ }^{1426}$ It follows that knowledge creation takes place in a context of different discursive practices or interpretive communities when members of such communities change their dominant logic or add new perspectives. As such, knowledge production usually involves communication. ${ }^{1427}$

To sum up, members of different interpretive communities need to establish some shared communication behaviors in order to make their underlying interpretive schemes transparent to the other side. At the same time, interpretive communities can shift their

1418

1419

1420

1421

1422

1423

1424

1425

1426

1427

See DiMaggio (1997), pp. 271-272; Prahalad/Bettis (1986), p. 489. See also Harris (1994); Bloor/Dawson (1994); Giola/Poole (1984); Louis (1980). Harris speaks about “conscious interpreting”. See also chapter D.III.1.2.3.

See Reihlen (1997), pp. 213 for an extensive discussion of this process. See also Bunge (1983a), pp. 286.

See DiMaggio (1997), pp. 269-271; Prahalad/Bettis (1986), p. 489.

See Bartunek/Moch (1987), p. 495; Fiol (1994), p. 404 and the discussion in the previous chapter.

See Bettis/Prahalad (1995), p. 10.

Schön (1983), p. 130.

See Tsoukas/Vladimirou (2003), p. 977.

Lane (1994), p. 99.

Tsoukas/Vladimirou (2001), p. 977.

See Boland/Tenkasi (1995), p. 351. Of course, an individual can create new knowledge without to interact with others. However, knowledge production is more often than not the result of collective, team efforts. See, e.g., Krohn/Küppers (1989), pp. 28. 
interpretive positions as a result of shared communication with members of other interpretive communities. ${ }^{1428} \mathrm{~A}$ dynamic interaction and an intensive sharing of perspectives between different interpretive communities can enhance their ability to reflect on their own knowledge and to reframe their perspectives. As a result, new knowledge can be created. In other words, shared communication is a prerequisite for learning and if established, it can result in the change of existing schemes and interpretations.

\subsubsection{Knowledge creation in client-consultant teams}

Following from the above arguments, the client-consultant team as a community of interpretive communities can be regarded as a source for knowledge creation, when it involves the introduction of new perspectives on problem situations through the involved individuals. ${ }^{1429}$ In general, innovation-related research shows that communication across boundaries supports innovations. ${ }^{1430}$ Thus, it is argued that consultants can serve as a source of "noise” in clients' organizations that disrupt established ways of doing and being. "Consulting practice produces and, then introduces, new language, deconstructing and disturbing established orders of discourse, translating and mediating between new and old languages and metaphors." ${ }^{1431}$ Because of its very nature as a mix of interpretive communities, consulting companies can be effective by increasing the variety and complexity of interpretations within the client organization. In addition, through the introduction of new "languages" and perspectives, consultants can change the way thinking is conventionally organized. ${ }^{1432}$

From this perspective, the role of consultants is to capture clients' mental models about the particular issue at hand and to assist clients in extending and changing these. However, it is not possible to capture and model all details of clients' understanding. ${ }^{1433}$ Rather, consultants have to include only those aspects of the system that the client considers important, or wishes to concentrate on. In this process, clients and consultant jointly engage in the production of a model as an artifact of their knowledge, understanding, and experience. Such models should be complex enough to represent the problem situation but simple enough for clients to understand and interpret. ${ }^{1434}$ Lane stresses that by creating a picture of a mental model, clients and consultants can access areas of their mental models that are usually not accessible. In addition, this process requires that participants express their ideas and knowledge as clearly as possible. All of this can help participants to view the complexity of a problem situation when perhaps

For example, when Heracleous and Barrett undertook an extensive empirical study looking at the role of communication and interpretive schemes for change processes, they found that communicative actions between members of different interpretive communities influence the underlying interpretive schemes of these individuals over the longer term. See Heracleous/Barrett (2001), p. 773.

Fosstenlokken et al. emphasize as well that multidisciplinary client-consultant teams are a "source of learning". See Fosstenlokken et al. (2003), p. 870.

See, e.g., Tushman (1977).

Clegg et al. (2004), pp. 36.

See Oztel/Hinz (2001), p. 168; Wimmer (2004), p. 288.

See Lane (1994), p. 96.

See Lane (1994), pp. 94. 
they had only viewed parts of it. ${ }^{1435}$ "The use of some means of clearly representing ideas does much to promote the discussion as it raises new lines of inquiry and questioning”. ${ }^{1436}$ Additionally, such models can be used for experimenting with different scenarios. In this way, clients and consultants can generate new connections or clarify proposed ones. Lane suggests that conceptual frameworks such as metaphors and analogies, scenarios, causal-loop diagrams, "magnetic hexagons”, and software packages designed to capture ideas, logics, and policies are some of the tools that can be used in constructing such models and using them to alter existing understanding and develop new ones. $^{1437}$

It is emphasized here that the knowledge creation process in client-consultant teams does not happen independently of the client. Rather, it is through a dynamic interaction and an intensive sharing of perspectives between different interpretive communities that it is possible for both client and consultant to reflect on their own knowledge and to reframe their perspectives. In this way, new knowledge can be created and established practices can be disrupted and transformed. ${ }^{1438}$ For example, Malefyt argues that the interaction process between clients and advertisers includes making models and metaphors, and finding facts and figures. As such, it is "more of a process of invention than one of any actual representation of consumer culture”. ${ }^{1439}$ Lopez argues for the case of lawyers that legal knowledge is "one practical knowledge among other practical knowledges", which prompts the recognition that clients, like lawyers, possess "special practical know-how" about "how things work and get done". ${ }^{1440}$ Moreover, he concludes that in order for lawyers and clients to transform routine acts into opportunities for collaborative problem-solving in which skills are combined and power is shared, it is necessary to reverse the "marginalization of clients' local knowledge". ${ }^{1441}$

Thus, the interpretive model emphasizes that clients are important actors in the process of knowledge creation and need to be actively involved in this process. Moreover, client's expertise is often a source for new ideas for consultants. For example, Fosstenløkken et al. found that learning through project work is by far the most important source of knowledge development in consulting firms and that it is strongly enhanced by multidisciplinary teams. ${ }^{1442}$ Similarly, Engwall and Kipping argue, “consultancies derive most, if not all, of their knowledge from client firms”. ${ }^{1443}$ Practitioners also often state that consulting companies need the exchange of perspectives with external partners if they want to remain successful. As John Stuckey, Director at McKinsey, puts it, "We have to be beware of the trap that many large successful companies have fallen into by

The role of different artifacts for knowledge transfer and creation is extensively discussed in chapter D.III.3.8.

See Boland/Tenkasi (1995), p. 369. Fosstenlokken et al. emphasize that there is a need for further research into the role of the client in knowledge creation during consulting projects. See Fosstenlokken et al. (2003), p. 876.

Malefyt (2003), p. 159.

Lopez (1992), pp. 38-50 cited in Alfieri (1994), p. 1758.

Lopez (1992), p. 51 cited in Alfieri (1994), p. 1760.

See Fosstenløkken et al. (2003), p. 868.

Engwall/Kipping (2002), p. 8.
} 
becoming too introverted, too satisfied with their own view of the world”. ${ }^{1444}$ According to another consulting professional, consultants are "dependent on creating new things in projects for demanding clients with varied sets of tasks to be solved". ${ }^{1445}$ Therefore, the client-consultant relationship becomes a process of mutual disruption and transformation, a source for knowledge creation. Thus, some consultancies actively search for innovative clients to work with in the hope that they will get insights into different, novel, and emerging perspectives and who will share new knowledge. ${ }^{1446}$ This is how one consultant from the Boston Consulting Group expresses it: "We have enormous opportunity to innovate in the consulting business because our clients represent an almost limitless laboratory". ${ }^{1447}$ In this way consultants function as interpretive or "knowledge brokers" 1448 or "cultural intermediaries". ${ }^{1449}$ Bessant and Rush, for example, argue that consultants often act as an intermediary in the technology or innovation transfer process. Their impact is not only direct, through transferring specific technological competence, which is the case in IT consulting, but they are also often involved in a wider and more flexible interaction with their clients. ${ }^{1450}$

Based on these arguments, it is proposed that a variety of perspectives and interpretations within the client-consultant team is positively associated with the creation of new knowledge and with innovative problem solutions. ${ }^{1451}$ Prahalad and Bettis point out that the variety of perspectives that the client-consultant team can handle depends on the composition of the team. ${ }^{1452}$ Therefore, consulting companies that aim at developing new knowledge need to look for clients that have very different perspectives than those of the consultants and vice versa. This argument contradicts suggestions in the literature that successful client-consultant relationships require similarity between clients and consultants. ${ }^{1453}$ As previously argued, in order to work effectively together and to be able to profit from the variety of perspectives in the problem-solving process, clients and consultants first need to develop shared task-related knowledge and, to some extent,

1444

1445

1446

Jonh Stuckey, cited in Bartlett (2000), p. 9.

See Fosstenløkken et al. (2003), p. 869.

Fosstenløkken et al. (2003), p. 869. They argue that clients, who are "right” from an operational or profit-maximization point of view may not always be the clients who are "right" from a knowledge-development point of view. "Hence, in future research it will be important to examine further which client characteristics enhance or constrain PSF [professional service firms] knowledge development.” Ibid, p. 876. It is suggested here that clients coming from totally different interpretive communities are the "right" partners from knowledge-creation point of view, but at the same time, the cooperation with such clients is more difficult, time consuming and expensive, as both client and consultants have to engage in intensive sharing of perspectives. See also the discussion of the economic aspects of client-consultant interaction in chapter B.II.4.2.

Stalk (1999), p. 70.

See Hargadon/Sutton (1997); Hargadon (1998). Bryson talks about “innovation transfer agents”. See Bryson (1997), p. 101.

Carter et al. (2004), p. 9. Semadeni argues that although many researchers have acknowledged the knowledge broker position of management consultants, the details how knowledge arbitrage occurs, what knowledge receives arbitrage by consultants, and the consequences of the arbitrage, are still largely unexplored. See Semadeni (2001), p. 44.

See Bessant/Rush (1995), pp. 101-102.

Several studies show that heterogeneous teams in general are more creative than homogeneous. See, e.g., Fosstenløkken et al. (2003); Kilduff et al. (2000); Walsh et al. (1988). Walsh et al. argue that high heterogeneity is especially important in the early phases of the problem-solving process as it helps in defining the nature of the problem. See Walsh et al. (1988), p. 206.

See Prahalad/Bettis (1986), p. 496.

See, e.g., Bettencourt et al. (2002), p. 116. 
shared task-specific knowledge. However, some differences in their understandings regarding the issue at hand are necessary if they are to develop new knowledge and innovative problem solutions. As Fiol puts it, "simultaneous agreement and disagreement is especially important in [] innovative efforts”. ${ }^{1454}$ In other words, if clients' and consultants' perspectives are too similar at the start of their cooperation, they will not be able to disrupt established ways of thinking and doing: "Similarity leads to interaction, and interaction leads to still more similarity." 1455 Therefore, a delicate balance of sharing and diversity is required. ${ }^{1456}$ Fiol suggests that such a balance is possible even when members of diverse teams do not agree upon the content of their interpretations, i.e. about what is expressed, if they learn to frame their arguments and interpretations in a more broad and ambiguous way. This requires, for example, problem solvers to include and attend to a higher number of issues, as initially suggested, and to proceed with less certainty during early stages of decision processes. ${ }^{1457}$ Similarly, Kilduff et al. argue that teams with better performance results are characterized by initially high cognitive ambiguity. They stress, however, that in successful teams, this ambiguity tends to reduce in the course of time. ${ }^{1458}$

Therefore, it can be postulated that a delicate balance of sharing and diversity is required if clients and consultants are to work effectively and creatively together. ${ }^{1459}$ In this regard, the fact that the initial diversity in perspectives, which stimulates knowledge creation, tends to decrease when team members begin to widely share their cognitive frames and perspectives, needs some additional attention. Such an increased conformity of interpretations can have negative consequences on the creativity of teams. ${ }^{1460}$ This effect usually occurs in long-term client consultant relationships and is examined briefly in the following chapter.

Before closing this chapter, it is necessary to point out that shared cognitive schemes do not guarantee successful knowledge creation. In general, because sharing of meaning involves translation, and translation always combines difference and repetition at the same time, knowledge transfer is a productive and creative process ${ }^{1461}$ that often enables knowledge creation. There are situations, however, when shared communication does not lead to alignment in the underlying interpretive schemes, in which case no agreement on a final interpretation is possible. ${ }^{1462}$ In other words, it is possible that although clients and consultants develop shared task-related knowledge and even share a similar understanding of the problem, they still do not agree on what is the best way to solve it. The reason is that knowledge creation or transformation processes are inherently

\footnotetext{
1454 Fiol (1994), p. 403. See also Mingers who shows that consulting projects are unsuccessful either when clients' and consultants' perspectives are too different or when they are too similar. Mingers (1996), cited in Iding (2000), p. 17.

Axelrod (1997), p. 205.

See Mohammed/Ringseis (2001), p. 313.

See Fiol (1994), p. 405.

See Kilduff et al. (2000), p. 32.

See also Mohammed/Ringseis (2001), p. 313.

See, e.g., Klimocki/Mohammed (1994), p. 405. This situation is often referred to as "groupthink".

See Clegg, et al. (2004), p. 39; Kirsch/Eckert (1998), p. 296.

See also Heracleous/Barrett (2001), p. 774.
} 
conflictual, involving different views about the direction of change and the role of the different involved actors. ${ }^{1463}$ Whereas some authors suggest rational ways for solving the problem of cognitive pluralism through, for example, dialectical inquiry based on logical reasoning, it is argued in this work that a rational problem-solving is not always possible. ${ }^{1464}$ Rather, it might be necessary for one interpretive community to take the lead and influence the direction of the problem-solving process if a solution is to be reached. This situation is discussed extensively in chapter IV.IV.

\subsection{The role of long-term social relationships}

Frequent, long-term social interaction between clients and consultants affects the process of knowledge transfer and creation. Through intensive longer-term interactions, common language and understandings between clients and consultants evolve which enhances knowledge transfer and results in better team processes and performance. ${ }^{1465}$ This kind of interaction leads often to the emergence of tighter socially embedded relationships between the involved actors. ${ }^{1466}$ Furthermore, long-term relationships allow consultants to invest in the development of intimate knowledge of the perspectives of different interpretive communities within the client organization, as well as their power position. ${ }^{1467}$ Uzzi and Lancaster conclude that only when such strong ties exist, will more fundamental learning between clients and consultants, or what March calls "exploration”, will occur. ${ }^{1468}$ Where there is a lower level of embeddedness in the client-consultant interaction only public available knowledge will be transferred-management fads are one example for this kind of knowledge-, and predominately incremental improvements will be realized in client organizations.

At the same time, an intensive, long-term social interaction may blur the distinction between members of different interpretive communities and thus may reduce the possibility of creating "noise” into each other's communities or organizations. Therefore, there is a trade-off between knowledge transfer, including efficiency of the cooperation and innovativeness within client-consultant teams, when regarding the effect of long-term relationships between clients and consultants, as shown in Figure 15. The dotted function within the figure represents the proposed change in the innovative ability of the clientconsultant team, as clients and consultants get more familiar with each other. The dashed function represents the proposed change in knowledge transfer, and the black function represents the combined effect.

The figure also shows that clients and consultants can try to find some "optimal" amount of time-point A in the chart-within which the same members of the client and consultant team will profit from knowing each other and from having established shared meanings and understanding but at the same will still be able to introduce new meanings

See, e.g. Bartunek/Ringuest (1989), p. 543; Reihlen (1997), pp. 232.

See the discussion in chapter D.IV.2.

See, e.g., Mathieu et al. (2000), p. 275.

See Granovetter (1985); Uzzi (1996, 1997).

See Morris (2000), p. 135.

See Uzzi/Lancaster (2003), pp. 395-396; also March (1991).
} 
and disrupt each other's perspectives. However, when they become too "close" so that they are not able to introduce new and different interpretations, it would be necessary to introduce some new members to the team who are members of different interpretive communities. Thus, consulting companies who tend to have long-term relationships with their clients should regularly change the members of the consultant team who work with particular clients.

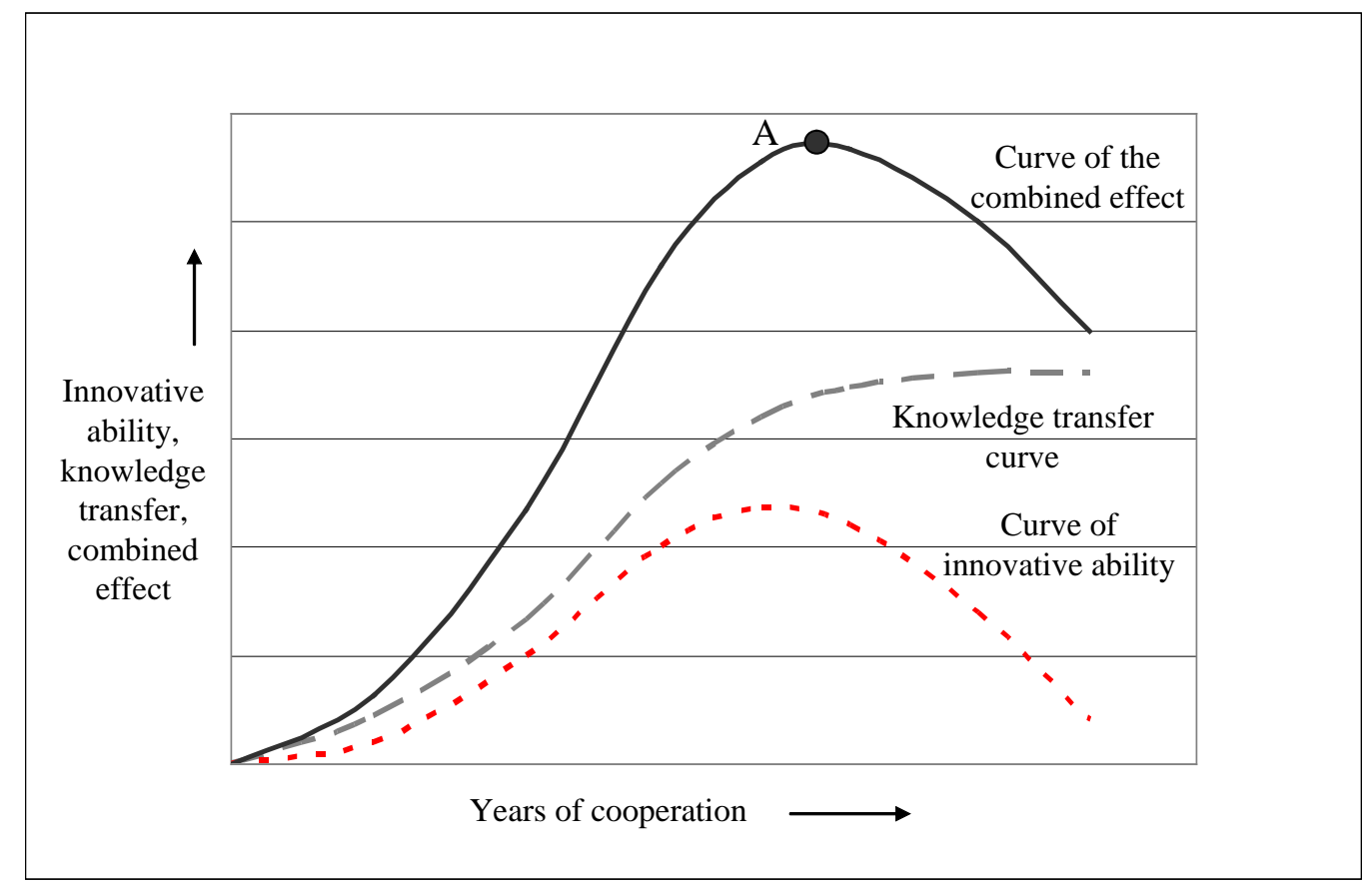

Figure 15: The role of long-term social relationships on knowledge transfer and creation

To sum up, the effect of widely shared meanings and perspectives or, respectively, of long-term social relationships, on knowledge transfer within client-consultant teams is proposed as being positive. However, the influence on knowledge creation is not so clear. It is argued that the effect of long-term relationships between the members of clientconsultant teams is first positive, and from a certain tenure on, negative. ${ }^{1469}$

\subsection{Mechanisms for knowledge transfer and creation}

The previous discussion showed that some mechanisms are needed that can trigger the development of shared knowledge within the restricted time frame of consulting projects. Traditionally offered mechanisms for developing of shared cognition such as training, job rotations, feedback programs, and working with other individuals for longer periods, ${ }^{1470}$ are not applicable for the case of client-consultant teams. As already discussed, Schön's suggestions to enable an open and minimally defensive interaction are also not sufficient

\footnotetext{
1469 It is important to note that the effect of long-term social relationships on knowledge transfer is mediated by the existence of shared meanings and frameworks within the client-consultant team. At the same time, the effect of long-term social relationships on knowledge creation is mediated by the variety of perspectives in the team. Long-term social relationships effect the client-consultant interaction also by enabling the involved individuals to develop trust to each other, which has major consequences for their relationship. The topic of trust and its influence on client-consultant teams is, however, beyond the scope of this work.

See, e.g., Mathieu et al. (2000), p. 281.
} 
to explain how is mutual understanding achieved. ${ }^{1471}$ Schein offers as well only a very general solution arguing that "cross-cultural dialogue" requires the establishment of communication that stimulates "mutual understanding rather than mutual blame". ${ }^{1472} \mathrm{He}$ emphasizes that dialogue, in contrast to discussion, is "a basic process for building common understanding, in that it allows one to see the hidden meanings of words, first by seeing such hidden meanings in our own communication". ${ }^{1473}$ Schein does not discuss, however, any concrete mechanisms, apart from facilitation as a form of brokering, for the development of such shared understanding. Furthermore, as Tyre and von Hippel argue, while research has concentrated on emphasizing the importance of communication for successful problem-solving and knowledge creation, the importance of the physical setting for these processes has been nearly overlooked. "People's usable skills often depend on their physical settings because people act skillfully by using specific machines or tools, by interpreting physical cues, by exploiting their intimate knowledge of local idiosyncrasies, and by responding to stimuli embedded in a specific context”. ${ }^{1474}$ Therefore, seeing, touching and manipulating objects is often as important for improving understanding as hearing and explaining. Additionally, it has been stressed that using cultural artifacts ensures the right impression of competency while creating a closer affinity between service provider and client. ${ }^{1475}$

In the following, an attempt is undertaken to overcome these shortcomings in the existing literature by introducing some concrete mechanisms that enhance the development of shared perspectives and reciprocal translations. The intensive use of these mechanisms within the client-consultant team can lead to the development of shared meanings and a common language, and thus, fosters knowledge transfer and learning. ${ }^{1476}$ In the following, first, the use of stories and other artifacts, also called boundary objects, in the knowledge transfer and creation process is discussed. Second, the role of argumentation and reasoning is outlined, before, third, another important social mechanism, brokering, is outlined. ${ }^{1477}$ Finally, some additional mechanisms are briefly analyzed.

\subsubsection{Boundary objects}

As argued in chapter B.II.4.1, problem-solving involves work and communicative interaction. ${ }^{1478}$ Furthermore, both cultural work and communication almost always involve the transformation of some artifacts through conducting experiments, surveys and

1471

1472

1473

1474

1475

1476

See the discussion on knowledge transfer within the reflective practitioner model in chapter C.III.7.

Schein (1996), p. 19.

Schein (1993), p. 47. See also Isaacs who speaks about dialogue as a "cool enquiry [that] focuses people's attention on collective thought and shared assumptions, and the living social processes that sustain them”. Isaacs (1993), p. 32. Isaacs offers a detailed description of the process of dialogue evolving between people with different viewpoints on a particular issue and emphasizes the importance of boundary objects for the establishment of successful dialogue. Ibid, pp. 34-38.

Tyre/von Hippel (1997), p. 73.

See Malefyt (2003), pp. 142.

See, e.g., Lane (1994), p. 110.

Boundary objects and brokering are also called intermediaries. They pass between actors and influence the relationship between them. See, e.g., Callon (1991), pp. 134-135.

See Tsoukas/Knudsen (2003), pp. 7-8. 
fieldwork as well as the design of new artifacts, such as reports, presentations, software, models, etc. ${ }^{1479}$ In other words, all cultural activities that are oriented towards knowledge transfer and creation always involve the use, transformation and creation of artifacts.

The previous discussion of knowledge transfer and creation within client-consultant teams showed that the interaction between clients and consultants is indeed supported and greatly enhanced by artifacts. ${ }^{140}$ The ability to share a perspective with others presupposes that one's interpretation-either in the case of an individual or as that of an interpretative community-is made visible for self-reflection. Such a visible representation can become a boundary object and provides a basis for sharing knowledge with others. Star defines a boundary object as an object that serves to coordinate the perspectives of various communities for some purpose. ${ }^{1481}$ Star and Greisemer offer the following description of boundary objects:

"Boundary objects are objects which are both plastic enough to adapt to local needs and the constraints of several parties employing them, yet robust enough to maintain a common identity across sites. They are weakly structured in common use, and become strongly structured in local use. These objects may be abstract or concrete. They have different meanings in different social worlds but their structure is common enough to more than one world to make them recognizable, a means of translation. The creation and management of boundary objects is a key process in developing and maintaining coherence across intersecting social worlds". ${ }^{1482}$

Some examples for boundary objects include cause and narrative maps, labels, physical models, diagrams, concepts, categories and encoded information, and other forms of reification. ${ }^{1483}$ As such, boundary objects do not always have a physical form.

Star and Greisemer identify four major types of boundary objects: repositories of things, ideal types, coincident boundaries, and standardized forms/work methods. Briers and Chua exemplify these types of boundary objects for the case of accounting companies. $^{1484}$

(1) In accounting companies cost driver matrices, customer/supplier databases, and general and subsidiary ledgers are data repositories.

(2) Costing and performance measurement systems represent ideal type objects, which are reasonably well understood by different groups. Different functional specialists from different locations, for example, will all have some knowledge about what is a standard ABC costing system. In consulting projects, the issue

Two theoretical approaches in particular, actor network theory and activity theory, pay special attention to the role of artifacts as mediators and enablers of social interactions. These approaches are not discussed in detail in this work. For a detailed discussion of actor network theory see Callon (1986a,b); Callon/Latour (1981); Law (1994, 1999); Law/Hassard (1999) and for a detailed discussion of activity theory see Engeström et al. (1999); Engeström/Middleton (1996).

Star, quoted in Wenger (1998), p. 106.

Star/Griesemer (1989), p. 393. 
diagram and the storyboard are such ideal type objects. ${ }^{1485}$ Their advantage is that they can be used to structure an ambiguous and complex situation in a collaborative manner. ${ }^{1486}$

(3) The physical contours of a product represent coincident boundaries, as they are the same whether they are seen as a cost object by accountants or as a sales item by marketers. ${ }^{1487}$ Such common objects enable members of different interpretive communities, for example functional specialists, "to use their different perspectives relatively autonomously and for cooperating parties to share a common referent". ${ }^{1488}$ Bechky, for example, shows that in a high technology manufacturing company tangible definitions, such as machine parts, were often necessary to overcome misunderstandings and enable knowledge transfer between members of different interpretive communities. ${ }^{1489}$ Tyre and von Hippel argue that physical locations and settings can provide important clues for understanding others' perspective and as such, help to confront various aspects of a problem and search for creative solutions. "Aspects of the local setting could affect which interactions took place, how interactions were interpreted, and what they accomplished." 1490 This is one of the reasons why consultants often interact with the problem owners in the concrete setting of the department or the part of the client organization that is investigated by the client-consultant team. Being present in the concrete local setting and being able to see what is going on enables consultants to understand better the problem situation and the perspective of the clients.

(4) Finally, off-the-shelf, stand-alone accounting software packages represent an example for standardized forms/work methods. Software packages are also available to and have been used by consultants in a number of different problem contexts.

Briers and Chua suggest that there is an additional, fifth type of boundary object, which they call "visionary objects". ${ }^{1491}$ Such conceptual objects have high level of legitimacy within a number of communities but they can be associated with different things in single interpretive communities. "Efficient work practices" and "precise costing systems" are slogans that have the quality of such visionary objects. They are appealing to a large number of different interpretive communities but their precise meaning is unclear until they are "customized and tailored to specific settings". ${ }^{1492}$ Knowledge management is an example for such a slogan within the realm of consulting projects. ${ }^{1493}$

See Nichols (2004), p. 172.

See Fombrun/Nevins (2004b), pp. 99-111 for a discussion of more or less complex issue diagrams and Nevins (2004), pp. 121-125 for a discussion of storyboards.

Callon speaks in this case about "technical artefacts”. Callon (1991), p. 135.

See Briers/Chua (2001), p. 242.

See Bechky (2003), pp. 314.

Tyre/von Hippel (1997), p. 78.

See Briers/Chua (2001), p. 242.

Briers/Chua (2001), p. 242.

See, e.g., Alvesson/Kärreman (2001), pp. 1003.
} 
Wenger argues that in general, boundary objects belong, to some degree in multiple communities. As such, they represent nexuses of perspectives and each community has only partial control over the interpretation of these objects. ${ }^{1494}$ As such, boundary objects possess a kind of symbolic adequacy that enables conversations without recourse to commonly shared meanings. ${ }^{1495}$

A number of studies support the relevance of the five types of boundary objects for the interaction process within consulting companies and projects. In larger management consultancies, for example, consultants have to attend a number of specific trainings in order to learn different techniques that enable them to visualize and structure their arguments and thoughts in accordance with specific prescribed models and frameworks. This facilitates their work during consulting projects. ${ }^{1496}$ In other words, the main contribution of such broad methods and tools, including different templates, process phases, and general descriptions of a sequence of activities, is their "ability to provide a common framework and terminology for the consultant's work process". ${ }^{1497}$ The authors state further that these tools are an "important facilitator of interaction between consultants, which in turn was referred to by individual consultants as the most important vehicle for learning”. ${ }^{1498}$ Creplet et al. agree that tools that enable codification of knowledge allow "the spanning across cultural and managerial boundaries through the setting of a sort of meta-language or meta-code". ${ }^{1499}$ Indeed, all large consultancies have instituted structured IT-based knowledge management systems that seek to provide standard toolkits and sharing of project experience aimed specifically at creating a standard look and feel even to the most exclusive firms. ${ }^{1500}$

Computer-mediated knowledge transfer within consulting companies is effective, however, only in transferring more general knowledge, i.e., broad concepts and methods. As Reihlen and Ringberg show, it cannot effectively capture and diffuse expertise that is more specific. ${ }^{1501}$ The main reason for this failure is that consulting companies are communities of interpretive communities, and tools designed during specific client projects, enhance learning only within the interpretive community where they are created. ${ }^{1502}$ As already discussed, project groups working on specific client problems develop site-specific, local knowledge, and not involved individuals have difficulties in recognizing and applying such situated knowledge. Bechky points out as well that standardized boundary objects are not effective in every situation, and tangible clients. However, as previously emphasized, full conformity is neither possible nor desirable in the context of consulting projects.

Ibid, p. 339. Olivera also found that best-practice documents stored in the database of consulting companies are not useful in practice due to the lack of background knowledge and context of the stored problem solutions. See Olivera (2000), pp. 825.
} 
definitions will not always be sufficient to create a common ground for understanding. ${ }^{1503}$ For example, when clients do not have an access to the general methods and tools available to the consultants, the use of general consulting definitions and tools can make the client-consulting interaction more difficult. ${ }^{1504}$ Thus, the difficulty associated with many consultancies in Third World countries is related sometimes to the client's failure to understand rudimentary managerial knowledge. Wong, for example, argues that this is the main reason for some serious and very public problems arising between McKinsey and its client in China. ${ }^{1505}$ Therefore, members of different interpretive communities have to be aware of the restrictions of boundary objects. Often, they can assess each other's interpretations or understand specific artifacts created through others only through direct communication because it enables the sharing of mental models. ${ }^{1506}$ Logical reasoning, stories, and narratives play an important role in such direct communications. ${ }^{1507}$ Furthermore, because of the restrictions of the above-mentioned types of boundary objects, some consulting companies organize workshops for the members of the clientconsultant team before the actual start of the project. Consultants use such workshops to discuss consulting methods and tools with the client in order to enhance their cooperation once the project starts. ${ }^{1508}$ Additionally, as Bettencourt et al. found, such workshops emphasize the importance of teamwork and effective communication and make clear what roles and responsibilities both parties have during the project. ${ }^{1509}$

As discussed in chapter B.II.4.2, relying heavily on existing boundary objects in order to enhance knowledge transfer and communication can have another negative effect in certain circumstances. It has been argued that existing categories attached to certain events influence the process of meaning creation and, therefore, knowledge creation. "Once a phenomenon is categorized, a confirmatory bias reinforces the original labeling and categorizing of the phenomenon. This bias affects processing of new information and recall of old information”. ${ }^{1510}$ Consulting methods and tools may have a standardizing effect on consultant's interpretations "by dictating the range and interpretation of experiences made”. ${ }^{1511}$ For example, many consultants feel that structured knowledge management systems have the impact of potentially creating "homogenized foot solders" as consultants fail to span newer and different interpretative communities. Therefore, consulting companies that expect consultants to work extensively with already developed

See Bechky (2003), p. 326.

See also Ojasalo who points out that client's possession of some general business knowledge increases client's expertise and understanding for consulting work practices. Ojasalo (2001), pp. 4-5.

See Wong (2001), p. B.9.E. Start Computer Group executives, in a nationwide TV interview, linked the company’s losses in two years in a row to advice from McKinsey.

Reihlen and Ringberg emphasize that informal networks between consultants are more important for knowledge transfer within consulting firms than formal structures, such as computer-based knowledge systems. See Reihlen/Ringberg (2006), pp. 336-337; also Greenwood/Suddaby (2001); Grosse (2000); Segelod (2000).

These mechanisms for knowledge transfer and creation are discussed in the following chapters.

See Bettencourt et al. (2002), pp. 116-119; also Pringle (1998), p. 7; Sommerlatte (2000), p. 141.

Such workshops enable, therefore, the development of shared task-related knowledge.

Dutton/Jackson (1987), p. 81.

Werr/Stjernberg (2003), p. 900. 
methods and tools, i.e. to use established knowledge, are locked into their dominant logic of solving problems ${ }^{1512}$ and may not be able to generate innovative solutions. ${ }^{1513}$

One boundary object that does not encounter this problem of standardized boundary objects is the physical setting and location of the members of the client team. ${ }^{1514}$ As previously stated, physical settings can provide important clues about clients' perspectives, as well as affect which interactions will take place. Moreover, repeated alternations between settings can provide opportunities to reframe a problem, as knowledge and experience grow. ${ }^{1515}$ Therefore, it is important that consultants organize some of the meetings of the client-consultant team in the physical location of the clients. In addition, different physical settings may be appropriate for different phases of the project. Thus, client-consultant teams might have to pay attention to the question of how to facilitate the movement of clients and consultants during the consulting project. ${ }^{1516}$ Tyre and von Hippel suggest that the use of physical settings as boundary objects will be most important for dealing with unfamiliar, unstructured problems. ${ }^{1517}$ The observation of client members in their physical setting might be especially important whenever verbal communication is difficult, i.e. especially in cases when clients and consultants have not yet developed shared meanings and frames. ${ }^{1518}$

The previous points highlight the importance of using boundary objects carefully when cooperating with members of other interpretive communities. It is dangerous to assume that members of other interpretive communities understand such objects in the same way. Thus, boundary objects have advantages and disadvantages, and require different levels of interaction.

Knowledge transfer and creation are mediated not only by boundary objects but also take place by direct speech acts, i.e. by argumentation. Schön, for example, emphasized the importance of argumentation in client-consultant interaction when discussing the role of "reflective conversations" between clients and consultants. ${ }^{1519}$ Therefore, it is necessary to differentiate between different types of argumentation. ${ }^{1520}$ Weick and Browning point out that argumentation and narration are the two prevailing forms of discourse. They are associated with different forms of interaction and different rules of evidence. ${ }^{1521}$ The following two chapters shed some light on the role and relevance of rational argumentation and of narrative forms of argumentation. Rational argumentation is still regarded as the prevalent and most effective way to communicate in organizational

Ibid, pp. 490; also Semadeni (2001), pp. 47-48 and p. 52. At the same time, as it was argued, standardized methods and tools increase the efficiency of consulting processes.

Physical settings differ in accordance to the position and task of clients and are, as such, not standardized.

See Tyre/von Hippel (1997), p. 80.

Ibid, p. 80.

Ibid, p. 80. Where problems are more familiar, physical location may be less important because problem solvers understand better what data must be collected and how to interpret it, independent of where they are located.

Ibid, p. 80.

See the discussion in chapter C.III.

This differentiation can be traced back to the work of Aristotle. See Skerlep (2001), p. 180.

See Weick/Browning (1986), p. 245.
} 
contexts. ${ }^{1522}$ In the following, it is shown that rational argumentation, although important, has some major shortcomings. It needs to be complemented by the use of stories and narratives, which enhance the transfer of meaning between individuals from different interpretive communities.

\subsubsection{Rational reasoning}

Rational argumentation can be defined as "sets of utterances that include a premise, an inference, and a conclusion, used in the context of disagreement to move another person to agreement through incremental steps." 1523 Thus, rational arguments are based on "the employment of reason in accord with an internally coherent set of agreed-upon rules or procedures.” 1524

Rational reasoning comes in different forms. Abstract argumentation, or rationalanalytic reasoning, is regarded still as the dominant mode of communication. ${ }^{1525}$ Research has shown that humans are theoreticians, i.e. they build and test theories by building hypotheses, testing them, attributing negative feedback to procedural error, rejecting anomalous data, and generating confirmatory data. ${ }^{1526}$ Thus, "systematic abstractions, or theory, play a vital and inevitable role in managerial action." 1527 The outcome of abstract argumentations is general knowledge that transcends context to provide potential guidance in a wide range of situations. ${ }^{1528}$ Rational-analytic reasoning is regarded as formal, explicit, regimented, and valid. ${ }^{1529}$ It is based on logic. ${ }^{1530}$ Consequently, relevant linguistic methods include self-evident propositions, demonstrations, proofs, and verbal expressions of certain and probable knowing. ${ }^{1531}$

However, logical or formal argumentation has been widely criticized for being a too narrow approach for solving problems. ${ }^{1532}$ In particular, logical statements are generalizations and as such, they cannot deal with particular circumstances or singular

1522

See Denning (2005), pp. 172-173.

Donnellon et al. (1986), p. 49; also Bunge (1996), p. 70. The premises of an argument may be tentative or well confirmed data, definitions, or hypotheses. See Bunge (1996), p. 70.

McKerrow (1982), p. 106, cited in Weick/Browning (1986), p. 246. The underlying rational paradigm presupposes, inter alia, that (1) the primary mode of decision-making is to use clear-cut, inferential, implicative arguments; (2) rational decision-making requires the participation of qualified individuals with technical knowledge, argumentative ability, and skill in employing the rules of advocacy; and (3) the world is a set of logical puzzles which can be resolved through analysis and the application of reasoned arguments. Ibid, p. 246.

See Weick/Browning (1986), p. 245. See also Denning who argues that abstract, analytical reasoning has been established as the dominant mode of communication since Plato and Aristotle, and was particularly strengthened by Descartes’ work. Denning (2005), pp. 172-173.

See Boland et al. (2001), pp. 395-396.

Boland et al. (2001), p. 396.

See Boland et al. (2001), p. 409. See Bunge (1983a), pp. 172-174 for a detailed discussion of forms of abstraction and its role.

See Bunge (1983a), p. 203. According to Bruner, this type of reasoning exhibits the following characteristics: theory driven, categorical, general, abstract, de-contextualized, ahistorical, non-contradictory, and consistent. Cited in Tsoukas/Hatch (2001), p. 983.

See Bunge (1983a), p. 209. This type of reasoning follows the concept of formal rationality. See Reihlen (1997), pp. 206208 for a discussion of the nature and shortcomings of formal rationality.

See Weick/Browning (1986), p. 246.

See Reihlen (1997), pp. 207-208 for a brief overview of the main critical points of this approach. See also Tsoukas/Hatch (2001), pp. 992-996. 
experiences. ${ }^{1533}$ As a result, there have been several suggestions for a form of rational argumentation that is not based on formal logic. Practical reasoning, as suggested by Toulmin and Rescher, is the most influential contemporary model of argumentation. ${ }^{1534}$ In brief, this type of reasoning starts with an assertion or a claim the validity of which needs to be established by providing "good" reasons for the claim. The more convincing the supporting reasons for a claim, the more rational, and acceptable the claim tends to be. ${ }^{1535}$ Thus, in this view, rationality does not depend on logic but on plausible and factual reasons and arguments. ${ }^{1536}$ In particular, this form of rationality implies a rational or justified consensus in situations where (1) only arguments count and the strongest argument wins; (2) where no irrelevant factors intervene and the only operating motive is the common pursuit of rational consensus; and (3) where all participants are truthful, sharing an equal status and having an unlimited amount of time at their disposal. ${ }^{1537}$ The concept further takes into consideration that the quality of these reasons can be somewhere between weakly probable and absolutely certain, and that extraordinary circumstances can undermine the force of the argument. ${ }^{1538}$

The literature on consulting confirms the role of rational reasoning in clientconsultant teams, even though it lacks clarity. Supporters of the expert model regard rational argumentation as critical for communication between clients and consultants. It is argued that consultants of the "pure researcher" type mostly rely on an abstract, analytical reasoning. Fombrun and Nevins, for example, argue that "skillful consultants are like scientists: They apply a deductive approach through which they identify key issues involved in a problem and specify causal hypotheses about the situation that they observe. [] A key role the consultants play is therefore to help clients construct a valid model of the company's situation”. ${ }^{1539}$ On the other hand, it has been suggested that consultants that mainly rely on their practical experience in a particular field use mostly practical reasoning. ${ }^{1540}$

Thus, it is clear that rational argumentation is an important mode for transfer of knowledge in client-consultant teams. ${ }^{1541}$ Argumentative rationality as a means of inquiry is proposed as especially relevant in the case of technical problems. In such contexts, it is assumed that law-like patterns exist even in the social environment. ${ }^{1542}$ At the same time,

See Tsoukas/Hatch (2001), p. 992.

See Reihlen (1997), pp. 210; Skerlep (2001), pp. 184-185.

See Reihlen (1997), pp. 211-212; Skerlep (2001), p. 184.

See Reihlen (1997), pp. 212-213; Kirsch (1997), p. 352. See also Bunge (1983a), pp. 210-218 for a discussion of plausible reasoning.

See Bernsen (1982), p. 236. These arguments also build the basis of Habermas' concept of the “ideal speech situation”, which is further discussed in chapter D.IV.2.

Skerlep (2001), p. 185.

Fombrun/Nevins (2004b), p. 104. The authors discuss concrete examples for the two types of models that consultants most often use: casual models and systemic models. Ibid, pp. 104-107. It should be clear that once these models have been put in some material form, e.g., drawn on paper, put into a presentation etc., they can serve as boundary objects.

See, e.g., McGivern/Fineman (1983), p. 426 and the discussion in chapter C.II.6 on "pure researachers" and "expert consultants". Kirsch and Eckert suggest that this form of reasoning is similar to the "reasoning from case to case", which is common in the law practice. See Kirsch/Eckert (1998), p. 283. 
it is more problematic to rely on argumentative rationality in complex and novel situations where problem solvers might have different perspectives on the problem situation and solution. It is suggested that concentrating on rational argumentation puts an emphasis on the transmission of information rather than on the transfer and creation of meaning during the interaction. ${ }^{1543}$ In other words, rational argumentation undervalues the context and path dependent nature of knowledge, as well as the fact that, because clients and consultants participate in different interpretive communities, they might have different but legitimate perspectives on the same issue. ${ }^{1544}$ Additionally, the assumption that individuals will behave rationally and will strive to achieve a rational consensus is highly problematic because it ignores that a number of factors, in particular power, obstruct "our grasp” for rationality. ${ }^{1545}$ It has been suggested that a narrative form of argumentation, rather than rational reasoning, enables the incorporation of multiple rationalities in interactions. As such, it enhances communication and knowledge transfer ${ }^{1546}$ because narratives provide or invoke a context for meaning. ${ }^{1547}$ In the following, the role of narration and narratives as mechanisms for knowledge transfer and creation is discussed.

\subsubsection{Narratives}

Narratives refer to three separate things: the written or spoken narrative statement, the events that are the subject of the narrative - the story-, and the act of narrating. ${ }^{1548}$ Narratives are regarded as powerful instruments for effective communication because they show one's own interpretation and understanding of topics: "Effective communicating requires that the point of view of the other be realistically imagined." 1549 Boje defines a story as an oral or written performance, or exchange, between two or more people during which a past or anticipated experience was being referenced, recounted, interpreted, or challenged. ${ }^{1550}$ Based upon discussions of neurobiology, Bunge suggests that using coherent stories can be helpful when transferring knowledge between individuals. ${ }^{1551}$ Moreover, telling a story is a way of "delivering a persuasive message that would be resisted or ignored if offered directly.” 1552

Narratives have three main functions. First, they help to build different meanings of the problem and thus to diagnose it. Second, they act as repositories of accumulated

1543

See Bernsen (1982), p. 238; Weick/Browning (1986), p. 248.

This critic is directed not only to logical reasoning but also to practical argumentation. For example, Tsoukas and Hatch argue that "the 'tyranny' of the local, the particular, and the timely cannot be escaped in the context of practical reasoning”. Tsoukas/Hatch (2001), p. 993.

See Bernsen (1982), pp. 237-238 and the discussion in chapter D.IV.2.

Weick/Browning (1986), p. 255.

See Tsoukas/Hatch (2001), p. 998.

Ibid, p. 997. Often, however, the terms story and narrative are used interchangeably, which is also adopted within this work.

Boland/Tenkasi (1995), p. 358.

See Boje (1991), p. 111; Boje (1995), p. 1000.

See Bunge (1983a), p. 49.

Scott (1994), p. 470. 
experience, ${ }^{1553}$ and as such are used both as a resource for templates of well-formulated proposals, as well as an inspiration for a new understanding of clients problems. ${ }^{1554}$ Third, they help to establish emotional bonds with clients. ${ }^{1555}$

Many authors have argued for the importance of stories as a model for understanding organizational realities. ${ }^{1556}$ Weick and Browning see the main advantage of stories in that they capture "complex experiences that combine sense, reason, emotion. and imagination". ${ }^{1557}$ Furthermore, stories "enable people to translate impressions of a distant event into a form that allows a listener to grasp its significance." ${ }^{1558}$ Denning supports this when he argues that stories communicate ideas holistically. As a result, individuals transfer ideas and knowledge not "dimension by dimension, but all at once with a new gestalt, which is transferred with a snap." ${ }^{1559}$ He gives several examples of how stories can turn resistance into enthusiasm, help understand complexity, and catalyze understanding. ${ }^{1560}$ Tsoukas and Hatch conclude that "in narrating, a narrator communicates and captures nuances of event, relationship, and purpose" that are dropped in the abstraction process of the logico-analytical mode of communication. Furthermore, narratives enable a "more concrete rendering of causality". Thus, narrative argumentation is "historical and specific, not general and contingent." 1561 Consequently, narrative rather than rational argumentation enables members of different interpretive communities to transfer interpretations and perspectives. Moreover, because telling narratives enables the narrator to reflect upon meaning and interpretation, narratives are especially suited to reflective conversations. ${ }^{1562}$ This was recognized by Schön, who stresses the importance of "reflective conversations" between clients and consultants. ${ }^{1563}$

Additionally, Greatbatch and Clark emphasize the importance of humor and humorous messages as a way for consultants to enhance their social interactions with the client. They argue that through "evoking and producing laughter, consultants and clients engage in public displays of consensus and 'like-mindedness' and thereby constitute themselves as 'in-groups"”. ${ }^{1564}$ Because of the nature of their knowledge, consulting firms face a particular dilemma: on the one hand, they have to present themselves as being competent in a service or skill that is perceived by the client to "add value". At the same time, they have to seek and emphasize human chemistry, and so, must demonstrate to the client that working together will be amicable, cooperative, and mutually beneficial. "This presents a challenge to negotiation since it requires one to stand apart as distinct, and yet

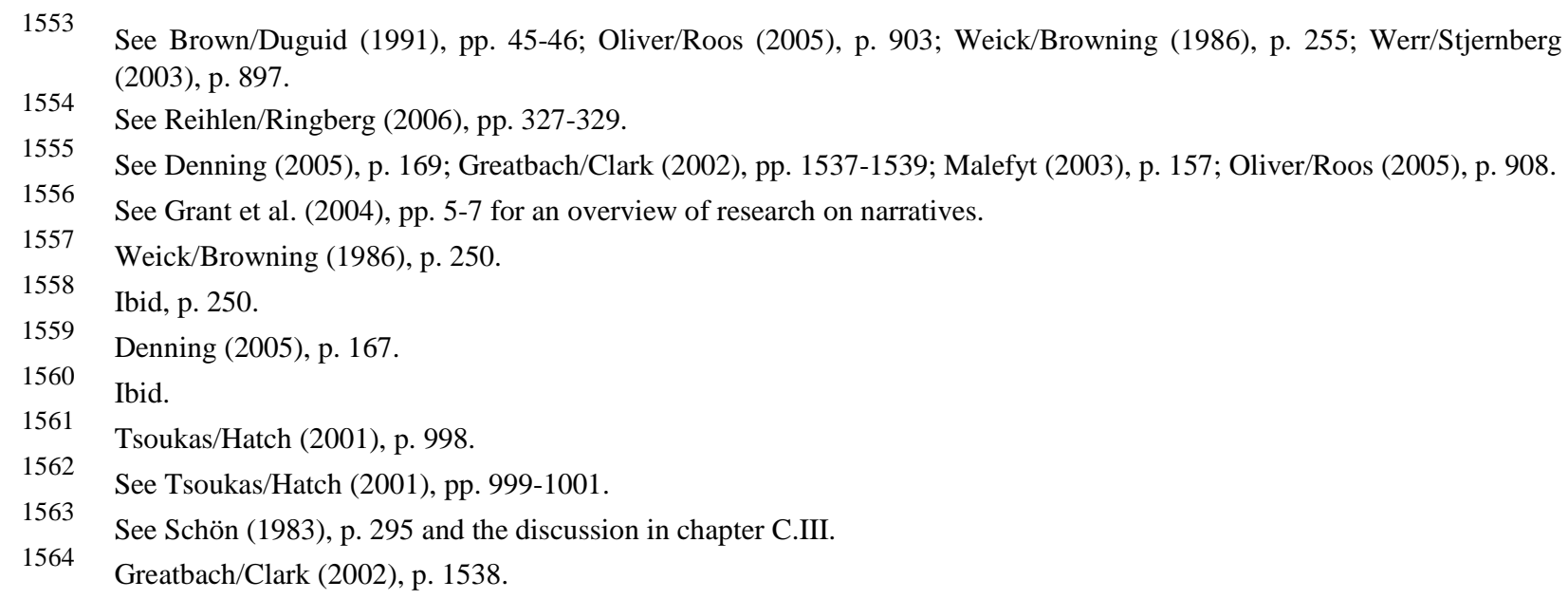


blend in and show affinity with others.” ${ }^{1565}$ Thus, through humorous stories, for example, consultants create the conditions necessary to win and retain converts. In conclusion, the narrative mode of communication is meaning centered, experimental, concrete, context sensitive, historical, and ironic. ${ }^{1566}$

Although storytelling is not a new phenomenon, ${ }^{1567}$ it is argued here that its importance for transferring of interpretations and stimulating innovation should be rethought, particularly in regard to the prevalence of abstract, analytic thinking in most problem-solving processes. Thus, narratives should be viewed as equal to rational analysis in the construction, maintenance, and change of perspectives in communities. ${ }^{1568}$ "The rational analytic elements of a perspective in a community of knowing are a product of a storytelling as much as they are medium for it."1569 Through storytelling, different experiences and interpretations converge, leading to a shared meaning and communal interpretation of previous uninterpretable data and experience. In this way, previous stories can be modified and new ones created. ${ }^{1570}$ This is a process of knowledge creation. Thus, it is important for organizations to identify those who tell good stories. ${ }^{1571}$ This is, however, not to say that rational argumentation is without any importance. What is argued is, rather, that the rational process of problem construction and solution needs to be enriched by the more figurative process of storytelling. This is especially important in the case of innovative problems, as argued in what follows.

As in the previous chapter stated, the problem-solving process in management consultancies is conceptualized often as analytic, paradigmatic, rational, following specific rules, and relying on facts and data. However, an examination of this process suggests that there are situations when consultants continually construct and reconstruct the meaning of their concepts through the formulation of stories. This is all the more relevant when the problem they have to solve is new and complex. In such situations, the ambiguity of the available information and the uncertainty about what is more or less important in the relationships between the relevant actors makes the understanding of the other's interpretations and perspectives crucial for a successful solution. Thus, the forming of a story of the problem is part of the problem diagnosis. ${ }^{1572}$ Presentation and discussion of different stories is one important way to make clear different perspectives and understandings of the situation. As a result, several different "pictures" of the problem can emerge, each of which can be examined and reflected upon to provoke old memories and new insights. Only when the problem is familiar and/or highly technical, and there is extensive experience and knowledge about how to solve such problems, will the problem-solving process follow a particular rational structure and logic. Therefore, a combination of rational reasoning, based not only on facts but also on stories that hold 
these facts together, offers a better way to communicate and transfer knowledge. In line with this argument, Boland et al. argue that abstract knowledge, which is used in rational forms of argumentation, should be portrayed in figurative as well as in literal forms of knowledge in order to enhance the knowledge transfer process. ${ }^{1573}$ Thereby, figurative knowledge includes narratives and stories, where intended meanings are ambiguous, and the knowledge content is left to the reader's interpretation. ${ }^{1574}$ In addition, case stories complement the abstract knowledge and show its use in specific situations. ${ }^{1575}$ Thus, in advertising agencies metaphoric language is used in order to calibrate and maximize interaction with the clients. ${ }^{1576}$ Weick and Browning confirm this by arguing that whereas rational argumentation is seen as a hierarchical process where only experts can debate experts and nonexperts are regarded merely as spectators, the emphasis on narration achieves a shift in the focus to all involved individuals, as everybody can judge stories and be an active participant in building stories. ${ }^{1577}$ Therefore, stories enable collaborative communication. ${ }^{1578}$

Consequently, the basic tenet of the critical perspective-that management consultants offer nothing more than stories and mere rhetoric to their clients-needs to be reconstructed to account for the importance of stories for knowledge transfer and creation. This chapter shows that stories and rhetoric are important communication mechanisms that enable sharing of interpretations and creative problem-solving. Thus, storytelling holds a symbolic importance and also serves as a powerful instrument for knowledge sharing.

\subsubsection{Brokering}

In this chapter, it is emphasized that certain individuals possess, to a greater extent than others the ability to make connections between members of different interpretive communities and to influence the knowledge sharing process. Such individuals transfer more easily between different communities and can understand differences in the interpretations and make them clear to the other members of these groups. Wenger calls this transfer of some elements of one practice into another "brokering". ${ }^{1579}$ Thorne speaks

See Boland et al. (2001), p. 406. Interpretive representations of knowledge combine abstract and concrete knowledge. Ibid, p. 397.

In contrast, in literal forms of knowledge, words are used in their usual way and the intended meaning is the customary one. Ibid, p. 397.

See Werr/Stjernberg (2003), pp. 891.

See Malefyt (2003), p. 154.

See Weick/Browning (1986), p. 249.

See Brown (2005), pp. 83-87; Denning (2005), p. 168.

See Wenger (1998), p. 103. Brokers are similar to what other authors have called "global travelers" or "cosmopolitans". See Briers/Chua (2001), pp. 240-241. Semadeni argues that brokering can occur at multiple levels: at the individual, firm and inter-firm-level. See Semadeni (2001), pp. 50-51. He furthermore states that brokering at the individual level involves different interchange mechanisms, e.g., analogy and metaphor, than brokering at the other two levels where the brokering process is more standardized and formal including such mechanisms as reports and presentations. The interpretive model contradicts this view. As in chapter D.III.3.6 argued, consulting companies often act as knowledge brokers between their clients. This is a form of brokering at the firm and inter-firm level. However, it is clear that knowledge is transferred between individuals, not between organizations as a whole. Consultancies are knowledge brokers to the extent that individual consultants transfer knowledge and interpretations between different interpretive communities, some of which are external to the consulting firm. Furthermore, the discussion of the different boundary objects makes it clear that formal, standardized boundary objects, e.g. reports, methods, and concepts, cannot always 
about "cultural chameleons" or members of a "cell-culture". ${ }^{1580}$ A common feature of the relationship of a community with the outside, brokering creates an indirect relation between people or communities where no direct relations exists. ${ }^{1581}$

According to Semadeni, knowledge brokers perform two fundamental roles. ${ }^{1582}$ First, knowledge brokers are engaged in transferring knowledge from one area to another. Burt, for example, points out that the main value of brokering is in connecting people who possess different information and in the entrepreneurial value that this bridging creates. ${ }^{1583}$ Tushman sees in the development of special boundary roles "one way to deal with the difficulties of communication across...boundaries" and emphasizes the need of specialized brokers, because several communities have to be connected. ${ }^{1584}$ However, building new connections across communities enables understanding, which also opens new possibilities of meaning. Hence, brokering is not simply transfer of information but involves processes of translation, coordination, and alignment between perspectives. It causes learning by introducing into one community the elements of another. ${ }^{1585}$ Werr and Stjernberg conclude that in consulting companies brokering is the most important way of transferring knowledge. ${ }^{1586}$

The second fundamental role of brokers is to select whose knowledge will and will not undergo arbitrage. This function puts brokers in a potentially powerful position. ${ }^{1587}$ They can influence, consciously or unconsciously, the direction of the problem-solving process. Moreover, they can exploit the ignorance or lack of knowledge of other members of the client-consultant team in order to force their own interpretation of the problem and their view of the problem solution. This would imply that the clientconsultant team does not profit from the existence of different interpretations, which could result in less creative problem solutions. At the same time, the role of brokers gives them the opportunity to direct the problem-solving process when no agreement can be reached about whose perspective should become the basis for the problem solution. ${ }^{1588}$

Brokering is a very complex activity, as Wenger emphasizes. ${ }^{1589}$ It requires "enough legitimacy to influence the development of a [community], mobilize attention, and address conflicting interests". ${ }^{1590}$ Thorne looks at how brokers develop and argues that they retain their original identity but are engaged, at the same time, in new or different

transfer knowledge between interpretive communities successfully. This is one reason why brokering is necessary. Hence, brokering always implies participation, and as such, it cannot be standardized and formal. Thorne (2000), p. 325. Gatekeeper is another term. See, e.g., Tushman (1977), pp. 591-592.

Burt calls such disconnected social clusters "structural holes” (see Burt, 1992); and Granovetter speaks about "weak ties" (see Granovetter, 1973). People who act as brokers possess social capital. Social capital predicts that the return to an individual's human capital depends on that individual's location. See Burt (1992), pp. 30; Burt (1997).

See Burt (1997), pp. 340-342; see also Burt (1992), pp. 20.

Tushman (1997), p. 591.

See Wenger (1998), p. 109.

See Werr/Stjernberg (2003), pp. 893-894.

See Abrahamson/Fombrun (1994), pp. 740.

See also the discussion in D.IV.5.

See Wenger (1998), p. 109.

Wenger (1998), p. 109. 
roles and tasks through which they develop new interpretive schemes and even change the way in which they conceive their original interpretive community. ${ }^{1591}$ Therefore, brokering is especially difficult because it involves multi-membership in communities while, at the same time, some isolation from these communities, which Wenger calls "uprootedness". ${ }^{1592}$ Similarly, Garsten argues that brokers take positions of high ambiguity and "double-sidedness". ${ }^{1593}$ As such, brokers in client-consultant teams are characterized by a double degree of liminality: they are not only members of the liminal space that the client-consultant team represents but they are also liminal regarding their membership in different interpretive communities. This double-sided liminality places specific requirements on the broker's person and abilities.

The extensive literature on boundary spanners implies that certain individuals seem to be more able and successful as brokers than others. ${ }^{1594}$ Tushman found that brokers have more work-related competence and experience and higher formal status than nonbrokers do. Bartunek et al. argue that people who have developed greater cognitive complexity are more capable than others of applying several different perspectives and sharing meaning across multiple communities. ${ }^{1595}$ Cognitive complexity is characterized through differentiation- "the ability to perceive several dimensions in a stimulus array"-and integration- “the development of complex connections among the differentiated characteristics". ${ }^{1596}$ Other important characteristics mentioned are the capacity for understanding others, the capacity of introspection and self-awareness, and the ability to build interpersonal relationships and increasingly broad views of society and social issues. ${ }^{1597}$ Moreover, all facets of cognitive complexity increase the ability of an individual to gain "interpretive dominance" over others, a concept that is discussed in chapter IV of this section, which can lead to advantages for the person in a broker position.

\subsubsection{Other mechanisms}

In an empirical study of naturally occurring communication behavior, Donnellon et al. observed how four different communication mechanisms enabled team members, who were in initial disagreement about joint action, to create shared meanings and undertake joint action. ${ }^{1598}$ The mechanisms they consider are: (1) metaphor, ${ }^{1599}$ which creates novel interpretations of experience by asking actors to see one thing in terms of something

\footnotetext{
1591 See Thorne (2000), p. 334.

1592 Wenger (1989), p. 110.

1593 See Garsten (1999), p. 615.

1594 See, e.g., Tushman (1981).

1595 See Bartunek et al. (1983), p. 274.

1596 Ibid, p. 274.

1597 Ibid, p. 274.

1598 See Donnellon et al. (1986), pp. 48-51.

1599 Metaphor, together with synecdoche, metonymy, and irony, are literary devices called tropes. See Grant et al. (2004), p. 7.
} 
else; ${ }^{1600}$ (2) logical argument; ${ }^{1601}$ (3) affect modulation, which is defined as "communication behaviors that evoke or alter sentiment in such a way as to cause the redefinition of a situation"; and, (4) linguistic indirection-“the purposeful use of behavioral forms that are ambiguous and therefore create equivocality". ${ }^{1602}$ They found that these mechanisms contribute to the development of minimal shared meanings, which are a precondition for successful knowledge transfer. In addition, Malefyt argues that metaphors exchanged in business meetings are "ideal devices for fostering emotional bonds [with the client] when there may be little affinity to begin with.”1603

In another study, Stokes and Hewitt investigate different concepts of aligning actions including "motive talk", which justifies one of several alternative acts; "accounts"statement made by an actor to explain unanticipated or untoward behavior-; "disclaimer", which is a verbal device employed in advance of an action that an actor thinks may discredit her/him in the eyes of others; "remedial interactions" that protect people by showing that they have a better relationship to specific rules than might be supposed; and "quasi-theories"—ad-hoc explanations brought to problematic situations to give them order and shape. ${ }^{1604}$ All these concepts can contribute to the alignment between individual actions and, consequently, between the cultural definitions and requirements of the communities to which they belong, thus contributing to knowledge transfer and learning between interpretive communities. ${ }^{1605}$

Table 14 summarizes the discussion of mechanisms that enable communication between individuals from different interpretive communities, and thus, knowledge transfer and creation.

\footnotetext{
1600 See also Oztel/Hinz (2001) and Tsoukas (1991) for an extensive discussion of the role of metaphors and Grant et al. (2004), pp. 7-8 and Heracleous (2004), pp. 183-185 for an overview of research on metaphor. Tsoukas stresses that metaphors are particularly suited for capturing and transfer of concrete experiences. See Tsoukas (1991), p. 571. See the discussion in chapter D.III.3.8.2.

1602 Donnellon et al. (1986), p. 48-51.

1603 Malefyt (2000), p. 154.

1604 Stoke/Hewitt (1976), p. 844.

Bartunek et al. discuss more methods on how people can be assisted to take different perspectives into account and what learning conditions are likely to support these processes. See Bartunek et al. (1983), pp. 275-277.
} 


\begin{tabular}{|c|c|c|}
\hline Mechanism & Definition & Function \\
\hline $\begin{array}{l}\text { Boundary } \\
\text { objects }\end{array}$ & $\begin{array}{l}\text { Objects that coordinate the perspectives } \\
\text { of various communities for some } \\
\text { purpose (e.g., Star and Greisemer, } \\
\text { 1989). }\end{array}$ & $\begin{array}{l}\text { Visual representations of interpretations; } \\
\text { provide a basis for sharing of knowledge with } \\
\text { others. Especially important whenever verbal } \\
\text { communication is difficult. It might have, } \\
\text { however, negative effects on knowledge } \\
\text { creation. }\end{array}$ \\
\hline $\begin{array}{l}\text { Rational } \\
\text { arguments }\end{array}$ & $\begin{array}{l}\text { "Sets of utterances that include a } \\
\text { premise, an inference, and a } \\
\text { conclusion.” (Bunge, 1996; Donnellon } \\
\text { et al., 1986). }\end{array}$ & $\begin{array}{l}\text { Used in a context of disagreement to move } \\
\text { another person to agreement through } \\
\text { incremental steps. Enable knowledge transfer by } \\
\text { direct speech acts that are non-random but } \\
\text { follow some form of rationality and logic (e.g., } \\
\text { Bunge, 1983a; Kirsch, 1997, Reihlen, 1997). }\end{array}$ \\
\hline $\begin{array}{l}\text { Narrative/ } \\
\text { Story }\end{array}$ & $\begin{array}{l}\text { An oral or written performance or } \\
\text { exchange between two or more people } \\
\text { during which a past or anticipated } \\
\text { experience was being referenced, } \\
\text { recounted, interpreted, } \\
\text { or challenged (Boje, 1991, 1995). }\end{array}$ & $\begin{array}{l}\text { Helps to build new meanings of a problem and } \\
\text { acts as a repository of accumulated experience. } \\
\text { Enables the building of emotional bonds } \\
\text { (Brown and Duguid, 1991; Werr and Stjernberg, } \\
\text { 2003). }\end{array}$ \\
\hline Brokering & $\begin{array}{l}\text { When people transfer some elements } \\
\text { of one community into another and } \\
\text { thus create indirect relation between } \\
\text { communities where no direct relations } \\
\text { (e.g., shared frameworks) exist } \\
\text { (Burt, 1992, 1997). }\end{array}$ & $\begin{array}{l}\text { Connects unconnected communities and enables } \\
\text { sharing of perspectives and new possibilities of } \\
\text { meaning. It might have, however, negative } \\
\text { effects on knowledge creation. }\end{array}$ \\
\hline Metaphor & $\begin{array}{l}\text { "Signification by similarity or } \\
\text { analogy" (Barley, 1983). }\end{array}$ & $\begin{array}{l}\text { Creates novel interpretations of experience by } \\
\text { asking actors to see one thing in terms of } \\
\text { something else (Donnellon et al., 1986). }\end{array}$ \\
\hline $\begin{array}{l}\text { Linguistic } \\
\text { indirection }\end{array}$ & $\begin{array}{l}\text { "The purposeful use of behavioural } \\
\text { forms that are ambiguous and therefore } \\
\text { create equivocality" (Donnellon et al., } \\
\text { 1986). }\end{array}$ & Achieves consensus or suppresses dissent. \\
\hline
\end{tabular}

Table 14: Communication mechanisms for knowledge transfer and creation

\subsection{Summary}

Figure 16 illustrates schematically the discussion about knowledge transfer and creation between matching interpretive communities. In contrast to figure 12, this figure shows that the involved interpretive communities share some cognitive frameworks: the circle representing the client-consultant team is now an intersection of the circles representing the involved interpretive communities. As previously discussed, the sharing of meanings and schemes is facilitated when the involved individuals are aware of their own interpretations. Therefore, reflecting on the own perspectives, as recognized by Schön, represents an important first step towards the development of cognitive consensus across members from different interpretive communities. However, teams can be slowed down by too much rational self-reflection. ${ }^{1606}$ This is especially important for client-consultant teams that often work under tight time restrictions. 


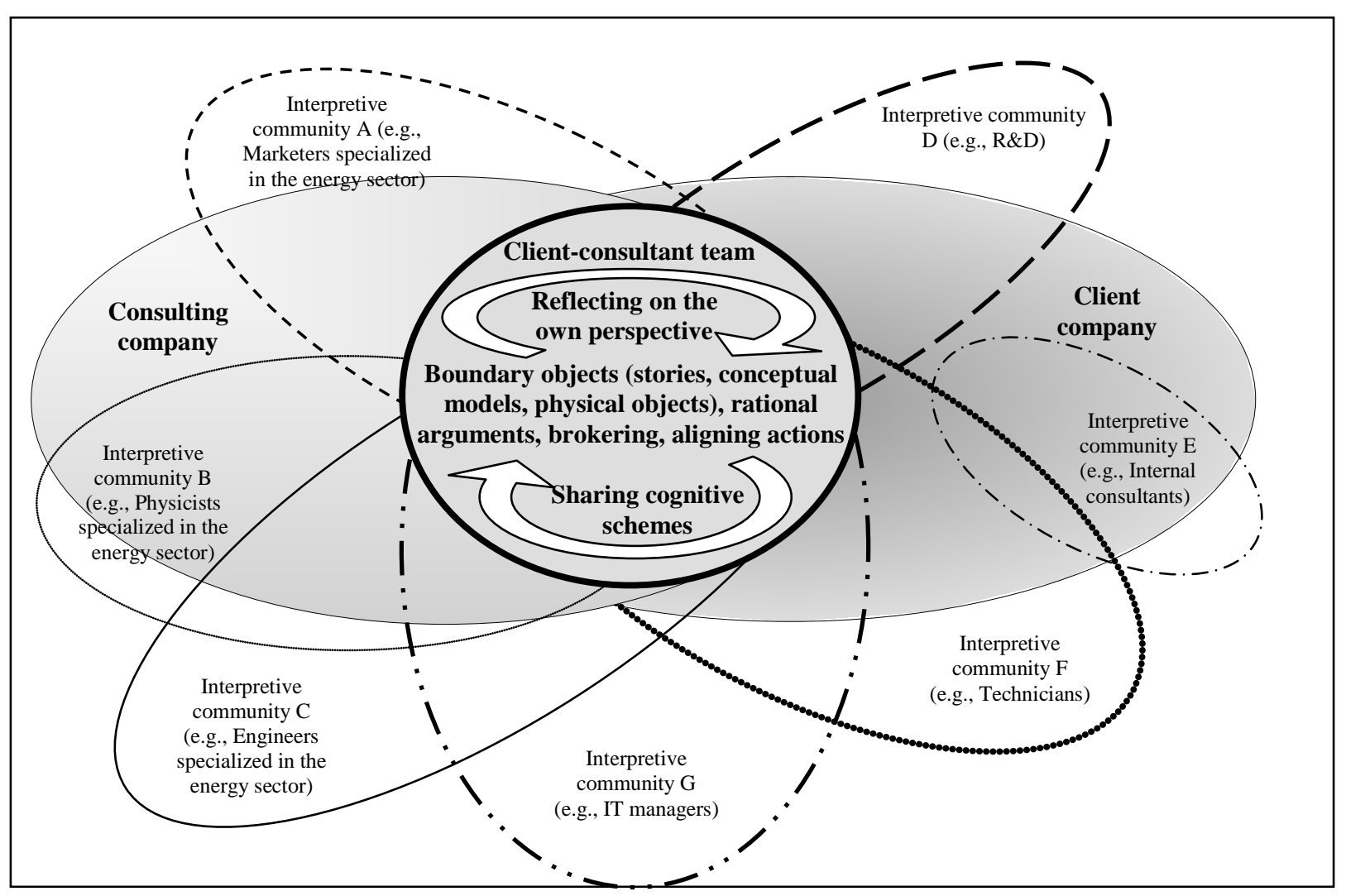

Figure 16: Knowledge transfer and creation in matching interpretive communities

Because clients and consultants belong to different interpretive communities, they may have problems in understanding each other's language resulting in less effective communication. Therefore, the development or the existence of some shared task-related knowledge within the client-consultant team facilitates the communication and social interaction between members of different interpretive communities and the transfer of task-specific knowledge within the team. Through an exchange of task-specific knowledge, members of the client-consultant team are able to create a more encompassing and truer picture of the problem situation, generate different paths for a problem solution and, in this way, enhance the problem-solving process and increase the possibility for better problem solutions. Through the development of shared task-related knowledge and the use of social mechanisms, members of the team are able to integrate and coordinate their activities, to reduce possible conflicts and create not only cognitive but also social and emotional bonds.

The establishment of shared interpretations and meanings is a necessary but not a sufficient condition for the creation of new knowledge and innovative problem solutions. For this purpose, it is important that there is some variety of perspectives within the client-consultant team. In the process of discussing different interpretations, clients and consultants may disrupt and reframe each other's established perspectives, and as a result, new knowledge and new problem solutions can be created.

The knowledge transfer and creation process is influenced, furthermore, by longterm social relationships within the client-consultant team. When clients and consultants work together for an extended time together, they develop shared frameworks and learn 
to "speak each other's language”. Thus, long-term relationships can enhance knowledge transfer. At the same time, an intensive, long-term social interaction may blur the distinction between members of different interpretive communities, and thus, may decrease the variety of perspectives within client-consultant teams. As a result, the possibility of creating “noise” into each other's communities or organizations may be reduced, and the innovativeness of the team may suffer.

The development of shared meanings and frameworks is mediated and stimulated by a number of different mechanisms for sharing of perspectives. Cultural and economic artifacts are important mechanisms that help members of different interpretive communities to transfer knowledge and learn in a situated way-through seeing, touching and experimenting-even if they are not able to exactly explicate what they learn during such interactions. ${ }^{1607}$ Because such artifacts enable the "crossing” of cognitive boundaries, i.e. they mediate knowledge transfer and learning, they are called boundary objects. Myths, stories, and metaphors are particularly important especially in the case of complex and innovative problem situations. ${ }^{1608}$ Rational reasoning also plays an important role in the communication and problem-solving process, as it brings rigor and structure to these processes. Additionally, brokers can also facilitate knowledge transfer and learning within client-consultant teams.

The discussion in this chapter does not cover all factors that influence knowledge transfer and creation in client-consultant teams. For example, it does not discuss the relationship between trust, which is the result of long-term social relationships, and the success of problem-solving. Nor are power effects discussed. It is clear, however, that both trust and power influence knowledge transfer and creation processes. Whereas the issue of trust is not further discussed, as it is beyond the scope of this work, power relations are at the heart of the following chapters of this work. It will be shown that power relations are highly relevant for the problem-solving process in client consultant teams. ${ }^{1609}$ Moreover, the transfer and creation of knowledge is always interwoven with actions of power. For example, the use and creation of boundary objects can be a center of intensive conflict. Thus, the "creating and reshaping of boundary objects is an exercise of power". ${ }^{1610}$ Next, the questions related to the nature of power and its influence on the problem-solving process within client-consultant teams are examined in detail.

\footnotetext{
1607 As already discussed, both action and the discursive examination of action, i.e. conception, are modes of effective cognition. See Bunge (1996), p. 323 and the discussion under D.III.1.2. See also Nicolini/Meznar (1995), pp. 738-740. 


\section{Power relations}

\section{Introduction}

Although it has been recognized that consulting processes are inherently political, ${ }^{1611}$ the nature of power in client-consultant teams, the process of power emergence, and the specific role that power plays in determining the success of consulting projects, is still poorly understood. Within both the expert and the critical model, consultants are usually described as powerful and clients as powerless and dependent. The origin of consultant's power is seen either in the superiority of their knowledge ${ }^{1612}$ or in the rhetoric and faddishness of consultant's language and concepts. ${ }^{1613}$ At the same time, a closer examination of this literature revealed that there are a number of rationales arguing for an opposing view of the client-consultant power distribution, where clients are regarded as the powerful actor and consultants as dependent and powerless. ${ }^{1614}$ Werr and Styhre conclude, "within these two approaches there is, however, some ambivalence in regard to the power distribution in the relationship". 1615

The tendency toward a belief in a unidirectional dependence within client-consultant relations has been strongly criticized, independent of the orientation of that dependency. Fincham, for example, emphasizes that the interaction between the consultants' and the managers' knowledge contextualizes the level of dependency between both parties. ${ }^{1616}$ Sturdy points out that the client-consultant relationship is dialectic, where managers and consultants both play an active role. ${ }^{1617}$ Several researchers have concluded that much of the existing research on consulting, and on knowledge transfer and learning in general, has tended to neglect or simplify issues of power and political activity. ${ }^{1618}$ Moreover, existing research does not tell much about the ongoing political process through which communication and problem-solving within client-consultant teams are forged. ${ }^{1619}$

Werr and Styhre examine the ambiguities existing in the literature on the clientconsultant relationship from an institutional perspective. ${ }^{1620}$ They argue that "images of

1611

1612

1613

1614

1615

1616

1617

1618

See, e.g., Bloomfield/Danieli (1995), p. 29; Ginsberg/Abrahamson (1991), p. 179.

See Haug/Sussman (1969), p. 154; Kubr (1996), pp. 4-6; Mills/Moshavi (1999), pp. 49-50; Sharma (1997), p. 759.

See Alvesson (1993, 2001); Clark (1995), p. 60 and pp. 93-94; Clark/Salaman (1998a, b); Kieser (1997, 2002).

See Alvesson/Johansson (2002), pp. 237-238 and the discussion in C.II.4. and C.IV.4.

Werr/Styhre (2003), p. 44.

See Fincham (1999), pp. 347-350.

See Sturdy (1997a, b). See also chapters C.II.7 and C.IV.7.

See Armbrüster/Kieser (2001), p. 693; Blackler (2000b), p. 833; Coopey/Burgoyne (2000), p. 869; Easterby-Smith et al. (1998), p. 261; Ferdinand (2004), p. 435; Iding (2000), p. 7 and p. 21; Marshall/Rollinson (2004), p. S72. Walsh and Fahey and Iding are amongst the few researchers looking at the connection between power and cognitive schemes in teams and how both influence decision-making processes. See Walsh/Fahey (1988); Iding (2000). However, Walsh and Fahey too simplify the influence of power, concentrating on the role of hierarchical power only. In contrast, this chapter shows that other types of power are often more relevant for the problem-solving process than power based on hierarchical authority. Iding, on the other hand, does not concentrate on the power issue within the client-consultant relationship and how it influences problem-solving within the client-consultant team. See also the following discussion.

See, e.g., Walsh/Fahey (1986), pp. 327.

See Werr/Styhre (2003), pp. 58. 
the dependent client, putting large responsibility in the hands of management consultants" and "images of the client in full control" during consulting projects were often observed simultaneously. ${ }^{1621}$ The authors explain this finding referring to the embeddedness of the client-consultant relationship in two different, widely accepted management discourses: the network discourse and the bureaucratic discourse. According to the former, clients have to cooperate closely with consultants if they are to help their organizations to tackle different challenges. At the same time, managers were following the bureaucratic discourse and regarded themselves as the actors in control who have to specify exactly the needed consulting services. Werr and Styhre conclude that these contrasting perspectives and behavior of managers towards consultants are the reason for the ambiguous empirical findings and theoretical remarks of power in client-consultant relationships.

In contrast to Werr and Styhre, it is claimed here that the main reason for the ambivalent accounts regarding the distribution of power in the client-consultant relationship is the lack of differentiation between the roles and extent of involvement of different actors in consulting projects. This is in line with Garrat who argued early on that there has been "confusion as to the relationship between the client (who commissioned the consultant) and the true owners of the problem (who were working on it and would be left to live with whatever results were obtained)". ${ }^{1622}$ Accordingly, there are three major actors in consulting projects: (1) the client manager who commissions the project, and who, within concrete consulting projects, can be represented by the client project manager, (2) members of the client organization who are directly involved in the project, i.e. the "problem owners", and (3) the consultants. Consequently, the power distribution between the sponsor of the project and the consultants differs from the power relation between the "problem owners" and the consultants. It is proposed that in the first case, positional or episodic power is at work, which does not always automatically imbue certain actors with the power to decide on the outcome of consulting projects. ${ }^{1623}$ In contrast, the emergence of power in the second relationship, called rhetorical power, ${ }^{1624}$ can have a stronger influence on the outcome of the project. Whereas positional power is grounded in the resource control through agents, rhetorical power is not predetermined but emerges as a result of negotiations and translations of meanings during clientconsultant projects, the outcome of which is "interpretive dominance". ${ }^{1625}$ Interpretive dominance means, thereby, that an actor or a group of actors have established their perspective on the problem and problem solution as the dominant one, which prevents the adoption of competing views by other members of the team. It is proposed that who holds what power, and the extent of that power, will vary, as will the degree to which these 
different types of power influence the outcome of consulting projects. ${ }^{1626}$ In this sense, client-consultant teams are regarded as pluralistic political systems. ${ }^{1627}$

The approach behind this view of power follows a critical realist epistemology to power. ${ }^{1628}$ It is suggested that there is mutual dependency between clients and consultants due to the pluralism of perspectives in client-consultant teams regarding any particular problem situation and its solution. Moreover, it is argued that when different communities interact with each other they are characterized more by distinct perspectives than by mutual understanding. ${ }^{1629}$ In such cases, the involved communities form a discursive community, "where each community maintains its own voice while listening to the voice of the Other [sic!], and where communication is both negotiated order and disorder". ${ }^{1630}$ Gherardi and Nicolini conclude that such situations are characterized by harmonization, negotiation of meanings, and the integration of local forms of knowledge as well as by competition, conflict, dominance, and exclusion. ${ }^{1631}$ This implies that when multiple interpretive communities interact with each other, often power rather than rationality is at work. Consequently, the process of problem-solving in client-consultant teams is often a highly political activity, the outcome of which often depends on the ability of actors to build alliances and coalitions and to develop interpretive dominance. The outcome of this process often confirms and reinforces existing consulting discourses and practices. However, as it will be shown, it can result in novel interpretations as well, which actors will, consequently, try to solidify and institutionalize as a means of gaining interpretative dominance.

In order to understand the nature and role of such political activities within clientconsultant teams, this chapter looks at the nature of power and introduces the concept of positional or episodic and rhetorical power within groups and organizations. This concept applied to the case of client-consultant teams shows the relevance of both positional and rhetorical power for the decision-making process. It is proposed that rhetorical power has a bigger impact on the outcome of consulting projects when it results in interpretive dominance. Accordingly, the nature of interpretive dominance, its development, and the role of symbolic resources as tools for developing interpretive dominance are discussed. Thus, this view of power emphasizes the importance of symbols, myths, metaphors, stories, humor, etc. when analyzing power. ${ }^{1632}$ Additionally, on the basis of the presented arguments, a different view of the nature of professional business services is suggested.

\footnotetext{
1626 Which type of power is more likely to influence the outcomes of consulting projects depends, inter alia, on the type of problem that the client-consultant team faces. This is discussed extensively in chapter D.IV.5 and D.VI.

See chapter D.II.

See Gherardi/Nicolini (2002), p. 420.

Gherardi/Nicolini (2002), p. 421.

Gherardi and Nicolini do not state, however, when harmonization and integration of meanings prevails over competition and vice versa. Furthermore, they do not discuss through what mechanisms power is gained and exercised in such "constellations of interconnected practices". See Gherardi/Nicolini (2002), p. 434. The following chapters of this work provide some answers to these questions.

See Bradshaw-Camball/Murray (1991), p. 382.
} 


\section{Power, rationality and the "ideal speech situation"}

As section III.3 of this chapter discussed, successful problem-solving within the clientconsultant team is dependent on the ability of the involved individuals to achieve some shared meanings and understandings. In this process, it is necessary for all involved actors to "strip away differences in rank and status" in order to develop cognitive consensus. ${ }^{1633}$ In other words, the interpretive model acknowledges the importance of both consultant's and client's interpretations for the problem-solving process. In particular, it acknowledges that only when both sides are free to share their task-specific knowledge a more complete picture of the problem situation can be built. Therefore, the interpretive model does not imply that consultants are more powerful than clients but advocates their mutual dependency. Mutual dependency or interpretive pluralism means, however, that when it comes to making a decision about whose interpretation should be taken as a basis for solution proposition, several interpretive positions will compete with each other. The best-case scenario for solving such situations would be the reaching of an agreement as a result of rational argumentation. ${ }^{1634}$

An example of such a scenario is Habermas' notion of the "ideal speech situation". ${ }^{1635}$ In this situation, the participants in a communicative act presuppose the absence of "all force-except the force of the better argument". 1636 Thus, Habermas constructs a model of conditions under which actors can make rational choices. He believes that any difference in agreement of the involved actors can be settled if the parties are mindful to do so and if the appropriate conditions exist. The implication for the client-consultant team would be that the involved individuals would be engaged in communicatively rational processes of evaluating alternative problem solutions until agreement is reached. ${ }^{1637}$ Action is, in the ideal speech situation, the product of speaking, hearing, and acting of actors but not of power. ${ }^{1638}$ Where power is present, communication is systematically distorted. ${ }^{1639}$ Thus, in an ideal speech situation, a transparency of language between speakers and hearers is assumed. ${ }^{1640}$

In the case of the ideal speech situation, team members can use three rational approaches in order to come to an agreement and to solve problems: consensus,

See Garsten (1999), p. 611.

See, e.g., Reihlen (1997), pp. 204.

Habermas argues that an ideal speech situation is determined by pure intersubjectivity. Furthermore, the assumption behind the ideal speech situation is the existence of "exclusively linguistic organization of speech and interaction". See Habermas (1970), pp. 369-375. Habermas, with his belief that language is the medium of reason and that individuals "can reach a 'universal consensus' of human experience", is a representative of a stream within modernism called critical modernism. See Cooper/Burrell (1988), p. 97. See Willmott (2003) for a very good discussion of Habermas’ ideas and contribution to organization theory, as well as of the major critical points of his work.

Habermas (1984), p. 25.

See Marshall/Rollinson (2004), p. S78. This is consistent with the previously mentioned concept of practical rationality. See Reihlen (1997), pp. 210 for an introduction in the concept of practical rationality and its implication for decisionmaking. See also Mitroff/Mason (1981), pp. 73-86 for some examples how rational problem-solving can be implemented in practice.

See also Schräder (1995), p. 42.

See Habermas (1970), p. 371.

See Clegg (1989a), p. 94.
} 
dialectical inquiry, and devil's advocacy. ${ }^{1641}$ Consensus requires that all team members agree upon the structure and characteristics of the problem at hand and that each of them believes that the created problem solution is the right one. ${ }^{1642}$ A dialectical inquiry involves the discussion of the issue at hand from different perspectives until a common interpretation and argumentation is reached. It requires that different individuals propose a thesis and an antithesis and keep constructing new assumptions and arguments until they can reach synthesis, i.e. agreement. ${ }^{1643}$ In devil's advocacy, which is similar to dialectical inquiry, ${ }^{1644}$ no antithesis is formulated. Instead, the thesis is criticized so that it is constantly revised until all involved individuals accept the proposed assumptions and recommendations. ${ }^{1645}$ In general, consensus approaches are seen as less appropriate than dialectical inquiry and devil's advocacy because although they may create some measure of agreement they do not alter the fundamental patterns that lead people to disagree on particular issues. "Consensus approaches usually do not have the ambition of exploring or altering underlying patters of meaning”. ${ }^{1646}$ Thus, Schweiger et al. show that both dialectical inquiry and devil's advocacy achieve more reevaluation of the group members' assumptions and perspectives than consensus. ${ }^{1647}$ At the same time, the consensus approach leads to a greater acceptance of group decisions than in the case of either of the other approaches, and as such, enhances implementation. ${ }^{1648}$

However, all three rational approaches to decision-making in diverse teams share the same problematic: that in reality "the better argument is not self-evident". ${ }^{649}$ As already discussed, people participate in different interpretive communities and have different perspective on topics, and there are situations when it is not easy to bridge these differences. Even if some agreement can be reached, the process might take such a long time that it would be economically inefficient, ${ }^{1650}$ a situation common in consulting projects with exceedingly tight time constraints. Additionally, even if the involved individuals can achieve agreement about a best available argument and they have the time to do so, they might not realize that the suggested solution is not the best available but is rather perceived as such due to previously fixed discourses and institutionalized beliefs, which render it to be the best. ${ }^{1651}$ "Even when agreement is present, consensus is false since the grounds for it cannot be rationally assessed". ${ }^{1652}$ Bersen confirms this by arguing, "to intend to open a rational dialogue is to assume or intend that the dialogue

See Schweiger et al. (1989), pp. 747; see also Raelin (1997), pp. 571-572; Walsh et al. (1988), p. 198.

See Reihlen (1997), pp. 281-282.

Ibid, pp. 233; see also Schweiger et al. (1989), p. 747; Coopey/Burgoyne (2000), pp. 877-881.

Schweiger et al. show empirically that there are no significant differences between both approaches regarding team performance, group members' reactions, critical re-evaluation, and meetings duration. See Schweiger et al. (1989), p. 766.

See Schweiger et al. (1989), p. 747.

Issacs (1993), p. 26; see also Reihlen (1997), pp. 281-282; Weick/Browning (1986), p. 254.

See Schweiger et al. (1989), p. 767.

Ibid, p. 768.

Marshall/Rollinson (2004), p. S80; see also Kirsch (1997), p. 358.

See also Bersen (1982), p. 238; Reihlen (1997), p. 282.

This is the Foucauldian understanding of power. See chapter B.II.4.3.3. See also Willmott (2003) for an extensive discussion and critic on Habermas' arguments. 
may further the discovery of truth and that all possible positive steps be taken, and hindrances avoided in order that the strongest argument may win and truth be attained. [However], it is impossible to enumerate all sources of error that may obstruct our grasp of truth, communicative or otherwise". ${ }^{1653}$ As Flyvbjerg notes, "communication is more typically characterized by nonrational rhetoric and maintenance of interests than by freedom from domination and consensus seeking”. ${ }^{1654}$ Ultimately, power is part of every relationship and it influences every human interaction. It acts through knowledge, influencing justifications and the direction of attention. ${ }^{1655}$ Thus, rationality is "contextdependent, the context often being power". ${ }^{1656}$ Therefore, to discuss a fully rational decision process without accounting for the influence of power would mean ignoring the reality of decision-making in human societies. ${ }^{1657}$ This makes the need to clarify the nature of power within the interpretive model apparent, as well as the need to discuss its influence and effects on problem-solving and the outcomes of consulting projects.

Some researchers have argued, however, that even if an ideal speech situation is not possible, it should not be accepted that, in the case of cognitive pluralism, a solution could be achieved only by using power. Instead, according to the argument, there are still some rational procedures that members of diverse teams can use in order to reach to a solution in a rational and non random way, i.e. not on the basis of power struggles. ${ }^{1658}$ Reihlen, for example, suggests that there are two practical procedures for such situations: a democratic ballot following the majority principle or independent expert advice. ${ }^{1659}$ Such rational procedures aim to ensure that even if not all individuals agree upon the suggested problem solution they will at least agree to implement it because a rational, i.e. fair procedure for reaching to the solution has been followed. However, these rational procedures have their shortcomings and limitations as well. For example, democratic ballots might not lead to rational problem-solving in client-consultant teams as other than cognitive aspects might influence the results, for example affiliation to the client versus the consulting organization, or to particular interpretive communities. In line with this, Thompson et al. argue that in general, the majority decision rule does not integrate all team members' interpretations. Instead, it distributes resources unequally and leads group members to form coalitions that effectively block some of the actors from sharing their

\footnotetext{
1653 Bernsen (1982), p. 238. See also Maturana who argues that due to the nature of man as a "relativistic self-referring autonomous system [] no absolute system of values is possible and all truth and falsehood in the cultural domain are necessarily relative". Furthermore, "the ultimate truth on which a man bases his rational conduct is necessarily subordinated to his personal experience and appears as an act of choice expressing preference that cannot be transferred rationally”. Maturana (1980), pp. 57-58.

Flyvbjerg (1998), p. 227. In line with this, Bersen points out that the assumption of rational dialogue means that no irrelevant or destructive factors infer, such as "polemics, propaganda, violence, master-slave relationship, irrelevant emotions, aesthetical preferences or interests, plain indifference, etc”. Bersen (1982), pp. 237-238. Flyvbjerg (1998), p. 227.

Ibid, p. 227. Similarly, Foucault argues that knowledge does not bring truth. The implication of his arguments is that there is no true knowledge per se. Rather, through the dominant regimes of power certain conceptions of truth and rationality are established, while others are marginalized. See Foucault (1980), pp. 131-133. power when studying decision-making and knowledge transfer undermines one's ability to understand and predict which decisions and ideas will successfully proceed through these processes. See Lawrence et al. (2005), p. 180. 
perspectives. As such, it fosters political behavior. ${ }^{1660}$ A decision through an independent expert is not an option either because consultants are usually seen as such independent experts, which would imply that consultants are seen as rational and independent actors, an assumption that was made within the expert model of consulting. ${ }^{1661}$ Thus, expert advice in general cannot be seen as a rational procedure for problem-solving because experts are consciously or unconsciously embedded in power relations and as such, their actions and advice are influenced by power. ${ }^{1662}$ It can be concluded that it is idealistic to argue that power relations do not influence decision-making processes. ${ }^{1663}$ Moreover, as some power relations are subtler than others, their influence is not easily recognizable. Thus, it is necessary to shed some light on forms of power within client-consultant teams that are more or less visible. In the following chapter, an in depth analysis of the power relations within client-consultant teams is provided and the following questions are answered: What is the nature of power in client-consultant teams? What kind of power is at work within client-consultant teams? How is it decided whose interpretation is better regarding a specific problem? How do the involved individuals win acceptance for their definition and representation of a problem and for particular solutions?

\section{Nature of power}

As outlined in chapter D.IV, the concept of power at work here is broad. It connects debates about power, emanating from interpretivism, to traditional views of power, and as such, it uses Foucault's work creatively ${ }^{1664}$ and introduces some important insights that differ from those of interpretivists. First, it is argued that power should not be seen as ubiquitous as suggested by the interpretivists. Rather, it can be regarded as flowing "through different circuits of social relations, with different effects". ${ }^{165}$ It encompasses, on the one hand, the small episodic power relations of everyday work, i.e. the power in the work relation between clients and consultants that are the result of previously institutionalized power positions. On the other hand, it includes the disciplinary effects of specific forms of knowledge and technologies that are the source of rhetorical power and which are, inter alia, mirrored in the hierarchical position and authoritative dominance of certain individuals. ${ }^{1666}$ In this view, power relationships amongst individual actors and

1660

1661

1662

1663

1664

1665

1666
See Thompson et al. (1988), p. 92.

See chapter C.II.

This is issue related to Foucaul's work (see chapter B.II.4.3.3) and is further discussed in the following chapters.

See, e.g., Flyvbjerg (1998).

See Clegg et al. (2006), p. 8-25; also Clegg (1989a), pp. 187-240 and Scott (2001), pp. 13. See also the discussion in chapter B.II.4.3.3.

Clegg et al. (2006), p. 8-25.

See Clegg (1989a), pp. 211. In the German speaking area, Ortmann and co-authors take a similar perspective on the nature of power in organizations. See Iding (2000), pp. 80-93. On the basis of Ortmann's work, Iding develops a theory of consulting, which he calls a micropolitical theory of consulting. As the name says, he concentrates mainly on issues of power, and develops a view of power in consulting that is quite similar to the one suggested within this work. See Iding (2000), pp. 189-203. Iding emphasizes, however, the role of consultant's in uncovering, analyzing, and utilizing power relations within the client organization, in order to develop paths for problem-solving. In other words, Iding does not concentrate on the power issue within the client-consultant relationship and how it influences problem-solving within the client-consultant team. This is due to Iding's view that consultants are always the powerful actor within client-consultant teams. Clients, as a result, engage continuously in micropolitical games and try to win the consultant on "their side". There is no discussion of the client as an important contributor to the problem-solving process in consulting projects. See Iding (2000), pp. 195-198 and p. 203. Thus, although Iding develops a very promising view of the nature of power in 
groups of actors are the result of previous discourses and institutionalized knowledge, or in Clegg and Palmer's terms, "recipes in use". ${ }^{1667}$ Accordingly, the formation and accumulation of knowledge that makes the translation of different interpretations possible is a simultaneous mechanism of power. Mailloux supports this when he argues that most knowledge translations involve political interests, consequences, coercion, persuasion, and rhetoric. ${ }^{1668}$

Second, this work assumes that agency and structure are in a reciprocal relationship. In other words, there are recurring social structures in which social interaction is embedded and at the same time, forms of social action influence such structures. ${ }^{1669}$ Actors and groups are not only influenced by, but they themselves influence, existing power relations and discourses through their ongoing interpretations and actions and by constructing the meaning of what others experience. ${ }^{1670}$ Thus, as Prahalad and Bettis argue, the power of a particular interpretation emerges from the reinforcement that results from actors doing the "right things", i.e. using the established "recipes". This reinforcement results in actors focusing again on the established knowledge. ${ }^{1671}$ Therefore, "agency, whether individual or collective, is not purely an effect of power/knowledge strategies that constrain through normalization, but neither can it be characterized wholly in terms of unconstrained, knowledgeable and intentional action.” ${ }^{1672}$ As such, this perspective fills a gap in the existing research on consulting as identified by Iding. ${ }^{1673}$ It takes a critical realist view of power by showing that there is space for the use of power through actors, albeit within a particular historical and discursive context. ${ }^{1674}$ It emphasizes that "discourses are never completely cohesive and devoid of internal tensions, and are therefore never able totally to determine social reality. They are always partial, often cross-cut by inconsistencies and contradiction, and almost always contested to some degree”. ${ }^{1675}$

Therefore, the interpretive model regards power as a social construct that is both a product of collective activity and the medium by which it is developed and enhanced. ${ }^{1676}$ Additionally, it shows that in a particular context, "power determines what counts as

organizations, his perspective on power within client-consultant relationships differs from the one suggested within this work, which argues that both clients and consultants are powerful and that their power is closely interrelated with their knowledge. See the discussion in the following chapters.

Clegg/Palmer (1996), p. 4. See also Barker (1993) and Sewell (1998) who show empirically the role of shared cognitive schemes, embodied in the form of normative rules, as power and control mechanisms in self-organizing teams.

See Mailloux (1990) cited in Weick (1995), p. 7.

See Reed (2000b), p. 55. This approach is also called “analytical dualism”. Ibid, p. 55.

See, e.g. Bradshaw-Camball/Murray (1991), p. 382; Weick/Browning (1986), p. 245. The view that interaction becomes translated into structures and rules, which constrain interactions and interpretations, is also known as "structuration" and was developed in the work of Giddens. See Weick/Browning (1986), p. 245.

See Prahalad/Bettis (1986), pp. 491-492.

Marshall/Rollinson (2004), p. S76; see also Fairclough (2005), pp. 925-927; Hardy/Phillips (2004), p. 303; Iding (2000), p. 86; Phillips (2003), pp. 225-226.

Iding argues that there is a need for a consulting theory that acknowledges the connection between structures and actions. See Iding (2000), p. 14.

See Hardy/Phillips (2004), p. 305.

Hardy/Phillips (2004), p. 304. See also the discussion in chapter B.II.4.3.3.

See Blackler (2000b), p. 835; Clegg (1989a), pp. 187; Clegg (1989 b), p. 107; Contu/Willmott (2003b), pp. 180; Iding (2000), p. 193. 
knowledge, what kind of interpretation attains authority as the dominant interpretation. Power procures the knowledge which supports its purposes, while it ignores or suppresses that knowledge which does not serve it". ${ }^{1677}$ As a result, "power makes knowledge as knowledge makes power". ${ }^{1678}$ In this way, power defines what reality is, e.g., what is seen as a problem and what is a rational problem solution. ${ }^{1679}$

Furthermore, this view of power and discourse is clearly connected to the assumption that organizations can be seen as combinations of different interpretive communities: because interpretive communities are characterized by "discursive practices", they effectively constitute power relations. ${ }^{1680}$ Solutions are, accordingly, created and transferred within the involved interpretive communities and are the result of an ongoing process of translation of different interpretations. Because members of interpretive communities are embedded in multiple discourses, they can "play one discourse against another, draw on multiple discourses to create a new form of interdiscursivity, and otherwise move between and across multiple discourses". ${ }^{1681}$ Thus, negotiations, contestations, and struggles between interpretive communities are a routine occurrence. ${ }^{1682}$ An important question to answer in this respect is what is it that determines the actual outcome of this mutual exertion of influence. As Fairclough puts it, "What is it that determines the cumulative outcomes of [dialogs between interpretive communities] in particular social domains or institutions, and differences between them in the reproductive as opposed to transformative tendencies of discourse?" $1683 \mathrm{He}$ suggests that "structures are reproduced or transformed depending on the state of relations, the 'balance of power', between those in struggle in a particular sustained domain of practice". ${ }^{1684}$ Therefore, it is important to look at the interactions between different interpretive communities and their power. Often, some of these practices will have greater power than others would: "If we treat organizations as communities [of interpretation], we will find that some communities attempt to enroll, or betray, the others." 1685 Organizations are, consequently, combinations of diverse disciplinary practices within which individuals struggle to fix rules and interpretations. ${ }^{1686}$

In order to devise the different power types that are relevant when looking at the client-consultant team, two major types of power are introduced: positional or episodic power and rhetorical power. This differentiation is adopted consequently for the case of

Flyvbjerg (1998), p. 226.

Ibid, p. 5.

See Flyvbjerg (1998), p. 227. See also Cooper and Burrell who argue, "Power precedes the answer through its subtle and covert prior structuring of the problem”. Cooper/Burrell (1988), p. 102.

See, e.g., Clegg (1989a), p. 153; Clegg (2001), p. 134.

Phillips (2003), p. 226; see also Hardy/Phillips (2004), p. 304.

See Clegg (1989a), pp. 181; Clegg (1989b), p. 109. Lawrence et al. argue that research needs to concentrate stronger on the study of power relations between multiple agents, e.g., coalitions or communities of agents. See Lawrence et al. (2001), p. 641.

Fairclough (1992), p. 58.

Ibid, p. 58.

Fox (2000), p. 863.

See Clegg (1989a), pp. 197-199; Clegg (1989b), p. 106; Phillips/Brown (1993), p. 1572 and the discussion in chapter D.III.2.6.
} 
client-consultant relationships. ${ }^{1687}$ This is necessary because, as Fiol suggests, "to understand the meaning of power in a given organizational context, we must be sensitive to the multiple dimensions of power and to the institutional rules that govern how power is played out in that context". ${ }^{1688}$

\section{Types of power}

\subsection{Positional power}

To the extent that power remains episodic, it can be analyzed "in terms of a modified version of the classical frameworks of an A getting B to do something that B would not otherwise have done". ${ }^{1689}$ Positional or episodic power is embedded in existing power relations and is based on resources. It is "power over" 1690 initiated by self-interested actors, ${ }^{1691}$ and it causes individuals to act, or prevents them from acting, by direct restraint or by influence over the conditions under which they make their decisions. ${ }^{1692}$ It is given and stable at a particular point of time. This is a very economical type of power as there is no need to struggle against relations of meaning or membership, or to institutionalize new discourses and interpretations. This power can efficiently deploy existing resources. Resistance, if it too remains episodic, will be overwhelmed. ${ }^{1693}$

In general, there are two sub-types of positional power: force and manipulation. Whereas force is the use of negative physical sanctions to prevent the actions of individuals and is based on resources such as weapons and prisons, manipulation includes the use of both positive and negative sanctions of various kinds. ${ }^{1694}$ Somech and Drach-Zahavy suggest that there are three general types of resources that are the basis of manipulation, i.e. they can be used by actors to influence the rational choices of others ensuring a particular behavior. ${ }^{1695}$ Accordingly, three types of manipulative power can be differentiated: (1) coercive power and its opposite (2) reward power-the power to punish/prevent or to reward actors for undesirable/desirable outcomes based on such things as money, credit, access to employment or projects, etc., which is also referred to as economic power; ${ }^{1696}$ (3) legitimate power-power grounded in the hierarchical position of individuals. In organizations, episodic power usually derives from the opportunities inherent in a person's position.

Clegg's concept of circuits of power is modified and used as the foundation for the following discussion. See Clegg (1989a), pp. 187.

1688 Fiol (1991), p. 550.

1689 Clegg (1989a), p. 18.

1690 Clegg (1989a), p. 215.

See Lawrence et al. (2005), p. 182. This type of power has been the traditional focus of organizational research and theory. See also the discussion in chapter B.II.4.3.3. 
Positional power automatically reproduces existing configurations of resources, rules, and domination, as there is no challenge to existing interpretations. The legitimacy of the resources it is based upon is sustained and institutionalized through the everyday action of relevant actors. In other words, positional power is grounded in resource control through agents (which can also include the control of decision-making processes), ${ }^{1697}$ whereas the nature of these resources is determined by existing relations and discourses between agents. Positional power is, therefore, similar to the notion of favorable "subject positions" as introduced by critical discourse analysis. ${ }^{1698}$ Subject positions imply that "some individuals, by virtue of their position in the discourse, will warrant a louder voice than others, while others may warrant no voice at all". ${ }^{1699}$ This also implies that agents with positional power are able to influence the discourses that stabilize their position as "nodal points" within particular communities or discourses. In other words, they might be in a favorable position to access and influence discourses-through planning and setting the presence of other participants, control over modes of participation, turn-taking, agenda, topics or style ${ }^{1700}$ —and to develop rhetorical power. At the same time, agents without positional power might be "silenced" 1701 so that they might have less chance to engage in processes of rhetorical power.

While episodic power may tell one something about the nature of power relations between $\mathrm{A}$ and $\mathrm{B}$, it cannot tell anything about the "constitutive nature of the relational field in which A and B presently are nor how this privileges and handicaps them respectively, in relation to those resources that are constituted as powerful". ${ }^{1702}$ In other words, if A's power is greater than B's power, on what basis are their respective powers fixed? Moreover, how is this fixation being achieved, through what moves have certain positions and discourses been fixed as powerful and dominant? In addition, how is change happening in these fixed discourses? Moreover, whereas positional power addresses the contextual, interactional, and organizational forms of control, it does not discuss the micro-level forms of power. ${ }^{1703}$ The answers to these issues can be found in the discussion of rhetorical power. ${ }^{1704}$

\subsection{Rhetorical power}

Rhetorical power is not predetermined by the possession or control of resources but emerges during agents' interactions. It "operates through the offering and acceptance of reasons for acting in one way rather than another". ${ }^{1705}$ For example, in advertising agencies power resides not in the possession of raw information about consumers and

1697

See Hardy/Leiba-O’Sullivan (1998), pp. 453-454.

See, e.g., Hardy/Phillips (2004), p. 306; Phillips (2003), p. 225. Subject positions are locations within the social space from which certain agents can produce certain kinds of "texts", i.e. interpretations, in certain ways.

Hardy/Phillips (1999), p. 4, cited in Phillips (2003), p. 225; see also Acroyd (2000), p. 103.

See van Dijk (1993), p. 256.

See Brown/Coupland (2005), pp. 1049; Newton (1996), pp. 725-727; Phillips (2003), p. 228.

Clegg (1989a), p. 209.

See van Dijk (1993), pp. 250-251.

See Sillince (2000), pp. 1131. Hardy and Leiba-O’Sullivan talk about the power to manage "the meanings that shape others' lives”. Hardy/Leiba-O’Sullivan (1998), p. 460.

Scott (2001), p. 13. 
brands, but in "the way in which the meaning of that information is presented, understood and interpreted for the client.”1706

In it simplest form, it rests upon a person's personality and attractiveness to others, i.e. in their charisma. ${ }^{1707}$ This type of power works independent of any arguments or discussions. However, rhetorical power is rarely the mere result of charisma. More often, it is the outcome of negotiations and translations of meanings and results in "interpretive dominance". ${ }^{1708}$ In this process, “intrinsically appropriate reasons for action" are constructed and offered to others so that a particular course of action or decision comes to be seen as cognitively, morally, or emotionally appropriate. ${ }^{1709}$ Such a persuasive influence does not depend on rational calculation but on arguments, appeals, and reasons that cause individuals to believe that a particular decision or action is more appropriate than another. ${ }^{1710}$ Persuasion can operate through cognitive symbols-ideas and representations that lead people to define situations in certain ways. This type of rhetorical power is also referred to as expert power-it arises from the attribution of expertise or knowledge to the influencing agent. ${ }^{1711}$ In other words, expertise is a form of persuasive influence, which draws individuals into a particular interpretive framework. ${ }^{1712}$ Rhetorical power can also operate through the building of value commitments to particular ideas or conditions. In such cases, individuals "defer to the views of those whom they regard as especially fitted to speak on behalf of these values", and so they build up commitment to these agents. ${ }^{1713}$ This type of rhetorical power is also called referent power-it arises when other actors identify themselves with the influencing actor. ${ }^{1714}$ Therefore, rhetorical power does not imply the mere rhetorical superiority based only on a person's charisma but also the power originating in cognitive symbols and arguments, as well as in value commitments. ${ }^{1715}$

Because rhetorical power is grounded in existing practices, negotiations, and translations of meanings, it is diffused throughout the social systems. ${ }^{1716}$ Similarly, in an organization, rhetorical power is distributed among many actors; no single actor is able to determine completely a dominant set of meanings. ${ }^{1717}$ In other words, rhetorical power is never in the possession of a single actor. Instead, it is exercised by a number of actors and groups of actors. As a result, rhetorical power is never complete, leaving space for

Malefyt (2003), p. 153.

See Scott (2001), p. 13. Charisma is a biological source of power. See also Scott (2001), pp. 148-154.

See Meindl et al. (1994), p. 291.

Scott (2001), p. 13. This type of power is also called “symbolic”, “cultural” or "normative” power. See Scott (2001), p. 25.

See Scott (2001), p. 14. Kirsch speaks in this case about the "secondary knowledge” of individuals. See Kirsch (1997), pp. 352-354. Translation through the author.

See Somech/Drach-Zahavy (2002), pp. 168-170. Van Dijk calls it “cognitive” power, whereas Scott speaks about “signification”. See van Dijk (1993), p. 254; Scott (2001), p. 15.

See Scott (2001), p. 23.

Ibid, p. 15.

See Somech/Drach-Zahavy (2002), pp. 168-170; Scott (2001), p. 15.

In practice, it is difficult to differentiate clearly between these subtypes of rhetorical power as they are more often than not interwoven in some way or another. See also Alvesson (2001), p. 871; Scott (2001), p. 30.

See Clegg (1989a), pp. 182; Scott (2001), pp. 13-15.

See Hardy/Phillips (2004), p. 307.
} 
resistance through the production of counter meanings and interpretations. ${ }^{1718}$ Thus, rhetorical power can lead to the disturbance of existing interpretations and practices and can introduce new ones.

It is important to point out that autonomous actors do not autonomously develop and hold rhetorical power; rather, existing practices and discourses work to advantage particular groups of actors, often without those groups being clearly connected to the establishment or maintenance of discourses and practices. ${ }^{1719}$ This is a view of power that examines "how the field of force in which power is arranged has been fixed, coupled and constituted in such a way that, intentionally or not, certain 'nodal points' of practice are privileged in this unstable and shifting terrain". ${ }^{1720}$ Such forms of power "tend to work in an ongoing, prosaic fashion, and they often do not appear to be forms of power". ${ }^{1721}$ This makes the development of rhetorical power an important strategic option for agents who try to establish a particular interpretation or discourse without being necessarily associated with that discourse on an ongoing basis. In other words, actors have the ability to legitimate and institutionalize particular meanings through their engagement in discourses and negotiations of meaning. ${ }^{1722}$ This ability is the result of micro processes of power development, which are best described through the concept of "interpretive dominance", i.e. the dominance of a particular interpretation that prevents the development of competing interpretations. ${ }^{1723}$ The concept of interpretive dominance implies that an individual or a group of individuals is able to persuade others that their perspective is the "right" one for the specific situation. In line with this Bryson argues, "success or failure [of client-consultant interaction] will not be related to the quality of expertise, but the way it is articulated by the consultants, and by the client". ${ }^{1724}$ The concept of interpretive dominance helps, as such, to explain the micro processes through which new discourses are created and dispersed, originally among groups of actors and, subsequently, in organizations and industries until they become broadly institutionalized.

As above stated, rhetorical power can lead to the fixation or transformation of existing meanings and discourses, in other words, to the reconfiguration of resources and the relations in which actors are embedded. In this case, episodic power relations are reinforced rather than radically changed. As such, it can be argued that rhetorical power can serve the institutionalization of domination. ${ }^{1725}$ However, rhetorical power can introduce, in addition, "uncertainty and dynamism in existing power relations by offering opportunities for empowerment and disempowerment, through the development of techniques of production and discipline”. ${ }^{1726}$ As such, it can undermine established

Ibid, p. 307.

See, e.g., Lawrence et al. (2005), p. 182.

Clegg (1989a), p. 17.

Lawrence et al. (2005), p. 630; see also Covaleski et al. (1998), pp. 295-230.

See, e.g., Sillince (2000), pp. 1133.

See Meindl et al. (1994), p. 291 and section D.IV.6 for a detailed discussion of interpretive dominance.

Bryson (1997), p. 103.

Clegg stresses that the term domination is derived from Weber's (1978) discussion of power (Macht) and authority (Herrschaft). See Clegg (1989a), p. 213-214.

Clegg (1989a), p. 236.
} 
configurations of episodic power when seeking to create new discourses and practices. In this case, episodic power can be radically changed and transformed as a result of rhetorical power. Newton supports this argument when stating that the location in an organizational hierarchy as an important source of power, i.e. episodic power, is "not some fixed entity, independent from other networks or from management and social science discourses". ${ }^{1727}$ At the same time, if the new discourses and interpretations are to be retained, they have to become institutionalized in fixed rules and resources; in other words, the effects of rhetorical power have to be institutionalized in new relations of episodic power. ${ }^{1728}$ The institutionalization of the effects of rhetorical power is not an automatic process, however. Agents have to be able to build alliances and networks in order to introduce or participate in these power processes.

Both endogenous and exogenous processes can facilitate the emergence of rhetorical power. ${ }^{1729}$ Endogenous change is the result of episodic power used to either transform the rules that fix discourses and interpretations or to enhance the development of new discourses and practices. Mumby and Clair argue, for example, "the most effective use of power occurs when those with power are able to get those without power to interpret the world from the former's point of view". ${ }^{1730}$ Exogenous change is the result of environmental influences, which can interrupt and disturb fixed rules and discourses. Such disturbances in the discourses of a particular interpretive community can occur as a result of interactions with different interpretive communities, especially when they are characterized by highly contradictory meanings and interpretations. ${ }^{1731}$

In the following chapter, the concept of episodic and rhetorical power is applied to the case of client-consultant teams. In this way, the concept is given "flesh and blood", and at the same time, the power relations within the client-consultant team are put into the above presented theoretical framework.

\section{Power within the client-consultant team}

In order to analyze the nature of power within client-consultant teams, it is necessary to look first at the specifics of the consulting project as an organizational form. As consulting projects occur outside the formal structures of organizations, they are, by definition, not wholly contained within corporate hierarchies. ${ }^{1732}$ However, projects still have a strong hierarchical dimension, as discussed in chapter B.II.4, which results in a number of cooperation barriers. ${ }^{1733}$ The actors with the most potential to influence the work of the client-consultant team due to their position in their companies are the

\footnotetext{
1727 Newton (1996), p. 726.

1728 See Clegg (1989a), p. 236.

1729 See Clegg (1989a), pp. 224-225.

1730 Mumby/Clair (1997), p. 184.

1731 See Gray et al. (1985). This would imply that the interaction with “dissenting” and "orthogonal” interpretive communities can be the source for exogeneous change in a particular interpretive community or discourse. See Bloor/Dawson (1994), pp. 283-292; Martin/Siehl (1983), pp. 52; Rose (1988), pp. 161-166 and the discussion in D.III.2.3. 
sponsor of the project and the consulting partner who bears the final responsibility for client service. Both of them have positional power. The potential power of the consulting partner originates in his/her hierarchical position within the consulting company in general and the client-consultant team in particular, which gives him/her the opportunity to influence the work of the other consultants. In contrast, the power of the sponsor to influence the client-consultant team is based also on his/her status-hierarchy and, additionally, on his/her role in choosing and evaluating the consultants, i.e. in his/her economic power. In reality, the sponsor often delegates part of his/her responsibility to the client project manager. Thus, the client project manager also has positional power. "The degree of perceived proximity of the project with the centre of the organization, the more or less innovative or strategic character of the project and the degree of control it is under, even the person behind the idea that drives the project [] all these will have an impact on the intensity and nature of authority of the project leader". ${ }^{1734}$ Therefore, the positional power of the project manager empowers him/her to decide upon deadlines, the use of resources, the selection, and removing of members of the client team as well as the selection and evaluation of consultants. ${ }^{1735}$

Additionally, the client project manager, as well as the sponsor, can also use their positional power to influence the problem-solving process in a desired direction. They can either influence directly the problem-solving process by restricting the solution alternatives that are discussed, or indirectly by organizing the discussion, allowing or prohibiting specific speech acts, monitoring the agenda, setting and changing topics, and removing/transferring members of the team that would oppose their view. ${ }^{1736}$ Such a strategy can move the client-consultant team toward uniformity by providing them with a predetermined course of action. Because of the power of the project sponsor or project manager, i.e. the power to select and evaluate consultants and to define the problem area, consultants will also follow clients' directions, and will offer solutions preferred by the client project or top managers. For example, when client managers want to introduce unpopular solutions within the organization they can use consultants and let them advise that a specific solution is necessary. In this way, client managers can keep their reputation. ${ }^{1737}$ In addition, client managers can have a clear expectation regarding the preferred problem solution, especially if they believe that the problem at hand is familiar and routine. ${ }^{1738}$ In such cases, they employ consultants only because they do not have enough in-house resources to generate the particular outcome. In both these cases, no knowledge transfer takes place. Only positional power is at work, as there is no struggle against relations of meaning, nor are new discourses and interpretations provided. "It is power which can efficiently deploy given capacities". ${ }^{1739}$ Practically, this would mean that no real interaction takes place between clients and consultants and that consultants

Clegg/Courpasson (2004), p. 527.

See also Iding (2000), p. 92.

Lawrence et al. speak in this case about “force”. See Lawrence et al. (2005), pp. 182-186. See also van Dijk (1993), pp. 255-256.

Such cases have been reported in the literature on consulting. See, e.g., Alvesson/Johansson (2002), p. 237; Jackall (1988), p. 140; Kieser (2002b), p. 214.

See also Quinn et al. (1996), p. 79.

Clegg (1989a), p. 18. 
are simply used to introduce unpopular solutions or to fill resource gaps in client organizations. Keegan and Turner support this by showing empirically that highly centralized projects do not promote learning. ${ }^{1740}$ As Freidson puts it, if the project sponsor or the client project manager is to decide on the problem solution, then consultants are no longer able to exercise the "authoritative discretion, guided by their independent perspective on what work is appropriate []. They become mere servants in a cafeteria, doing whatever is demanded of them and seeking above all to please”. ${ }^{1741}$

If the client is interested in a truly cooperative work with the consultants then it makes little sense for both the sponsor and the client project manager to influence directly the problem-solving process. First, the sponsor "is rarely directly involved in knowledge of or care about the problem that needs investigation" ${ }^{1742}$ and is thus not in a position to decide upon the best possible problem solution. Second, whereas the positional power of the client project manager is based on the legitimacy of rules and routines, project authority typically requires creativity and open communication in the accomplishment of the objectives. ${ }^{1743}$ The client project manager can express, of course, what solution s/he wishes, such as a cost reduction of $10 \%$ or quality improvements in a specific number of processes. However, the means of achieving these project goals are often not trivial, leaving the client manager unable to dictate how these results are to be achieved. Dominance in the client-consultant team is, accordingly, not so much located in the legitimated hierarchical position of the project manager or in the economic power of the sponsor but rather in the discourses within the client-consultant team-in particular between the problem owners and the consultants-about the best problem solution, i.e., in rhetorical power. ${ }^{1744}$ In other words, cooperative client-consultant teams are structures in which the positional power of an actor based on hierarchy, rules, and other resources is less important than the power emerging out of interactions and the management of contradictions. $^{1745}$ For example, in advertising agencies, power resides not in the possession of raw information about consumers and brands, but in "the way in which the meaning of that information is presented, understood, and interpreted for the client". ${ }^{1746}$ The use of rhetorical rather than positional power can also enhance the implementation of a suggested problem solution as it causes the involved individuals to believe that a particular solution is better than another. ${ }^{1747}$ Rhetorical power works in a more subtle way than positional power. Often, actors might not even be aware of the exercise of rhetorical power: by being involved in the negotiation process, they can be slowly "enrolled" into a

\footnotetext{
1740 See Keegan/Turner (2001).

1741 Fredson (1994), p. 211.

1742 Garratt (1981), p. 97.

1743 See Clegg/Courpasson (2004), p. 527; Iding (2000), p. 92.

1744 Similarly, Boland and Tenkasi argue, "the vertical authority structure plays a muted role while the principle value adding activities of knowledge creation and knowledge application are carried out [by the project team]”. Boland/Tenkasi (1995), p. 366; see also Quinn et al. (1996), p. 78. 
particular perspective. ${ }^{1748}$ Thus, when there is no awareness of this process, there will be no resistance.

It is clear, however, that certain individuals with positional power might have a better chance of developing rhetorical power and persuading the rest of the team that a particular solution is the best available. ${ }^{1749}$ Additionally, it is possible that actors who posses strong charisma and are rhetorically elaborated are also in advantage when considering who can develop rhetorical power. This argument is strongly supported within the critical model of consulting, which points out that consultants' influence during consulting projects is due to their charisma and rhetorical skills. On this basis, consultants are able to sell their services even if they do not have real value for their clients. ${ }^{1750}$ This is the case particularly in regard to management gurus. ${ }^{1751}$ The discussion of power within the interpretive model emphasizes, in contrast, that in reality it is difficult to differentiate clearly between different sources of rhetorical power. Rhetorical power can be based on the charisma of particular consultants but it is also based in the ability of consultants (and clients) to present "good" arguments for their perspective and to persuade others in their value for problem-solving. This ability depends on the existing practices and interpretations in the field of management knowledge, and on the ability of clients to relate their arguments to these practices. Additionally, in client-consultant teams, consultants often build rhetorical power by referring to their expertise. In other words, clients accept consultant's dominance because they regard them as especially fitted to speak and act in regard to particular problem situations. ${ }^{1752}$ Thus, it is important for clients and consultants to be aware of the different power dynamics within clientconsultant teams and the way different power types influence problem-solving.

Whether rhetorical power is used to reestablish and confirm existing interpretations or to introduce new perspectives depends, inter alia, upon the ability of the involved actors to build alliances for their perspectives and upon the composition of the clientconsultant team. High degrees of isomorphism across the involved agents-either individuals or interpretive communities-will produce stability and will reinforce the hegemony of the existing discourses and practices. Plurality of meanings will lead, on the other hand, to competitive bases of legitimation giving rise to differential capacities and discourses. ${ }^{1753}$ Generally, however, because "prevailing discourses are experienced as reality, alternative discourses are difficult to conceive of, let alone enact. [] More common are attempts to refute, challenge, modify, or amend existing discourses". ${ }^{1754}$ Thus, as the above analysis shows, consulting projects provide potentially fruitful avenues for understanding how the different types of power are set in motion through

This process is discussed extensively in next chapter.

Kirsch argues as well that the positioning af an actor in the relevant field of action or decision-making influences its rhetorical power. See Kirsch (1997), p. 353.

See Clark/Salaman (1998a), p. 149; Jackson (2001), p. 32. The claim that consultants' influence often originates in their charisma and rhetorical elaboration results in the view of consultants as impression managers. See also Scott (2001), p. 150.

See Jackson (2001), pp. 31-36 and the discussion in chapter C.IV.

Scott (2001), p. 15.

See Clegg (1989a), p. 237.

Hardy/Leiba-O’Sullivan (1998), p. 460.
} 
specific episodes of action and interaction. In particular, such projects offer opportunities to discuss the transformative effect of power where the often taken for granted interpretations and power discourses are disrupted, and established patterns are challenged and potentially transformed. ${ }^{1755}$

The proposed approach to power solves the problem of ambivalence within the expert and critical model regarding the direction of power in client-consultant teams. It shows that client managers may often have positional or episodic power. However, if it is acknowledged that both the "problem owners" and the consultants possess valuable knowledge, which requires that they engage in a cooperative teamwork, the power that is more relevant for the problem-solving process is rhetorical power. Moreover, different actors can be more or less successful in applying rhetorical power, which implies no unidirectional power dependency. The previous discussion makes it further clear that the shortcomings of the expert and the critical model regarding their discussion of the direction and role of power within client-consultant teams can be traced back to two main areas. First, to the lack of differentiation between all involved individuals in consulting projects, and second, to the models' view of consulting projects as non-cooperative interactions. This results in the models' ignorance of the importance of client's knowledge and of the ability of clients to utilize this knowledge in negotiations and discourses. Figure 17 summarizes the previous arguments.

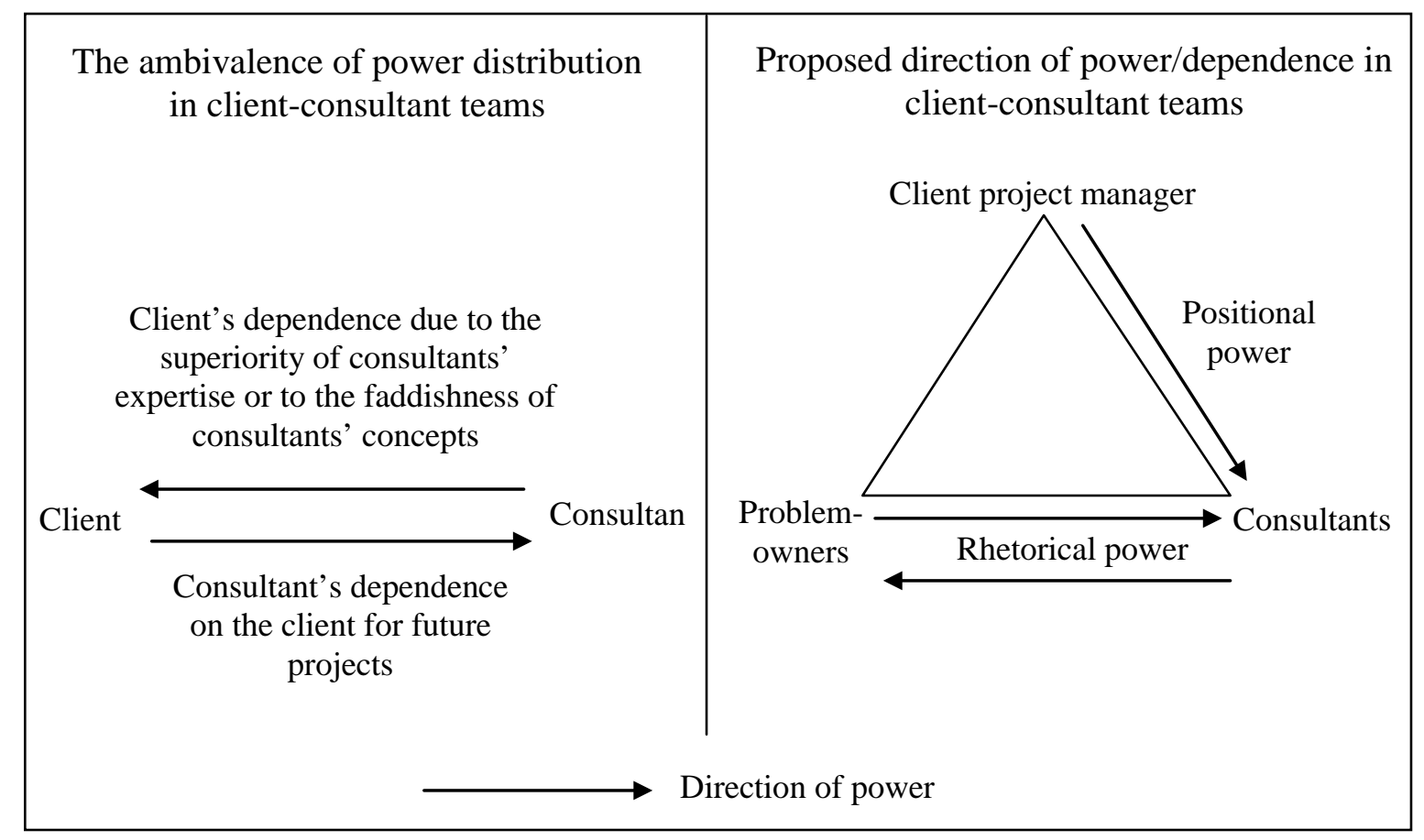

Figure 17: Power/dependence in the client-consultant relationship ${ }^{1756}$

Client project managers may exercise, of course, rhetorical rather than episodic power towards both consultants and problem-owners. This would imply, however, that client project managers are actively involved in the daily work of the client-consultant team. As previously suggested, this is often not the case because the role of the client project manager is to coordinate deadlines and budgets rather than to be actively involved in the problem-solving process. The aim of this discussion and figure is to establish what is believed to be the most critical links between power and client-consultant interaction. It does not suggest that in examining the nature of power in client-consultant teams one will only find the here stated forms of power and actors. For example, the project manager from the consulting side might be, in some projects, also a powerful actor who can influence the outcome of consulting projects. The point here is, therefore, that the 
In order to understand the processes through which rhetorical power works, it is necessary to discuss how particular agents develop rhetorical power, which allows them to fix or transform interpretations. In other words, how discourses within the clientconsultant team are converted into rhetorical power, which results in interpretive dominance.

\section{Interpretive dominance}

\subsection{Callon's four moments of translation}

"The notion of interpretive dominance conceptualizes a belief system as an active arena, where interest groups [] compete to impose their preferred psychological order onto nonbelievers". ${ }^{1757}$ Similarly, Mumby and Clair argue that "[rhetorical] power is exercised through a set of interpretive frames”. ${ }^{1758}$ In order to illustrate how interpretive dominance evolves, it is helpful to use some of the arguments that a group of sociologists around Michel Callon and Bruno Latour developed under the name of "sociology of translation". ${ }^{1759}$ The approach seeks to demonstrate how actors constitute and reproduce networks of interests and dominance and "enroll" others into their conceptions and interpretations. It seeks to "map how agents actually 'translate' phenomena into resources, and resources into organization networks of control, alliance, coalition, antagonism, interest and structure". ${ }^{1760}$ Thus, "through carefully managing communication [] individuals and groups can legitimate their positions and institute a form of social control that removes the need to exercise control directly" ${ }^{1761}$ Translation is the process through which these outcomes are achieved. ${ }^{1762}$ Additionally, critical discourse analysis also offers some important insights on how actors engage in "discursive activity in attempts to secure advantage from particular subject positions or to silence other subjects”, ${ }^{1763}$ which are further utilized in the following discussion.

Next, the so-called four "moments of translation"1764 are introduced and used to explain how power emerges between interpretive communities within client-consultant

proposed connections represent the connections most likely to influence the outcome of consulting projects. See for a similar argumentation, Lawrence et al. (2005), p. 188.

Meindl et al. (1994), p. 291. Alfieri speaks about "interpretive authority” and discusses it for the case of lawyers-client relationships. See Alfieri (1994), p. 1758. Lawrence et al. discuss a somewhat similar concept, which they call influence. "Interpreting an idea so that it becomes accepted by others necessarily involves influence, whether on the part of the originator of the idea or some other actor who champions the idea”. See Lawrence et al. (2005), p. 185; also Lawrence et al. (2001), pp. 629-635. Their concept of influence is, however, too broad as they include in it episodic power, whereas interpretive dominance, as discussed here, is the result of rhetorical power only. The notion of interpretive dominance is, perhaps, closer to the notion of "hegemonic struggle” as suggested by Fairclough. See Fairclough (2005), p. 931 Mumby/Clair (1997), p. 184.

See Callon (1986a), pp. 196. This approach includes empirical studies conducted on the sociology of science. The approach is also known under the name "Actor Network Theory” (ANT). See, e.g., Callon (1986b); Callon/Latour (1981); Law (1994, 1999). It is beyond the scope of this work to discuss ANT and its advantages and disadvantages; rather some of its basic concepts are used to illustrate the emergence of interpretive dominance. See Callon (1986a,b); Callon/Latour $(1981)$ and Law $(1994,1999)$ for an extensive discussion of ANT.

Clegg (1989a), p. 204.

Phillips/Brown (1993), p. 1551, emphasis added.

See also Lindlof (1988), p. 102-103.

Hardy et al. (2000), p. 1234-1235.

See Callon (1986a), p. 203-221. 
teams. ${ }^{1765}$ The following discussion also shows how the different types of rhetorical power are combined in the pursuit of interpretive dominance. The four moments of translation are (1) problem formulation, (2) interéssement, (3) enrolment, and (4) mobilisation of allies.

\subsubsection{Problem formulation}

As discussed in section III.3.5 of this chapter, problem formulation takes place in the early stages of the interaction within the liminal space that consulting projects represent and is characterized by uncertainty over appropriate interpretations of the problem situation. It starts with misunderstandings, suspicion, and anxiety of disclosure and is only successful when members of the client-consultant team begin to act and interpret using some shared meanings that have developed within the team rather than their original interpretations. ${ }^{1766}$ This implies that some of the team members must change their initial perspectives. ${ }^{1767}$ How does this change happen?

At the foundation of such a change is the attempt by some actors to manage meanings. This involves the creation and presentation of particular artifacts or "texts", ${ }^{1768}$ such as conceptual models, narratives, and metaphors to the other actors. The goal is to associate the particular problem situation with the preferred concept and perspective of the first set of actors. ${ }^{1769}$ However, the first set of actors also needs to "engage" the other into this interpretation and discourse. This requires the suggested perspective to be embedded in a larger discursive context so that it would have some meaning for the individuals to whom it is directed, i.e. for the second set of actors. ${ }^{1770}$ This process has been called elsewhere "strategic fitting" ${ }^{1771}$ and encompasses the (intentional) tailoring and fitting of interpretations to the background and experiences of the other party. ${ }^{1772}$ Next, the first set of actors draw the others' attention to certain aspects of their own experience, accenting and highlighting some issues or aspects as being more salient than others. ${ }^{1773}$ In this way, they impose a pattern of meaning on otherwise ambiguous contexts. ${ }^{1774}$ This process of meaning construction involves the introduction of certain concepts and interpretations, the establishing of certain relationships between concepts,

Callon's research does not focus on client-consultant relationships. However, his concept is valid for the consulting industry as well, as argued by Bloomfield/Best (1992), pp. 538, Fox (2000), p. 864 and Newton (1996), pp. 717. Tichy also shows that change agents, such as consultants, directly influence key individuals in the client system in order to persuade them to implement their suggested solutions. See Tichy (1976), p. 963. See also Bloor/Dawson (1994) for a discussion of similar interaction processes between interpretive communities within one organization.

See Bettenhausen/Murnighan (1985), p. 356.

See Tindale et al. (1993), p. 470 ; also Mohammed/Ringseis (2001), pp. 316-317.

Within critical discourse analysis, the notion of text is rather broad including written documents, verbal reports, artwork, spoken words, pictures, symbols, buildings, and other artifacts. See, e.g., Fairclough (1992), p. 4; Phillips et al. (2004), p. 636.

Ibid, pp. 1233-1236.

See also Fairclough who uses the term "recontextualization”. Fairclough (2005), p. 932.

See Benford/Snow (2000), p. 627. Benford and Snow concentrate on the macro processes of interpretation construction but their analysis is also helpful when considering such micro processes.

Benford and Snow call this process "frame amplification”. See Benford/Snow (2000), p. 623. The role of experience for the evaluation of different solution paths was discussed in chapter D.III.3.5. 
imparting of values ${ }^{1775}$ as well as the use of particular language. ${ }^{1776}$ Whereas actors can use mere rhetoric based on inspirational appeals and emotional requests that can arouse enthusiasm by appealing on the other's values and ideals, rational persuasions based on the use of logical arguments and factual evidence are the prevalent influence tactics at this stage. ${ }^{1777}$ Charisma, if used, can only strengthen the power of actors’ influence.

If the first set of actors are successful in this process, they can establish themselves as so-called "obligatory passage points" ${ }^{1778}$ or "necessary nodal points", ${ }^{1779}$ i.e., as agents for indispensable "conduit” practices for others' problems. ${ }^{1780}$ Such “obligatory passage points" are pivotal points within discourses and represent "fixed" knowledge domains or practices that are regarded as the rule or normal practices. Thus, "problematization seeks to construct 'hegemony' by fixing [obligatory passage points]”. ${ }^{1781}$

It is important to note that sometimes actors engage in such processes unintentionally. ${ }^{1782}$ In other words, they might try to impose their interpretation of a problem or an issue, and translate it in a way that positions them as "obligatory passage points”, because they are part of existing discourses and practices, which influence what they see and how they interpret what they see. Thus, it is stressed here that interpretive dominance is often the result of much subtler processes, which is why actors are often not aware that power is present in their actions and interactions and that they reinforce existing structures, relations and practices, and as such, existing power relations.

Bloomfield and Best offer an interesting illustration how the process of problematization works in the context of client-consultant teams. They show that IT consultants use managerial discourse to establish themselves, i.e., their knowledge and practices, as an "obligatory passage point" in the eyes of their clients and how they reinforce their perspective on a situation or a problem as the "right one". ${ }^{1783}$ The whole process builds upon consultants' claims that they possess the expertise and experience to solve particular problems. Thus, through discursive moves, consultants challenge client's definition of a problem and translate it by appealing on their knowledge and experience of similar situations. In such a way, they attempt to forge "an indissoluble association between their knowledge claims and their presumed status as [] experts". ${ }^{1784}$ Therefore, consultants are often in a better position to promote their interpretation of the problem

1775

See Gray et al. (1985), p. 89. Benford and Snow speak in this case about “frame articulation”. See Benford/Snow (2000), p. 623. See also the discussion on meaning in chapterD.III.1.2.2.

See Lawrence et al. (2005), p. 184.

See Yukl/Falbe (1990), pp. 132-133.

See Callon (1986a), pp. 204-206.

See Clegg (1989b), p. 106. “Nodal discourse” is another term. Fairclough (2005), p. 933.

See Clegg (1989a), pp. 225.

Clegg (1989a), p. 204.

See van Dijk (1993), p. 262.

See Bloomfield/Best (1992), p. 544. See also Zelizer who provides a very interesting account of how journalists establish themselves as "obligatory passage points" or what she calls "interpretive authorities" for past and present events. See Zelizer (1993).

Marshall/Rollinson (2004), p. S81. 
situation due to their status as experts, which gives them positional power within the client-consultant team. ${ }^{1785}$

Consultants' protected and profitable position as experts, which often gave them prevalence in client-consultant relationships, was not (widely) questioned as long as the view of consultants as experts akin to the expert model was the dominant discourse in the field of management knowledge and practice. In other words, the traditional discourse of consultants as experts provided the source for and reinforced their power position within client-consultant teams. However, with increased clients' dissatisfaction with the services of consultants, the new, critical discourse emerged within the field of management knowledge and practice, which is represented by the critical model of consulting. As a result of this discourse, the status of the consultants as experts was shaken. This discourse increased clients' awareness of the rhetorical power of consultants but it did not provide them with real options for counter actions, as in the view of the supporters of the critical model, clients cannot escape consultants' dominance. In contrast, the interpretive model is based in a different form of discourse, a discourse that emphasizes the need for clients to scrutinize consultants' expertise and opens the possibility for clients to question consultants' interpretations of problem situations and to try to endorse their own perspectives. This is a discourse that views the process of meaning construction during the problem formulation phase in consulting projects is a contested process, a view, which is becoming more popular both in the research and in the practice community. ${ }^{1786}$ Accordingly, it is argued that all involved actors engage to some extent in translation and signification. Members of the client team can resist the interpretation of the problem that has been proposed by consultants. They can seek to establish their knowledge area as the “obligatory passage point” for the discussed problem situation by engaging in so-called "counterframing”: attempts to undermine or neutralize consultants' version of the problem and interpretive framework. ${ }^{1787}$ Expertise is, therefore, not a stable and uncontested resource as argued by the expert model. Rather, it is always "in the making" within specific discourses between interpretive communities; it is "provisional, negotiated and emergent”. ${ }^{1788}$ The character of expertise as a latent capacity or resource is only present to the extent that it is enacted as such, and Callon's four steps of translation describe this process of enactment.

That problem formulation can be a contested process has a second important implication: only when some counterframing takes place there is a chance for the clientconsultant team to break out of standard, established interpretations and views and to develop a novel understanding. However, this can be difficult because actors would have to undo first all already existent interpretations by mobilizing and enrolling new alliances

See the discussion under D.IV.4 where expertise was suggested as one of the sources of positional power.

Accounts of this view have been suggested by a number of researchers. See, e.g., Sturdy (1997a, b). Nevertheless, empirical studies of client-consultant relationships still show that in many cases consultants are still the dominant actor. See, e.g., Bloomfield/Best (1992); Fox (2000); Newton (1996).

Benford/Snow (2000), p. 626. 
with other actors. ${ }^{1789}$ In such situations, the next three steps of the "translating” process become even more important.

\subsubsection{Interéssement}

In the second step of the translation process, the actors who have established their expertise as the pivotal point of the interaction lock the other actors into the role or identity they have defined for them by building an interpretation or a story that attempts to interrupt all potential competing interpretations. One of the goals of this step is, therefore, to prevent actors from taking or expressing preferences for a different interpretation of the problem than the one suggested. For example, if consultants have established their interpretations of the problem situation as the central discourse within the client-consultant team, they will now seek to persuade clients to "take" their interpretation with the help of arguments, stories and other rhetorical methods. In other words, in this phase, actors use rhetorical strategies to influence the construction of cognitive maps on the part of the others. Alfieri suggests that in lawyer-client relationships, “it is the lawyer's construction of a client's identity, of her story, and finally, of the law, that predominates". ${ }^{1790}$ He further adds, "lawyers' exertion of what they perceive to be necessary authority subordinates clients by erasing their identities, silencing their narratives, and suppressing their histories”. ${ }^{1791}$ Actors' rhetoric in this phase often utilizes emotional aspects by stressing that the suggested interpretation leads to a positive future to which the others are attracted and related to, implying that this particular interpretation will take them closer to a desired perspective and action. ${ }^{1792}$ Thus, in this phase, the use of symbolic and emotional appeals and possibly charisma is more prevalent than in the first phase.

A successful "intéressement" results in the emergence of "shared" understandings between some of the involved individuals. It confirms the validity of the problem formulation and the proposed role for the involved actors, and is followed by enrolment of actors into coalitions and alliances. "Intéressement achieves enrolment if it is successful". ${ }^{1793}$ However, if it is unsuccessful, actors will be no longer able to communicate with each other effectively. Callon suggests that in such cases, "through a process of disalignment they reconfigure themselves in separate spaces with no common measure." ${ }^{1794}$ In other words, the interaction process will not lead to an agreement and shared understanding of the action to be taken. For the context of client-consultant projects, this would imply that the project will not lead to a problem solution that is shared by the involved individuals.

Alfieri (1994), p. 1759, emphasis in the original. See also Sturdy et al. (2004), pp. 338-339. Phillips and Brown discuss in detail how companies use advertising campaigns to shape the understandings of the public. See Phillips/Brown (1993), pp. 1555. 


\subsubsection{Enrolment}

Enrolment is a process of multilateral negotiations between actors during which the identity of the actors is determined and tested. In this phase, actors seek to build alliances and coalitions between the members of the client-consultant team and the meanings and interpretations, which they have sought to fix. ${ }^{1795}$ The goal is to "enact" what started as a discourse - the transformation of the proposed interpretation into new ways of acting and interacting, into new ways of being and new identities, and finally in the materialization of the suggested interpretation, which can take form of, for example, new structures, layouts, rules, strategies, practices, etc. ${ }^{1796}$ The result of this process is the "disciplining or maintaining the proposed translation in order to stabilize a powerful network". ${ }^{1797}$ All types of rhetorical power can be appropriated in this phase.

Going back to the client-consultant example, enrolment implies that consultants start to "build [an informal] coalition" with the members of the client team who they have persuaded in the value of their interpretation. This involves a transformation in the interpretations and behavior of these members of the client team: they begin to act and to identify with the proposed perspective on the problem and the problem solution and begin to work together with the consultants on the development of cultural artifacts, such as conceptual models, figures, presentations, etc. that explain and visualize the suggested problem solution. ${ }^{1798}$ At this stage, when the previous steps have been successful, consultants have achieved interpretive dominance within the client-consultant team. It is very important to secure in this phase the support of the client project manager as well as of some of the senior client managers. For this purpose, the members of the client team who joined the interpretive position of the consultants and the consultants themselves have to engage into a second stage of intéressement and enrolment involving some actors outside of the client-consultant team. Only when they succeed in enrolling this group of actors the proposed course of action will be carried out. ${ }^{1799}$ In other words, finding support for the implementation of a particular problem solution involves the use of rhetorical power in order to gain the support of actors with positional power. The combination of both positional and rhetoric power enables, ultimately, the implementation of the problem solution.

\subsubsection{Mobilisation of allies}

The last phase in the translation process is the "mobilisation of allies". ${ }^{1800}$ This phase refers to methods and actions that ensure that interpretations, which were fixed in the previous phases, are dispersed through further discourses. In other words, this phase does

\footnotetext{
1795 See Clegg (1989a), p. 205.

1796 See Fairclough (2005), p. 934.

1797 Star (1991), p. 32.

1798 See also Lawrence et al. (2005), p. 186. Elsewhere, this process has been called "acculturation", meaning that interpretations and practices of one community diffuse across the boundaries of another and subsequently alter the second community's interpretations and practices. Acculturation entails the transfer of behaviors and rituals, as well as linguistic change. See Barley et al. (1988), p. 27. 
not concentrate on the interaction process within the boundaries of a particular context or problem but on the actions of actors into the broader environment following this interaction process.

In the case of client-consultant projects, this phase can be interpreted as the phase that follows the end of consulting projects, when consultants promote the generated solutions and concepts in order to win future projects with the same or other clients as well as to ensure support for their future work in their own companies. Some of the actions that take place in this phase involve the storage of the project results in the databases of the consulting company, the presentation of the problem solution to actors not involved in the project, whereas these can be both members of the consulting company and outside actors, the publishing of articles and books, etc. ${ }^{1801}$ Clients as well can engage to some degree in disseminating of the results of concrete consulting projects.

Thus, in this phase, individual statements and practices are accumulated and they can start to influence the context for future discourse activities. The extent of their influence depends, thereby, on the innovativeness of the developed problem solution and on the support for its dissemination by powerful actors and groups. ${ }^{1802}$ In other words, as a result of such actions, prevailing discourses will be more or less "contested, displaced, transformed, modified or reinforced". ${ }^{1803}$ These existing discourses influence, at the same time, this process of dispersion of interpretations. The dispersion process is, therefore, unpredictable "since there are a number of contradictory ways in which knowledge can be consumed, some of which may be quite different from the intentions of the original producers". ${ }^{1804}$ This is particularly the case when other actors take and reinterpret the original interpretations and/or connect them in different ways than intended to existing discourses. Thus, a problem solution (or an artifact that represents it) generated within a particular consulting project can be adopted in a way that does not correspond with the underlying interpretation or knowledge, and this can diminish the value of the problem solution in the eyes of the adopters. Reihlen and Ringberg provide an example for this case. ${ }^{1805}$ They show that specific consulting methods and tools that are tailored to the needs of a particular client are often not adopted appropriately by consultants who did not participate in the projects in which they were created. These consultants most probably misunderstand and misuse the tools and methods because they use them in a way that is more appropriate with an interpretation or a knowledge base that they know. As a result, even if some of these tools and methods, and the underlying knowledge, might be quite valuable, they were not properly disseminated and used in the studied consulting company. ${ }^{1806}$ 


\subsection{The outcomes of interpretive dominance}

On the one hand, if the development of an interpretive dominance of a certain group of actors results in a problem solution that is based on existing interpretations and procedures, rhetorical power is at work aiming to further fix and endorse existing discourses. ${ }^{1807}$ In this case, the rest of the client-consultant team is "locked" into an established interpretation of the problem situation. Therefore, such power can prevent the creation of novel problem solutions. As above mentioned, in practice, consultants often seek to reinforce their position as an "obligatory passage point", which was "fixed" in previous projects, through the development and utilization of networks with other clients and external organizations. ${ }^{1808}$ The result is that with a growing dispersion of existing consulting practices the diversity of interpretations for a particular issue can decrease because members of client-consultant teams would be "disciplined" by the existing practices and discourses. ${ }^{1809}$ For example, Alfieri argues that "the interpretive, identitymaking acts of lawyers are based on a pre-understanding of dependency that operates to marginalize, subordinate, and discipline clients". ${ }^{1810}$

However, rhetorical power does not always have negative effects. For example, the existence of established meanings and interpretive positions could enhance the solution of problems that fall within the domain of existing knowledge positions and, hence, fasten the problem solution in an efficient way, which is what clients sometimes wish. ${ }^{1811}$ Therefore, rhetorical power can enhance the process of exploitation of existing interpretations and problem solutions. ${ }^{1812}$ In contrast, in the case of complex and innovative problems, where several interpretive views of a problem and problem solution might be legitimate because each of the involved interpretive communities sees different aspects of the problem and generates different solution paths, the involved individuals might not be able to agree on one. If the involved individuals are to follow a rational procedure for problem-solving based on rational argumentation, it is possible that they will continuously present new information and arguments, which can jeopardize the team's ability to generate a problem solution, especially within the usually tight time restrictions of consulting projects. ${ }^{1813}$ In other words, rational decision-making might not be a valuable alternative. ${ }^{1814}$ Thus, in order to overcome the ambiguity and uncertainty associated with pluralist interpretations, it will be necessary for one interpretive community to impose its interpretive dominance on others, especially in cases when teams face deadlines. ${ }^{1815}$ Otherwise, an agreement on collective action might not be possible.

\footnotetext{
1807 See Clegg (1989a), pp. 224-231.

1808 See Bloor/Dawson (1994), p. 291; Hislop et al. (2000), pp. 408-409.

1809 See Foucault (1977), pp. 135; also Lawrence et al. (2005), pp. 186; Lawrence et al. (2001), pp. 636.

1810 Alfieri (1994), p. 1758, emphasis added.

1811 See Creplet et al. (2001), p. 1518.

1812 See also Lawrence et al. (2005), p. 189.

The shortcomings of rational problem-solving procedures were already discussed in chapter D.IV.2.

See also Schräder (1995), pp. 43-44.

See also Lawrence et al. (2005), p. 186; Quinn et al. (1996), p. 79.
} 
On the other hand, if consultants' interpretive dominance is the result of innovative, knowledge creation processes that result in novel problem solutions, consultants can use their rhetorical power to translate the problem solution into an expertise for handling similar situations with other clients. In this way, consultants can disturb existing discourses and institutionalize new ones. ${ }^{1816}$ Through other projects and discourses, they can seek to achieve a partial fixing of the novel interpretation or problem solution. At the same time, they can try to ensure that clients themselves "promote" the problem solution. A wide dispersion of the novel interpretation can lead to the development of new practices and rules that can shape other actors' understanding and interpretations. The result is the emergence and institutionalization of new consulting concepts and models or "recipes in use", ${ }^{1817}$ which can over time develop into new management "fashions" if they are widely adopted. At this stage, these "new" discourses and practices will turn into established discourses and practices.

From this perspective, rhetorical power can have negative and positive effects. It can provide "the energy that fuels" decision-making in a pluralist environment. ${ }^{1818}$ Therefore, power in the interaction process is not a dysfunctional aspect that needs to be remedied. It is rather an intrinsic part of this process that should be appreciated and understood, as well as appropriately leveraged by clients and consultants. As Hardy puts it, "without it, we face strategic paralysis because we lack a mechanism with which to make change happen”. ${ }^{1819}$

\subsection{Interpretive dominance as a contested process}

The previous discussion showed that the dissemination of existing consulting concepts and models, or the development of new ones, is the result of discourses between different interpretive communities based on different perspectives or knowledge. Interpretive dominance in the client-consultant relationship arises out of a discourse over which perspective should be taken as a basis for the problem solution. As previously stated, the process whereby certain actors develop interpretive dominance is, however, not always successful. ${ }^{1820}$ In other words, it is a contested process. ${ }^{1821}$ For example, clients can decide not to follow the role proposed by consultants, thus choosing a different interpretation and rejecting their involvement in the problem solution process. Then a new phase of problem formulation and negotiation starts. There are also situations when the members of the client team might strive to gain interpretive dominance and lead the problem-solving process when they believe that their perspective is the "right" one. As Fincham points out, "in some instances there will be competition between managers and consultants, each side seeing the other as threatening rivals". ${ }^{1822}$ Pellegrinelli confirms this view by arguing that "consultants are influenced as well as influence during the 
course of an intervention, subtly being drawn into the webs of meaning and co-opted into prevailing discourses." 1823

Empirical results suggest that when clients face novel problems and new managerial discourses emerge, consultants usually have an interpretive dominance over clients. ${ }^{1824}$ However, after clients adopt the new discourse consultants no longer possess interpretive dominance and the role of positional power grows; the consultant's role changes to carrying out tasks that are defined tightly by the client. In line with this, Legge points out that it is more difficult for consultants to enforce their interpretation and solution if potential clients have familiar problems for which they require a known solution. ${ }^{1825}$ Having former consultants in clients' companies and/or managers with education from the leading business schools can also affect the relative interpretive rights of clients and consultants.

\subsection{A socio-cognitive model of the emergence of consulting "fads"}

The emergence and outcomes of interpretive dominance during the interaction of a group of actors from different interpretive communities can be summarized in Figure 18.

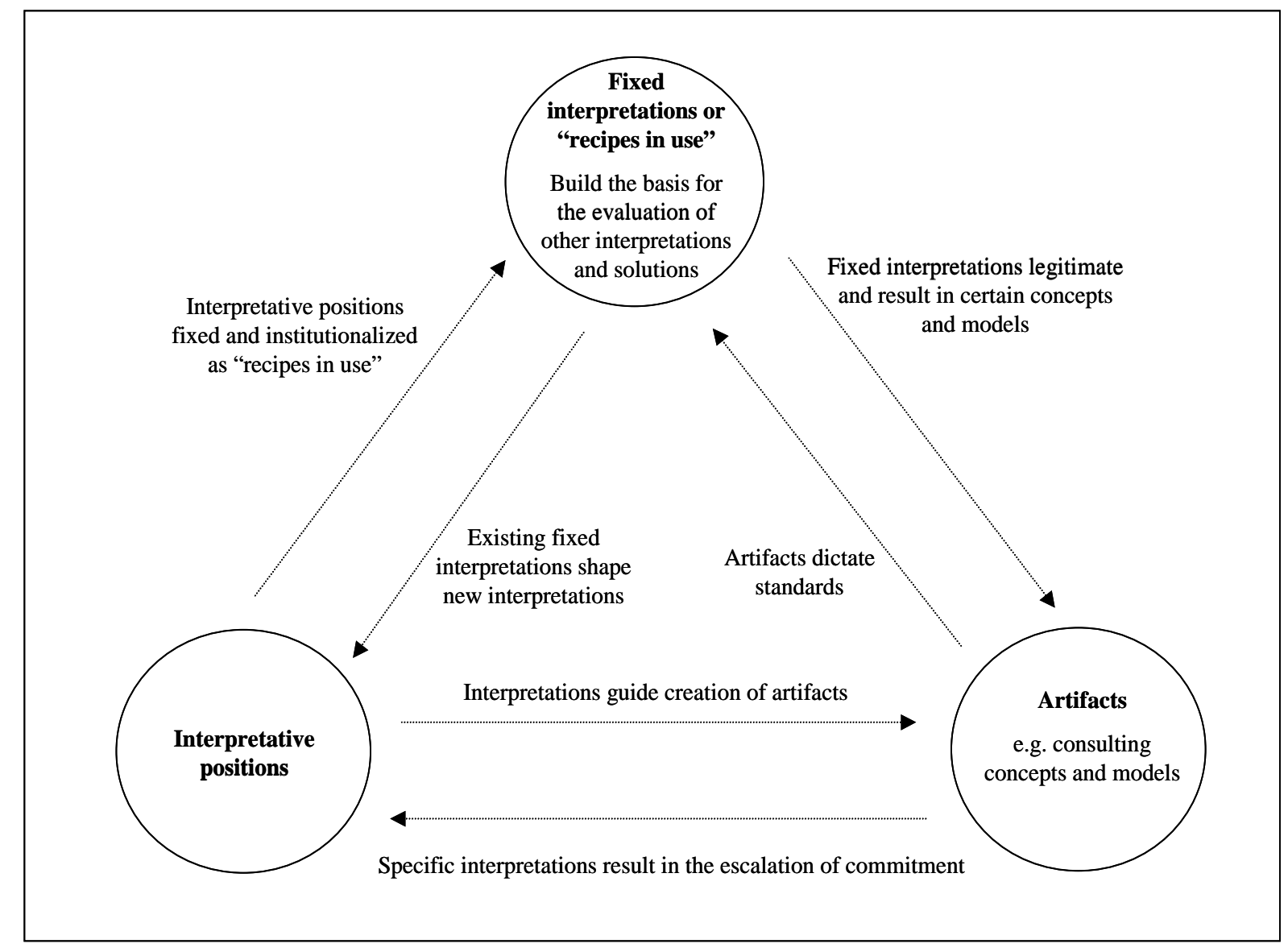

Figure 18: A socio-cognitive model of the emergence of consulting "fads" Source: Adapted from Garud/Rappa (1994), p. 346. 
Figure 18 shows that interpretive dominance creates the connection between interpretations, fixed interpretive positions, and consulting artifacts. It offers a micro, socio-cognitive view of the processes that lead to the emergence of management or consulting "fads". ${ }^{1826}$

The first reciprocal relation in the model is between interpretations and artifacts. Artifacts such as consulting concepts and models are the result of human cognitive processes; hence, they are influenced by actors' interpretations. At the same time, existing concepts and models represent established or previously "fixed" and disseminated interpretations. Through their further implementation and dissemination, future interpretations are shaped and directed. In this way, interpretations are externalized as artifacts, which in turn shape the interpretations of actors that use and develop these artifacts. ${ }^{1827}$ Artifacts are, therefore, material outcomes of interpretive dominance.

The second interaction is between "new" interpretations and institutionalized "recipes in use" or interpretations. The discussion of interpretive dominance showed how new interpretations can turn into and influence already fixed interpretations. New interpretations that are consistent with established interpretations are cognitively rearranged so that they reinforce the existing "recipes in use". Interpretations inconsistent with existing "recipes in use" are either ignored or "appear as noise". ${ }^{1828}$ Only when there is a strong coalition of actors that "promotes" such divergent interpretations can they develop into new fixed interpretive positions with the time. Therefore, similar to the relation between artifacts and interpretations, there is a reciprocal relation between fixed interpretive positions and new interpretations.

The third reciprocal relation is the one between fixed interpretive positions and artifacts. Fixed interpretations, when used to evaluate artifacts that are the result of other, divergent interpretive positions, can prematurely terminate the growth and dissemination of those artifacts. At the same time, "recipes in use" "develop the power to select out particular paths [i.e. interpretations] only when they become widely accepted and commonly applied through a highly negotiated political process". ${ }^{1829}$ Artifacts provide a basis for the stabilization and legitimation of certain interpretations and discourses. As discussed in the following section, interpretive communities often use artifacts and symbolic resources in order to persuade others in the "advantage" of their own

This model can be also used to discuss the macro processes of management fashions dissemination as well as the competition between single fashions. For example, it can be argued that at a macro level, several possible interpretations and concepts can evolve for the solving of similar types of problems. In such cases, when multiple fixed interpretations exist, the result might be an escalation of commitment to single concepts/recipes in use and the rise of conflicts between the supporters of the one or the other. How does a certain fixed interpretation, represented in certain artifacts, become commonly accepted in such cases? The answer is through the emergence of interpretive dominance on a macro level. For example, as a result of consultants trying to "enroll" other actors who play a significant role in the institutional field of management knowledge production and dissemination, such as management journalists, business schools, etc., into a coalition that supports their interpretation/artifacts. See Suddaby/Greenwood (2001) and chapter B.II.3.4 for further discussion of the macro institutionalization processes within the organizational field of management knowledge production and dissemination.

Garud/Rappa (1994), p. 347.

Ibid, p. 348. 
interpretation. As such, artifacts are important tools for the development of interpretive dominance that, at the same time, is mirrored in widely disseminated artifacts. ${ }^{1830}$

\subsection{Symbolic resources as tools for interpretive dominance}

Callon makes it clear that in the process of translation, language plays an important role- “to translate is to express in one's own language what others say and want, why they act in the way they do and how they associate with each other". ${ }^{1831}$ Similarly, Marshall and Rollinson argue that the translation "quality" is closely related to the use of specialist language: the ability to engage in sophisticated technical explanations of problems and their solutions using specialist terms is an important part of achieving interpretive dominance over actors who are not able to participate in this conversation with the same degree of fluency. ${ }^{1832}$ Boland et al. point out that boundary objects can be "a center of intensive conflict as easily as one of cooperative effort. Creating and reshaping boundary objects is an exercise of power that can be collaborative or unilateral.” ${ }^{1833}$ In line with this, Phillips and Brown point out that by carefully managing communication, interpretive communities can legitimate their positions and establish interpretive dominance. ${ }^{1834}$ Accordingly, symbolic resources and maneuvers, such as strong stories, rhetoric, humor, and rituals are important instruments of rhetorical power, the result of which may mean that clients are unwittingly locked into new management procedures or management fads. ${ }^{1835}$ This has been recently reinforced by two new publications from former consultants revealing the negative effects of consultants' rhetorical power on their clients. ${ }^{1836}$ The presentation of consulting stories may also be regarded as a certain consulting ritual, one that evokes images familiar to the members of the client team, such as the role of a teacher, a father, or other relatively powerful figure. ${ }^{1837}$ Such images confirm the "rightness" of the consultants' perspective. For example, Malefyt found that certain communicative styles-based on proprietary models and figurative language-are powerful tools that advertising agencies use to demonstrate their competence and win support from a client. ${ }^{1838}$ Moch and Huff conclude that the negotiation of meaning is an inherently political process, whereas communicative acts are especially important when there are divergent interpretations on topics and issues. ${ }^{1839}$

Van Dijk suggests the following categories of persuasive moves that can be used to construct meanings and develop interpretive dominance: ${ }^{1840}$ (a) argumentation; (b) rhetorical figures such as euphemisms, denials, understatements, and hyperbolic

\footnotetext{
1830 See also Kirsch (1997), p. 353.

1831 Callon (1986a), p. 223.

1832 See Marshall/Rollinson (2004), p. S82.

1833 Boland et al. (1995), p. 362, emphasis added.

1834 See Phillips/Brown (1993), p. 1551.

1835 See Hardy/Phillips (2004), pp. 308-311; Newton (1996), p. 718.

1836 See Skapinker (2005), p. 13.

1837 See Moch/Huff (1983), p. 307.

1838 See Malefyt (2003), p. 152.

1839 See Moch/Huff (1983), p. 297.

1840 See van Dijk (1993), p. 264.
} 
enhancement; (c) lexical style, i.e. choice of words; (d) storytelling; (e) structural emphasis, such as headlines, leads, summaries, and other properties of text schemata; and (f) quoting credible sources or experts. As previously stated, these categories are, at the same time, important mechanisms for knowledge transfer and creation. ${ }^{1841}$

Therefore, what the proponents of the critical model see as the "dark" nature of consulting work can be now regarded in a new light. It is true that with the help of persuasive moves consultants can attempt to force their interpretations on clients and thus, to achieve partial fixings of meanings that can make them to an "obligatory passage point" and "lock" their clients in management fashions and fads. At the same time, however, the use of rhetoric and symbolic resources is a way of finding a solution for a problem when there are several legitimate interpretations and solution paths. Thus, the critical model regards power as a result of mastering the impression of possessing authoritative knowledge in areas that clients value and concentrates on its negative effects of "locking" clients into management fashions. ${ }^{1842}$ By contrast, the interpretive model proposes that power in the client-consultant relationship is based at least to some degree in the knowledge and interpretations of the involved individuals and can also have positive effects.

\section{Power within one interpretive community}

The interpretive model acknowledges that both positional and rhetorical power exist in single interpretive communities as well, which can influence the interaction between members of different interpretive communities. As already discussed, interpretive communities do not represent an unalterable "fixed system of positions". ${ }^{1843}$ Instead, they are constantly influenced by new members and the changing interpretations of existing members. Thus, single interpretive communities can be regarded also as political arenas, where members compete to impose their own interpretation on others and gain interpretive dominance. ${ }^{1844}$ For example, power conflicts within one interpretive community may emerge where different members of the community compete with one another over the development of the community. ${ }^{1845}$ Also, there might be disagreements regarding how reality should be presented to members of other interpretive communities so as to maximize their mobilization. Benford and Snow call such internal disputes "frame resonance disputes". ${ }^{1846}$

\footnotetext{
1841 See chapter D.III.3.8. Discourse analysis researchers pay special attention to the forms and role of these different texts or persuasive resources.

Clegg (2001), p. 135; see also Carley (1991), p. 332.

See Clegg (2001), pp. 134; Contu/Willmott (2003a), pp. 287; Reihlen/Ringberg (2004), p. 28; Wimmer (2004), p. 291. Consequently, it is dangerous to assume consensus in single interpretive communities as it is done by many of the adherents of the CoP concept. See Contu/Willmott (2003a), p. 287 and the discussion in chapter D.III.2.4. 
Power can also emerge from the brokering position of a community member. ${ }^{1847}$ Members of the communities brokers connect with are dependent on them for access to different interpretations. Brokers can use this advantageous position to enforce their preferred interpretation by translating other perspectives in a manner favorable to this interpretation. In this way, brokers can reinforce their broker position. Thus, if brokers are able to translate between several communities, their power will increase due to information benefits. However, as this work concentrates on client-consultant relationships, a discussion of the impact of internal power conflicts on the learning process between different interpretive communities is beyond its scope.

\section{Nature of professional business services}

In this chapter, on the basis of the insights gained in the previous discussion, a brief analysis of the nature of professional business services is provided. According to the interpretive model, professional business services are produced by companies that gain their competitive advantage primarily through their ability to create, transfer, and protect knowledge that they use in solving problems for and with their clients. ${ }^{1848}$ "Contrary to labor work aiming at transforming material resources into more valuable things by means of physical production, professional work ultimately seeks to modify ideas of people by means of cultural production like inventing, speculating, testing, arguing, communicating, training, or story-telling." 1849 This type of professional work requires, like every other type of work that is based on social interaction, the development of shared task-related knowledge. Additionally, it requires that the involved individuals share task-specific knowledge in order to be able to understand each other's specific "language" and interpretations and to agree on a problem solution. The task-specific knowledge of different professions is, thereby, a product of professional action, and is established through work and performance within the professional context. This is achieved not only through the accumulation of theoretical, academic knowledge but also "through the integration, tuning and restructuring of theoretical knowledge to the demands of practical situations and constraints". ${ }^{1850}$ It evolves gradually in a process of "enculturation" of professionals within the working context of their specific interpretive communities ${ }^{1851}$ and is not accessible to individuals from other interpretive communities. Additionally, professional expertise includes not only technical knowledge about facts and proven methods for problem-solving, but also rhetoric, images, metaphors, and narratives. ${ }^{1852}$ Thus, the interpretive model stresses that professional knowledge is not a "neutral”, “disinterested" knowledge but is often the carrier of power and certain interests. The power of professionals derives from their ability to establish "interpretive dominance” in concrete client-consultant relationships and to legitimatize their "authority

See Granovetter (1973); Newton (1996), p. 725.

See Reihlen (2003a), p. 2; also Creplet et al. (2001), p. 1519.

Reihlen (2003a), p. 5.

Bromme/Tillema (1995), p. 262.

Ibid, p. 262.

Ibid, p. 263.
} 
of competence", ${ }^{1853}$ through building alliances and coalitions with other actors within the organizational field of management knowledge and practice. Accordingly, modern expert groups, such as management consultants, provide legitimate discourses through which technologies of organizational surveillance and control can be mobilized, and as such, they contribute to the building of the system of discipline. ${ }^{1854}$ The expert application of discipline requires the establishment of specific structures and mechanisms. ${ }^{1855}$ In the case of consulting companies, through the institutionalization of management fashions, consultants shape and affect the way in which organizational members perceive organizational issues. As such, management fashions can influence the identities of organizational members, and as a result, their interpretations of organizational "reality". The result is the rationalization and normalization of organizational members and their behavior. Expert power, as such, extends beyond the formal boundaries of organizations and affects those who work with experts, in particular their clients.

However, consultants themselves are not excluded from such normalization and rationalization processes. ${ }^{1856}$ On the contrary, expert power bases are constructed and defended by normalization and rationalization themselves. "As such, expert power and control is an unstable and contestable outcome of the interaction between social constructions and structural constraints". ${ }^{1857}$ Therefore, professional expertise "has to be established and continuously re-negotiated with actors, and in terms of criteria, varying historically and culturally (e.g., 'clients' versus 'customers', public good versus efficiency)". ${ }^{1858}$ According to Foucauldian analysis, the possession of truth or expertise is not sufficient for the establishment and survival of professions and professional service firms because truth or knowledge is indeterminate and contestable. What is seen as true knowledge depends upon the specific context and historical environment. ${ }^{1859}$ Thus, the meaning of professionalism is not fixed but negotiated and contestable and as such, it is a subject to various forms of resistance or re-articulation, ${ }^{1860}$ which was already discussed for the case of management consultants. Clients in particular play a major role in this process. As Bloomfield and Danieli put it, "the consultancy process takes place in within a context of perceptions, identities, accounts, and representations. A consultant's advice on a particular matter, as well as its perceived legitimacy, depends on the mutual understanding between consultant and client. This is not something that is given; it depends on their discursively negotiated identities, normative assertions about what should be done, who significant others are, what they stand for or represent [].”1861

Scott (2001), p. 102.

See Reed (1996), p. 576; Scott (2001), p. 95. In other words, they are agents of the norm. See Covaleski et al. (1998), p. 297.

See Scott (2001), pp. 95-96.

See also Covaleski et al. (1998), p. 297.

Reed (1996), p. 578.

Fournier (1999), p. 303; see also Bloomfield/Danieli (1995), p. 29.

See, e.g., Foucault (1980), pp. 131-133 and the discussion in chapter B.II.4.3.3. This is in contrast to the implicit assumption within the work-related approach to professional business services that the professional expertise or knowledge is objective and "true" knowledge. See chapter B.I.1.4.

See Fournier (1999), pp. 302-303

Bloomfield/Danieli (1995), p. 29. 
Therefore, professions should be seen as cultural artifacts ${ }^{1862}$ that are jointly created by a number of different actors, which, at the same time, influence the identities and actions of the actors. Brante supports this view when he argues that modern professions should be understood as "products of a historically specific social mode of production". ${ }^{1863}$

In addition, Foucault's work puts the importance of professional conduct and norms, which is also the focus of the norm-oriented approach to professional business services, in a new light. ${ }^{1864}$ For Foucault, professional conduct serves the construction and maintenance of professional identity and acts as a form of discipline over otherwise autonomous professional labor. ${ }^{1865}$ "Thus induction into professions, in terms both of knowledge and conduct, serves to construct a specifically 'governable' subject controlled through self-disciplinary mechanisms”. ${ }^{1866}$ In such way, differences in the interpretive positions of the involved interpretive communities are controlled and a sufficient conformity is achieved. As previously stated, the introduction of a specific consulting terminology, such as consulting stories, conceptual models, consulting metaphors, etc., further enforces such conformity. In other words, consulting terminology effectively controls the discursive resources available to consultants when making sense of problem situations. As a result, interpretive perspectives that do not reflect the accepted and institutionalized discourses can be marginalized as lacking expertise and being unprofessional. ${ }^{1867}$ Consulting terminology helps, therefore, to monopolize and fix the representation and interpretation of certain problems. In this way, such terminology not only ensures some degree of conformity among the involved individuals and their interpretations, but it also prevents outsiders from offering similar services. Furthermore, this "established" terminology helps consultants to gain interpretive dominance over clients and as such, to secure the "obligatory passage point” position of the consultants.

As previously pointed out, the predominance of the expert model until the 1980s shows that management consultants were successful in establishing themselves and the solutions they provide as an "obligatory passage point” for organizations that wish to increase, or to show efforts towards increasing their efficiency and competitivenss. Consultants were the established "helper" and "rational problem-solver", thus successfully justifying their view and perspective as "the right one" and their knowledge as objective, coherent, and effective. There was, in a sense, a prevalent discourse about the role and the need for consultants that "normalized" their clients as well as clients' requirements on the consultants. Only after increasing critic of consultants both in the practice and in the research community, did the critical view of management consulting develop, trying to establish a different discourse about the role of consultants and questioning the "obligatory passage point" position of consultants in modern economic societies. This critical approach was necessary and positive as it caused both clients and consultants to review their joint practices and cooperation. The interpretive model can be

Brante (1988), p. 137.

See the discussion of the norm-oriented approach to professional services in chapter B.I.1.1.

See Hodgson (2002), p. 806.

Ibid, p. 806.

See Hodgson (2002), p. 815.
} 
regarded as the outcome of a third discourse, one that is grounded in a realist view of knowledge and power.

The view of the models of client-consultant interaction as particular, historically embedded discourses reveals that the nature of the client-consultant relationship cannot be seen as predetermined and dependent on the needs of clients and consultants only. Rather, it has to be acknowledged that how this relationship is perceived by clients and consultants, as well as by researchers, is also influenced by the broader institutional environment. In particular, it is influenced by the established discourses that "lend legitimacy and reason to some relations, while at the same time making other kinds of relations more difficult". ${ }^{1868}$ From this perspective, this work provides a historically orientated overview and analysis of the research on client-consultant interaction, leading the reader from one discourse into another, ultimately guided by a critical realist discourse on knowledge and power.

\section{A typology of client-consultant relationships}

After discussing the interpretive model of the client-consultant relationships in general, in this chapter it is outlined as to what extent the model is relevant and applicable in different contexts of client-consultant interaction. In other words, the critical question is whether the implications of the interpretive model are relevant for all three types of consulting projects that were outlined in chapter B.II.3.2., and whether these implications differ depending on the problem context that clients and consultants encounter.

Before proceeding to discuss these questions, it is necessary to emphasize that the interpretive model implies a different view of the problem typology suggested in chapter B.II.3.2. According to the interpretive model, it is not possible for clients and consultants to decide at the start of the consulting project whether they face a routine, complex, or innovative problem. As Creplet et al. note, "firms encounter problems the pattern of which is not recognized at first glance". ${ }^{1869}$ Rather, it is assumed that clients and consultants will more often than not have different interpretations of the problem at hand, and consequently, of the appropriate solution, i.e. different task-specific knowledge, because they are members of different interpretive communities. In other words, the level of cognitive consensus and dissensus within client-consultant teams influences their perception of the problem, not the other way around, which further affects the group process dynamics. Thus, the members of the team need, first, to share their perspectives and knowledge of the problem before they can reach a conclusion as to the type of problem they face and, consequently, about the characteristics of their interaction. Moreover, their roles and responsibilities cannot be determined ex ante but have to be negotiated in the course of the project. ${ }^{1870}$ Therefore, these crucial decisions are a result consultants, which they choose from depending on the client and the problem situation. See, e.g., Lippitt/Lippitt (1978), pp. 27-44. 
of the client-consultant interaction, and as such, they are endogenous to the problemsolving process. ${ }^{1871}$ Consequently, it is possible that an initial decision about the problem they face has to be changed during their interaction when new interpretations are developed.

This recognition puts additional requirements on the management of consulting projects, as it implies that it is neither possible to state exact project goals and results at the start of the project, nor to strictly define roles and responsibilities for clients and consultants. All of these issues have to be negotiated and agreed upon during the consulting project. Additionally, this argument raises the following question: What if clients and consultants have different perspective about the type of problem they have to solve? Whose perspective should be taken into consideration if clients "see" a complex or innovative problem and consultants a routine one? What about the case when clients believe that the problem is a routine one but consultants see it as rather complex? The definition of consulting success as presented in chapter B.I.2.3 implies that consultants would agree with client's perspective in order to ensure client's satisfaction. From consultants' perspective, this would be less problematic in the first case, which some consultants might even see as profitable: clients will be willing to spend more resources on a project because they believe that they face a complex or innovative problem, whereas consultants could solve it with less effort due to their existing knowledge about such problems. However, in the second case, consultants who adopt clients' perspective and approach the problem with existing methods and tools might risk that the suggested solution will not work in the context of a problem that is, in fact, complex or innovative. ${ }^{1872}$ Alternatively, the consultants might have to persuade their clients that the problem requires a different or innovative approach and risk that clients might remain with the impression that the consultants are trying to "sell" them a solution that they do not really need. Thus, a successful consulting project requires, on the first place, that clients and consultants develop a shared expectation about the problem structure as early in the project as possible. This implies the willingness of both parties to have their views on the problem questioned and the ability to break with normalized perspectives and interpretations. Consequently, the type of client-consultant interaction depends on two main factors: problem type and client's expectations. ${ }^{1873}$

Based on these arguments, in the following, the problem typology proposed in chapter B.II.3.2 is further developed. It is assumed that clients and consultants have engaged in some preliminary sharing of meaning and negotiation regarding the nature of the problem and have achieved, in some way or another, shared understanding on of the type of the problem they face. The presented typology combines, first, insights from the existent literature on the client-consultant interaction including both conceptual models and empirical studies; second, insights from the interpretative framework of the clientconsultant relationship; and third, previous classification efforts. The typology aims to provide a deep understanding of different client-consultant relationships and their

1871

1872

1873

See also Larsen (2001), p. 87.

See also Schräder (1995), p. 67. Schräder further argues that in such cases it would be better for the consultants to withdraw from the project. Ibid, p. 68.

See also Schräder (1995), p. 67. 
characteristics, and is summarized into three major areas: (1) nature of the problemsolving process and necessary degree of perspective alignment; (2) power relations within client-consultant teams; and (3) personal attributes of clients and consultants. A major advantage of this typology is that it explicitly differentiates between the three major groups of actors involved in consulting projects: project sponsor, problem owners, and consultants.

With respect to the nature of the problem-solving process and the necessary degree of perspective alignment, only the need for sharing of task-specific knowledge is discussed within this typology. It was already argued that problems can be solved and decisions made even when team members do not develop shared understanding of the issue at hand, i.e. shared task-specific knowledge, but such a situation has negative effects on the implementation of the solution. In contrast, shared task-related knowledge is necessary in all types of consulting projects because it is crucial for a successful teamwork. ${ }^{1874}$

The second area of interest, the nature of power relations, is closely related to the first point. The existence of a dominant interpretation of the problem implies that most of the team members have shared perspectives on the problem and there is no struggle over whose perspective should be taken as a basis for the problem solution. This is not the case when the client-consultant team faces a complex or an innovative problem, where team members have to intensively share task-specific knowledge and, at the same time, will be engaging in power struggles in order to develop interpretive dominance and to suppress the development of different interpretations.

Concerning the personal characteristics of consultants, although some authors suggest that consultants in general need to possess "the capability to rely on previous knowledge (experience) and to re-articulate pieces of knowledge in a new way", ${ }^{1875}$ it will be shown that the required "cognitive architecture" of consultants varies depending on the problem at hand. Additionally, it is suggested that different problems put different requirements on consultants' interactive skills. Motivational attributes are not further discussed, as it was suggested that they are generally important because they increase team members' efforts. Thus, whereas there is a lack of discussion in the literature regarding the appropriate personal attributes of clients depending on the project type, this work provides few suggestions regarding this issue.

\section{Expert “consulting”}

This type of consulting is appropriate when both clients, in particular the problem owners, and consultants share the view that they face a simple routine problem and when the problem has these characteristics. In addition to the discussion of the three major issues of power relations, nature of problem-solving process, and attributes of clients and consultants, this chapter also provides a critical discussion of the expert consulting. This is necessary because of the very restricted form of interaction that takes place within this type of consulting, which implies that expert consulting should be used in practice with 
great care. Some of the insights regarding expert consulting originate in the research within the traditional, expert model of consulting. However, the expert type of consulting proposed here is embedded into the theoretical framework of the interpretive model and does not follow the theoretical assumptions of the expert model.

\subsection{Nature of problem-solving process and problem solutions}

Expert consulting is a form of consulting that represents the purchasing of a standardized service. For example, client managers sometimes look outside their own organizations for specialists able to sell them "diagnostic advice" about market and competition development in a particular industry, ${ }^{1876}$ or to provide them with a "set of solutions that have to be [simply] matched to firms' problems”. ${ }^{1877}$ Client managers' expectations are that they will receive a proven and efficient solution, without themselves investing a lot of time and effort. They delegate the problem-solving activities to consultants in order to hasten the problem-solving process in an efficient way. Another reason why client managers engage consultants for solving simple routine problems that their employees could (potentially) solve themselves is to ensure neutrality in the decision-making process, or to have an "independent expert opinion" to protect management from any potential litigation - fair price paid in an acquisition, comfort letters, etc. would be some example for such services. In some cases, client managers simply need "an extra pair of hands or two". ${ }^{1878}$ On the other hand, consultants accept such projects because they can utilize previously created knowledge and achieve high leverage. ${ }^{1879}$

Because of the nature of such problems, they can be defined and solved based on an existent dominant interpretation or "management fad". ${ }^{1880}$ The original problem can be decomposed in single sub problems, each of which has a previously created, proven, and legitimated problem solution. Furthermore, there is an established procedure, for example in the form of consulting models and methods, for integrating the solutions into the sub problems to create a coherent problem solution for the original problem. As a result, in such type of projects the interaction between problem owners and consultants is very restricted, taking the form of the problem-solving process as discussed within the expert model, because no sharing of understanding between clients and consultants takes place. Such sharing is not necessary if all involved individuals share the dominant interpretation and have similar perspectives on the structure of the problem and problem solution. The interaction is restricted to the problem owners providing some task-specific knowledge as an input for the problem-solving process and the consultants presenting the solution as an output. The problem-solving process is executed solely by the consultants. It involves describing the problem, decomposing it into sub problems, detailing the solutions to the sub problems, and integrating the sub solutions. ${ }^{1881}$ No concept or ideas development

See the discussion in chapter B.II.4.2 where the relevance of economic considerations for consulting projects was extensively discussed.

See also Prahalad/Bettis (1986), p. 490.

See also Behrens/Delfmann (2002), pp. 34-40.
} 
takes place. ${ }^{1882}$ Even within the consulting team, there is only a limited interaction. Consultants engage in directional or local search, guided solely by their existing knowledge and experience from prior projects. ${ }^{1883}$ Pragmatism, which implies the use of proven ideas, outweighs other considerations. ${ }^{1884}$

\subsection{Power relations}

Because both problem owners and consultants agree upon the nature of the problem and due to the existence of a dominant interpretation about the required solution path, there is no struggle about perspectives and interpretations in these types of projects. If all team members have the same view of the problem and the problem solution, no one in the team is capable of challenging the existing interpretation with new insights. For these reasons, Walsh and Fahey speak of concentrated power and broad sharing of identical beliefs about "limited belief structures". ${ }^{1885}$ Solutions are created "by hegemonic fiat" and are usually made quite quickly. ${ }^{1886}$

Power relations in this type of client-consulting relationship are characterized by a unidirectional dependency. On the one hand, this is the case when the client manager, either the sponsor or the client project manager, describes the problem at hand as well as outlines the expected problem solution with the consultants following this description and delivering exactly what is required. ${ }^{1887}$ In other words, the sponsor's positional power based in economic power is at work. On the other hand, in their relationship with the problem owners, consultants act as the experts, i.e. the dominant actors, who know what is to be done and how. ${ }^{1888}$ There is no need for them to intensively discuss the situation with the problem owners, as this would only reduce the efficiency of the project and will not lead to major new insights. Thus, consultants' dominance is based in their expert power and is embedded in the previously institutionalized discourses and practices that represent the dominant interpretation of the issue at hand. The consultant's rhetorical power is only used to reinforce the existing interpretations and discourse.

\section{Attributes of consultants ${ }^{1889}$}

The most relevant personal attributes in such projects are the domain-related skills of consultants. Consultants need to have the technical knowledge and experience of how to approach the problem in the most efficient way. In such cases, they do not have to change their existing knowledge and the existing dominant interpretation. ${ }^{1890}$ Thus, creativity skills are not required. Similarly, an analytical rather than an intuitive cognitive style is

See Nutt (1984), pp. 420-436.

Nickerson/Zenger (2004), p. 620.

See Nutt (1984), p. 434. See also Carroll (1998), p. 712.

See Walsh/Fahey (1986), pp. 328-330.

Ibid, pp. 329.

See also Schräder (1995), p. 66.

See Schräder (1995), p. 66.

Because consultants are seen as the dominant actor within the client-consultant team, only consultant's skills are emphasized as important for successful problem-solving.

See also Argyris/Schön (1996), pp. 20-21.
} 
emphasized. Communication skills, as well as persuasion skills, are much less important in such projects than technical knowledge. The existence of an agreement regarding the nature of the problem as well as a dominant interpretation of how to solve it implies that there is less need for members of the team to persuade others in the value of the suggested solution path. Thus, such projects can be executed to a very high degree by junior consultants. ${ }^{1891}$

\subsection{Shortcomings}

Because this form of consulting economizes on interactions and discourages the development of any divergent ideas or solution paths, it is characterized by inflexibility and lack of novelty. It is very efficient and provides good results only when all involved individuals share the same view of the problem, and the problem is indeed a simple routine problem.

However, apart from market or competition analysis, few management problems are so simple today that they can be handled effectively in a standardized way, relying only on existing knowledge. As Czerniawska puts it, "almost all business situations are, in practice, open and complex". ${ }^{1892}$ Similarly, Schön argues, "in the varied topography of professional practice, there is a high, hard ground where practitioners can make effective use of research-based theory and technique, and there is a swampy lowland where situations are confusing 'messes' incapable of technical solution. The difficulty is that the problems of the high ground, however great their technical interest, are often relatively unimportant to clients or to the larger society, while in the swamp are the problems of greatest human concern". ${ }^{1893}$ Blackler speaks about situations of "fluctuating communities around familiar activities" and argues that it is important not to rely on the known, standard solutions, but to promote dialogue for a new understanding of the situation. ${ }^{1894}$ Consequently, while some clients' problems may be seen as simple routine problems, in reality, management problems are rather complex problems. ${ }^{1895}$ This implies that even if the problem looks familiar, and both clients and consultants agree upon its nature "at first glance", ${ }^{1896}$ they still should recognize that structuring the relationship based on the known problem definition and solution is only one possible way to approach it. The high number of unsuccessful consulting projects, for example in the IT area where it is often argued that projects can be easily outsourced to an external service provider, ${ }^{1897}$ thus implicitly assuming that they are based on simple routine problems, is evidence that clients and consultants need to engage in an intensive interaction even when the problem definition and solution seem to be known. Giola and Poole conclude that decision-

\footnotetext{
1891 See, e.g., Maister (2004), p. 21.

1892 Czerniawska (1999), p. 112.

1893 Schön (1983), p. 42.

1894 Blackler (2000b), p. 838.

1895 See chapter B.II.3.3 where some trends in the consulting environment were outlined.

1896 Creplet et al. (2001), p. 1517.

1897 See, e.g., Quelin/Duhamel (2003).
} 
making based on existing interpretations without questioning them might lead to inappropriate results. ${ }^{1898}$

However, adopting the expert type of consulting does not allow clients and consultants to question their views of the problem. The discussion of this type of consulting revealed that when client managers believe that the issue at hand is a simple routine problem, they tend to "dictate" the expected solution, making it hard for the consultants to develop divergent propositions. Consequently, while the project sponsor might believe that the issue at hand is a simple routine problem, which needs a particular methodology in order to be solved, and engages consultants that can offer exactly this methodology, the problem owners might have a different view of the problem. As Yanow argues, often workers have been long familiar with problems that managers suddenly become aware of and have developed workable solutions to them. ${ }^{1899}$ However, this knowledge is wasted because consultants, who have been engaged with a strictly defined task by the project sponsor and are seen as the experts regarding this task, do not consult with the problem owners about either the problem or its solution. ${ }^{1900}$ Consequently, because consultants are outsiders and do not engage in a more intensive interaction with the problem owners, they often suggest problem solutions that do not "fit the lived realities (or Lebenswelt []) of the workers and their work practices". ${ }^{1901}$ As Bettenhausen and Murnighan argue, teams that do not discuss the basis for their interaction are likely to have a relatively poor performance in the case of a threat or challenge, for example, if something goes wrong during the consulting project. ${ }^{1902}$ This emphasizes the need for consultants to recognize that following the directions of the project sponsor in order to secure client's satisfaction might not be the best option for the client organization as a whole.

The interpretive model emphasizes, at the same time, that consultants, as well as the other actors involved in consulting projects, are often "disciplined" and embedded into existing management practices and methods so that no "escape" is possible. In other words, consultants might agree with the project sponsor not only in order to ensure his/her satisfaction with their work but because they believe in the proposed problem solution. The only way to escape is, indeed, if consultants would be willing to give up their comfortable and dominant position in relation to the problem owners in order to learn from and with them and share knowledge to which they, as outsiders, do not have access. This would require, however, the adoption of a different consulting model.

Consequently, clients and consultants need to be aware when approaching familiar looking problems, that they can be biased by their previous knowledge and by existing problem solutions when constructing the problem. If they do not invest some time in reflecting on their knowledge and interpretations, they might not see important features of the problem that require a different solution. This is particularly important for client 
managers because, as Bettencourt et al. argue, more sophisticated or expert clients show higher inflexibility and a know-it-all attitude that detracts from project success. ${ }^{1903}$

Similar arguments have been made for the law profession. Alfieri suggests that the traditional view of clients as victims in civil rights and poverty law contexts reduces them to powerless and pathological objects. ${ }^{1904}$ Lopez states that there is a tendency of legal institutions to be "hostile" and "often systematically ignorant" of client needs. ${ }^{1905} \mathrm{He}$ asserts that "clients and lawyers can transform routine acts into opportunities for collaborative problem-solving in which skills are combined and power is shared. [] In advocacy, collaboration may generate lawyer-client, client-client, and client-community alliances. Collaboration is an empowerment or enabling strategy that redefines traditional lawyer-client roles, reorganizes divisions of legal and nonlegal labor, and reallocates the authority to designate and to execute advocacy tasks”. 1906

This work argues that only a limited number of management problems can be solved successfully if clients and consultants operate according to the expert type of consulting. Furthermore, it suggest that clients and consultants have to be very careful when they decide that the issue at hand is a simple routine problem due to the large negative consequences of this type of consulting in cases when the "real" problem is rather complex or innovative. In such cases, a successful consulting process requires a different type of interaction between clients and consultants, as proposed in the following two sections.

\section{Confirmatory consulting}

\subsection{Nature of problem-solving process and problem solutions}

When a client-consultant team faces a complex routine problem, a more intensive interaction between the problem owners and the consultants is required if they are to generate a successful problem solution. ${ }^{1907}$ Because of the complexity of the problem, different interpretations exist about what the problem is and how to solve it. As Quinn et al. put it, "when problems become more complex or less well defined, no one person or organization may know exactly what their full dimensions are, where key issues will ultimately reside, or who may have potential new solutions". ${ }^{1908}$ Intensive interaction is necessary in order for the team to achieve a better solution, especially because the problem owners often possess extensive organization-specific knowledge that is crucial for the understanding of the problem. ${ }^{1909} \mathrm{~A}$ major hurdle with such problems is the achievement of cognitive consensus regarding the structure of the original problem. Thus, whereas complex problems can be decomposed into a number of less complex sub

See Bettencourt et al. (2002), p. 116.

See Alfieri (1994), p. 1761.

Lopez (1992), cited in Alfieri (1994), p. 1761.

Alfieri (1994), p. 1761.

See also the discussion in chapter B.II.3.2.2.

Quinn et al. (1996), p. 78.

See Morris (2000), p. 135.
} 
problems, which can be solved independently of one another on the basis of existing interpretations and experience regarding the sub problems, the interrelationships between the sub problems can be interpreted in different ways by members of different interpretive communities. In such cases, existing institutionalized perspectives can allow for an implicit aligning of individuals' interpretations resulting in compatible interpretations of the problem. For example, if the problem is to improve the measurement and controlling of certain performances within the client organization, usually the concept of the Balanced Scorecard, which has been institutionalized as the dominant measurement model, can be used in order to structure the different views and interpretations of the problem. However, the concept should not be applied without adjusting it to the specific aspects of the client organization, i.e. without enriching it with specific knowledge. For each area to be measured sub problems have to be defined, i.e. appropriate measurements need to be created. However, the value of the solution of one sub problem is not fully independent of the decisions made regarding other sub problems. Therefore, "[shared] cognitive maps in this setting aid in discovering regions of the solution landscape particularly attractive for search, while directional search involving independent actors effectively explores these regions". ${ }^{1910}$

The existence of dominant interpretations regarding the sub problems associated with a particular complex routine problem implies that once members of a team have agreed on solving some sub problems, a particular perspective is established on what the structure and nature of the original problem is. In other words, a particular decomposition of a problem imputes a particular view of the nature of the problem. Thus, if all involved individuals agree upon certain decomposition, decision-making in such cases can still be made relatively quickly; only some adjustment of the problem solution takes place but no new knowledge is created. Consequently, this type of consulting economizes on individual cognition. ${ }^{1911}$

However, because of the complex structure of such problems, it is possible that the involved individuals do not reach cognitive consensus about the structure of the original problem. Different members of the client-consultant team might have different experiences with somewhat similar complex problems and might have a different perspective on what the structure of the problem is and on the interrelations of the sub problems. In particular, different actors might see different solution paths as promising after engaging in heuristic search. ${ }^{1912}$ To apply the example above, some individuals might not agree that the Balanced Scorecard is the best method to approach a measurement problem because they take a different view on what areas or activities are to be measured and how to measure them altogether. Therefore, a solution suggested by one group of actors might not be implemented properly if there are actors who believe that a different solution is more appropriate. Moreover, if the problem decomposition that is followed has been established in other contexts, there is less chance that the clientconsultant team will create a novel problem solution. Ford and Gioia point out that "prior 
knowledge, or the extent to which decision makers know of possible alternative solutions as they begin working on a problem, has an important influence on the creativity of [client's and consultant's] decisions." ${ }^{1913}$ In an empirical study they found that the novelty of the problem solution was enhanced when decision makers were unfamiliar with potential solutions. Other researchers confirm these findings. For example, Gioia and Poole argue that organizational actors tend to resort to familiar, scripted actions even in the face of considerable ambiguity. ${ }^{1914}$ Van de Ven states that non-threatening or stable situations with existing solutions provide little incentive to produce original solutions. ${ }^{1915}$ Thus, this type of consulting is negatively associated with creative, innovative problem solutions. What it provides are solutions based on "fixed" interpretations customized to meet the specific characteristics and requirements of a client. ${ }^{1916}$ In other words, it is characterized by the reframing of existing knowledge and a "step-increase" in learning. ${ }^{1917}$ Because this type of client-consultant interaction achieves an adjustment of existing solutions to the specifics of particular clients, it can be a driving force behind the further dissemination of existing discourses and management practices. ${ }^{1918}$

\section{$2.2 \quad$ Power relations}

In the case of confirmatory consulting, two situations regarding the power relations between clients and consultants are possible. If the problem is familiar for the consultants but novel for the client, including the sponsor and the problem owners, consultants can use their existing knowledge to gain interpretive dominance over the clients referring to the legitimacy of their knowledge and experience. In such cases, clients may expect the consultant to be "prescriptive", ${ }^{1919}$ trying to persuade clients that the suggested problem decomposition and the path to aggregate sub solutions are the right ones to follow. However, consultants have to be aware that because of their inexperience, client managers may not be able to describe the problem correctly or specify their needs and preferences, and they may change their mind on vital issues. Many consulting companies find themselves in similar situations when they work with clients from Third World countries. McKinsey, for example, faced exactly these kinds of problems while working with a new client from China. ${ }^{1920}$ In addition, a dominant position of the consultants in relation to the problem owners can "silence" them and stop the problem owners from sharing important knowledge. Additionally, if the problem owners do not agree with the

Ford/Gioia (2000), p. 711.

See Gioia/Poole (1984), pp. 454-455.

See Van de Ven (1986), pp. 594-595; see also Walsh/Fahey (1986), p. 331.

Customized solutions imply that elements of existing solutions are recombined in a different way to build the customized solution. Creplet et al. suggest that in such cases knowledge creation may occur at the margin of the problem-solving process. They call it knowledge "spill-over". Creplet et al. (2001), p. 1521. Other authors speak about "recombinative” or "architectural" innovations. Gallouj/Weinstein (1997), p. 550. In the case of such "innovations", however, no new knowledge is created. Therefore, the potential of such consulting projects to generate novel solutions is, as discussed, very limited.

1918 See DiMaggio/Powell (1983), pp. 150-153 and the discussion in chapter C.IV.5. This is the reason why it is called "confirmatory consulting" within this work. 
proposed solution, they can later on hinder its implementation. Thus, as discussed in the previous section, in such cases consultants should also be open for new perspectives in areas that they believe they have extensive knowledge in and engage in a process of perspective sharing with their clients in order to adjust a dominant perspective to the specific client situation. Furthermore, as Sharma states, because clients may be unaware of the potential to solve some of the sub problems themselves, consultants need to be proactive in explaining how they can improve their performance in sub areas in order to contribute to a better performance in the main area of interest. ${ }^{1921}$ This proactive strategy implies the use of arguments, stories, and rhetoric as mechanisms to inform clients about existing, institutionalized ways for solving of these sub problems.

However, it is also possible that client managers have experience and knowledge in decomposing similar complex problems and in solving some of the sub problems. In such cases, it is possible that the project sponsor directs the problem-solving process by deciding on the overarching framework for the problem solution. ${ }^{1922}$ Accordingly, consultant's role is restricted to mainly carrying out tasks in the narrowly defined sub areas of the total problem. Empirical research shows that client managers often engage different consulting companies to work on pieces of the total project, ${ }^{1923}$ effectively keeping control over the problem solution of the original problem.

\subsection{Attributes of clients and consultants}

\section{Cognitive attributes}

Consultants who engage more often in consulting projects of this type base their activity to a high degree on standardized and codified knowledge. In such cases, they merely adapt their existing knowledge and the existing dominant interpretations to changing contexts. ${ }^{1924}$ Hence, the role of creativity remains insignificant. ${ }^{1925}$ More relevant are the domain-relevant cognitive skills of the consultants as well as an analytical cognitive style. ${ }^{1926}$ These skills allow them to analyze the different sub problems and provide them with techniques for the integration of the existing knowledge sets. ${ }^{1927}$ Accordingly, the shared cognitive schemes of the involved consultants would be fairly concrete and simple, and their sharing with the client members will not require a time extensive interaction. ${ }^{1928}$

See Sharma (1994), p. 24.

See Carter et al. (2004), pp. 26-27; also Sharma (1994), p. 19.

See Sharma (1994), p. 19. Sharma stresses that clients have a bargaining power in such situations, which they can use to minimize the fees paid for the service. However, if the client has an established relationship with the consulting company, quality issues are more important.

See also Argyris/Schön (1996), pp. 20-21.

See Creplet et al. (2001), p. 1518.

See Hough/ogilvie (2005), p. 440; Klimoski/Mohammed (1994), p. 420 and the discussion in chapter B.II.2.1. and B.II.3.2.3.

See Coopey/Burgoyne (2000), p. 879.

See Klimoski/Mohammed (1994), p. 420.
} 
The implication for the composition of the client-consultant team is that team members should come from interpretive communities that are in orthogonal and enhancing relations to each other. ${ }^{1929}$ Whereas members of orthogonal communities would ensure that some original interpretations and ideas are provided, they will, at the same time, have enough shared cognition with other actors as to not jeopardize the efficiency of the communication and problem-solving. Through supporting the interpretations of the community presenting the dominant view of the problem, members of enhancing interpretive communities facilitate the problem-solving process. ${ }^{1930}$ They can also serve as knowledge brokers when it comes to integrating the interpretations and knowledge sets related to the sub problems. In contrast, if some team members have a totally different perspective on the problem and the solution path, this can slow down the problem-solving process and decrease its efficiency.

\section{Interactive attributes}

Because consultants rely only to some extent on standardized knowledge when solving complex routine problems, they need to possess some persuasion skills in order to develop interpretive dominance and persuade the clients that the solution path they suggest is the best one to follow. The existence of a dominant and legitimized framework that can be used for solving of the problem at hand implies, however, that consultants can rely upon their experience and do not have to engage in intensive impression management. In most cases, clients will be rather willing to accept the suggested interpretation because it is seen as the "rational" and "established" way to solve such problems.

Communication skills are important to the extent that consultants and clients have to agree upon the decomposition of the original problem into sub problems as well as on the integration of the solutions generated independently by team members. Often, the communication and integration skills of a broker are crucial for a successful integration of the distinct knowledge sets and interpretations into the final problem solution.

\section{Disturbing consulting}

\subsection{Nature of problem-solving process and problem solutions}

In situations when clients and consultants face novel, non-decomposable problems, an established dominant interpretation of the problem and a "fixed" solution does not exist. Such problem situations are characterized by high ambiguity, i.e. there is no clear interpretation of the events or issues at hand. ${ }^{1931}$ Therefore, an intensive involvement of the problem owners in the problem-solving process and an intensive sharing of relevant knowledge are the most important factors for the successful solution of such

\footnotetext{
1929 These types of interpretive communities were introduced in chapter D.III.2.3.

1930 See Bloor/Dawson (1994).

1931 Similar terms are “dialectical belief structures” (see Walsh/Fahey, 1986, p. 331), “multiple 'expert' mental models” (see Mathieu et al., 2000, p. 281) and “contexts of action and reflection” (see Creplet et al., 2001, p. 1518).
} 
problems. ${ }^{1932}$ Additionally, it is clear that in such cases the project sponsor or other client managers should not try to use their positional power to influence the direction of the problem-solving process.

Using analogy, consultants can try to find out if innovative problems can be related to previously known problems and existing fixed interpretations and then propose matching solutions. ${ }^{1933}$ The process of drawing analogies is very common when organizational actors are trying to understand ambiguous and novel situations. ${ }^{1934}$ However, although reasoning by analogy has been shown to be effective in generating creative solutions to a number of problems, in situations that involve a great deal of uncertainty and complexity, the "use of simple analogies may mislead the decisionmakers into an over-simplistic view of the situation". ${ }^{1935}$ In such situations, there is no existing institutionalized framework that can be used to bring structure to the problem and to identify less complex sub problems. Thus, multiple perspectives are needed that can outline different solution paths. ${ }^{1936}$ Mirvis supports this argument by stating that it is necessary to extend the "gene pool of values, beliefs and ideas" and that the team members have to use "rich language to interpret and label complex situations". ${ }^{1937}$ As a result, the problem-solving process is not based on independent local search in sub areas but on a cognitive search involving the intensive sharing of knowledge sets between consultants and clients. ${ }^{1938}$ Only an intensive interaction between team members and a demanding problem-generating process can ensure that established interpretations are disrupted and new knowledge is created. ${ }^{1939}$ This presupposes that some shared frameworks are developed and a reconciliation of the divergent beliefs about the proper shape of the problem-solving process is achieved. ${ }^{1940}$

The main task of "disturbing consulting" or, in Clegg et al.'s terms, "parasitic consulting", ${ }^{1941}$ is to initiate translation processes between different interpretive communities and thus to enact new worldviews. This type of consulting is, therefore, positively associated with creative, innovative problem solutions. However, such type of problem-solving is very time intensive, especially if the team tries to achieve full synthesis of the different interpretations. ${ }^{1942}$ Therefore, the development of novel alternatives is restricted when there are time constraints and cost limits for the project. ${ }^{1943}$

See Nickerson/Zenger (2004), pp. 620-621 and the discussion in chapter B.II.3.2.

See Creplet et al. (2001), p. 1518; Prahalad/Bettis (1986), p. 493; Schön (1983), p. 194. Schön calls this process "Seeingas", which takes the form of a "generative metaphor”. Schön (1983), p. 184. He further states that intuition and creativity may be regarded as a reflection on "seeing-as".

See Schwenk (1988), p. 48.

Ibid, p. 48.

See Coopey/Burgoyne (2000), p. 878; Prahalad/Bettis (1986), p. 498.

Mirvis (1996), p. 17.

See Nickerson/Zenger (2004), p. 621 and chapter B.II.3.2.3.

See also McGivern/Fineman (1983), pp. 433.

See Kogut/Zander (1996), pp. 509-510; Nickerson/Zenger (2004), p. 621; Walsh/Fahey (1986), p. 331.

See Clegg et al. (2004), pp. 38-39.

See Walsh/Fahey (1986), p. 331.

In other words, not only cognitive but also economic aspects influence the problem-solving process. See Nutt (1984), pp. 414 and the discussion in chapter B.II.4.2. 


\subsection{Power relations}

Because of the novelty of the problem, several different interpretations and suggestions for its solution may arise. At the start of the project, no team member has an interpretive dominance and who gains an interpretive dominance depends on who has better access to the knowledge areas with the highest potential for solving the problem. At the same time, interpretive dominance also depends on who has the ability to persuade the rest of the client-consultant team of the importance of their knowledge for the problem solution. ${ }^{1944}$ In other words, both the access to relevant knowledge and the ability to build alliances and find support for one's perspective, decides who is going to develop interpretive dominance. Often, individuals who are in the role of the broker between different interpretive communities have an advantage as they can manipulate the transfer and translation of interpretations in order to promote a view that they prefer. Thus, if such projects are executed in an appropriate way, the positional power of individuals should not be used to influence the problem-solving process, especially in its early phases. In contrast, rhetorical power will play an important role in the interaction process, as individuals will use their rhetorical power to influence the interpretations of others and "enroll" them in their preferred perspective. The extent to which rhetorical power will influence the problem-solving process, as well as whether it will lead to the reinforcement of existing discourses and interpretations, or to the development of new perspectives, depends therefore on the internal dynamics within the team.

\subsection{Attributes of clients and consultants}

\section{Cognitive attributes}

In innovative projects, consultants cannot apply standardized methodologies to solve problems. Here, creativity and a higher sensibility to the specific client situation are crucial cognitive attributes. Creplet et al. refer to these types of skills as the "artist's knowledge, a real mix of imagination, creativity and vision in a given context". ${ }^{1945}$ Thereby, individual creativity is facilitated by the ability of an individual to create unusual interpretations of the issues at hand. ${ }^{1946}$ In addition, it is crucial that there are some team members with an analytical cognitive style, and some with an intuitive cognitive style. ${ }^{1947}$ The analytical problem solvers will approach the problem in an analytical and systematic way and will try to develop a method or procedure that systematically utilizes existing knowledge and experience. As such, their work can help in economizing time and effort during problem-solving. ${ }^{1948}$ In contrast, the intuitive team members can "sense" unusual connections and elements of the problem. They will

\footnotetext{
1944 See also Lachman (2000), p. 630. Empirical material suggests, however, that when clients face novel problems and new managerial discourses emerge, consultants usually have an interpretive dominance over clients. See Carter et al. (2004), p. 26.

Creplet et al. (2001), p. 1521.

See Ford (1996) and the discussion in chapter B.II.2.

See Hough/ogilvie (2005), p. 440; Mintzberg (1976), p. 57.

See Armstrong/Priola (2001), p. 288; Slocum (1978), p. 142 and the discussion in chapter B.II.2.
} 
impose less structure and will accept the ambiguity of problem situation, thus perceiving it in a holistic rather than reductionist way.

Because the client-consultant team constitutes the immediate social context in which the creative behavior occurs, certain characteristics of the client-consultant team can increase or decrease individual creativity. In other words, individual creativity can be greatly enhanced by social interaction and sharing of perspectives with individuals from different interpretive communities. ${ }^{1949}$ The most important factors that are found to increase individual creativity are group diversity and a collaborative work environment. ${ }^{1950}$ Group diversity ensures that members of the team are exposed to different interpretations and perspectives and increases the chances for the development of innovative solutions. Some level of group diversity can be achieved by the involvement of individuals from "dissenting” interpretive communities, i.e. interpretive communities with some unique beliefs and interpretive schemes that offer the potential for innovation and change. ${ }^{1951}$ On the other hand, a collaborative work environment ensures that such differences will be used in a constructive way for the development of novel interpretations and ideas. It is crucial because of the high conflict potential in client-consultant teams that face ambiguous situations.

\section{Interactive attributes}

As above argued, innovative problems require a very intensive interaction between clients and consultants and bear, at the same time, a very high conflict potential. For these reasons, persuasion and communication skills are of a far greater importance than in the case of the other types of consulting. Both clients and consultants can try to establish their perspective as the dominant one and the result of this struggle will depend not only on the cognitive skills of the team members but also on their persuasive skills. Thus, the use of rhetoric, powerful stories, metaphors, humor, and other symbolic strategies takes a prominent part in the team interactions.

\section{Structural relations in client-consultant projects}

The previous discussion showed to what extent cultural and power relations differ among the three types of client-consultant relationships. The following table summarizes the presented arguments and shows some suggestions about the differences that the three types of consulting relationships exhibit regarding their relations with the broader environment. ${ }^{1952}$ Structural relations orientated towards the management and coordination of the social interaction of the team members, including both the sharing of task-related knowledge and the development and use of concrete social mechanisms, are not included pp. 11. See also chapter B.II.4 where the different types of structural relations were introduced. Reihlen's concept is adapted for the purposes of this work; only activities that are directly related to the interaction within the client-consultant team are discussed. For example, the engagement of members of client-consultant teams in public discourse is not further analyzed within this work because it is rather detached from concrete client-consultant relationships.
} 
in this table because, as previously argued, they are crucial for successful teamwork independent of the concrete problem context.

Although informing and impressing relationships of the team with its broader environment are not discussed extensively within this work, table 15 suggests that the nature of cultural relations has a direct impact on these practices of client-consultant teams. It is also suggested that in the longer term, the reputation of consulting companies depends to a high degree on the type of cultural production that predominates within these firms. 


\begin{tabular}{|c|c|c|c|c|}
\hline & Functional goal & Expert consulting & Confirming consulting & Disturbing consulting \\
\hline Nature of problem & $\mathrm{n} / \mathrm{a}$ & Simple routine problems & Complex routine problems & Innovative problems \\
\hline $\begin{array}{l}\text { Cultural relations: } \\
\text { Problem-solving }\end{array}$ & $\begin{array}{l}\text { Knowledge } \\
\text { production/ } \\
\text { adapting to client } \\
\text { needs }\end{array}$ & $\begin{array}{l}\text { No new knowledge production; } \\
\text { efficient and standardized diagnosis } \\
\text { and treatment of problems; cultural } \\
\text { relations are restricted to the mere } \\
\text { application of existing knowledge; } \\
\text { very restricted adapting to client } \\
\text { needs (no adaptation of the used } \\
\text { techniques or models) }\end{array}$ & $\begin{array}{l}\text { Enhancing knowledge/experience of } \\
\text { familiar knowledge domains and existing } \\
\text { cultural artifacts; increasing efficiency of } \\
\text { problem-solving; sharing task-specific } \\
\text { knowledge between members of } \\
\text { orthogonal and enhancing interpretive } \\
\text { communities; adapting established } \\
\text { knowledge and "fixed” interpretations to } \\
\text { specific client needs }\end{array}$ & $\begin{array}{l}\text { Engaging in search for novel problem } \\
\text { structuring and problem solutions, } \\
\text { enhancing creativity; intensive sharing } \\
\text { of task-specific knowledge between } \\
\text { members of dissenting and orthogonal } \\
\text { interpretive communities; ongoing } \\
\text { alignment to client needs, preferences } \\
\text { and requirements through creation of } \\
\text { new solutions }\end{array}$ \\
\hline $\begin{array}{l}\text { Power relations: } \\
\text { Problem-solving }\end{array}$ & $\begin{array}{l}\text { Influencing } \\
\text { problem-solving }\end{array}$ & $\begin{array}{l}\text { No struggles for interpretive } \\
\text { dominance, problem-solving follows } \\
\text { an existing dominant interpretation } \\
\text { that is widely legitimized }\end{array}$ & $\begin{array}{l}\text { Problem-solving influenced by either } \\
\text { clients or consultants; struggle for } \\
\text { interpretive dominance regarding the } \\
\text { decomposition/ structure of the problem; } \\
\text { no struggle regarding sub problems }\end{array}$ & $\begin{array}{l}\text { Problem-solving influenced by both } \\
\text { clients and consultants; intensive } \\
\text { struggle for interpretive dominance } \\
\text { regarding the structuring and solving of } \\
\text { the problem }\end{array}$ \\
\hline $\begin{array}{l}\text { Relations } \\
\text { with the } \\
\text { environment: } \\
\text { Informing }\end{array}$ & $\begin{array}{l}\text { Information/ } \\
\text { communication of } \\
\text { results within the } \\
\text { own organization } \\
\text { and the professional } \\
\text { community }\end{array}$ & $\begin{array}{l}\text { Communicating results in order to } \\
\text { signal efficient use of existing } \\
\text { knowledge and efficient project } \\
\text { management }\end{array}$ & $\begin{array}{l}\text { Communicating results in order to signal } \\
\text { higher efficiency of problem-solving } \\
\text { and/or ability to modify/adjust existing } \\
\text { management techniques/problem } \\
\text { solutions to specific client needs }\end{array}$ & $\begin{array}{l}\text { Communicating innovative } \\
\text { solutions/ideas in order to achieve } \\
\text { knowledge diffusion and acceleration } \\
\text { of knowledge production, as well as } \\
\text { integration of dispersed knowledge }\end{array}$ \\
\hline $\begin{array}{l}\text { Relations } \\
\text { with the } \\
\text { environment: } \\
\text { Impressing }\end{array}$ & Reputation creation & $\begin{array}{l}\text { Developing and communicating } \\
\text { reputation based on the price } \\
\text { advantage of the offered service } \\
\text { rather than on special knowledge or } \\
\text { problem-solving; reputation built } \\
\text { upon the ability to solve problems in } \\
\text { the most efficient way }\end{array}$ & $\begin{array}{l}\text { Developing and communicating } \\
\text { reputation of a trustworthy problem } \\
\text { solver showing consistence with } \\
\text { legitimated, accepted organizational } \\
\text { techniques or practices but still providing } \\
\text { an individualized service; reputation } \\
\text { built upon the ability to modify } \\
\text { knowledge and problem solutions }\end{array}$ & $\begin{array}{l}\text { Developing and communicating } \\
\text { reputation of an innovative, creative } \\
\text { problem solver able to break with } \\
\text { established ways of thinking and doing; } \\
\text { of a creative, cooperative interpretation } \\
\text { or "sparring" partner; reputation built } \\
\text { upon the ability to disturb established } \\
\text { practices and ways of thinking }\end{array}$ \\
\hline
\end{tabular}

Table 15: Structural relations in client-consultant projects 


\section{Discussion}

\section{Contributions}

The proposed interpretive model of the client-consultant relationship provides a multifaceted picture of the complex interaction between clients and consultants during the process of problem-solving. The following discussion summarizes some of the major contributions of the model towards an enhanced understanding of the client-consultant relationship and its success factors.

First, within the interpretive model it is emphasized that two main types of knowledge are relevant when discussing the success of client-consultant teams: taskrelated knowledge, which enables effective teamwork, and task-specific knowledge, which is problem oriented and is relevant for the concrete problem-solving process. Client-consultant teams are regarded as social communities, which emphasizes the importance of shared task-related knowledge between team members as well as the importance of concrete social mechanisms that serve the management and coordination of team members' activities. Without shared task-related knowledge and such mechanisms, client-consultant teams cannot work effectively together. The importance of this type of shared understanding has been largely ignored by the existing models of client-consultant interaction, which concentrate on issues related to task-specific knowledge. Thus, the interpretive model provides some important insights in this area emphasizing that clients and consultants need to pay special attention to the coordination and integration of their actions if they are to work effectively as a team.

Second, for knowledge transfer to take place between clients and consultants, it is not sufficient to enable an open and minimally defensive interaction between them, as Schön suggests. The involved individuals need to recognize their different perspectives and reflect upon them but they also need to use a number of different mechanisms that can help them to transfer knowledge and to learn from each other. The ability to share a perspective with others presupposes that one's interpretation-either in the case of an individual or as that of an interpretative community-is made visible for self-reflection. Such a visible representation can become a boundary object and provides a basis for sharing knowledge with others. Stories, metaphors, and concepts are some examples of such artifacts. The interpretive model shows how boundary objects can be used to facilitate problem-solving processes within client-consultant teams. In addition, the role of communication between the involved individuals is also emphasized, either in a direct way, involving reasoning and argumentation, or indirectly, with the help of brokers.

Third, because existing knowledge structures the way individuals use information, to create new knowledge, team members need to critically reflect on their knowledge and reframe it. Such reflection is enabled to a high degree by the communication with individuals with different perspectives. Therefore, the interpretive model emphasizes that knowledge creation takes place in a context of different discursive practices or interpretive communities. In particular, it argues that the knowledge creation process in 
client-consultant teams is more successful when clients are actively involved in the problem-solving process.

Forth, acknowledging the existence of different interpretive communities and the importance of both consultant's and client's interpretations for the problem-solving process, the interpretive model does not imply that consultants are more powerful than clients. Rather, it advocates mutually dependency, which leads to natural questions about the balancing of the relationship. Furthermore, the model argues that interpretive communities are often engaged in on-going struggles to enforce their own perspectives on problem situations and problem solutions. The model discusses this issue for the case of client-consultant teams and explains the creation and dissemination of new management practices. It shows that consultants often try to gain repeatedly acceptance for their own perspectives in particular problem contexts in order to establish themselves as the experts, or "obligatory passage points", for solving such problems. Through discursive moves, consultants challenge client's definitions of problems and translate them by appealing on their knowledge and experience of similar situations. After finishing a specific consulting project, consultants promote the problem solution as the legitimate one and themselves as the experts in this area in an attempt to win future projects with other clients. In this process, clients that have been "enrolled" into consultants' discourse often play an active role as adopters and disseminators of consultants' interpretations. After a number of projects, consultants achieve a partial fixing of their interpretation or problem solution, which is consequently adopted by other actors within the organizational field of management knowledge production. In such a way, a new management "fashion" is born.

By showing how the reputation of being an expert is "fixed" in previous consulting projects and discourses, the interpretive model advances the expert model. At the same time, it stresses that clients as well can gain interpretive dominance. Thus, the model emphasizes that both clients and consultants possess important knowledge and that a successful problem-solving requires a more or less intensive sharing of their perspectives. Furthermore, it is recognized that in complex and innovative problem contexts, several possible interpretations and solution paths can be proposed. Moreover, the differences between these perspectives often cannot be overcome with the help of rational problemsolving methods and practices, which brings in considerations of power. The interpretive model stresses that in such situations, it is necessary for one party to achieve interpretive dominance; otherwise, it will be difficult to find a problem solution. Thus, it is recognized that power can be both negative and positive but ultimately, it is an important part of problem-solving processes and cannot be ignored. Therefore, the interpretive model broadens the critical model. The latter regards power as a result of mastering the impression of possessing authoritative knowledge in areas that clients value and emphasizes its negative effects. The former emphasizes that power is not always predetermined through existing structures and management fads, but arises during the client-consultant interaction out of a discourse over which perspective should be taken as a basis for a problem solution. In other words, power has both a symbolic and a strategic character. 
The interpretive model proposes that in the case of simple routine problems a limited interaction between clients and consultants is sufficient, as it is more efficient to rely on existent problem solution paths. However, it is emphasized that simple routine problems are not very common in the context of management and clients and consultants should use this type of consulting with a great care. In particular, they should always carefully consider if the problem situation really is so familiar and unspecific. Otherwise, there is the danger that they will generate solutions that do not fit the problem, something that is reported quite often in practice and is a major reason for clients' dissatisfaction with consulting services. In the case of novel and/or complex problems with high degree of “interpretive viability”, a much more intensive interaction within the client-consultant team is required. Stories, rhetoric, metaphors, and other boundary objects have an important role as communication mechanisms but clients and consultants should be aware that they often represent existing knowledge and can negatively influence the development of novel interpretations. In addition, boundary objects are important power tools that both clients and consultants can use, consciously or unconsciously, when attempting to gain interpretive dominance and "enroll" others into their perspective. Thus, compared to Schön's reflective practitioner model, the interpretive model suggests concrete mechanisms that can be used in the problem-solving process within clientconsultant teams for knowledge transfer and creation, as well as for influencing other members of the team. As such, the model offers an in depth study of the nature and role of power for the success of problem-solving within client-consultant team, a topic ignored by Schön.

It can be concluded that the interpretive model does not only offer a different theoretical view of client-consultant relationships but also has important practical implications for the management of client-consultant teams. The proposed typology of client-consultant relationships outlines some of the major differences in consulting projects including differences in cultural and power relations as well as differences in the requirements related to the personal attributes of the team members. Additionally, table 15 briefly shows the influence of cultural and power relations on the relations of clientconsultant teams with their broader environment.

\section{Shortcomings}

The interpretive model could be criticized because it is theoretically deduced rather than empirically induced. Although it is recognized that the further development of the model requires it to be empirically tested, in one way or another, it can be argued that several of the theoretical works that the model builds upon are based on empirical research, and as a consequence, that the model's insights are not foreign to the reality of client-consultant relationships. Therefore, it is believed that the model, although theoretical and explanatory in nature, still can provide clients and consultants with some helpful insights regarding their cooperation.

In addition, critical readers might remark that in providing some (prescriptive) suggestions on how to improve the collaboration between clients and consultants, as well as by stating that certain types of client-consultant interaction are more efficient in some 
circumstances then other forms of interaction, the model, which is based in the philosophical tradition of critical realism, is rather compatible with positivist and functionalist epistemology. In particular, it could be criticized that although the model studies the role of subjective meanings and interpretations of the involved individuals and communities, the relationships between the variables and actors are explained in a positivist way, constructed by an external analyst. In recognition of such critical arguments, the aim of the interpretive model could be interpreted as to generate a "reflective dialogue" between readers rather than to offer generalizable normative prescriptions. In other words, the model would not pretend to be able to offer practitioners universal generalizations but it would empower practitioners to make links with and reflect upon the implications of the model, "thus leading practitioners to undertake potentially novel forms of action”. ${ }^{1953}$ Ultimately, the model aims at directing the attention of both practitioners and their clients to hitherto under explored aspects of client-consultant relationships.

An additional critical point to the model could be related to the suggestion that dominant interpretive communities or coalitions often take over the problem-solving process, therefore reducing the probability for the generation of creative problem solutions. It was argued that the problem-solving process is influenced by emerging power relations within the client-consultant team. Furthermore, it was suggested that if an actor, or a group of actors, succeeds in gaining interpretive dominance over the rest of the client-consultant team, such that the rest of the team is "locked" into an established interpretation of the problem situation, there would be only a low possibility for the creation of novel problem solutions. Moreover, a number of critics of consulting argue that consultants usually develop interpretive dominance and use their rhetorical power to persuade clients "to pay for more", ${ }^{1954}$ pointing out to new and additional problems, and making themselves "indispensable". ${ }^{1955}$ Thus, readers could put the question, is this always the case? Does the interpretive model conclude that no innovation is possible or that clients are powerless "marionettes on the strings of [consulting] fashions"? ${ }^{1956}$ As argued in chapter D.IV.6.3, the interpretive model emphasizes that the development of interpretive dominance is a contested process, in which clients can be successful as well. Furthermore, it is stressed that the rhetorical power of consultants (or clients) does not always have negative effects. For example, the existence of established meanings and interpretive positions could enhance the solution of problems that fall within the domain of existing knowledge positions and, hence, fasten the problem solution in an efficient way, which is what clients sometimes wish. ${ }^{1957}$ Furthermore, if several interpretive views of a problem and problem solution are legitimate because each of the involved interpretive communities sees different aspects of the problem and generates different solution paths, the involved individuals might not be able to agree on one solution by following a rational problem-solving procedure. In other words, rational decision-making

Tsoukas/Knudsen (2003), pp. 15-16.

See Skapinker (2005), p. 13; one of the recent examples.

See Ashford (1998), p. 31.

See Kieser (2002a), p. 176.

See Creplet et al. (2001), p. 1518.
} 
based on argumentations would not be possible. Given the tight time frames that clients and consultants have to solve problems, it would be necessary for one interpretive community to impose its interpretive dominance on others for a solution to be created. Otherwise, it would be difficult to finish the project on time. ${ }^{1958}$ In other words, interpretive dominance or rhetorical power respectively can have both a positive and negative influence on the outcome of consulting projects. Thus, it is important for clients and consultants to be aware of possible power dynamics during their interactions in order to react appropriately. In particular, it is only if they are aware of how existing power structures and relations influence their thinking and interactions, that there is a chance for them to break out of these structures.

An additional shortcoming of the model, as already stated, is that ignores a number of important issues when considering client-consultant relationships, especially those that are related to long-term cooperation between clients and consultants. ${ }^{1959}$ Trust, for example, is an important aspect of client-consultant relationships that influences not only the process of knowledge transfer and creation but also the power relations between clients and consultants. It can be argued, for example, that when both parties know and trust each other there is no need for actors to develop interpretive dominance. Rather, the involved actors will be willing to adopt each other's perspectives on particular issues if they trust their knowledge and experience. What the interpretive model makes clear is, however, that trust might not be independent of power. In other words, it might be the result of previous interactions, when some of the involved individuals were not aware they were being "enrolled" into a particular perspective and being made a part of an alliance for the further promotion of this perspective. Thus, trust in one's expertise can be attributed to institutionalized discourses presented as rational and true. ${ }^{1960}$

\section{Summary}

This chapter introduced a model of client-consultant interaction based on the concept of interpretive communities. This concept rests upon Loasby's notion that all people, “in varying ways and to varying extents, interpret what they observe and take decisions according to their interpretation”. ${ }^{1961}$ People who share similar meanings about a range of issues and events build specific worldviews or perspectives, or an interpretive community. ${ }^{1962}$ As such, interpretive communities are manifested through individuals' interpretive schemes or shared cognitive maps.

\footnotetext{
1958 The discussion on power within the interpretive model emphasized that actors often engage in a process of interpretive struggle and try to develop interpretive dominance without being aware of it. In other words, this process is often nonintentional.

As stated in the introduction, long-term client-consultant relationships are not discussed within this work as it concentrates on the interaction between clients and consultants in particular projects. This is, of course, not to say that such long-term relationships are nor relevant, as briefly indicated in chapter D.III.3.7.

See the discussion in chapter D.IV.

Loasby (1983), p. 357.

See Fish (1980), p. 14.
} 
Because the shared schemes of an interpretive community influence the interpretation of the members of this community, different schemes can lead to dramatically different analysis of the same event or topic. ${ }^{1963}$ Therefore, one can argue persuasively that the norms and rules associated with the interpretation of any topic are embedded in the practices and assumptions of interpretive communities. Hence, interpretive communities differ in their knowledge base not only at a specific point of time but also permanently, as they will interpret many common events in a different way. Unfortunately, schemes are not infallible guides to individuals. Some of them can be relatively inaccurate representations of the world, particularly as environmental and contextual conditions change. In such situations, solutions based on experience or solutions by analogy may be inappropriate, ${ }^{1964}$ the implication being that the most successful decision makers will be those individuals who learn to revise their perspectives appropriately. Often, such revisions of one's perspective are facilitated through one's interaction with members from different interpretive communities. If such revisions take place on a large scale, the shared meanings of any particular community can, and generally will, be transformed. ${ }^{1965}$ Therefore, interpretive communities are not stable.

In this model, the client-consultant team is conceptualized not only as a group of people from different organizations but also as a specific combination of interpretive communities. It is a community of interpretive communities, which implies that in any consulting project there are many different perspectives and frames with regard to any particular situation. Accordingly, clients and consultants may have problems in understanding each other's "language". Therefore, successful cooperation requires the translation of the different perspectives so that some sharing of meanings is achieved. Furthermore, the interpretations of all involved individuals are potentially important when discussing the problem. This implies the existence of mutual dependency between clients and consultants. In such cases, rational problem-solving based on the best available interpretation and argument is not possible as there is no generally best interpretation, nor are there general agreed upon methods of even determining which interpretation is the most appropriate. As Flyvbjerg notes, "communication is more typically characterized by nonrational rhetoric and maintenance of interests than by freedom from domination and consensus seeking". ${ }^{1966}$ Ultimately, power is part of every relation and it influences every human interaction. It acts through knowledge, influencing justifications and the direction of attention. Therefore, to discuss a fully rational decision process without accounting for the influence of power would mean ignoring the reality of decision-making in human societies.

In a next step, a multifaceted picture of the nature and role of power within clientconsultant teams was provided. Drawing the argument upon a critical realist approach to organizations and power, it was argued that both knowledge and power are not given and stable resources but rather are contested areas, which influence each other. This has a 
number of implications for the outcome of consulting projects. First, positional, or episodic power, as expressed through the authority of the client sponsor and client project manager, can influence the outcome of consulting projects, accounts of which have been reported by previous research ${ }^{1967}$ but in this case, no real interaction between clients and consultants takes place. Second, rhetorical power that emerges during the interaction between the "problem owners" and the consultants has a direct influence on the outcome of consulting projects, which is mirrored in the ability of certain actors to "enroll" others into their perspectives and develop interpretive dominance. Rhetorical power is dependent on the relevance and importance of actors' knowledge and on their on-going ability to enforce their perspective and persuade others of the superiority of their knowledge. ${ }^{1968}$ It can result either in the enforcement of existing discourses and interpretations or in the creation of new interpretations and solutions. Third, symbolic resources are important tools not only for communication and knowledge transfer but also for the development of rhetorical power and the maintenance of interpretive dominance. Forth, rhetorical power does not always have a negative influence as it can fasten problem solutions in cases when the problem is rather familiar or when no consensus can be found by following rational decision-making procedures. Consequently, rhetorical power has both a strategic and symbolic character.

By taking into account the historical development of management knowledge and practices, the source of established interpretations becomes clear. They are the result of interpretations or problem solutions "fixed" as dominant interpretive positions through previous discourses or projects. Therefore, previous problem solutions may represent power positions in future client-consultant projects, and as such, they may influence future problem-solving processes. Accordingly, this model suggested an interpretivist view of the nature of professional services, emphasizing that professional knowledge and expertise is ultimately imbued with power. 


\section{E. Conclusion}

The rising diversity and complexity of knowledge in the modern economic world requires firms to learn to work effectively together if they want to be successful in the longer term. This work concentrates on one type of companies-professional business service firms in general and management consulting in particular-that belong to the most advanced organizations with regard to knowledge transfer and knowledge management. Because of the nature of their services, the interaction with their clients is crucial for a successful value creation. Therefore, professional business service firms are reliant on their ability to transfer and create knowledge in their day-to-day work with clients.

The existing research on the nature of the client-consultant relationship in professional business service firms was systemized in three major models of the clientconsultant interaction. Following the proposed framework for the analysis of clientconsultant relationships, the models' contributions and shortcomings were pointed out. The need of a different model was thus identified, a model that accounts for the complex and multifaceted nature of the client-consultant relationship and puts it into a new theoretical background.

The suggested interpretive model provides a valuable contribution to the existing literature, as it builds upon and advances the existing models of client-consultant interaction. It also has value for the practice of professional business service firms, as it makes managers and consultants aware of under explored issues in their interactions during consulting projects, and gives them some operational mechanisms for improving their interaction. The interpretive model stresses that clients need to be aware of the different roles that consultants play during client-consultant interactions. It is too simplistic to regard consultants as only experts, impression managers, reflective practitioners, or disturbers of established interpretations. They are, rather, all of these to some degree, which depends on the problem situation, the client's qualities as a partner and client's goals when engaging consultants. Consultants might use, for example, symbolic interaction in order to open meanings to new inflections in experimentation. However, at the same time they can try to manage the flow of shifting perspectives in order to secure their legitimacy and to guarantee the generation of a problem solution within the tight time frames of the project-as they have, not to forget, to demonstrate efficiency as well. Therefore, knowledge transfer and creation can be at the same time strategic and symbolic.

Although the interpretive model is not normative, it proposes possible paths as how to reform professional practice in order to foster individual and collective acts of professional-client collaborations and the successful realization of professional-client interpretive and social communities. The core of these suggestions resides in the practices of daily client-professional encounters. ${ }^{1969}$ Thus, in order to improve their collaboration, 
both clients and professionals have to "relearn their habits of knowing, thinking, and speaking”. ${ }^{1970}$ Professionals must learn that their claims for neutrality are false and recognize their role in reality construction. They must learn to enlarge their professional discourses to fit, rather than silence, clients' stories. In addition, they must learn to redefine institutional roles and relations to permit clients and interpretive communities to collaborate in telling their stories and sharing their interpretations, "even if the bridges of collaboration are makeshift and short-lived". ${ }^{1971}$ At the same time, clients need to be aware of the shifting nature of consulting. They have to choose carefully which type of consulting will meet their needs in the best possible way, and to take into account the consequences this has for their relationship with the consultants and for the outcomes of the consulting project. Thus, rather than looking for the "'ideal' type of client interaction”, as suggested by some, ${ }^{1972}$ clients should be aware that there are different types of appropriate client-consultant relationships and that the choice of one depends on the particular problem at hand, and is an outcome of construction and deconstruction of meanings and interpretations. As such, it is often difficult to decide ex ante upon the best business model for a particular consulting project. Rather, this decision has to arise during the interaction between clients and consultants. Thus, whereas this work aimed at explaining the nature of client-consultant relationships, based on the insights of the interpretive model, an extensive normative approach to client-consultant relationships can be developed in future research.

The interpretive model is a knowledge and power based approach to the clientconsultant relationship. The value of the interpretive model is the same as any other model - it offers the readers the possibility to see how various components, elements, and forces come together to explain the issue of interest, in this case, the client-consultant interaction. Therefore, an important advantage of the interpretive model is its ability to integrate diverse perspectives, each of which captures aspects of some explanatory power. The model provides a way of illustrating a number of possible explanatory constructs, some of which have received empirical support from one or more streams of research. As such, this model offers the opportunity to study the chosen phenomenon in a more thorough and integrating way than previously done. The model overcomes long existing boundaries between different research streams and perspectives, thus presenting a more realistic, less complexity avoiding view of the client-consultant relationship. Ultimately, the empirical examination of the question, to what extent are the main components of this model used in practice, is a necessary next step of the development of this model. The process of power emergence and its role are two topics that are still only scarcely empirically analyzed.

Furthermore, because client-consultant interactions are embedded in a broader environment consisting not only of different interpretive communities but also of different national structures and relationships, it can be assumed that the relationship between clients and consultants and the type of interaction they adopt, differs from

\footnotetext{
1970 Ibid, p. 1763.

1971 Alfieri (1994), p. 1764.

1972 See, e.g., Fosstenlokken et al. (2003), p. 876.
} 
country to country. Some existing historical accounts about the role of consulting companies support this argument. Kipping, for example, points out that in the 1980's consultants in Germany acted predominantly as change facilitators or trainers due to the involvement of middle managers and workers in the organizational change processes in Germany. ${ }^{1973}$ In France, in contrast, consultants operated mainly as direct advisors to the company's executives, collecting information, and providing justification for 'unpopular' measures. It can be suggested, then, that consultants in Germany were using a more interaction intensive consulting model, whereas consultants in France were probably following the expert model. Thus, additional empirical research is needed in order to find out to what extent national differences influence the adopted consulting model.

Future research on consulting needs, above all, to recognize the complex nature of client-consultant relationships and to combine different theoretical and methodological approaches when studying the work of professional business service firms. This work is a first step towards such multidisciplinary approach. 


\section{F. References}

“Consultant, Heal Thyself”(2002) The Economist (US Edition), Nov 2, 2002.

Abbott, A. (1988) The System of Professions. Chicago: University of Chicago Press.

Abbott, A. (1991) The order of professionalization. An empirical analysis. Work \& Occupations, Vol. 18, No. 4, 355-385.

Abrahamson, E. (1991) Managerial fads and fashions: The diffusion and rejection of innovations. Academy of Management Review, Vol. 16, No. 3, 586-612.

Abrahamson, E. (1996) Management fashion. Academy of Management Review, Vol. 21, No. 1, 254-285.

Abrahamson, E./Fombrun, C. (1994) Macrocultures: Determinants and consequences. Academy of Management Review, Vol. 19, No. 4, 728-755.

Ackoff, R. (1974) Redesigning the Future: A Systems Approach to Societal Problems. New York: Willey.

Ackroyd, S. (2000) Connecting organisations and societies: a realist analysis of structures. In: Ackroyd, S./Fleetwood, S. (Eds.), Realist Perspectives on Management and Organisations. London: Routledge, 87-108.

Ackroyd, S./Fleetwood, S. (2000) Realism in contemporary organisation and management studies. In: Ackroyd, S./Fleetwood, S. (Eds.), Realist Perspectives on Management and Organisations. London: Routledge, 3-25.

Aharoni, Y. (1993a) Globalisation of professional business services. In: Aharoni, Y. (Ed.), Coalitions and Competition. London: Routledge, 1-19.

Aharoni, Y. (1993b) Ownerships, networks and coalitions. In: Aharoni, Y. (Ed.), Coalitions and Competition. London: Routledge, 121-142.

Aharoni, Y. (1995) The role of reputation in global professional business services. Working paper CR-MM-95-01, Université de Neuchâtel, Faculté de droit ed des sciences économiques, Division économique et sociale. Neuchatel.

Aharoni, Y. (1997) Management consulting. In: Aharoni, Y. (Ed.), Changing Roles of State Intervention in Services in an Era of Open International Markets. Albany: State University of New York Press.

Alfieri, A. (1994) Practicing community. Harvard Law Review, Vol. 107, No. 7, 17471764.

Alvesson, M. (1993) Organizations as rhetoric: Knowledge-intensive firms and the struggle with ambiguity. Journal of Management Studies, Vol. 30, No. 6, 9971015.

Alvesson, M. (1995a) Management of Knowledge-Intensive Companies. Berlin, New York.

Alvesson, M. (1995b) The meaning and meaninglessness of postmodernism: Some ironic remarks. Organization Studies, Vol. 16, No. 6, 1047-1075.

Alvesson, M. (2001) Knowledge work: Ambiguity, image and identity. Human Relations, Vol. 54, No. 7, 863-886.

Alvesson, M./Deetz, S. (2000) Doing Critical Management Research. London: Sage. 
Alvesson, M./Johansson, A. (2002) Professionalism and Politics in Management Consultancy Work. In: Clark T./Fincham, R. (Eds.), Critical Consulting. New Perspectives on the Management Advice Industry. Oxford: Blackwell Business, 228-246.

Alvesson, M./Kärreman, D. (2000) Taking the linguistic turn in organizational research. The Journal of Applied Behavioral Science, Vol. 36, No. 2, 136-158.

Alvesson, M./Kärreman, D. (2001) Odd couple: Making sense of the curious concept of knowledge management. Journal of Management Studies, Vol. 38, No. 7, 9951018.

Alvesson, M./Willmott, H. (1992) On the idea of emancipation in management and Organization Studies. Academy of Management Review, Vol. 17, No. 3, 432-464.

Amabile, T. (1983) The social psychology of creativity: A componential conceptualization. Journal of Personality and Social Psychology, Vol. 45, No. 2, 357-377.

Amabile, T. (1988) A model of creativity and innovation in organizations. Research in Organizational Behavior, Vol. 10, 123-167.

Argyris, C. (1970) Intervention Theory and Method. Reading: Addison Wesley.

Argyris, C./Schön, D. (1996) Organizational Learning II: Theory, Method, and Practice. Reading, MA: Addison-Wesley Publishing.

Armbrüster, T./Kieser, A. (2001) Unternehmensberatung-Analysen einer Wachstumsbranche. Die Betriebswirtschaft, Vol. 61, No. 6, 688-709.

Armbrüster, T./Kipping, M. (2002) Strategy consulting at the crossroads: Technical change and shifting market conditions for top-level advice. International Studies of Management \& Organization, Vol. 32, No. 4, 19-42.

Armstrong, S./Priola, V. (2001) Individual cognitive styles and the composition of selfmanaging work-teams. Small Group Research, Vol. 32, No. 4, 283-312.

Ashford, M. (1998) Con Tricks. The Shadowy World of Management Consultancy and How to Make it Work for You. London: Simon \& Schuster.

Axelrod, R. (1997) The dissemination of culture. A model with local convergence and global polarization. The Journal of Conflict Resolution, Vol. 41, No. 2, 203-226.

Ayas, K./Zeniuk, N. (2001) Project-based learning: building communities of reflective practitioners. Management Learning, Vol. 32, No. 1, 61-76.

Barker, J. (1993) Tightening the iron cage: Concertive control in self-managing teams. Administrative Science Quarterly, Vol. 38, 408-437.

Barley, S. (1983) Semiotics and the study of occupational and organisational cultures. Administrative Science Quarterly, Vol. 28, No. 3, 393-413.

Barley, S./Meyer, G./Gash, D. (1988) Cultures of culture: Academics, practitioners and the pragmatics of normative control. Administrative Science Quarterly, Vol. 33, No. 1, 24-60.

Barney, J. (1991) Firm resources and sustained competitive advantage. Journal of Management, Vol. 17, No. 1, 99-120.

Bartlett, C. (2000) McKinsey \& company: managing knowledge and learning. Boston: Harvard Business School Case, 9-396-357. 
Bartunek, J./Gordon, J./Wathersby, R. (1983) Developing “complicated” understanding in administrators. Academy of Management Review, Vol. 8, No. 2, 273-284.

Bartunek, J./Moch, M. (1987) First-order, second-order, and third-order change and organization development interventions: A cognitive approach. Journal of Applied Behavioral Science Vol. 23, 481-500.

Bartunek, J./Ringuest, J. (1989) Enacting new perspectives through work activities during organizational transformation. Journal of Management Studies, Vol. 26, 541-560.

Bechky, B. (2003) Sharing Meaning across occupational communities: The transformation of understanding on a production floor. Organization Science, Vol. 14, No. 3, 312-330.

Becker, M. (2001) Managing dispersed knowledge: Organizational problems, managerial strategies, and their effectiveness. Journal of Management Studies, Vol. 38, No. 7, 1037-1051.

Behrens, W./Delfmann, W. (2002) Quantitative Planung. Stuttgart: Schäffer-Poeschel.

Bell, D. (1973) The Coming of Post-industrial Society: A Venture in Social Forecasting. New York: Basic Books.

Benford R./Snow D. (2000) Framing processes and social movements: An overview and assessment. Annual Review of Sociology Vol. 26, 611-639.

Benveniste, G. (1987) Professionalizing the Organization: Reducing Bureaucracy to Enhance Effectiveness. San Francisco: Jossey-Bass.

Berger, P./Luckman, T. (1967) The Social Construction of Reality: A Treatise in the Sociology of Knowledge. Harmondsworth, Middlesex: Penguin.

Berkowitz, D./TerKeurst, J. (1999) Community as interpretive community: Rethinking the journalist-source relationship. Journal of Communication, Vol. 49, No. 3, 125136.

Bernsen, N. (1982) Elementary knowledge: transcendental pragmatics without consensus theory and ideal community of communication. Acta Sociologica, Vol 25, No. 3, 235-47.

Bessant, J./Rush, H. (1995) Building bridges for innovation: The role of consultants in technology transfer. Research Policy, Vol. 24, 97-114.

Bettencourt, L./Ostrom, A./Brown, S./Roundtree, R. (2002) Client co-production in knowledge-intensive business services. California Management Review, Vol. 44, No. 4, 100-128.

Bettenhausen, K. (1991) Five years of group research: What have we learned and what needs to be addressed. Journal of Management, Vol. 17, No. 2, 345-381.

Bettenhausen, K./Murnighan, J. (1985) The emergence of norms in competitive decisionmaking groups. Administrative Science Quarterly, Vol. 30, 350-372.

Bettis, R./Prahalad, C. (1995) The dominant logic: Retrospective and extension. Strategic Management Journal, Vol. 16, 5-14.

Blackler, F. (1995) Knowledge, knowledge work and organizations: An overview and interpretation. Organization Studies Vol. 16, No.6, 1021-1046.

Blackler, F. (2000a) Collective wisdom. People Management, Vol. 6, No. 13, 61-63. 
Blackler, F. (2000b) Power, mastery and organizational learning. Journal of Management Studies, Vol. 37, No. 6, 833-851.

Blau, J. (1996) Organizations as overlapping jurisdictions: Restoring reason in organizational accounts. Administrative Science Quarterly Vol. 41, 172-179.

Block, P. (2001) Flawless Consulting. Fieldbook \& Companion. A Guide to Understanding Your Expertise. San Francisco: Jossey-Bass/Pfeiffer.

Bloomfield, B./Best, A. (1992) Management consultants: systems development, power and the translation of problems. The Sociological Review, Vol. 41, 533-560.

Bloomfield, B./Danieli A. (1995) The role of management consultants in the development of information technology: the indissoluble nature of of sociopolitical and technical skills. Journal of Management Studies, Vol. 33, No. 1, 2746.

Bloomfield, B./Vurdubakis, T. (2002) The vision thing: Constructing technology and the future in management advice. In: Clark, T./Fincham, R. (Eds.), Critical consulting. New perspectives on the management advice industry. Oxford: Blackwell Publishers, 115-129.

Bloor, G./Dawson, P. (1994) Understanding professional culture in organizational context. Organization Studies, Vol. 15, No. 2, 275-295.

Boje, D. (1991) The storytelling organization: A study of story performance in an office supply firm. Administrative Science Quarterly, Vol. 36, No. 1, 106-126.

Boje, D. (1995) Stories of the storytelling organization: A postmodern analysis of Disney’s as “Tamara-Land”. Academy of Management Journal, Vol. 38, No. 4, 997-1035.

Boland, R./Singh, J./Salipante, P./Aram, J./Fay, S./Kanawattanachai, P. (2001) Knowledge representations and knowledge transfer. Academy of Management Journal, Vol. 44, No. 2, 393-417.

Boland, R./Tenkasi, R. (1995) Perspective making and perspective taking in communities of knowing. Organization Science, Vol. 6, No. 4, 350-372.

Boland, R./Tenkasi, R./Te'eni, D. (1994) Designing information technology to support distributed cognition. Organization Science Vol. 5, No. 3, 456-475.

Bonchek, M. (2002) Consultant, heal thyself. Business Week, February 4, Issue 3768, 14.

Bradshaw-Camball, P./Murray, V. (1991) Illusions and other games: A trifocal view of organizational politics. Organization Science, Vol. 2, No. 4, 379-398.

Brante, T. (1988) Sociological approaches to the professions. Acta Sociologica, Vol. 31, No. 2, 119-142.

Briers, M./Chua, W. (2001) The role of actor-networks and boundary objects in management accounting change: a field study of an implementation of activitybased costing. Accounting, Organizations and Society, Vol. 26, No.3, 237-269.

Bromme, R./Rambow, R./Nückles, M. (2001) Expertise and estimating what other people know: The influence of professional experience and type of knowledge. Journal of Experimental Psychology: Applied, Vol. 7, No.4, 317-330.

Bromme, R./Tillema, H. (1995) Fusing experience and theory: the structure of professional knowledge. Learning and Instruction, Vol. 5, 261-267. 
Bronner, R. (1993) Decision-making in complex situations - results of german empirical studies. Management International Review. Vol. 33, No. 1, 7-25.

Brown, A. (1995) Managing understandings: Politics, symbolism, niche marketing and the quest for legitimacy in IT implementation. Organization Studies, Vol. 16, No. 6, 951-969.

Brown, A./Coupland, C. (2005) Sounds of silence: Graduate trainees, hegemony and resistance. Organization Studies, Vol. 26, No. 7, 1049-1069.

Brown, J. (2005) Narratives as a knowledge medium in organizations. In: Brown, J./Denning, S./Groh, K./Prusak, L. (Eds.), Storytelling in Organizations. Burlington: Elsevier, 53-96.

Brown, J./Collins, A./Duguid, P. (1989) Situated cognition and the culture of learning. Educational Researcher, Vol. 18, No. 1, 32-42.

Brown, J./Duguid, P. (1991) Organizational learning and communities-of-practice: Toward a unified view of working, learning, and innovation. Organization Science, Vol. 2, No. 1, 40-57.

Brown, J./Duguid, P. (2001) Knowledge and organization: A social-practice perspective. Organizational Science, Vol. 12, No. 2, 198-213.

Bryson, J. (1997) Business service firms, service space and the management of change. Journal of Entrepreneurship and Regional Development, Vol. 9, No. 2, 93-111.

Bunge, M. (1979) Treatise on Basic Philosophy Vol. 4. Ontology II: A World of Systems. Dordrecht: D. Reidel Publishing.

Bunge, M. (1983a) Treatise on Basic Philosophy Vol. 5. Epistemology \& Methodology I: Exploring the World. Dordrecht: D. Reidel Publishing.

Bunge, M. (1983b) Treatise on Basic Philosophy Vol. 6. Epistemology \& Methodology II: Understanding the World. Dordrecht: D. Reidel Publishing.

Bunge, M. (1985) Treatise on Basic Philosophy Vol. 7. Epistemology \& Methodology III: Philosophy of Science and Technology. Dordrecht: D. Reidel Publishing.

Bunge, M. (1996) Finding Philosophy in Social Science. New Haven: Yale University Press.

Bunge, M. (1998) Social Science under Debate. Toronto: University of Toronto Press.

Buono, A. (2001) Introduction. In: Buono, A. (Ed.), Current Trends in Management Consulting. New York: Information Age Publishing, vii-xvi.

Burrell, G./Morgan, G. (1979) Sociological Paradigms and Organisational Analysis. London: Heinemann.

Burt, R. (1992) Structural Holes: The Social Structure of Competition. Cambridge, MA: Harvard University Press.

Burt, R. (1997) The contingent value of social capital. Administrative Science Quarterly, Vol. 42, 339-365.

Byrnes, N. (2004) Professional services: Auditors applaud, consultants cope. Business Week, Jan. 12 2004, No. 3865, 120.

Calas, M./Smircich, L. (1999) Past postmodernism? Reflections and tentative directions. Academy of Management Review, Vol. 24, No. 4, 649-71. 
Callon, M. (1986a) Some elements of a sociology of translation: domestication of the scallops and the fishermen of St Brieuc Bay. In: Law, J. (Ed.), Power, Action and Belief. London: Routledge \& Kegan Paul, 196-233.

Callon, M. (1986b) The sociology of an actor-network: The case of the electric vehicle. In: Callon, M./Law, J./Rip, A. (Eds.) Mapping the Dynamics of Science and Technology. Houndmills: MacMillan, 19-34.

Callon, M. (1991) Techno-economic networks and irreversibility. In: Law, J. (Ed.) A Sociology of Monsters: Essays on Power, Technology and Domination. London: Routledge, 132-164.

Callon, M./Latour, B. (1981) Unsrewing the big Leviathan: how actors macro-structure reality and how sociologists help them to do so. In: Knorr-Cetina, K./Cicourel, A. V. (Eds.) Advances in Social Theory and Methodology. Boston: Routledge \& Kegan Paul, 277-303.

Cannon-Bowers, J./Salas, E. (2001) Reflections on shared cognition. Journal of Organizational Behavior Vol. 22, 195-202.

Carley, K. (1991) A theory of group stability. American Sociological Review , Vol. 56, No. 3, 331-354.

Carley, K. (1997) Extracting team mental models through textual analysis. Journal of Organizational Behavior, Vol. 18, 533-538.

Carlile, P. (2002) A pragmatic view of knowledge and boundaries: Boundary objects in new product development. Organization Science, Vol. 13, No. 4, 442-455.

Carroll, J. (1998) Organizational learning activities in high-hazard industries: The logics underlying self-analysis. Journal of Management Studies, Vol. 35, 699-717.

Carter, C./Clegg, S./Kornberger, M./Mueller, F. (2004) "No Guru, No Method, No Teacher"- No way. Forthcoming.

Casson, M. (1999) The organization and evolution of the multinational enterprise: an information cost approach. Management International Review, Vol. 39 (Special issue), 77-121.

Chia, R. (2003) Organization theory as a postmodern science. In: Tsoukas, H./Knudsen, C. (Eds.) The Oxford Handbook of Organization Theory. Oxford: Oxford University Press, 113-141.

Churchman, C. (1971) The Design of Inquiring Systems: Basic Concepts of Systems and Organization. New York: Basic Books.

Clark, T. (1995) Managing Consultants. Consultancy as the Management of Impressions. Buckingham: Open University Press.

Clark, T./Mangham, I. (2004a) From dramaturgy to theatre as technology: The case of corporate theatre. Journal of Management Studies, Vol. 41, No. 1, 37-59.

Clark, T./Mangham, I. (2004b) Stripping to the undercoat: A review and reflections on a piece of organization theatre. Organization Studies, Vol. 25, No. 5, 841-851.

Clark, T./Salaman, G. (1996a) Telling tales: Management consultancy as the art of story telling. In: Oswick, C./Grant, D. (Ed.), Metaphor and Organizations. London: Sage, 166-184. 
Clark, T./Salaman, G. (1996b) The use of metaphor in the client-consultant relationship: a study of management consultants. In: Oswick C./Grant, D. (Eds.), Organisation Development. Metaphorical Explorations. London: Pitman Publishing, 154-174.

Clark, T./Salaman, G. (1996c) The management guru as organizational witchdoctor. Organization, Vol. 3, No. 1, 85-107.

Clark, T./Salaman, G. (1998a) Telling tales: Management gurus' narratives and the construction of managerial identity. Journal of Management Studies, Vol. 35, No. 2, 137-161.

Clark, T./Salaman, G. (1998b) Creating the 'right' impression: Towards a dramaturgy of management consultancy. Service Industries Journal, Vol. 18, No.1, 18-38.

Clegg, S. (1987) The language of power and the power of language. Organization Studies, Vol. 8, No. 1, 61-70.

Clegg, S. (1989a) Frameworks of Power. London: Sage.

Clegg, S. (1989b) Radical revisions: Power, discipline and organizations. Organization Studies, Vol. 10, No.1, 101-119.

Clegg, S. (2001) Changing concepts of power, changing concepts of politics. Administrative Theory \& Praxis, Vol. 23, No. 2, 126-150.

Clegg, S./Courpasson D. (2004) Political hybrids. Tocquevillean views on project Organizations. Journal of Management Studies, Vol. 41, No. 4, 525-547.

Clegg, S./Courpasson D./Phillips, N. (2006) Power and Organizations. Thousand Oaks, CA: Sage. Forthcoming.

Clegg, S./Kornberger, M./Rhodes, C. (2004) Noise, parasites and translation: Theory and practice in management consulting. Management learning, Vol. 35, No. 1, 31-44.

Clegg, S./Palmer, G. (1996) Introduction: Producing management knowledge. In: Clegg, S./Palmer, G. (Eds.), The Politics of Management Knowledge. London: Sage, 118.

Cohen, W./Levinthal, D. (1990) Absorptive capacity: A new perspective on learning and innovation. Administrative Science Quarterly, Vol. 35, No. 1, 128-152.

Conger, J. (1998) The necessary art of persuasion: The language of leadership is misunderstood, underutilized - and More Essential than Ever. Harvard Business Review, Vol. 76, No. 3, 84-95.

Conner, K./Prahalad, C. (1996) A Resource-based theory of the firm: Knowledge versus opportunism. Organizational Science, Vol. 7, No. 5, 477-501.

Contu, A./Willmott, H. (2000) Knowing in practice: A "delicate flower" in the organisational learning field. Organization, Vol. 7, No. 2, 269-76.

Contu, A./Willmott, H. (2003a) Re-Embedding situatedness: The importance of power relations in learning theory. Organization Science, Vol. 14, No. 3, 283-296.

Contu, A./Willmott, H. (2003b) Macht, Lernen and Organisation. In: Weiskopf, R. (Ed.), Personal, Organisation, Poststrukturalismus: Anwendungen. Wiesbaden: Westdeutscher Verlag, 159-187.

Cooper, R./Burrell, G. (1988) Modernism, postmodernism, and organizational analysis: An introduction. Organization Studies, Vol. 9, No.1, 91-112.

Coopey, J./Burgoyne, J. (2000) Politics and organizational learning. Journal of Management Studies, Vol. 37, No. 6, 869-885. 
Covaleski, M./Dirsmith, M./Heian, J./Samuel, S. (1998) The calculated and the avowed: techniques of discipline and struggles over identity in Big Six public accounting firms. Administrative Science Quarterly, Vol. 43, No. 2, 293-327.

Creplet, F./Dupouet, O./Kern, F./Mehmanpazir, B./Munier, F. (2001) Consultants and experts in management consulting firms. Research Policy, Vol. 30, No. 9, 15171535.

Crossan, M./Lane, H./White, R. (1999) An organizational learning framework: From intuition to institution. Academy of Management Review, Vol. 24, No. 3, 522-537.

Crozier, M. (2003) Theatres of innovation: Political communication and contemporary public policy. Paper presented at the Structure and Organization of Government Research Committee 2003 Conference, International Political Science Association, George Washington University, Washington DC, 22-24 May 2003.

Czarniawska, B. (2001) Is it possible to be a constructionist consultant? Management Learning, Vol. 32, No. 2, 253-266.

Czarniawska, B./Mazza, C. (2003) Consulting as a liminal space. Human Relations, Vol. 56, No. 3, 267-290.

Czerniawska, F. (1999) Management Consultancy in the 21st Century. Houndmills: Macmillan Business.

Czerniawska, F. (2005) Will consulting go online? In: Greiner, L./Poulfelt, F. (Eds.), The Contemporary Consultant. Mason: Thomson South-Western, 329-344.

Czerniawska, F./May, P. (2004) Management Consulting in Practice. London: Kogan Page.

Daft, R./Huber, G. (1987) How organizations learn: A communication framework. Research in the Sociology of Organizations, Vol. 5, 1-36.

Daft, R./Weick, K. (1984) Toward a model of organizations as interpretative systems. Academy of Management Review, Vol. 9, No. 2, 284-295.

Davenport, T./Prusak, L. (2005) Knowledge management in consulting. In: Greiner, L./Poulfelt, F. (Eds.), The Contemporary Consultant. Mason: Thomson SouthWestern, 305-326.

Davey, N. (1979) The consultant's role in organizational change. In: Bell, C./Nadler, L. (Eds.), The Client-Consultant Handbook. Houston: Gulf Publishing Company, 5055.

Day, D./Lord, R. (1992) Expertise and problem categorization: The role of expert processing in organizational sense-making. Journal of Management Studies, Vol. 29, No. 1, 35-47.

Deetz, S. (1995) Transforming Communication, Transforming Business: Building Responsive and Responsible Workplaces. Cresskill: Hampton Press.

Deetz, S./Kersten, A. (1983) Critical models of interpretive research. In: Putnam, L./Pacanowsky, M. (Eds.) Communication and Organizations. An Interpretive Approach. Beverly Hills: Sage, 147-171.

Denning, S. (2001) The Springboard. How Storytelling Ignites Action in Knowledge-Era Organizations. Boston, MA, Butterworth Heinemann. 
Denning, S. (2005) The role of narrative in organizations. In: Brown, J./Denning, S./Groh, K./Prusak, L. (Eds.), Storytelling in Organizations. Burlington: Elsevier, 165-182.

Dietrich, M./Roberts, J. (1997) Beyond the economics of professionalism. In: Broadbent, J./Dietrich, M./Roberts, J. (Eds.), The End of the Professions? The Restructuring of Professional Work. London: Routledge, 14-33.

DiMaggio, P. (1997) Culture and cognition. Annual Review of Sociology, Vol. 23, 263287.

DiMaggio, P./Powell, W. (1983) The iron cage revisited: Institutional isomorphism and collective rationality in organizational fields. American Sociological Review, 48, 147-160.

Donaldson, L. (2003) Organization theory as a positive science. In: Tsoukas, H./Knudsen, C. (Eds.) The Oxford Handbook of Organization Theory. Oxford: Oxford University Press, 39-61.

Donnellon, A./Gray, B./Bougon, M. (1986) Communication, meaning, and organized action. Administrative Science Quarterly, Vol. 31, No. 1, 43-55.

Dougherty, D. (1992) Interpretive barriers to successful product innovation in large firms. Organization Science, Vol. 3, No. 2, 179-202.

Drucker, P. (1969) The Age of Discontinuity: Guidelines to our Changing Society. London: Heinemann.

Durrant, C./Baxley D. (2004) Aligning business and technology strategy. In: Fombrun, C./Nevins, M. (Eds.), The Advice Business. Essential Tools and Models for Management Consulting, New Jersey: Pearson Prentice Hall, 288-314.

Dutton, J./Jackson, S. (1987) The categorization of strategic issues by decision makers and its links to organizational action. Academy of Management Review, Vol. 12, 76-90.

Easterby-Smith, M./Snell, R./Gherardi, S. (1998) Organizational learning: Diverging communities of practice? Management Learning, Vol. 29, No.3, 259-272.

Empson, L. (2001) Introduction: Knowledge management in professional service firms. Human Relations, Vol. 54, No. 7, 811-817.

Engeström, Y./Middleton, D. (1996) Cognition and Communication at Work. Cambridge: Cambridge University Press.

Engeström, Y./Miettinen, R./Punamäki, R.-L. (1999) Perspectives on Activity Theory. Cambridge: Cambridge University Press.

Engwall, L./Kipping, M. (2002) Introduction: Management consulting as a knowledge industry. In: Kipping, M./Engwall, L. (Eds.), Management Consulting. Emergence and Dynamics of a Knowledge Industry. Oxford: Oxford University Press, 1-16.

Fairclough, N. (1992) Discourse and Social Change. Cambridge: Polity Press.

Fairclough, N. (2005) Discourse analysis in organization studies: The case for critical realism. Organization Studies, Vol. 26, No. 6, 915-939.

Fairclough, N./Wodak, R. (1997) Critical discourse analysis. In: van Dijk, T. (Ed.), Discourse as Social Interaction. London: Sage, 258-254.

Ferdinand, J. (2004) Power, politics and state intervention in organizational learning. Management Learning, Vol. 35, No. 4, 507-509. 
Fincham, R. (1992) Perspectives on power processual, institutional and internal form of organizational power. Journal of Management Studies, Vol. 29, No. 6, 741-759.

Fincham, R. (1999) The consultant-client relationship: Critical perspectives on the management of organizational change. Journal of Management Studies, Vol. 36, No. 3, 335-351.

Fincham, R. (2002) Charisma versus technique: Differentiating the expertise of management gurus and management consultants. In: Clark, T./Fincham, R. (Eds.), Critical Consulting. New Perspectives on the Management Advice Industry. Oxford: Blackwell Publishers, 191-205.

Fincham, R./Clark, T. (2002) Introduction: The emergence of critical perspectives on consulting. In: Clark T./Fincham, R. (Eds.), Critical Consulting. New Perspectives on the Management Advice Industry. Oxford: Blackwell Publishers, 1-20.

Fincham, R./Clark, T. (2002-3) Preface. Management consultancy: Issues, perspectives, and agendas. International Studies of Management and Organization, Vol. 32, No. 4, 3-18.

Fincham, R./Roslender, R. (2004) Rethinking the dissemination of management fashion. Management Learning, Vol. 35, No. 3, 321-336.

Fiol, C. (1991) Seeing the empty spaces: Towards a more complex understanding of the meanings of power in organisations. Organisation Studies, Vol. 12, No. 4, 547566.

Fiol, C. (1994) Consensus, diversity, and learning in organizations. Organization Science, Vol. 5, No. 3, 403-420.

Fish, S. (1976) Interpreting the variorum. Critical Inquiry, Vol. 2, No. 3, 465-485.

Fish, S. (1980) Is there a Text in this Class? The Authority of Interpretive Communities. Cambridge: Harvard University Press.

Flyvbjerg, B. (1998) Rationality and Power. Chicago: The University of Chicago Press.

Flyvbjerg, B. (2001) Making Social Sciences Matter: Why Social Inquiry Fails and How It Can Succeed Again. Cambridge: Cambridge University Press.

Fombrun, C. (2004) The consultant's toolkit. In: Fombrun, C./Nevins, M. (Eds.), The Advice Business. Essential Tools and Models for Management Consulting, New Jersey: Pearson Prentice Hall, 78-97.

Fombrun, C./Nevins, M. (2004a) Introduction: Of doctors and witch doctors. In: Fombrun, C./Nevins, M. (Eds.), The Advice Business. Essential Tools and Models for Management Consulting, New Jersey: Pearson Prentice Hall, vi-xx.

Fombrun, C./Nevins, M. (2004b) Thinking like a consultant. In: Fombrun, C./Nevins, M. (Eds.), The Advice Business. Essential Tools and Models for Management Consulting, New Jersey: Pearson Prentice Hall, 98-112.

Ford, C. (1996) A theory of individual creative action in multiple social domains. Academy of Management Review, Vol. 21, No. 4, 1112-1142.

Ford, C./Gioia, D. (2000) Factors influencing creativity in the domain of managerial decision making. Journal of Management, Vol. 26, No. 4, 705-732.

Ford, J./ Ford, L. (1995) The role of conversations in producing intentional change in organizations. Academy of Management Review, Vol. 20, No. 3, 541-570. 
Ford, J./Ford, L. (1994) Logics of identity, contradiction, and attraction in change. Academy of Management Review, Vol. 19, No. 4, 756-785.

Fores, M./Glover, M./Lawrence, P. (1991) Professionalism and rationality: A study in misapprehension. Sociology, Vol. 25, No. 1, 79-100.

Fosstenløkken, S./Løwendahl, B./Revang., Ø. (2003) Knowledge development through client interaction: A comparative study. Organization Studies, Vol. 24, No. 6, 859879.

Foucault, M. (1972) The Archaeology of Knowledge. London: Tavistock.

Foucault, M. (1977) Discipline and Punish. The Birth of the Prison. London: Penguin.

Foucault, M. (1980) Power/Knowledge: Selected Interviews \& Other Writings 19721977. Colin Gordon. New York: Pantheon Books

Fournier, V. (1999) The appeal to 'professionalism' as a disciplinary mechanism. The Sociological Review, Vol. 47, No. 2, 280-307.

Fox, S. (1991) Situated learning theory versus traditional cognitive learning theory: Why management education should not ignore management learning. Systems Practice, Vol. 10, No. 8, 727-747.

Fox, S. (2000) Communities of practice, Foucault and actor-network theory. Journal of Management Studies, Vol. 37, No. 6, 853-867.

Franz, R. (2003) Herbert Simon. Artificial intelligence as a framework for understanding intuition. Journal of Economic Psychology, Vol. 24, 265-277.

Freidson, E. (1970) Dominant professions, bureaucracy, and client services. In: Rosengreen, W./Lefton, M. (Eds.), Organizations and Clients. Columbus: Charles E. Merrill Publishing, 71-92.

Freidson, E. (1984) Are professions necessary? In: Haskell, T. (Ed.), The Authority of Experts. Bloomington: Indiana University Press, 3-27.

Freidson, E. (1986) Professional Powers: A Study in the Institutionalization of Formal Knowledge. Chicago: University of Chicago Press.

Freidson, E. (1994) Professionalism Reborn: Theory, Prophecy, and Policy. Cambridge: Polity.

Freidson, E. (2001) Professionalism: The Third Logic. Cambridge: Polity.

Fritz, W./Effenberger, J. (1998) Strategische Unternehmensberatung. Die Betriebswirtschaftslehre, Vol. 58, No. 1, 103-118.

Fullerton, J./West, M. (1996) Consultant and client-working together? Journal of Managerial Psychology, Vol. 11, No. 6, 40-49.

Gable, G. (1996) A multidimensional model of client success when engaging external consultants. Management Science, Vol. 42, No.8, 1175-1198.

Gadrey, J./Gallouj, F. (1998) The provider-customer interface in business and professional services. Services Industries Journal, Vol. 18, No. 2, 1-15.

Gallessich, J. (1982) The Profession and Practice of Consultation. San Francisco, CA: Jossey-Bass Publishers.

Gallouj, F./Weinstein, O. (1997) Innovation in services. Research Policy, Vol. 26, 537556. 
Gann, D./Salter, A. (2000) Innovation in project-based, service-enhanced firms: the construction of complex products and systems. Research Policy, Vol. 29, 955-972.

Garratt, R. (1981) From expertise to contingency: Changes in the nature of consulting. Management Education and Development, Vol. 12, No. 2, 95-101.

Garrick, J./Clegg, S. (2001) Stressed-out knowledge workers in performative times: A postmodern take on project-based learning. Management Learning, Vol. 32, No. 1, 119-134.

Garsten, C. (1999) Betwixt and between - temporary employees as liminal subjects in flexible organizations. Organization Studies, Vol. 20, No. 4, 601-617.

Garud, R./Rappa, M. (1994) A social-cognitive model of technology evolution: the case of cochlear implants. Organization Science, Vol. 5, No. 3, 344-362.

Gergen, K. (1995) Relational theory and the discourses of power. In: Hoskins, D.M./Dachler, P./Gergen, K. (Eds.), Management and Organization: Relational Approaches to Individualism. Aldershot: Avebury, 29-50.

Gherardi, S. (2000) Practice-based theorizing on learning and knowing in organizations. Organization, Vol. 7, No. 2, 211-223.

Gherardi, S./Nicolini, D. (2002) Learning in a constellation of interconnected practices: Canon or dissonance? Journal of Management Studies, Vol. 39, No. 4, 419-436.

Gherardi, S./Nicolini, D./Odella, F. (1998). Toward a social understanding of how people learn in organizations. Management Learning, Vol. 29, No. 3, 273-297.

Giddens, A. (1991) Modernity and Self-Identity. Cambridge: Polity.

Ginsberg, A./Abrahamson, E. (1991) Champions of change and strategic shifts: The role of internal and external change advocates. Journal of Management Studies, Vol. 28, No. 2, 173-190.

Gioia, D./ Poole, P. (1984) Scripts in organizational behavior. Academy of Management Review, Vol. 9, 449-459.

Gluckler, J./Armbruster, T. (2003) Bridging uncertainty in management consulting - the mechanisms of trust and networked reputation. Organization Studies, Vol. 24, No. 2, 269-297.

Goodman, P. (1952) The measurement of an individual's organization map. Administrative Science Quarterly, Vol. 13, No. 2, 246-265.

Granovetter, M. (1973) The strength of weak ties. American Journal of Sociology, Vol. 78, No. 4, 1360-1380.

Granovetter, M. (1985) Economic action and social structure: The problem of embeddedness. American Journal of Sociology, Vol. 91, No. 3, 481-510.

Grant, D./Hardy, C./Oswick, C./Putnam, L. (2004) Introduction: Organizational discourse: Exploring the field. In: Grant, D./Hardy, C./Oswick, C./Putnam, L. (Eds.), The SAGE Handbook of Organizational Discourse. London: Sage, 1-36.

Grant, R. (1996) Toward a knowledge-based theory of the firm. Strategic Management Journal, Vol. 17 (winter special issue), 109-122.

Gray, B./Bougon, M./Donnellon, A. (1985) Organizations as constructions and destructions of meaning. Journal of Management, Vol. 11, No. 2, 83-98.

Greatbach, D./Clark, T. (2002) Laughing with the gurus. Business Strategy Review, Vol. 13, No. 3, 10-18. 
Greatbach, D./Clark, T. (2003) Displaying group cohesiveness: Humour and laughter in the public lectures of management gurus. Human Relations, Vol. 56, No. 12, 1515-1544.

Grosse, R. (2000) Knowledge creation and transfer in global service firms. In: Aharoni, Y./Nachum, L. (Eds.), Globalization of Services: Some Implications for Theory and Practice. London: Routledge, 217-232.

Guilford, J. (1984) Varieties in divergent production. Journal of Creative Behaviour, Vol. 18, No. 1, 1-10.

Gupta, A./Govindarajan, V. (2000) Knowledge flows within multinational corporations. Strategic Management Journal, Vol. 21, No. 4, 473-496.

Habermas, J. (1970) Towards a theory of communicative competence. Inquiry Vol. 13, 360-375.

Hakkio, S./Laaksonen P. (1998) Relationships in marketing channels: Examining communication abilities through cognitive structures. Psychology \& Marketing, Vol. 15, 215-240.

Hall, R. (1969) Occupations and the Social Structure. Englewood Cliffs, N.J.: PrenticeHall.

Halliday, T. (1985) Knowledge mandates: Collective influence by scientific, normative and syncretic professions. The British Journal of Sociology, Vol. 36, No. 3, 421447.

Hamilton, G./Biggart, N. (1985) Why people obey: theoretical observations on power and obedience in complex organizations. Sociological Perspectives, Vol. 28, No. 1, 328.

Hanlon, G. (1997) A shifting professionalism. An examination of accountancy. In: Broadbent, J./Dietrich, M./Roberts, J. (Eds.), The End of the Professions? The Restructuring of Professional Work. London: Routledge, 123-139.

Hansen, T./Nohria, N./Tierney, T. (1999) What is your strategy for managing knowledge. Harvard Business Review, March-April, 106-116.

Hardy, C. (1985) The nature of unobtrusive power. Journal of Management Studies, Vol. 22, No. 4, 384-399.

Hardy, C. (1996) Understanding power: Bringing about strategic change. British Journal of Management, Vol. 7, Special Issue (March 1996), S3-S16.

Hardy, C./Clegg, S. (1996) Some dare call it power. In: Clegg, S./Hardy, C./Nord, W. (Eds.), Handbook of Organization Studies. London: Sage, 622-641.

Hardy, C./Lawrence, T./Grant, D. (2005) Discourse and collaboration: The role of conversations and collective identity. Academy of Management Review, Vol. 30, No. 1, 58-77.

Hardy, C./Leibia-O'Sullivan, S. (1998) The power behind empowerment: implications for research and practice. Human Relations, Vol. 51, No. 4, 451-83.

Hardy, C./Palmer, I./Phillips, N. (2000) Discourse as a strategic resource. Human Relations, Vol. 53, No. 9, 1227-1248.

Hardy, C./Phillips, N. (2004) Discourse and power. In: Grant, D./Hardy, C./Oswick, C./Putnam, L. (Eds.), The SAGE Handbook of Organizational Discourse. London: Sage, 299-316. 
Hargadon, A. (1998) Firms as knowledge brokers: Lessons in pursuing continuous innovations. California Management Review, Vol. 40, No. 3, 209-227.

Hargadon, A./Sutton, R. (1997) Technology brokering and innovation in a product development firm. Administrative Science Quarterly, Vol. 42, 716-749.

Hargie, O./Tourish D. (1994) Communication skills training: Management manipulation or personal development? Human Relations, Vol. 47, No. 11, 1377-1389.

Harmon, J./Rohrbaugh, J. (1990) Social judgement analysis and small group decision making: Cognitive feedback effects on individual and collective performance. Organizational Behavior and Human Decision Processes, Vol. 46, No. 1, 34-54.

Harris, S. (1989) A schema-based perception on organizational culture. In Hoy, F. (Ed.), Proceedings of the 49th Academy of Management meeting, Washington, DC: Academy of Management, 178-182.

Harris, S. (1994) Organizational culture and individual sensemaking: A schema-based perspective. Organization Science, Vol. 5, No. 3, 309-321.

Harrison, D./Price, K./Gavin, J./Florey, A. (2002) Time teams, and task performance: Changing effects of surface- and deep-level diversity on group functioning. Academy of Management Journal, Vol. 45, No.5, 1029-1045.

Hart, C./Moon, G./Goel, S. (2004) Consultant-client partnerships. In: Fombrun, C./Nevins, M. (Eds.), The Advice Business. Essential Tools and Models for Management Consulting, New Jersey: Pearson Prentice Hall, 314-326.

Hassard, J. (1999) Postmodernism, philosophy and management: concepts and controversies. International Journal of Management Reviews, Vol. 1, No. 2, 171196.

Hatch, M./Yanow, D. (2003) Organization theory as an interpretive science. In: Tsoukas, H./Knudsen, C. (Eds.), The Oxford Handbook of Organization Theory. Oxford: Oxford University Press, 63-86.

Haug, M./Sussman, M. (1969) Professional autonomy and the revolt of the client. Social Problems, Vol. 17, No. 2, 153-161.

Heracleous, L. (2004) Interpretivist approaches to organizational discourse. In: Grant, D./Hardy, C./Oswick, C./Putnam, L. (Eds.), The SAGE Handbook of Organizational Discourse. London: Sage, 175-192.

Heracleous, L./Barrett, M. (2001) Organizational change as discourse: communicative actions and deep structures in the context of information technology implementation. Academy of Management Journal, Vol. 44, No. 4, 755-778.

Hermelin, B. (1997) Professional Business Services. Conceptual Framework and a Swedish Case Study. Uppsala: Uppsala Universitet.

Hickson, D./Hinings, C./Lee, C./Schneck, R./Pennings, J. (1971) A strategic contingencies theory of intraorganizational power. Administrative Science Quarterly, Vol. 16, No. 2, 216-229.

Hill, V./Carley, K. (1999) An approach to identifying consensus in a subfield: The case of organizational culture. Poetics, Vol. 27, 1-30.

Hilmer, F./Donaldson, L. (1996) Management Redeemed. Debunking the Fads that Undermine Corporate Performance. New York: The Free Press. 
Hislop D./Newell, S./Scarbrough, H./Swan, J. (2000) Networks, knowledge and power: Decision making, politics and the process of innovation. Technology Analysis \& Strategic Management, Vol. 12, No. 3, 399-411.

Hislop, D. (2002) The client role in consultancy relations during the appropriation of technological innovations. Research Policy, Vol. 31, No. 5, 657-671.

Hodgson, D. (2002) Disciplining the Professional: the case of project management Journal of Management Studies Vol. 39, No. 7, 803-821.

Hoffmann, W. (1991) Faktoren Erfolgreicher Unternehmensberatung. Wiesbaden: Gabler.

Hofstede, G. (1983) National cultures in four dimensions: A research-based theory of cultural differences among nations. International Studies of Management \& Organization, Vol. 13, No. 1-2, 46-75.

Holt, D. (1997) Poststructuralist lifestyle analysis: Conceptualizing the social patterning of consumption in postmodernity. Journal of Consumer Research, Vol. 23, 326350.

Hosking, D.-M. (1995) Constructing power: Entitative and relational approaches. In: Hoskins, D.-M./Dachler, P./Gergen, K. (Eds.), Management and Organization: Relational Approaches to Individualism. Aldershot: Avebury, 51-70.

Hough, J./ogilvie, dt, (2005) An Empirical Test of Cognitive Style and Strategic Decision Outcomes. Journal of Management Studies, Vol. 42, No. 2, 417-448.

Huczynski, A. (1993) Management Gurus. London: Routledge.

Hussey, D. (1998) Techniques, methods and models of consulting. In: Sadler, P. (Ed.), Management Consultancy: A Handbook of Best Practice. London: Kogan Page, 310-326.

Hymes, D. (1980) Language in Education: Ethnolinguistic Essays. Washington: Center for Applied Linguistics.

Iding, H. (2000) Hinter den Kulissen der Organisationsberatung. Opladen: Leske + Budrich.

Isaacs, W. (1993) Taking Flight: Dialogue, Collective Thinking, and Organizational Learning. Organizational Dynamics, Vol. 22, No. 2, 24-39.

Jackall, R. (1988) Moral Mazes. The World of Corporate Managers. New York: Oxford University Press.

Jackson, B. (2001) Management Gurus and Management Fashions. A Dramatistic Inquiry. New York: Routledge.

Jacobs, C./Heracleous, L. (2001) Seeing without being seen: Towards an Archaeology of Controlling Science. International Studies of Management and Organization, Vol. 31, No. 3, 113-135.

Kaas, K./Schade, C. (1995) Unternehmensberater im Wettbewerb. Zeitschrift für Betriebswirtschaftslehre, Vol. 65, No. 10, 1067-1089.

Kanter, R. (2002) Strategy as improvisational theater. Sloan Management Review, Winter 2002, 76-81.

Kast, F./Rosenzweig, J. (1973) Contingency Views of Organization and Management. Chicago: Science Research Associates. 
Kates, S. (2002) Researching brands ethnographically: An interpretive community approach. In: Broniarczyk, S./Nakamoto, K. (Eds.), Advances in Consumer Research, Association for Consumer Research Conference, Provo, Utah, 1-29..

Kaye, M. (1996) Myth-Makers and Story-Tellers. Sydney: Business \& Professional Publishing.

Keegan, A./Turner, J. (2001) Quantity versus Quality in Project-based Learning. Practices. Management Learning, Vol. 32, No. 1, 77-98.

Kennedy Information (2004) The Global Consulting Marketplace, 2004-2006: Key Data, Trends \& Forecasts. Peterborough, New Hampshire: Kennedy Information.

Kieser, A. (1997) Rhetoric and Myth in Management Fashion. Organization, Vol. 4, No. 1, 49-74.

Kieser, A. (2002a) Managers as marionettes? Using fashion theories to explain the success of consultancies. In: Engwall, L./Kipping, M. (Eds.), Management Consulting. Emergence and Dynamics of a Knowledge Industry. Oxford: Oxford University Press, 167-183.

Kieser, A. (2002b) On communication barriers between management science, consultancies and business organizations. In: Clark T./Fincham, R. (Eds.), Critical Consulting. New Perspectives on the Management Advice Industry. Oxford: Blackwell Publishers, 206-227.

Kilduff, M./Angelmar, R./Mehra, A. (2000) Top management-team diversity and firm performance: Examining the role of cognitions. Organization Science, Vol. 11, 2134.

Kipping, M. (1996) The U.S. influence on the evolution of management consultancies in Britain, France, and Germany since 1945. Business and Economic History, Vol. 25, No. 1, 112-123.

Kipping, M. (1999) American management consulting companies in Western Europe, 1920 to 1990: Products, reputation, and relationships. Business History Review, Vol. 73 (Summer), 190-220.

Kipping, M. (2002) Jenseits von Krise und Wachstum. Zeitschrift für die Organisation, Vol. 71, No. 5, 269-276.

Kipping, M./Armbruester, T. (2002) The burden of otherness: Limits of consultancy interventions in historical case studies. In: Engwall L./Kipping, M. (Eds.), Management Consulting. Emergence and Dynamics of a Knowledge Industry. Oxford: Oxford University Press, 203-221.

Kipping, M./Sauviat, C. (1996) Global management consultancies: Their evolution and structure. Discussion Papers in International Investment and Business Studies, Series B, vol. IX, No. 221, University of Reading, Reading.

Kirsch, W. (1997) Wegweiser zur Konstruktion einer Evolutionären Theorie der Strategischen Führung, München: Kirsch.

Kirsch, W./Eckert, N. (1998) Die Strategieberatung im Lichte einer evolutionären Theorie der strategischen Führung. In: Bamberger, I. (Ed.), Strategische Unternehmensberatung. Konzeptionen-Prozesse-Methoden. Wiesbaden: Gabler.

Kitay, J./Wright, C. (2003) Expertise and Organizational Boundaries: The Varying Roles of Australian Management Consultants. Asia Pacific Business Review, Vol. 9, No. 3, 21-40. 
Klimoski, R./Mohammed, S. (1994) Team mental model: Construct or metaphor? Journal of Management Vol. 20, No. 2, 403-437.

Kogut, B./Zander, U. (1992) Knowledge of the firm, combinative capabilities, and the replication of technology. Organization Science, Vol. 3, No. 2, 382-397.

Kogut, B./Zander, U. (1996) What firms do? Coordination, identity, and learning. Organization Science, Vol. 7, No. 5, 502-518.

Köppen, R. (1999) Erfolgsfaktoren von Unternehmensberatungen. Wiesbaden: Gabler.

Koppl, R./Langlois, R. (2001) Organizations as language games. Journal of Management and Governance Vol. 5, 287-305.

Krogh, G. v./Roos, J. (1995) Organizational Epistemology. New York: St. Martin’s Press.

Krohn, W./Küppers, G. (1989) Die Selbstorganisation der Wissenschaft. Frankfurt/Main: Suhrkamp.

Kubr, M. (1996) Management Consulting. A Guide to the Profession. Geneva: International Labour Office.

Lachman, R. (2000) Stepping into the kitchen: Lay clients as co-producers of a professional service. International Journal of Human Resource Management, Vol. 11, No. 3, 617-634.

Laclau, E./Mouffe, C. (1985) Hegemony \& Socialist Strategy. London: Verso.

Lakomski G. (2000) Education and cognition-naturalistic explorations into the nature of mind and learning. Australian Journal of Education, Vol. 44, No. 3, 203-209.

Lakomski, G. (2004) On knowing in context. British Journal of Management, Vol. 15, S89-S95.

Lane, D. (1994) Modeling as learning: A consultancy methodology for enhancing learning in management firms. In: Morecroft, J./Sterman, J. (Eds.), Modeling for Learning Organizations. Portland: Productivity Press, 85-117.

Lane, J./Wenger, E. (2002) Situated Learning. Legitimate Peripheral Participation. Cambridge: Cambridge University Press.

Larsen, J. (2001) Knowledge, human resources and social practice: The knowledgeintensive business service firm as a distributed knowledge system. The Service Industries Journal, Vol. 21, No. 1, 81-102.

Larson, M. (1977) The Rise of Professionalism. Berkely: University of California Press.

Laud, R. (2004) Innovation: the growth engine of consulting. In: Fombrun, C./Nevins, M. (Eds.), The Advice Business. Essential Tools and Models for Management Consulting, New Jersey: Pearson Prentice Hall, 42-56.

Laukkanen, M. (1994) Comparative cause mapping of organizational cognitions. Organization Science, Vol. 5, No. 3, 322-343.

Lave, J./Wenger, E. (2002) Situated Learning. Legitimate Peripheral Participation. Cambridge: Cambridge University Press.

Law, J. (1991) Strategies of power. In: Law, J. (Ed.), A Sociology of Monsters: Essays on Power, Technology and Domination. London: Routledge, 165-191.

Law, J. (1994) Organizing Modernity. Oxford: Blackwell. 
Law, J. (1999) After ANT: Complexity, naming and topology. In: Law, J./Hassard, J. (Eds.), Actor Network Theory and after. Oxford: Blackwell, 1-14.

Lawrence, T./Mauws, M./Dyck, B./ Kleysen, R. (2005) The politics of organizational learning: Integrating power into the 4I framework. Academy of Management Review, Vol. 30, 180-191.

Lawrence, T./Winn, M./ Jennings, P. (2001) The temporal dynamics of institutionalization. Academy of Management Review, Vol. 26, No. 4, 624-645.

Legge, K. (2002) On knowledge, business consultants and the selling of total quality management. In: Clark T./Fincham, R. (Eds.), Critical Consulting. New Perspectives on the Management Advice Industry. Oxford: Blackwell Publishers, 74-90.

Leinhardt, G./Young, K./Merriman, J. (1995) Integrating professional knowledge: The theory of practice and the practice of theory. Learning and Instruction, Vol. 5, 401408.

Levesque, L./Wilson, J./Wholey, D. (2001) Cognitive divergence and shared mental models in software development project teams. Journal of Organizational Behavior, Vol. 22, 135-144.

Lilja, K./Poulfelt, F. (2001) The anatomy of network building in management consulting firms. In: Buono, A. (Ed.), Current Trends in Management Consulting. New York: Information Age Publishing, 3-21.

Lindlof, T. (1988) Media Audiences as Interpretive Communities. In: Anderson, J. A. (Ed), Communication Yearbook 11. Newbury Park, CA: Sage, 87-107.

Lippitt, G./Lippitt, R. (1978) The Consulting Process in Action. San Diego: University Associates, Inc.

Loasby, B. (1983) Knowledge, learning and enterprise. In: Wiseman, J. (Ed.), Beyond Positive Economics? London: Macmillan, 349-366.

Loasby, B. (2000) Organizations as interpretive systems. Working paper, Amiens, May 26, Department of Economics, University of Sterling.

Loasby, B. (2001a) Time, knowledge and evolutionary dynamics: why connections matter. Journal of Evolutionary Economics, Vol. 11, 393-412.

Loasby, B. (2001b) Cognition, imagination and institutions in demand creation. Journal of Evolutionary Economics, Vol. 11, 7-21.

Loasby, B. (2002) The evolution of knowledge: beyond the biological model. Research Policy, Vol. 31, 1227-1239.

Lorenz, E. (2001) Models of cognition, the contextualisation of knowledge and organisational theory. Journal of Management and Governance, Vol. 5, 307-330.

Lorsch, J. (2005) High-performance consulting firms. In: Greiner, L./Poulfelt, F. (Eds.), The Contemporary Consultant. Mason: Thomson South-Western, 293-304.

Louis, R. (1980) Surprise and sense making: What newcomers experience in entering unfamiliar organizational settings. Administrative Science Quarterly, Vol. 25, No. 2, 226-251.

Lovelace, K./Shapiro, D./Weingart, L. (2001) Maximizing cross-functional new product teams' innovativeness and constraint adherence: A conflict communications perspective. Academy of Management Journal, Vol. 44, No. 4, 779-793. 
Lowendahl, B. (1997) Strategic Management of Professional Service Firms. Copenhagen: Handelshøjskolens Forlag.

Lowendahl, B. (2000) The globalization of professional business service firms. In: Aharoni, Y./Nachum, L. (Eds.), Globalization of Services. London: Routledge, 142-162.

Lukes, S. (1974) Power: A Radical View. London: Macmillan.

Macdonald, K./Ritzer, G. (1988) The sociology of the professions. Dead or alive? Work and Occupation, Vol. 15, No. 3, 251-272.

Madhok, A. (1996) The organization of economic activity: Transaction costs, firm capabilities, and the nature of governance. Organization Science, Vol. 7, No. 5, 577-590.

Maister D. (2004) The anatomy of a consulting firm. In: Fombrun, C./Nevins, M. (Eds.), The Advice Business. Essential Tools and Models for Management Consulting, New Jersey: Pearson Prentice Hall, 17-32.

Maister, D. (1982a) Balancing the professional service firm. Sloan Management Review, Vol. 24, No. 1, 15-29.

Maister, D. (1982b) The one-firm firm: What makes it successful. Sloan Management Review, Fall 1985, 3-13.

Maister, D. (1993), Managing the Professional Service Firm. New York: Simon \& Schuster.

Maister, D. (2005) Professionalism in consulting. In: Greiner, L./Poulfelt, F. (Eds.), The Contemporary Consultant. Mason: Thomson South-Western, 23-34.

Malefyt, T. (2003) Models, metaphors and client relations: The negotiated meanings of advertising. In: Malefyt, T. D./Moeran, B. (Eds.), Advertising Cultures. Oxford: Berg.

March, J. (1991) Exploration and exploitation in organizational learning. Organization Science, Vol. 2, No. 1, 71-87.

Markowitz, A. (2001) The case of Pricilla and the red pen. In: Block, P. (Ed.), Flawless Consulting. Fieldbook \& Companion. A Guide to Understanding Your Expertise. San Francisco: Jossey-Bass/Pfeiffer, 97-116.

Marks, M./Mathieu, J./Zaccaro, S. (2001) A temporally based framework and taxonomy of team processes. Academy of Management Review, Vol. 26, No. 3, 356-376.

Marshak, R./Keenoy, T./Oswick, C./Grant, D. (2000) From outer words to inner worlds. The Journal of Applied Behavioral Science, Vol. 36, No. 2, 245-258.

Marshall, N./Rollinson, J. (2004) Maybe Bacon had a point: The politics of interpretation in collective sensemaking. British Journal of Management, Vol. 15, S71-S86.

Martin, J. (1990) Deconstructing organizational taboos: The suppression of gender conflict in organizations. Organization Science, Vol. 1, No. 4, 339-359.

Martin, J./Siehl C. (1983) Organizational culture and counterculture: an uneasy symbiosis. Organizational Dynamics, Vol. 12, No. 2, 52-64.

Mathieu, J./Goodwin, G./Heffner, T./Salas, E./Cannon-Bowers, J. (2000) The influence of shared mental models on team process and performance. Journal of Applied Psychology Vol. 85, No. 2, 273-283. 
Maturana, M. (1980) Biology of cognition. In: Maturana, H./Varela, F. (Eds.), Autopoesis and Cognition. Dordrecht: D. Reidel Publishing, 1-58.

McGivern, C. (1983) Some facets of the relationship between consultants and clients in organizations. Journal of Management Studies, Vol. 20, No. 3, 367-386.

McGivern, C./Fineman, S. (1983) Research and consultancy: towards a conceptual synthesis. Journal of Management Studies, Vol. 20, No. 4, 425-439.

McKenna, C. (2006) The World's Newest Profession: Management Consulting in the Twentieth Century. Cambridge University Press, forthcoming.

Meindl, J./Stubbart, C./Porac, J. (1994) Cognition within and between organizations: Five key questions. Organization Science, Vol. 5, No. 3, 289-293.

Meyer, J./Rowan, B. (2002) Institutionalised organizations: Formal structures as myth and veremony. American Journal of Sociology, Vol. 83, No. 1, 340-363.

Micklethwait, J./Wooldridge, A. (1996) The Witch Doctors. Making Sense of the Management Gurus. New York: Random House.

Milgrom, P./Roberts, J. (1992) Economics, Organization and Management. New Jersey: Prentice Hall.

Mills, P./Chase, R./Marguilies, N. (1983b), Motivating the client/employee system as a service production strategy. Academy of Management Review, Vol. 8, No. 2, 301310.

Mills, P./Hall, J./Leidecker, J./Margulies, N. (1983a) Flexiform: A model for professional service organizations. Academy of Management Review, Vol. 8, No. 1, 118-131.

Mills, P./Morris, J. (1986) Clients as 'partial' employees of service organizations: role development in client participation. Academy of Management Review, Vol. 11, No.4, 726-735.

Mills, P./Moshavi, D. (1999) Professional concern: Managing knowledge-based service relationships. International Journal of Service Industry Management, Vol. 10, 4867.

Mintzberg, H. (1976) Planning on the left-side, managing on the right. Harvard Business Review, July-August, 49-58.

Mintzberg, H. (1979) The Structuring of Organizations. A Synthesis of the Research. Englewood Cliffs, N.Y.: Prentice Hall.

Mintzberg, H. (1984) Power and organizational life cycles. Academy of Management Review, Vol. 9, No. 2, 207-224.

Mintzberg, H. (1985) The organization as political arena. Journal of Management Studies, Vol. 22, No. 2, 133-154.

Mir R./Watson, A. (2000) Strategic management and the philosophy of science: Imperatives for a constructivist methodology. Strategic Management Journal, Vol. 21, No. 9, 1-13.

Mirvis, P. (1996) Historical foundations of organizational learning. Journal of Organizational Change Management, Vol. 9, No. 1, 13-31.

Mitroff, I./Mason, R. (1981) Creating a Dialectical Social Science. Dordrecht: D. Reidel Publishing.

Moch, M./Huff, A. (1983) Power enactment through language and ritual. Journal of Business Research, Vol. 11, 293-316. 
Mohammed, S./Dumville, B. (2001) Team mental models in a team knowledge framework: Expanding theory and measurement across disciplinary boundaries. Journal of Organizational Behavior, Vol. 22, 89-106.

Mohammed, S./Ringseis, E. (2001) Cognitive diversity and consensus in group decision making: The role of inputs, processes, and outcomes. Organizational Behavior and Human Decision Processes, Vol. 85, No. 2, 310-335.

Moore, K./Birkinshaw, J. (1998) Managing knowledge in global service firms: Centers of excellence. Academy of Management Executive, Vol. 12, No. 4, 81-92.

Moore, W. (1970) The Professions: Roles and Rules. New York: Russell Sage Foundation.

Morgan, G. (1983) Beyond Method. Beverly Hills: Sage.

Morris, T. (2000) From advice to execution: Consulting firms and the implementation of strategic decisions. In: Flood, P./Dromgoole, T./Carroll, S./Gorman, L. (Eds.), Managing Strategy Implementation. Oxford: Blackwell Business.

Morris, T./Empson, L. (1998) Organization and expertise : An exploration of knowledge bases and the management of accounting and consulting firms. Accounting, Organizations and Society, Vol. 23, No. 5/6, 609-624.

Müller-Stewens, G./Drolshammer, J./Kriegmeier, J. (1999) Professional Service FirmsBranchenmerkmale und Gestaltungsfelder des Managements. In: Müller-Stewens, G./Drolshammer, J./Kriegmeier, J. (Eds.), Professional Service Firms, Frankfurt am Main: Frankfurter Allgemeine Buch, 11-153.

Mulligan, J./Barber, P. (1998) The client-consultant relationship. In: Sadler, P. (Ed.), Management Consultancy: A Handbook of Best Practice. London: Kogan Page, 66-85.

Mumby, D./Clair, R. (1997) Organizational discourse. In: van Dijk, T. (Ed.), Discourse as Social Interaction. London: Sage, 181-205.

Nachum, L. (1996) Winners and losers in professional services: What makes the difference? The Service Industries Journal, Vol. 16, No. 4, 474-490.

Nachum, L. (1999) The Origins of the International Competitiveness of Firms. Cheltenham: Edward Elgar.

Neiman, R. (2004) Facilitating change: Implementing a results orientation. In: Fombrun, C./Nevins, M. (Eds.), The Advice Business. Essential Tools and Models for Management Consulting, New Jersey: Pearson Prentice Hall, 215-299.

Neisser, U. (1976) Cognition and Reality. New York: Freeman.

Nelson, R./Winter, S. (1982) An Evolutionary Theory of Economic Change. Cambridge, Mass.: Belknap Press of Harvard University Press.

Nevins, M. (2004) From insight to impact: Communicating to influence. In: Fombrun, C./Nevins, M. (Eds.), The Advice Business. Essential Tools and Models for Management Consulting, New Jersey: Pearson Prentice Hall, 112-125.

Newell, A./Simon, H. (1976) Computer science as empirical enquiry: Symbol and search. Communications of the ACM, Vol. 19, No. 3, 113-126.

Newton, T. (1996) Agency and discourse: Recruiting consultants in a life insurance company. Sociology, Vol. 30, No. 4, 717-723. 
Nichols, C. (2004) Managing projects. In: Fombrun, C./Nevins, M. (Eds.), The Advice Business. Essential Tools and Models for Management Consulting, New Jersey: Pearson Prentice Hall, 153-177.

Nickerson, J./Zenger, T. (2004) A knowledge-based theory of the firm. The problemsolving perspective. Organization Science, Vol. 15, No. 6, 617-632.

Nicolini, D./Menzar, M. (1995) The social construction of organizational learning: Conceptual and practical issues in the field. Human Relations, Vol. 48, No. 7, 727746.

Nikolova, N./Reihlen, M./Stoyanov, K. (2001) Kooperationen von Managementberatungs- unternehmen: eine explorative Analyse. Arbeitsbericht Nr. 103 des Seminars für Allgemeine Betriebswirtschaftslehre, Betriebswirtschaftliche Planung und Logistik, Prof. Dr. W. Delfmann, Universität zu Köln.

Nonaka, I. (1994) A dynamic theory of organizational knowledge creation. Organization Science, Vol. 5, No. 1, 14-37.

Nord, M. (1996) The consulting mindset: a foundation for teaching problem solving and communication skills. Business Communication Quarterly, March, 103-108.

Noyelle, T./Dutka, A. (1988) International Trade in Business Services. Cambridge: Ballinger Publishing.

Nutt, P. (1984) Types of organizational decision processes. Administrative Science Quarterly, Vol. 29, 414-450.

O’Farrell, P./Moffat, L. (1991) An interaction model of business service production and consumption. British Journal of Management, Vol. 2, 205-221.

O'Farrell, P./Wood, P. (1999) Formation of strategic alliances in business services: Towards a new client-oriented conceptual framework. The Service Industries Journal, Vol. 19, No. 1, 133-151.

O’Shea, J./Madigan, C. (1997) Dangerous Company. London: Nicholas Brealey Publishing.

Obolensky, N. (1998) Implementation. In: Sadler, P. (Ed.), Management Consultancy: A Handbook of Best Practice. London: Kogan Page, 137-168.

Ojasalo, J. (2001) Customer expertise: A challenge in managing customer relationships in professional business-to-business services. Services Marketing Quarterly, Vol. 22, No. 2, 1-16.

Oliver, D./Roos, J. (2005) Decision-making in high-velocity environments: The importance of guiding principles. Organization Studies, Vol. 26, No. 6, 889-913.

Olivera, F. (2000) Memory systems in organizations: An empirical investigation of mechanisms for knowledge collection, storage, and access. Journal of Management Studies, Vol. 37, No. 6, 811-832.

Oztel, H./Hinz, O. (2001) Changing organizations with metaphors. The Learning Organization, Vol. 8, No. 3/4, 153-168.

Parker, M. (1992) Post-modern organizations or postmodern organization theory? Organization Studies, Vol. 13, No. 1, 1-17.

Pellegrinelli, S. (2002) Managing the interplay and tensions of consulting interventions. The consultant-client relationship as mediation and reconciliation. The Journal of Management Development, Vol. 21, No. 5/6, 343-365. 
Peters, T. (1992) Liberation Management. New York: Knopf.

Pfeffer, J. (1992) Understanding power in organizations. California Management Review, Vol. 35, 29-50.

Pfeffer, J./Salancik, G. (1974) Organizational decision making as a political process. Administrative Science Quarterly, Vol. 19, 135-151.

Phillips, N. (2003) Discourse or institution? Institutional theory and the challenge of critical discourse analysis. In: Westwood, R./Clegg, S. (Eds.), Debating Organization. Point-Counterpoint in Organization Studies. Oxford: Blackwell Publishing, 220-231.

Phillips, N./Brown, J. (1993) Analyzing communication in and around organizations: A critical hermeneutic approach. Academy of Management Journal, Vol. 36, No. 6, 1547-1576.

Phillips, N./Lawrence, T./Hardy, C. (2004) Discourse and institutions. Academy of Management Review, Vol. 29, No. 4, 635-652.

Picot, A./Reichwald, R./Wigand, R. (1996) Die Grenzenlose Unternehmung. Information, Organisation und Management. Wiesbaden: Gabler.

Polanyi, M. (1966) The Tacit Dimension. New York: Doublebay \& Company, Inc.

Poole, P./Gray B./Gioia, D. (1990) Organizational script development through interactive accommodation. Group \& Organization Studies, Vol. 15, 212-232.

Poulfelt, F./Greiner, L./Bhambri, A. (2005) The changing global consulting industry. In: Greiner, L./Poulfelt, F. (Eds.), The Contemporary Consultant. Mason: Thomson South-Western, 3-22.

Powell, M./Brock, D./Hinings, C. (1999) The changing professional organization. In: Brock, D./Powell, M./Hinings, C. (Eds.), Restructuring the Professional Organization. Accounting, Health Care and Law. London: Routledge, 1-19.

Power, M. (1991) Educating accountants: Towards a critical ethnography. Accounting, Organisations and Society, Vol. 4, No. 4, 333-353.

Prahalad, C./Bettis, R. (1986) The dominant logic: A new linkage between diversity and performance. Strategic Management Journal, Vol. 7, 485-501.

Prahalad, C./Hamel, G. (1990) The core competence of the corporation. Harvard Business Review, May-June, 79-91.

Prakash, A./Samwick, A. (2003) The announcement and long-term effects of hiring a management consulting firm. Manuscript.

Pringle, E. (1998) Do proprietary tools lead to cookie cutter consulting? Consulting to Management, Vol. 10, No. 1, 3-7.

Probst, G./Raub, S./Romhardt, K. (2000) Managing Knowledge: Building Blocks for Success. Chichester: J. Willey.

Putnam, L. (1983) The interpretive perspective: An alternative to functionalism. In: Putnam, L./Pacanowsky, M. (Eds.), Communication and Organizations. An Interpretive Approach. Beverly Hills: Sage, 31-54.

Quelin, B./Duhamel, F. (2003) Bringing together strategic outsourcing and corporate strategy: Outsourcing motives and risks. European Management Journal, Vol. 21, No. 5, 647-661. 
Quinn, B./Anderson, P./Finkelstein, S. (1996) Managing professional intellect: Making the most of the best. Harvard Business Review, March-April 1996, 71-80.

Raelin, J. (1997) A model of work-based learning. Organization Science, Vol. 8, No. 6, 563-578.

Raelin, J. (2001) Public reflection as the basis of learning. Management Learning, Vol. 32, No. 1, 11-30.

Rambow, R./Bromme, R. (1995) Implicit psychological concepts in architects' knowledge: How large is a large room? Learning and Instruction, Vol. 5, 337-355.

Rassam, C. (1998) The management consultancy industry. In: Sadler, P. (Ed.), Management Consultancy: A Handbook of Best Practice. London: Kogan Page, 330.

Reed, M. (1996) Expert power and control in late modernity: An empirical review and theoretical synthesis. Organization Studies, Vol. 17, No. 4, 573-597.

Reed, M. (2000a) The limits of discourse analysis in organizational analysis. Organization, Vol. 7, No. 3, 524-530.

Reed, M. (2000b) In praise of duality and dualism: rethinking agency and structure in organisational analysis. In: Ackroyd, S./Fleetwood, S. (Eds.), Realist Perspectives on Management and Organisations. London: Routledge, 45-65.

Reed, M. (2004) Getting real about organizational discourse. In: Grant, D./Hardy, C./Oswick, C./Putnam, L. (Eds.), The SAGE Handbook of Organizational Discourse. London: Sage, 413-420.

Reihlen, M. (1997) Entwicklungsfähige Planungssysteme. Wiesbaden: Gabler.

Reihlen, M. (2003a) The ecology of professional service production. Paper presented at the 2003 EGOS Colloquium, Copenhagen, July 2003.

Reihlen, M. (2003b) Wege zur Neuorientierung des Wissensmanagements-eine kritisch-konstruktive Würdigung des Beitrages von Schreyögg und Geiger. Die Betriebswirtschaftslehre, Vol. 63, No. 5, 569-579.

Reihlen, M./Ringberg, T. (2004) Exploring competing views on knowledge in management studies. Working paper, University of Wisconsin-Milwaukee.

Reihlen, M./Ringberg, T. (2006) Computer-mediated knowledge systems in consultancy firms: Do they work? Research in the Sociology of Organizations, Vol. 24, 317347.

Reihlen, M./Ringberg, T./Wildhirt, K. (2005) Rethinking knowledge: Putting knowledge back into the mind. Paper presented at the 21st EGOS Colloquium, Berlin, 30th June-2nd July 2005.

Rescher, N. (1989) Cognitive Economy. The Economic Dimension of the Technology of Knowledge. Pittsburg: University of Pittsburgh Press.

Rescher, N. (1990) A Useful Inheritance. Savage: Rowman \& Littlefield Publishers, Inc.

Rescher, N. (2000) Nature and Understanding. The Metaphysics and Method of Science. Oxford: Clarendon Press.

Rescher, N. (2005a) Epistemic Logic. A Survey of the Logic of Knowledge. Pittsburg: University of Pittsburgh Press.

Rescher, N. (2005b) Realism and Pragmatic Epistemology. Pittsburg: University of Pittsburgh Press. 
Riley, P. (1983) A structurationist account of political culture. Administrative Science Quarterly, Vol. 28, No. 3, 414-437.

Ritsema, van E./van Peet, H./Broekhuis, M./Gruisen, M (1992) Problems of quality management in the professional services. The International Journal of Quality \& Reliability Management, Vol. 9, No. 7, 23-37.

Ritzer, G. (2004) The Globalization of Nothing. Thousand Oaks, CA: Pine Forge Press.

Robertson, M./Swan, J. (1998) Modes of organizing in an expert consultancy: A case study of knowledge, power and egos. Organization, Vol. 5, No. 4, 543-564.

Robertson, M./Swan, J. (2003) Control - what control? Culture and ambiguity within a knowledge intensive firm. Journal of Management Studies, Vol. 40, No. 4, 831858.

Rorty, R. (1992) Metaphilosophical difficulties of linguistic philosophy. In: Rorty, R. (Ed.), The Linguistic Turn. Chicago: The University of Chicago Press, 1-39.

Rose, R. (1988) Organizations as multiple cultures: A rules theory analysis. Human Relations, 41(2), 139-170.

Sackmann, S. (1992) Culture and subcultures: An analysis of organizational knowledge. Administrative Science Quarterly, Vol. 37, 140-161.

Sadler-Smith, E. (2004) Cognitive style and the management of small and medium-sized enterprises. Organization Studies, Vol. 25, 155-181.

Saint-Martin, D. (2000) Building the New Managerialist State. Oxford: Oxford University Press.

Salancik, G./Pfeffer, J. (1974) The bases and use of power in organizational decision making. Administrative Science Quarterly, Vol. 19, 453-473.

Sarvary, M. (1999) Knowledge management and competition in the consulting industry. California Management Review, Vol. 41, No. 2, 95-107.

Sawney, M./Prandelli, E. (2000) Communities of creation: Managing distributed innovation in turbulent markets. California Management Review, Vol. 42, No. 4, 24-54.

Scarbrough, H. (1996) The Management of Expertise. Houndmills: MacMillan Business.

Scarbrough, H./Swan, J. (2000) Explaining the diffusion of knowledge management: The role of fashion. British Journal of Management, Vol. 12, 3-12.

Schaffer, R. (2002) High-Impact Consulting. How Clients and Consultants Can Work Together to Achieve Extraordinary Results. San Francisco: Jossey-Bass.

Schein, E. (1987) Process Consultation. Lessons for Managers and Consultants. Reading, Mass.: Addison-Wesley Pub.

Schein, E. (1988) Process Consultation. Its Role in Organization Development. Reading, Mass.: Addison-Wesley Pub.

Schein, E. (1993) On dialogue, culture, and organizational learning. Organizational Dynamics, Vol. 22, No.2, 40-51.

Schein, E. (1996), Three cultures of management: The key to organizational learning. Sloan Management Review, Vol. 38, No. 1, 9-20.

Schein, E. (1999) Process Consultation Revisited. Reading, Mass.: Addison-Wesley. 
Schein, E. (2002) Consulting: What should it mean? In: Clark T./Fincham, R. (Eds.), Critical Consulting. New Perspectives on the Management Advice Industry. Oxford: Blackwell Publishers, 21-27.

Schelley, G. (1997) Dealing with smart clients. Ivey Business Quarterly, Autumn 1997, 50-55.

Scherer, G./Steinmann, H. (1999) Some remarks on the problem of incommensurability in Organization Studies. Organization Studies, Vol. 20, No. 3, 519-544.

Schipper, F. (1999) Phenomenology and the Reflective Practitioner. Management Learning, Vol. 30, No. 4, 473-485.

Schipper, F. (1999) Phenomenology and the reflective practitioner. Management Learning, Vol. 30, No. 4, 473-485.

Schneider, B./Bowen, D. (1995) Winning the Service Game. Boston: Harvard Business School Press.

Schön, D. (1983) The Reflective Practitioner. How Professionals Think in Action. New York: Basic Books.

Schön, D. (1987) Educating the Reflective Practitioner. San Francisco: Jossey-Bass.

Schrädler, J. (1995) Unternehmensberatung aus Organisationstheoretischer Sicht. Wiesbaden: Gabler.

Schuster, J. (2001) Sneaking the spirit in. In: Block, P. (Ed.), Flawless Consulting. Fieldbook \& Companion. A Guide to Understanding Your Expertise. San Francisco: Jossey-Bass/Pfeiffer, 229-235.

Schwandt, T. (2000) Three epistemological stances for qualitative inquiry. In: Denzin, N./Lincoln, Y. (Eds.), Handbook of Qualitative Research, 2nd ed. Thousand Oaks, Calif.: Sage, 187-213.

Schweiger, D./Sandberg, W./Rechner, P. (1989) Experiential effects of dialectical inquiry, devils' advocacy and consensus approaches to strategic decision making. Academy of Management Journal, Vol. 32, 745-772.

Schwenk, C. (1988) The cognitive perspective on strategic decision making. Journal of Management Studies, Vol. 25, No. 1, 41-55.

Scott, J. (2001) Power. Cambridge: Polity.

Scott, J. (2004) Developing proposals. In: Fombrun, C./Nevins, M. (Eds.), The Advice Business. Essential Tools and Models for Management Consulting, New Jersey: Pearson Prentice Hall, 126-152.

Scott, L. (1994) The bridge from text to mind: Adapting reader-response theory to consumer research. Journal of Consumer Research, Vol. 21, 461-480.

Scott, M. (1998) The Intellect Industry. Chichester: John Wiley \& Sons.

Segelod, E. (2000) Investments and investment processes in professional service groups. International Journal of Production Economics, Vol. 67, 135-154.

Semadeni, M. (2001) Toward a theory of knowledge arbitrage: Examining management consultants as knowledge arbiters and arbitragers. In: Buono, A. (Ed.), Current Trends in Management Consulting. New York: Information Age Publishing, 4367. 
Sewell, G. (1998) The discipline of teams: the control of team-based industrial work through electronic and peer surveillance. Administrative Science Quarterly, Vol. 43, 397-428.

Sharma, A. (1997) Professional as agent: Knowledge and asymmetry in agency exchange. Academy of Management Review, Vol. 22, No. 3, 758-799.

Sharma, D. (1994) Classifying buyers to gain marketing insight: A relationships approach to professional services. International Business Review, Vol. 3, No. 1, 15-30.

Sibson, R. (1971) Managing Professional Services Enterprises. The Neglected Business Frontier. New York: Pitman Pub. Corp.

Sillince, J. (2000) Rhetorical power, accountability and conflict in committees: An argumentation approach. Journal of Management Studies, Vol. 37, No. 8, 11251156.

Simon, H. (1979) Models of Thought. New Haven : Yale University Press.

Skapinker, M. (2005) There is a public interest in dishing the dirt on consultants. Financial Times, May 11 2005, 13.

Skerlep, A. (2001) Re-evaluating the role of rhetoric in public relations theory and in strategies of corporate discourse. Journal of Communication Management, Vol. 6, No. 2, 176-187.

Slocum, J. (1978) Does cognitive style affect diagnosis and intervention strategies of change agents? Group \& Organization Studies, Vol. 3, 142-156.

Smith, M. (2003) Communities of practice. The encyclopedia of informal education. [http://www.infed.org/biblio/communities_of_practice.htm].

Smith-Jentsch, K./Campbell, G./Milanovich, D./Reynolds, A. (2001) Measuring teamwork mental models to support training assessment, development, and evaluation: two empirical studies. Journal of Organizational Behavior, Vol. 22, 179-194.

Sole, D./Edmondson, A. (2002) Situated knowledge and learning in dispersed teams. British Journal of Management, Vol. 13, S17-S34.

Somech, A./Drach-Zahavy, A. (2002) Relative Power and influence strategy: The effects of agent/target organizational power on superiors' choices of influence strategies. Journal of Organizational Behavior, Vol. 23, 167-179.

Sommerlatte, S. (2000) Lernorientierte Unternehmensberatung. Wiesbaden: Gabler.

Spender, J.-C. (1996) Making knowledge the basis of a dynamic theory of the firm. Strategic Management Journal, Vol. 17 (Winter Special Issue), 45-62.

Spender, J.-C. (1998) Pluralist epistemology and the knowledge-based theory of the firm. Organization, Vol. 5, No. 2, 233-256.

Spybey, T. (1989) Frames of meaning as a concept of organization. International Studies of Management \& Organization, Vol. 19, No. 3, 16-33.

Squires, S./Smith, C./McDougall, L./Yeack, W. (2003) Inside Arthur Andersen. Shifting Values, Unexpected Consequences. New York: Prentice Hall.

Stalk, G. (1999) Innovation in consulting. In: Biswas, S./Twitchell, D. (Eds.), Management Consulting. A Complete Guide to the Industry. New York: John Wiley \& Sons, 70-74. 
Star, S. (1991) Distributions of power. In: Law, J. (Ed.), A Sociology of Monsters: Essays on Power, Technology and Domination. London: Routledge, 26-56.

Star, S./Griesemer, J. (1989) Institutional ecology, 'translations,' and boundary objects: Amateurs and professionals in Berkeley's Museum of Vertebrate Zoology, 19071939. Social Studies of Science, Vol. 19, 387- 420.

Starbuck, W. (1992) Learning by knowledge-intensive firms. Journal of Management Studies, Vol. 29, No. 6, 713-740.

Stehr, N. (1994) Knowledge Societies. London: Thousand Oaks.

Stock, J./Zinszer, P. (1987) The industrial purchase decision for professional services. Journal of Business Research, Vol. 15, 1-16.

Stokes, R./Hewitt, J. (1976) Aligning actions. American Sociological Review, Vol. 41, October, 838-849.

Strang, D./Macy, M. (2001) In search of excellence: Fads, success stories and Adaptive emulation. American Journal of Sociology, Vol. 107, 147-182.

Sturdy, A./Clark, T./Fincham, R./Handley, K. (2004) Silence, procrustes and colonization. Management Learning, Vol. 35, No. 3, 337-340.

Sturdy, A. (1997a) The consultancy process- an insecure business? Journal of Management Studies, Vol. 34, No. 3, 389-413.

Sturdy, A. (1997b) The dialectics of consultancy. Critical Perspectives on Accounting, Vol. 8, 511-535.

Suddaby, R./Greenwood, R. (2001) Colonizing knowledge: Commodification as a dynamic of jurisdictional expansion in professional service firms. Human Relations, Vol. 54, No. 7, 933-953.

Sundbo, J./Gallouj, F. (2000) Innovation as a loosely coupled system in services. International Journal of Services Technology and Management Vol. 1, No. 1, 1537.

Sveiby, K. (1992) The knowhow company: Strategy formulation in knowledge-intensive industries. International Review of Strategic Management, Vol. 3, 167-186.

Sveiby, K./Lloyd, T. (1987) Das Management des Know-how. Frankfurt: Campus Verlag.

Swan, J./Scarbrough, H./Robertson, M. (2002) The construction of 'communities of practice' in the management of innovation. Management Learning, Vol. 33, No. 4, 477-496.

Teece, D./Pisano, G./Shuen, A. (1997) Dynamic capabilities and strategic management. Strategic Management Journal, Vol. 18, No. 7, 509-533.

Tenkasi, R./Boland, R. (1996) Exploring knowledge diversity as a basis for integration in knowledge intensive firms: A new role for information technology. Journal of Organizational Change Management, Vol. 9, No. 1 (Special Issue), 79-91.

Tetenbaum, T./Carrucci, R. (2004) Gathering data and dignosing situations. In: Fombrun, C./Nevins, M. (Eds.), The Advice Business. Essential Tools and Models for Management Consulting, New Jersey: Pearson Prentice Hall, 179-204.

Thakor, M./Kumar, A. (2000) What is a professional service? A conceptual review and bi-national investigation. Journal of Services Marketing, Vol. 14, No. 1, 63-82. 
Thompson, J. (1956) Authority and power in identical organizations. American Journal of Sociology, Vol. 62, 290-301.

Thompson, L./Mannix, E./Bazerman, M. (1988) Group negotiation: Effects of decision rule, agenda, and aspiration. Journal of Personality \& Social Psychology, Vol. 54, No. 1, 86-95.

Thorne, M. (2000) Cultural chameleons. British Journal of Management, Vol. 11, 325339.

Tichy, N. (1975) How different types of change agents diagnose organizations. Human Relations, Vol. 28, No. 9, 771-799.

Tichy, N./Hornstein, H. (1976) Stand when your number is called: An empirical attempt to classify types of social change agents. Human Relations, Vol. 29, No. 10, 945967.

Tilles, S. (1961) Understanding the consultant's role. Harvard Business Review, Vol. 39, No. 6, 87-99.

Tindale, R./Sheffey S./Scott L. (1993) Framing and group decision-making: Do cognitive changes parallel preference changes. Organizational Behavior and Human Decision Processes, Vol. 55, 470-485.

Tordoir, P. (1995) The Professional Knowledge Economy. Dordrecht: Kluwer Academic Publishers.

Townley, B. (1994) Reframing Human Resource Management. London: Sage.

Tsoukas, H. (1991) The missing link: A transformational view of metaphors in organizational science. Academy of Management Review, Vol. 16, No. 3, 566585.

Tsoukas, H. (1996) The firm as a distributed knowledge system: A constructionist approach. Strategic Management Journal, Vol. 17, Winter Special Issue, 11-25.

Tsoukas, H. (2000) False dilemmas in organization theory: Realism or social constructivism? Organization, Vol. 7, No. 3, 531-535.

Tsoukas, H. (2000) What is management? An outline of a metatheory. In: Ackroyd, S./Fleetwood, S. (Eds.), Realist Perspectives on Management and Organisations. London: Routledge, 26-44.

Tsoukas, H. (2005) Afterword: Why language matters in the analysis of organizational change. Journal of Organizational Change Management, Vol. 18, No. 1, 96-104.

Tsoukas, H./Hatch, M. (2001) Complex thinking, complex practice: The case for a narrative approach to organizational complexity. Human Relations, Vol. 54, No. 8, 979-1013.

Tsoukas, H./Knudsen, C. (2003) Introduction: The need for meta-theoretical reflection in organization theory. In: Tsoukas, H./Knudsen, C. (Eds.), The Oxford Handbook of Organization Theory. Oxford: Oxford University Press, 1-36.

Tsoukas, H./Vladimirou, E. (2001) What is organizational knowledge. Journal of Management Studies, Vol. 38, No. 7, 973-993.

Tushman, M. (1977) Special boundary roles in the innovation process. Administrative Science Quarterly, Vol. 22, 587-605.

Tushman, M. (1981) Characteristics and external orientations of boundary spanning individuals. Academy of Management Journal, Vol. 24, No. 1, 83-98. 
Tushman, M./Anderson, P. (1986) Technological discontinuities and organizational environments. Administrative Science Quarterly, Vol. 31, No. 3, 439-465.

Tyre, M./von Hippel, E. (1997) The situated nature of adaptive learning in organizations. Organization Science, Vol. 8, No. 1, 71-84.

Uzzi, B. (1996) The sources and consequences of embeddedness for the economic performance of organizations: The network effect. American Sociological Review, Vol. 61, 674-698.

Uzzi, B. (1997) Social structure and competition in interfirm networks: The paradox of embeddedness. Administrative Science Quarterly, Vol, 42, 35-67.

Uzzi, B./Lancaster, R. (2003) Relational embeddedness and learning: The case of bank loan managers and their clients. Management Science, Vol. 49, No. 4, 383-399.

Van de Ven, A. (1986) Central problems in the management of innovation. Management Science, Vol. 32, 590-607.

Van Dijk, T. (1993) Principles of critical discourse analysis. Discourse \& Society, Vol. 4, No. 2, 249-283.

Von Hippel, E. (1988) The Sources of Innovation. New York: Oxford University Press.

Walsh, J. (1995) Managerial and organizational cognition: Notes from a trip down memory lane. Organization Science, Vol. 6, No. 3, 280-321.

Walsh, J./Fahey L. (1986) The role of negotiated belief structures in strategy making. Journal of Management, Vol. 12, 325-338.

Walsh, J./Henderson, C./Deighton, J. (1988) Negotiated belief structures and decision performance: An empirical investigation. Organizational Behaviour and Human Decision Processes, Vol. 42, 194-216.

Walsh, K. (2001) The role of relational expertise in professional service delivery. In: Buono, A. (Ed.), Current Trends in Management Consulting. New York: Information Age Publishing, 23-42.

Watson, T. (1982) Group ideologies and organizational change. Journal of Management Studies, Vol. 19, No. 3, 259-275.

Weeks, J./Galunic, G. (2001) Managing knowledge at Booz-Allen \& Hamilton: knowledge on-line and off. In: de la Torre, J./Doz, Y./Devinney, T. (Eds.), Managing the Global Corporation. New York: McGraw-Hill.

Weick, K. (1995) Sensemaking in Organizations. London: Thousand Oaks.

Weick, K./Browning, L. (1986) Argument and narration in organizational. communication. Journal of Management, Vol. 12, No. 2, 243-59.

Weiss, R. (2000) Taking science out of organization science: How would postmodernism reconstruct the analysis of organizations? Organization Science, Vol. 11, No. 6, 709-731.

Wenger, E. (1998) Communities of Practice. Learning, Meaning, and Identity. Cambridge, UK: Cambridge University Press.

Wensley, A. (1998) The value of story telling. Knowledge and Process Management, Vol. 5, No. 1, 1-2.

Wernerfelt, B. (1984) A resource-based view of the firm. Strategic Management Journal, Vol. 5, No. 2, 171-180. 
Werr, A./Stjernberg, T. (2003) Exploring management consulting firms as knowledge systems. Organization Studies, Vol. 24, No. 6, 881-908.

Werr, A./Styhre, A. (2003) Understanding the ambiguous consultant-client relationship. International Studies of Management and Organization, Vol 32, 43-66.

Whitley, R. (1989) On the nature of managerial tasks and skills: Their distinguishing characteristics and organization. Journal of Management Studies, Vol. 26, No. 3, 209-224.

Wilensky, H. (1964) The professinalization of everyone? The American Journal of Sociology. Vol. LXX, No. 2, 137-158.

Willmott, H. (2003) Organization theory as a critical science? In: Tsoukas, H./Knudsen, C. (Eds.), The Oxford Handbook of Organization Theory. Oxford: Oxford University Press, 88-111.

Wilson, A. (1972) Marketing of Professional Services. London: McGraw-Hill.

Wimmer, R. (2004) Organisation und Beratung-Systemtheoretische Perspektiven für die Praxis. Heidelberg: Carl-Auer-Verlag.

Winter, S. (1987) Knowledge and competence as strategic assets. In: Teece, D. (Ed.), The Competitive Challenge: Strategies for Industrial Innovation and Renewal. New York: Ballinger, 159-184.

Wohlgemuth, A. (1989) Führung im Dienstleistungsbereich. Interactionsintensität und Produktionsstandardisierung als Basis einer neuen Typologie. Zeitschrift für die Organisation, Vol. 5, 213-224.

Wohlgemuth, A. (1995) Professionelle Unternehmensberatung. Sonderausdruck aus: Wohlgemuth, A./Treichler, C. (Eds.), Unternehmensberatung und Management. Die Partnerschaft zum Erfolg, Zürich: Versus Verlag, 25-51.

Wong, J. (2001) McKinsey and Chinese client spar over advice. Wall Street Journal (Eastern Edition), Jun 18, B.9.E.

Woodman, R./Sawyer, J./Griffin, R. (1993) Toward a theory of organizational creativity. Academy of Management Review, Vol. 18, No.2, 293-321.

Woodman, R./Schoenfeldt L. (1990) An interactionist model of creative behavior. The Journal of Creative Behavior, Vol. 24, No.4, 279-290.

Wright, C. /Kitay, J. (2004) Spreading the word: Gurus, consultants and the diffusion of the employee relations paradigm in Australia. Management Learning, Vol. 35, No. 3, 271-286.

Yanow, D. (2004) Translating local knowledge at organizational peripheries. British Journal of Management, Vol. 15 (Special Issue), S9-S25.

Yoshino, M. (1993) Egon Zehnder International. Boston: Harvard Business School Case 9-395-07.

Yukl, G./Falbe, C. (1990) Influence tactics in upward, downward, and lateral influence attempts. Journal of Applied Psychology, Vol. 75, 132-140.

Zelizer, B. (1993) Journalists as interpretive communities. Critical Studies in Mass Communication, Vol. 10, 219-237. 